US Army Corps

of Engineers

Waterways Experiment

Station

\title{
Los Angeles Harbor Pier 400 Harbor Resonance Model Study
}

by William C. Seabergh, Leonette J. Thomas

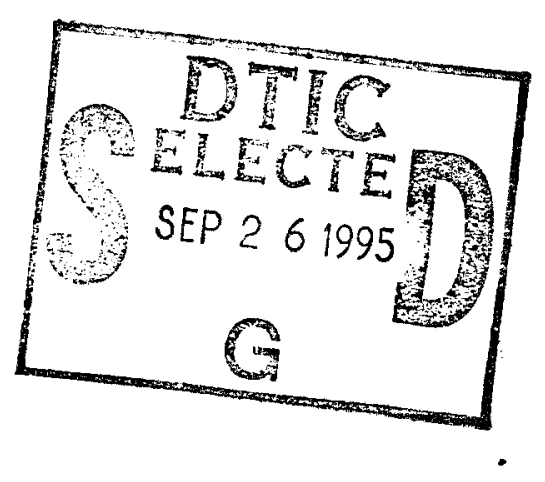

\section{6}


The contents of this report are not to be used for advertising, publication, or promotional purposes. Citation of trade names does not constitute an official endorsement or approval of the use of such commercial products. 


\section{Los Angeles Harbor Pier 400 Harbor Resonance Model Study}

by William C. Seabergh, Leonette J. Thomas

U.S. Army Corps of Engineers

Waterways Experiment Station

3909 Halls Ferry Road

Vicksburg, MS 39180-6199

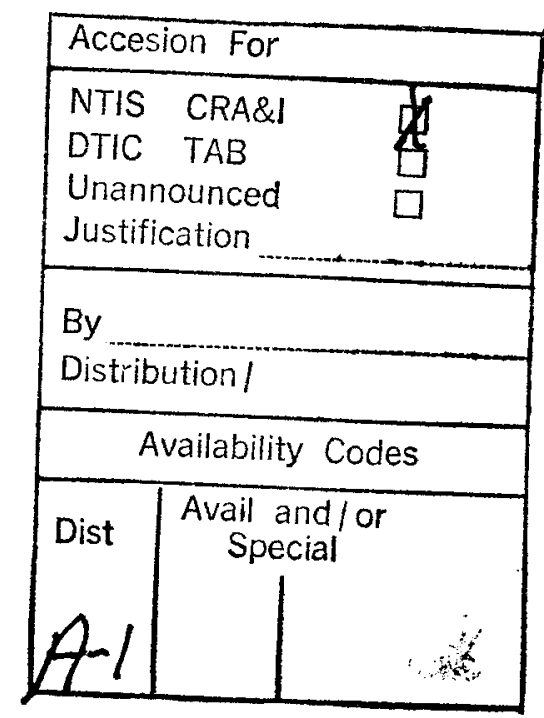

Final report

Approved for public release; distribution is unlimited 


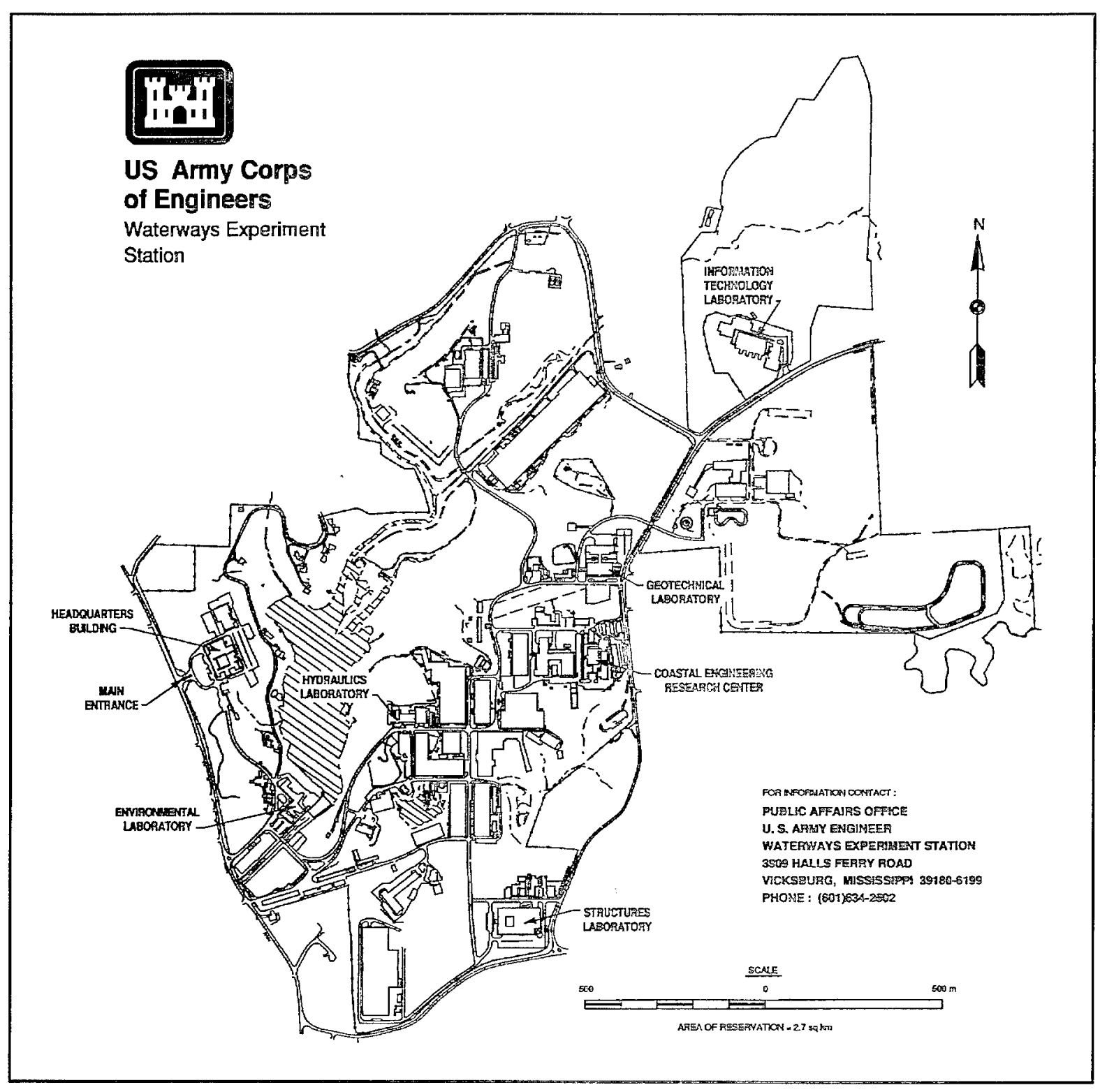

\section{Waterways Experiment Station Cataloging-in-Publication Data}

Seabergh, William $C$.

Los Angeles Harbor Pier 400 Harbor Resonance Model Study / by William C.

Seabergh, Leonette J. Thomas ; prepared for U.S. Army Engineer District, Los Angeles.

284 p. : ill. ; $28 \mathrm{~cm}$. - (Technical report ; CERC-95-8)

Includes bibliographic references.

1. Harbors - California - Los Angeles - Hydrodynamics. 2. Water waves Simulation methods. 3. Ocean waves - Simulation methods. 4. Hydraulic models. I. Thomas, Leonette J. II. United States. Army. Corps of Engineers. Los Angeles District. III. U.S. Army Engineer Waterways Experiment Station. IV. Coastal Engineering Research Center (U.S. Army Engineer Waterways Experiment Station) V. Title. VI. Series: Technical report (U.S. Army Engineer Waterways Experiment Station) ; CERC-95-8.

TA7 W34 no.CERC-95-8 


\section{Contents}

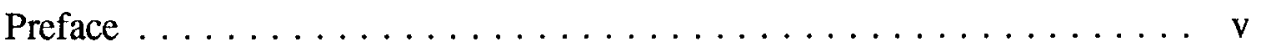

Conversion Factors, Non-SI to SI Units of Measurement $\ldots \ldots \ldots \ldots$ vi

1 -Introduction $\ldots \ldots \ldots \ldots \ldots \ldots \ldots \ldots \ldots \ldots$

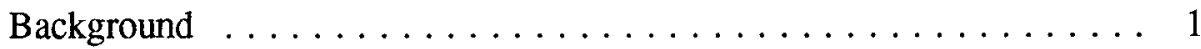

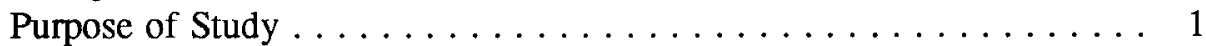

2-Los Angeles-Long Beach Harbors Physical Model . . . . . . . . . . 7

Model Description . . . . . . . . . . . . . . . . 7

Model Design Conditions . . . . . . . . . . . . . . . 7

Model Appurtenances . . . . . . . . . . . . . . . . . . 12

3 -Model Testing Approach $\ldots \ldots \ldots \ldots \ldots \ldots \ldots \ldots \ldots$

Selection of Test Conditions . . . . . . . . . . . . . . . . . 13

Model Data Collection . . . . . . . . . . . . . . . . . . . . . 16

Model-Prototype Comparison $\ldots \ldots \ldots \ldots \ldots \ldots \ldots$

4 Discussion of Harbor Resonance Testing . . . . . . . . . . . . 20

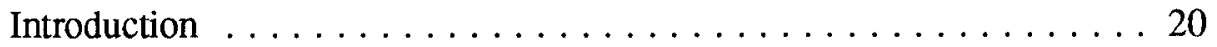

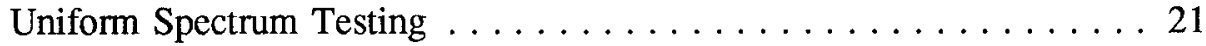

February Spectrum Testing . . . . . . . . . . . . . . 27

January Spectrum Testing . . . . . . . . . . . . . . . 28

Surface Current Photographs . . . . . . . . . . . . . . . . . 29

5- Use of Model Results to Evaluate Potential for Moored Ship Motion Problems . . . . . . . . . . . . . . 30

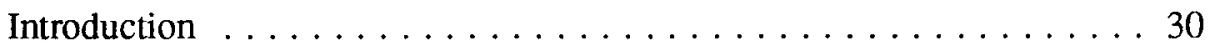

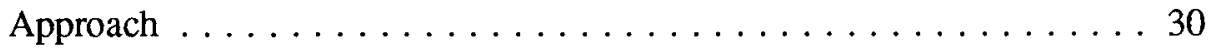

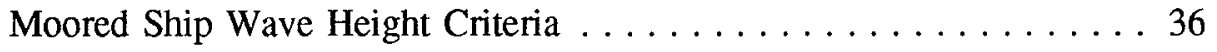

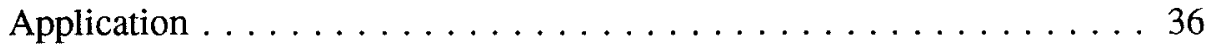

Results . . . . . . . . . . . . . . . . . . . . . . . 39

6 -Summary and Conclusions . . . . . . . . . . . . . . 43

References ............................. 45

Tables 1-5

Photos 1-5 
Plates $1-30$

Appendix A: Wave Amplification, Uniform Spectrum, Gages 1-55 . . . A 1

Appendix B: Wave Amplification, Uniform Spectrum, Gages 56-77,

Open and Closed East End at Pier $300 \ldots \ldots \ldots \ldots \ldots$. . . . . 1

Appendix C: Wave Amplification, Uniform Spectrum, Gages 1-30,

Open and Closed East End at Pier $300 \ldots \ldots \ldots \ldots \ldots \ldots$ C1

Appendix D: Wave Amplification, February Spectrum, Gages 1-55 . . . . D1

Appendix E: Wave Amplification, February Spectrum, Gages 41-42,

51-77, Open and Closed East End of Pier $300 \ldots \ldots \ldots$. . . . . E1

Appendix F: Wave Amplification, January Spectrum, Gages 1-55 . . . . F1

Appendix G: Wave Amplification, January Spectrum, Gages 41-42,

51-77, Open and Closed End of Pier $300 \ldots \ldots \ldots$. . . . . .

SF 298 


\section{Preface}

This report was prepared by the Coastal Engineering Research Center (CERC) at the U.S. Army Engineer Waterways Experiment Station (WES) for the U.S. Army Engineer District, Los Angeles (SPL). The investigation was conducted during the period December 1992 through November 1993 by personnel of the Wave Processes Branch (WPB), Wave Dynamics Division (WDD), CERC. WPB personnel involved in the study were Mr. William C. Seabergh, Ms. Leonette E. Thomas, Mr. Larry A. Barnes, and Ms. Bettye Stephens, under the direct supervision of Mr. Dennis G. Markle, Chief, WPB, and Mr. C. E. Chatham, Chief, WDD. Mr. Seabergh and Ms. Thomas prepared the report. Ms. Debbie Fulcher, WPB, assisted in preparation of the final report and Mr. Rick Floyd, Instrumentation Services Division, provided instrumentation support. This study was conducted under the general supervision of Dr. James R. Houston, Director, CERC, and Mr. Charles C. Calhoun, Jr., Assistant Director, CERC.

During the course of the study, significant liaison was maintained between WES, SPL, and the Port of Los Angeles and their Pier 400 Design Consultants. Ms. Jane Grandon was SPL point of contact and provided timely and valuable input. Mr. John Warwar, Mr. Dick Wittkop, and Mr. John Foxworthy were points of contact for the Port of Los Angeles and provided valuable input along with their Pier 400 Design Consultant contacts, Dr. Kimo Walker, Mr. Russ Boudreau, and Dr. Paul Szwetlot.

Dr. Robert W. Whalin was Director of WES during model testing and the preparation and publication of this report. COL Bruce K. Howard, EN, was Commander.

The contents of this report are not to be used for advertising, publication, or promotional purposes. Citation of trade names does not constitute an official endorsement or approval of the use of such commercial products. 


\section{Conversion Factors, Non-SI to SI Units of Measurement}

Non-SI units of measurement used in this report can be converted to SI (metric) units as follows:

\begin{tabular}{||l|c|l|}
\hline Multiply & By & To Obtain \\
\hline \hline acres & 4046.8564 & square meters \\
\hline feet & 0.3048 & meters \\
\hline square feet & 0.09290304 & square meters \\
\hline square miles & 2.589998 & square kilometers \\
\hline miles (U.S. nautical) & 1.852 & kilometers \\
\hline
\end{tabular}




\section{Introduction}

\section{Background}

In response to the expansion of oceanborne world commerce, the Ports of Los Angeles and Long Beach (LA/LB) (Figure 1) are conducting planning studies for harbor development in coordination with the U.S. Army Engineer District, Los Angeles (SPL). Ports are a natural resource, and enhanced port capacity is vital to the Nation's economic well-being. Existing terminals at the Port of Los Angeles (Figure 2) are operating beyond efficient capacity, requiring double handling of cargo and causing safety hazards, traffic congestion, higher costs, and other environmental impacts. In a feasibility study conducted by SPL (1992), a well-defined and necessary expansion to allow the Port of Los Angeles to efficiently meet its forecast cargo handling requirements for the year 2020 was recommended. The Corps of Engineers will be charged with responsibility for providing deeper channels and determining effects of this construction on the local environment. This includes changes in harbor resonance caused by expansion (landfills) and channel deepening. A physical scale model of Los Angeles and Long Beach Harbors, located at the U.S. Army Engineer Waterways Experiment Station, was available for application to this study.

\section{Purpose of Study}

The Pier 400 project was tested in the Los Angeles and Long Beach Harbors model for long wave resonance. Initially, Stage 1 was constructed in the model, followed by Stage 2. Figures 3 and 4 show the stages for the plan. Stage 1 is a short-term configuration that initiates the project by providing a 19.20-m (63-ft) mean lower low water (mllw) datum, deep entrance channel, and transitions to a $13.71-\mathrm{m}(45-\mathrm{ft})$, mllw, deep channel in front of Pier 300. This initial Pier 400 landfill provides protection from wind waves for development of berths along the south face of Terminal Island, east of Fish Harbor, known as Pier 300. This area was part of a landfill developed in 1984.

Stage 2 expands the landfill region and provides a deeper, $24.7-\mathrm{m}$ (81-ft), entrance channel and extends the Pier 300 channel to its terminus at the city limits. As changes are made in geometry and depths in the harbors, the propagation of long waves can be affected. Long wave energy is ever-present in the 


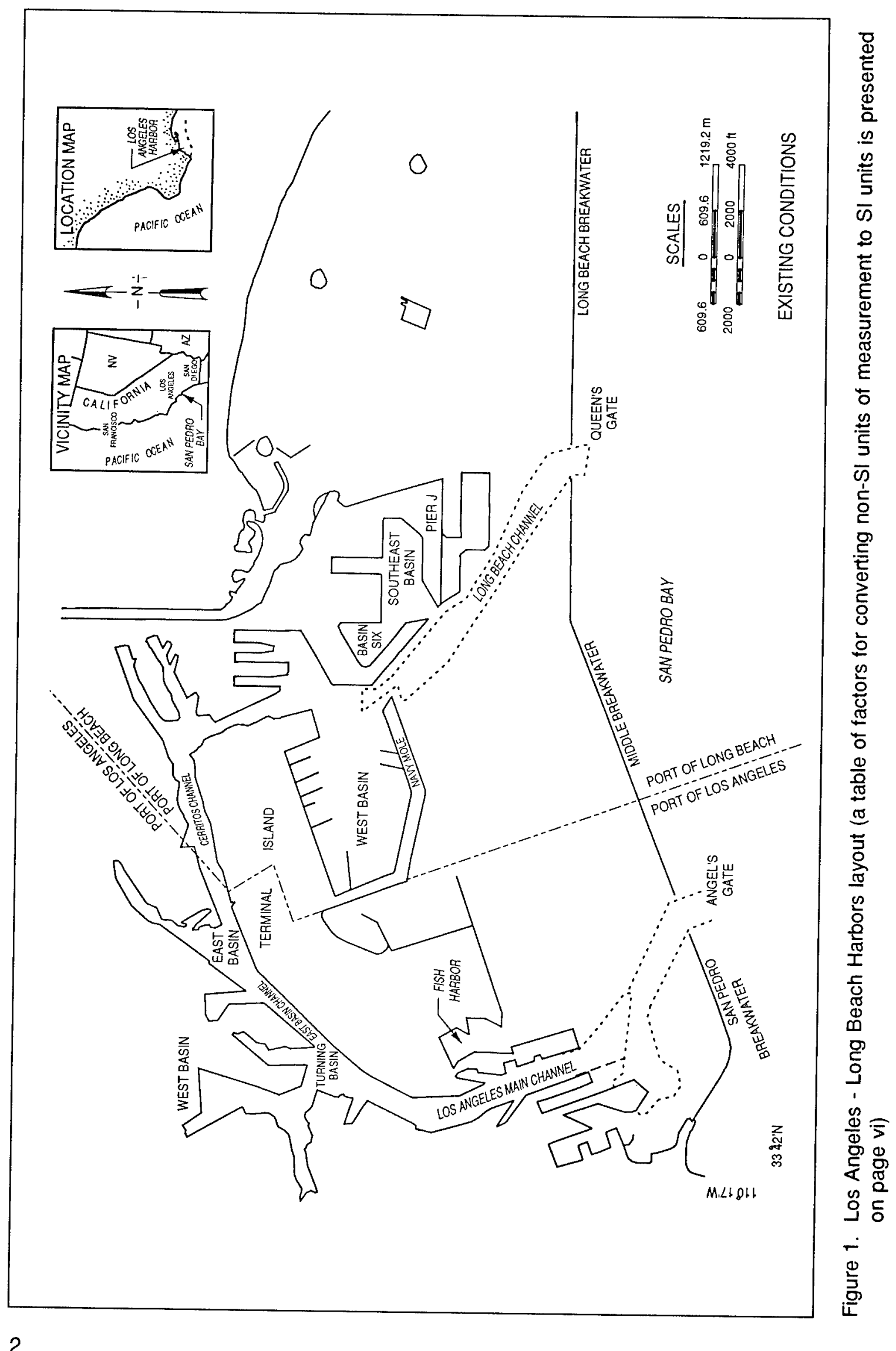




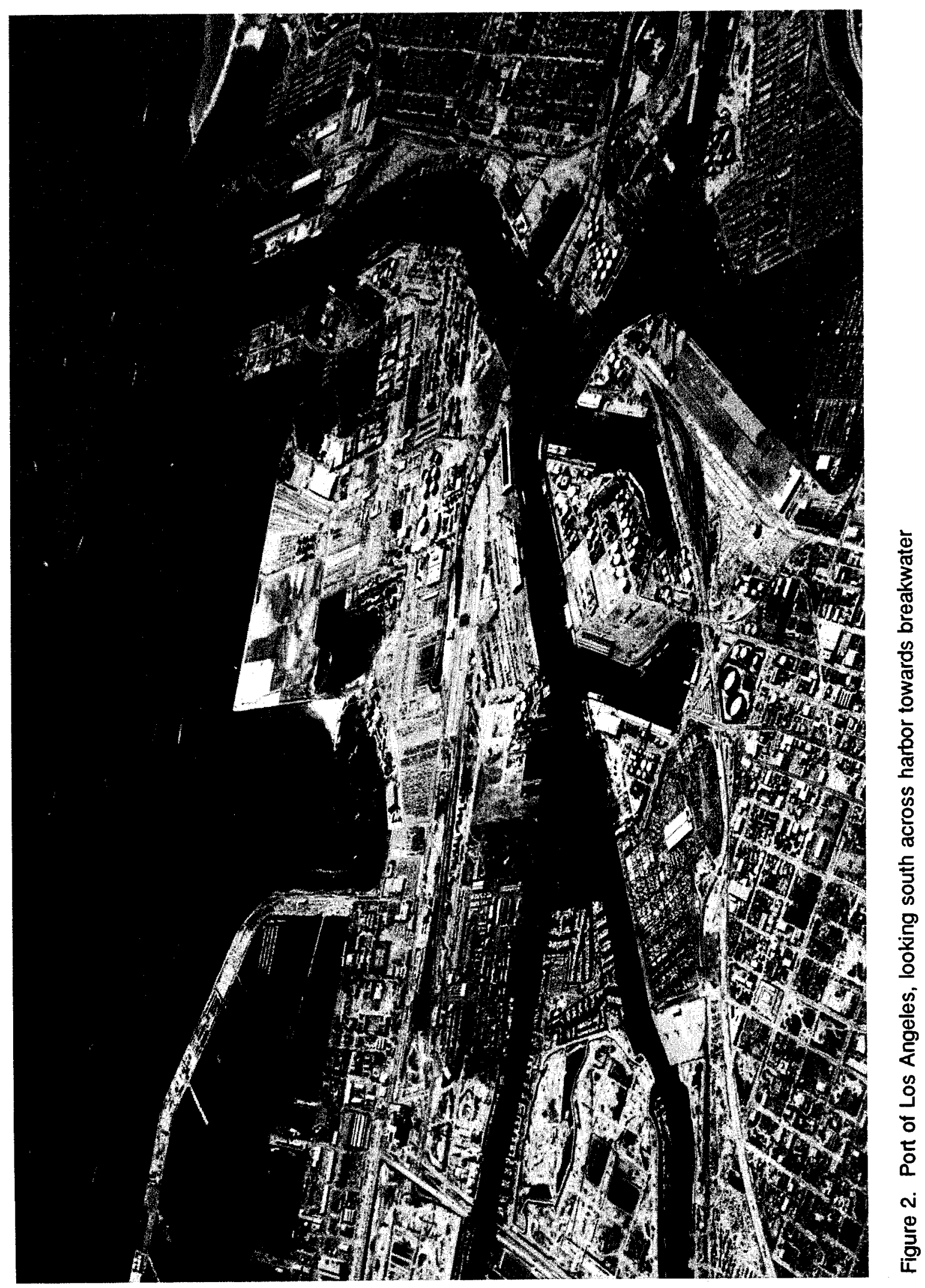




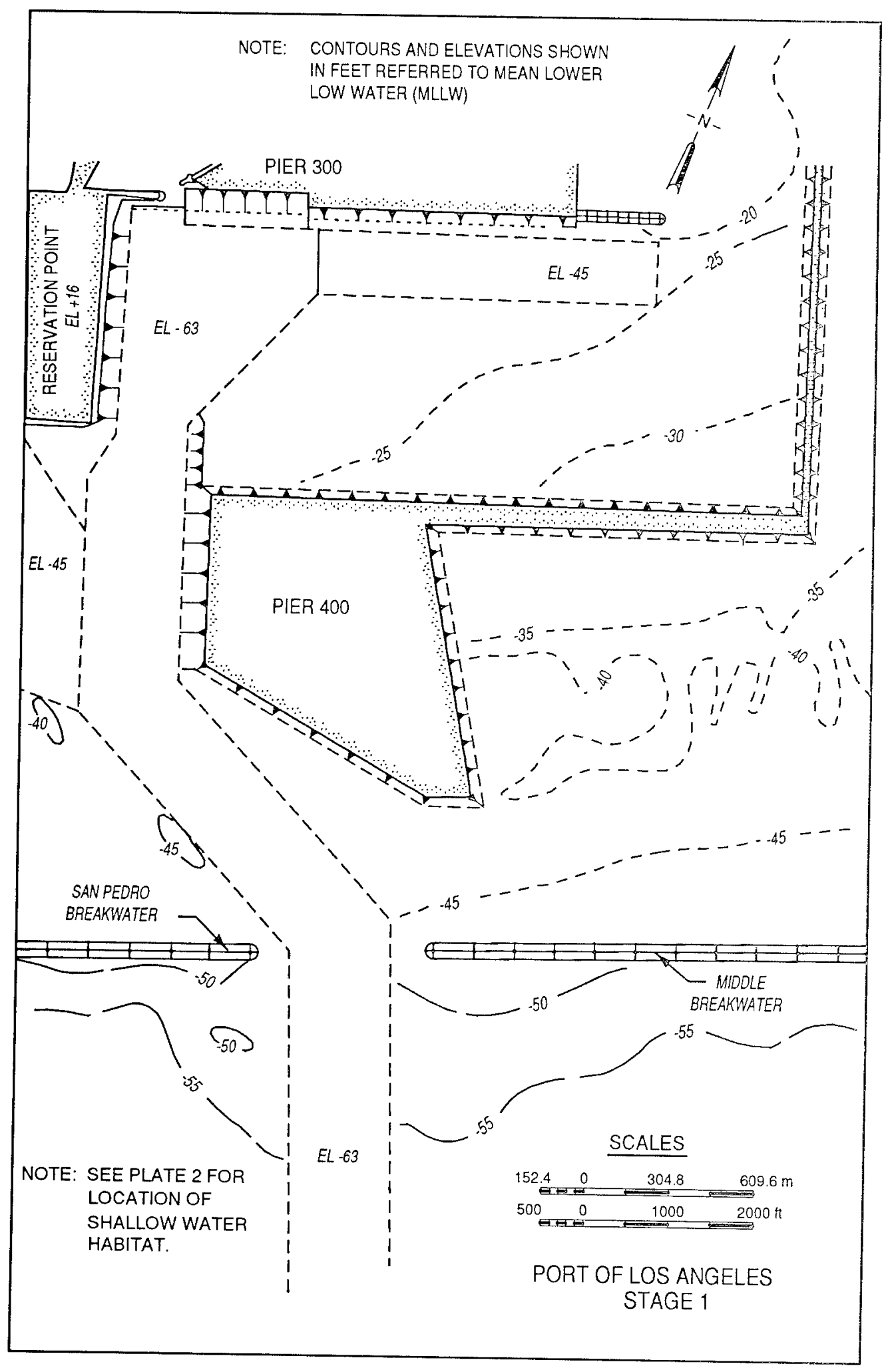

Figure 3. Stage 1 


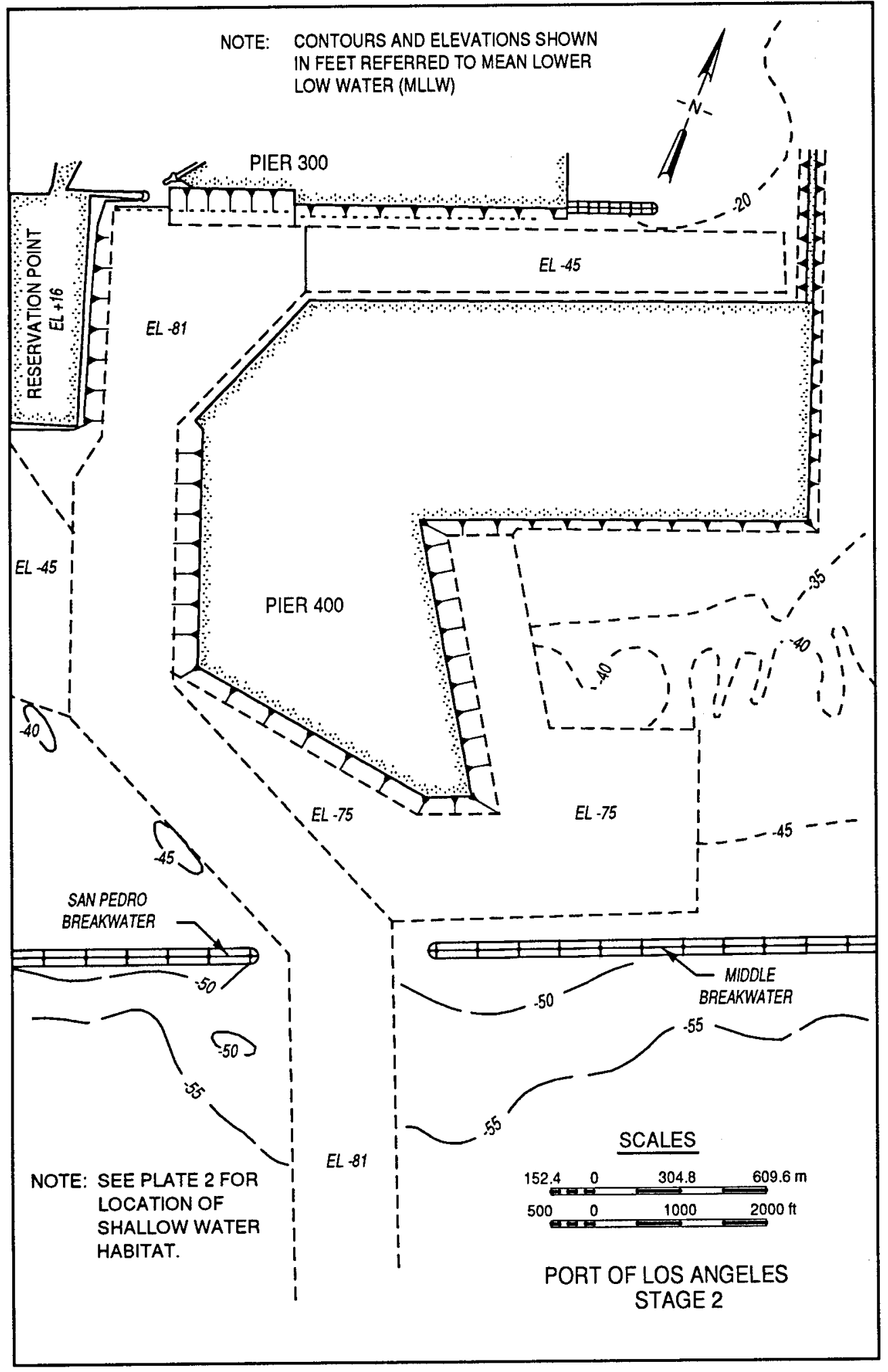

Figure 4. Stage 2 
ocean and in wave periods which impact moored ships; long waves can be correlated to the normal wind waves which approach the harbors. As the 4- to 24 -sec wind waves increase in energy, propagating toward the harbors from distant or local storms, long wave energy also increases. Long wave periods associated with wind waves are typically from 30 to $400 \mathrm{sec}$ in period, and usually the entire range of periods are present in the long wave spectrum, with energy varying over this period range dependent on elements of the short wave period spectrum such as wave period, directional variation, and wave height.

Long-wave spectra were reproduced in the LA/LB physical model so that plan effects could be measured by wave gages placed at berth locations and at the end of slips where the highest water level variation typically occurs and compared to what is known as base data, or data collected for today's existing condition of the harbor. Long waves are relatively low in amplitude (centimeters in height) when compared to wind waves (meters in height). Wavelengths of long waves are on the order of hundreds to thousands of meters long, and due to this length being similar to the lengths of slips and berths for modem ships, the possibility of waves reaching resonant conditions may occur. This increase in wave height due to resonant conditions is examined in this model study. If resonant wave conditions are reached, strong horizontal velocities are associated with them. If these strong horizontal velocities are in tune with the moored ship system (determined by line number, orientation, configuration, material, and many ship characteristics), they may cause strong ship movement, in tum causing loading/unloading delays, and if severe enough, create damage to the ship and facilities, and endanger personnel. 


\section{Los Angeles - Long Beach Harbors Physical Model}

\section{Model Description}

The Los Angeles and Long Beach Harbors model was molded in concrete grout at a vertical scale of $1: 100$ and a horizontal scale of 1:400 and reproduced San Pedro Bay and the Pacific Ocean seaward of the harbor out to the -91.44-m (-300-ft) mllw contour. The model shoreline extended from $3.2 \mathrm{~km}$ ( 2 miles) northwest of Point Fermin to Huntington Beach. The total area reproduced in the model covered about $474 \mathrm{sq} \mathrm{m}$ (44,000 sq ft), representing $655 \mathrm{sq} \mathrm{km}$ (253 square miles) in the prototype. Model layout is shown in Figure 5. Figure 6 shows the harbor basins and the channels modeled.

The model was originally constructed to conditions as they existed in the early 1970's and has been periodically updated. For this work, care was taken to ensure that the latest bathymetry and harbor geometry were in place. The Long Beach Harbor Pier J Expansion and projected increased channel depths, which were completed in 1990, also were included in the definition of current conditions. Plans for Stages 1 and 2 were provided by the Los Angeles District and the Port of Los Angeles. Photos 1 and 2 show these stages as constructed in the model.

\section{Model Design Conditions}

During initial model design, a number of specific investigations were made to aid in selection of model scales and to ensure accurate reproduction of longperiod wave phenomena. Details are found in Outlaw et al. (1977). Items studied include the following:

a. Wave refraction.

b. Energy transmission through the breakwaters. 


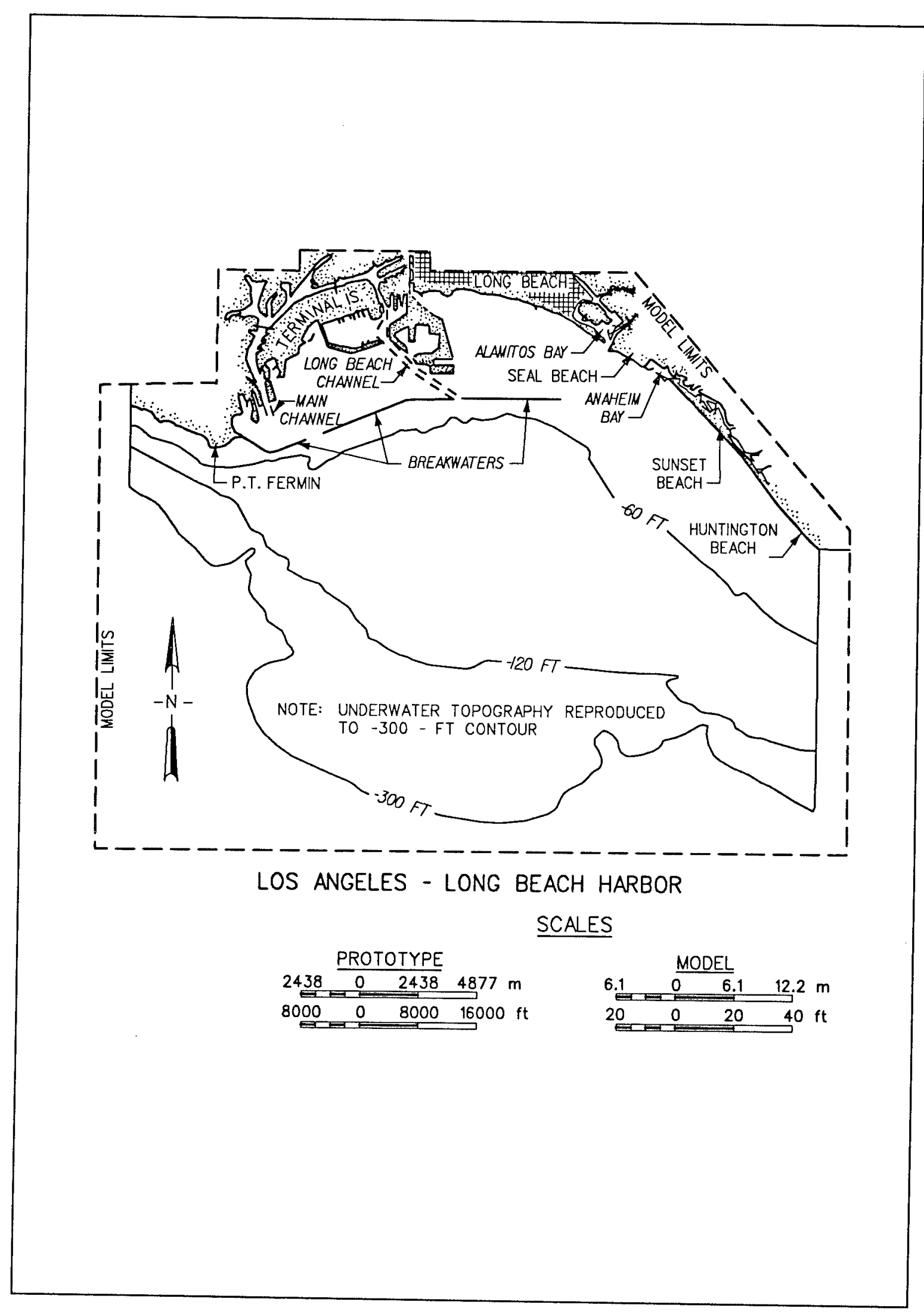

Figure 5. Model layout 


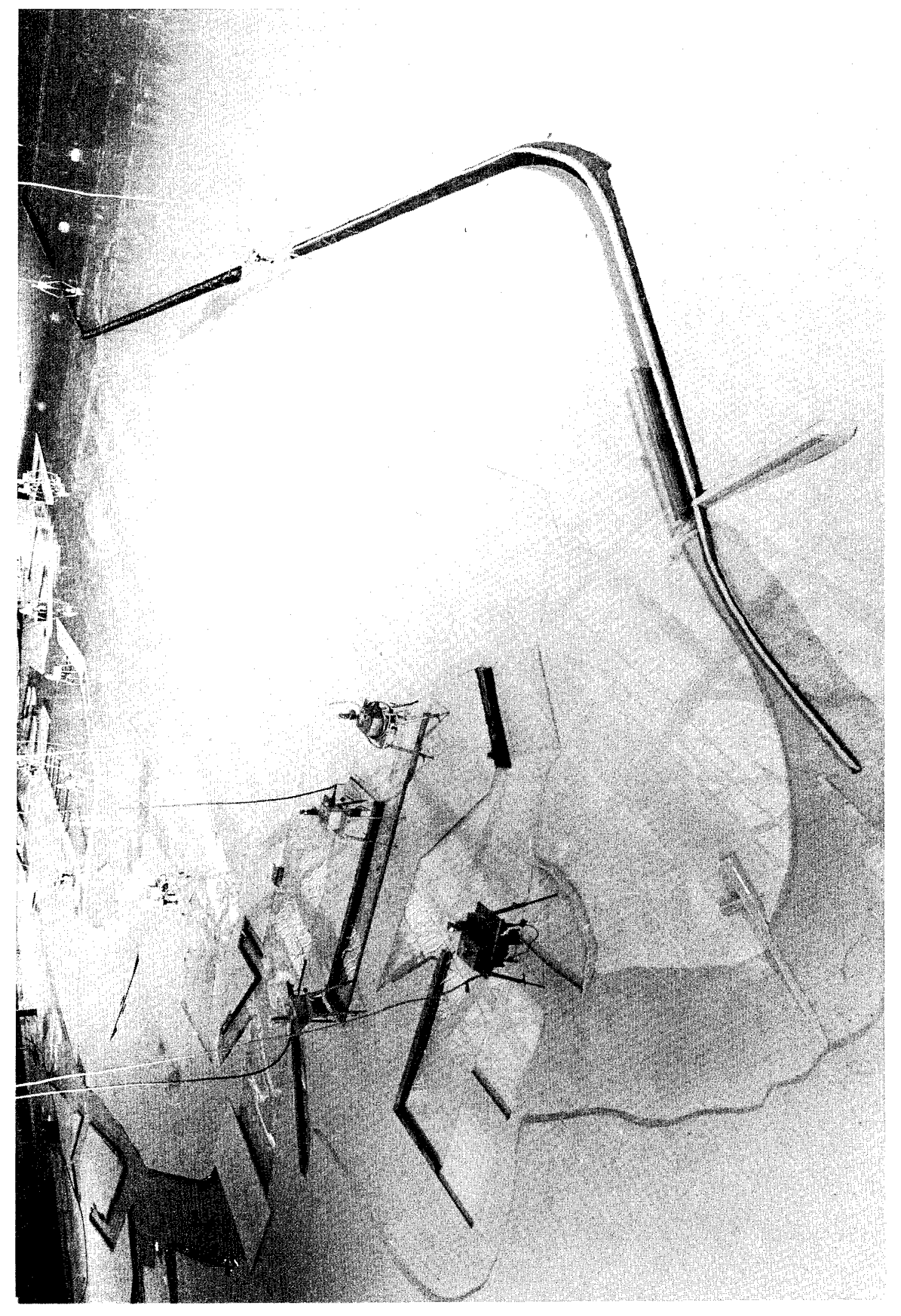

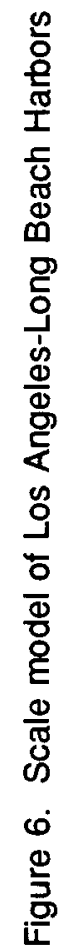

Chapter 2 Los Angeles - Long Beach Harbors Physical Model 
c. Wave diffraction.

d. Reflection from the offshore bathymetry and harbor boundaries.

e. Model wave filters and absorbers.

f. Model wave height attenuation.

Items $a$ and $c$ are important wave phenomena that govern how wave energy is distributed along the coast and throughout the harbors. For short-period waves, both refraction and diffraction cannot be scaled simultaneously in a distorted scale model; however, due to the nature of long-period waves, a solution can be found for exact scaling of diffraction and exact scaling of refraction down to the 85 -sec wave period, below which adjustments to wave generator position can be made to correctly reproduce refraction. It should be noted that for reproduction of long wave spectra, a compromise wave generator must be selected during a calibration process. A brief discussion follows.

Diffraction is the phenomenon in which energy is transmitted laterally along a wave crest, as when waves propagate into the lee of a structure. It is a function of $x / L$ or $y / L$ (the ratio of horizontal distance to wavelength $L$ ). Refraction is the process by which wave direction and amplitude are changed due to the part of the wave in shallower water advancing more slowly than that in deeper water. Refractive effects depend on wave celerity and are a function of $h / L$ (the ratio of water depth $h$ to wavelength). Consequently, if wavelength is scaled by the vertical scale in a distorted scale model, refraction is in exact similitude. If wavelength is scaled by the horizontal scale, diffraction is in exact similitude. Furthemore, in the Los Angeles - Long Beach Harbors model study it is desired to obtain similitude of mode shapes and resonant frequencies of oscillation. The governing Helmholtz equation for harbor oscillations is

$$
\frac{\partial}{\partial x}\left(h \frac{\partial \eta}{\partial x}\right)+\frac{\partial}{\partial y}\left(h \frac{\partial \eta}{\partial y}\right)+\frac{\sigma^{2}}{g} \eta=0
$$

where

$$
\begin{aligned}
x, y, z= & \text { axes of a rectangular coordinate system fixed at the mean water } \\
& \text { surface } \\
\eta= & \text { local surface elevation } \\
\sigma= & \text { angular frequency } \\
g= & \text { acceleration due to gravity }
\end{aligned}
$$

Since the same equation applies in model and prototype, it may be written as 


$$
\begin{aligned}
\left(h_{r} \frac{\eta_{r}}{x_{r}^{2}}\right) \frac{\partial}{\partial x_{p}}\left(h_{p} \frac{\partial \eta_{p}}{\partial x_{p}}\right) & +\left(h_{r} \frac{\eta_{r}}{y_{r}^{2}}\right) \frac{\partial}{\partial y_{p}}\left(h_{p} \frac{\partial \eta_{p}}{\partial y_{p}}\right) \\
& +\eta_{r} \sigma_{r}^{2}\left(\frac{\sigma_{p}^{2}}{g}\right) \eta_{p}=0
\end{aligned}
$$

where the subscript $p$ represents the prototype and the subscript $r$ represents the scale ratio of model to prototype. From inspectional analysis, the coefficients of the above equation must be equal, or

$$
\frac{h_{r}}{x_{r}^{2}}=\frac{h_{r}}{y_{r}^{2}}=\sigma_{r}^{2}
$$

after dividing by $\eta_{r}$. This indicates that a hydraulic model may be distorted for proper simulation of harbor resonant oscillation frequencies. Angular frequency may be written in terms of wavelength and water depth and this equation indicates that wavelength must be scaled by the horizontal scale.

From the previous paragraph it was determined that when wavelength is scaled by the horizontal scale, diffraction and harbor resonance conditions will be in similitude. However, refraction can have a scale effect due to model distortion, but if the wave is a shallow-water wave where wave celerity is governed by local depth, model distortion will have little effect on refraction. This is seen from the equation for wave celerity $c$ from small-amplitude wave theory

$$
c=\left(\frac{g L}{2 \pi} \tanh \frac{2 \pi h}{L}\right)^{\frac{1}{2}}
$$

As wave period increases, tanh $2 \pi h / L$ approaches $2 \pi h / L$, and celerity becomes

$$
C=(g h)^{\frac{1}{2}}
$$

This indicates that for shallow-water waves, celerity (and thus refraction) is independent of wavelength, and the use of model distortion has no significant effect on wave refraction.

Based on Froudian similitude, the time scale for model wave period, using a horizontal scale for wave length as shown earlier, is written as (Outlaw et al. 1977) 


$$
T_{r}=\left[L_{r} \frac{\tanh \left(\frac{2 \pi}{L_{p}} h_{p}\right)}{\tanh \left(\frac{2 \pi}{L_{m}} h_{m}\right)}\right]^{\frac{1}{2}}
$$

with the subscript $m$ referring to the model. As $\tanh (2 \pi h / L)$ approaches $(2 \pi h / L)$, the time scale ratio can be approximated by

$$
T_{r}=\frac{L_{r}}{\left(h_{r}\right)^{\frac{1}{2}}}
$$

which, when applicable, indicates a model-to-prototype time scale of 1:40 for wave period.

\section{Model Appurtenances}

\section{Wave generator}

The electrohydraulic wave generator was composed of 13 segments, each independently controlled from a computer-generated command signal and equipped with a $4.57-\mathrm{m}$ (15-ft) paddle. The segments can be positioned to approximate a curved wave front 23,774 $\mathrm{m}$ (78,000 ft) long (prototype). Details of the generator design are found in Outlaw et al. (1977).

\section{Data acquisition}

Wave data acquisition, wave generator control signals and feedback, and wave gage calibration were performed using an Automated Data Acquisition and Control System (ADACS). At the heart of the system is a Digital Equipment Corporation (DEC) Microvax computer. Wave data are collected at various locations throughout the model. ADACS can handle 30 gages for a test run. The sensor used is a water-surface-piercing, parallel-rod resistance type wave gage where the conductance between the two rods is measured and is directly proportional to submergence. This system can detect changes in water elevation to $0.03048 \mathrm{~cm}(0.001 \mathrm{ft})$. 


\section{Model Testing Approach}

Since 1985, wave data have been collected at an offshore oil platform (Platform Edith) $15 \mathrm{~km}$ (8 miles) south of the harbors (see Figure 7 for location of Edith and seven harbor gages operated over the same period).. At the time of selection of long wave spectra for modeling, Platform Edith data covered 1985-1988 (however, these data are not continuous, as there were data gaps due to funding constraints and gage fouling). Using this information, long-period spectra were selected for programming the model wave generators, data were collected in the model at locations of prototype gages, and these data were compared to prototype spectra. Needed adjustments to wave generator energy distribution were made and model-prototype comparisons were rechecked. Following this, base data spectra were collected at stations throughout the harbor to be used for comparison with data from tests of proposed harbor expansion plans.

\section{Selection of Test Conditions}

Platform Edith long-period wave data were analyzed to determine appropriate input to the model wave generators. Three long-period spectra were selected for test conditions. Two storms were outstanding in the data record as far as their impact on the harbors and were chosen for modeling. The largest event recorded was the Martin Luther King Day storm of 17 January 1988. The short-period portion of the wave spectrum had a significant wave height of $7.5 \mathrm{~m}(24.6 \mathrm{ft})$, peak wave period of $16.5 \mathrm{sec}$, and approached from $245 \mathrm{deg}$ during the time of maximum energy measured at Platform Edith. The longperiod portion of the wave spectrum contained $270 \mathrm{sq} \mathrm{cm}(0.29 \mathrm{sq} \mathrm{ft})$ of energy and was distributed as seen in Figure 8. This event caused significant damage to the southern California coastline. The second event selected occurred on 2 February 1986, had a significant wave height of $3.11 \mathrm{~m}$, 17.6-sec peak period, direction of $250 \mathrm{deg}$, and resulted in significant harbor agitation with numerous reports of moored ship difficulties (Figure 8). The long-period portion of the spectrum contained $66.6 \mathrm{sq} \mathrm{cm}$ of energy. The third long-wave spectrum selected was based on an average, or mean, long-period wave spectrum condition representative of a southerly approach (Figure 8). Since the mean, or average, values for each prototype long energy bandwidth are fairly similar (the spectrum's energy is nearly uniformly distributed across 


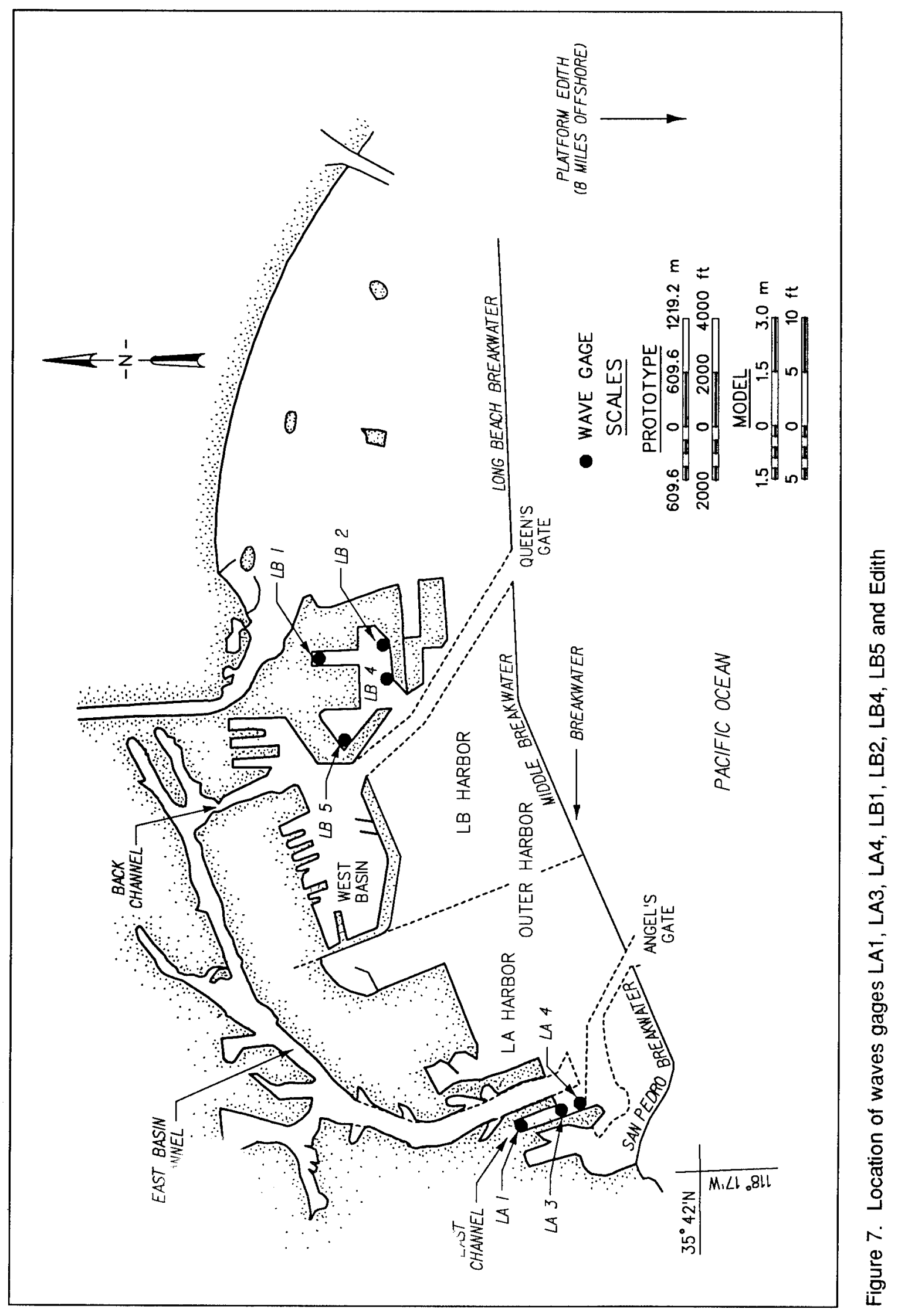




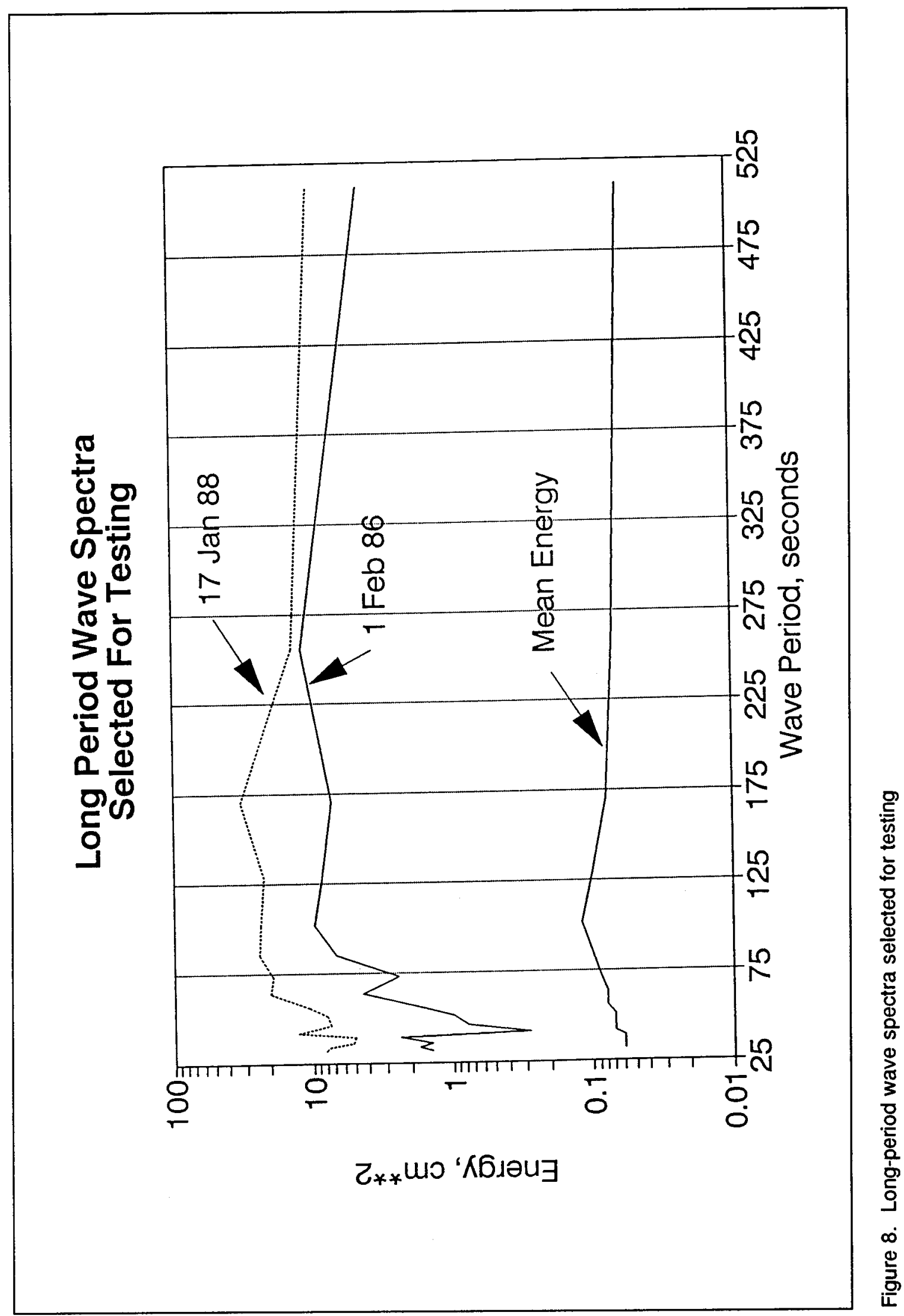


the 25- to 512-sec period range), a flat, constant-energy spectrum of $1.3 \mathrm{sq} \mathrm{cm}$ was created for use in the model.

In order to transform the spectral representation into an actual time series of waves in the model, the program TSGMN3P0 takes the discretely defined spectral energy ( 36 frequency components from 0.1 to $1.33 \mathrm{cps}$ ) and creates a control signal which has 256 frequency bands $(\Delta f=0.00479)$ for the wave generator. The control signal is input to the program SPLASH, which will control the wave paddle to create the desired wave spectrum. In order to produce an analysis that accurately defines the energy in the broad range of wave periods contained in the long-period spectrum, each test was run for $512 \mathrm{sec}$, a duration long enough to produce an appropriate degree of bandwidth resolution and statistical confidence without being so long as to set up spurious oscillations. Runs of shorter test durations compared closely to the $512-\mathrm{sec}$ test, and indicated no problems with contamination of the wave records due to waves rereflected off model boundaries or the wave generator. Model boundaries have multiple layers of a fibrous matrix wave absorber and the irregular ocean contours and shoreline boundary do not appear to direct significant energy back to the wave generator. The 13 individual units that make up the wave generator were operated in phase, but wave amplitude was varied along the wave front to create an appropriate energy distribution approaching the harbors. Since two of the storms being run approached from a westerly quadrant, energy distribution was adjusted for that approach. The uniform-spectrum energy distribution was adjusted for a southerly wave approach, more typical of summer conditions. Ship motion observations in the prototype (Burke, unpublished data) indicate that these two directional approaches (the west for winter storms, and the south for hurricane and Southem Hemisphere swell) create an annual bimodal distribution for significant moored ship motion events.

\section{Model Data Collection}

Model wave height data were collected at the locations seen in Plates 1 and 2 (for Stages 1 and 2, respectively). These wave heights are typically converted to a wave height amplification. Wave height amplification is sometimes defined (but not used for this study) as the ratio of the wave height at a particular location in a harbor to twice the incident wave height at the harbor mouth. This definition results from the fact that the standing wave height for a fully reflective straight coast with no harbor would be twice the incident wave height due to superposition of the incident and reflected waves. However, in the hydraulic model there is variation in wave height along the harbor boundary due to wave refraction. In the previous Los Angeles - Long Beach Harbor resonance studies, incident wave height in deep water is used and amplification $R$ is defined as 


$$
R=H_{s} / H_{i}
$$

$H_{s}=$ significant wave height at gage in harbor

$$
H_{i}=\text { deepwater incident wave height }
$$

In this study, data were available at the ocean wave gage on Platform Edith. In order to facilitate direct comparison with prototype data for model verification and as a transfer function to permit conversion of model amplification data to prototype values of wave height (discussed in Chapter 5), wave height data at each harbor gage were divided by wave height measured at a gage located at the analogous location of Platform Edith in the model ocean. Since the waves being studied were composed of many frequencies (or a spectrum), digital output from the gage was analyzed by Fast Fourier Transform (FFT) to determine an energy level that could be converted to a wave height (by taking four times the square root of the energy) for each frequency band. Water elevation data were collected at a rate of 20 readings per second at each gage location. A total of 8,192 data points were collected at each gage during a test. Data were windowed with a cosine square taper and after FFT analysis, the raw spectral estimates $(\Delta \mathrm{f}=0.0024414)$ were smoothed by averaging eight bands, so that $\Delta \mathrm{f}$ for model data was 0.01953 . Table 1 shows the period bands, frequency, and period range that each band covers. Table 2 shows period bands which were used in the analysis of prototype data.

\section{Model-Prototype Comparison}

Figures 9 and 10 show a comparison between model and prototype wave height amplification (determined by the square root of the ratio of energy for a certain frequency band at a given harbor gage to that at the ocean gage at Platform Edith) for the February 1986 storm at gages LB-2 and LA-1. The comparison is not direct since the prototype data were analyzed with a wider frequency interval, while the model data have finer frequency (or wave period) resolution. For example, the prototype data point at wave period $256 \mathrm{sec}$ on the gage LA-1 plot is averaged over a bandwidth covering 204 to $341 \mathrm{sec}$. In the model, the data point at $242 \mathrm{sec}$ covers the period range of 229 to $258 \mathrm{sec}$, and the data point at $275 \mathrm{sec}$ covers 258 to $295 \mathrm{sec}$. At lower wave periods, the comparison is more easily made. Figures 9 and 10 indicate that the model harbor spectral response closely reproduced the prototype for the February storm. Comparison of other gage locations and long wave spectra may be found in Seabergh and Thomas (1993). 


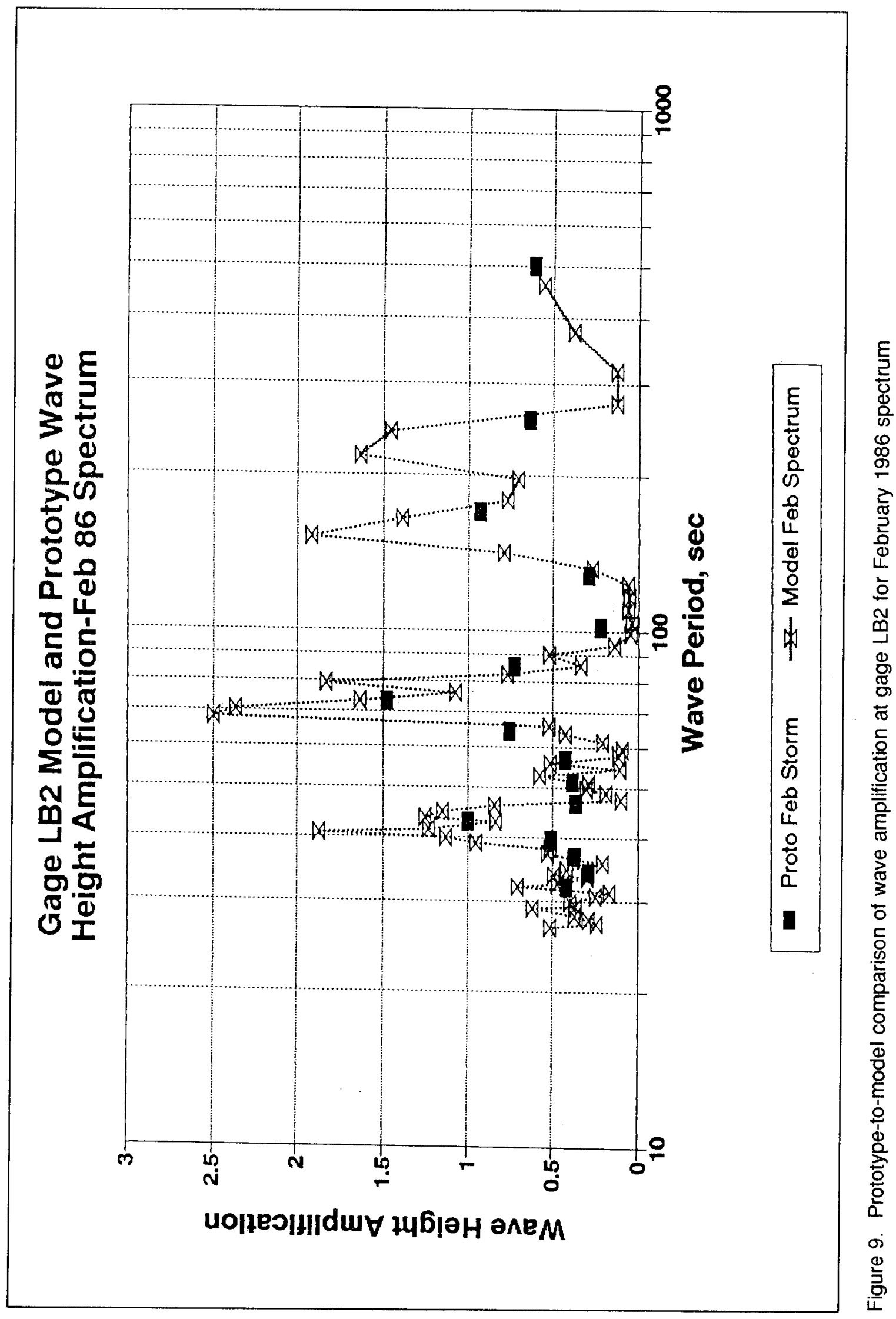




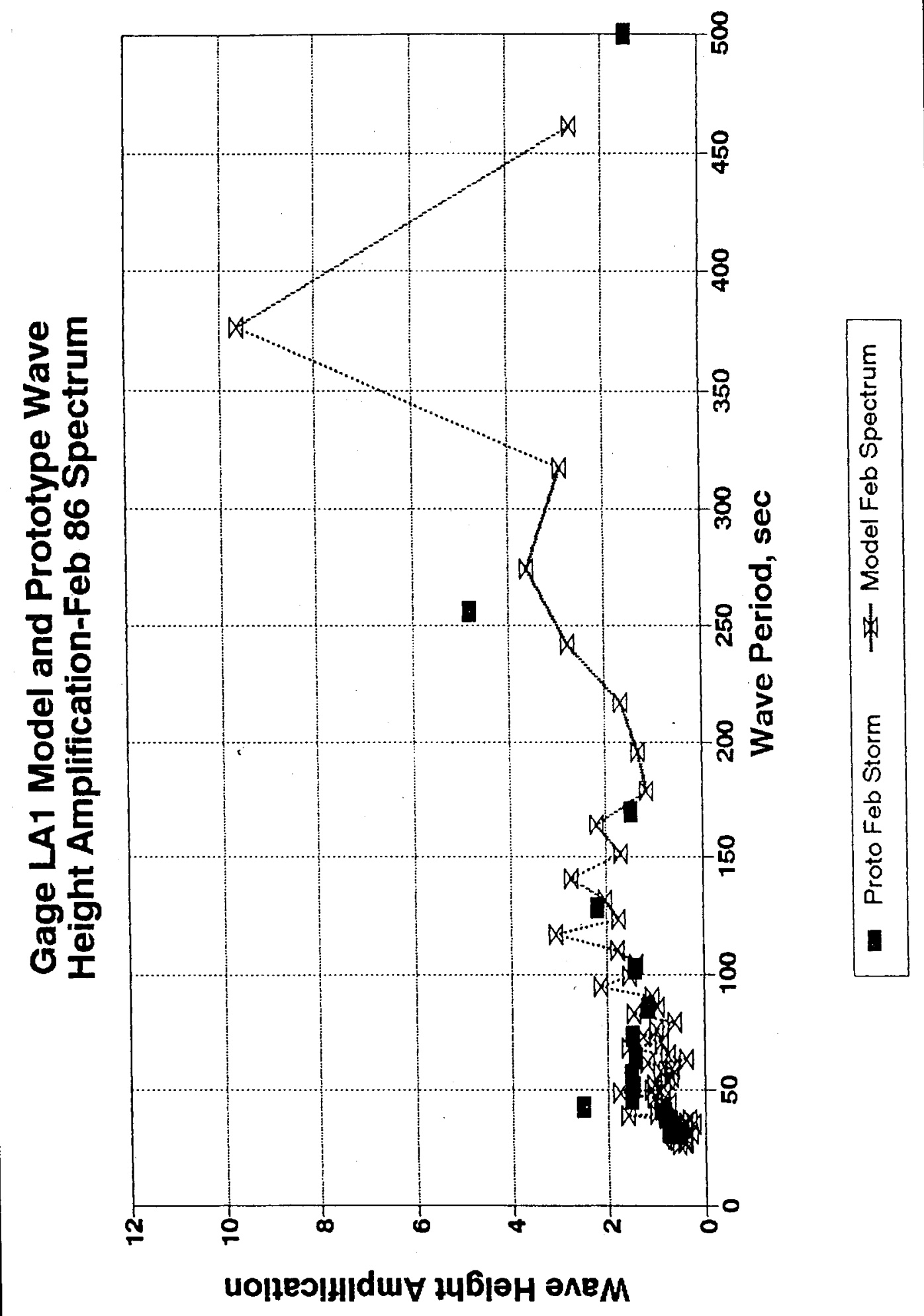

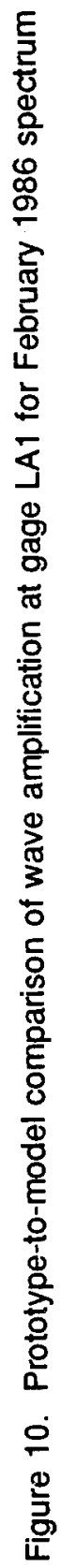




\section{Discussion Of Harbor Resonance Testing}

\section{Introduction}

Wave height amplification data were collected at a large number of gage locations throughout the model harbors. Gages 1-55 (see Plate 1) were base gages, or locations where wave height amplifications were collected in the model for existing harbor conditions (as of 1990). It should be noted that since the base conditions were collected, the Port of Long Beach has widened and deepened the approach to the Navy Basin along Pier F to a greater degree than what was originally tested for base, or existing, conditions. This deepening and widening was due to sand mining for landfill material. Gage numbers higher than 55 represented gages at new or proposed berth locations, and therefore have no base data for comparison. For some gage locations, especially in the Pier 300 area, data were collected for two conditions for both Stages 1 and 2. These conditions relate to whether a $243-\mathrm{m}-(800-\mathrm{ft}-)$ wide opening was in place, or not, in the transportation corridor joining Terminal Island to the Pier 400 landfill. The opening was centered on the centerline of the Pier 300 channel area. The model data plates refer to whether the opening was present or not as "plug removed" or "plug inserted," respectively. The three spectra discussed earlier (uniform, January, and February) were tested for all of the above discussed conditions. A data set was collected for the uniform spectrum for gages 1-30 for the open condition and compared with the closed condition. Otherwise, unless noted on the plot, test conditions were for the closed condition. The hypothesis was that the closed condition would produce the greatest wave height amplifications in the Pier 300 area because a solid wall at the end of the channel would set up a stronger standing wave system than the open condition. This assumed all wave energy was propagating from west to east in the Pier 300 channel. All wave height amplification data are presented in Appendices A through $\mathrm{G}$ in order of gage number. 


\section{Uniform Spectrum Testing}

The uniform spectrum represented more typical wave conditions coming from the south, usually from low to mid-range energy conditions for the harbors. Data for gages 1-55 (note, there is no gage 49) are shown in Appendix A and compare base, Stage 1, and Stage 2 wave height amplifications. Discussion of existing harbor gage locations is followed by examination of data for new berth locations.

\section{Summary data for existing harbor berths' wave height amplifications}

Plates 3-6 provide summary information for the Uniform Spectrum testing at existing berth locations. Wave period bands were averaged into three wider band groups of 25-40 sec, 41-205 sec, and 206-519 sec to look at overall trends. The 41- to 205-sec wave period band is probably the most important with regard to moored ship motion response. Plate 3 shows gage number versus the average wave height amplification for the three wave period bands. Plates 4, 5, and 6 show the average base amplification for each gage over a given band and two difference curves, where the base condition average wave height amplification was subtracted from the Stage 1 and Stage 2 wave height amplification. Positive values of the difference curve indicate increases in amplification for Stage 1 or 2, while negative values indicate decreases in wave height amplification for Stage 1 or 2 . As seen in Plates 4, 5, and 6, there was a net decrease in wave height amplifications for Stages 1 and 2. At locations of greatest increases (Stage 1, Gages 32 and 43), there were reductions in increase for Stage 2. At locations where Stage 2 tended to show increases (Plate 4, Gages 18-27; Plate 5, Gages 20, 21, 25, and 26) the increases were small and located in areas of relatively low response. A more detailed discussion follows below.

\section{Results in LA East and West Channel Basins}

Stage 1. Gages 1, 2, 3, 4, 5, 6, 31, 32, and 33 (Plate 1 shows locations) are on the west side of Los Angeles Harbor in the West Channel and East Channel Basins. The most significant wave height amplification increases over base conditions were in the 242-sec energy band (229- to 258-sec range), with Gages 3 and 31 doubling amplitudes (up to 6.6 amplification). Gage 2 amplifications decreased. Gage 4 showed changes in the 200 - to $300-\mathrm{sec}$ range but amplifications were less than 1.0. Gage 5 (Coal Terminal) had some slight increases in the 40- to 100 -sec period range, with amplifications less than a maximum of 1.6. Large decreases were noted in the 376-sec band at Gage 5. Gage 6, East Channel, indicated a decrease of 50 percent in its highest amplification period band. The 376-sec band (344- to 414-sec range) decreased from an amplification of 10 , to 4.8 for Stage 1. Gage 32 in Cabrillo Basin increased significantly for Stage 1 for periods over $100 \mathrm{sec}$. Gage 33 in East Channel had some increase in the 70- to $80-\sec$ range (amplification up to 2.7) 
and in the 164-sec band (158- to 171-sec period range), up to 3.3 from a base value of 2.0. Probably the most important factors for changes in the region just discussed are the geometry and depth of the shallow-water habitat.

Stage 2. The most significant wave height amplification increases over base conditions were in the 242-sec energy band (229- to 258-sec range), with Gages 1, 3, and 31 doubling amplitudes (up to 5.9 amplification) for Stage 2. Gage 2 indicated an increase at $50 \mathrm{sec}$ from 0.7 to 1.8 amplification. Gage 4 showed changes in the 200- to 300 -sec range but amplifications were less than 1.2. Gage 5 had some slight increases in the 40- to 100-sec period range, with amplifications less than a maximum of 1.6. Gage 6, East Channel, indicated a decrease of its highest amplification period band. The 376-sec band (344- to 414-sec range) decreased from an amplification of 10 , to 7.5 for Stage 2, increasing from the Stage 1 value of 4.8 . Gage 32 on Cabrillo Basin, which increased significantly for Stage 1 for periods over $100 \mathrm{sec}$, reduced significantly for Stage 2. Gage 33 in East Channel had some increase in the 70- to 80-sec range (amplification up to 2.7) but decreased with respect to both Stage 1 and base in the $164-\mathrm{sec}$ band (158- to $171-\mathrm{sec}$ period range). Decreases over the 300 -sec period range were significant.

\section{Results in LA Main Channel and Inner Harbor}

Stage 1. Gages $7,8,9,10,11,34,35,36,37$, and 38 were located along Los Angeles Harbor's Main Channel and Inner Harbor. Gage 7 at Berth $240 \mathrm{C}$ remained similar to base with an amplification of 10 for the $242-\mathrm{sec}$ band, while slight increases occurred in lower period but amplifications were in the range of 1. Gage 8 (Berth 230) showed doubling of peaks up to $100 \mathrm{sec}$, but amplifications remained relatively low (less than 1.7), until the 242-sec band where amplifications increased from a base value of 0.9 to 2.6. Also, the 125 -sec band nearly doubled in value. Gage 9, at the passenger ship terminal, showed decreases over all periods. Gage 10 (Berth 109) had complete reductions in wave height amplifications. Gage 11 increased to amplifications of 1 in the 55- to 65 -sec period. Gage 34 showed overall reduction. Gages 35 and 36 decreased overall, except for a peak at $63 \mathrm{sec}$ (Gage 35) of 1.5. Gage 37 increased in the 200 - to 400 -sec band with a maximum amplification of 2.0. Gage 38 showed no significant change.

Stage 2. Gage 7 decreased significantly to an amplification of 5 for the 242 -sec band Stage 2 test, while Stage 1 was near base value at an amplification of 9. Gage 8 showed more than doubling of peaks up to $100 \mathrm{sec}$, but amplifications remained relatively low (less than 1.7). Stage 2 caused the greatest increases in this lower period range, but amplifications at $242 \mathrm{sec}$ reduced significantly from Stage 1, below existing conditions. Gage 9, at the passenger ship terminal, showed decreases over all periods. Gage 10 had complete reductions in wave height amplifications. Gage 11 increased in the 55- to 65-sec period range with maximum amplification of 2.4 for Stage 2 . Gage 34 showed overall reduction, with increases up to only 3.7 for wave height amplification (from base maximum amplification of 3.2) for Stage 2 in 
the 111- to $124-\mathrm{sec}$ band region. Gages 35 and 36 decreased overall, with increases only at Gage 35 for a peak of $95 \mathrm{sec}$, with maximum amplification of 2.6. Gage 37 increased relative to base but decreased relative to Stage 1 in the 200 - to $400-\mathrm{sec}$ band. Maximum amplifications were less than 1.4. Gage 38 showed no significant change.

\section{Results in Fish Harbor}

Stages 1 and 2. Gages 12, 13, and 39 are located in Fish Harbor. Each gage overall had significant wave height amplification decreases for both Stages 1 and 2. Only one minor increase was noted (Gage 39, at $45 \mathrm{sec}$ ) where wave height amplitude increased from 0.9 to 1.8 for Stage 1 .

\section{Results at existing condition gages in Pier 300 Channel}

Stages 1 and 2. Gages 14 and 40, located in the new Pier 300 channel region have base data taken for existing conditions, i.e., no Pier 300 channel or Pier 400 landfill. Data showed that both Stage 1 and 2 wave height amplifications decreased significantly from existing conditions.

\section{Results at Long Beach Naval Basin}

Stage 1. Gages 17, 18, 43, and 44 are located in Long Beach Harbor's Navy Basin. Gage 17 indicated significant decreases at peak periods of 74 and $83 \mathrm{sec}$. A slight increase in the 300 - to 400 -sec range occurred, with peak amplification of 2 for Stage 1, compared with base amplification of 1.8. Gage 18 showed reductions for the larger amplification period bands of 83,164 , and all bands beyond $217 \mathrm{sec}$. Period bands with increases of amplification were $61 \mathrm{sec}(1.7), 105 \mathrm{sec}$ (1.3), and $196 \mathrm{sec}$ (1.6). Gage 43, in the northwest corner of the Navy Basin, was in a shallow depth, which results in shoaling of the wave and an increase in wave height as it traveled into shallow water. Therefore, the amplifications were relatively higher than the other three Navy Basin gages. Most of the base condition peaks were reduced from $80 \mathrm{sec}$ on up, except for the change in amplification from a value of 3 to 5 at $124 \mathrm{sec}$. Increases in the 30- to 70 -sec range had amplifications as high as 3.5 at $50 \mathrm{sec}$. Gage 44 had notable increases at $43 \mathrm{sec}$ (amplification $=2.5$ ) and in the 300-400 period range. Changes from base conditions in the Long Beach Inner Harbor area, including the Navy Basin, may be due in part to the increased width and depth of the navigation channel along Pier F leading up to the Navy Basin, which was not constructed in the prototype or the model when model base tests were run.

Stage 2. Gage 17 indicated significant decreases at peak periods of 74 and $83 \mathrm{sec}$. A slight increase in the 300 - to 400 -sec range occurs. Gage 18 showed reductions for the larger amplification period bands of 83,164 , and all bands beyond $217 \mathrm{sec}$. Period bands with increases of amplification were 
$61 \mathrm{sec}(1.7), 105 \mathrm{sec}$ (1.3), and $196 \mathrm{sec}$ (1.9). Most of the base condition peaks at gage 43 were reduced from $80 \mathrm{sec}$ on up except for the change in amplification from a value of 3 to 4.2 at $124 \mathrm{sec}$. Increases in the 30 - to 70 -sec range had amplifications as high as 3.6 at $50 \mathrm{sec}$. Gage 44 had increases at $43 \mathrm{sec}$ (amplification $=1.8$ ) and had decreases relative to Stage 1 .

\section{Results at Long Beach Inner Harbor and East Basin}

Stages 1 and 2. The gages in the Long Beach Inner Harbor and East Basin region (Gages 19, 20, 21 (Slip 3), 22 (Slip 2), 23 (Slip 1), 24 (Pier A), 45 and 46 (Arco Oil Terminal) are considered next. There is some interaction at certain longer wave periods between most of these gage locations, particularly in the 300- to 400 -sec range. Increases over base conditions for this period range occurred at these gage locations, though increases at Slips 1 to 3 were low. Peaks in the 200-sec period range also increased for Gages 20 and 21 by about 25 to 40 percent. A large peak at Gage $22(77 \mathrm{sec})$ was reduced from 4 to 2 .

\section{Results at Long Beach Southeast Basin}

Stages 1 and 2. Gages 25 (Banana Terminal), 26 (Berth 205), 27 (Berth 226), 28 (Berth 231), 29 (Berth 242), 30 (Berth 245), 47 (Berth 211) and 48 (Berth 247) are located in the Port of Long Beach's Southeast Basin. Some of the larger peak periods increased from the base condition for a variety of wave periods. This common rise may indicate change due to those differences in the Long Beach channel configuration since the base data were collected. However, the only way to positively determine this would be to run new base conditions, i.e., remove the Port of Los Angeles Stage 2 configuration and place existing condition contours in the model. There are, however, some periods which do indicate an effect of Pier 400 on the response of the Long Beach gages. The peaks at $164 \mathrm{sec}$ at Gages 25, 26, 27, and 30 indicated a decrease for Stage 1 and an increase for Stage 2 relative to base conditions. Gages 29,47 , and 48 showed increases for both stages at the $164-\mathrm{sec}$ period. Gage 48 showed no change at $164 \mathrm{sec}$.

\section{Results at Long Beach Pier J}

Stages 1 and 2. Gages 50, 52, 53, and 54 were in the Long Beach Pier $\mathbf{J}$ region and had only slight change. It should be noted that additional information was provided for recent dredging east of the Pier $J$ expansion berthing area. This was included in the model construction for this study and does not appear to impact model results. 


\section{Summary Data at New Berth Locations - Stages 1 and 2}

Plates 7-10 provide average wave height amplifications for the three bands as discussed earlier: $25-41 \mathrm{sec}, 42-205 \mathrm{sec}$, and 206-519 sec. Data are presented in two ways. First, Stage 1 data are compared for closed and open conditions at the transportation corridor (Plate 7) followed by the same comparison for Stage 2 data (Plate 8). Second, Stage 1 is compared to Stage 2 data for the closed transportation corridor (Plate 9), then similarly for open transportation corridor data (Plate 10). Plate 7 shows that for Pier 300 berths (Gages 64-68) with Stage 1 there was a slight increase in wave height amplification for the open condition at all locations except Gage 66 in the longer wave period bands. For Stage 2 (Plate 8), the same trend continued. Plates 9 and 10 indicate that for the 25 - to 40 -sec range, Stage 2 had greater amplifications than Stage 1 for closed or open conditions. In the 41- to 205-sec range, Stage 2 generally had a slightly lower response than Stage 1 for closed conditions, but had a slightly higher response when open. In the 206- to 519-sec range, Stage 2 showed increased response for both open and closed conditions.

\section{New Berth Locations Response - Stages 1 and 2}

Plates 1 and 2 show gage locations for new berth areas. Data are located in Appendix B. Gages 59A, 62A, and 71A were only used for Stage 1 testing. Gages 71-77 were only used for Stage 2 tests. At locations where data were collected for both stages, there is a data plot for the closed test, i.e., no opening in the transportation corridor connecting Terminal Island to Pier 400 and another plot for the open test, which had the 244-m (800-ft) opening. Stages 1 and 2 are included in each of these data plots.

Gage 56, located on the corner of the shallow-water habitat, indicated a moderate response (amplifications no greater than 2.1) at all wave periods for both Stages 1 and 2. Data for Gages 57, 58, and 59 should only be considered for Stage 2, as Stage 1 did not incorporate a channel along that east side of the landfill. Gage 57 in the corner of the southern slip showed moderate response with maximum amplifications of 3.5 in the 100 - to $150-\mathrm{sec}$ and 250 - to $350-\mathrm{sec}$ period ranges. The status of the transportation corridor opening did not affect this area. Gages 58 and 59 followed the same trend as 57, but had slightly lower response; Gage 60 , not a berth location, facing the entrance channel, showed low to moderate response. Gages 61 and 62, on Pier 400's west side, indicated low-to-moderate response also, with maximum wave amplifications of 2.3 at gage 61 and 2.2 at gage 62 .

Gages 63-68 and 71-77 are located in the channel area on the north side of the Pier 400 landfill. Results for Stages 1 and 2 are contained in Appendix B. Important to note is that all gages had very moderate responses. There are only a few peaks which exceed a wave height amplification of 2 for Stage 1, and these are at the long-period band of $376 \mathrm{sec}$ at Gages 63 and 64 (amplifications of 2.5 and 2, respectively, open condition). Variations occurred when comparing open versus closed conditions at the transportation corridor. For 
Stage 1 conditions, surprisingly, the open condition indicated a greater response than when there was no opening. Evidently, energy from the Long Beach side was "feeding" the berth area through the opening in the transportation corridor, because when closed (and maximum standing waves would be expected), there was lower energy. The effect of Stage 2, seen by examining Gages 68 and 70 (closed condition), indicates that increased energy occurred due to greater channel depth, particularly at longer periods with the closed condition. Maximum values of wave height amplification were near 3 for the 318 -sec period band at both these locations. There were a few increases in lower periods for Stage 2, but maximum amplifications remained about 2 .

Gage 69 was located between the transportation corridor and the Navy Mole. This was a shallow area and was gaged in order to see if resonance conditions occurred there which contributed to flushing this area. As noted, there are large amplifications of wave height at $50 \mathrm{sec}, 150 \mathrm{sec}$, and $275 \mathrm{sec}$ for all conditions tested, indicating good mixing potential due to long waves in this narrow corridor.

\section{Effect of closure/opening of transportation corridor on existing berth locations - Stage 2 condition}

Wave height amplification data for Gages 1-30 (existing sites), Stage 2 conditions, were obtained for the 244-m- (800-ft-) wide "open" condition and compared to the "closed" condition. These data are found in Appendix C. Previously, discussion for the existing berths (Appendix A) were for the "closed" condition. Therefore, these plates will be examined to contrast the effect of the opening with the "open" condition. Gages 1-6 on the west side of Los Angeles Harbor showed slight decreases for the open condition relative to the closed condition. Gages 7-11 are along Los Angeles Main Channel and Inner Harbor area. Except for Gage 7, slight decreases were noted in wave height amplification for the open condition. Gage 7 showed some increase, especially at the 242-sec band peak for the open condition. Opening the transportation corridor for Stage 2 reduced amplifications in Fish Harbor (Gages 12 and 13 ), which already had been reduced significantly with the closed condition. Gage 14 in the Pier 300 channel showed slight increases for the open condition, similar to Gage 66 (adjacent gage, discussed earlier).

On the Long Beach side of the harbor, Gages 17 and 18 in the Navy Basin indicated slight decreases of wave height amplification for the "open" condition when compared to "closed." Gages 19 and 20, in the Long Beach Inner Harbor area, had a similar trend, with a few increases at shorter periods. Gages 21-24, in the Long Beach East Basin area, all showed some decrease with the "open" condition for resonant peaks. Gages 25-30 in Southeast Basin indicated decreases in peak amplitudes except at Gage 27 for the open condition. 
Generally, with the 243.84-m (800-ft) opening, slight decreases of peak amplitudes at existing gage locations outside the Pier 300 berth area were noted.

\section{February Spectrum Testing}

\section{Summary data plots}

The February spectrum was representative of storm conditions from the west. Plate 11 shows results of grouping wave periods in 25 - to $40-\mathrm{sec}, 41$ - to 205-sec, and 206- to 519-sec period bands, and plotting these average wave height amplifications for existing condition base gage locations. Plates 12-14 show differences between base amplifications and Stage 1 and 2 amplifications. Trends are similar to those of the Uniform Spectrum (Plates 3-6), except for a slightly increased response at the Long Beach end of the harbors for Stage 2.

Plates 15-18 show the wave period band averaging for the February spectrum at the new berths and may be compared to Plates 7-10, Uniform Spectrum data. The trends shown for the "open/closed" data (Plates 15 and 16) were similar to Uniform Spectra data except that amplifications are slightly increased and the increase for "open" versus "closed" transportation corridor is slightly greater for the February spectrum than the uniform spectrum.

\section{Response at existing berths}

An examination of the existing location harbor gages indicates, for the most part, a response very similar to that for uniform wave spectrum conditions (wave height amplification data located in Appendix D). For example, Gage 5, uniform spectrum, can be compared to the February spectrum Gage 5 data. Trends between the two data sets were very similar. The increase for Stage 2 at 75 and $95 \mathrm{sec}$ and the relative changes between base, Stage 1, and Stage 2 at $132 \mathrm{sec}$ (decrease in wave height amplification), $164 \mathrm{sec}$ (increase), and $376 \mathrm{sec}$ (decrease), were similar. Amplifications for the February spectrum tended to be slightly greater than the uniform spectrum. Gage locations with some difference in response from the uniform spectrum were Gages 32 and 33, indicating less response in Cabrillo Basin and Berth 52, respectively, for the February spectrum for Stage 1. Gage 50 at the Shoreline Marina showed higher response for $38 \mathrm{sec}$ and $52 \mathrm{sec}$ for both Stages 1 and 2.

\section{Response at new berths}

Responses at new berth locations for the February spectrum (Appendix E) indicated trends similar to the Uniform Spectrum, except that some amplifications were higher. When open-versus-closed causeway conditions are compared, trends were similar to that of the Uniform Spectrum. 


\section{Summary}

In summary, responses for the February spectrum wave height amplification data were very similar to the uniform spectrum data at most gages, with some increase in peak amplifications occurring for the higher energy condition from the west.

\section{January Spectrum Testing}

\section{Summary data plots}

Averaged January spectrum wave height amplifications are shown on Plate 19 for existing gage locations. Plates 20-22 show differences from base conditions for the 25- to 40-sec, 41- to 205-sec, and 206- to 519-sec period bands, respectively. Trends were similar to the February spectrum data in Plates 12-14 discussed earlier.

\section{Response at existing berths}

Appendix F contains wave height amplifications for base gage locations. Gages 1-6 and 31-33 on the west side of Los Angeles Harbor followed trends of the uniform spectrum tests, indicating decreases in wave height amplifications with only a few exceptions. At Gage 5, the coal terminal, amplifications increased to 2.5 and 3.2 in the 70 - and $90-\mathrm{sec}$ period ranges, respectively, for Stage 2 (where base values were 1 and 1.6 respectively, and Stage 1 values were 1.5 and 2.1 , respectively).

Gages 7-11 and 34-38 indicated similar trends between base, Stage 1, and Stage 2 as for the Uniform Spectrum, with the following exceptions. Gage 8 had increases for Stage 2 at $40 \sec (2.4$, base 0.6$)$ and $55 \sec (2.4$, base 1.4), Gage 34 for Stage 2 - $32 \mathrm{sec}$ (4, base 1.2). Gage 38 indicated decreases relative to base conditions while the uniform spectrum had increases at the $242-\mathrm{sec}$ band.

Gages 12, 13, and 39 (Fish Harbor) had some increases over base for Stage 2 where the Uniform Spectrum indicated decreases. The period range was 95-120 sec and maximum amplifications were less than 3.

The Long Beach Naval Ship Yard (Gages 17, 18, 43, and 44) had some increases relative to base which uniform spectrum tests did not have at 150 and $200 \mathrm{sec}$ for both stages. Gages 22, 23, and 24 showed the same trend for $150 \mathrm{sec}$.

The Long Beach Southeast Basin had a few locations which indicated increased response at a few wave periods. Gage 27 peaked at 5.0 for $152 \mathrm{sec}$ for Stage 1 compared to a wave height amplification of 3.2 for base. Gage 29 
had a wave height amplification of 5.0 for Stage 2, compared to a base condition of 2.5 .

\section{Response at new berths}

Trends in response for new berth locations for the January spectrum (Appendix G) were similar to the Uniform Spectrum, except average wave amplification was greater, usually by a small amount, especially in the 30 - to 100 -sec period range. Occasionally some relatively narrow peaks increased significantly over those of the Uniform Spectrum data. Also, the slight increase is greater at the new berth locations when there is an opening in the causeway as opposed to a closed condition.

Plates 23-26 show average wave height amplifications at new berth locations and are very similar to February spectrum results (Plates 15-18). The trend for higher amplifications for the condition with an opening in the transportation corridor for both Stages 1 and 2 was repeated, plus the trend for slightly higher amplifications for Stage 2 than for Stage 1 was again seen. Plates 27-30 compare similar test conditions for all three spectra tested. The January spectrum had higher wave height amplifications than the February spectrum for the 25 - to 41 -sec period range but was very close for the 42 - to 205-sec and 206- to 519-sec ranges.

\section{Summary}

Responses for the January spectrum wave height amplification data were very similar to responses seen for the Uniform Spectrum at most gages, with some increases in peak amplifications occurring for this infrequent high energy condition.

\section{Surface Current Photographs}

Photos 3-5 show time-lapse movement of surface current floats in the Pier 300-Pier 400 channel. Each photo compares the corridor-closed condition to the corridor-open condition for the three spectra tested. All photos were taken at identical times during the test. The duration of the exposure $(8 \mathrm{sec})$ was sufficient to capture all period modes. The length of white streaks is proportional to current speed. Among each individual pair, there was slightly greater movement for the corridor-open condition, except at one location beneath the sign for the February spectrum corridor-closed condition. The above supports the wave height amplification data, which indicated more energy in the channel for the corridor-open condition. The lengths of these streaks were notably less than would be seen in more energetic berth areas such as the Port of Los Angeles' East Channel. 


\section{Use Of Model Results To Evaluate Potential for Moored Ship Motion Problems}

\section{Introduction}

In order to attach a more quantitative interpretation to the physical model results, the following rationale for translating model data to prototype conditions was developed.

Model data discussed in this report are presented in a nondimensional format, in terms of wave height amplification. This amplification, as discussed earlier, is a ratio of wave height at a harbor gage to an ocean wave height. This report, up to now, has focussed on relative changes occurring in the harbors. It is known that large wave amplifications are indicative of problem areas. For example, maximum amplifications at Gage 6 (see Appendices A, D, and $\mathrm{F}$ for data) range from 10 to 14 , and values this high can be considered to be an indicator of troublesome conditions, because the prototype slip is used little due to the excessive motion of moored ships. However, it is difficult to determine at exactly what level of wave height amplification and wave period a problem may develop at a berth without using some criteria related to moored ship motion in terms of energy or wave height. Problems with regard to moored ship motion include an increase in loading/unloading time, abrasion of lines and/or bollards (in the case of steel lines), or breaking of lines. Possibly useful criteria are discussed below.

\section{Approach}

If wave energy probability distribution for long waves in the ocean is known, it is proposed that energy probability distribution at a given gage in the harbor can be determined by use of a transfer function, which is the wave 
energy amplification measured in the model. This in turn may be converted to a wave height distribution by using the relationship

$$
H_{s}=4 \sqrt{E}
$$

with $E=$ energy in the frequency range of interest and $H_{s}$ the significant wave height representative of the frequency range specified. Rosati and McKinney (in preparation) have compiled long-wave data from 1984-1991 to develop probability of exceedance plots and tables for wave energy at Platform Edith and other harbor gages (see Figure 7 for locations) for the wave energy frequency bands from 0.04 to $0.001953 \mathrm{cps}$, which covers energy in a wave period range of 25 to $1,024 \mathrm{sec}$. Figure 11 shows a sample plot of this data for Gage LA-1, with long-period energy grouped into two bands. This type of information can be used with the model harbor resonance information and criteria for the occurrence of moored ship problems (discussed below), to determine if a location could potentially have a problem.

A basic assumption under which the analysis was made is that the longwave energy measured for each frequency at the prototype wave gage in the ocean is the same energy transformed to the harbor entrance. Possible reasons this may not be true would be the existence of free long-wave energy reflected from the shore and moving seaward so that a portion of the measured ocean energy would not be approaching the harbor, or free long-wave energy could be trapped by alongshore contours and propagate along the shore. Also, there may be other mechanisms creating free long waves. However, analysis of wave data indicates a good correlation between wave energy at Platform Edith and the harbors. At the harbor gages themselves, a possible reduction in correlation of harbor response to offshore long-wave conditions could be due to nonlinear transfer of energy to other harmonics, but this does not appear to be a strong mechanism for a harbor of large depth, like LA-LB Harbors.

Examining prototype wave data, a good correlation between long-wave energy at Edith and the harbor gages is noted. An example of this is shown in Figure 12, where a 1-month record of total long energy in the 25- to 512-sec bands is plotted for the ocean gage at Platform Edith and the harbor gage LA-4 (see Figure 7 for gage locations). As the ocean long-wave energy increases and decreases, so does the harbor long-wave energy. Also there is good correlation between short-period wave energy approaching the harbor and long-period energy measured at Platform Edith, indicating that most longperiod energy measured at Edith is bound energy and that long free energy is a small part of the long energy measured at Edith for most wave conditions. Figure 13 shows how long- and short-wave energy at Platform Edith correlate strongly to each other, to hurricanes and tropical storms off Mexico, and to Southern Hemisphere swell. Figure 14 shows the strong correlation between the short, or wind-wave height and the long-wave height (see Figures 13 and 14 , note that "infragravity" and "long" wave energy are identical terms). 


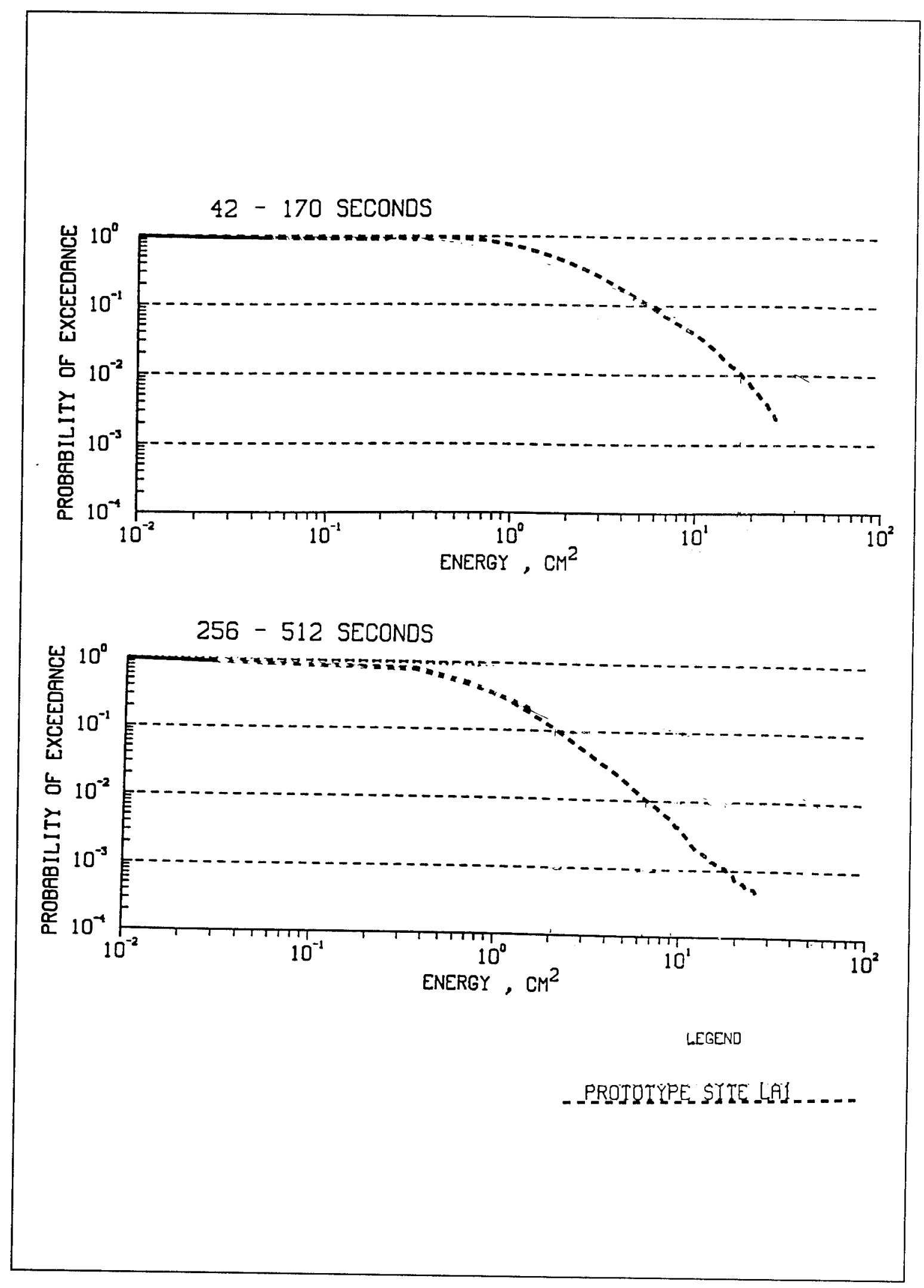

Figure 11. Energy probability of exceedance for $42-$ to $170-\mathrm{sec}$ and 256- to $512-\mathrm{sec}$ energy bands at Gage LA-1 


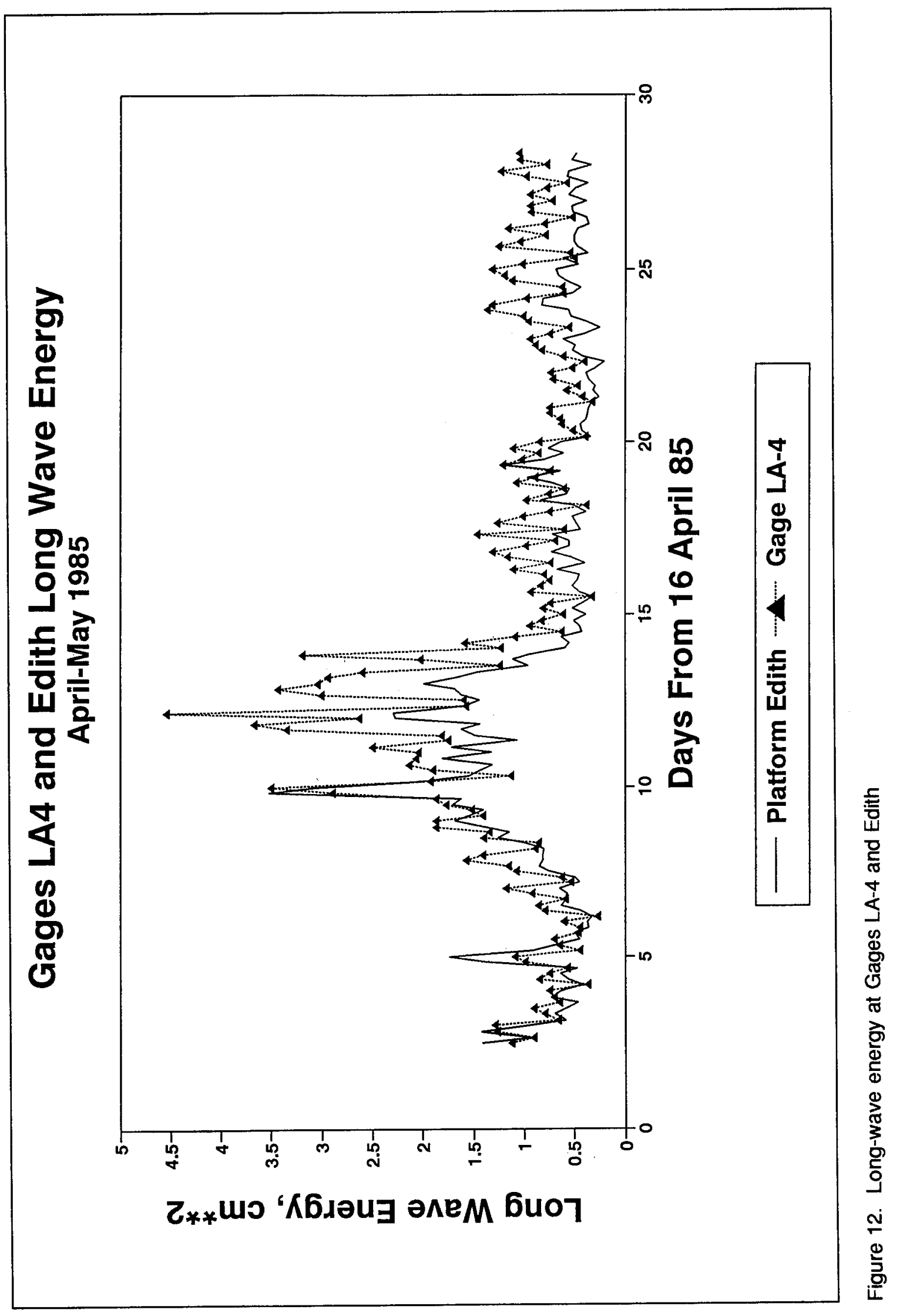




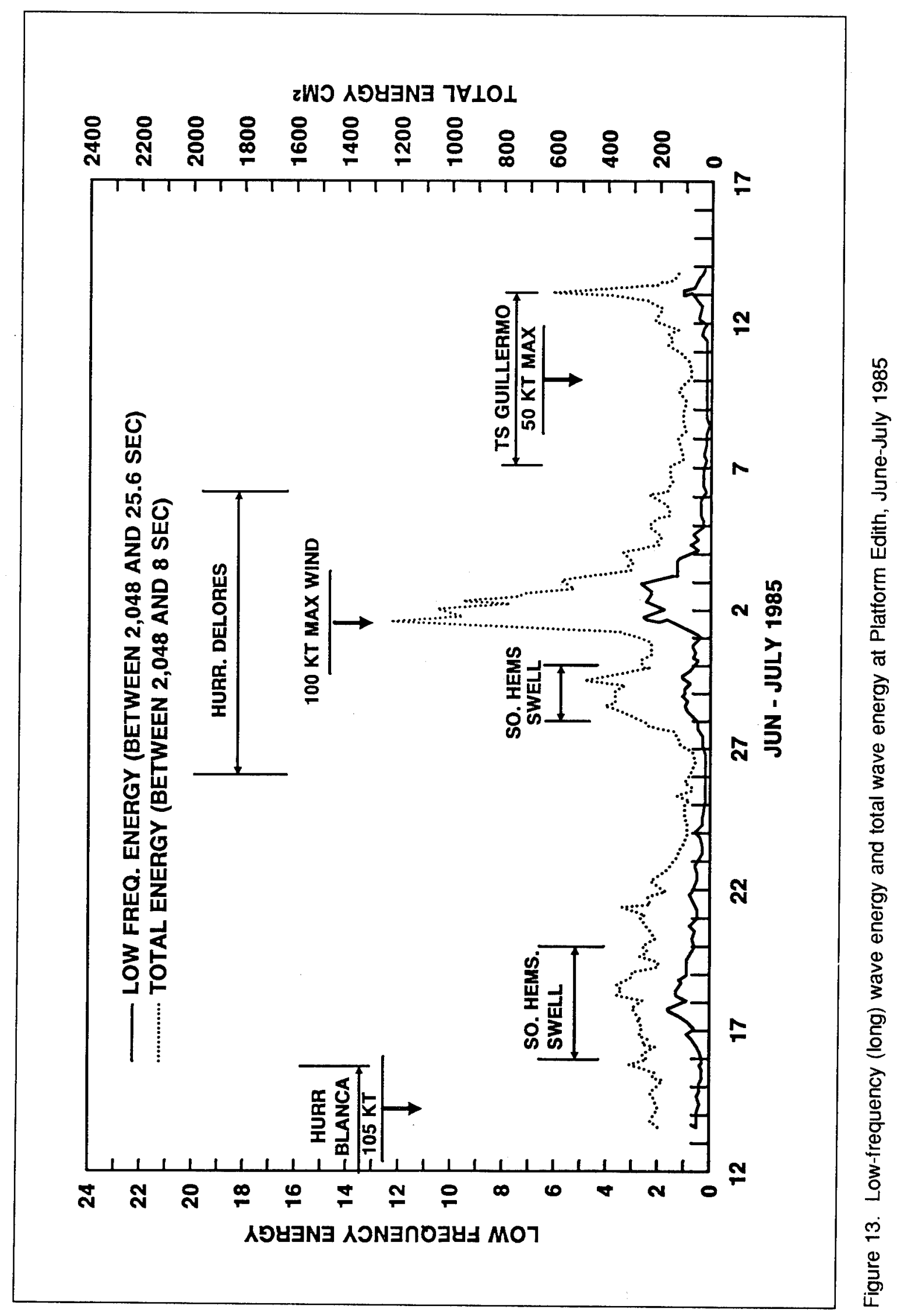




\section{Infragravity vs Wind Wave Height In Ocean, All Data}

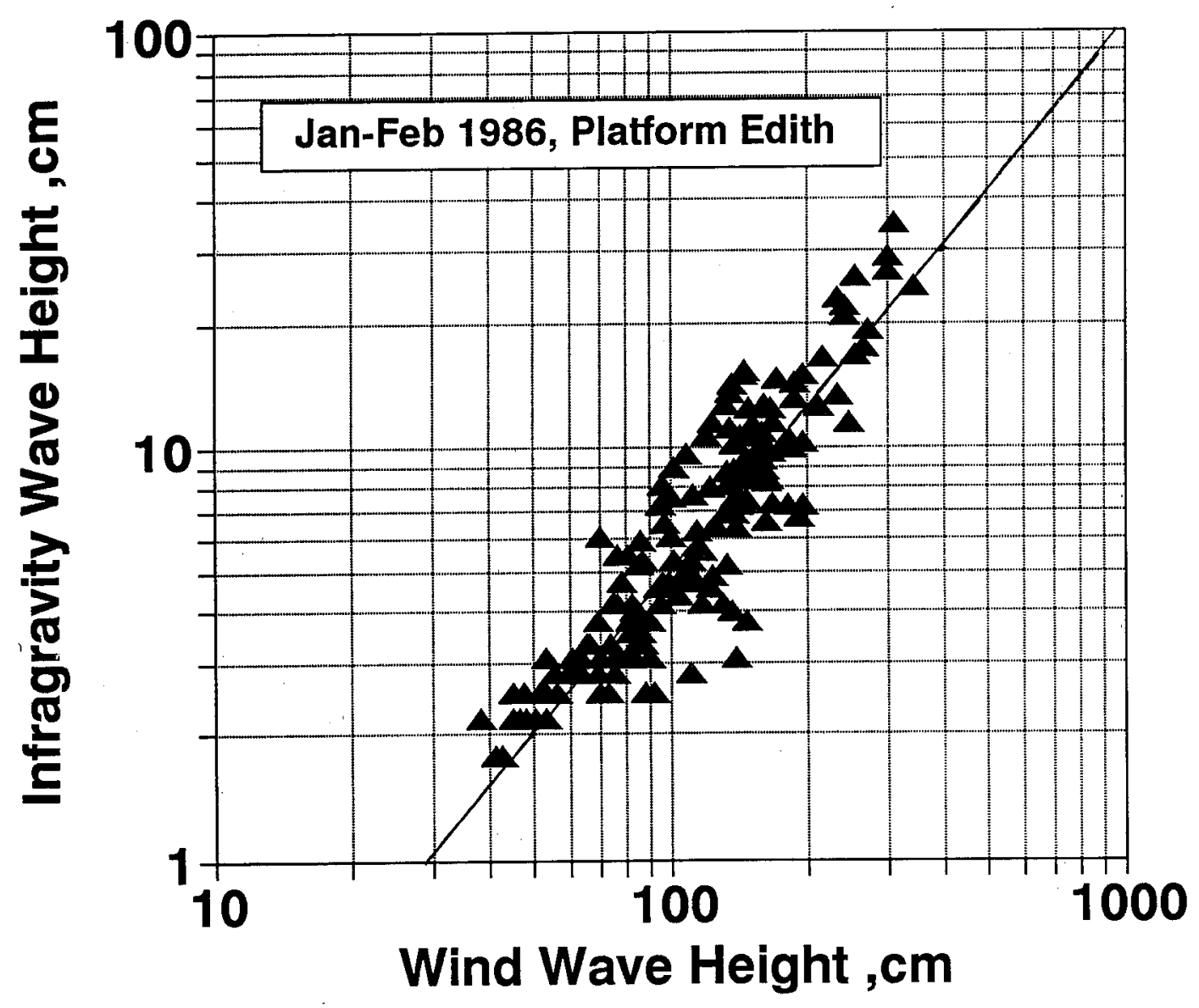

- All Data

Figure 14. Infragravity (long) wave height versus wind wave height at Platform Edith, January-February 1986 


\section{Moored Ship Wave Height Criteria}

Based on field studies, Wilson (1967) determined a relationship between long wave period and wave height, which indicates the level at which problems for berthed ships might occur. Examining Wilson's relationship in Figure 15, it is seen that as long wave period increases, a greater wave height is required to cause damage. Another reference suggests that for 100 -percent cargo handling efficiency, the significant wave height for long waves should be less than 5-10 cm if man-made fiber lines are used, and less than $10-15 \mathrm{~cm}$ if steel wires are used for mooring. ${ }^{1}$ Comparing this to Wilson's curve, it is seen that the two criteria are in reasonable agreement.

Ship motion observations were made by personnel working at Berth 245 in Long Beach Harbor near Gage LB2 (Burke, unpublished data) (location shown in Figure 7) using a classification of moored container ship movement as light, medium, and heavy, and then matched with the long period wave height in the 41- to 205-sec period range (Seabergh, in preparation). These data indicate wave heights ranging between 2 and $17 \mathrm{~cm}$ for notable ship movement. Figure 16 shows a set of this data.

Based on all of these data and the criteria discussed above, a threshold value for long-wave height of $5 \mathrm{~cm}$ was selected on which to determine if concern should be directed to particular berth locations for the wave period range of 41 to $205 \mathrm{sec}$. For the 206- to 1,024-wave period range, the threshold value was raised to $10 \mathrm{~cm}$ in light of Wilson's relationship (Figure 15).

\section{Application}

The next step was to combine the prototype 42- to 170-sec energy bands (covering the 40 - to 205 -sec period range) for each analyzed prototype data record, and then ordering the data to create a probability of exceedance curve of wave energy for Platform Edith. This curve then was multiplied by the model's amplification factor (in this instance the model amplification factor was a ratio of model wave energy at a harbor gage to a wave energy in the ocean) at a given harbor gage for both base and plan condition. The energy value for the 0.01 probability of exceedance was selected, from which wave height was determined. Therefore, from $E_{0.01, \text { total } 41-205}$ the wave height $H_{s}$ was determined by

$$
H_{s}=4 \sqrt{E_{\text {total } 41-205}}
$$

\footnotetext{
1 Personal Communication, 13 October 1993, Drs. Kimo Walker and Paul Szwetlot, Pier 400 Design Consultants, Los Angeles, CA.
} 


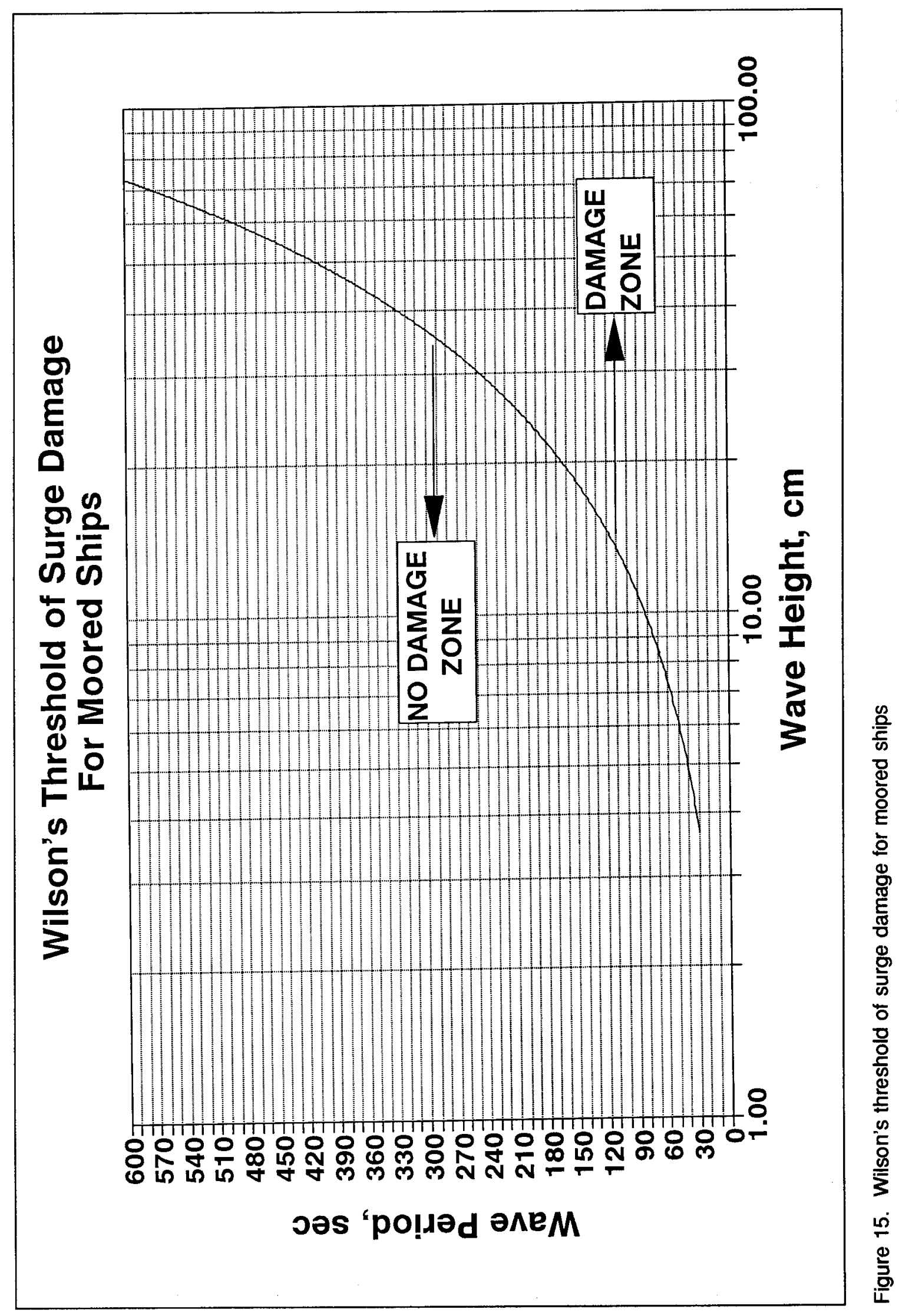



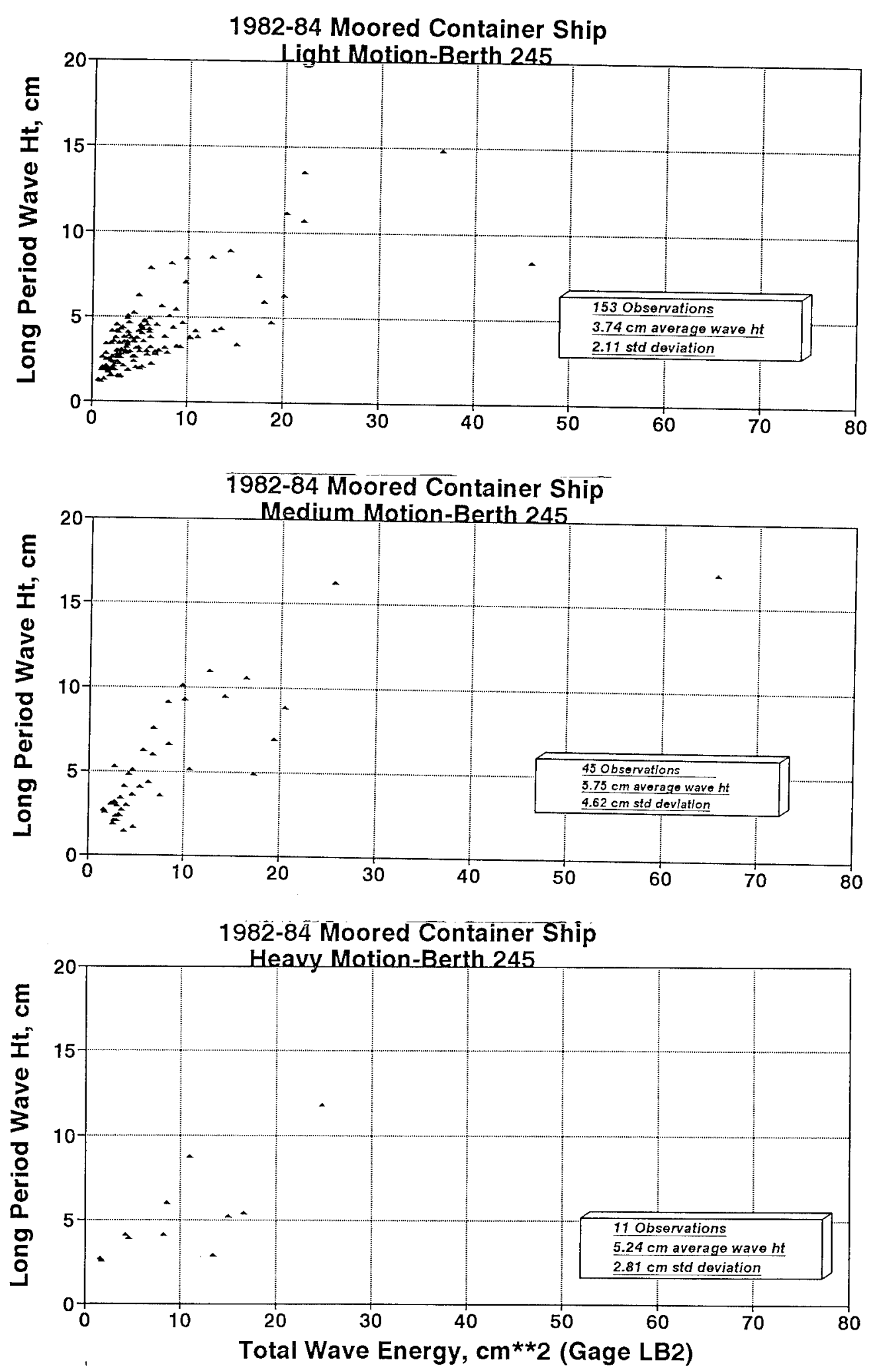

Figure 16. Moored ship observations, Berth 245 
The 0.01 probability represents a wave height which would be equaled or exceeded for 3.65 days a year.

Figure 17 shows a comparison of the 0.01 probability of exceedance wave at the prototype gages for the 41- to 205-sec wave period range and model values determined by applying the model harbor gage amplification to the Platform Edith data as described in the previous paragraph. Data points are plotted along with an equal value line. The trend was for the model value to be higher than the prototype value, indicating this analysis technique gave conservative results, i.e., the model slightly overpredicted wave height. The reason for this result was likely to be use of the model "Uniform" Spectrum, which has its primary approach from the south. The larger energy conditions are usually from the west and the protection the harbor receives from larger storms out of the west would result in slightly lower amplification values when the Platform Edith gage is used as reference. Also, there is more directional spreading of long-wave energy for storm conditions which would reduce energy directed at the harbors, compared to the direct southerly approach of the Uniform Spectrum in the model.

\section{Results}

This section will examine the model results in light of some of the above techniques and criteria. Figure 18 shows the results of the analysis technique at Gage 40 (see Plate 1 for wave gage locations), located in the proposed new berth at Pier 300 area as an example. Plots like this one were prepared comparing the base and Stage 1 energy amplifications and are presented in Rosati and McKinney (in preparation). Values of energy amplification were determined at the $0.01\left(10^{-2}\right)$ exceedance level. Table 5 presents the results of applying the technique discussed above (see Plate 1 for gage locations). Only Stage 1 data were analyzed in this manner. It should be emphasized that the values in the table are conservative, as discussed above, and that the 0.01 level represents just 3.65 days per year. In the $42-$ to $170-\mathrm{sec}$ period band range, which is the likely range producing inefficiency in loading/unloading, most changes between base and Stage 1 were decreases in wave height and most increases were slight. Larger increases (over 20 percent) for Stage 1 included gage locations 8 (LA Harbor container terminal along main channel) and 32 (LA small boat marina).

In the longer period range ( $>205 \mathrm{sec}$ ), where moored ship response is likely to be less than that for the $41-$ to $205-\mathrm{sec}$ period range at a given energy level and problems relate to strength of lines used, Gage 19 (LB oil terminal), Gage 21 (LB slip 3), Gage 22 (LB slip 2), Gage 28 (LB container terminal), Gages 31 and 32 (LA Cabrillo Marina), Gage 43 in the Navy Basin and Gage 45 in the LB back harbor had increases greater than 20 percent and 0.01 probability of exceedance levels greater than the $10-\mathrm{cm}$ wave height. The most extreme changes were in the LA Cabrillo Basin, which is a small craft basin and should not affect the boats themselves; however, it could affect 


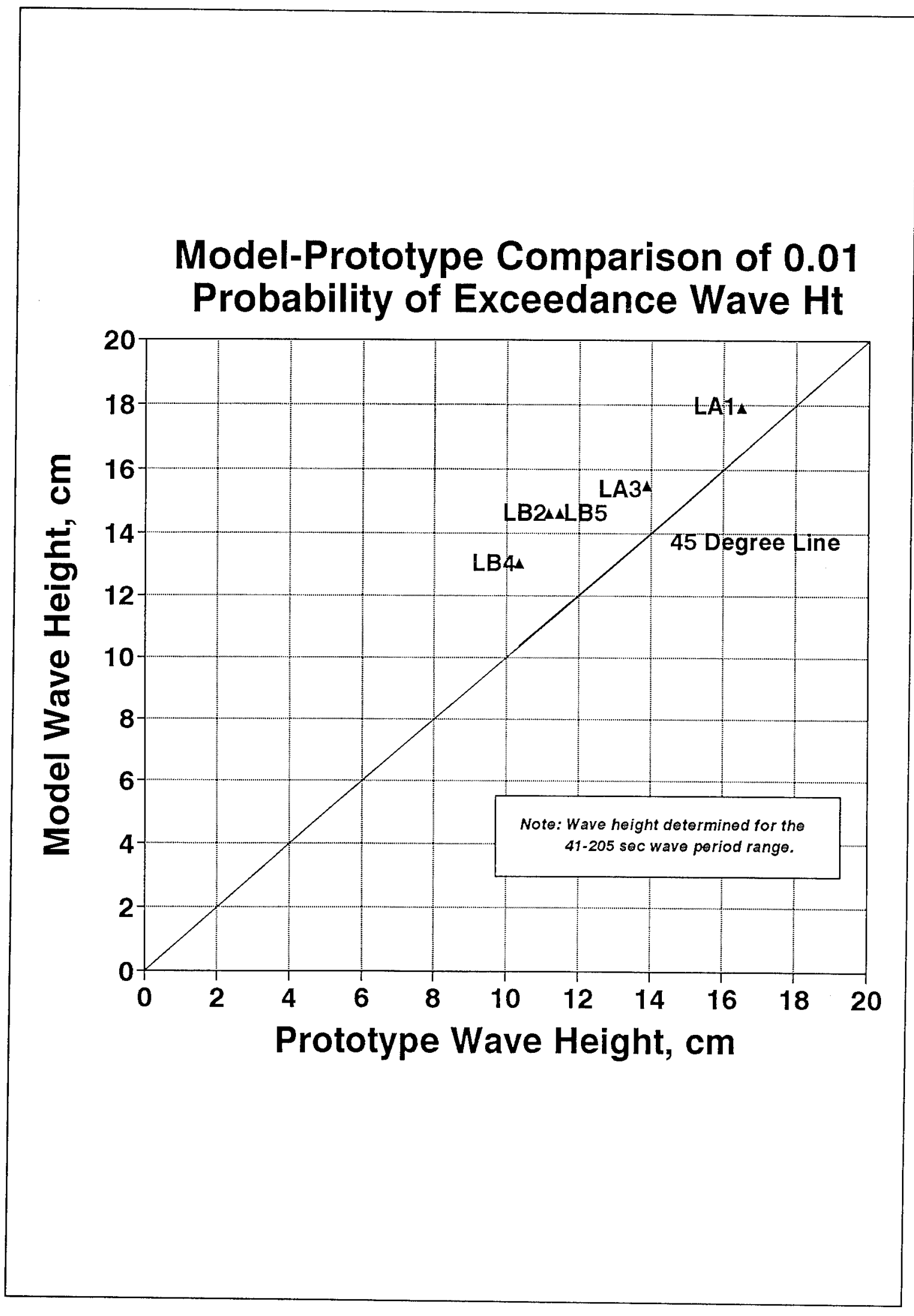

Figure 17. Model-prototype comparison of 0.01 probability of exceedance wave height 


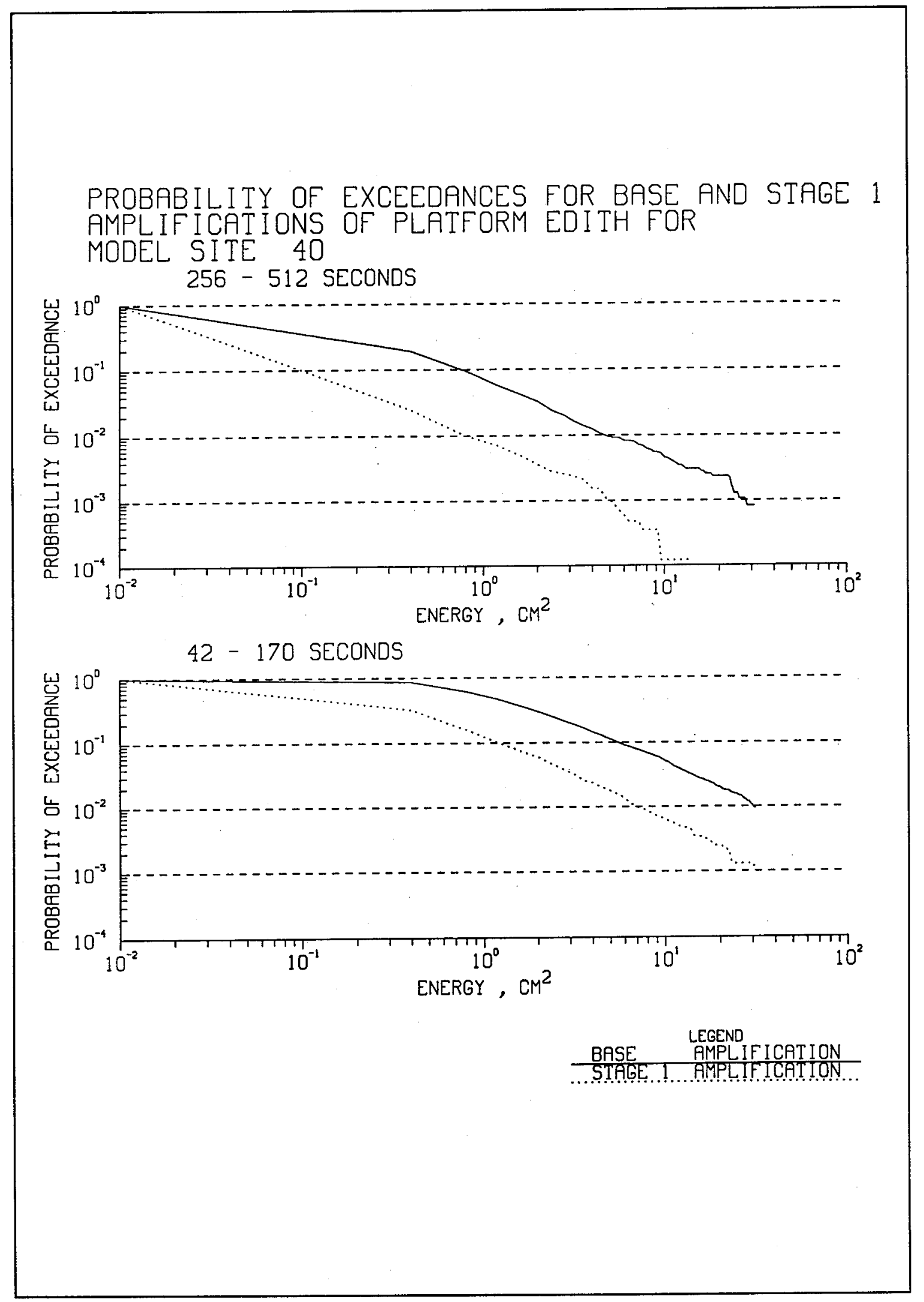

Figure 18. Probability of exceedances for base and Stage 1 energy amplifications at Gage 40 
floating dock systems. The other increases, as seen in Table 5, were not extreme, and in some cases base values were already above the selected threshold level. Tables 3 and 4 present the results in terms of duration of days over threshold determined from plots presented in Rosati and McKinney (in preparation). For the 42- to $170-\mathrm{sec}$ band, Table 3 considers both a $5-$ and $10-\mathrm{cm}$ threshold to give a range of days for existing and Stage 1 results. These data may be contrasted with results at Gage 52, where troublesome conditions have occurred. Table 4 is similar to Table 3 except the threshold range is raised to $10-15 \mathrm{~cm}$ for the longer period 256- to 512-sec band. Again, Gage 52 data are presented for reference. Without performing a moored ship motion analysis at the few container terminals affected by increases, a monitoring program of these sites might be needed to further refine parameters for design of berthing and mooring vessels. 


\section{Summary and Conclusions}

Effects of the Port of Los Angeles Stage 1 and Stage 2 plans on existing gage (and berth) locations throughout the harbors with regard to harbor resonance, evaluated in terms of wave height amplification, were as follows:

a. Results from testing the Uniform Spectrum, representing long waves from the south, indicated a net reduction in response (wave height amplification) relative to "base" or existing harbor conditions for existing, gaged, berth locations. Exceptions to this trend included Cabrillo Basin in the Port of Los Angeles, which had the greatest increase from low- to high-wave period portions of the long wave spectrum for Stage 1. Smaller increases were noted in the Long Beach Inner Harbor area in the longer period range (206-519 sec), and may be partially attributable to changes in Port of Long Beach bathymetry since the time when base tests were conducted in the model. One gage (of 4) in the Navy Basin (Gage 43) indicated wave height amplification increases over most of the period range for Stage 1, but were reduced for Stage 2. In summary, on the average, neither Stage 1 nor 2 caused significant change at existing berths. In locations where Stage 1 caused some increase, the Stage 2 results indicated reductions from Stage 1. Where Stage 2 did cause an increase, it tended to occur where wave height amplifications were low.

b. Results from tests with the January and February spectra, representative of more storm-like conditions from the west, indicated net increases in wave height amplification in the lower period range (25- to 40-sec periods). Stage 2 indicated slightly higher increases in this period range, though the usual increase in wave height amplification for either stage was less than 1 for all but two locations, and usually was much less than 1. Net change in the 41- to 205-sec period range indicated a decrease in wave height amplification, with Stage 1 indicating the greatest decrease over Stage 2. Increases were relatively small in the 41- to 205-sec period range. Results for the 206- to 519-sec period range also indicated net decrease in wave height amplification and at gages where increases were noted, average increases were less than 1. 
Resonant responses at new berth locations for Stage 1 were relatively low, especially for the more typical conditions of the Uniform Spectrum. In particular:

a. Stage 1 tests, Uniform Spectrum indicated that, for new berths along Pier 300, wave height amplifications were low, with averages for the 25- to 41-sec, 42- to 205-sec and 206- to 519-sec period groups usually at 1 or less. Having a $244-\mathrm{m}(800-\mathrm{ft})$ opening in the transportation corridor joining Terminal Island and Pier 400 resulted in slight increases in wave height amplifications in the Pier 300 area.

$b$. Testing with January and February spectra for Stage 1 indicated only slight increases at Pier 300 berth locations, with average values for the three period ranges discussed above less than one for the transportation corridor closed condition. With an opening on the causeway for the January or February tests, there were proportionately greater increases from the Uniform Spectrum results than for the non-opened condition, though average wave height amplifications were less than 1 except for the 206- to 519-sec period range, where wave height amplifications greater than 1 were noted at two locations along Pier 300 .

c. Resonant response at new berth locations for Stage 2 remained relatively low, similar to, but, on the average slightly greater than, Stage 1 results. Wave height amplifications for the 25- to 40-sec and 41- to 205 -sec period ranges were very close for both Stage 1 and Stage 2. There were three locations along Pier 300 where average increases from Stage 1 for the 206- to 519-sec period range brought average wave height amplifications to near a value of 1 . Slight increase in wave height amplifications for an opening in the causeway were similar to Stage 1 results. Responses for January and February spectra, relative to Stage 1 results, were similar to that seen for the Uniform Spectrum tests. Greatest increases were for the 243.84-m (800-ft) opening in the causeway and in the 206- to 519-sec period range, where average wave height amplifications of 2 were reached.

Analysis of Stage 1 results in terms of threshold wave height, where troublesome mooring conditions might begin to occur, indicated only one container berth in Los Angeles Harbor with increases in time above the threshold for the 42- to 170-sec wave energy band, thought to be the most critical wave period range to impact loading/unloading of ships. Two container slips in Long Beach Harbor had increases in the longer period 256-512 band. 


\section{References}

Burke, M. G. (1986). "Analysis of moored ship observations, Port of Long Beach," unpublished report, Port of Long Beach.

Outlaw, D. G., Durham, D. L., Chatham, C. E., and Whalin, R. W. (1977). "Los Angeles and Long Beach Harbors' model study; Report 4, model design," Technical Report H-75-4, U.S. Army Engineer Waterways Experiment Station, Vicksburg, MS.

Rosati, James, and McKinney, J. P. "Los Angeles Harbor Pier 400 Long Wave Probability Analysis Data Summary," in preparation, U.S. Army Engineer Waterways Experiment Station, Vicksburg, MS.

Seabergh, W. C. "Los Angeles and Long Beach Harbors Model Enhancement Program, Harbor Resonance Analysis," in preparation, U.S. Army Engineer Waterways Experiment Station, Vicksburg, MS.

Seabergh, W. C., and Thomas, L. J. (1993). "Los Angeles and Long Beach Harbors Model Enhancement Program, Improved Physical Model Harbor Resonance Methodology," Technical Report CERC-93-17, U.S. Army Engineer Waterways Experiment Station, Vicksburg, MS.

U.S. Army Engineer District, Los Angeles. (1992). "Deep draft navigation improvements, Los Angeles and Long Beach Harbors, San Pedro Bay, California," Draft Feasibility Report.

Wilson, B. W. (1967). "The threshold of surge damage for moored ships." Proceedings of the Institute of Civil Engineers. London, Vol 38, 107-32. 


\begin{tabular}{|c|c|c|}
\hline Period Band & Frequency-cps & Period Range \\
\hline 30.37 & 0.03293 & $30.1-30.6$ \\
\hline 30.83 & 0.03244 & $30.6-31.1$ \\
\hline 31.30 & 0.03195 & $31.1-31.5$ \\
\hline 31.78 & 0.03146 & $31.5-32.0$ \\
\hline 32.28 & 0.03098 & $32.0-32.5$ \\
\hline 32.80 & 0.03049 & $32.5-33.1$ \\
\hline 33.33 & 0.03 & $33.1-33.6$ \\
\hline 33.89 & 0.02951 & $33.6-34.2$ \\
\hline 34.46 & 0.02902 & $34.2-34.8$ \\
\hline 35.05 & 0.02853 & $34.8-35.4$ \\
\hline 35.66 & 0.02805 & $35.3-36.0$ \\
\hline 36.29 & 0.02756 & $36.0-36.6$ \\
\hline 36.94 & 0.02707 & $36.6-37.3$ \\
\hline 37.62 & 0.02658 & $37.3-38.0$ \\
\hline 38.33 & 0.02609 & $38.0-38.7$ \\
\hline 39.06 & 0.0256 & $38.7-39.4$ \\
\hline 39.82 & 0.02512 & $39.4-40.2$ \\
\hline 40.60 & 0.02463 & $40.2-41.0$ \\
\hline 41.43 & 0.02414 & $41.0-41.8$ \\
\hline 42.28 & 0.02365 & $41.8-42.7$ \\
\hline 43.17 & 0.02316 & $42.7-43.6$ \\
\hline 44.10 & 0.02267 & $43.6-44.6$ \\
\hline 45.07 & 0.02219 & $44.6-45.6$ \\
\hline 46.09 & 0.0217 & $45.6-46.6$ \\
\hline 47.15 & 0.02121 & $46.6-47.7$ \\
\hline 48.26 & 0.02072 & $47.7-48.8$ \\
\hline 49.42 & 0.02023 & $48.8 \cdot 50.0$ \\
\hline 50.65 & 0.01974 & $50.0-51.3$ \\
\hline 51.93 & 0.01926 & $51.3-52.6$ \\
\hline 53.28 & 0.01877 & $52.6 \cdot 54.0$ \\
\hline 54.7 & 0.01828 & $54.0 \cdot 55.4$ \\
\hline
\end{tabular}




\begin{tabular}{|c|c|c|}
\hline Period Band & Frequency-cps & Period Range \\
\hline 56.21 & 0.01779 & $55.4-57.0$ \\
\hline 57.79 & 0.0173 & $57.0-58.6$ \\
\hline 59.47 & 0.01682 & $58.6-60.3$ \\
\hline 61.25 & 0.01633 & $60.3-62.2$ \\
\hline 63.14 & 0.01584 & $62.2-64.1$ \\
\hline 65.15 & 0.01535 & $64.1-66.2$ \\
\hline 67.29 & 0.01486 & $66.2-68.4$ \\
\hline 69.57 & 0.01437 & $68.4-70.8$ \\
\hline 72.02 & 0.01389 & $70.7-73.3$ \\
\hline 74.64 & 0.0134 & $73.3-76.0$ \\
\hline 77.47 & 0.01291 & $76.0-79.0$ \\
\hline 80.51 & 0.01242 & $79.0-82.1$ \\
\hline 83.81 & 0.01193 & $82.1-85.6$ \\
\hline 87.38 & 0.01144 & $85.6-89.3$ \\
\hline 91.28 & 0.01096 & $89.2-93.3$ \\
\hline 95.53 & 0.01047 & $93.3-97.8$ \\
\hline 100.21 & 0.00998 & $97.8-102.7$ \\
\hline 105.36 & 0.00949 & $102.7-108.2$ \\
\hline 111.08 & 0.009 & $108.2 \cdot 114.2$ \\
\hline 117.45 & 0.00851 & $114.2-121.0$ \\
\hline 124.59 & 0.00803 & $120.8-128.5$ \\
\hline 132.66 & 0.00754 & $128.5-137.1$ \\
\hline 141.85 & 0.00705 & $137.1-147.0$ \\
\hline 152.41 & 0.00656 & $147.0-158.4$ \\
\hline 164.66 & 0.00607 & $158.4 \cdot 171.7$ \\
\hline 179.06 & 0.00558 & $171.7-187.4$ \\
\hline 196.22 & 0.0051 & $187.1-206.0$ \\
\hline 217.01 & 0.00461 & $206.0-229.1$ \\
\hline 242.73 & 0.00412 & $229.1-258.1$ \\
\hline 275.36 & 0.00363 & $258.1-295.4$ \\
\hline 318.14 & 0.00314 & $295.4-345.4$ \\
\hline 376.64 & 0.00266 & $344.2-414.1$ \\
\hline 461.52 & 0.00217 & $414.1 \cdot 519.5$ \\
\hline
\end{tabular}




\begin{tabular}{|c|c|}
\hline \multicolumn{2}{|c|}{$\begin{array}{l}\text { Table } 2 \\
\text { Prototype Period Band Resolved for Prototype Data }\end{array}$} \\
\hline Period Band & Band Range \\
\hline 25.6 & $25.0-\quad 26.2$ \\
\hline 26.9 & $26.2-\quad 27.6$ \\
\hline 28.4 & $27.6-\quad 29.2$ \\
\hline 30.1 & $29.2-31$ \\
\hline 32 & $31-33$ \\
\hline 34 & $33-35$ \\
\hline 36 & $35-38$ \\
\hline 39 & $38-40$ \\
\hline 42 & $40-44$ \\
\hline 46 & $44-48$ \\
\hline 51 & $48-53$ \\
\hline 56 & $53-60$ \\
\hline 64 & $60-68$ \\
\hline 73 & $68-78$ \\
\hline 85 & $78-93$ \\
\hline 102 & $93-113$ \\
\hline 128 & $113-146$ \\
\hline 170 & $146-204$ \\
\hline 256 & $204-341$ \\
\hline 512 & $341-1022$ \\
\hline
\end{tabular}




\begin{tabular}{|c|c|c|c|c|c|}
\hline \multicolumn{6}{|c|}{$\begin{array}{l}\text { Table } 3 \\
\text { Gages Excesing Giteria for the } 42-10170-\text { sec Band }\end{array}$} \\
\hline \multirow[b]{2}{*}{ Gage } & \multicolumn{2}{|c|}{$\begin{array}{l}\text { Existing Condinions, } \\
\text { Time Above Threshold, } \\
\text { days }\end{array}$} & \multicolumn{2}{|c|}{$\begin{array}{l}\text { Siage } 7 \text {, } \\
\text { Time Above Threshold, } \\
\text { days }\end{array}$} & \multirow[b]{2}{*}{$\begin{array}{l}\text { Type of Berth at } \\
\text { Gage Location }\end{array}$} \\
\hline & $\begin{array}{l}10-\mathrm{cm} \\
\text { Threshold }\end{array}$ & $\begin{array}{l}\text { 5-cm } \\
\text { Threshold }\end{array}$ & $\begin{array}{l}\text { 10-cm } \\
\text { Threshold }\end{array}$ & $\begin{array}{l}5-\mathrm{cm} \\
\text { Threshold }\end{array}$ & \\
\hline 8 & 2 days & 11 days & 5 days & 29 days & Container \\
\hline $52^{1}$ & 110 & 290 & 105 & 270 & Container \\
\hline \multicolumn{6}{|c|}{$\begin{array}{l}1 \text { Gage } 52 \text { did not have increased energy due to Stage } 1 \text { and is presented for comparison } \\
\text { purposes. }\end{array}$} \\
\hline
\end{tabular}

\begin{tabular}{|c|c|c|c|c|c|}
\hline \multicolumn{6}{|c|}{$\begin{array}{l}\text { Table } 4 \\
\text { Gages Exceeding Criteria for the } 256 \text { - to } 512-\mathrm{sec} \text { Band }\end{array}$} \\
\hline \multirow[b]{2}{*}{ Gage } & \multicolumn{2}{|c|}{$\begin{array}{l}\text { Existing Conditions, } \\
\text { Time Above Threshold, } \\
\text { days }\end{array}$} & \multicolumn{2}{|c|}{$\begin{array}{l}\text { Sirage 1, } \\
\text { Time Above Threshold, } \\
\text { days }\end{array}$} & \multirow[b]{2}{*}{$\begin{array}{l}\text { Type of Berth at } \\
\text { Gage Location }\end{array}$} \\
\hline & $\begin{array}{l}\text { 15-cm } \\
\text { Threshold }\end{array}$ & $\begin{array}{l}\text { 10-cm } \\
\text { Threshold }\end{array}$ & $\begin{array}{l}\text { 15-cm } \\
\text { Threshold }\end{array}$ & $\begin{array}{l}10-\mathrm{cm} \\
\text { Threshold }\end{array}$ & \\
\hline 19 & 1 day & 3 days & 2 days & 6 days & Oil \\
\hline 21 & 7 & 18 & 15 & 33 & Container \\
\hline 22 & 2 & 4 & 3 & 7 & Container \\
\hline 45 & 1 & 2 & 2 & 4 & Oil \\
\hline $52^{1}$ & 35 & 85 & 33 & 75 & Container \\
\hline
\end{tabular}




\begin{tabular}{|c|c|c|c|c|c|c|c|c|c|}
\hline \multicolumn{10}{|c|}{$\begin{array}{l}\text { Table } 5 \\
\text { Wave Helghts (in cm) with a Probabllity of Exceedance of } 1 \%\end{array}$} \\
\hline \multirow[b]{2}{*}{$\begin{array}{c}\text { Gage } \\
\text { Number }\end{array}$} & \multicolumn{4}{|c|}{$42-170 \mathrm{sec}$} & \multicolumn{4}{|c|}{$256-512 \mathrm{sec}$} & \multirow[b]{2}{*}{ Location Description } \\
\hline & \begin{tabular}{c|} 
Base \\
Wave ht \\
\end{tabular} & \begin{tabular}{|c|} 
Stage I \\
Wave ht \\
\end{tabular} & Delta & $\begin{array}{l}\text { Percent } \\
\text { Change } \\
\end{array}$ & \begin{tabular}{c|} 
Base \\
Wave ht \\
\end{tabular} & \begin{tabular}{|l|} 
Stage I \\
Wave ht
\end{tabular} & Delta & $\begin{array}{l}\text { Percent } \\
\text { Change }\end{array}$ & \\
\hline 1 & 6.4 & 3.1 & -3.3 & $-52 \%$ & 6.9 & 5.1 & -1.7 & $-25 \%$ & 22nd St Landing Sportfishing \\
\hline 2 & 12.6 & 8.4 & -4.2 & $-34 \%$ & 3.3 & 2.4 & -0.9 & $-28 \%$ & Cabrillo Marina near Watchorn Walk \\
\hline 3 & 26.0 & 19.4 & -6.5 & $-25 \%$ & 4.7 & 7.5 & 2.9 & $61 \%$ & Cabrillo Boat Yard \\
\hline 4 & 9.2 & 6.1 & -3.1 & $-33 \%$ & 3.0 & 2.8 & -0.2 & $-7 \%$ & Mobil Oil Corporation \\
\hline 5 & 15.2 & 14.3 & -0.9 & $-6 \%$ & 7.1 & 3.3 & -3.8 & $-54 \%$ & Kaiser Bulkloading Facility \\
\hline 6 & 23.8 & 23.6 & -0.3 & $-1 \%$ & 28.1 & 16.1 & -12.0 & $-43 \%$ & East Channel, NW Corner \\
\hline 7 & 10.9 & 12.1 & 1.1 & $10 \%$ & 21.5 & 19.5 & -2.0 & $-9 \%$ & Mobil Oil Company \\
\hline$\%$ & 7.2 & 11.0 & 3.8 & $53 \%$ & 5.2 & 6.8 & 1.6 & $31 \%$ & Evergreen Container Terminal \\
\hline 9 & 40.3 & 19.9 & -20.4 & $-51 \%$ & 12.5 & 4.3 & -8.2 & $-65 \%$ & World Cruise Passenger Terminal \\
\hline 10 & 12.8 & 5.3 & -7.5 & $-58 \%$ & 14.2 & 4.0 & -10.2 & $-72 \%$ & Formerly Todd Shipyard \\
\hline 11 & 4.3 & 3.8 & -0.5 & $-12 \%$ & 4.5 & 3.2 & -1.3 & $-29 \%$ & Wilmington Liquid Bulk \\
\hline$\overline{12}$ & 14.7 & 8.8 & -5.9 & $-40 \%$ & 13.7 & 5.0 & -8.7 & $-64 \%$ & Fish Harbor, Fire Boat Area \\
\hline 13 & 18.6 & 6.5 & -12.1 & $-65 \%$ & 7.7 & 2.4 & -5.3 & $-69 \%$ & Los Angeles Yatch Club \\
\hline 14 & 27.9 & 7.8 & -20.1 & $.72 \%$ & 16.9 & 2.6 & -14.4 & $-85 \%$ & Pier 300 \\
\hline 15 & 12.9 & 13.0 & 0.1 & $1 \%$ & 3.6 & 3.8 & 0.2 & $5 \%$ & Outside Angel's Gate, Ocean Gage \\
\hline 16 & 25.2 & 19.7 & -5.5 & $-22 \%$ & 7.2 & 6.6 & -0.6 & $-8 \%$ & Outside Queen's Gate, Ocean Gage \\
\hline 17 & 17.6 & 12.0 & -5.5 & $-32 \%$ & 6.6 & 7.0 & 0.5 & $7 \%$ & NE Naval Station Dock \\
\hline 18 & 13.5 & 8.9 & -4.6 & $-34 \%$ & 5.7 & 2.4 & -3.4 & $-58 \%$ & Naval Station Mole \\
\hline 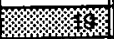 & 16.7 & 11.9 & -4.8 & $-29 \%$ & 8.5 & 11.4 & 2.9 & $34 \%$ & ARCO Marine Department \\
\hline$\frac{10}{20}$ & 12.9 & 14.3 & 1.4 & $11 \%$ & 6.0 & 9.4 & 3.4 & $57 \%$ & ARCO Oil Terminal:LB Back Channel \\
\hline 证 & 18.6 & 17.3 & -1.3 & $-7 \%$ & 18.6 & 25.2 & 6.7 & $36 \%$ & Calif. United Terminals:LB Slip 3 \\
\hline$\%$ & 14.5 & 10.3 & -4.1 & $-29 \%$ & 10.5 & 14.4 & 3.9 & $37 \%$ & Calif. United Terminals:LB Slip 2 \\
\hline 23 & 13.9 & 10.5 & -3.3 & $-24 \%$ & 14.5 & 16.6 & 2.1 & $15 \%$ & Cool Garriers: LB Slip 1 \\
\hline 24 & 10.8 & 8.3 & -2.5 & $-23 \%$ & 7.8 & 8.4 & 0.7 & $9 \%$ & Long Beach Container Terminal \\
\hline 25 & 15.8 & 15.7 & -0.1 & $-1 \%$ & 3.5 & 3.5 & 0.0 & $1 \%$ & SE Basin, Lucky Cement \\
\hline 26 & 9.8 & 9.5 & -0.4 & $-4 \%$ & 2.4 & 2.4 & -0.0 & $-0 \%$ & SE Basin, Cooper T. Smith Stevedoring \\
\hline 27 & 11.9 & 8.6 & -3.3 & $-28 \%$ & 2.4 & 3.1 & 0.7 & $31 \%$ & Iruck Barge To THUMS Oil Island \\
\hline 然 & 10.7 & 12.6 & 1.9 & $17 \%$ & 8.0 & 14.0 & 6.0 & $75 \%$ & Sea-Land Container Terminal \\
\hline 29 & 14.2 & 15.9 & 1.7 & $12 \%$ & 3.1 & 4.1 & 1.0 & $31 \%$ & Westway Trading Corp. \\
\hline 30 & 14.2 & 11.3 & -2.8 & $-20 \%$ & 3.2 & 3.7 & 0.5 & $14 \%$ & Pacific Container Terminal \\
\hline 3 & 8.9 & 6.7 & -2.2 & $-25 \%$ & 7.8 & 13.3 & 5.5 & $70 \%$ & Cabrillo Landing \\
\hline 3 & 30.8 & 56.6 & 25.8 & $84 \%$ & 5.7 & 22.9 & 17.2 & $302 \%$ & Cabrillo Marina, SW Area \\
\hline 33 & 18.5 & 21.6 & 3.1 & $17 \%$ & 9.9 & 5.8 & -4.2 & $-42 \%$ & East Channel, SE Corner \\
\hline 34 & 20.6 & 14.5 & -6.1 & $-30 \%$ & 5.3 & 2.4 & -3.0 & $-56 \%$ & Southwest Marine \\
\hline 35 & 11.6 & 9.8 & -1.9 & $-16 \%$ & 4.9 & 2.4 & -2.5 & $-52 \%$ & Trans Pacific Container Service Corp \\
\hline 36 & 36.2 & 18.2 & -18.0 & $-50 \%$ & 31.2 & 7.6 & -23.6 & $-76 \%$ & Wickland Oil Company, LA Slip 1 \\
\hline 37 & 7.2 & 8.0 & 0.7 & $10 \%$ & 3.1 & 5.2 & 2.1 & $69 \%$ & Matson Container Terminal \\
\hline 38 & 5.0 & 4.6 & -0.4 & $-8 \%$ & 6.5 & 6.0 & -0.5 & $-7 \%$ & Yusen Container Terminal \\
\hline 39 & 13.3 & 7.1 & -6.2 & $-46 \%$ & 9.6 & 2.4 & -7.2 & $-75 \%$ & Fish Harbor, Berth 259 \\
\hline 40 & 22.1 & 10.6 & -11.4 & $-52 \%$ & 8.7 & 3.6 & -5.1 & $-58 \%$ & Pier 300 \\
\hline 41 & 12.4 & 13.7 & 1.3 & $10 \%$ & 5.6 & 4.5 & -1.1 & $-19 \%$ & Angel's Gate \\
\hline 42 & 32.1 & 33.4 & 1.3 & $4 \%$ & 11.3 & 9.6 & -1.6 & $-15 \%$ & Queen's Gate \\
\hline 移 & 30.3 & 32.7 & 2.4 & $8 \%$ & 9.9 & 13.6 & 3.6 & $37 \%$ & NW Corner Naval Station \\
\hline 44 & 15.8 & 14.5 & -1.3 & $.8 \%$ & 6.5 & 8.4 & 1.9 & $29 \%$ & Naw Yatch Club \\
\hline 4 & 10.0 & 8.8 & -1.2 & $-12 \%$ & 7.5 & 11.1 & 3.6 & $48 \%$ & Queen's Wharf Landing \\
\hline 46 & 12.6 & 12.1 & -0.5 & $-4 \%$ & 5.9 & 8.4 & 2.5 & $43 \%$ & ARCO Oil Terminal \\
\hline 47 & 15.6 & 17.6 & 2.1 & $13 \%$ & 3.9 & 4.6 & 0.7 & $19 \%$ & $\mathrm{KOCH}$ Carbon \\
\hline 48 & 10.7 & 11.0 & 0.3 & $3 \%$ & 2.4 & 3.9 & 1.5 & $63 \%$ & Pacific Container Terminal \\
\hline 49 & \multicolumn{4}{|c|}{ Gage number 49 was not used } & & & & & \\
\hline 50 & 34.2 & 34.7 & 0.5 & $1 \%$ & 3.4 & 3.3 & -0.1 & $-3 \%$ & Long Beach Marina \\
\hline 51 & 40.9 & 38.2 & -2.6 & $-6 \%$ & 11.2 & 10.6 & -0.6 & $-6 \%$ & Pier J \\
\hline 52 & 37.1 & 35.5 & -1.7 & $-4 \%$ & 37.8 & 36.0 & -1.7 & $-5 \%$ & Pier J-MAERSK Container Terminal \\
\hline 53 & 18.6 & 19.7 & 1.0 & $5 \%$ & 30.8 & 30.9 & 0.1 & $0 \%$ & Pier J-MAERSK Container Terminal \\
\hline 54 & 25.9 & 25.6 & -0.3 & $-1 \%$ & 19.7 & 19.7 & 0.0 & $0 \%$ & Pier J-MAERSK Container Terminal \\
\hline 55 & 47.5 & 46.0 & -1.5 & $-3 \%$ & 12.9 & 11.5 & -1.4 & $-11 \%$ & Pier J \\
\hline
\end{tabular}




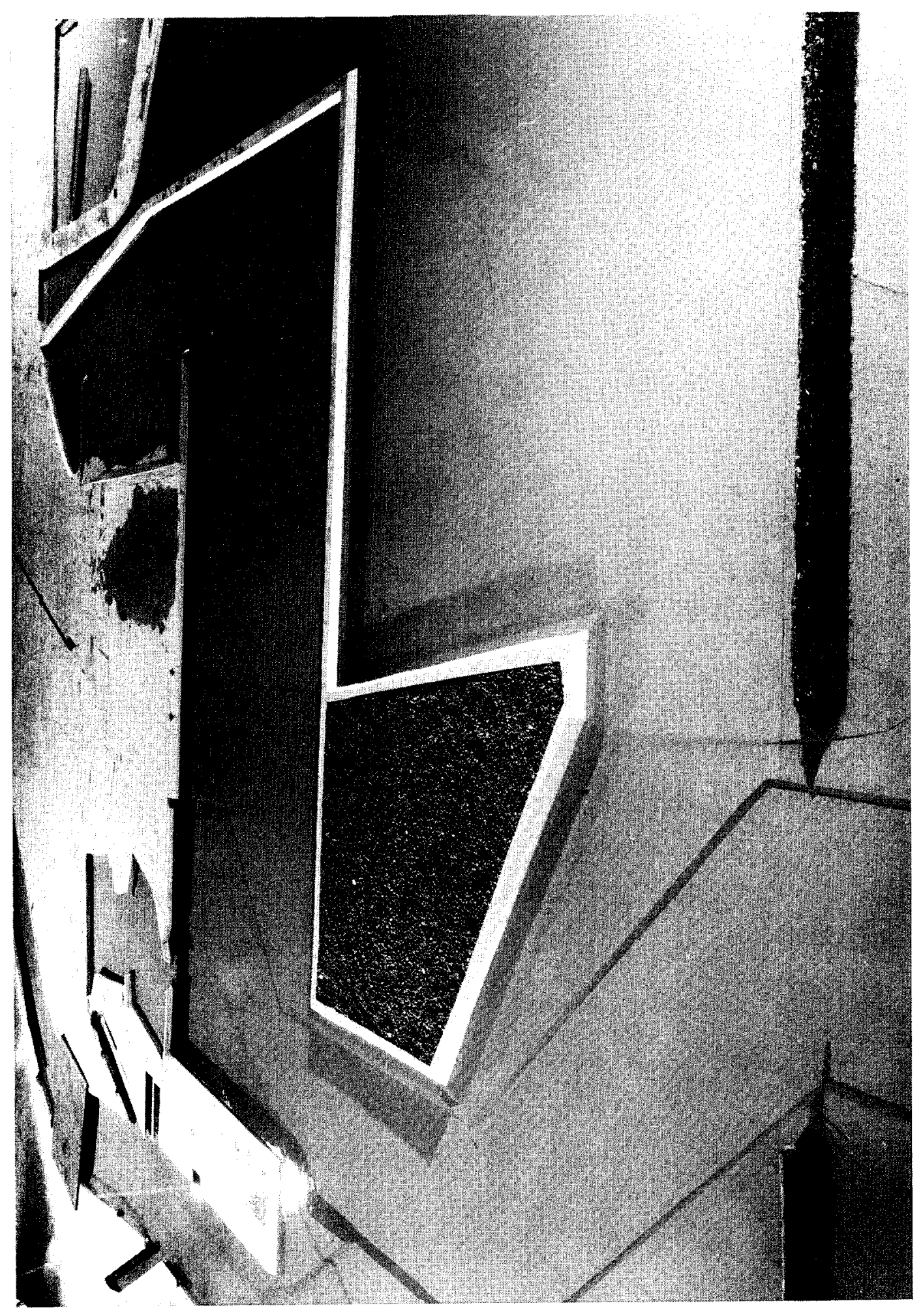

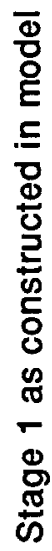

$\frac{5}{\frac{0}{0}}$ 


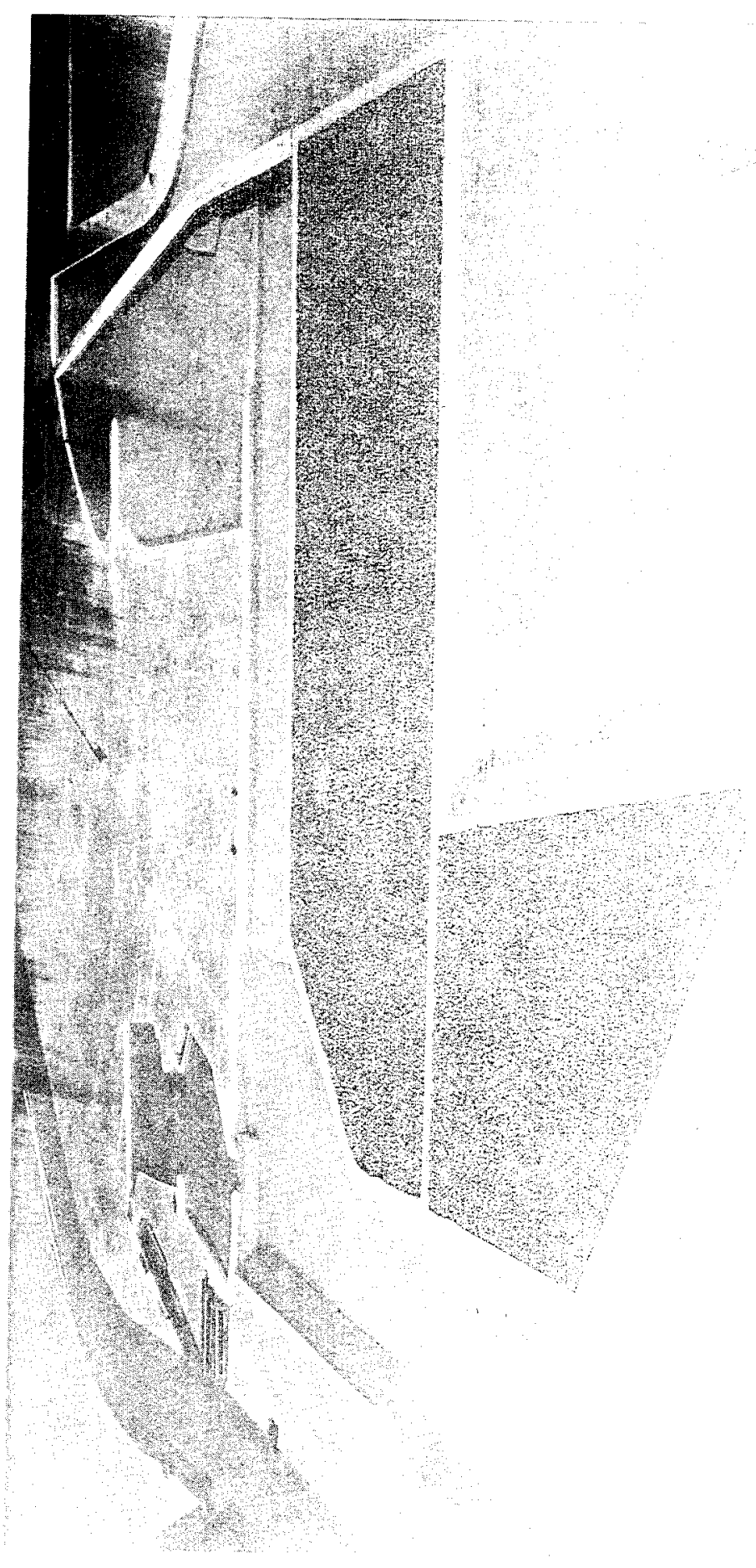

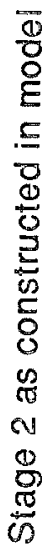

$\dot{N}$
$\stackrel{0}{0}$
$\frac{1}{0}$ 

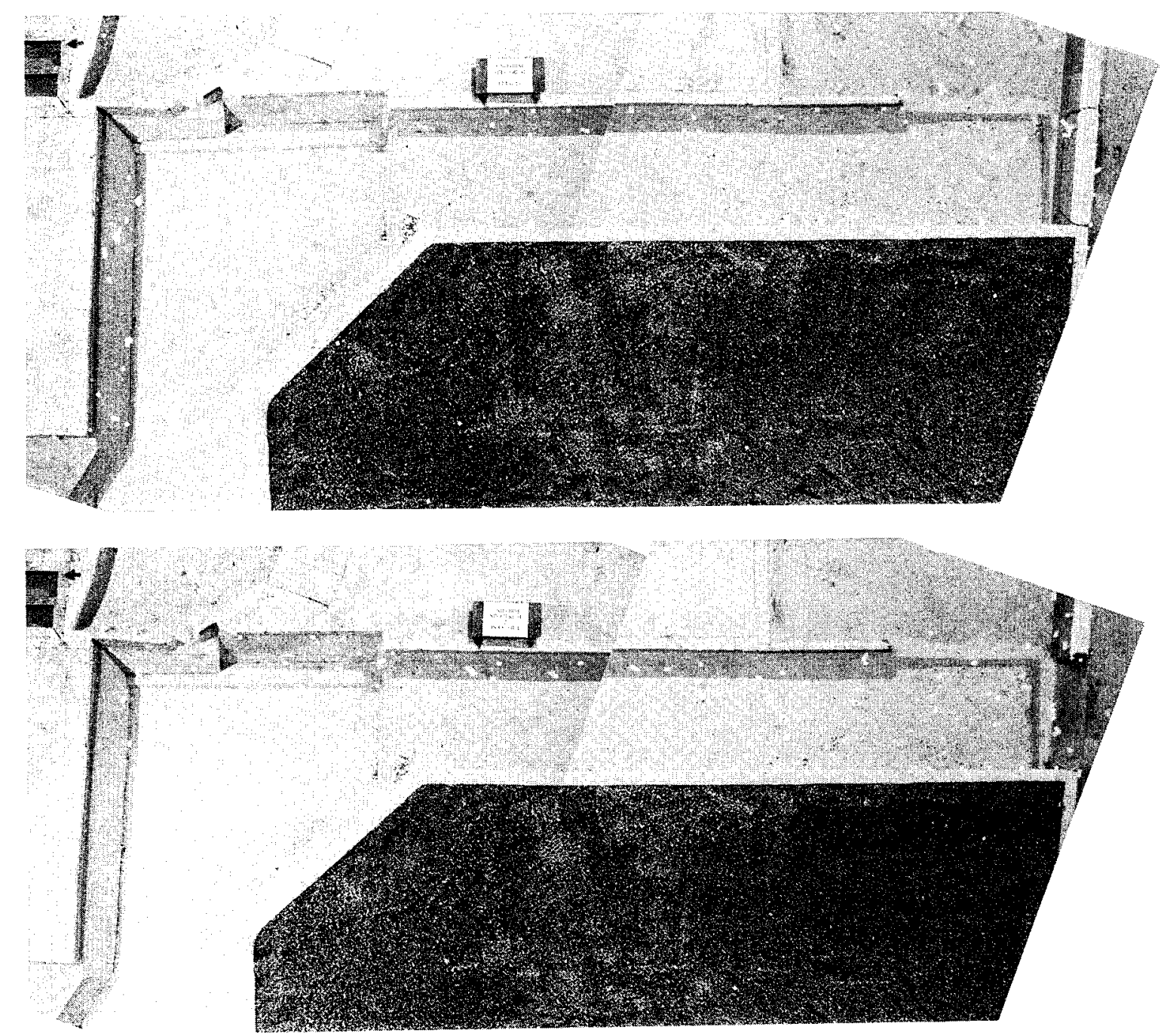

Photo 3. Surface current patterns, due to long waves, for uniform spectrum with (top) and without (bottom) opening in transportation corridor 

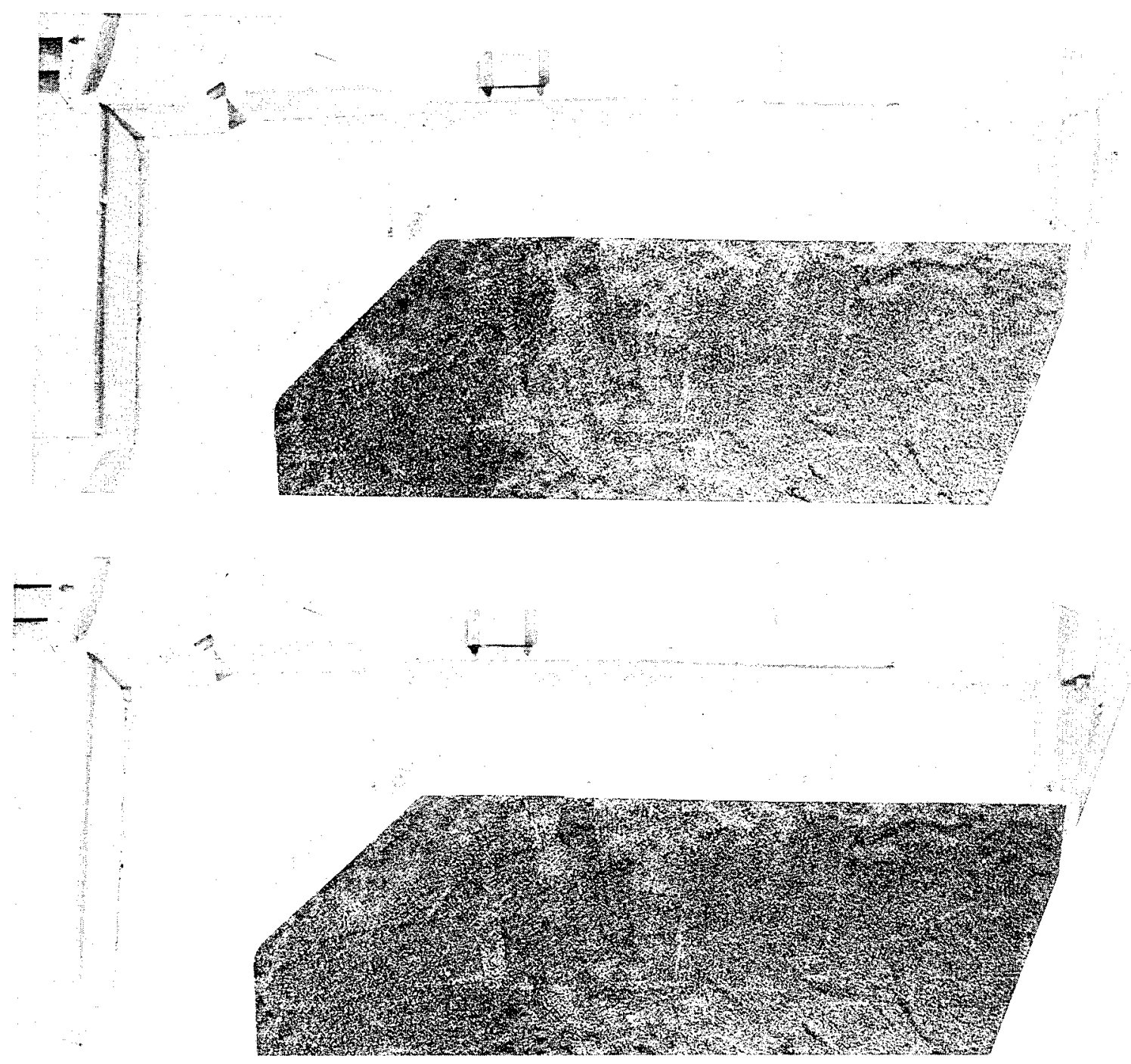

Photo 4. Surface current patterns, due to long waves, for January spectrum, with (top) and without (bottom) opening in transportation corridor 

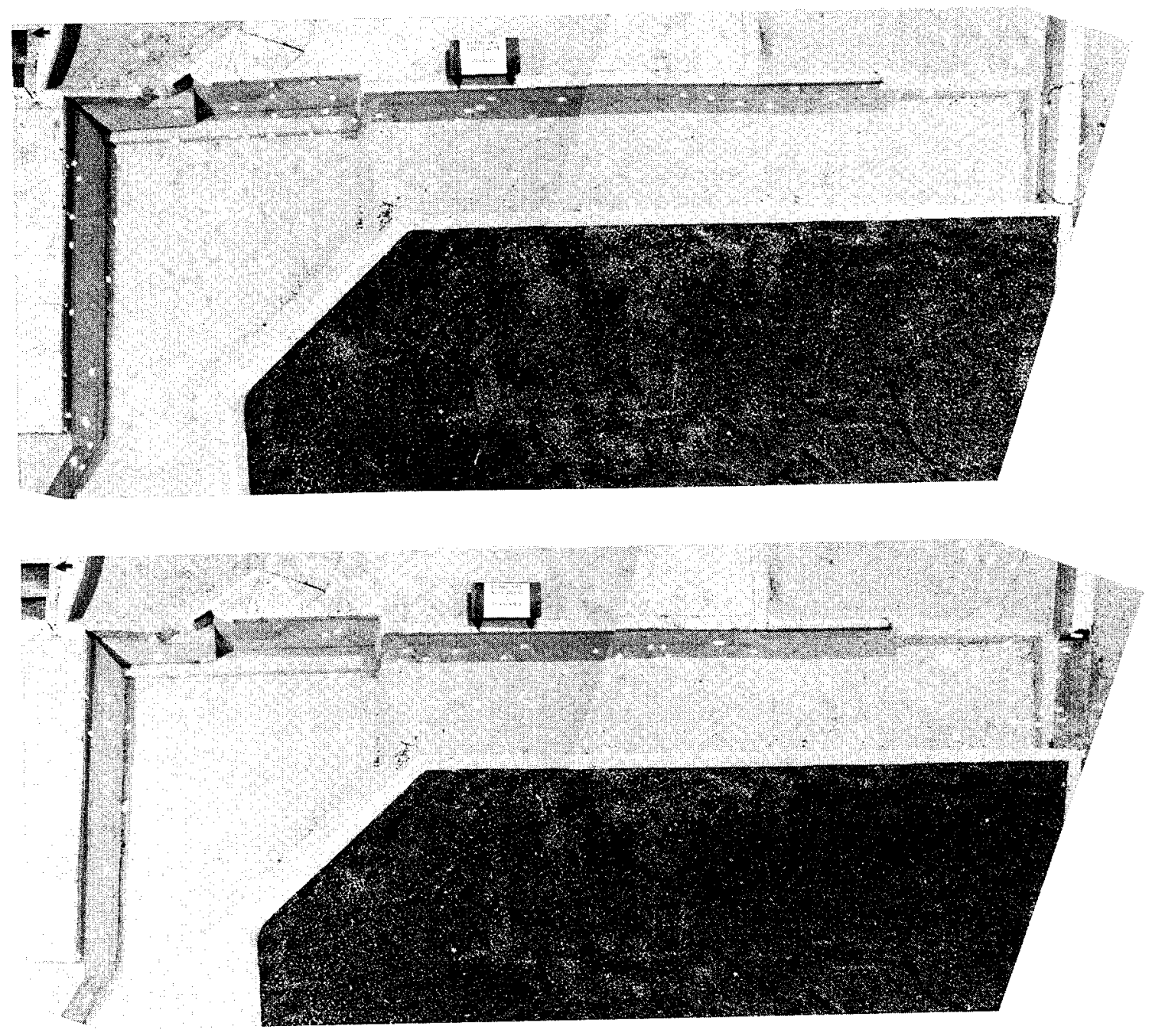

Photo 5. Surface current patterns, due to long waves, for February spectrum, with (top) and without (bottom) opening in transportation corridor 


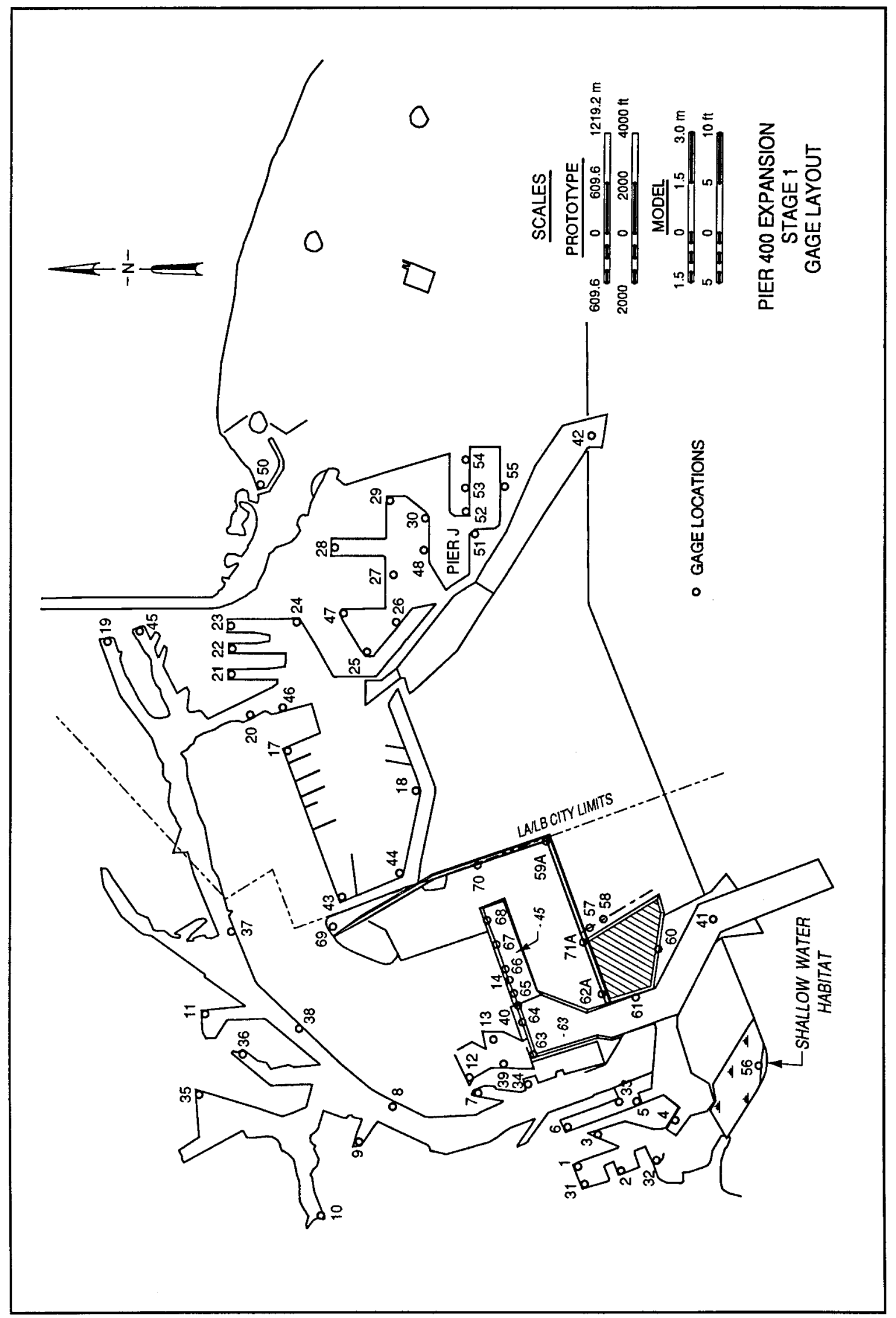

Plate 1 


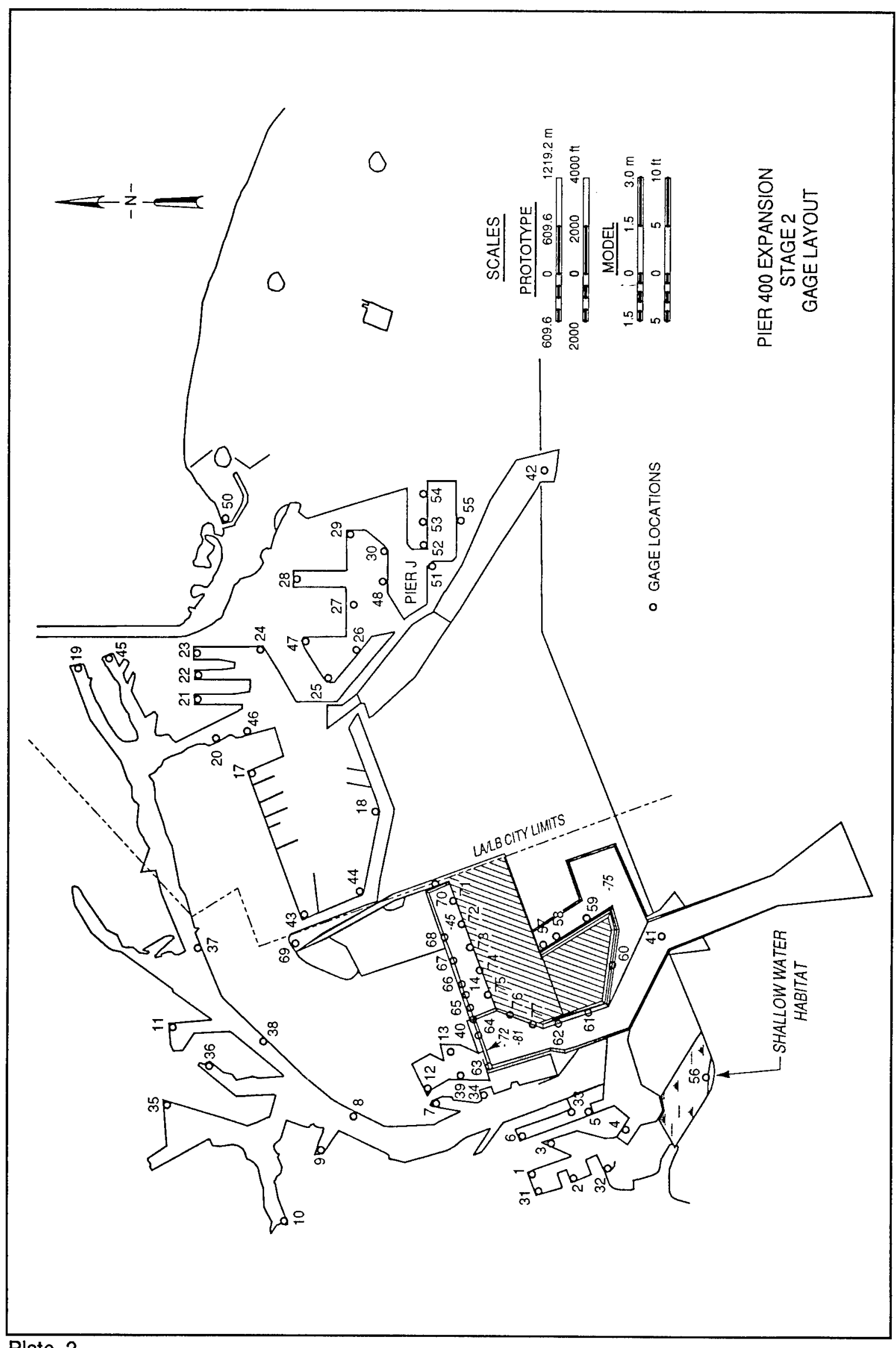

Plate 2 

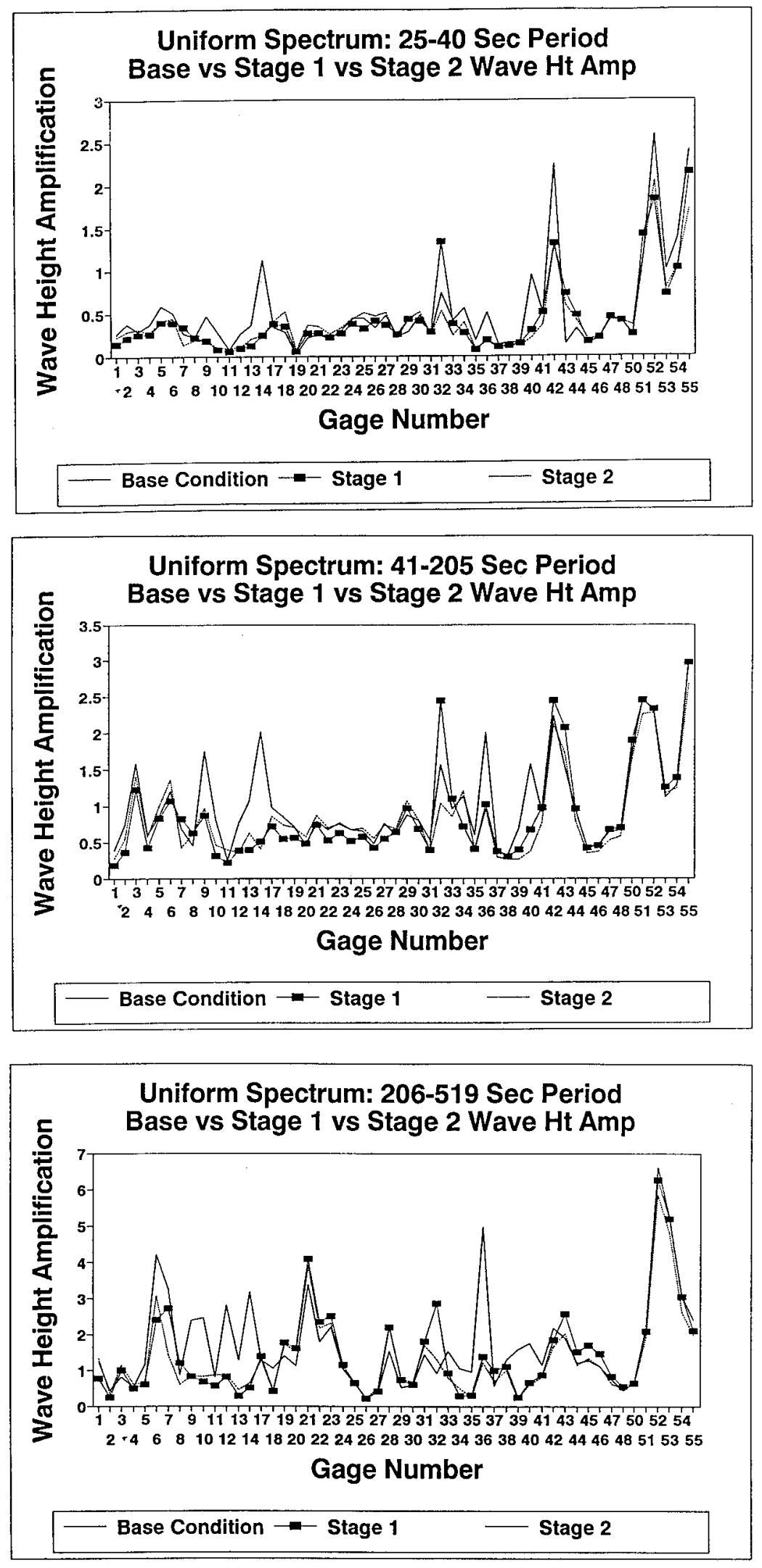


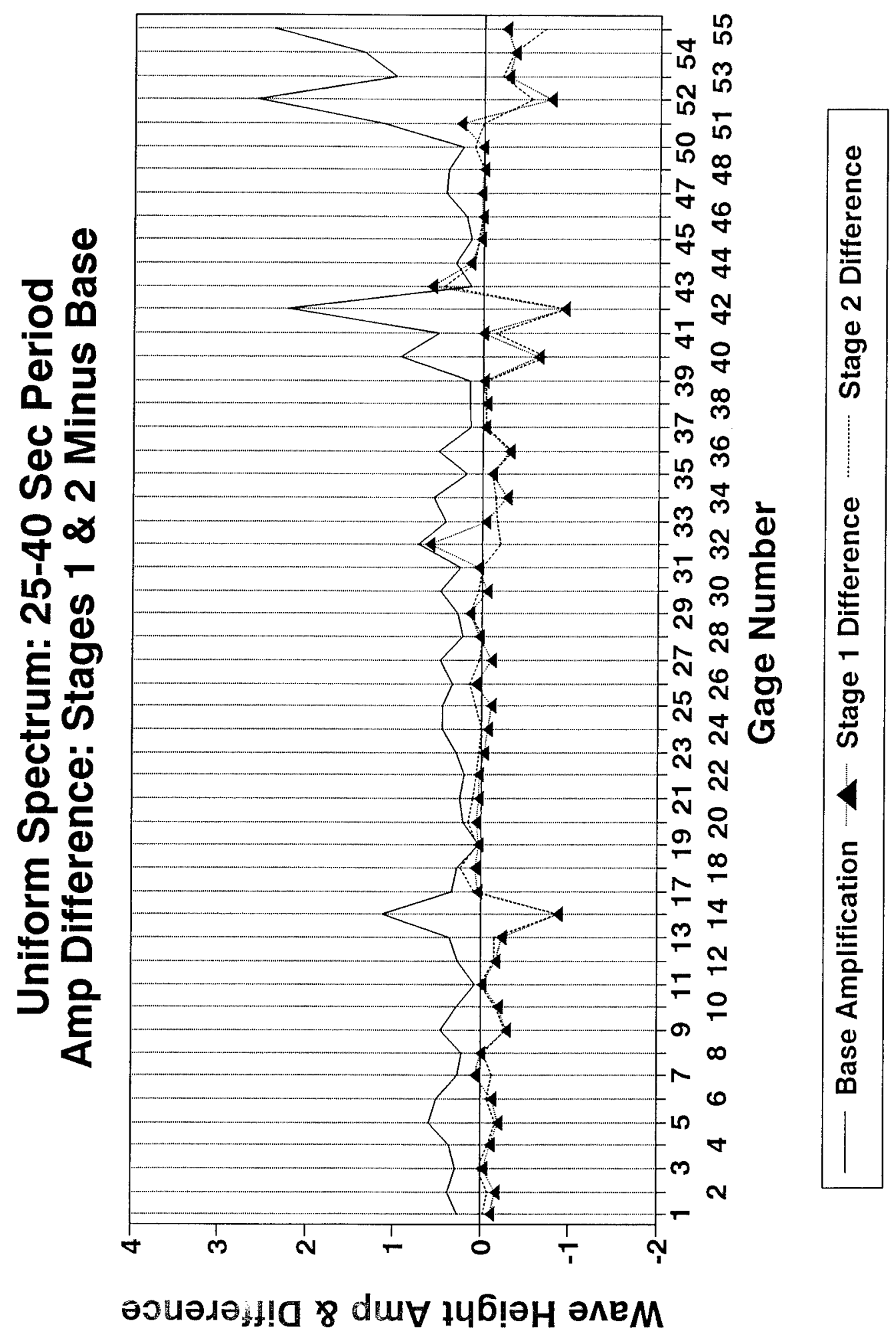

Plate 4 


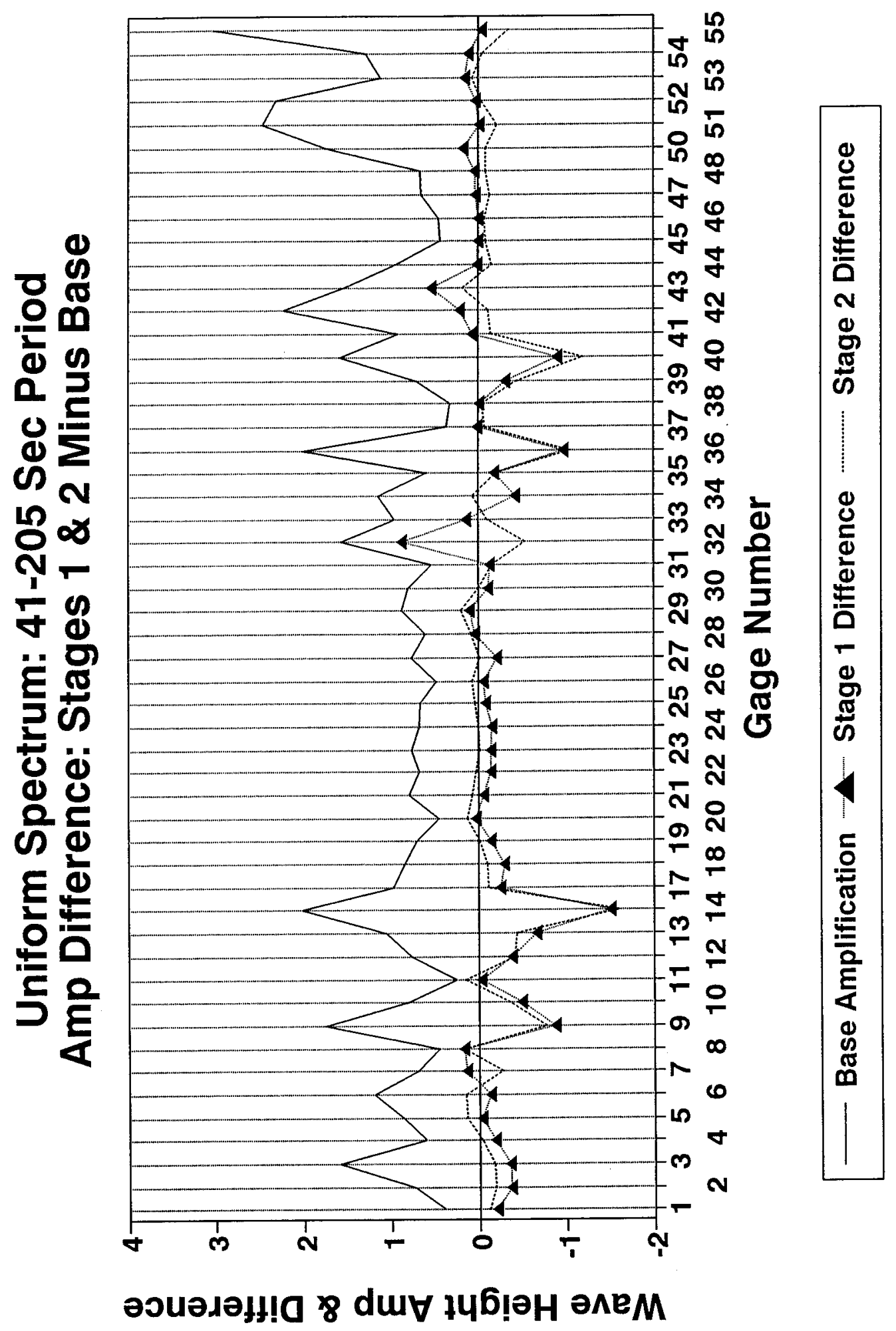




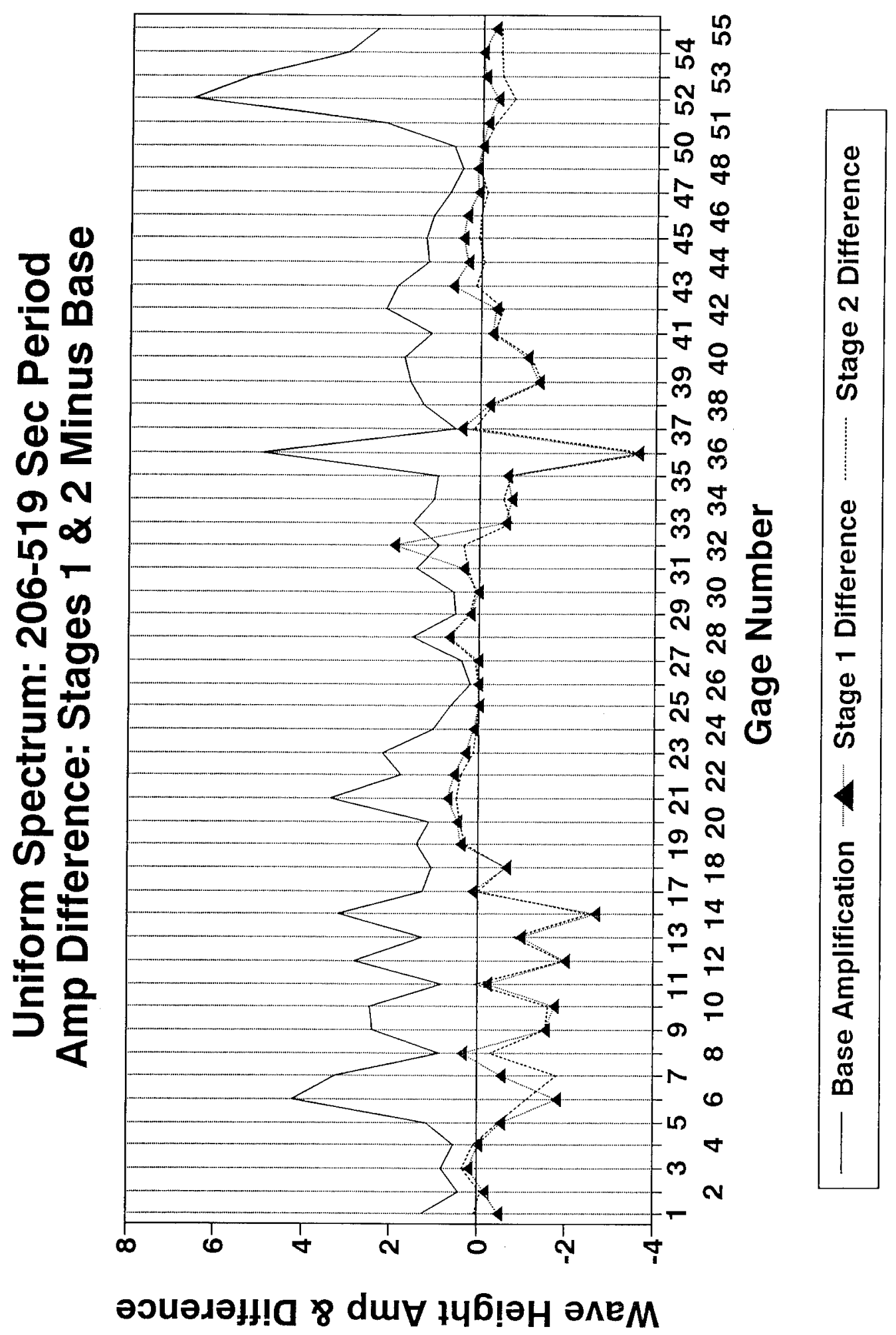

Plate 6 

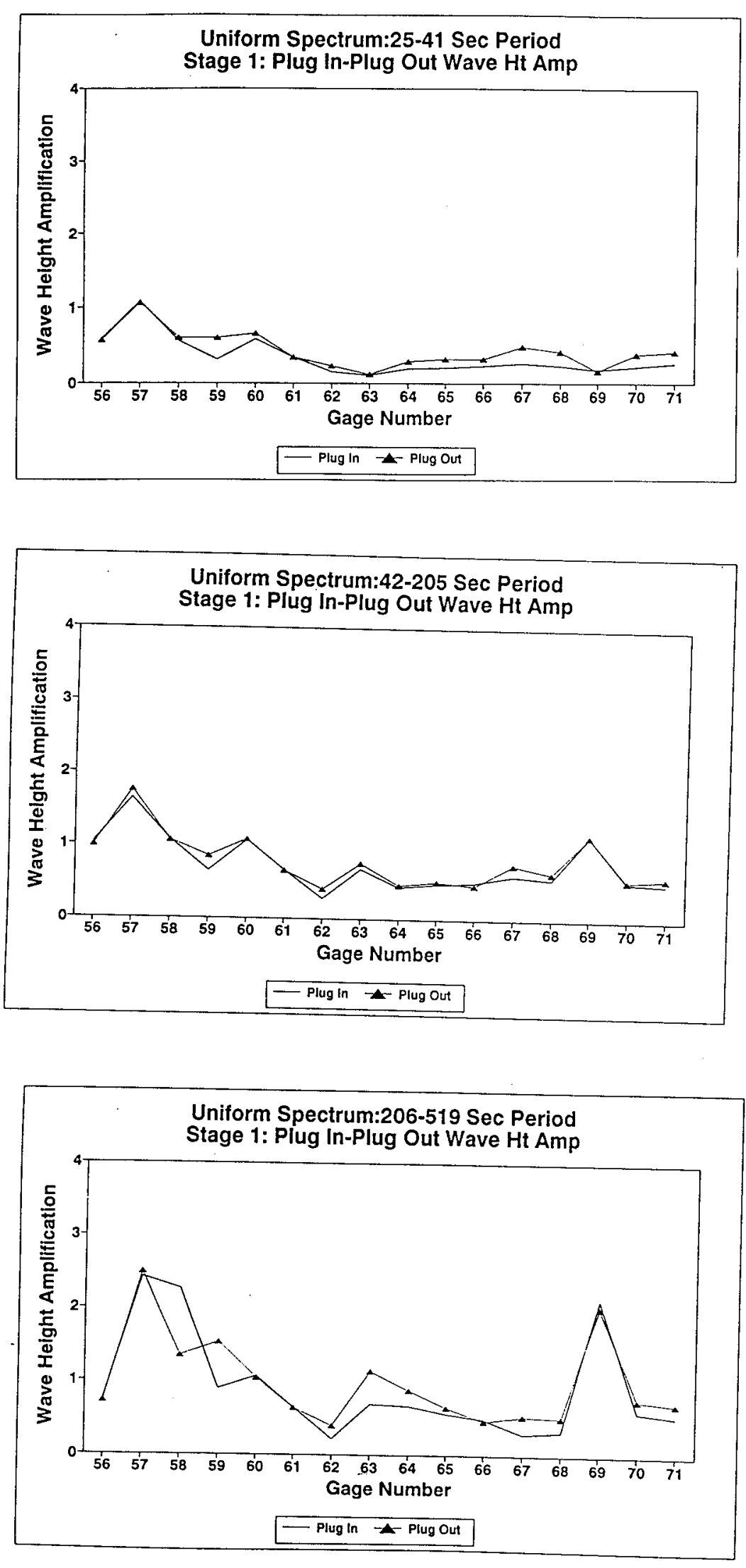


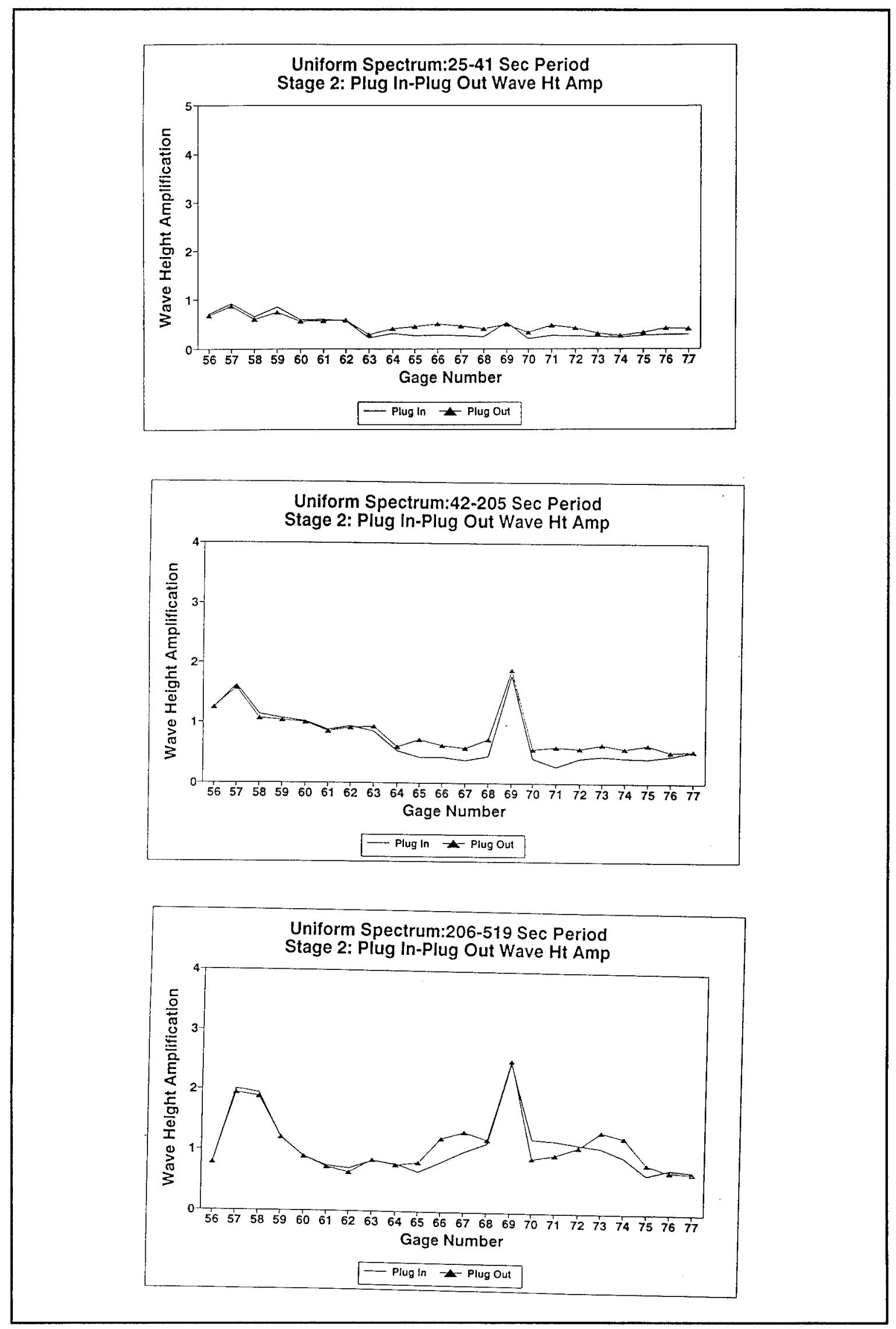

Plate 8 

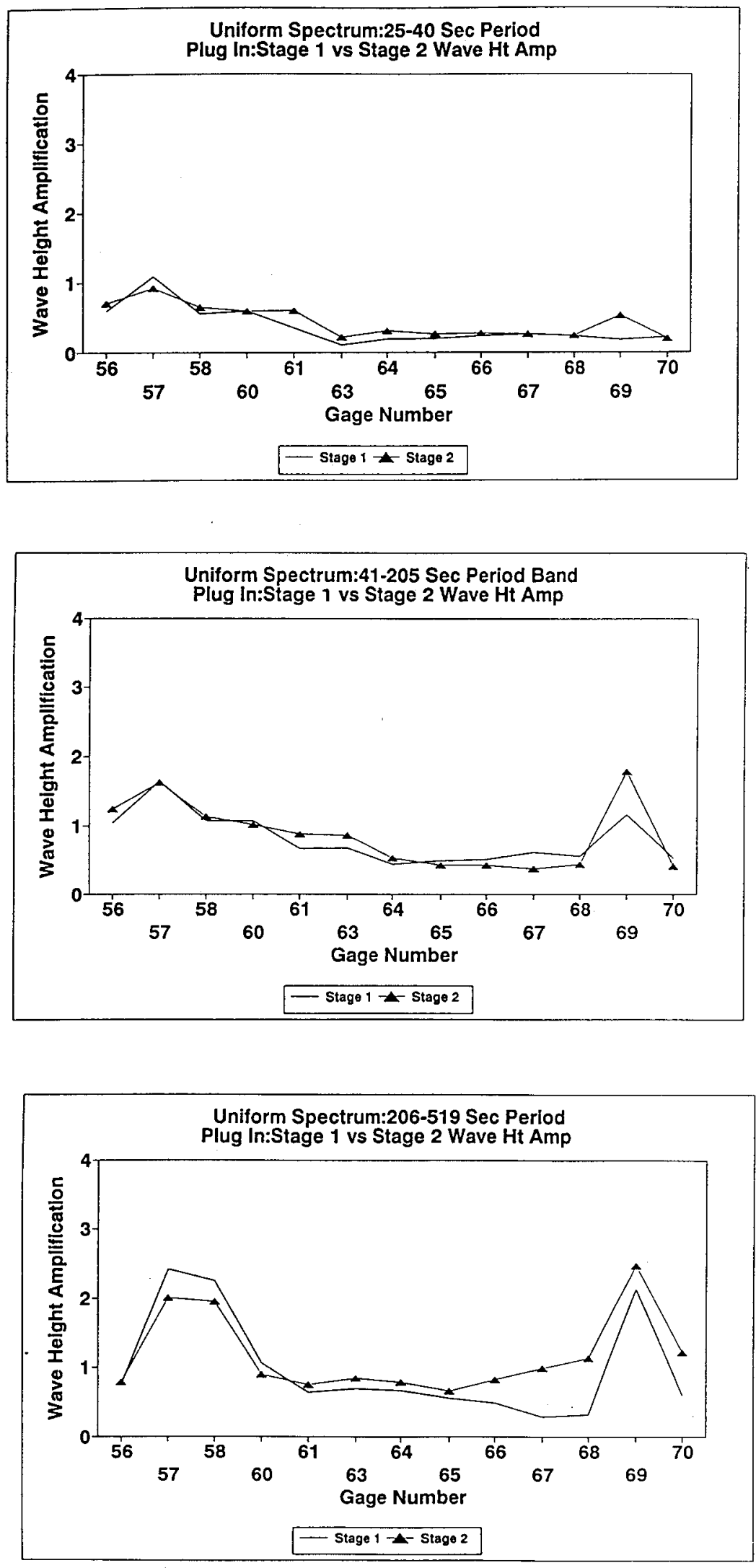

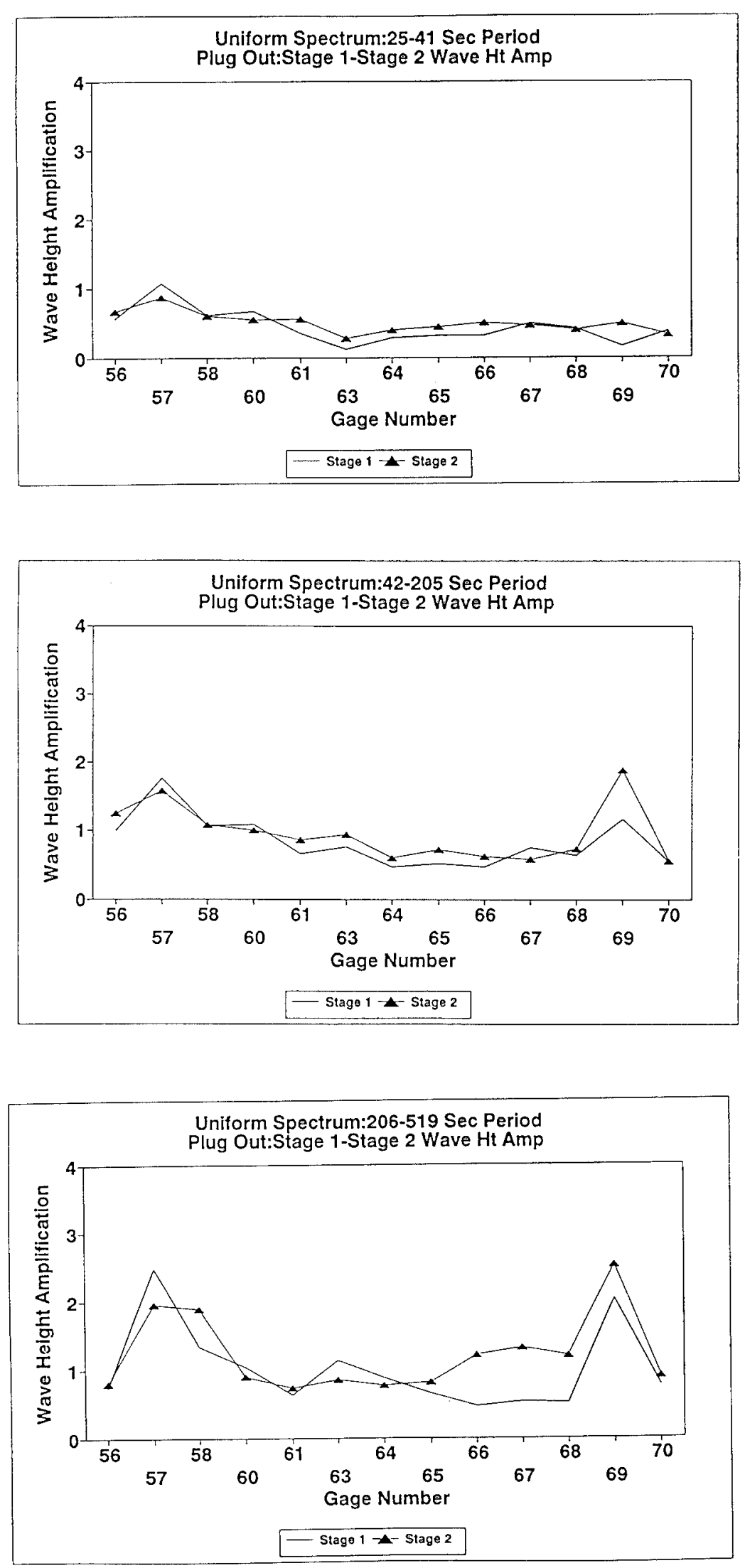

Plate 10 

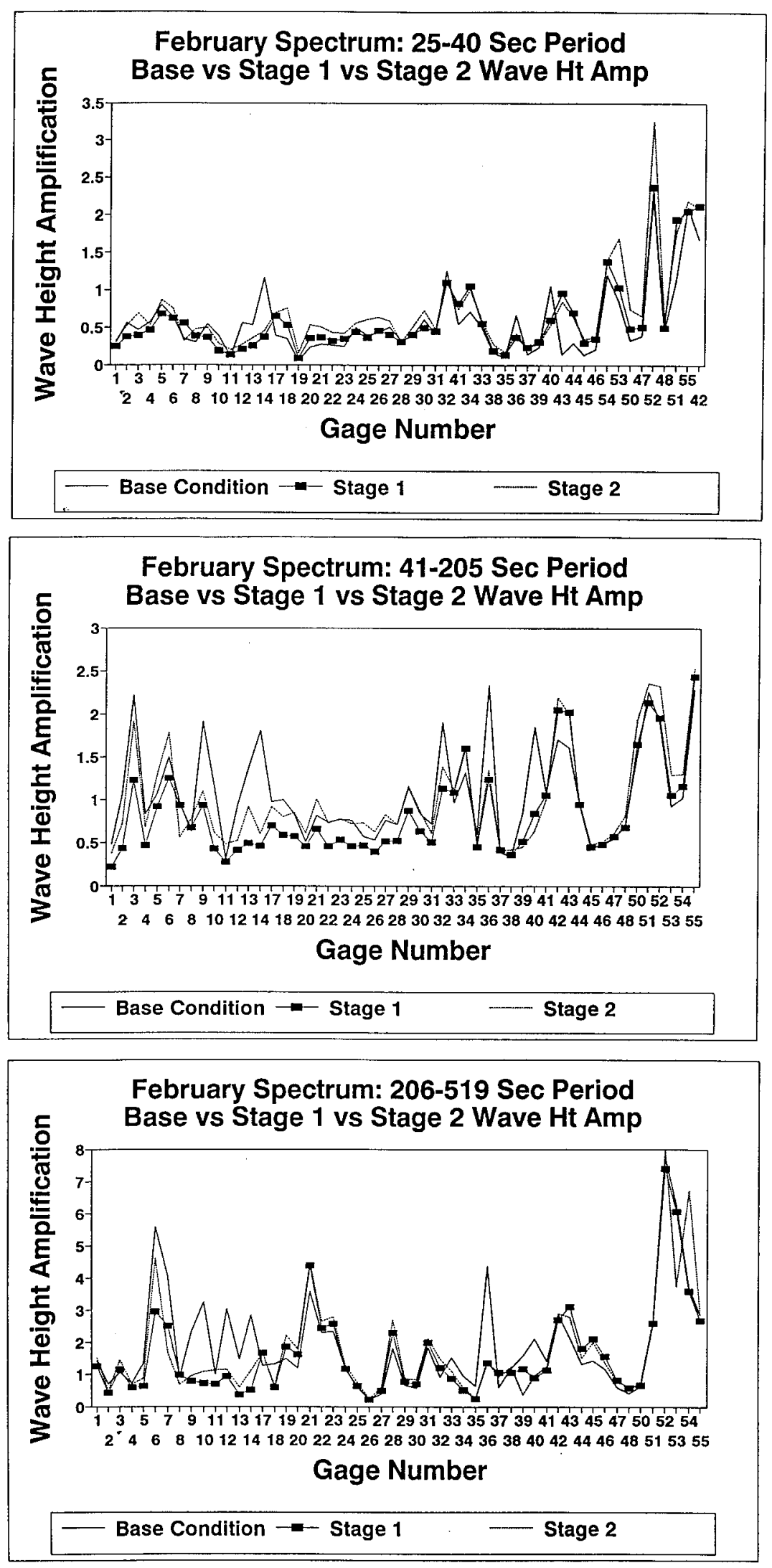


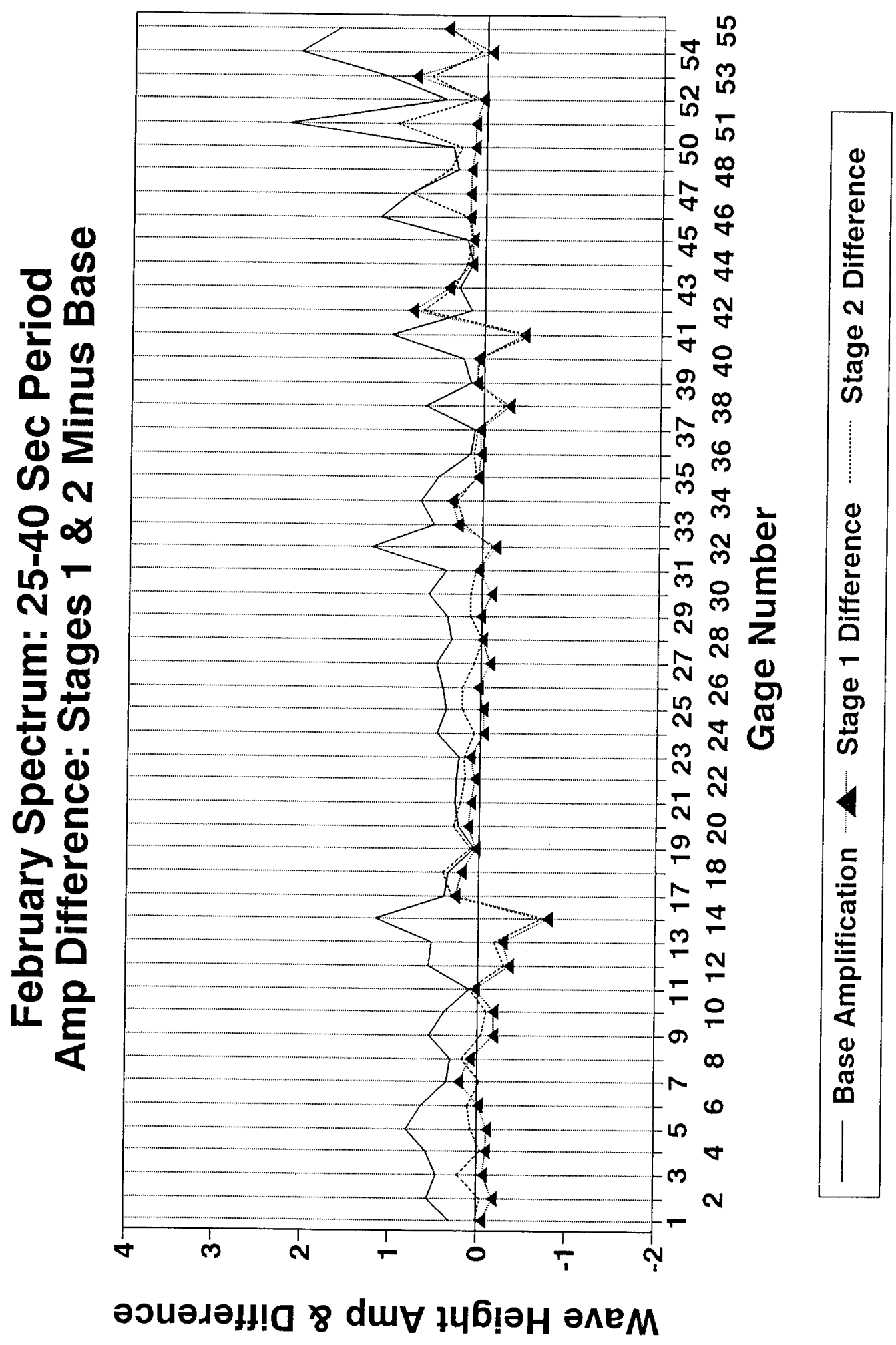

Plate 12 


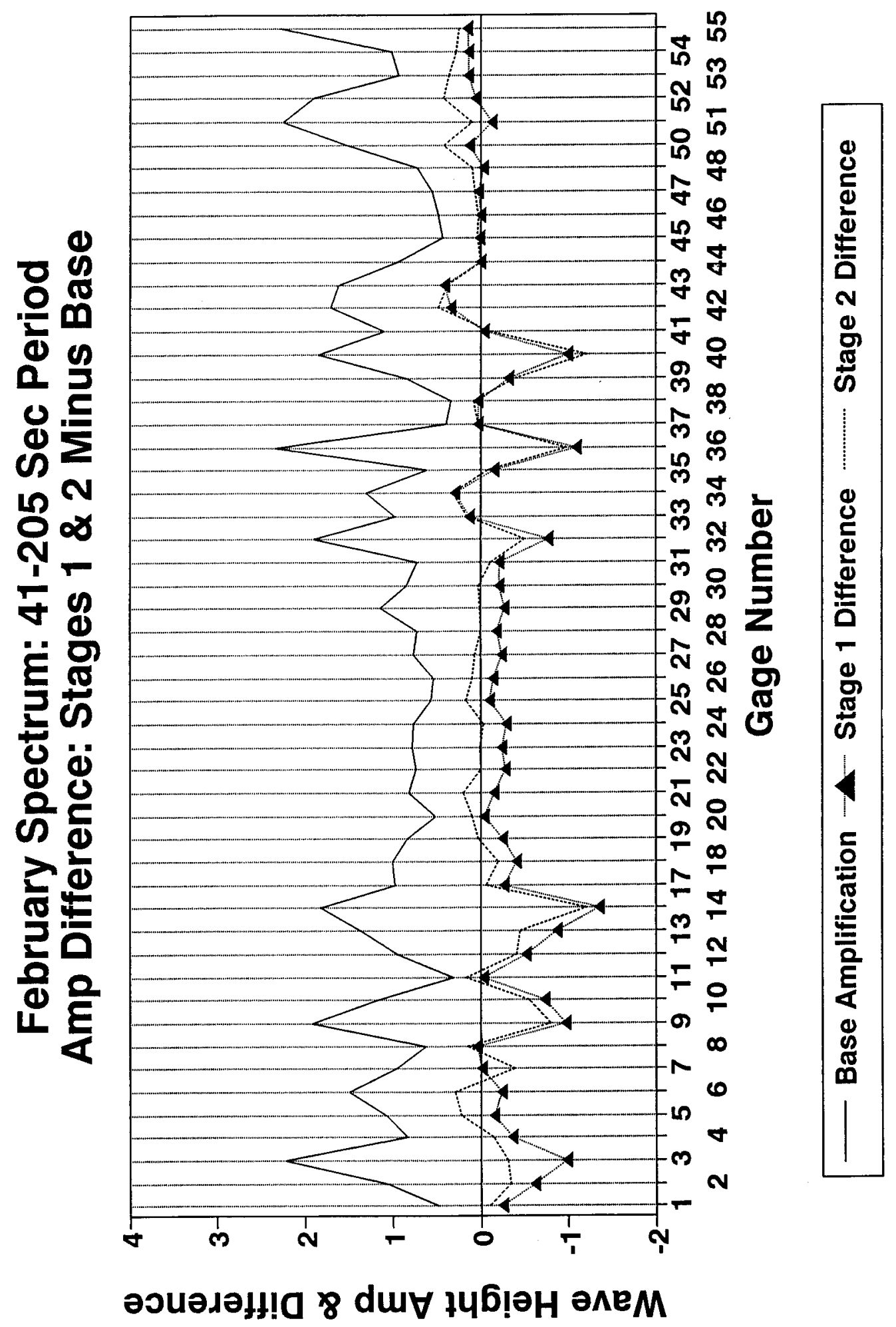




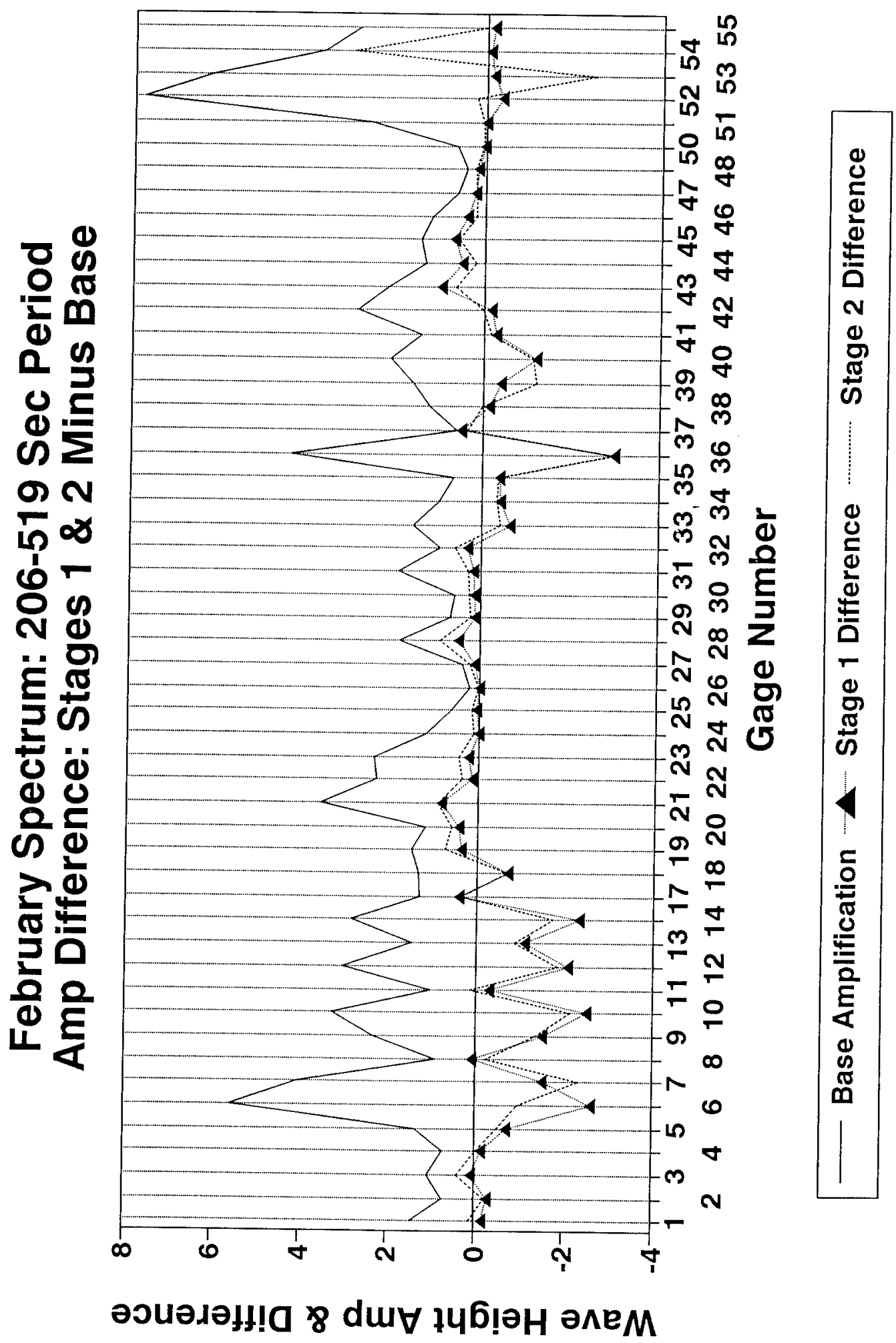

Plate 14 

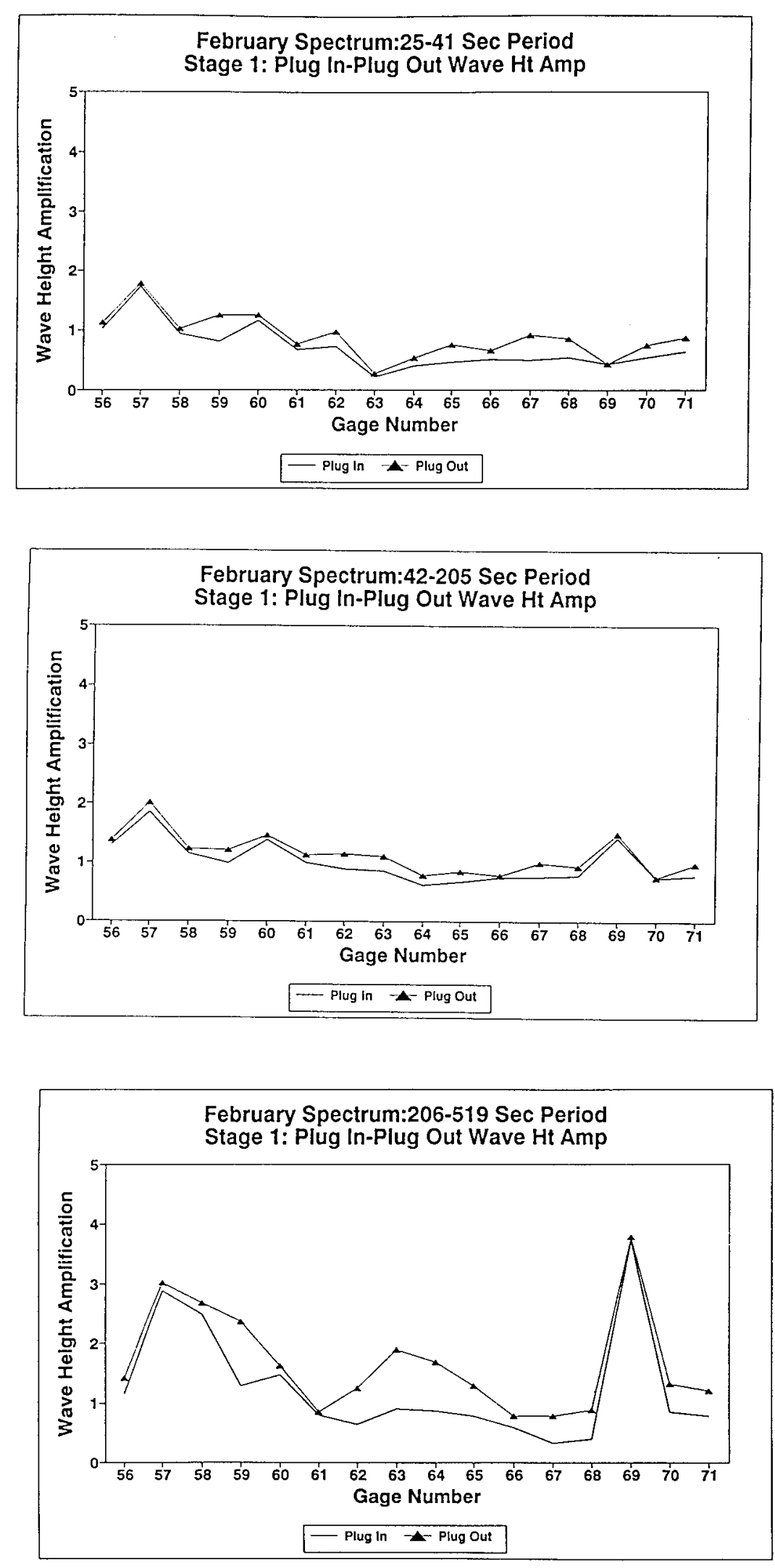

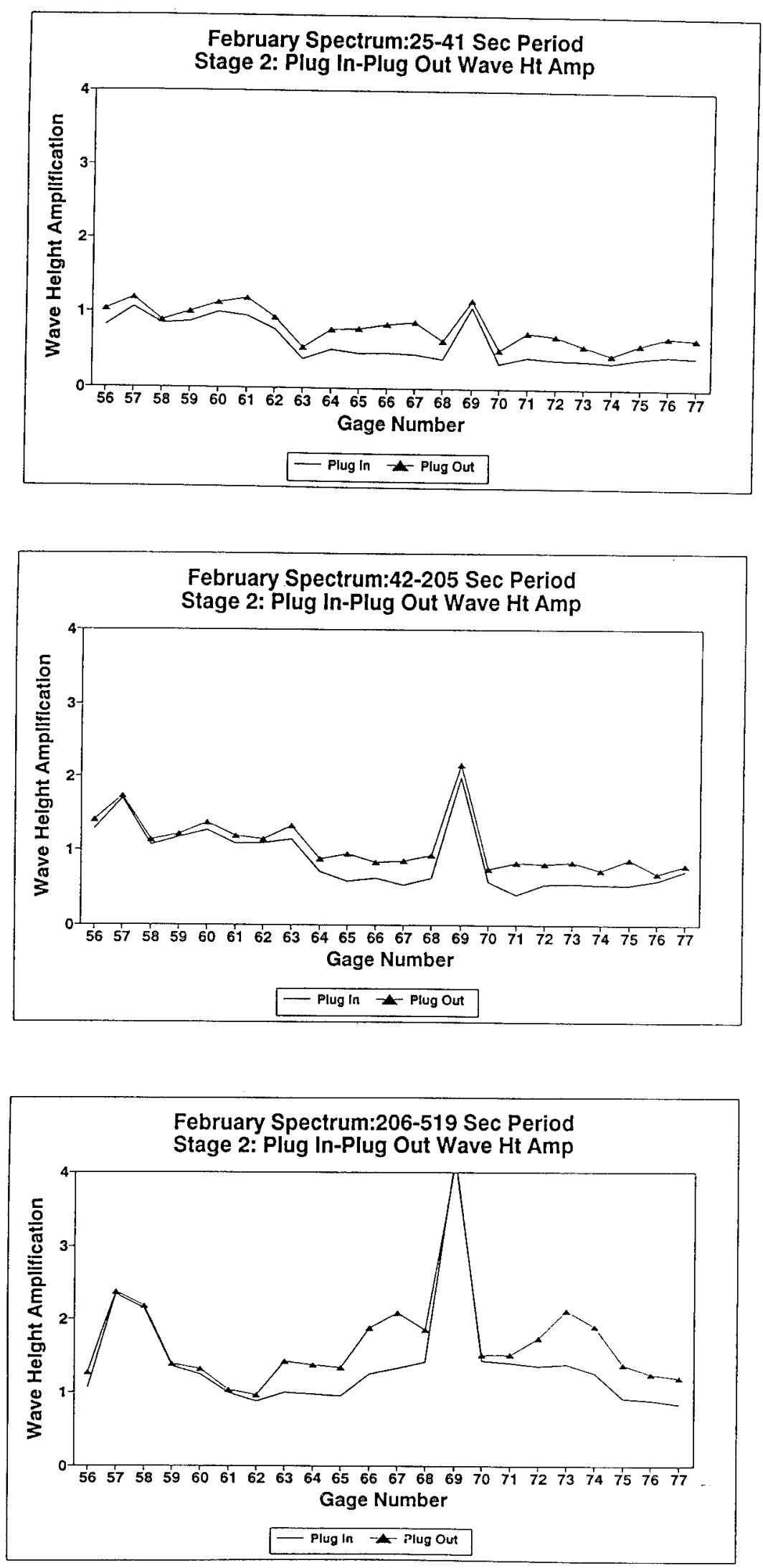

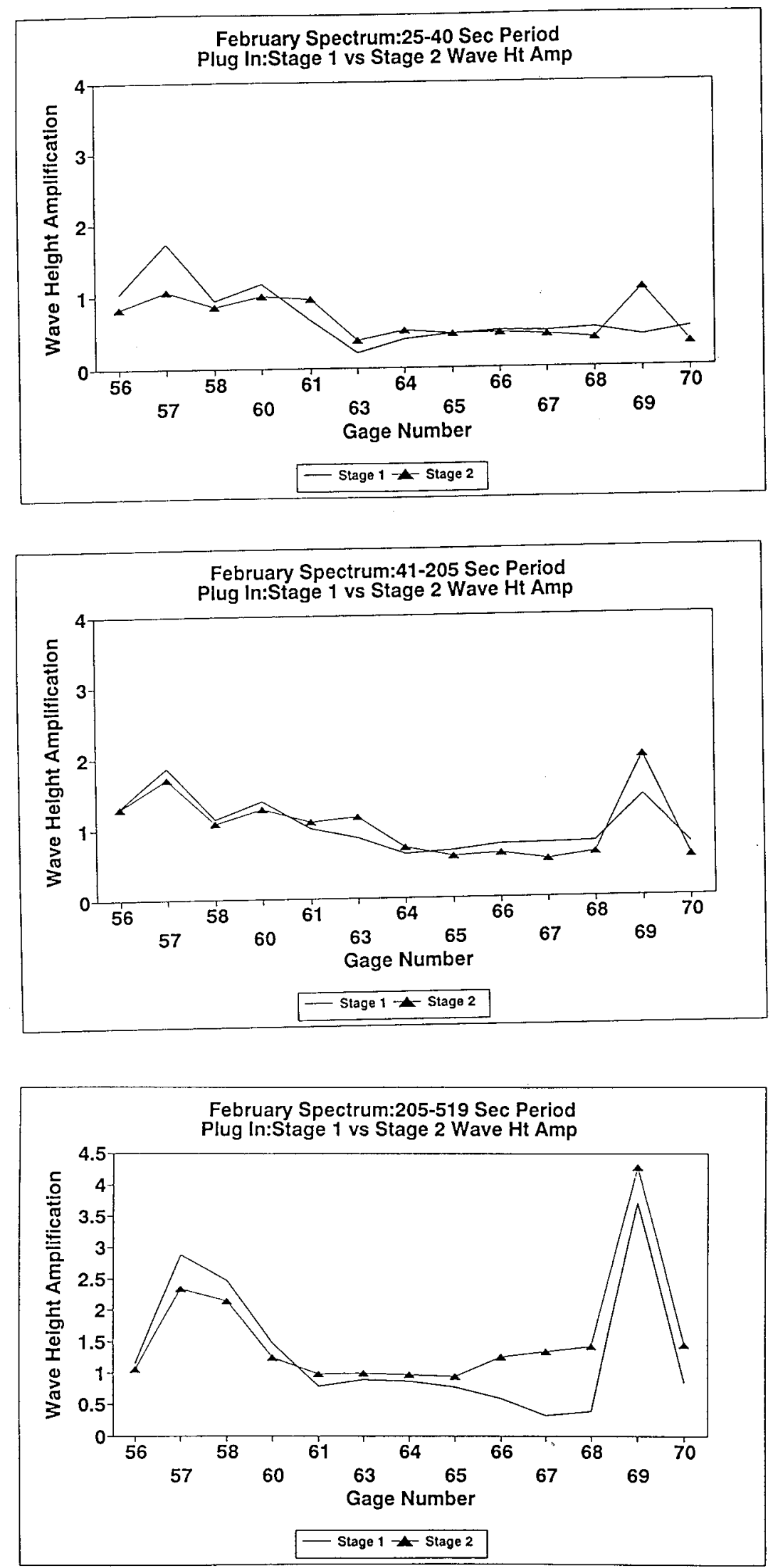

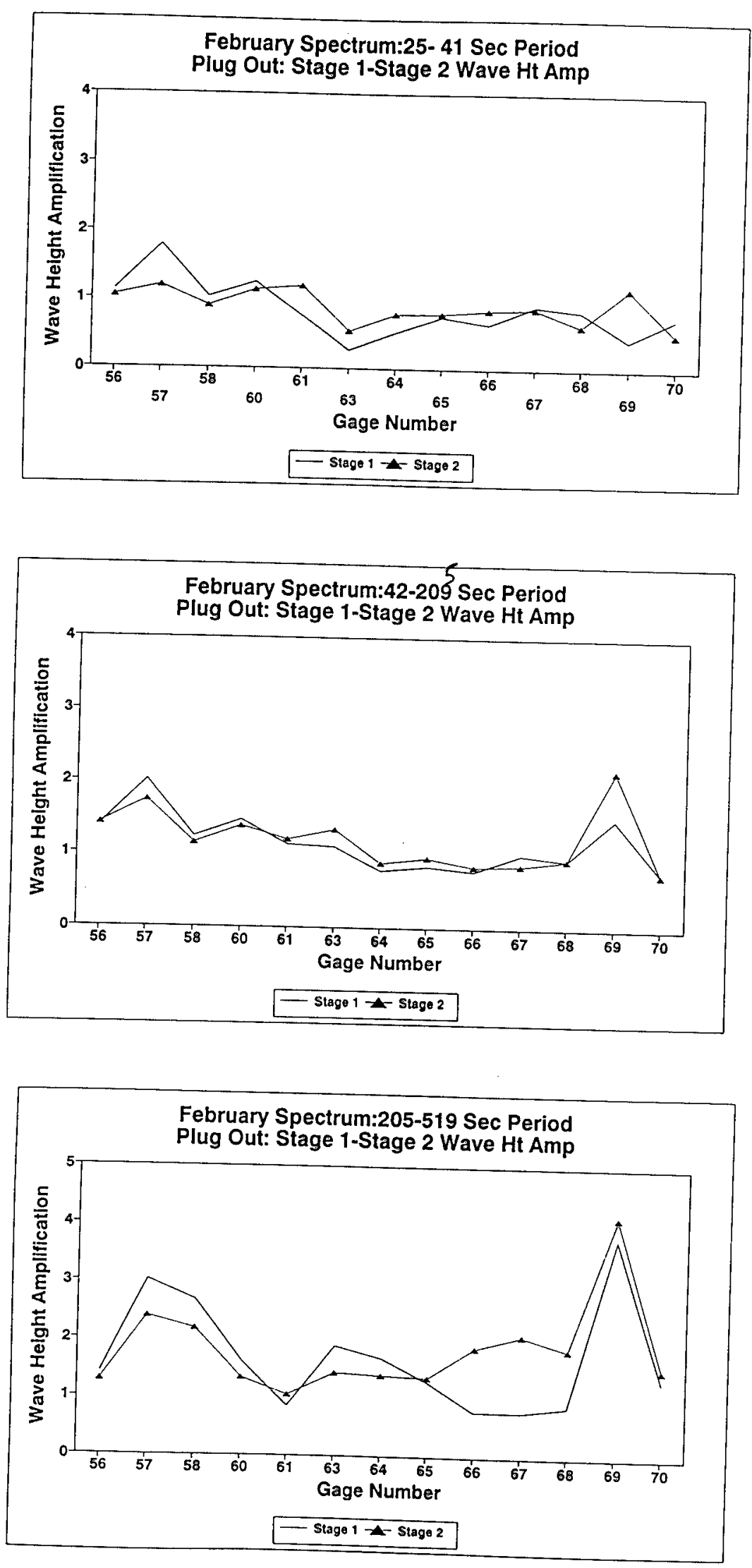

Plate 18 

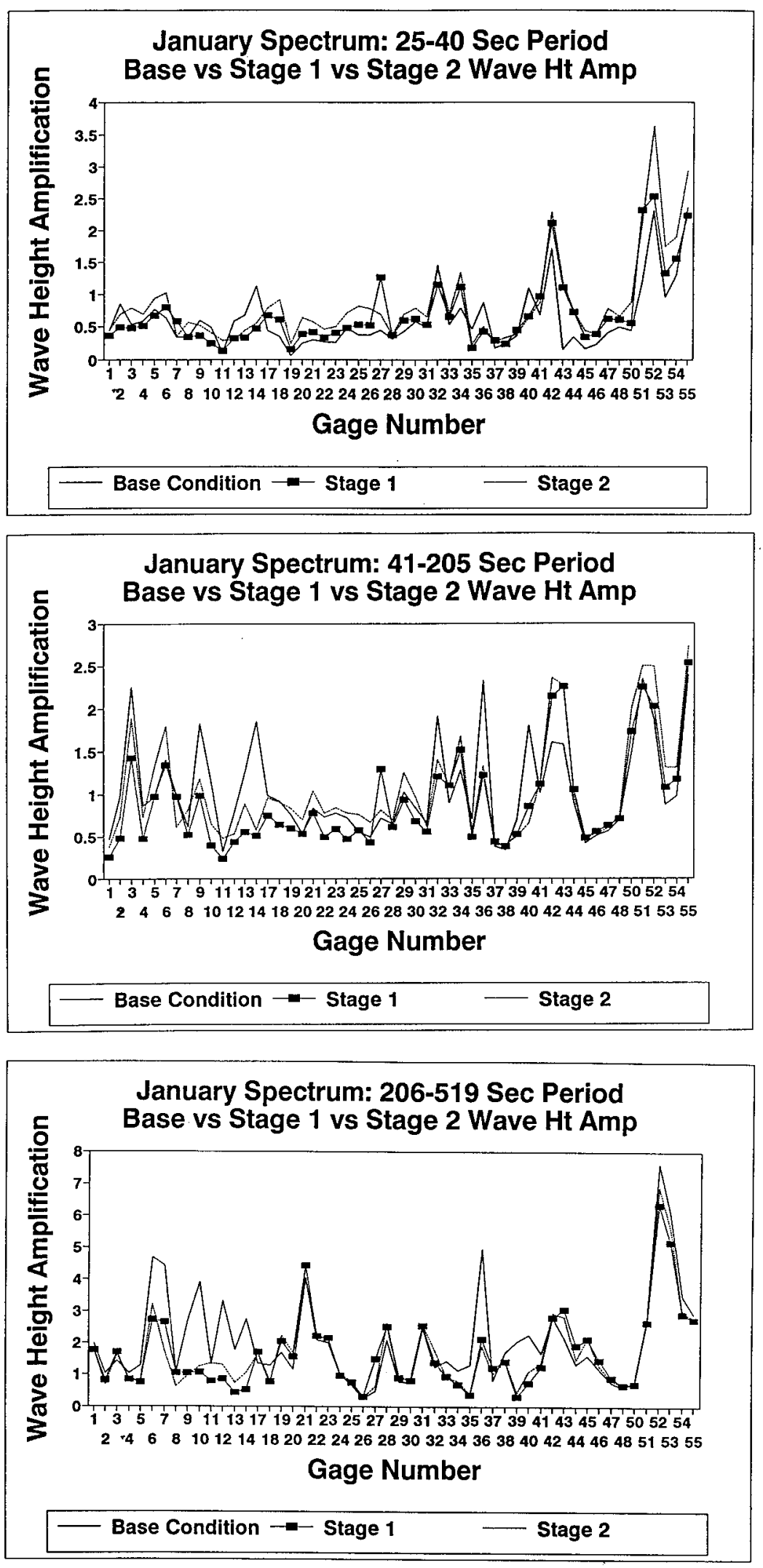


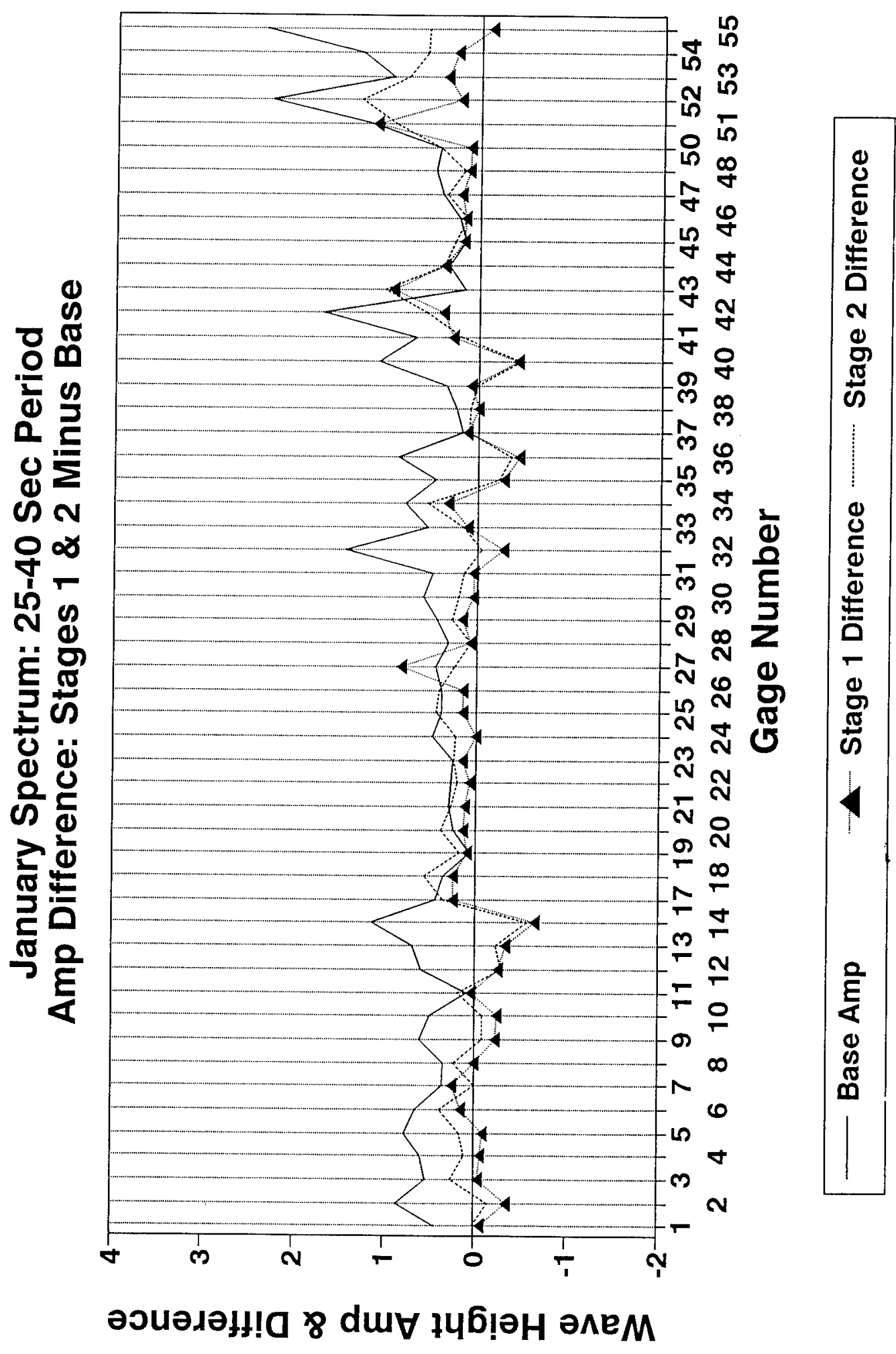

Plate 20 


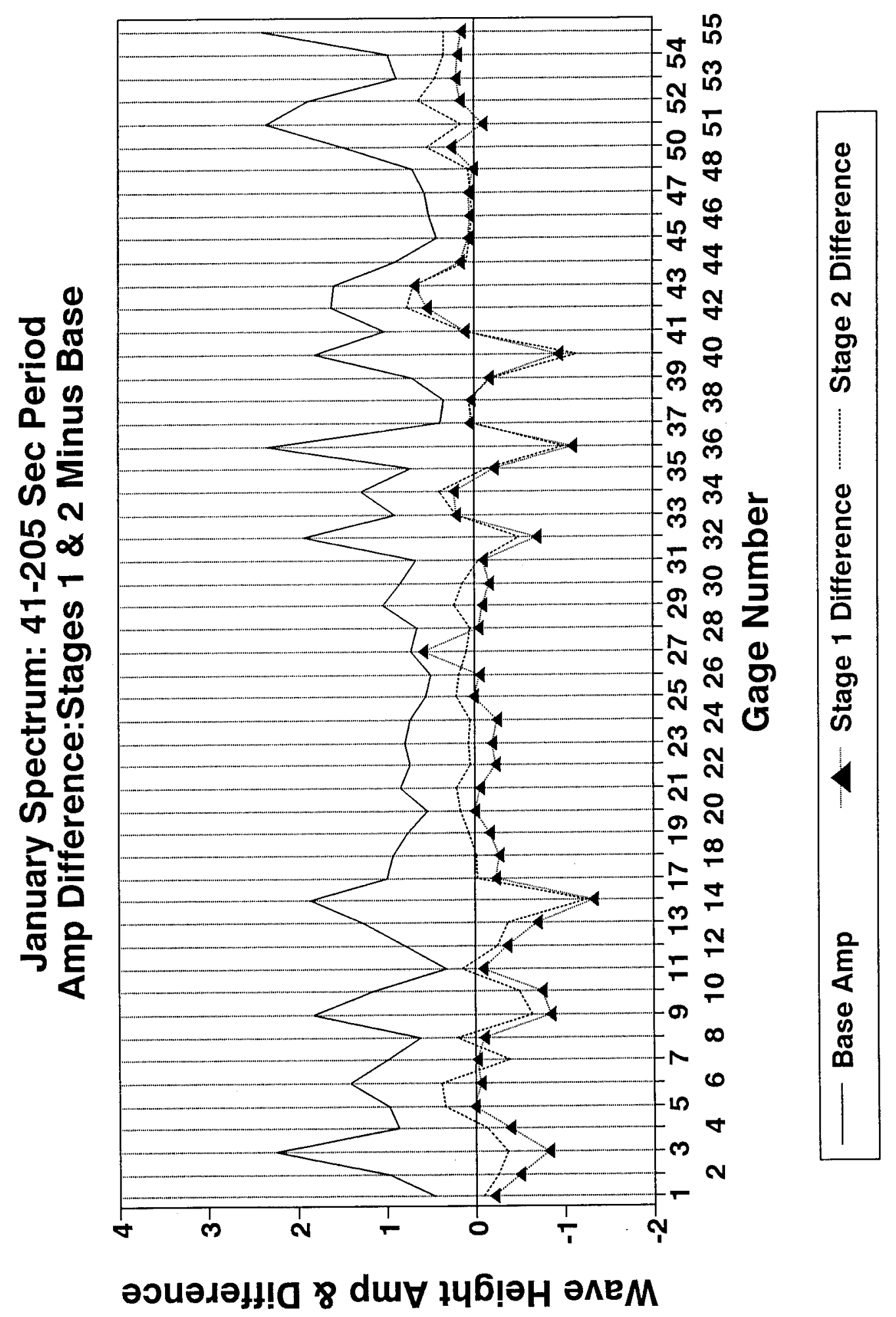

Plate 21 


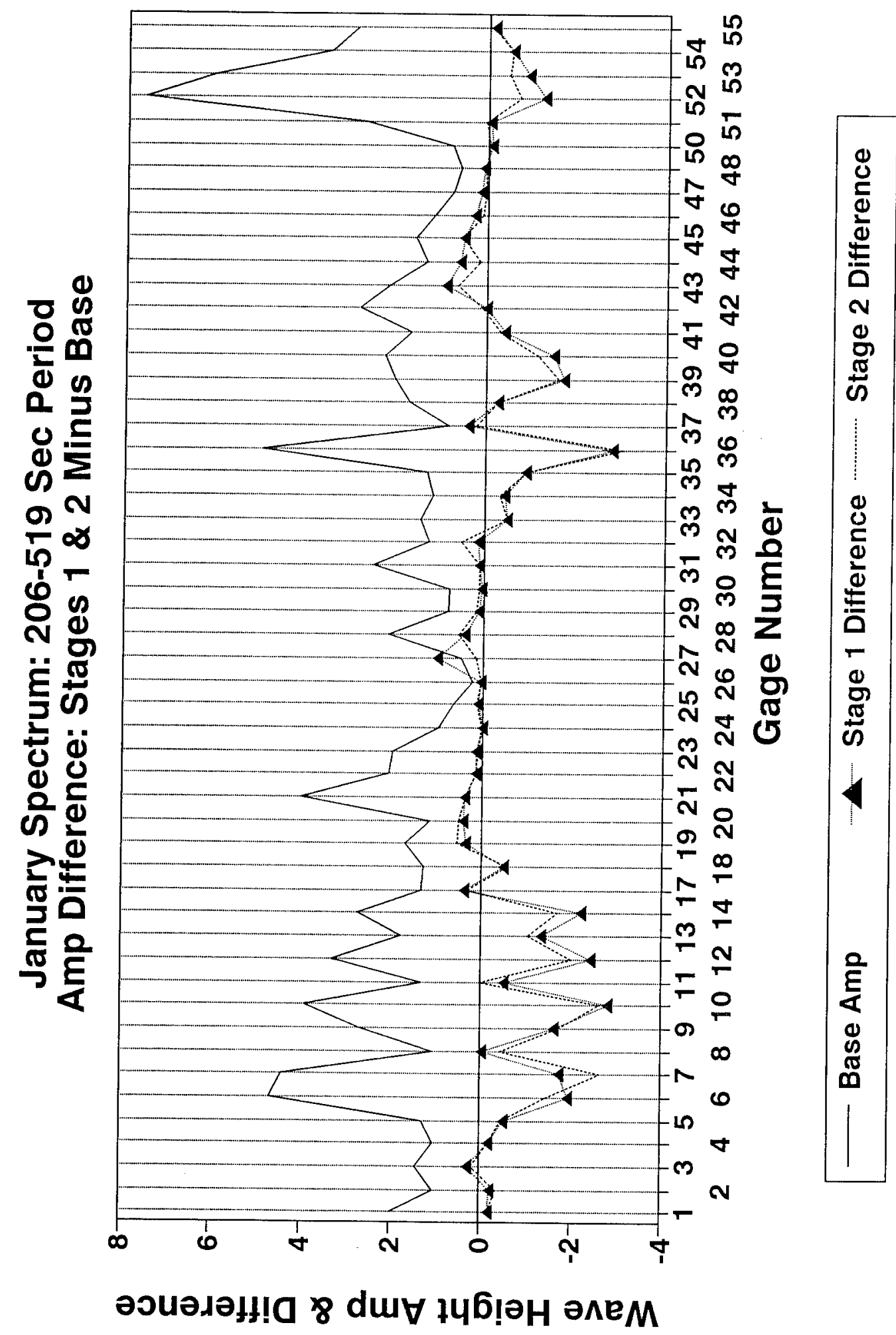

Plate 22 

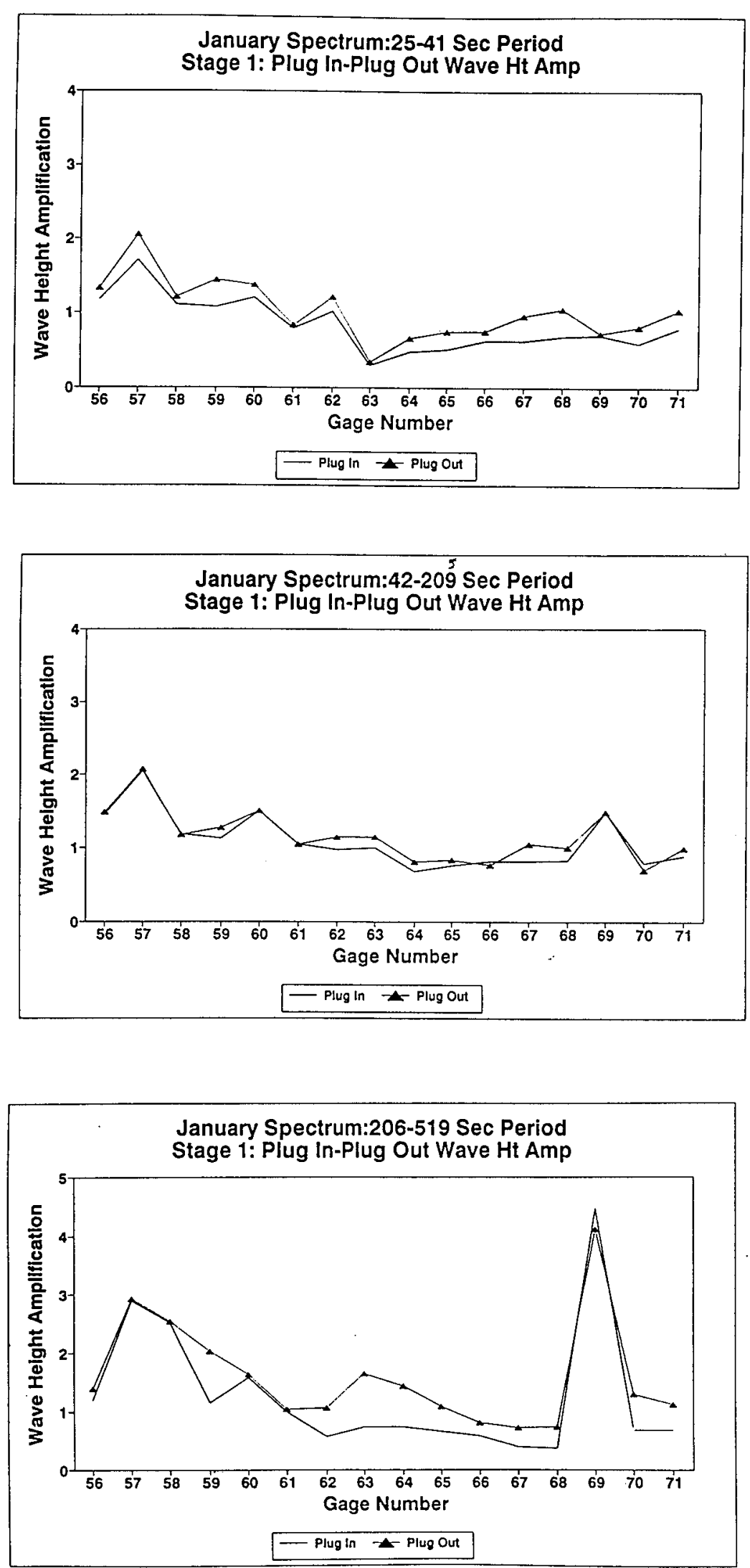

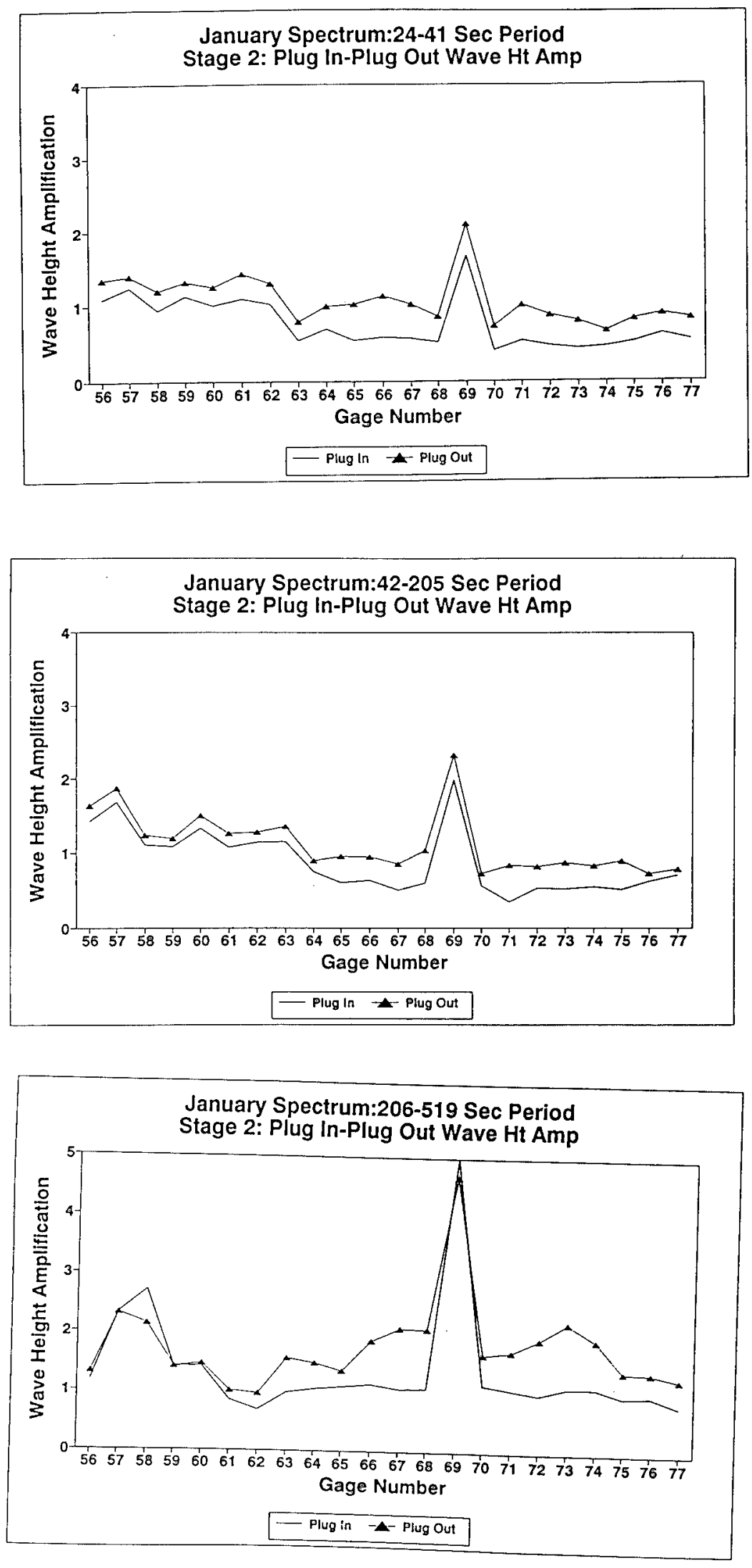

Plate 24 

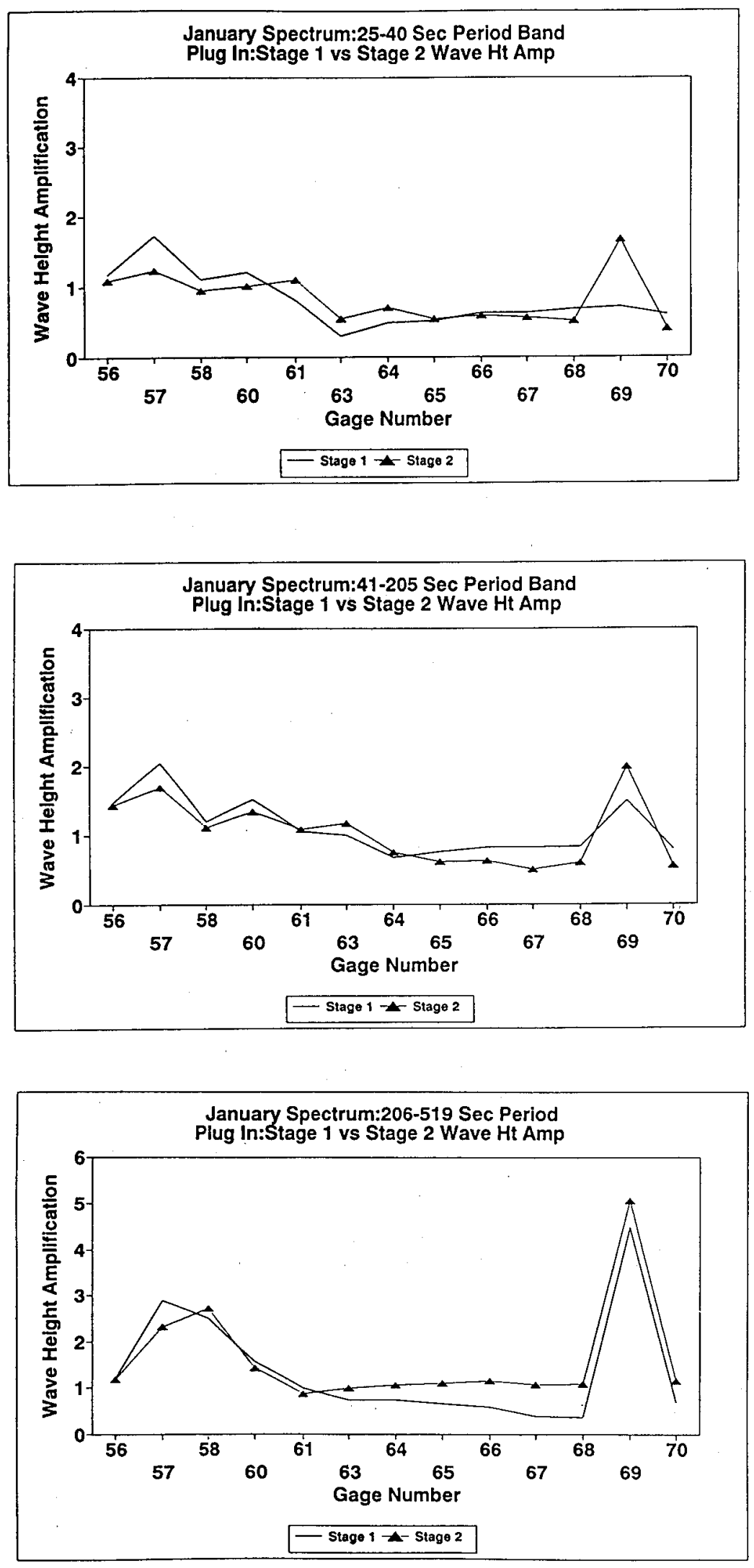

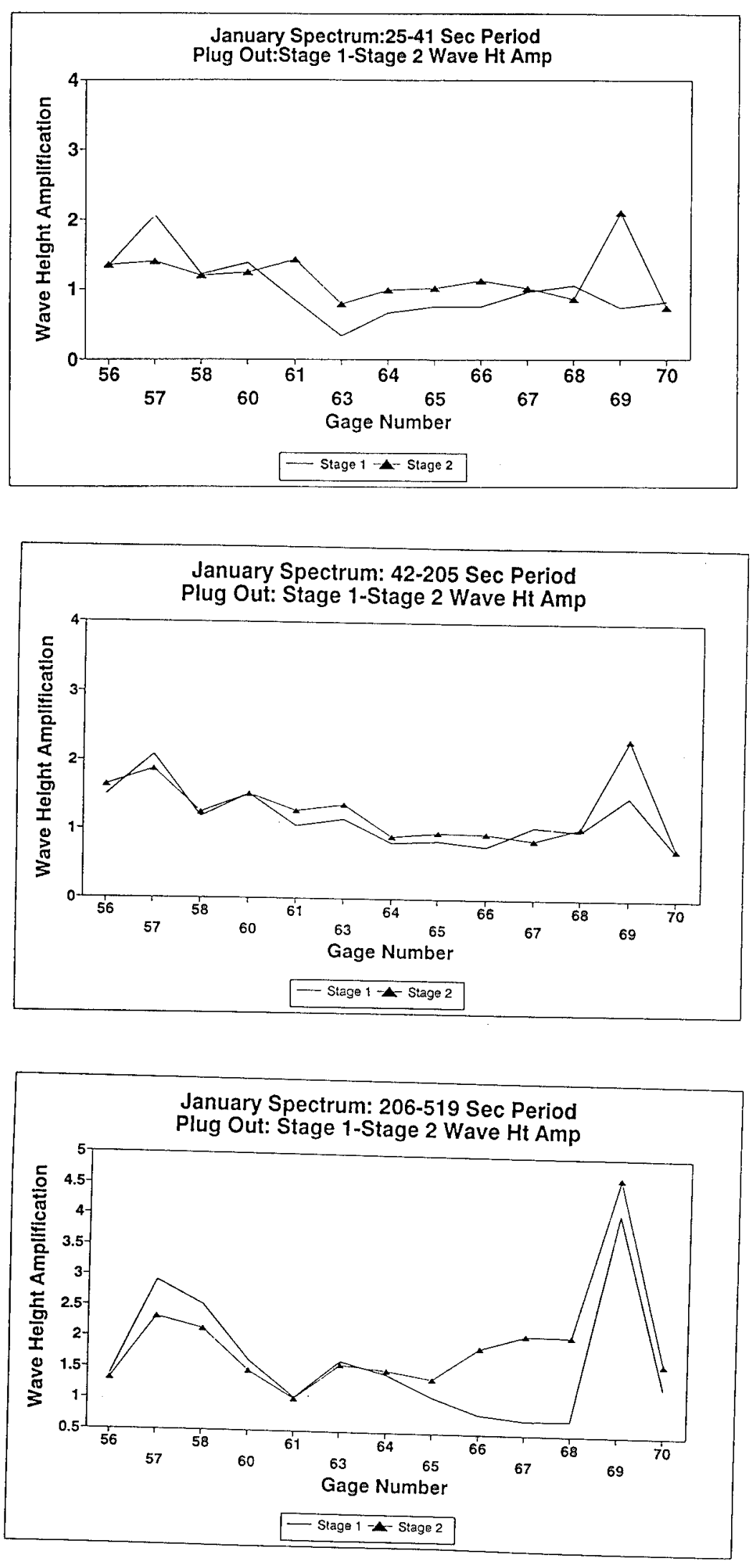

Plate 26 

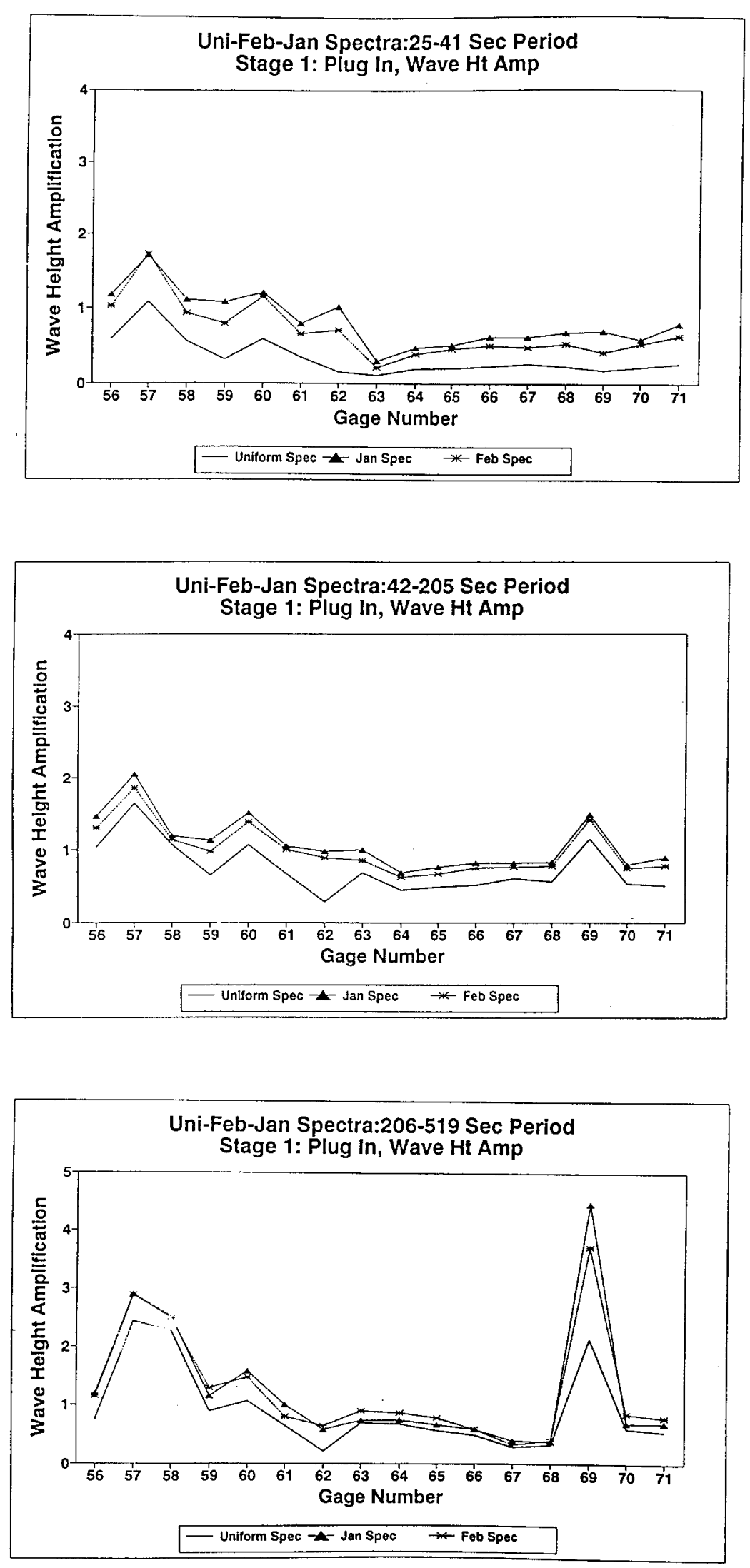

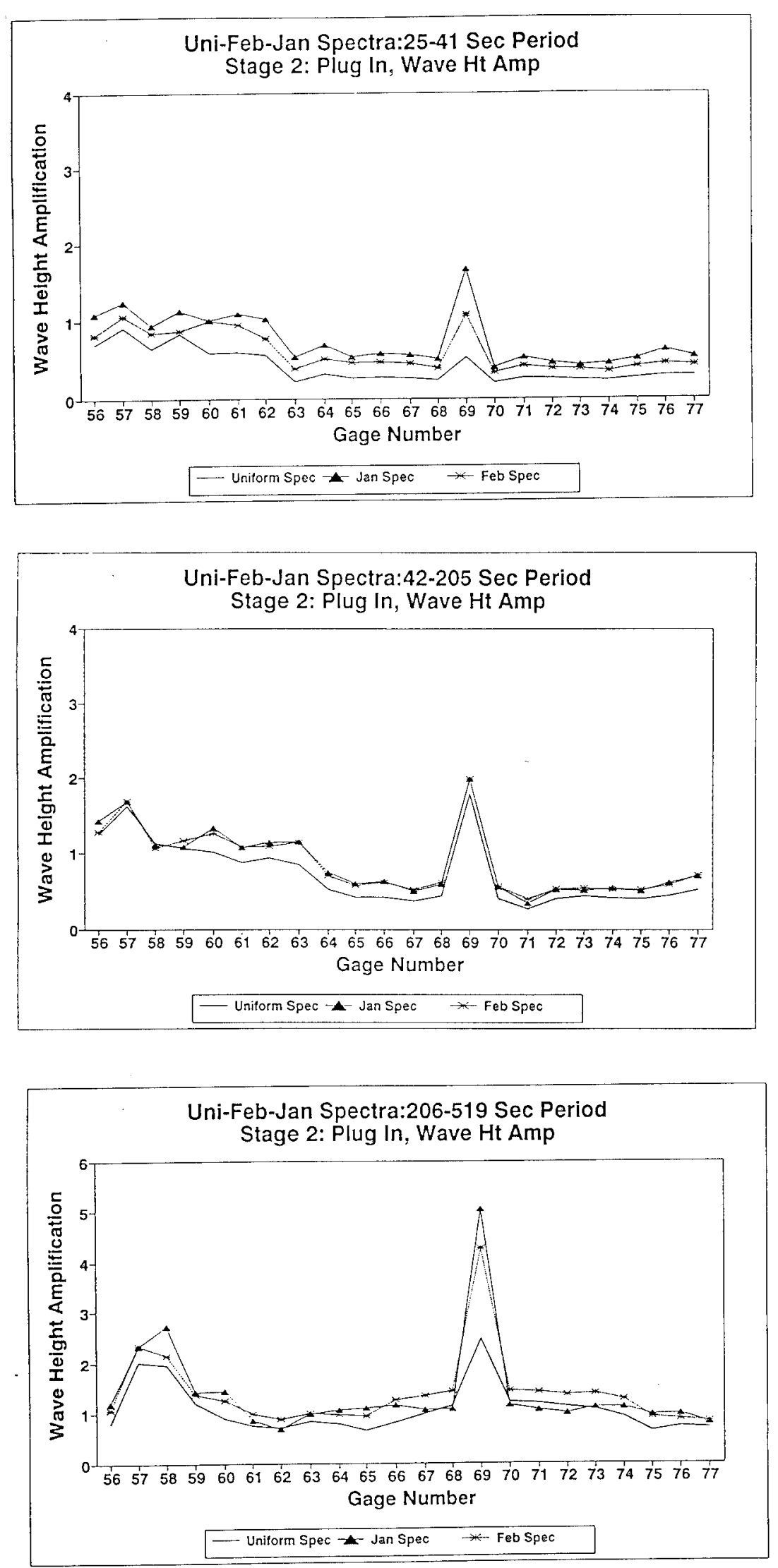

Plate 28 

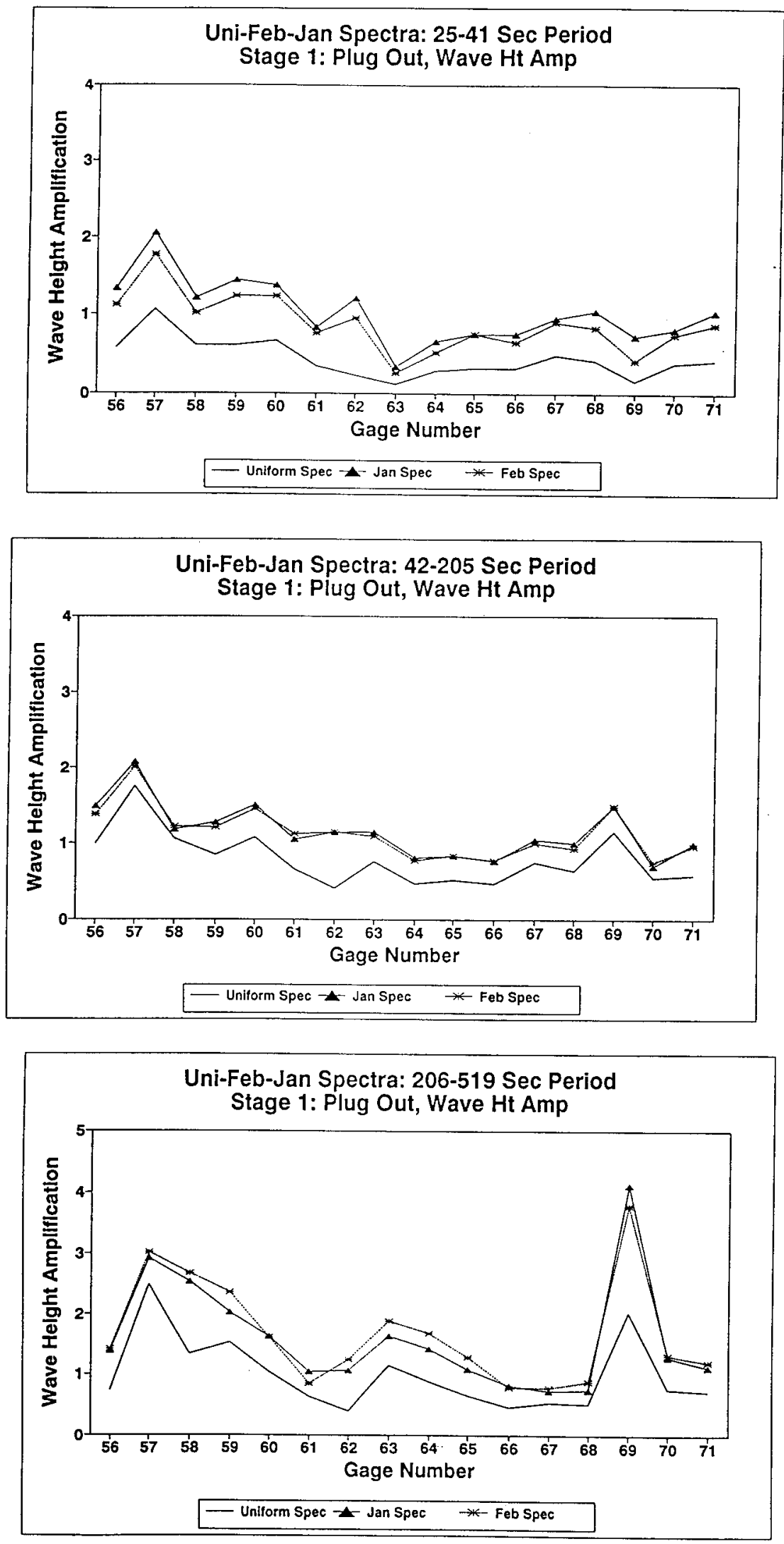

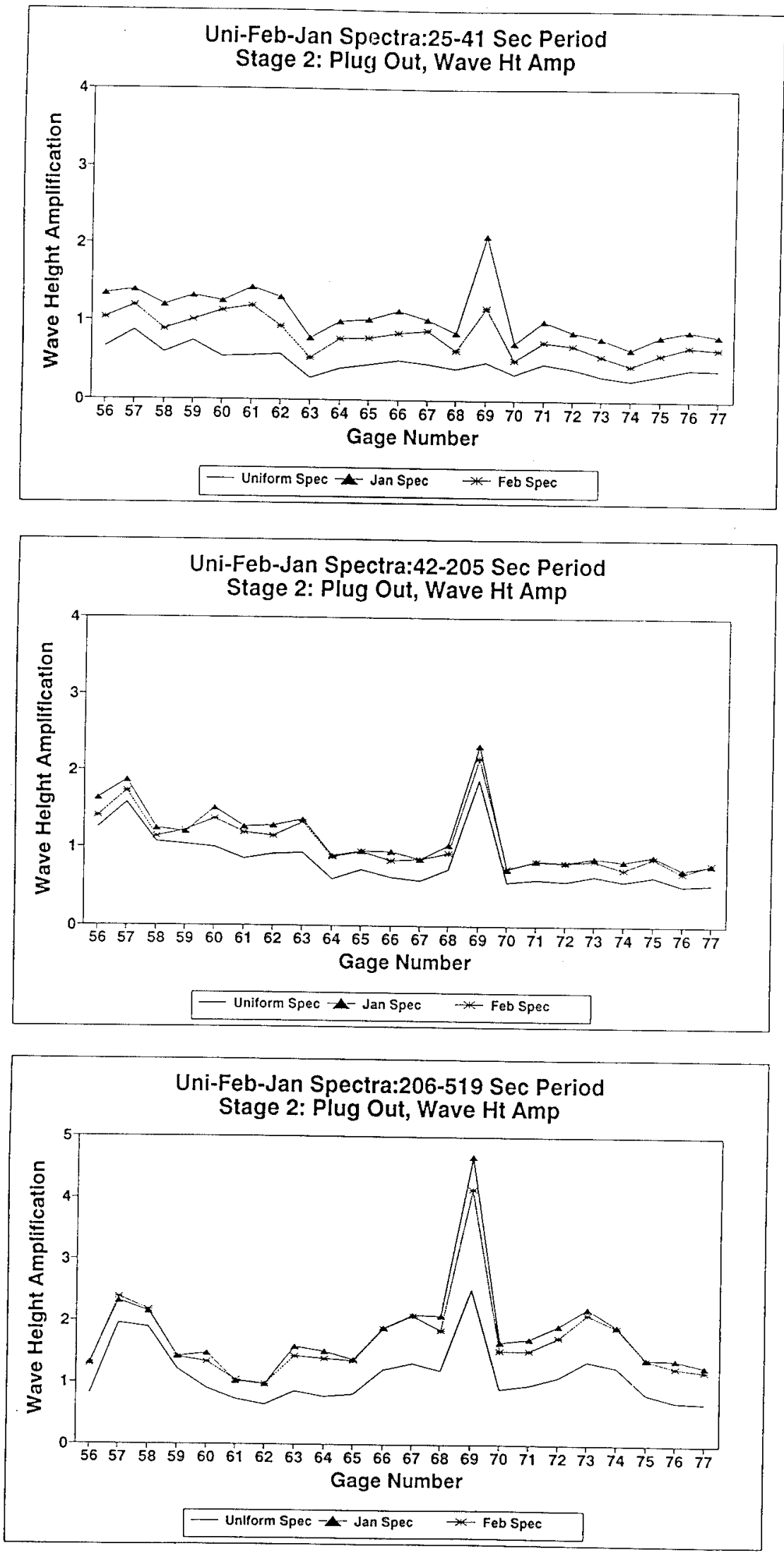

Plate 30 


\section{Appendix A Wave Amplification, Uniform Spectrum, Gages 1-55}



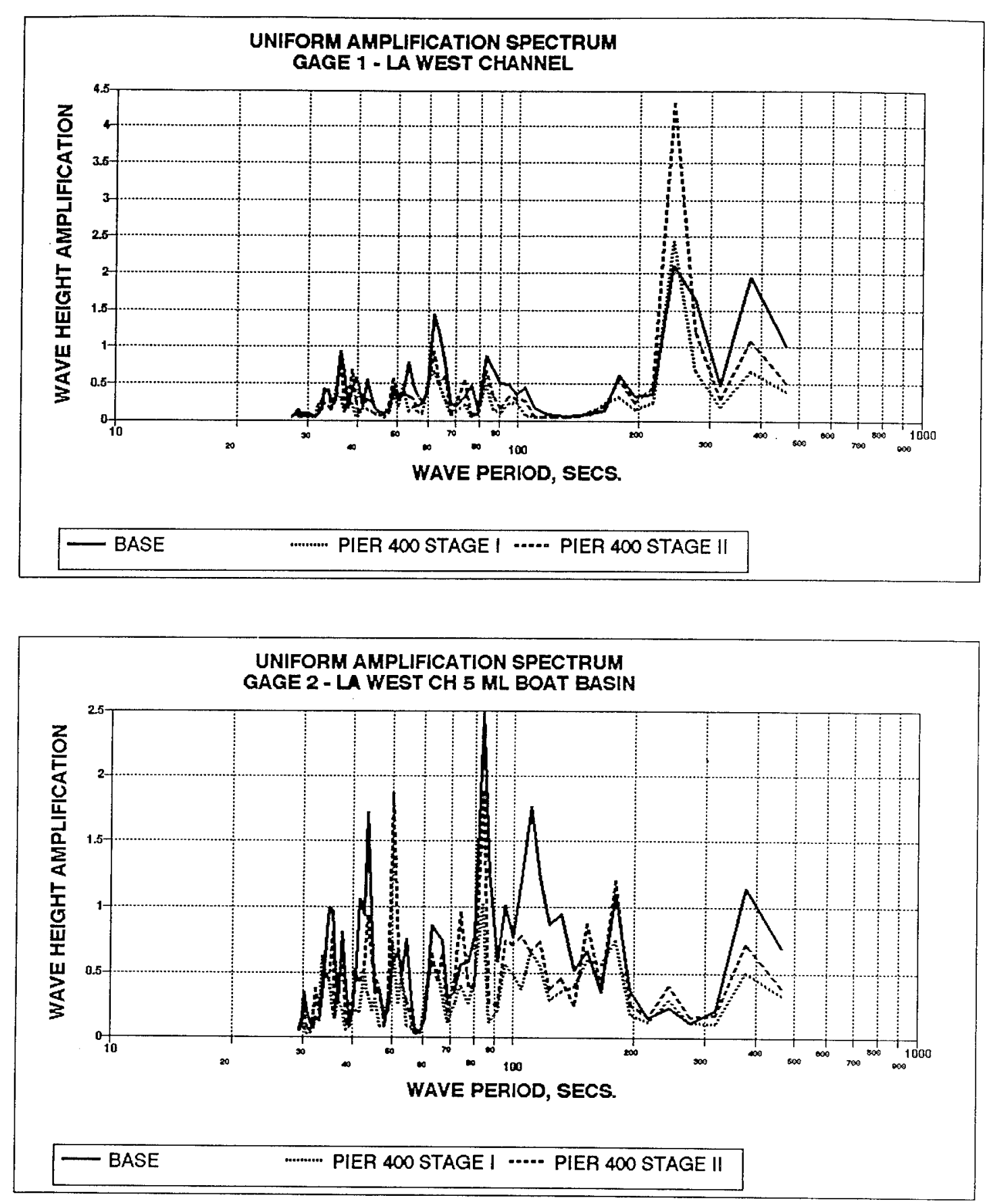

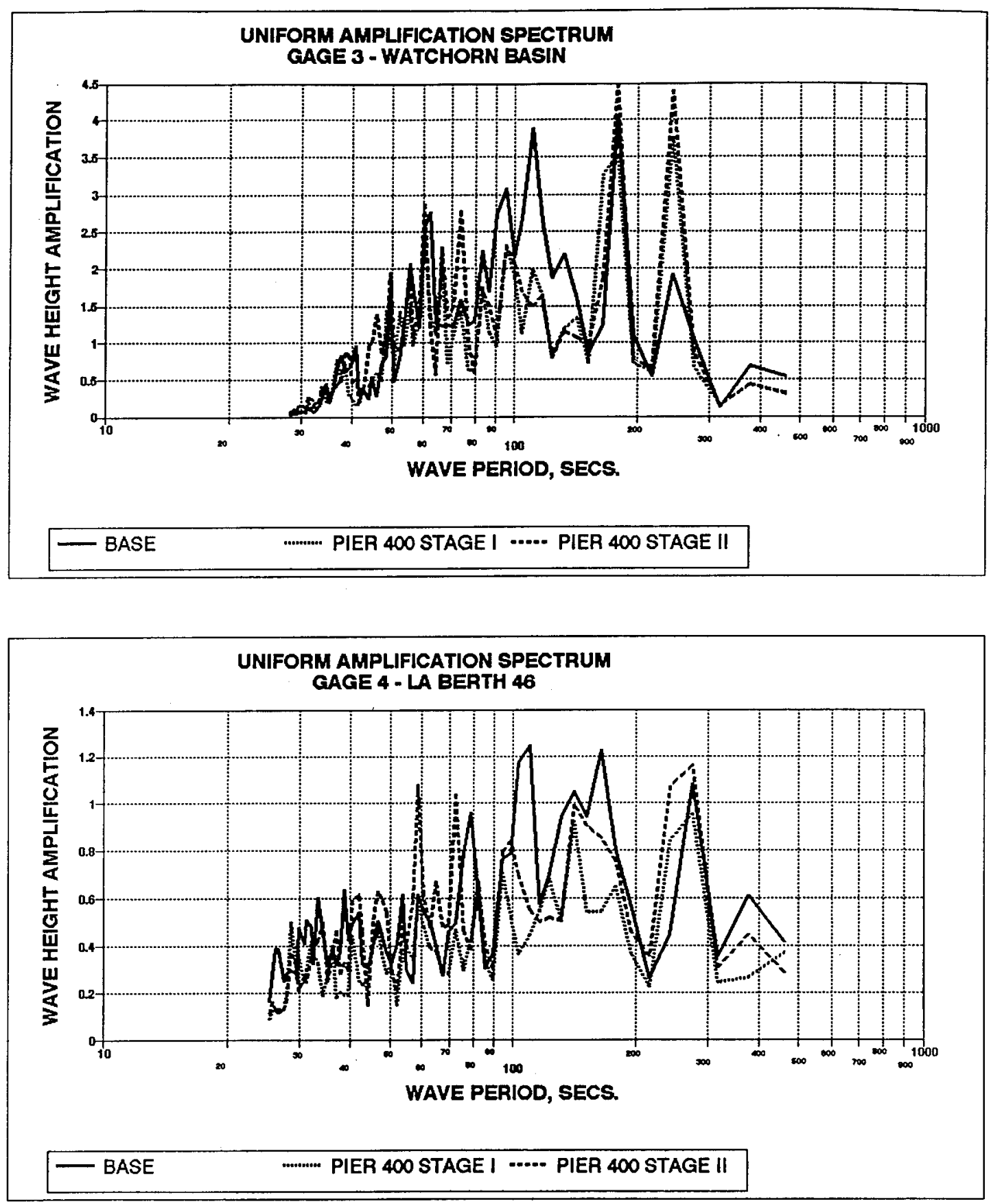

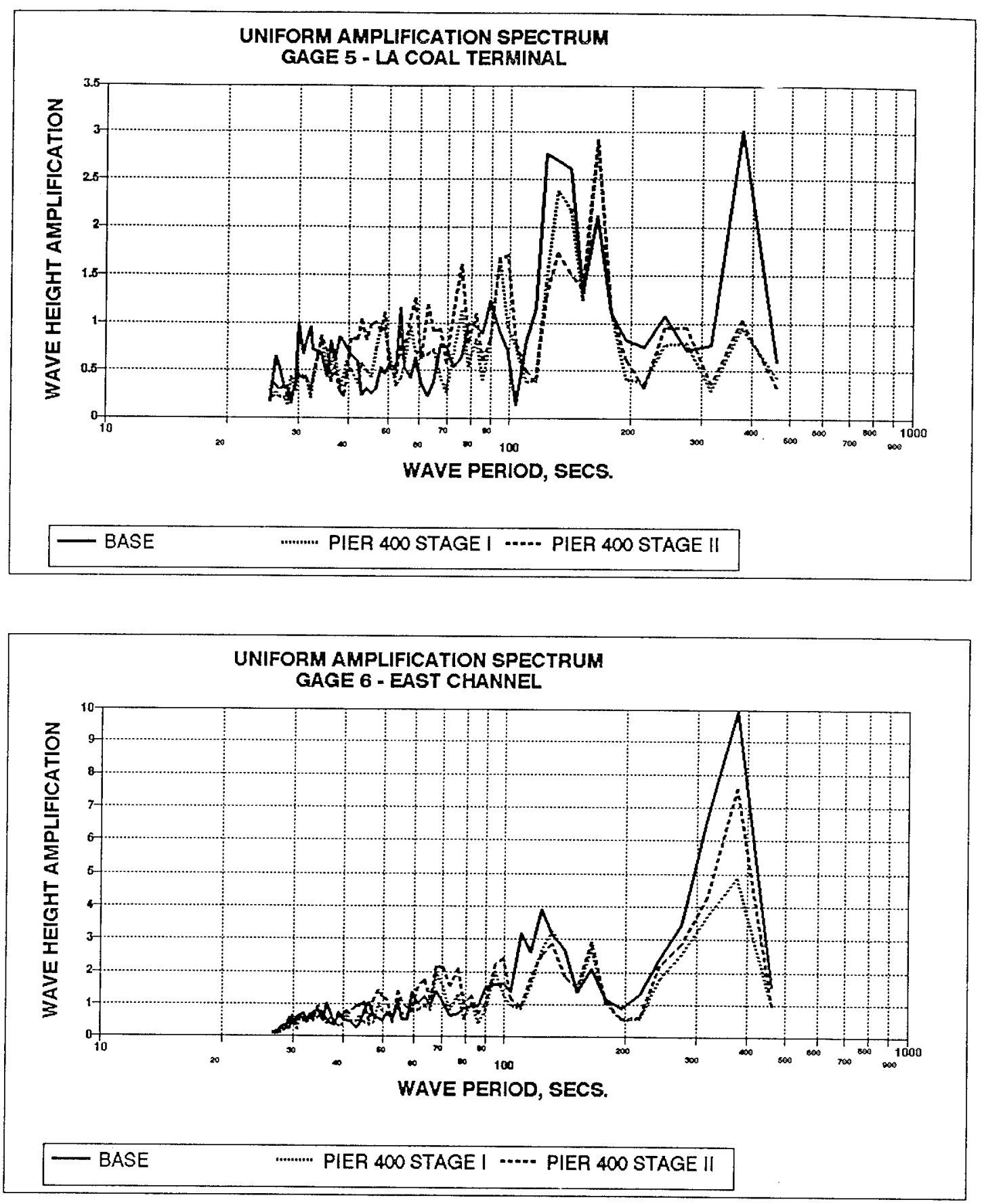


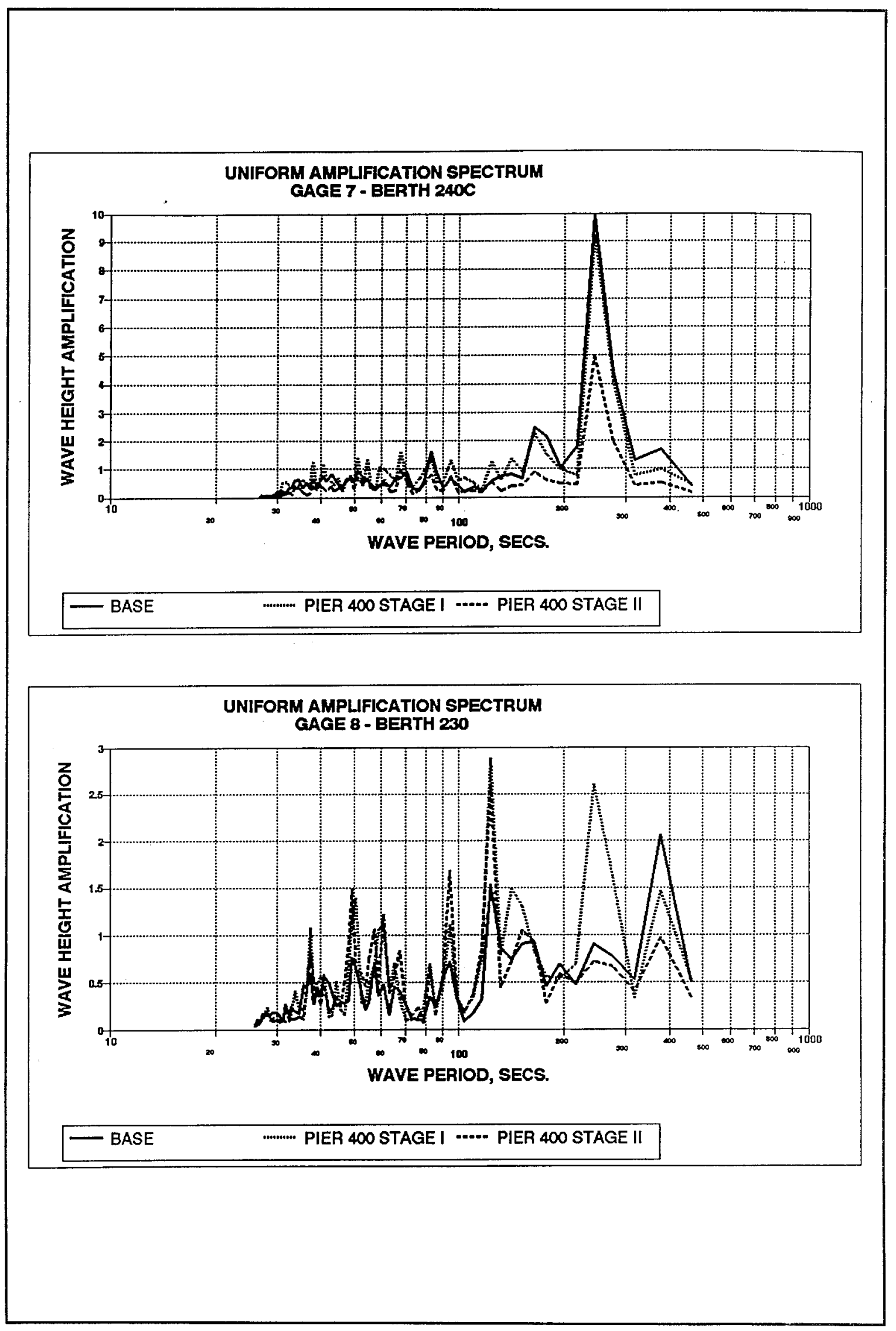



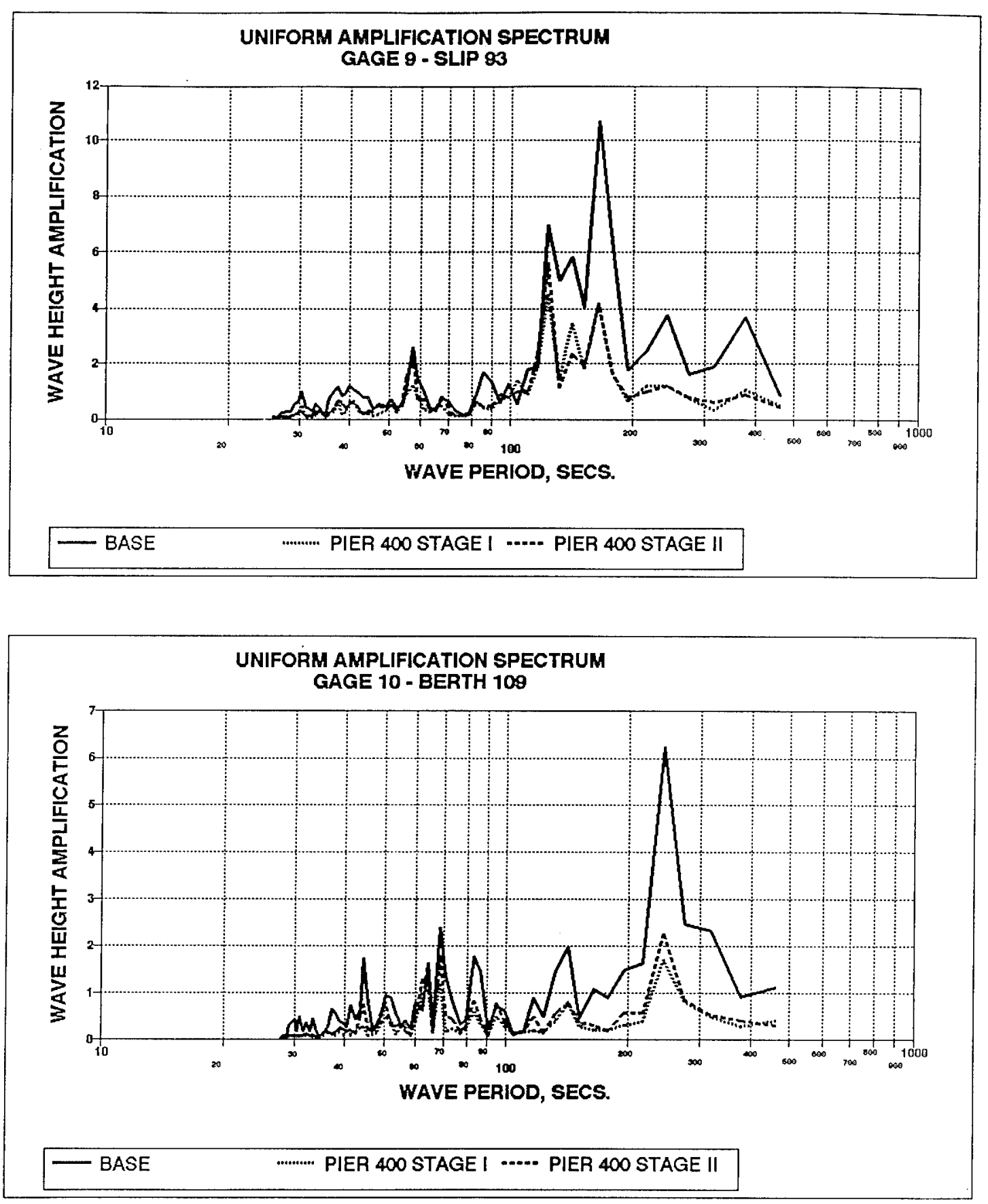

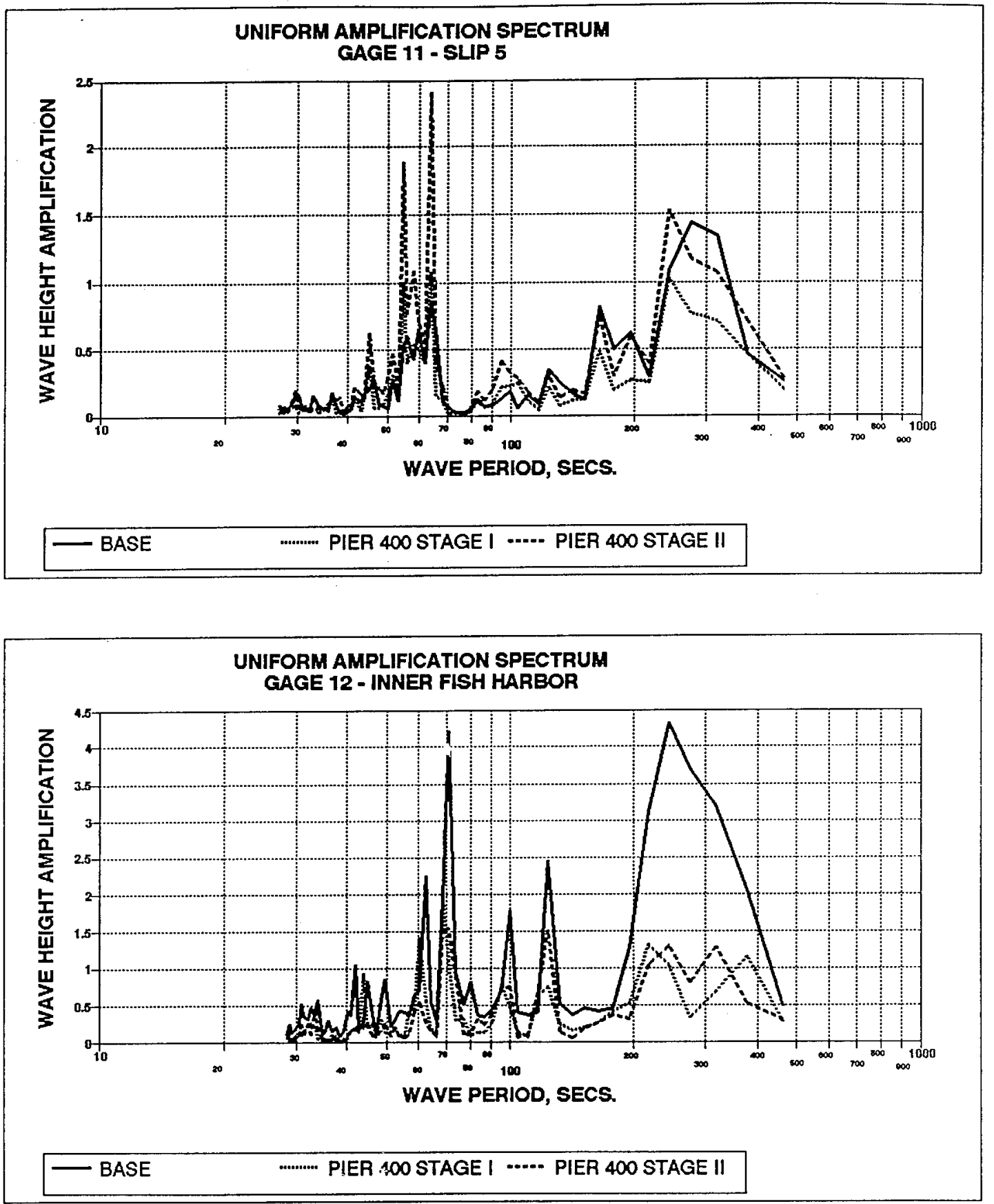


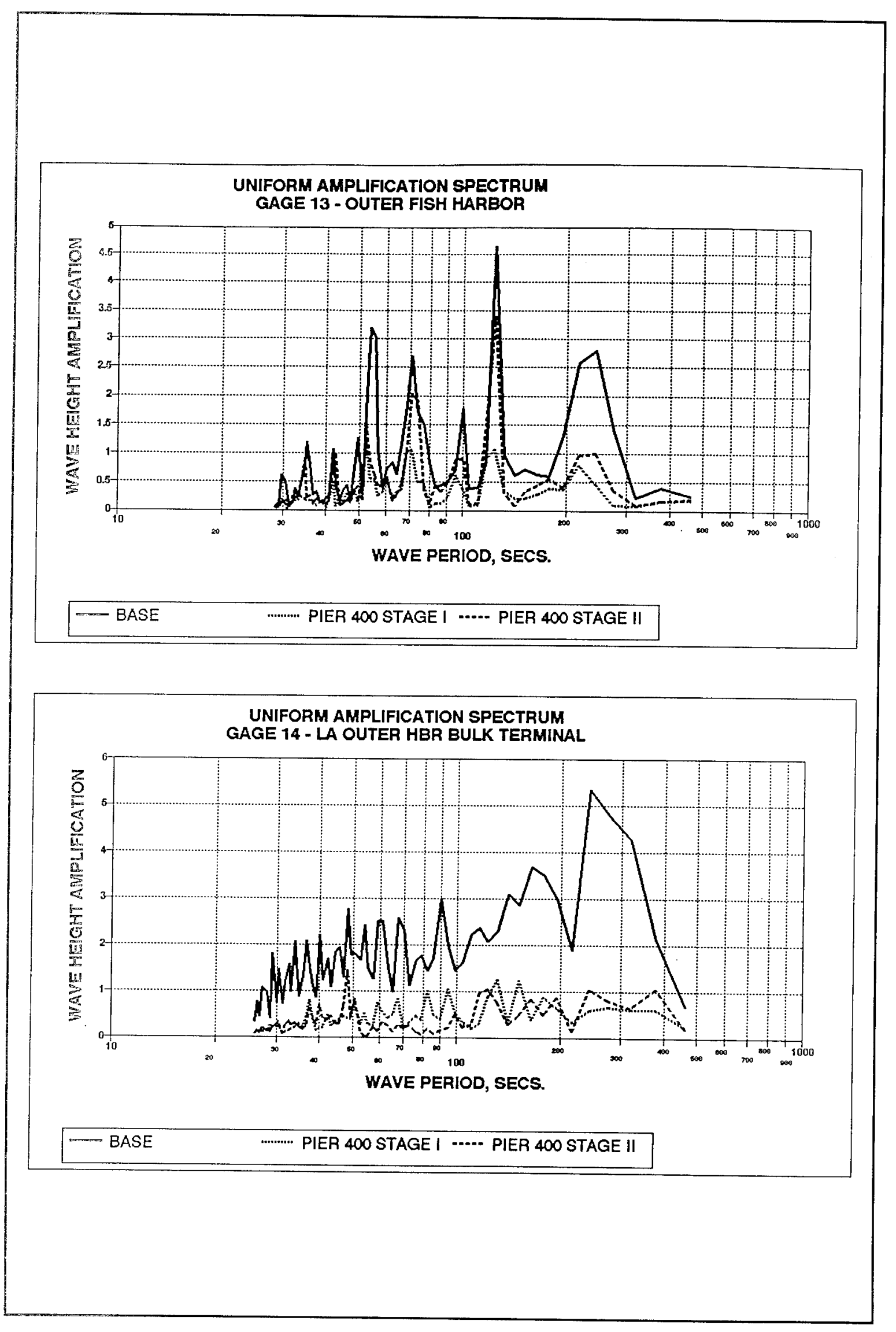



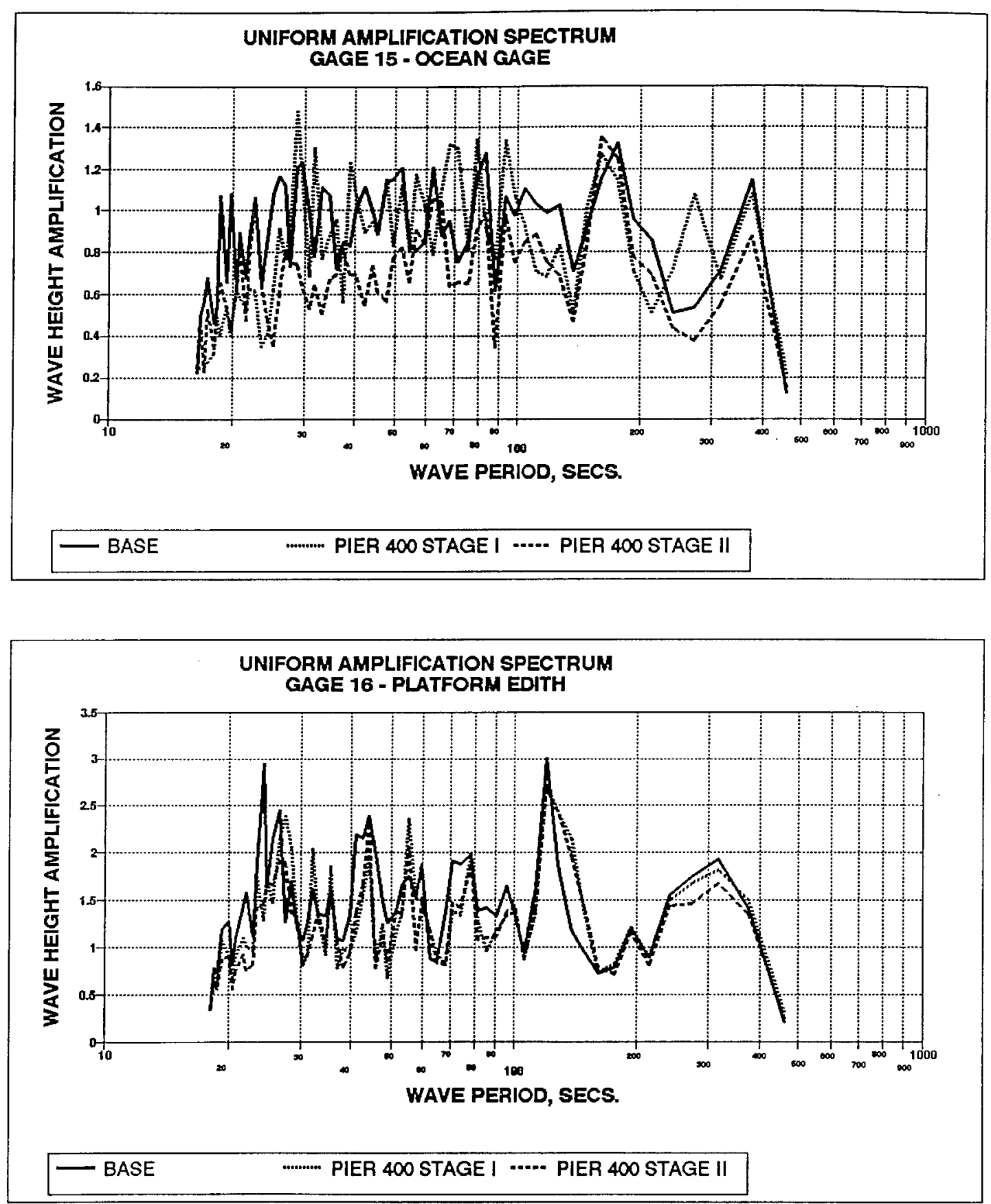


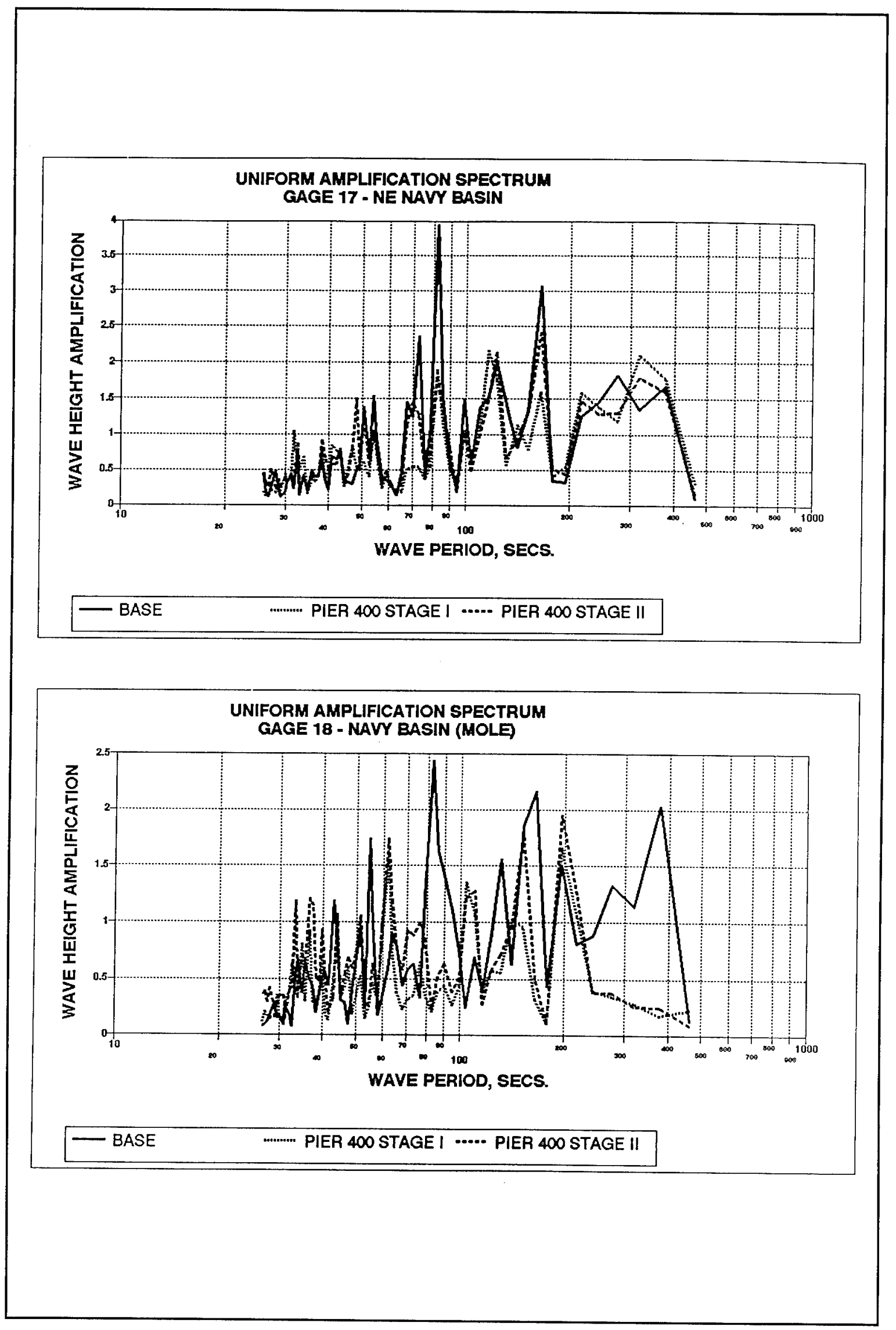



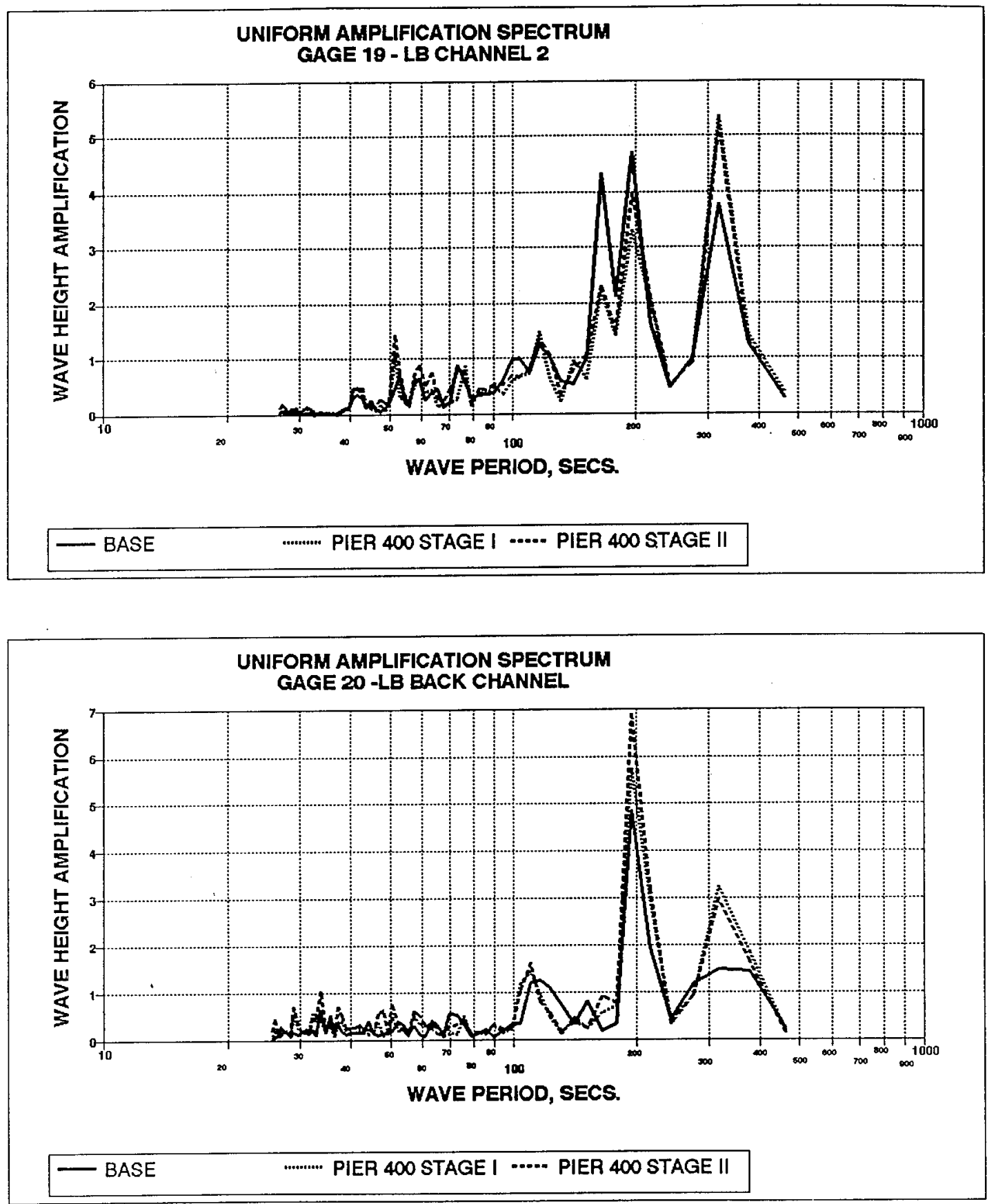

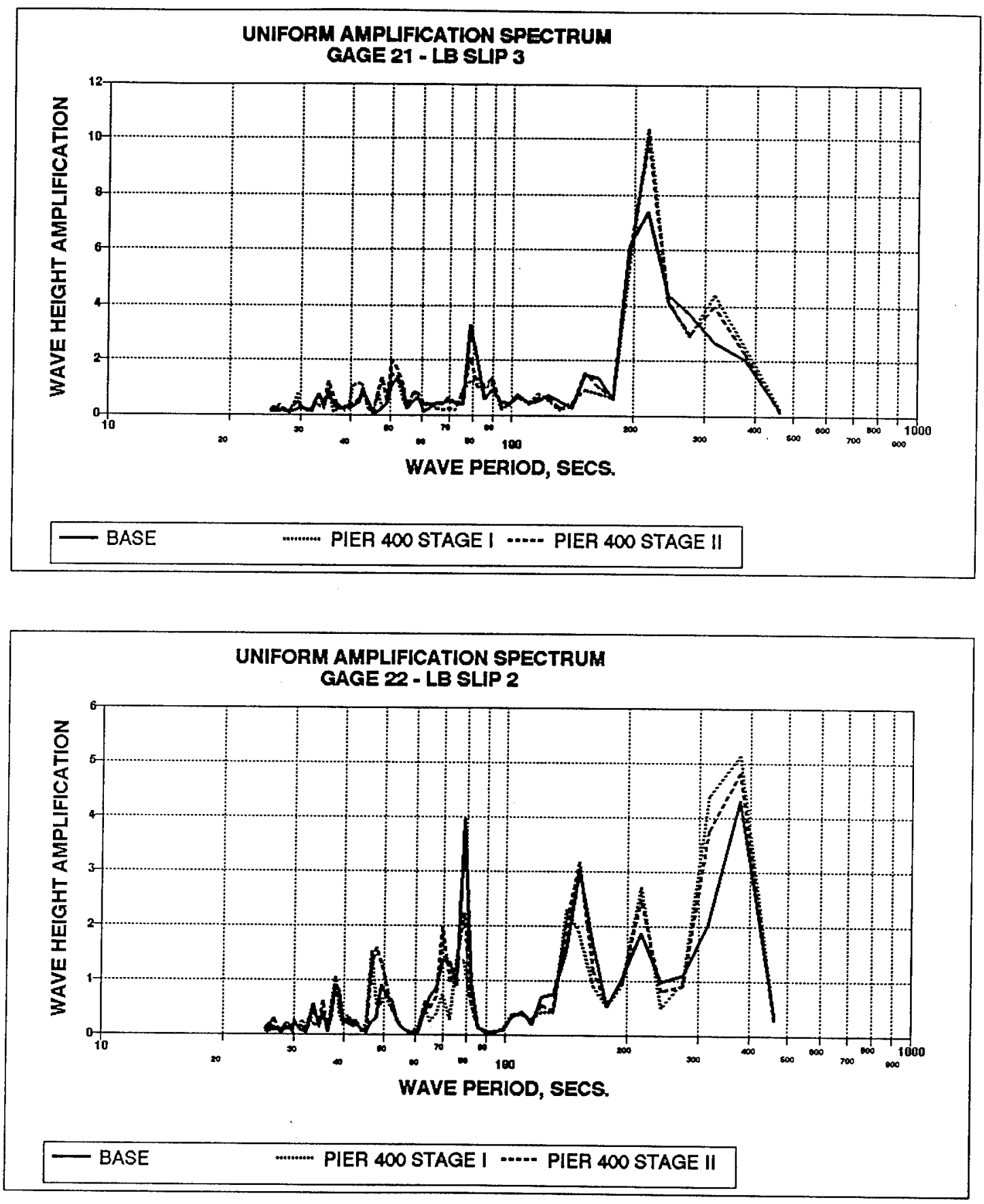

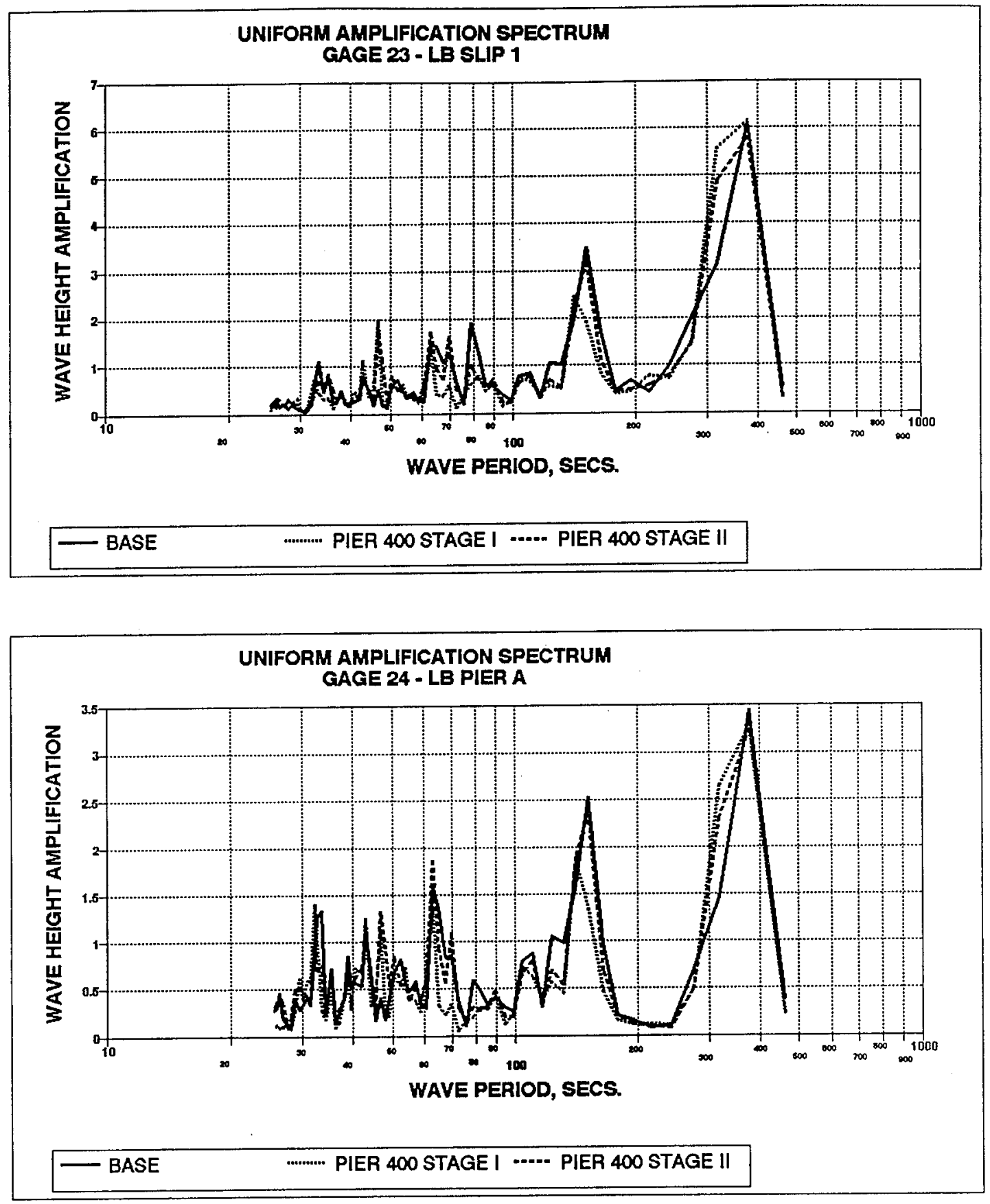

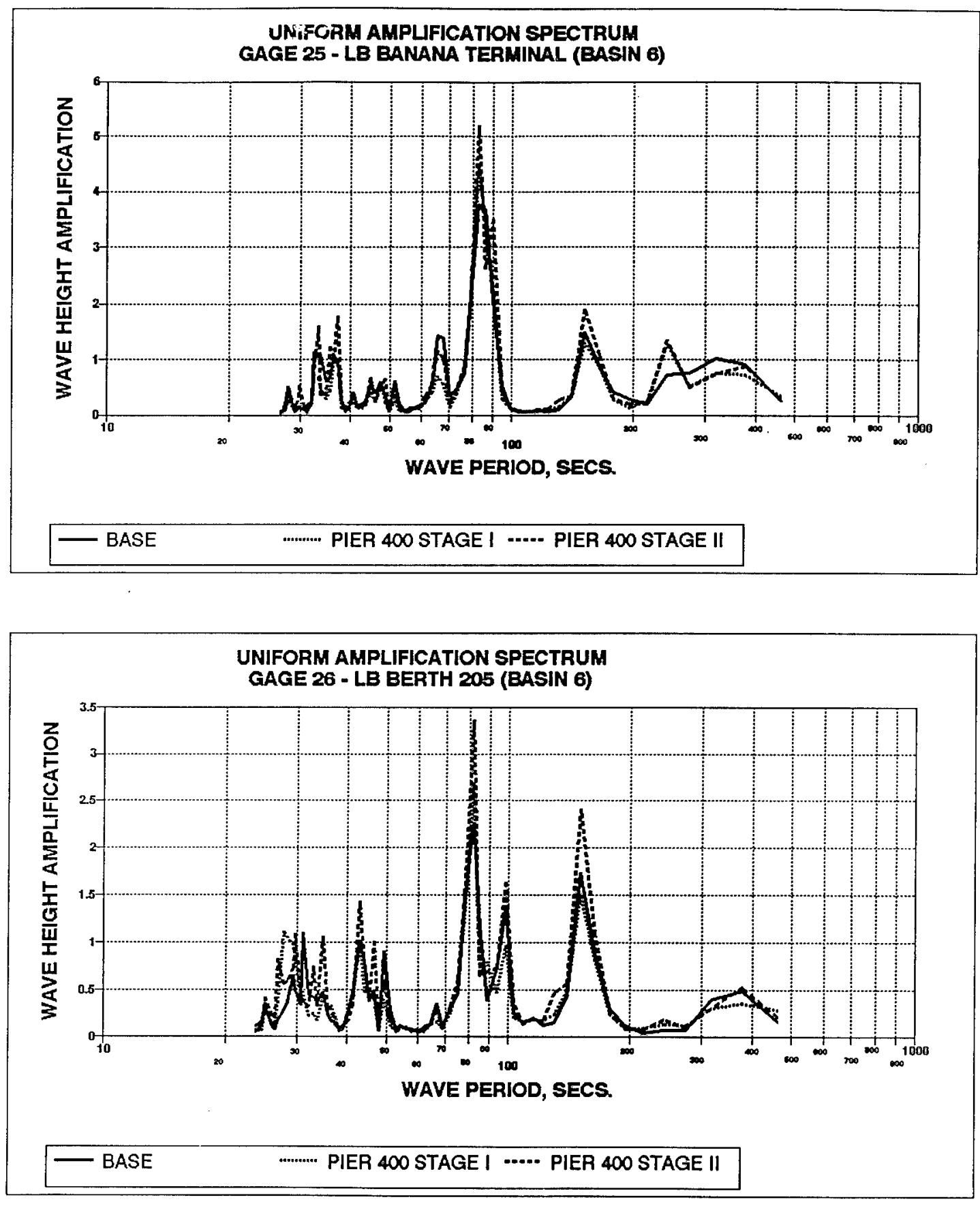

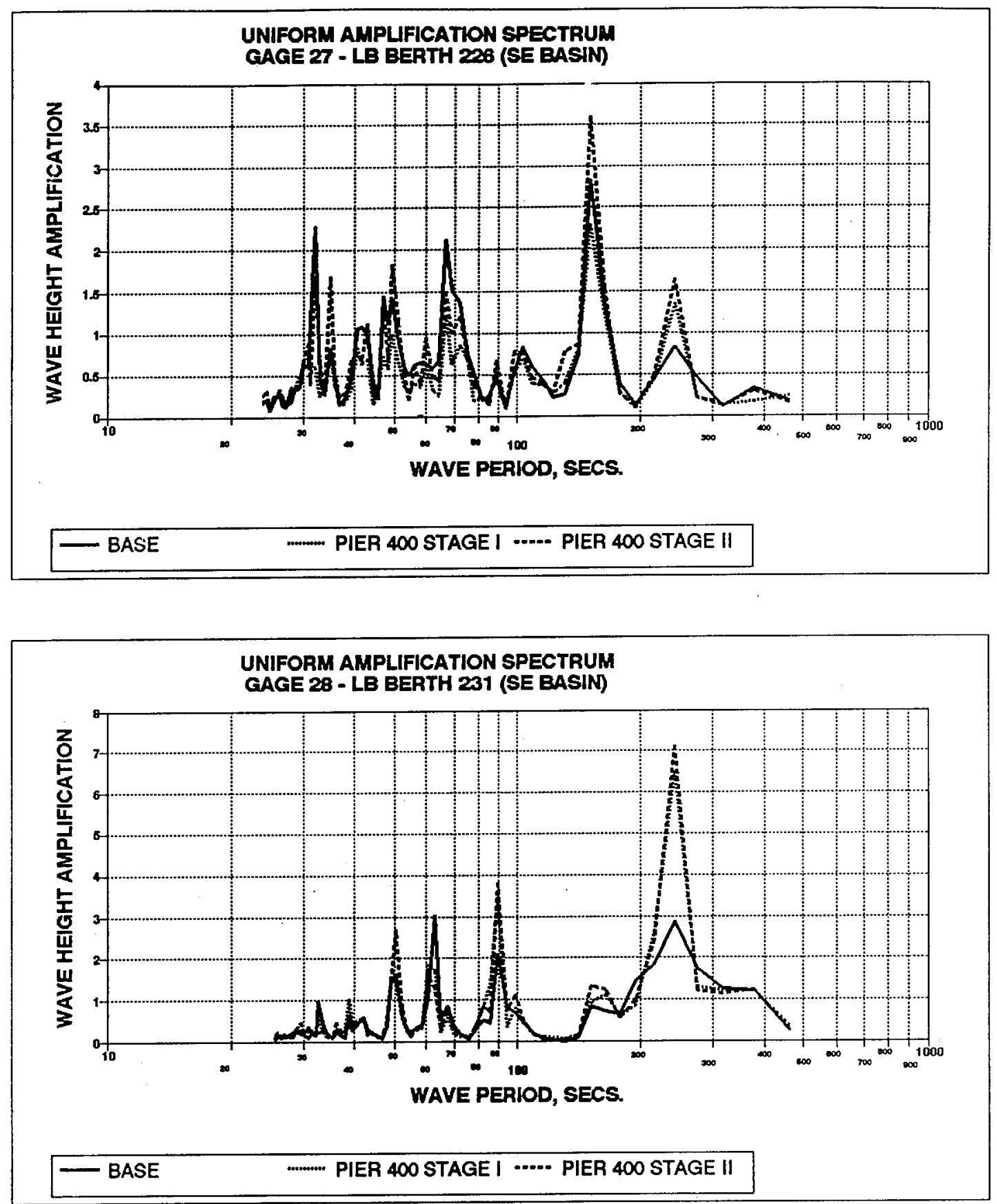

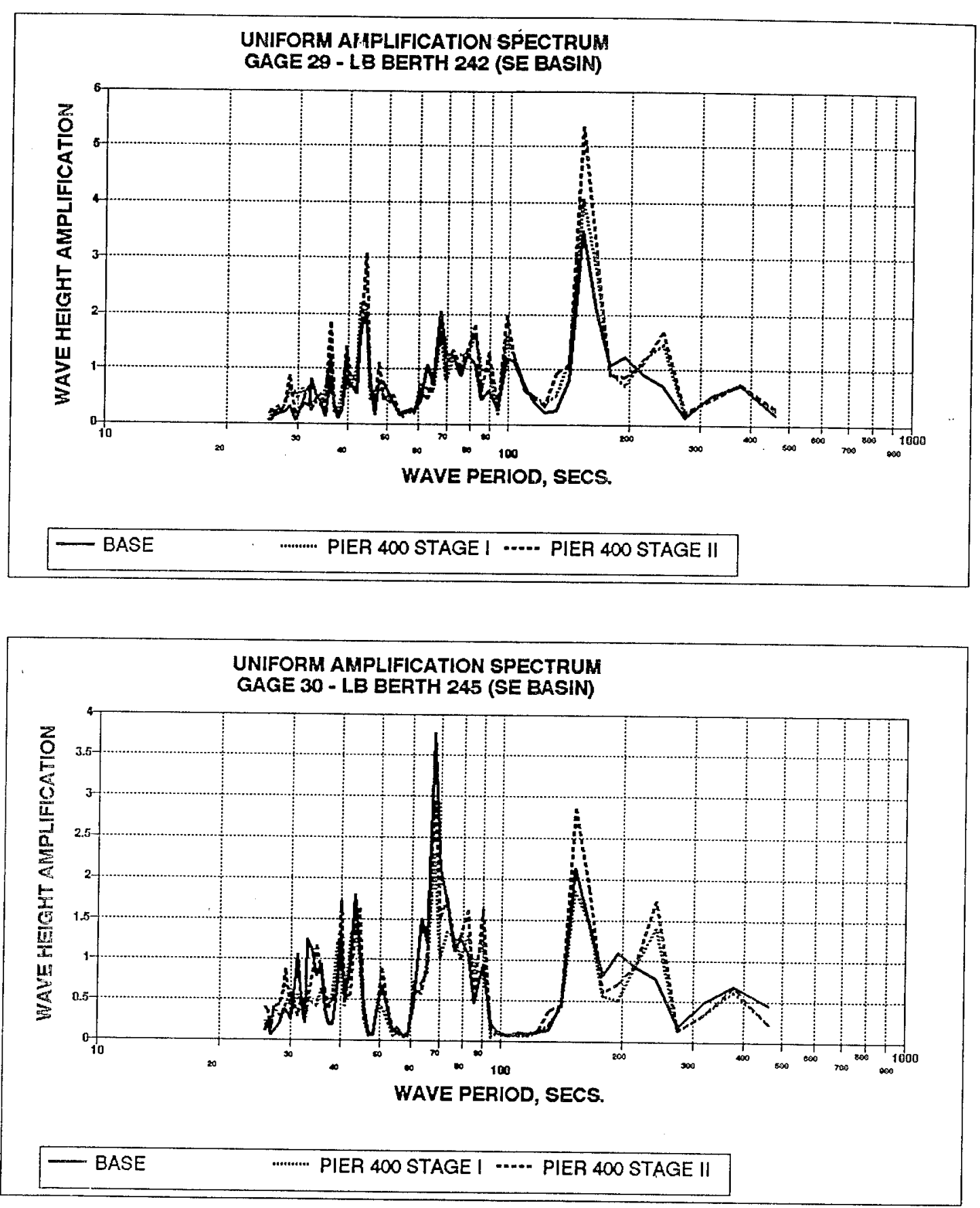

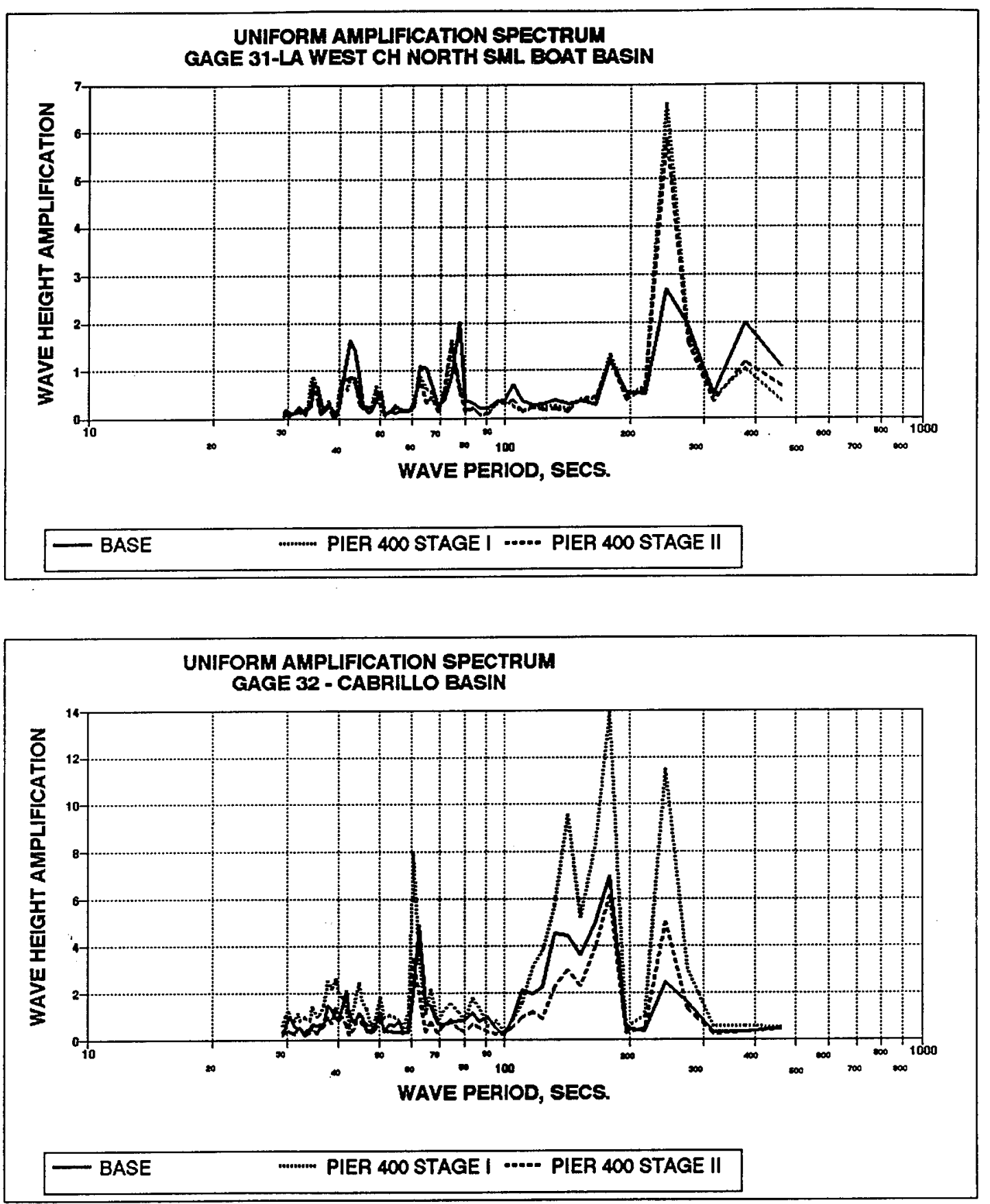


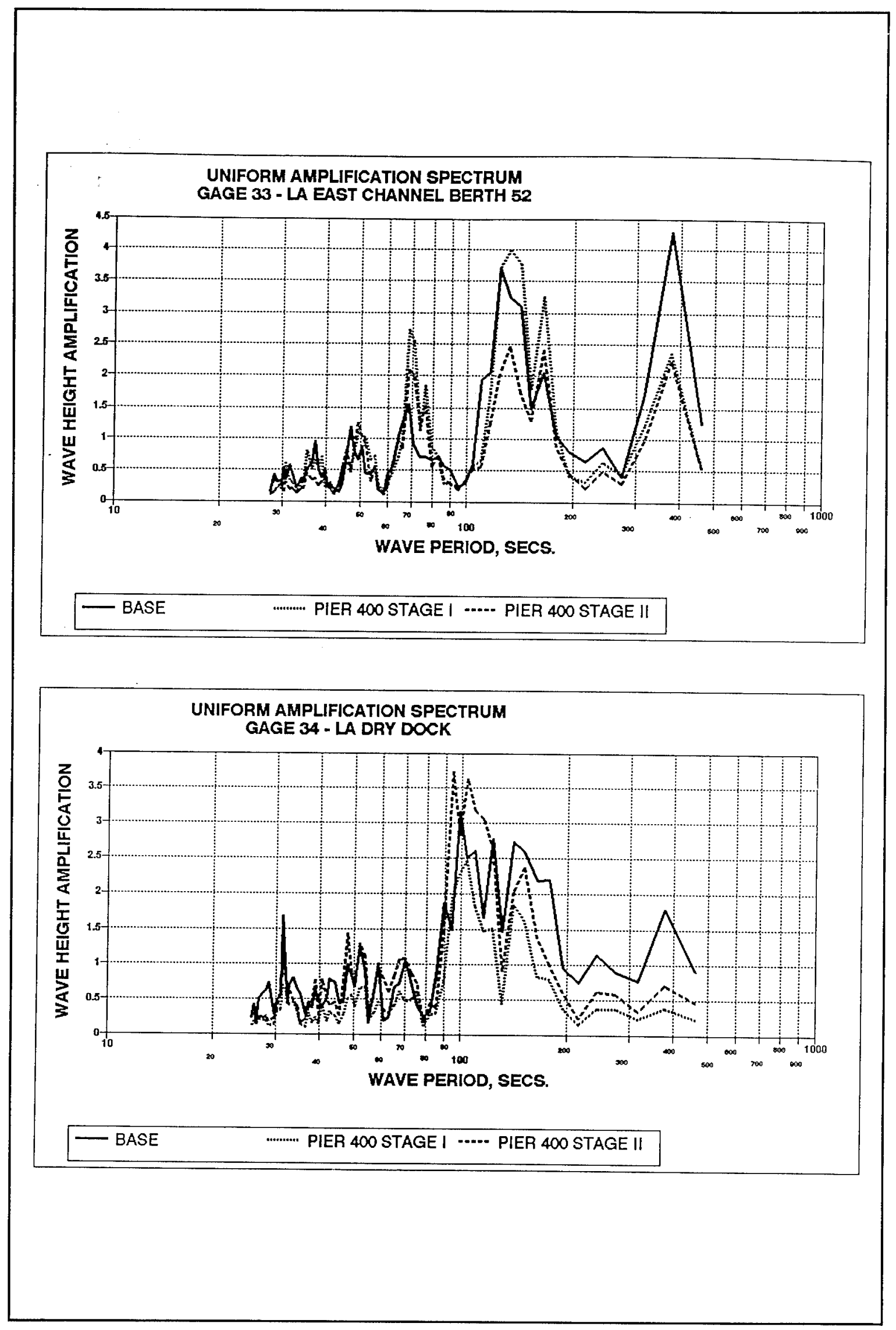



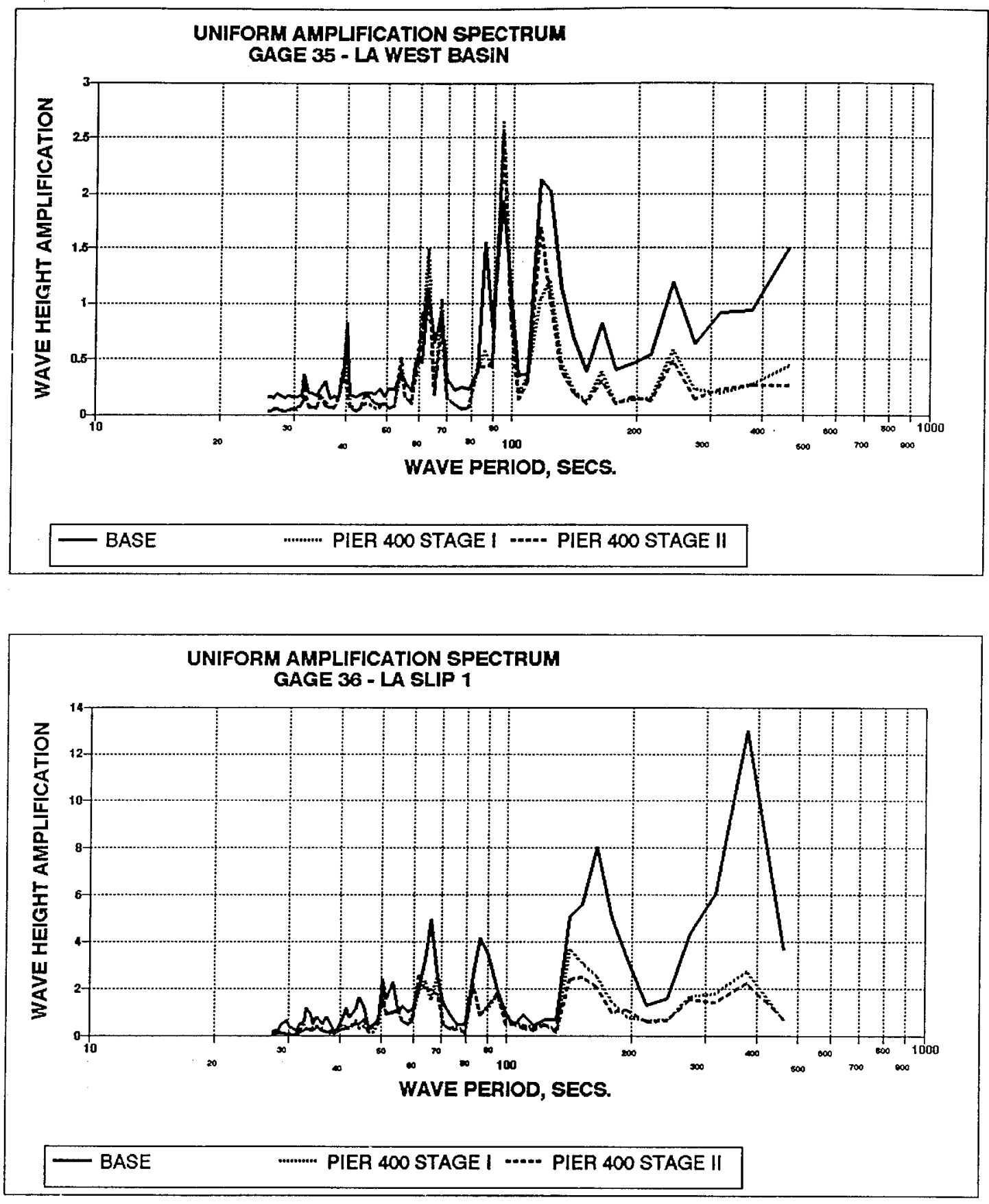

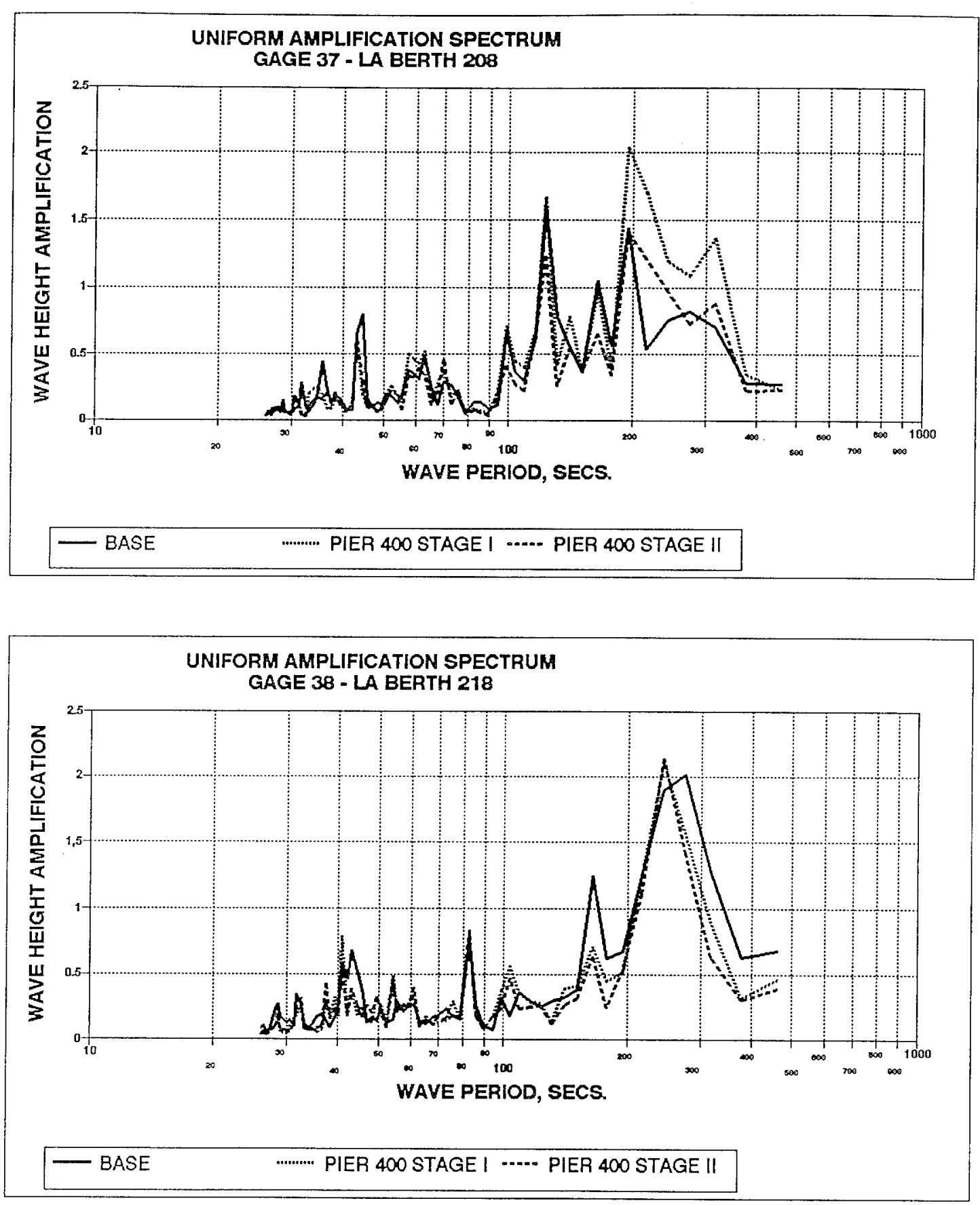


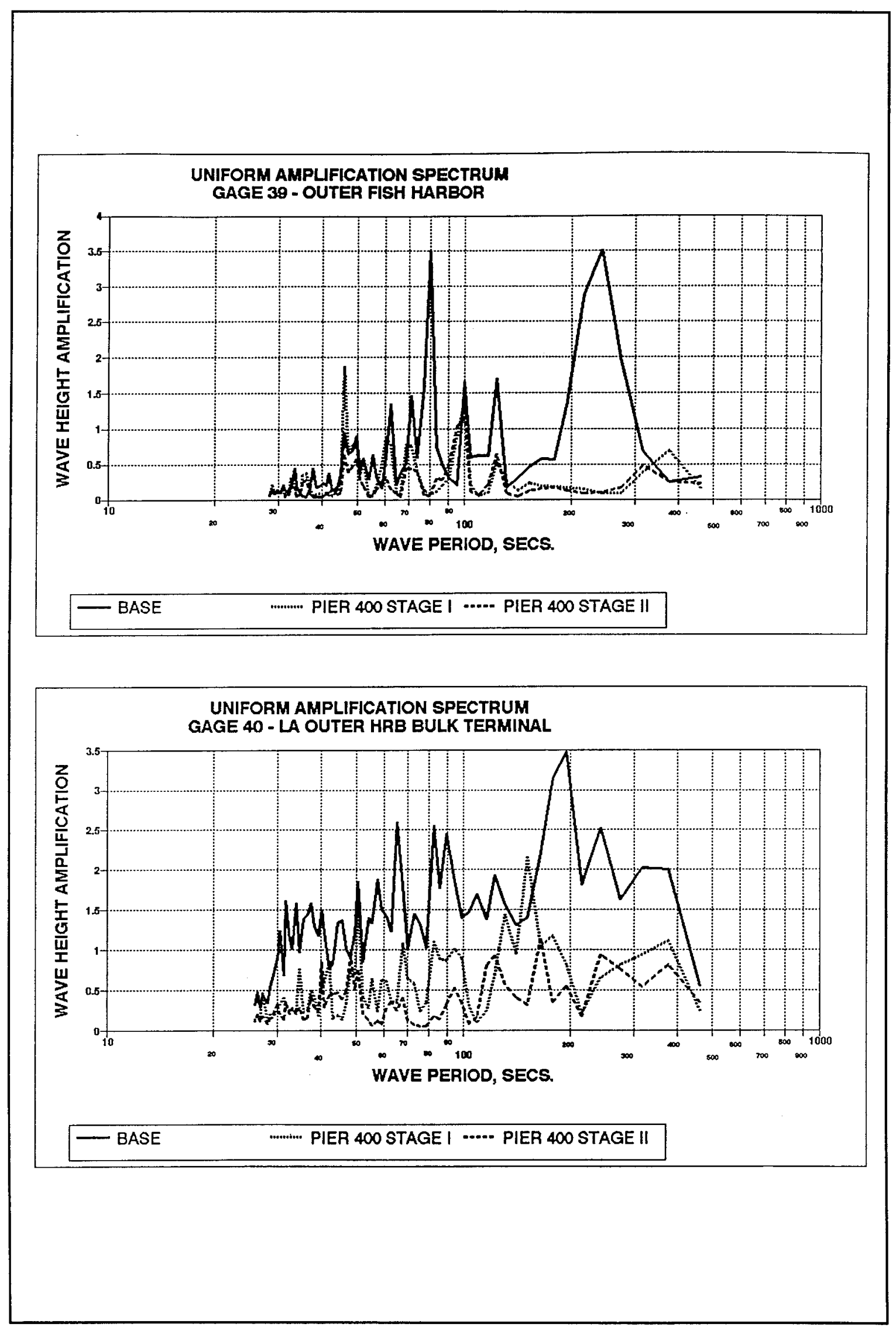



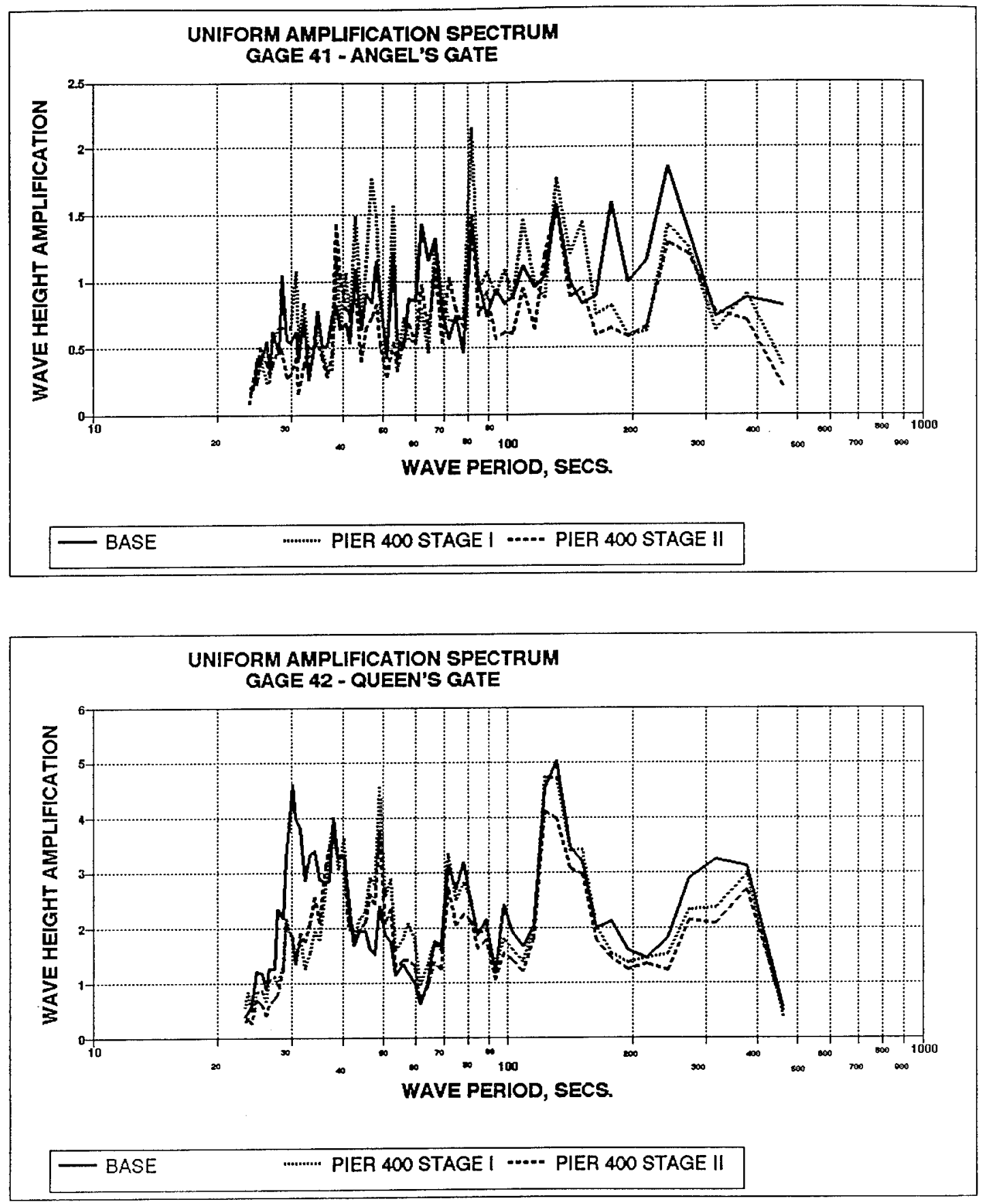

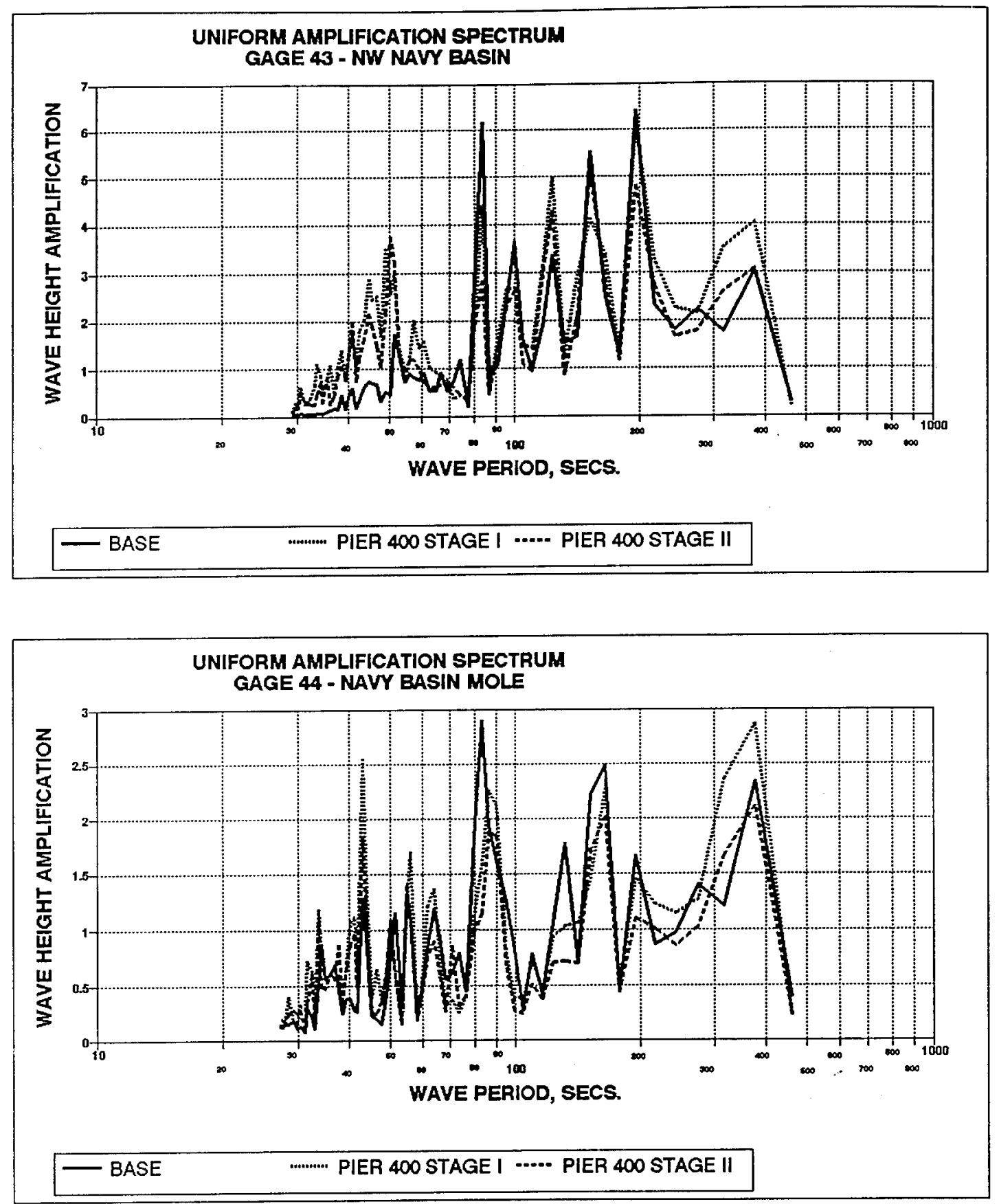

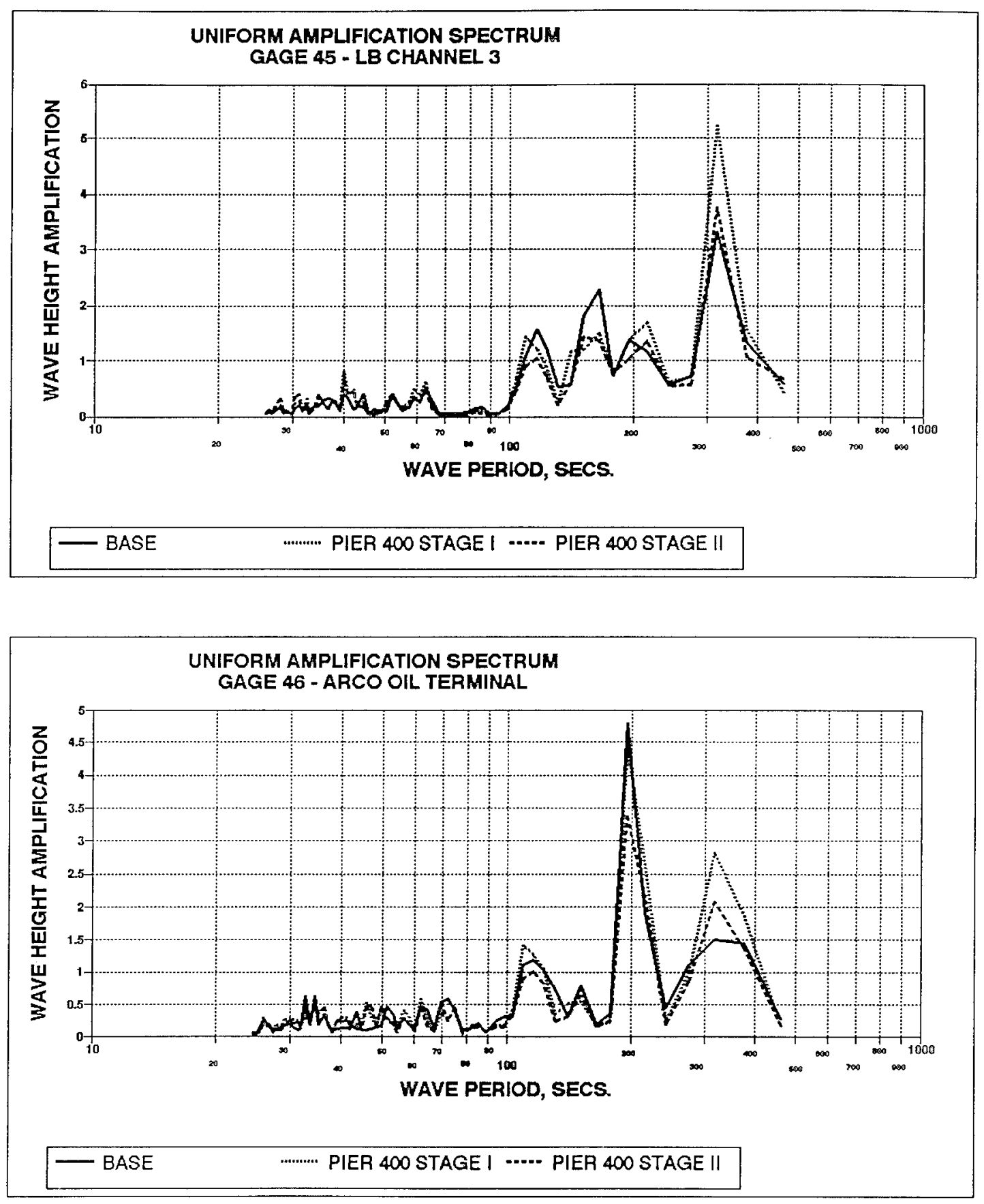

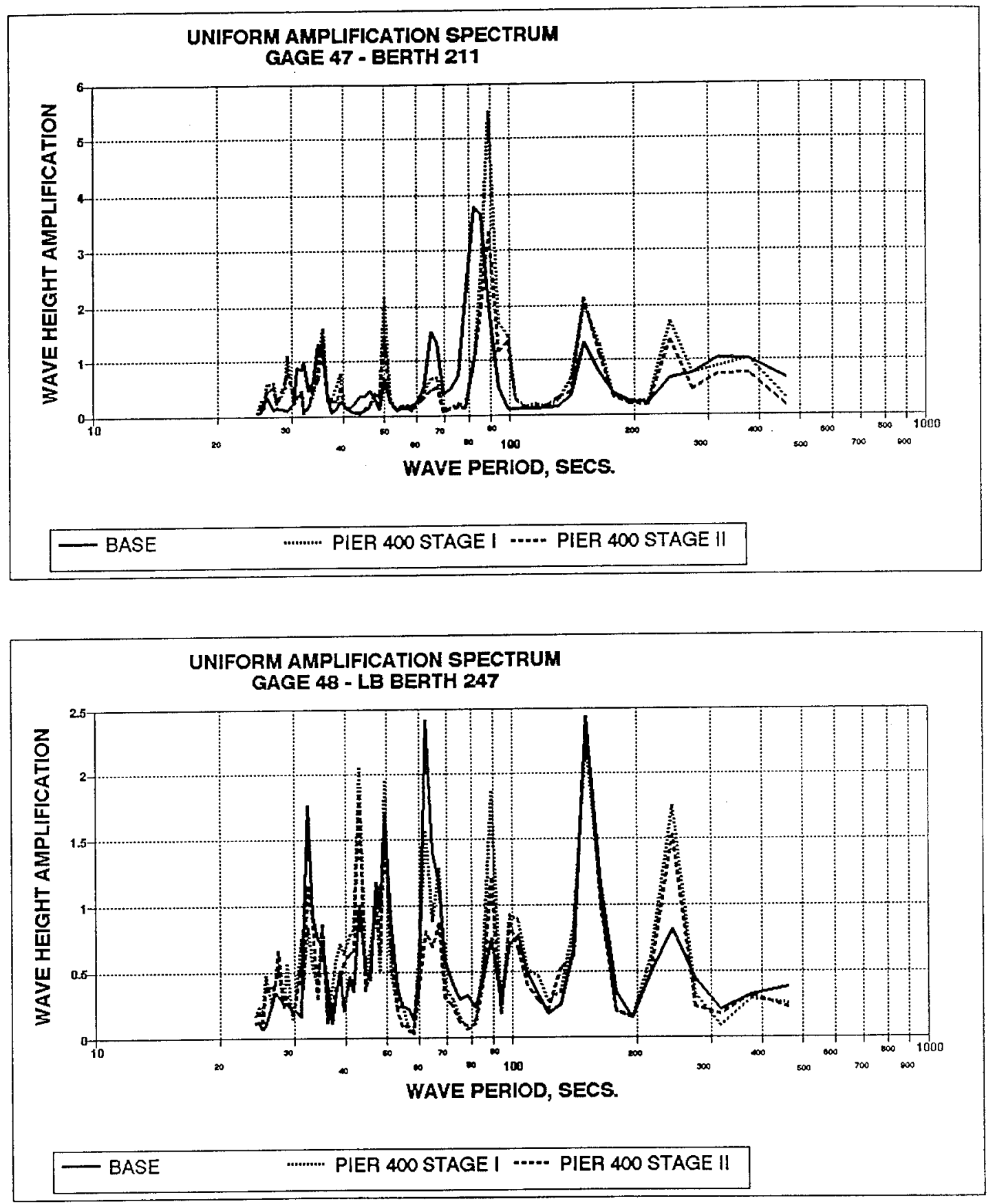

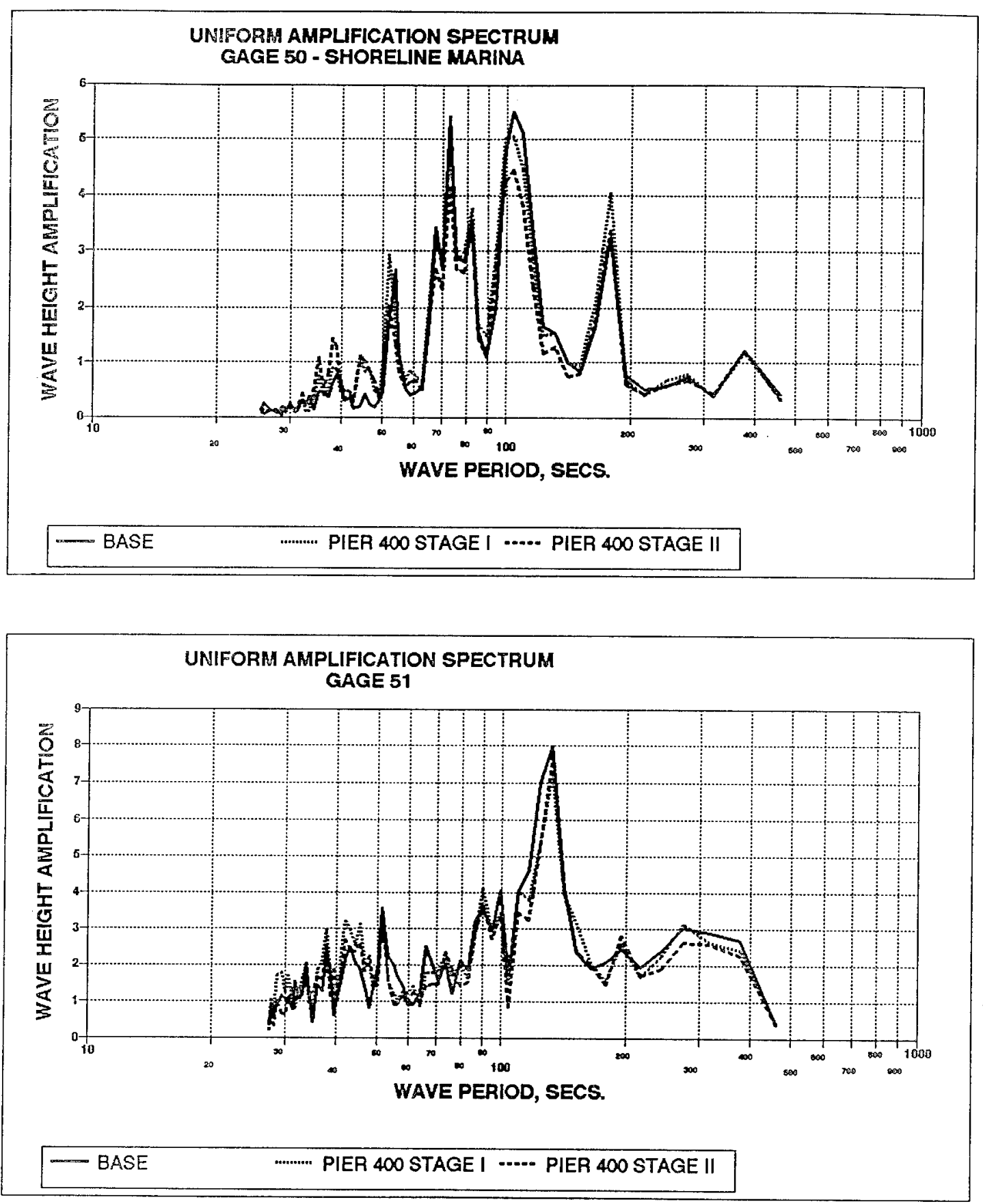

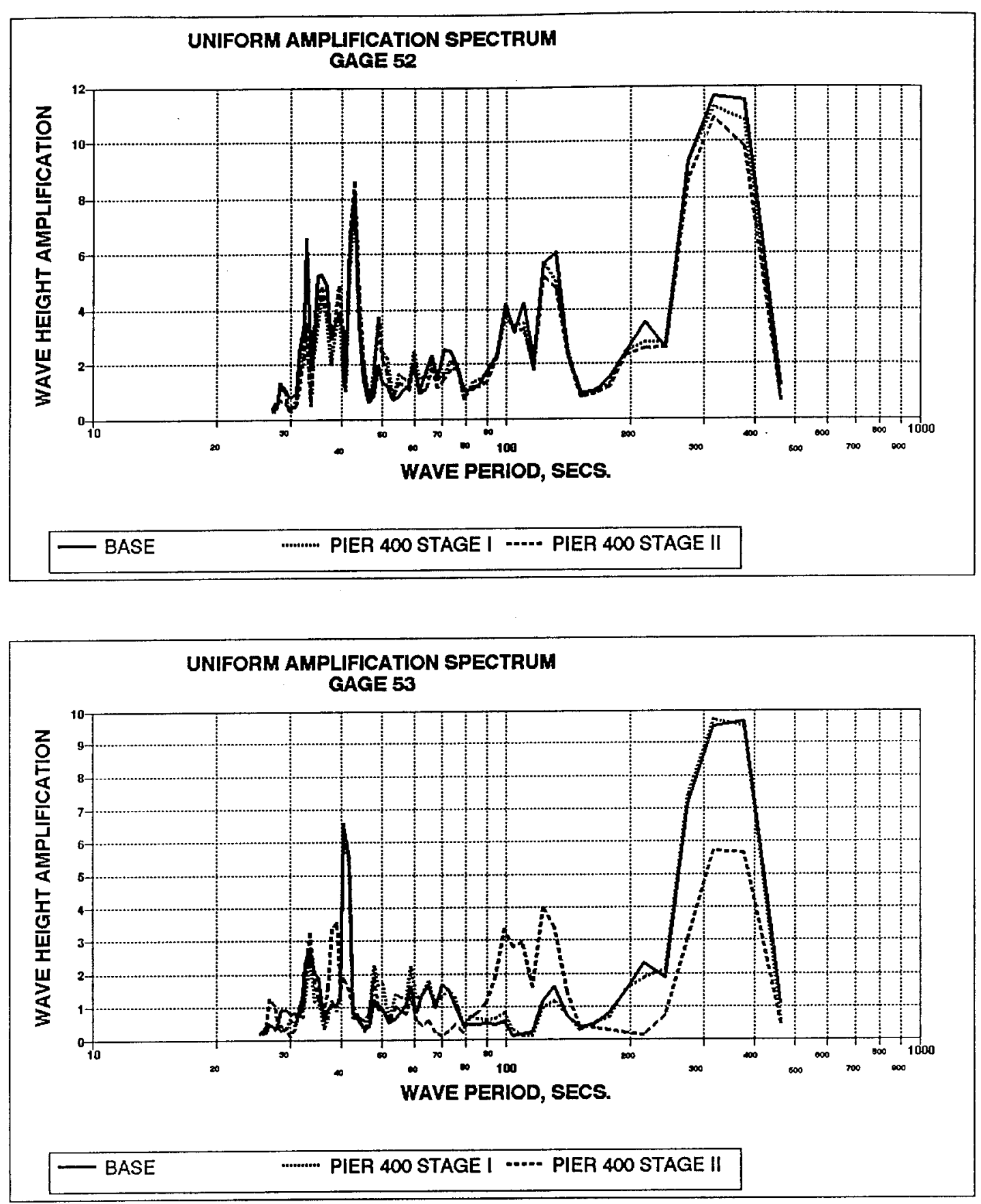

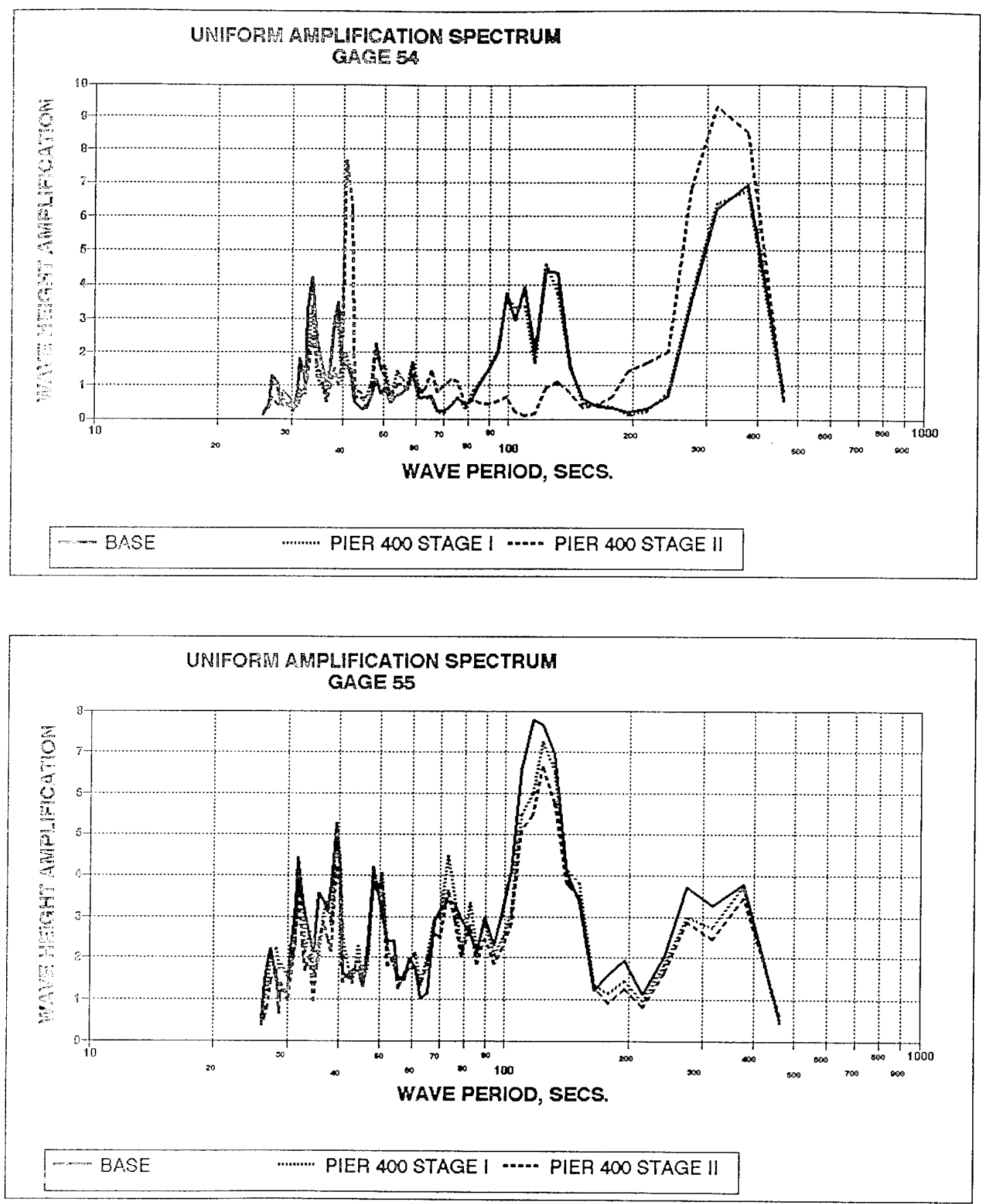


\section{Appendix B \\ Wave Amplification, Uniform Spectrum, Gages 56-77, Open and Closed East End at Pier $\mathbf{3 0 0}$}




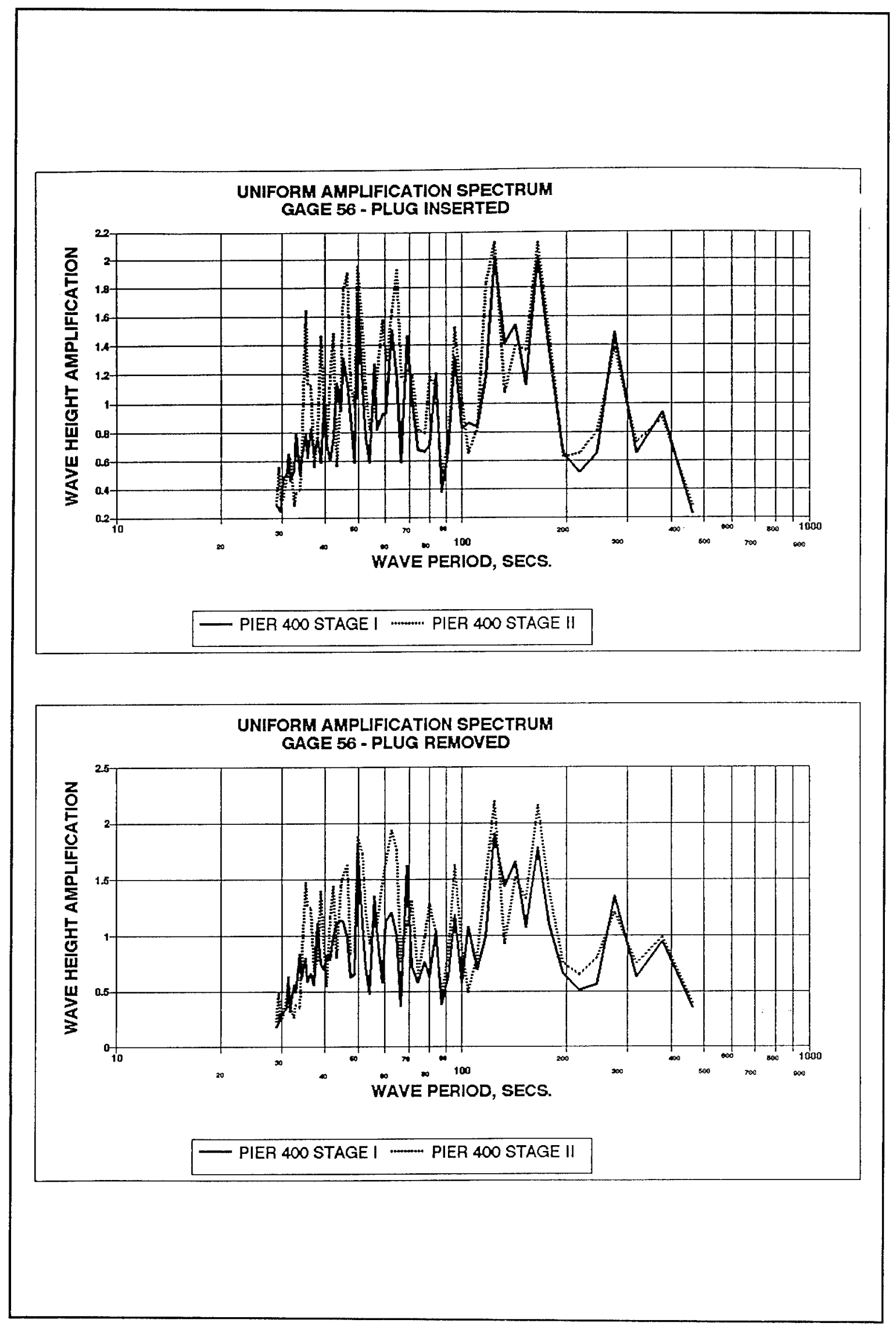



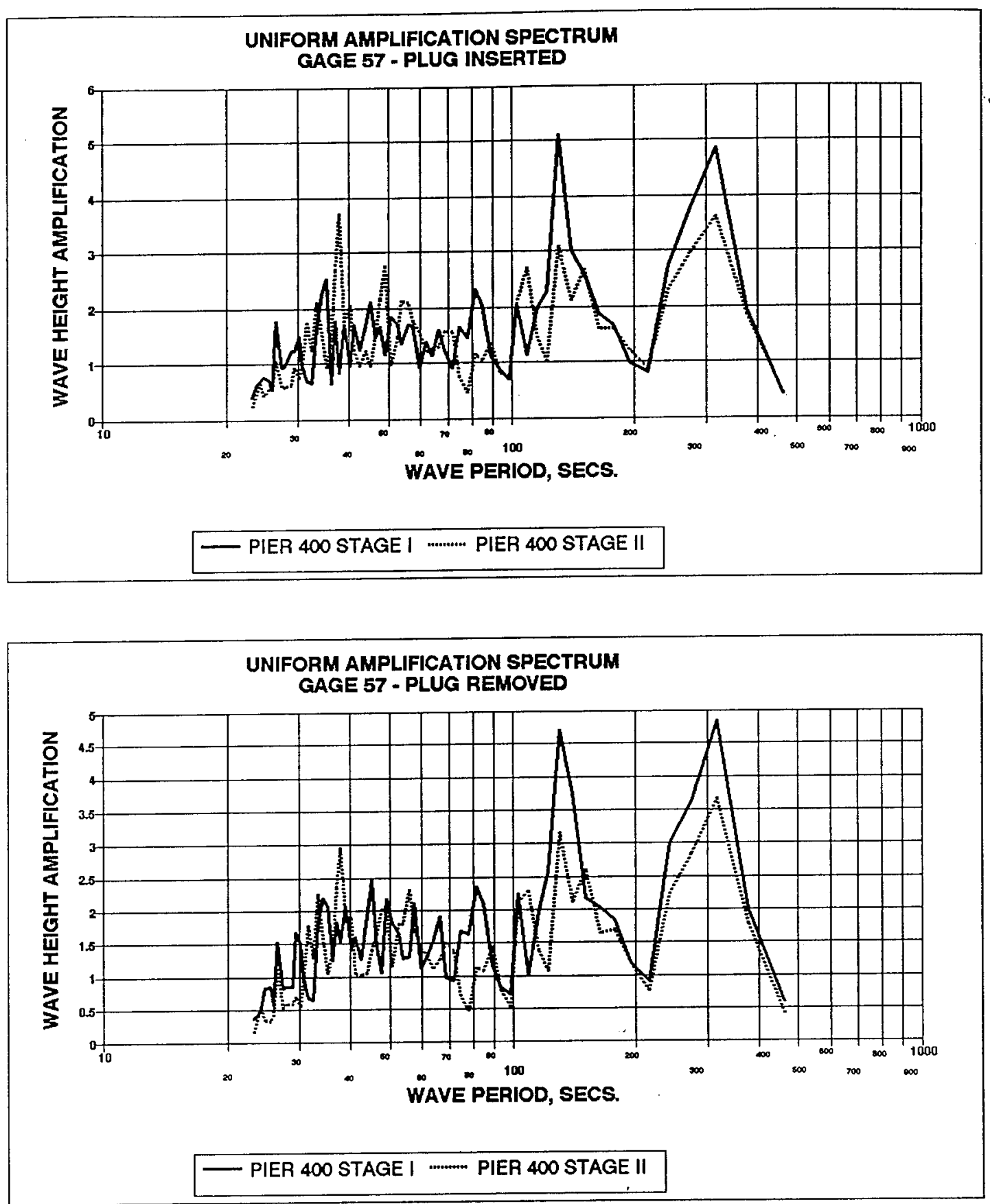


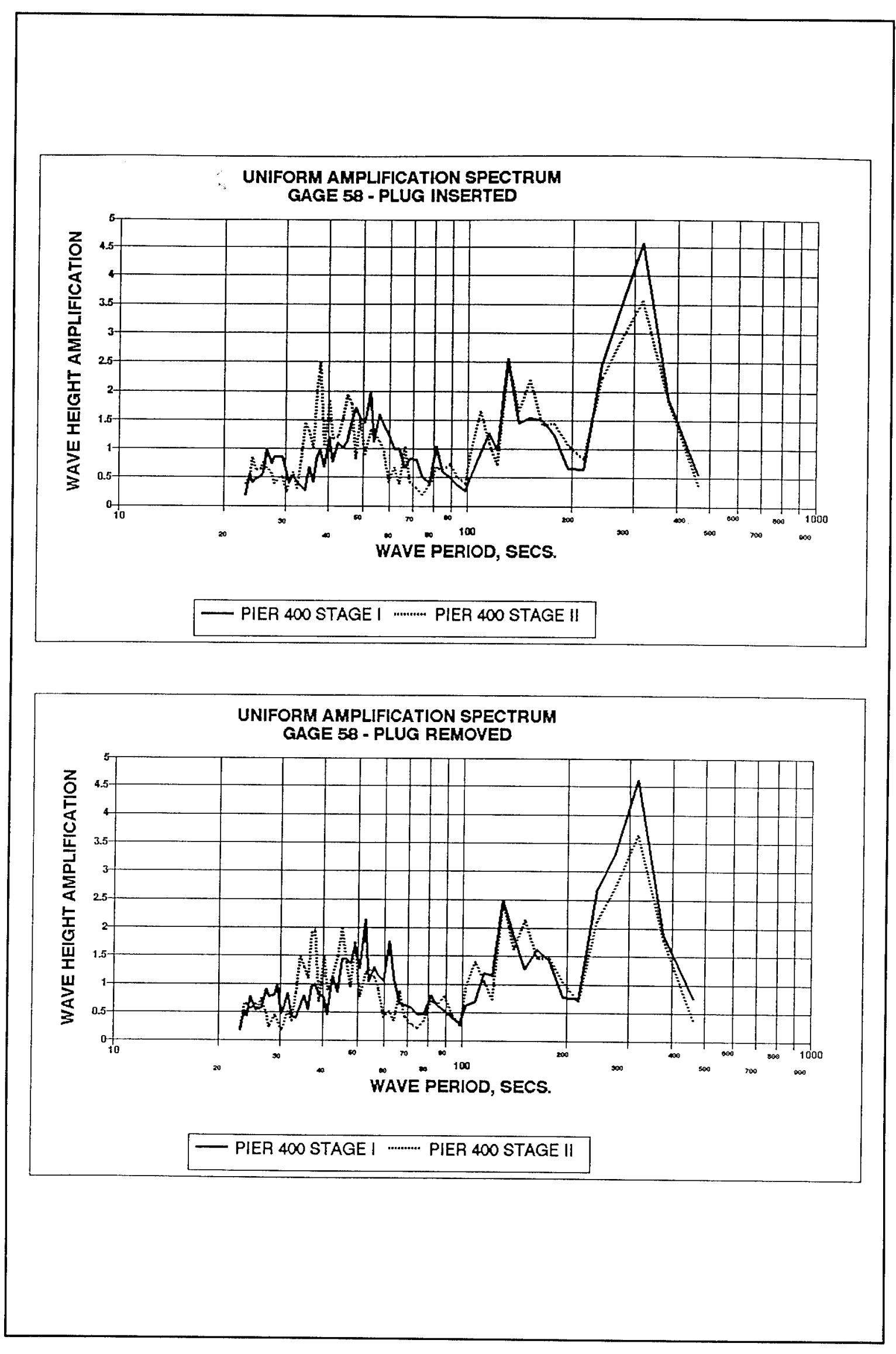



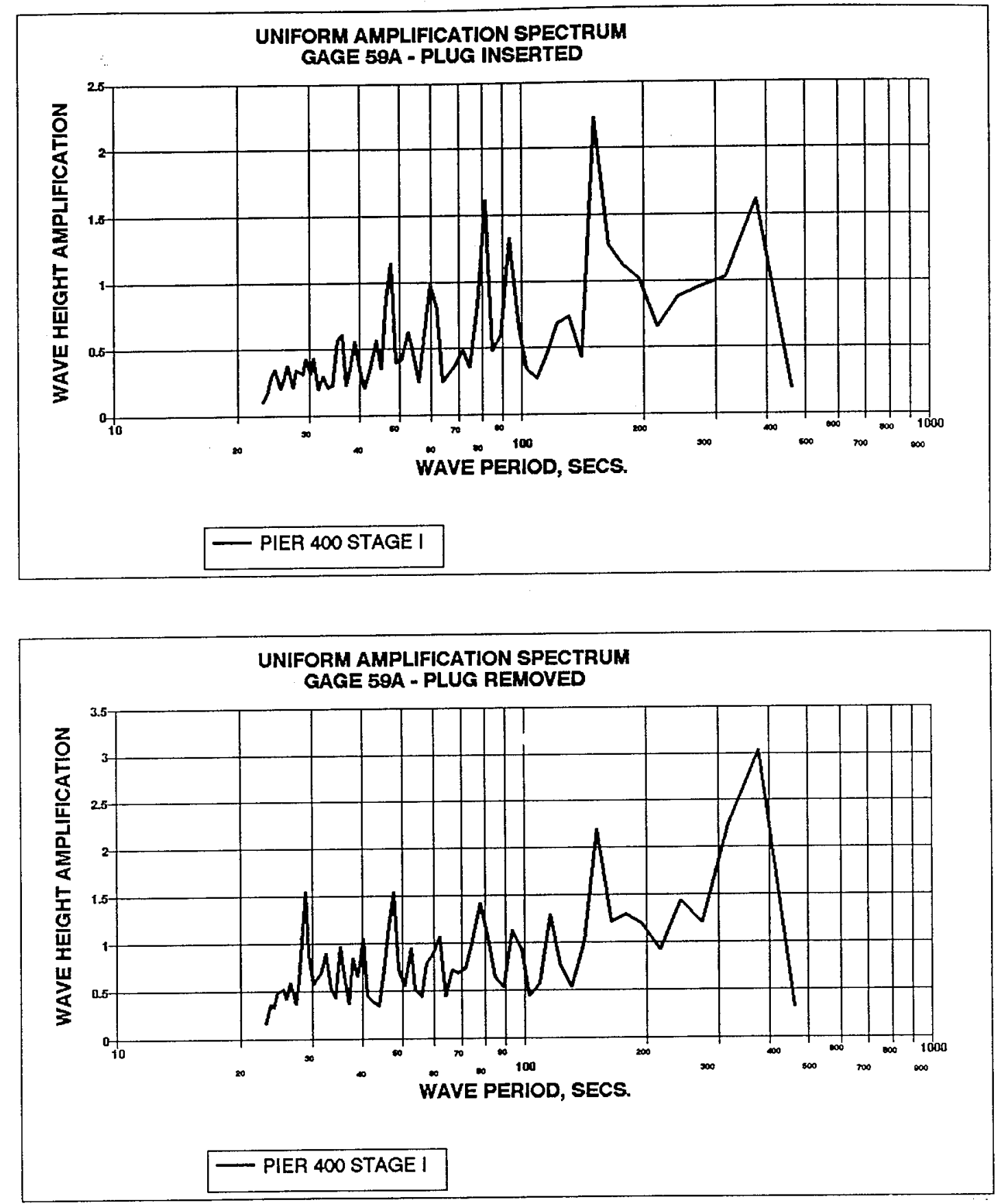

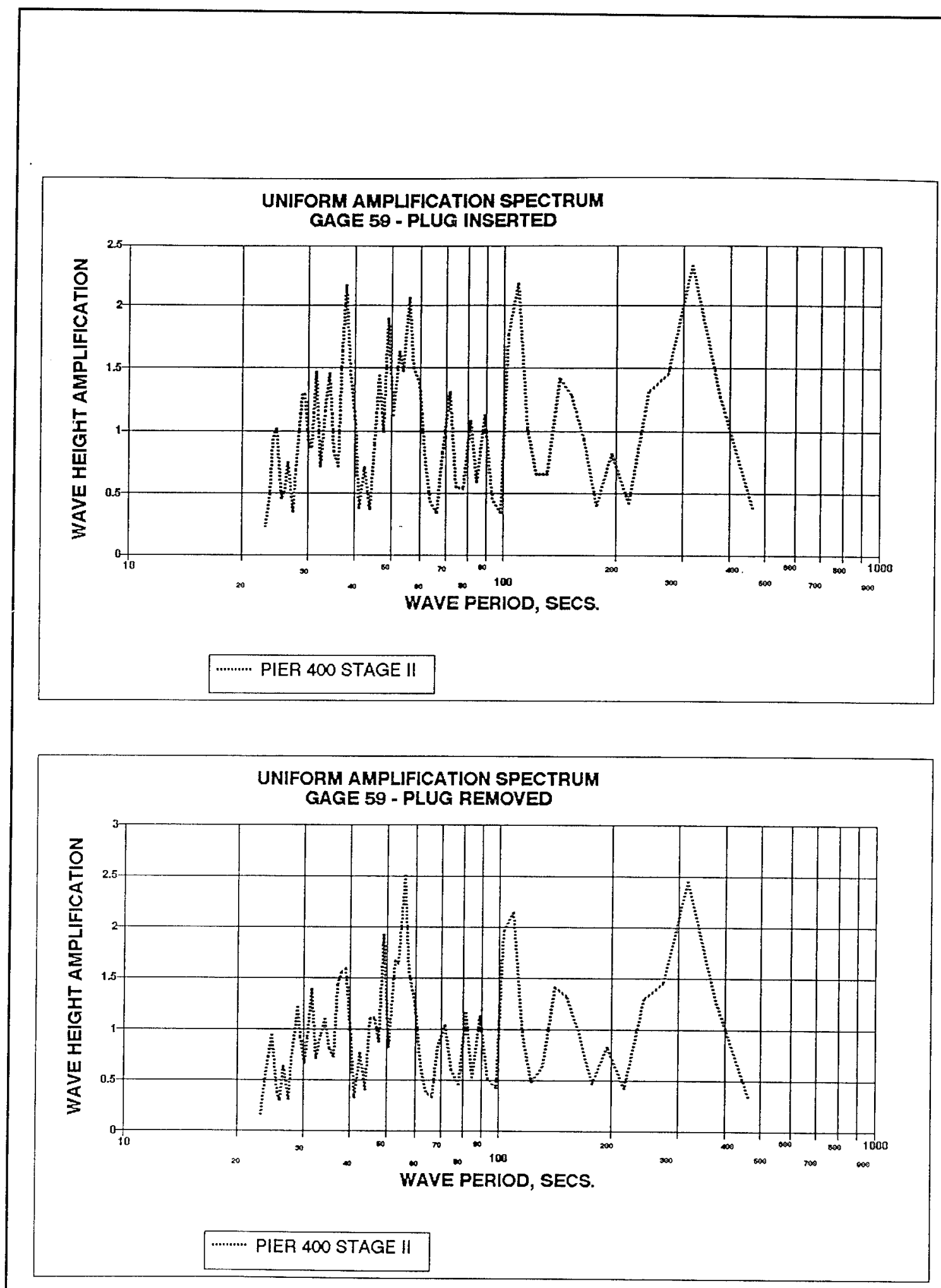

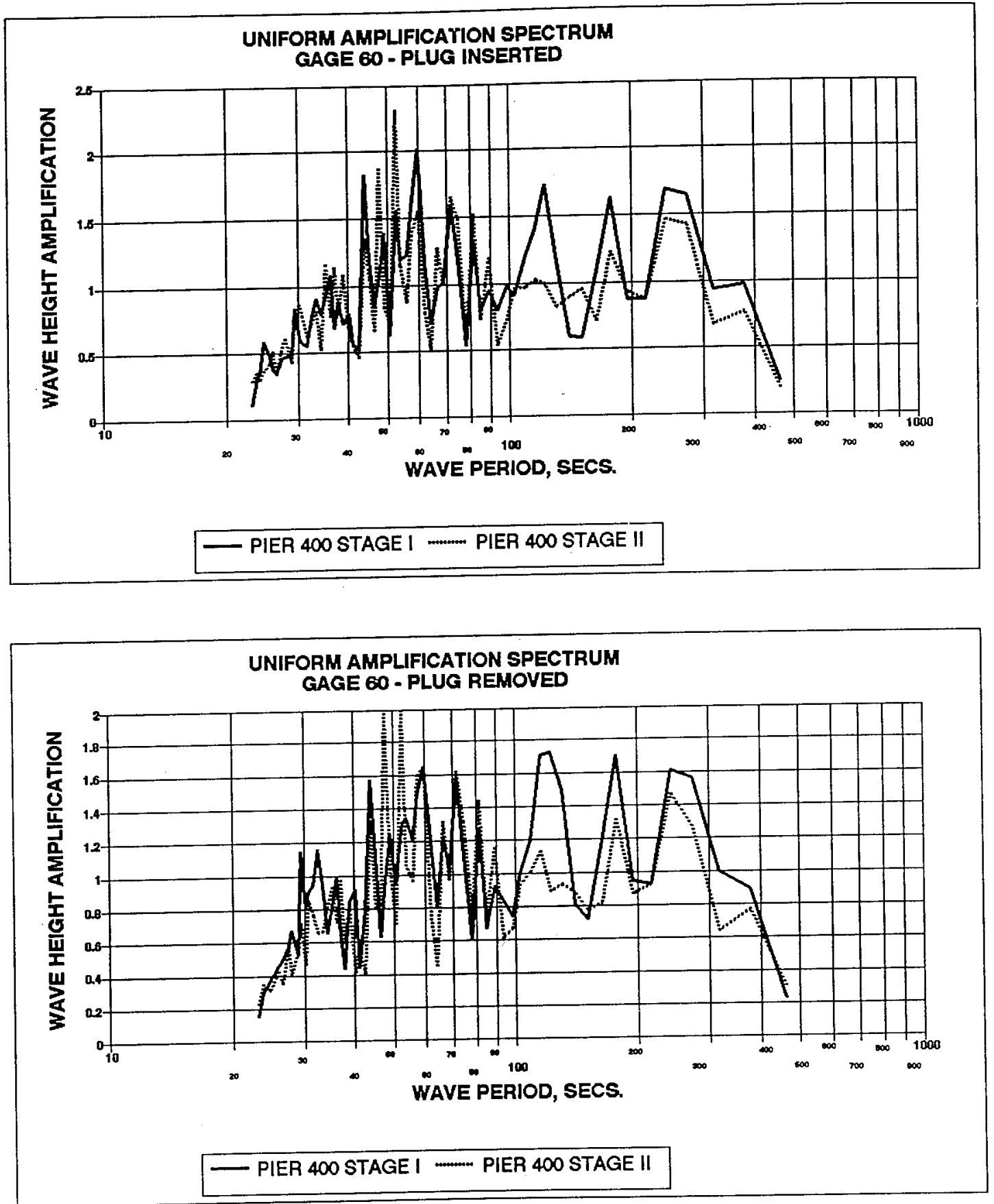

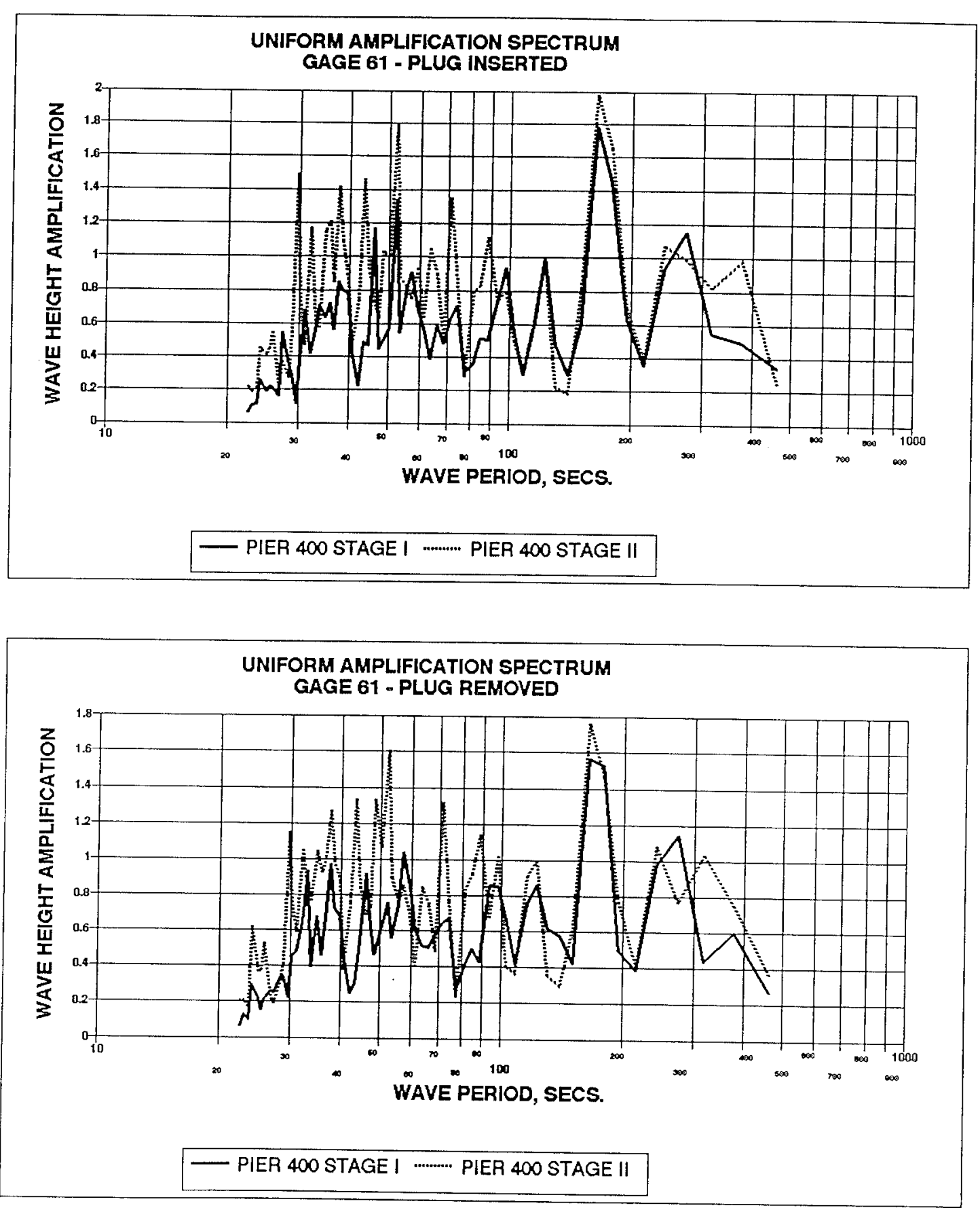

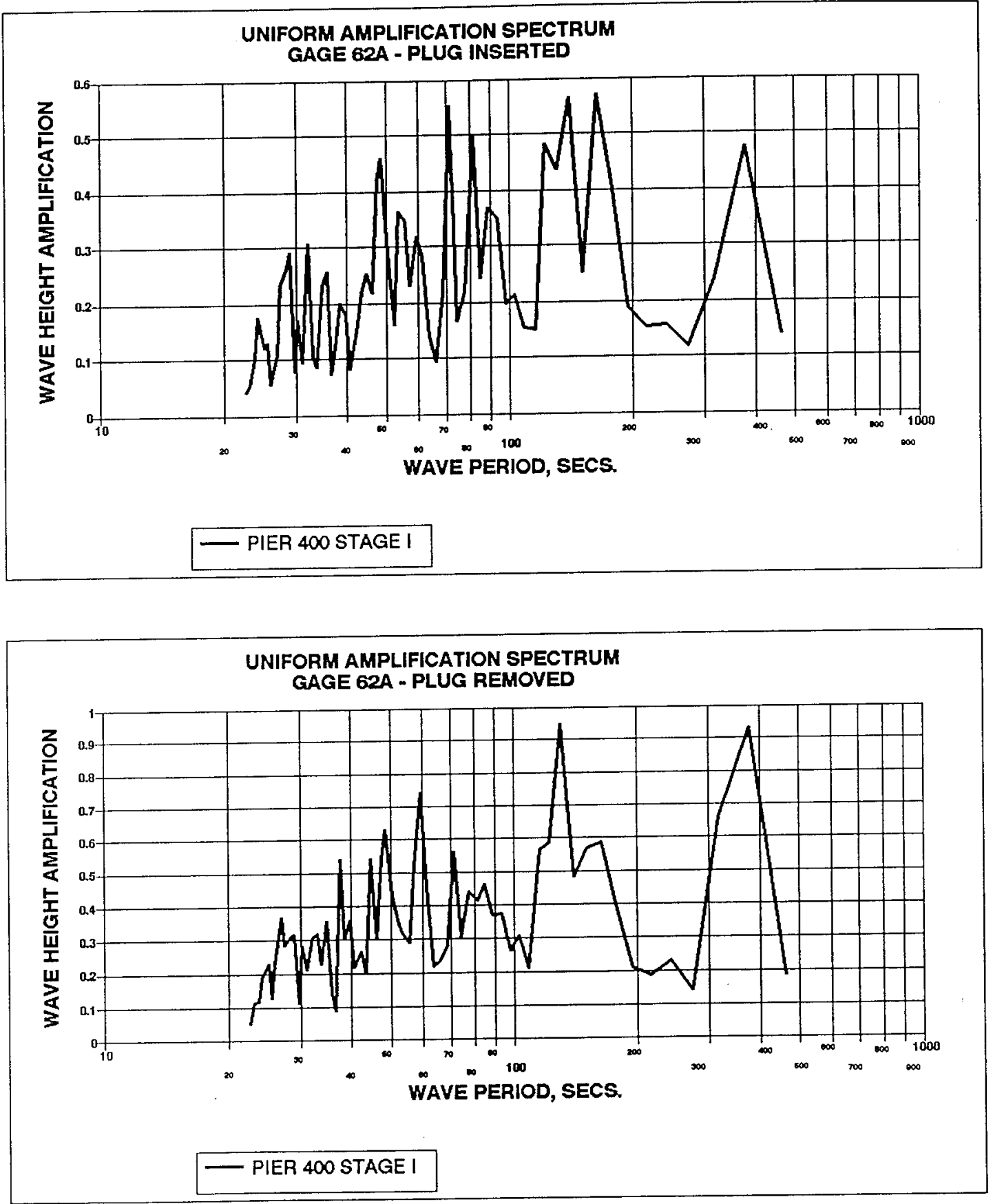


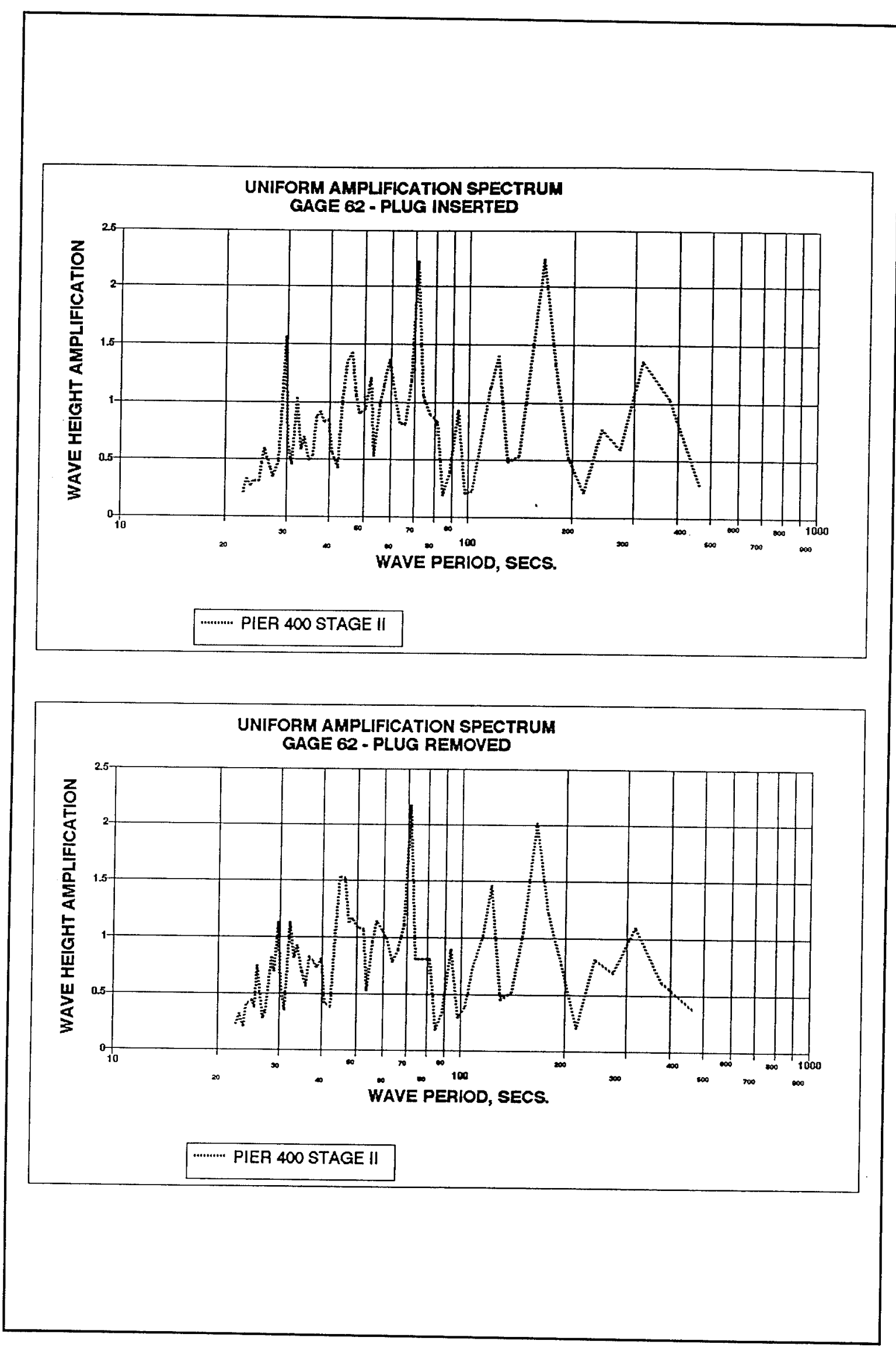



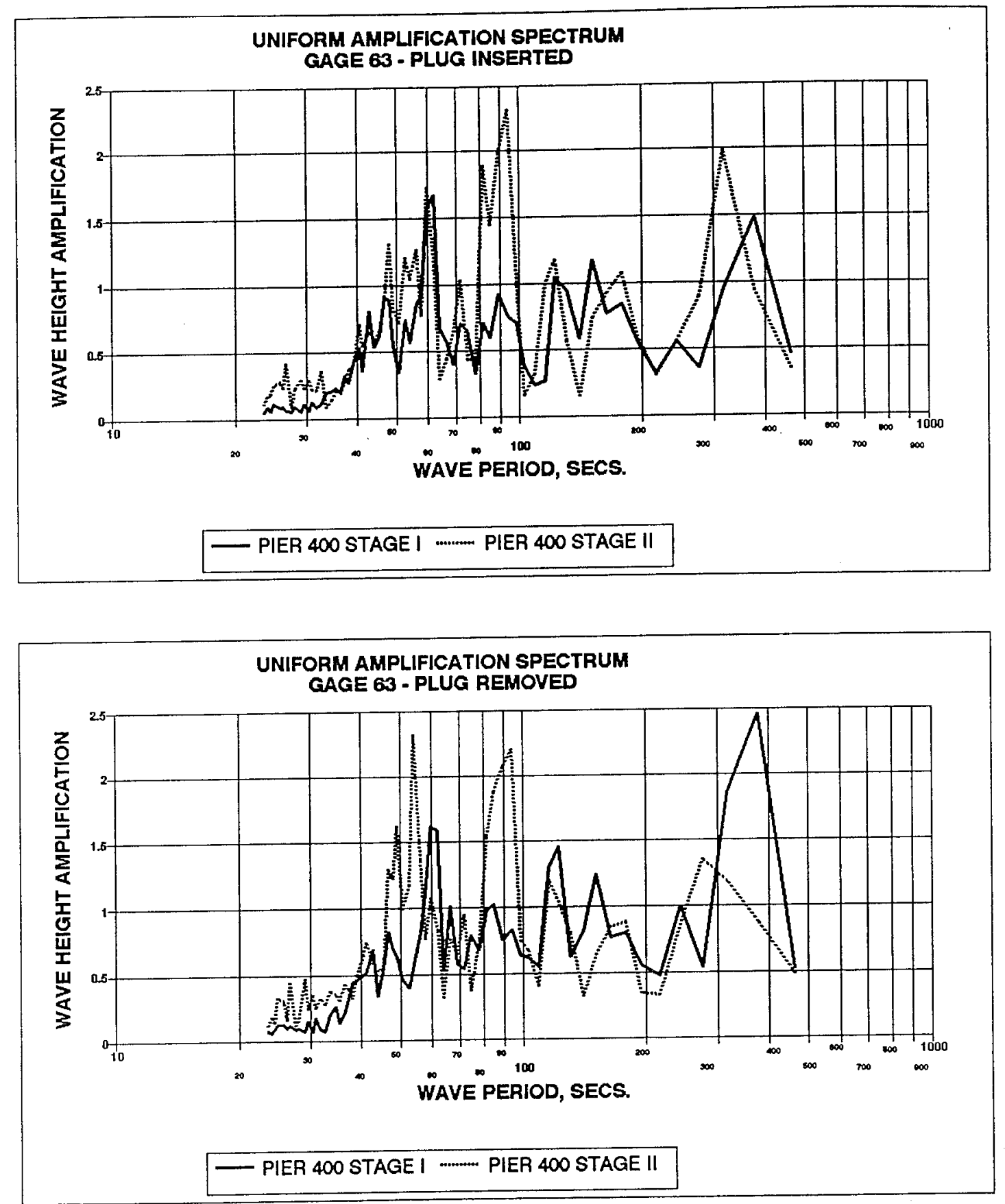

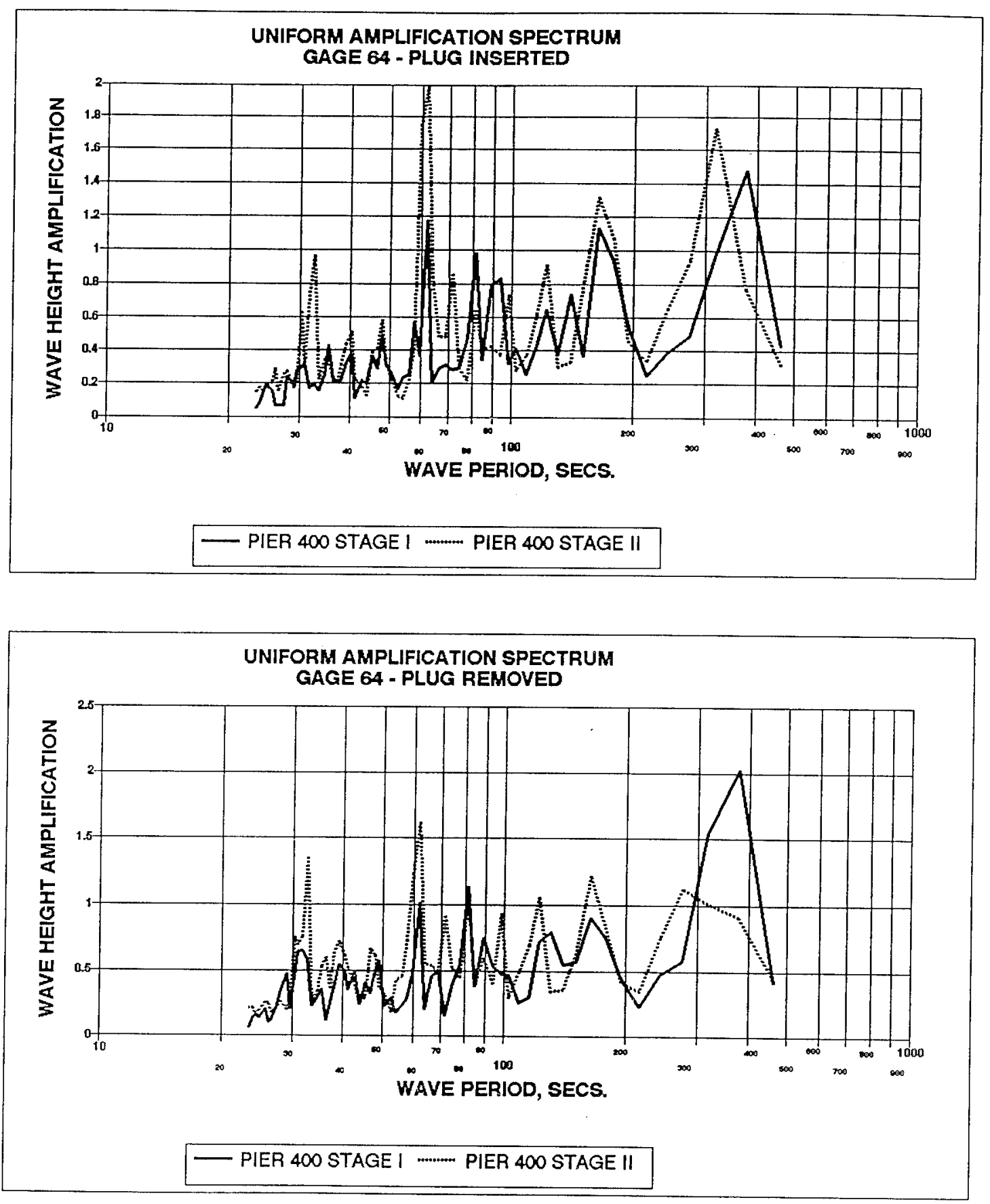

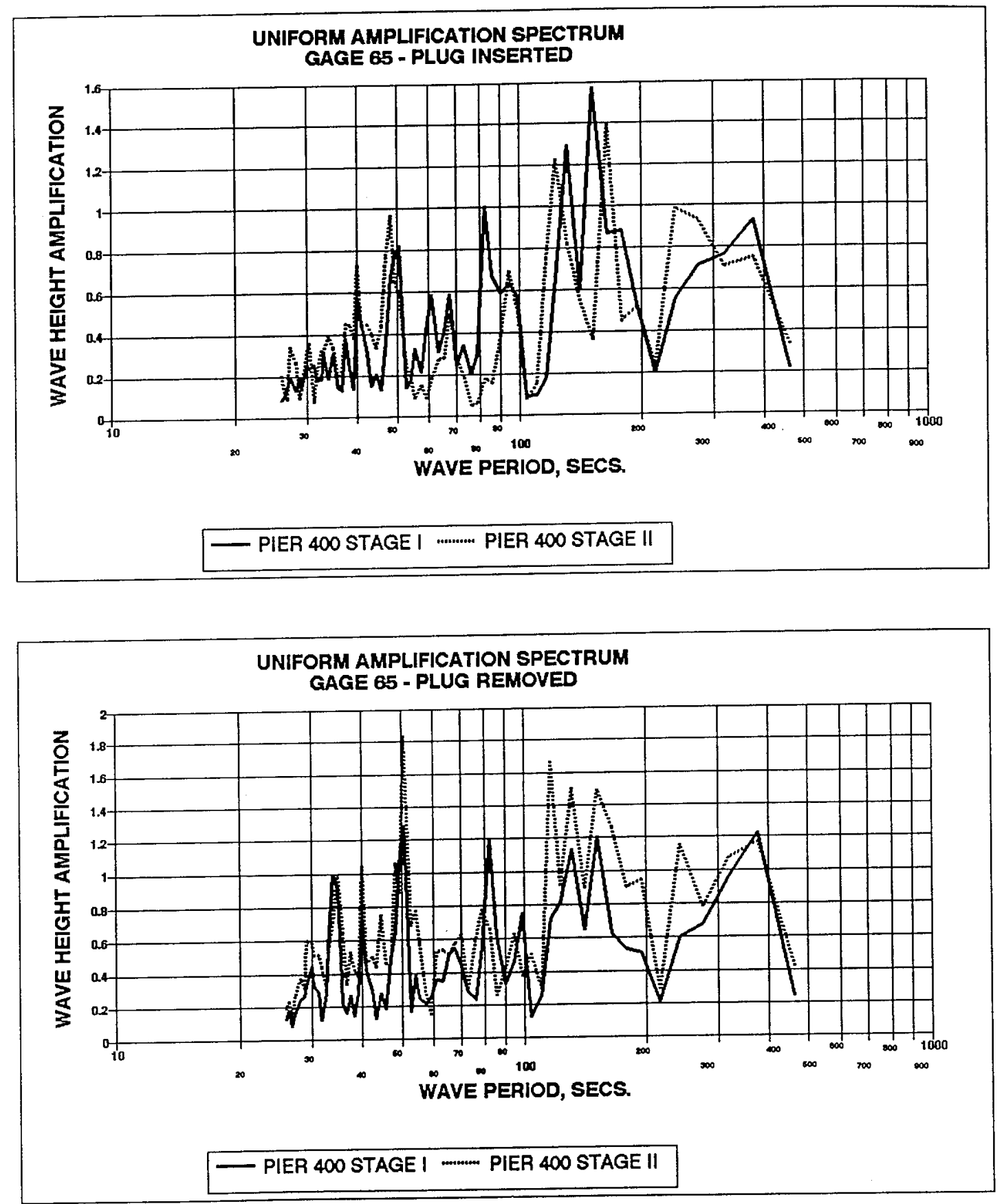


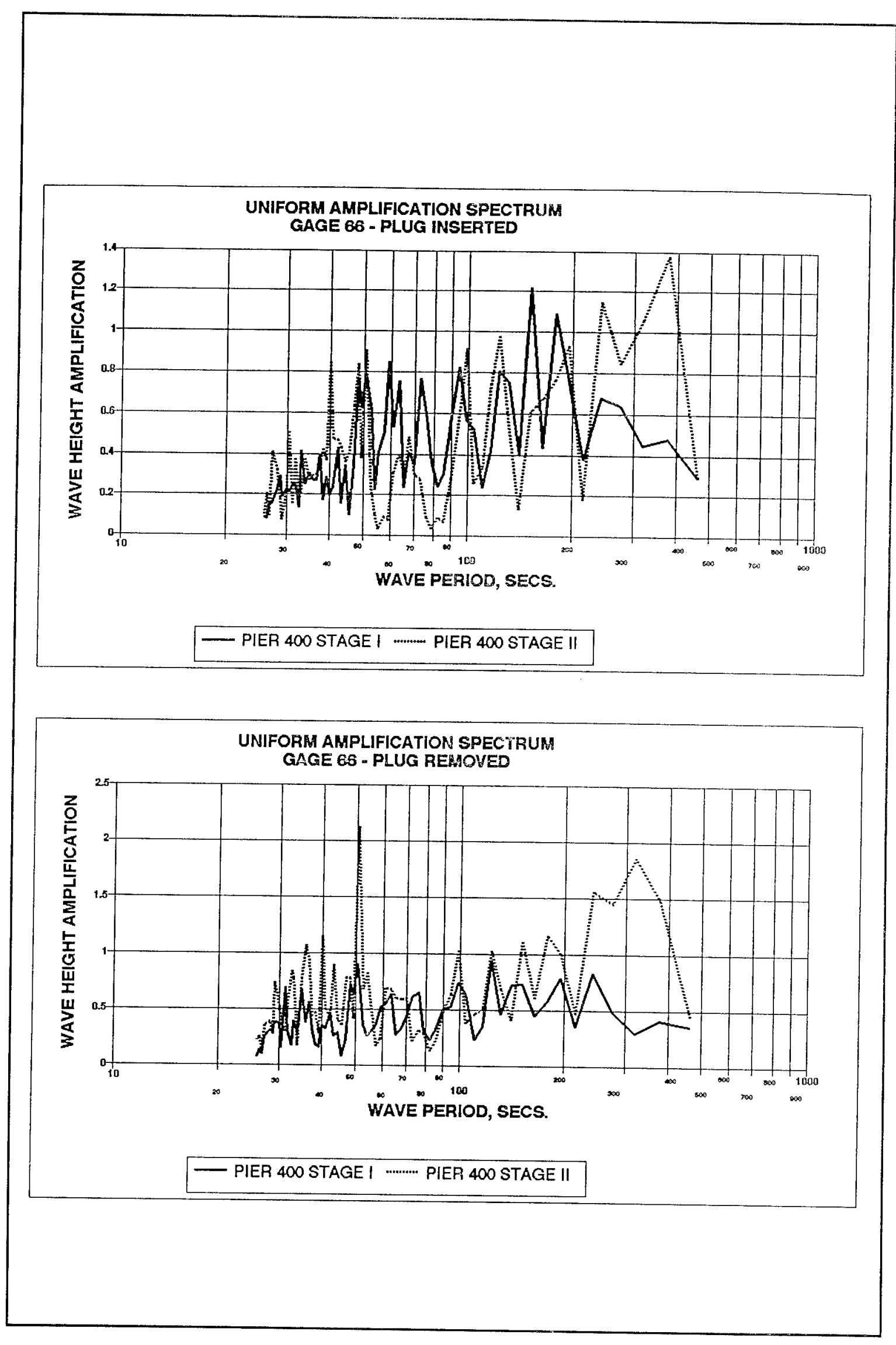



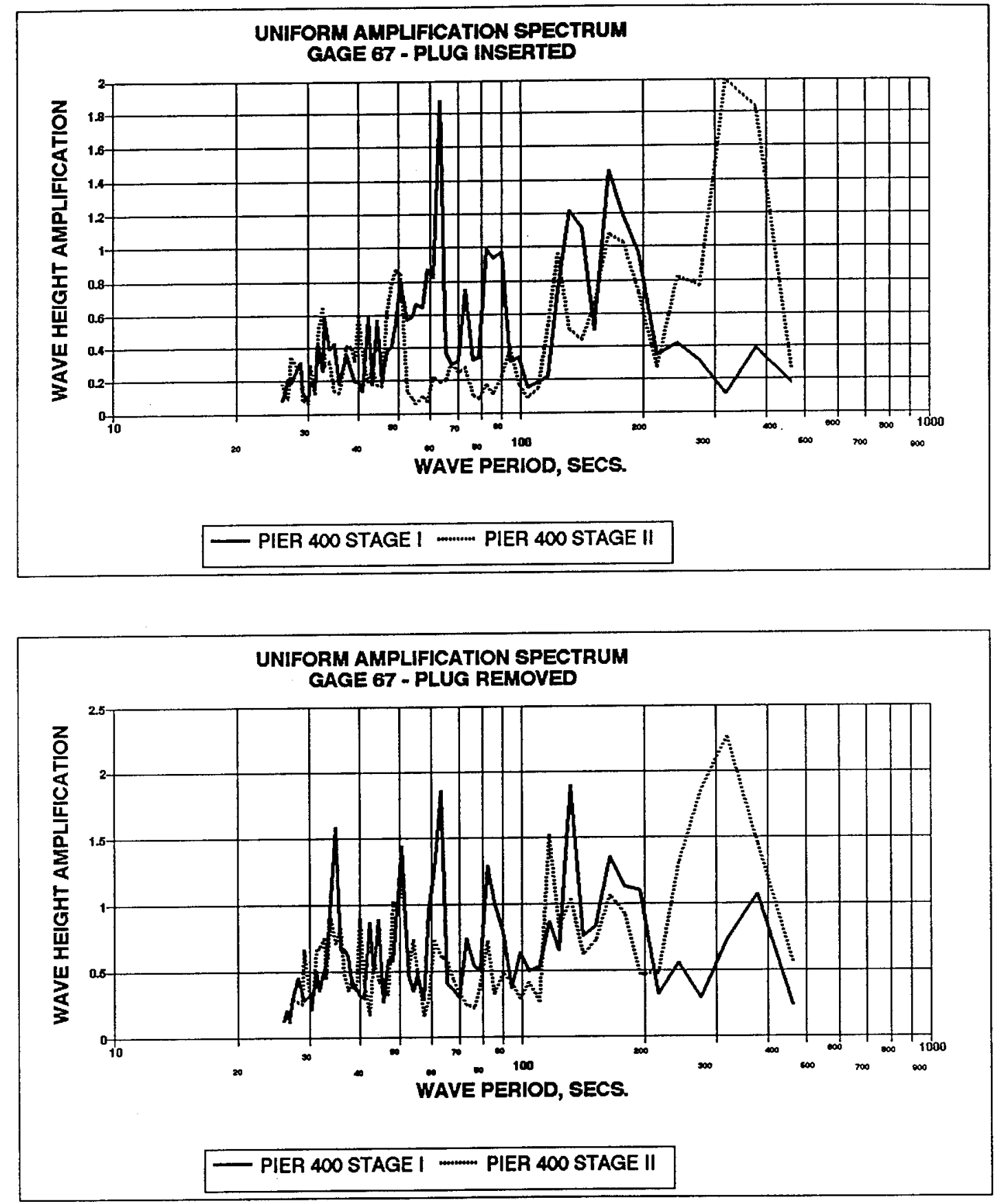


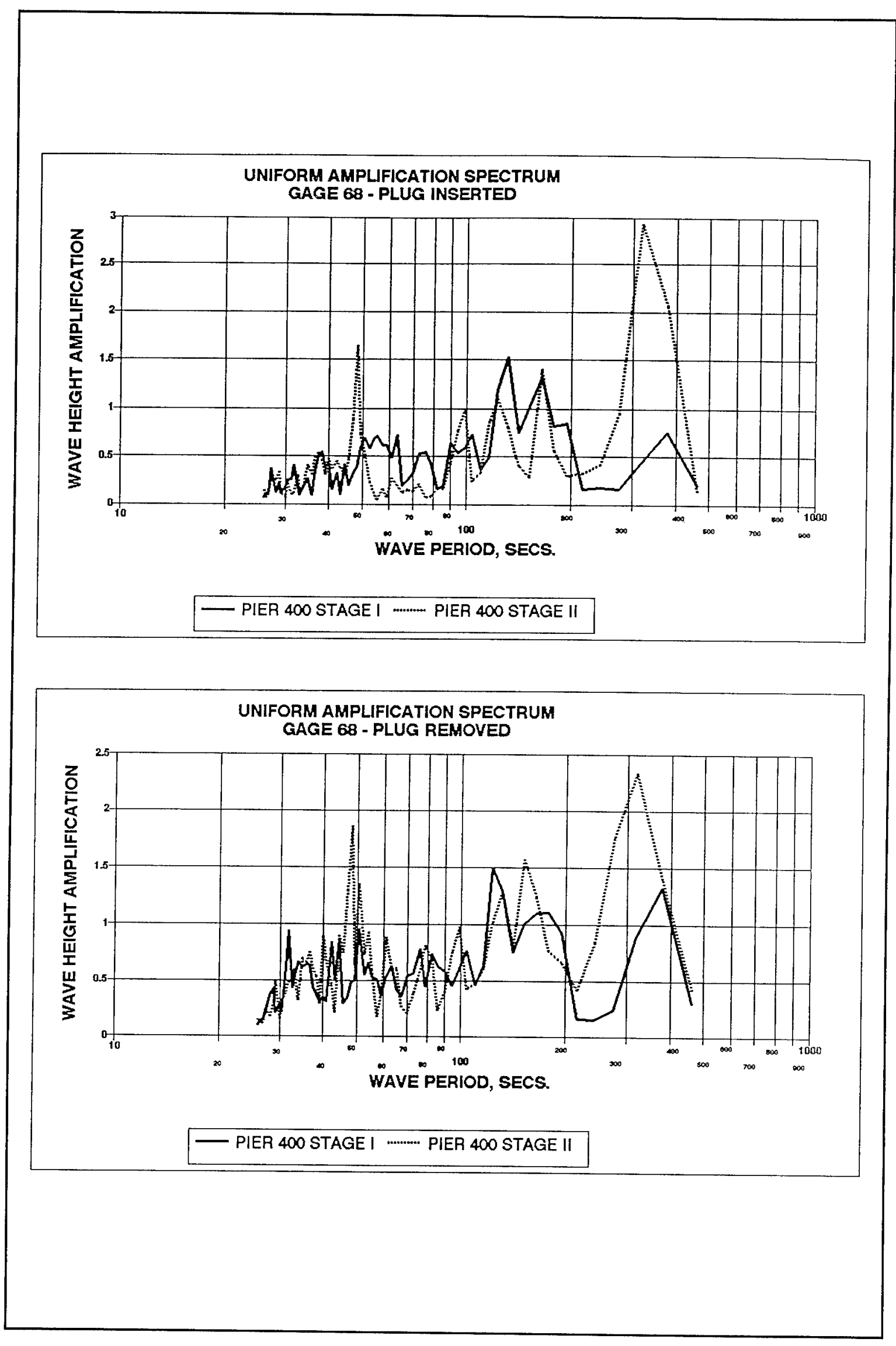



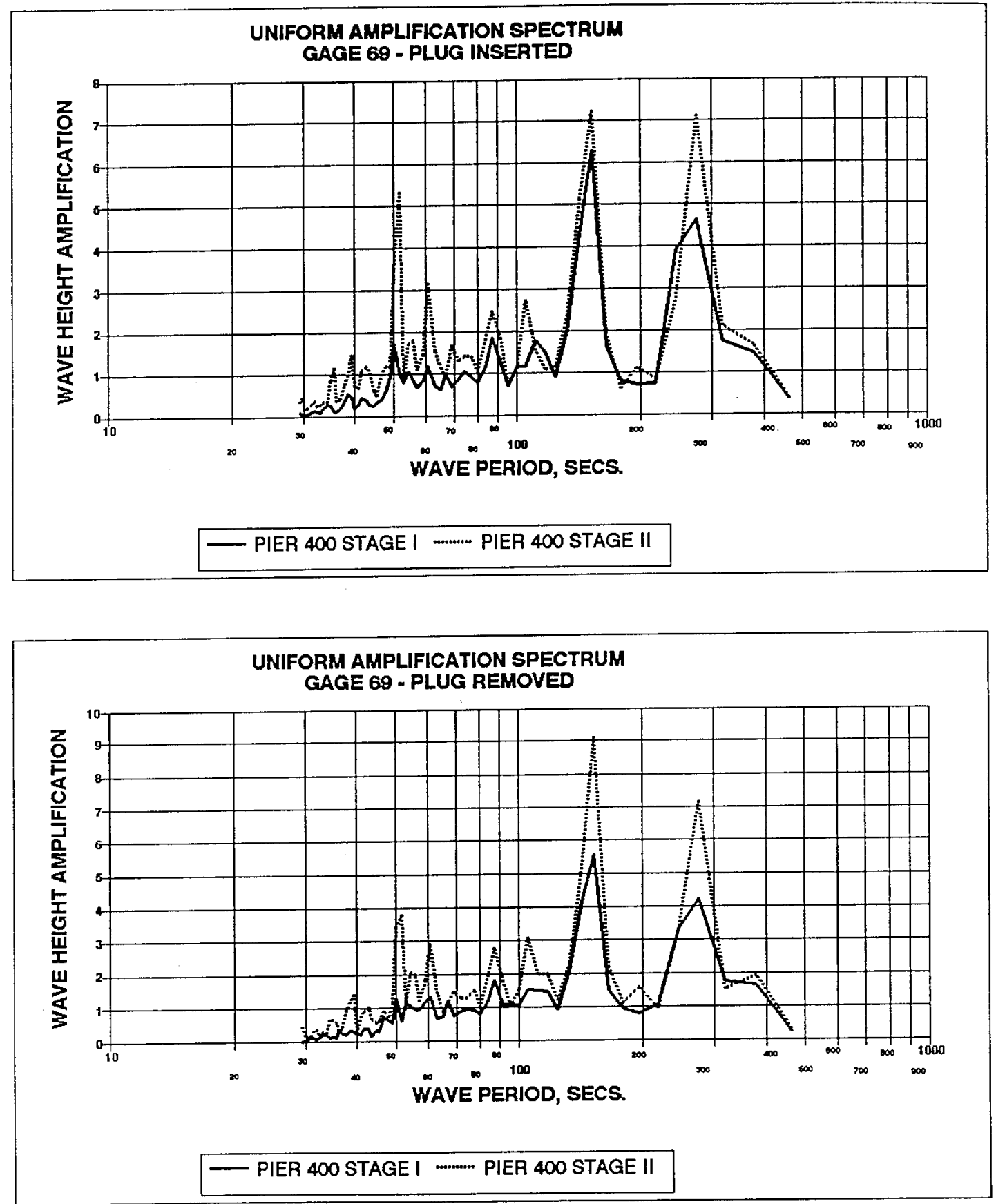

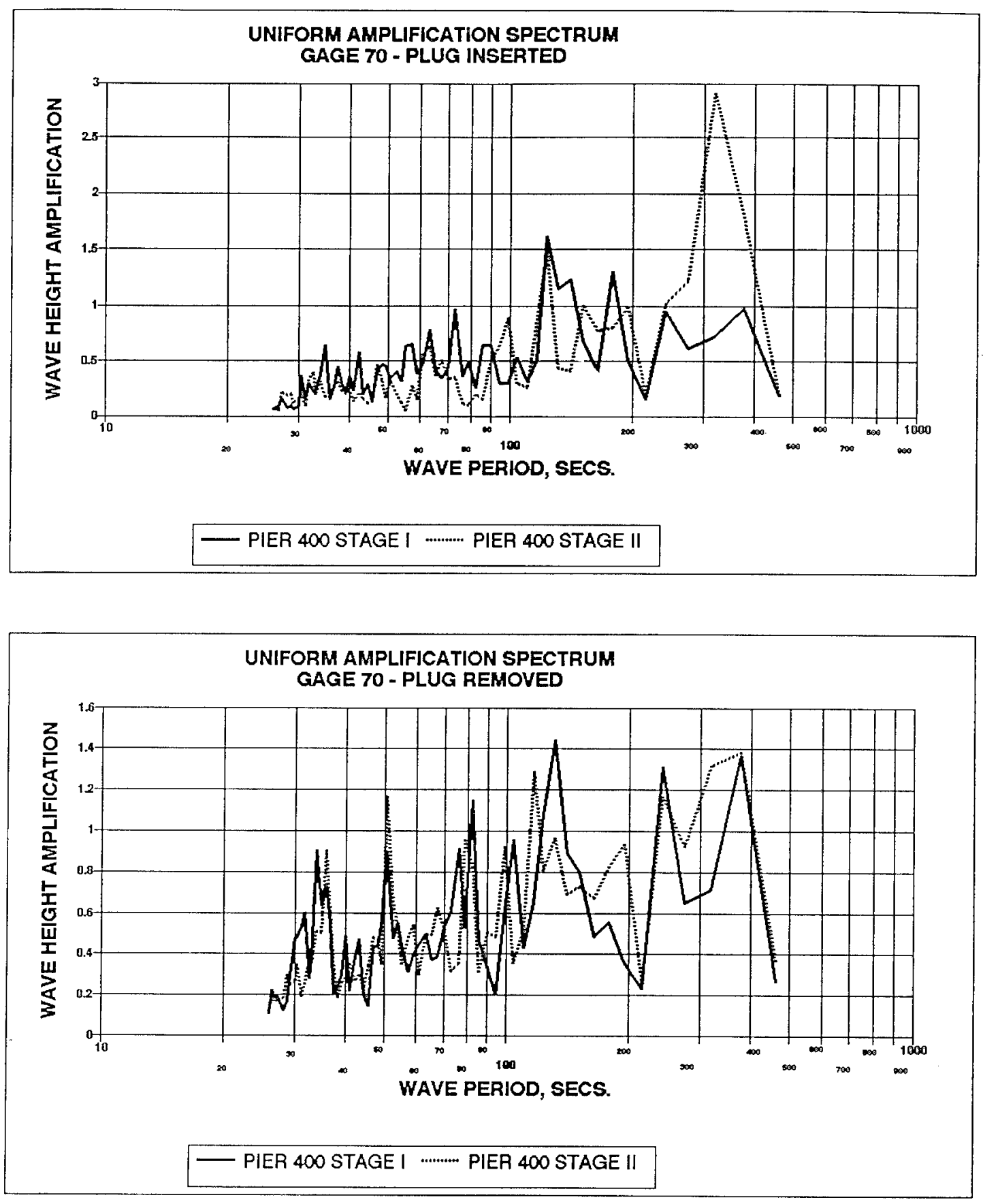

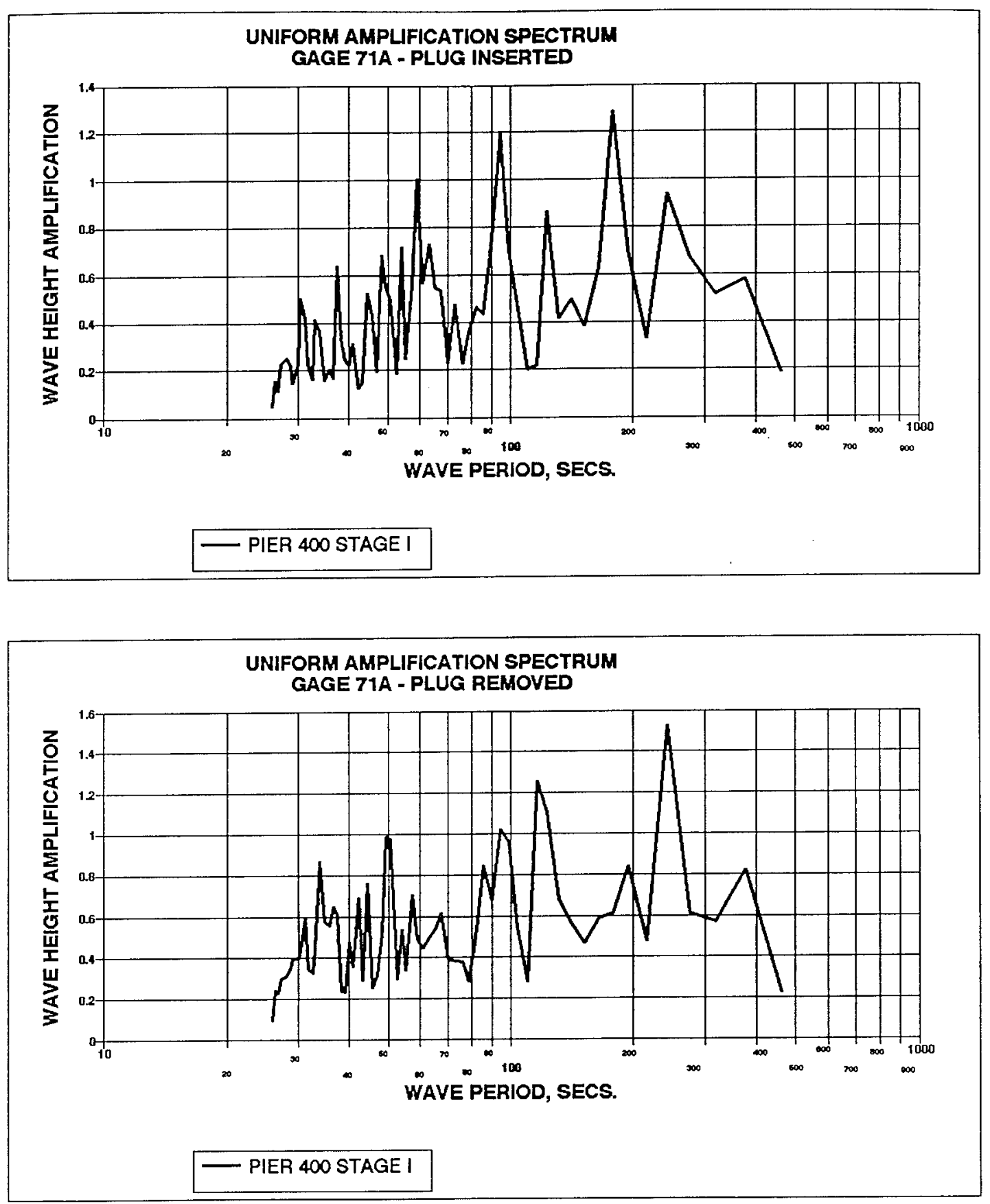


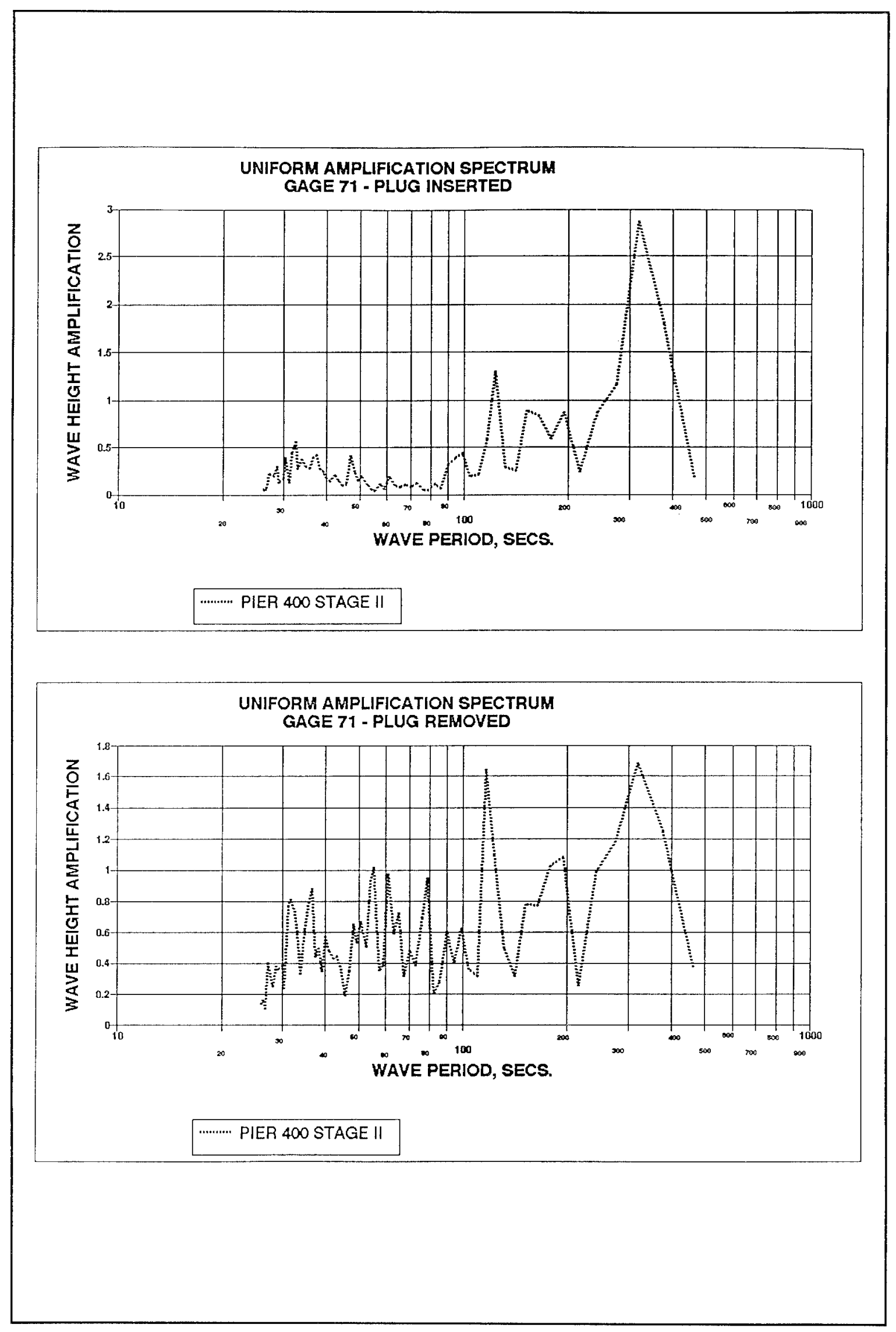



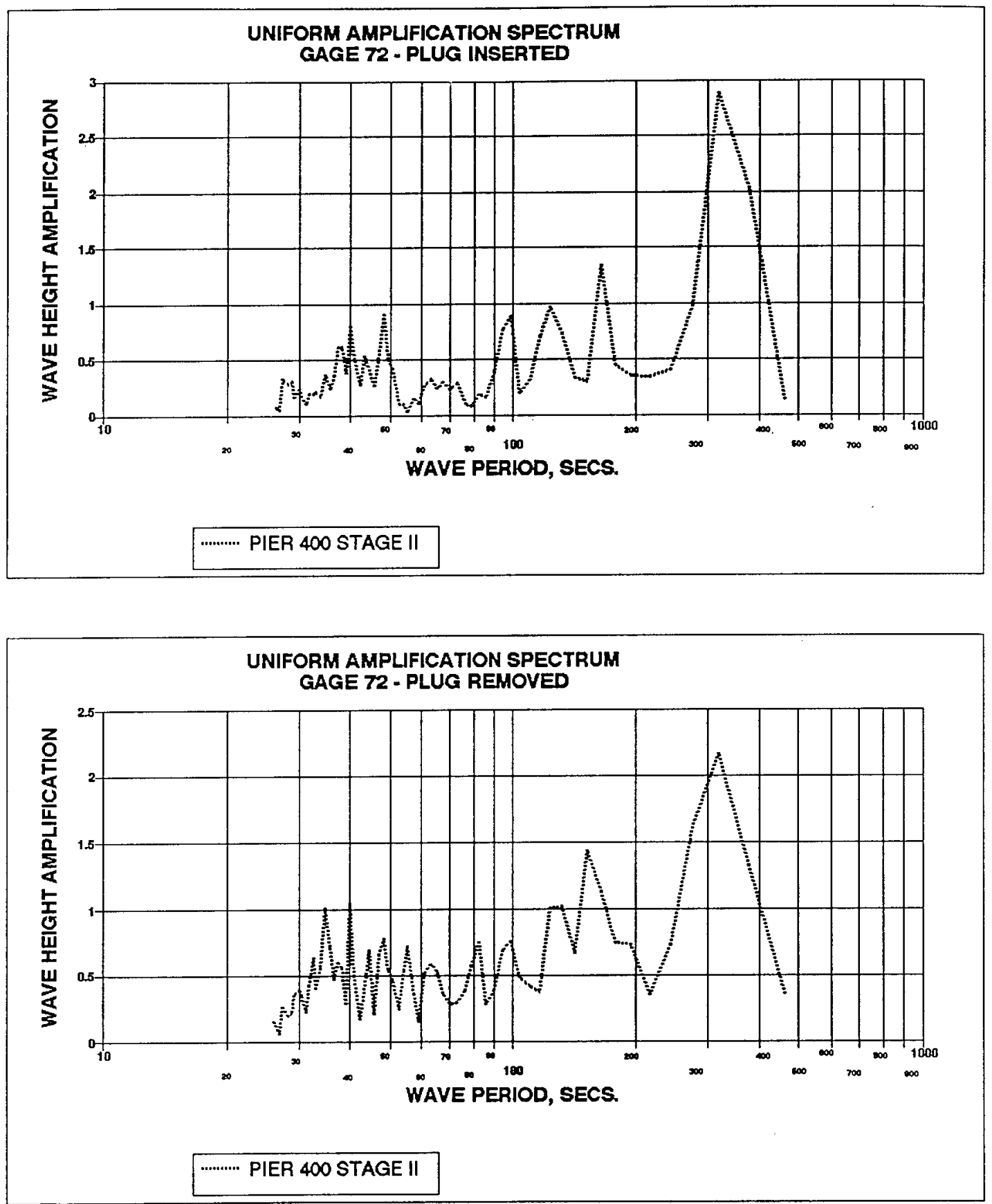

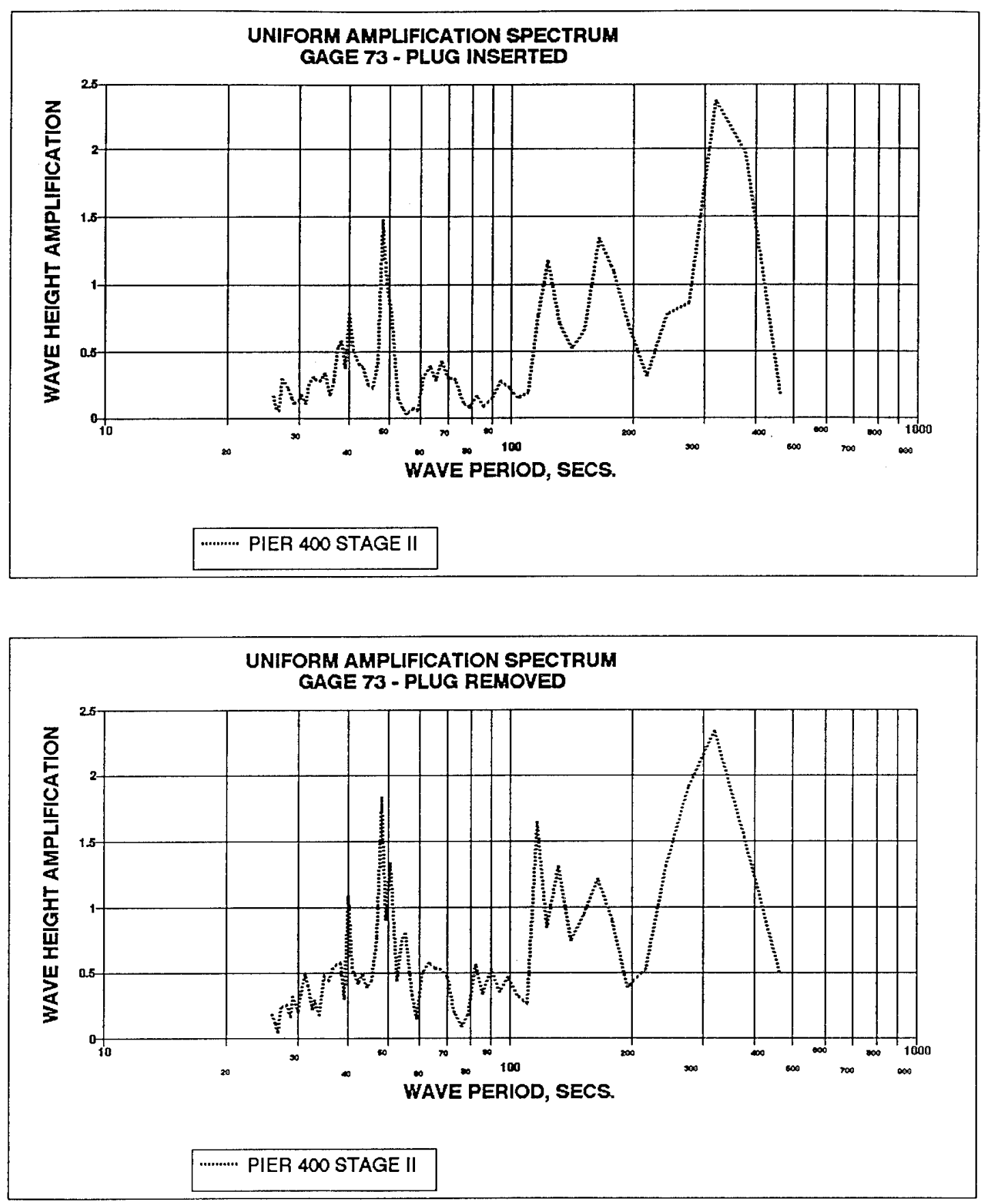

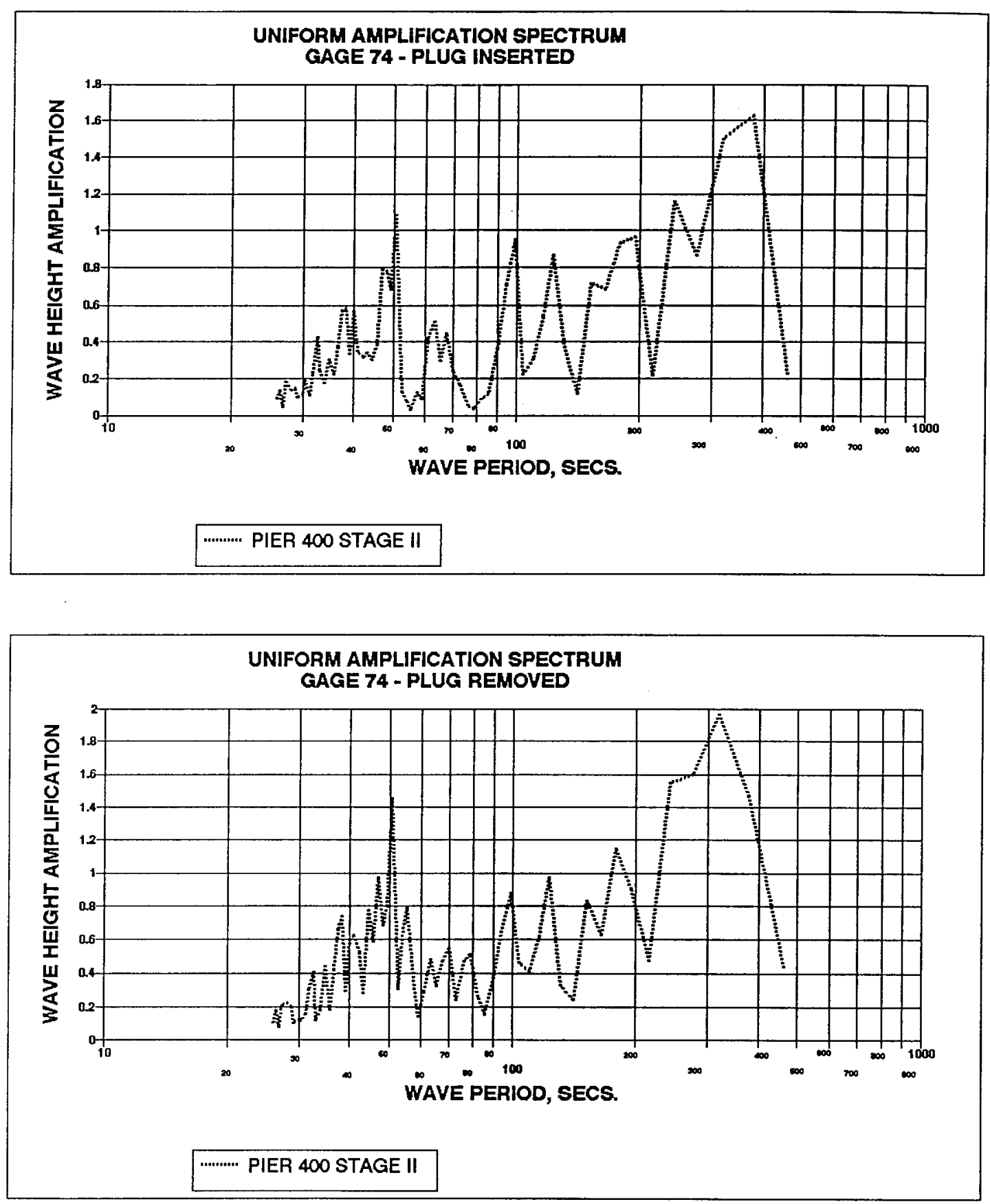

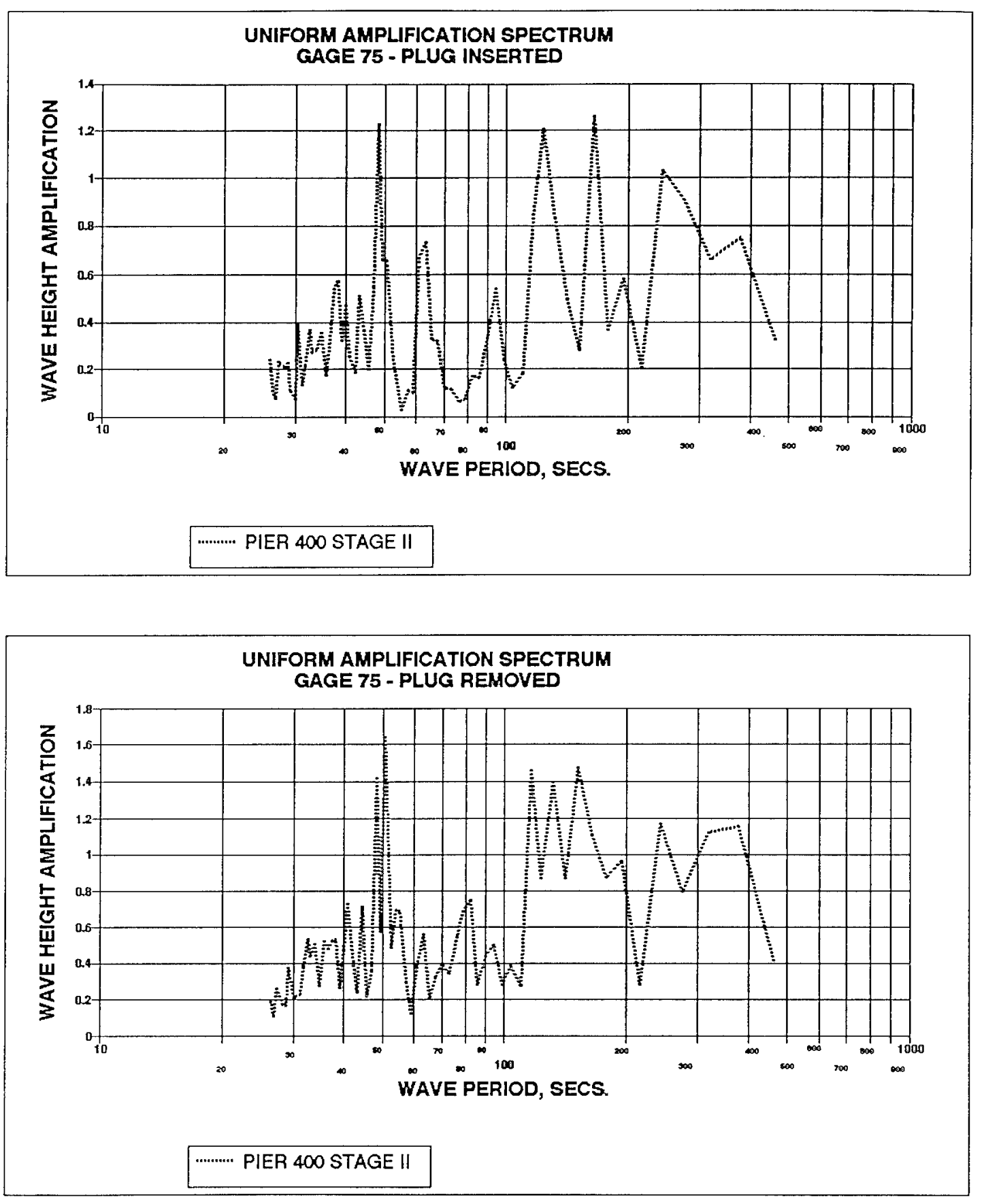

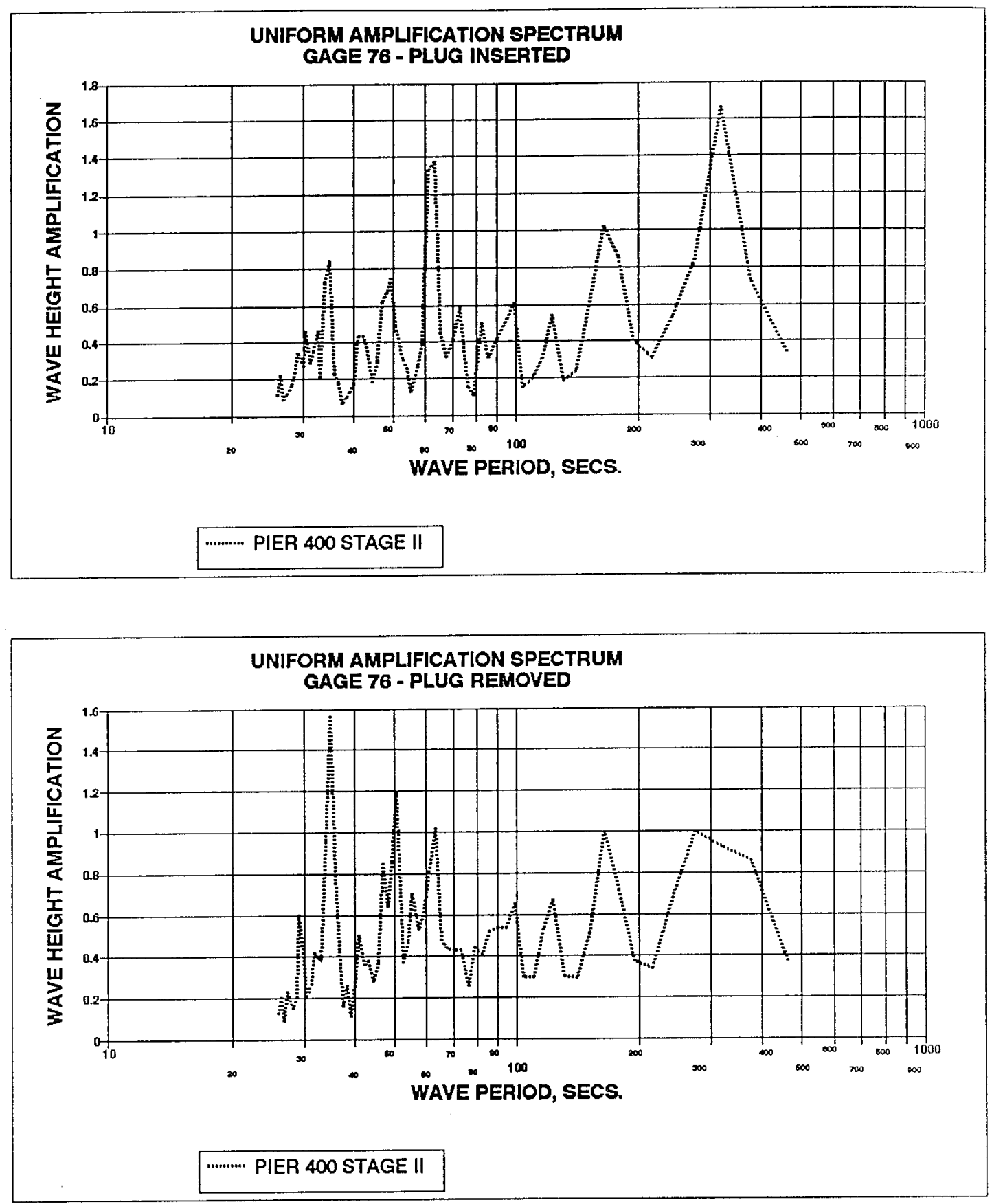

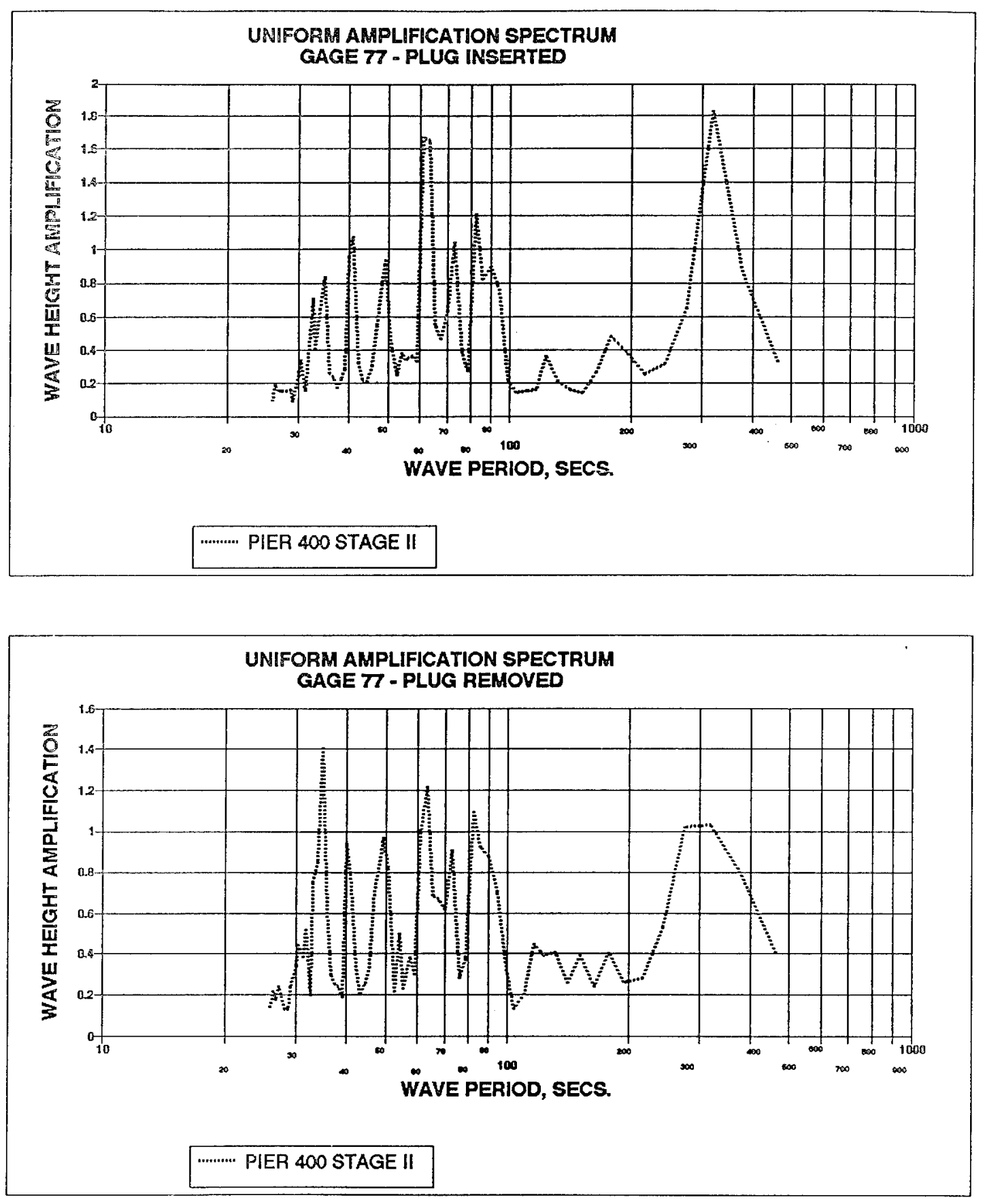


\section{Appendix C \\ Wave Amplification, Uniform \\ Spectrum, Gages 1-30, Open \\ and Closed East End at Pier $\mathbf{3 0 0}$}



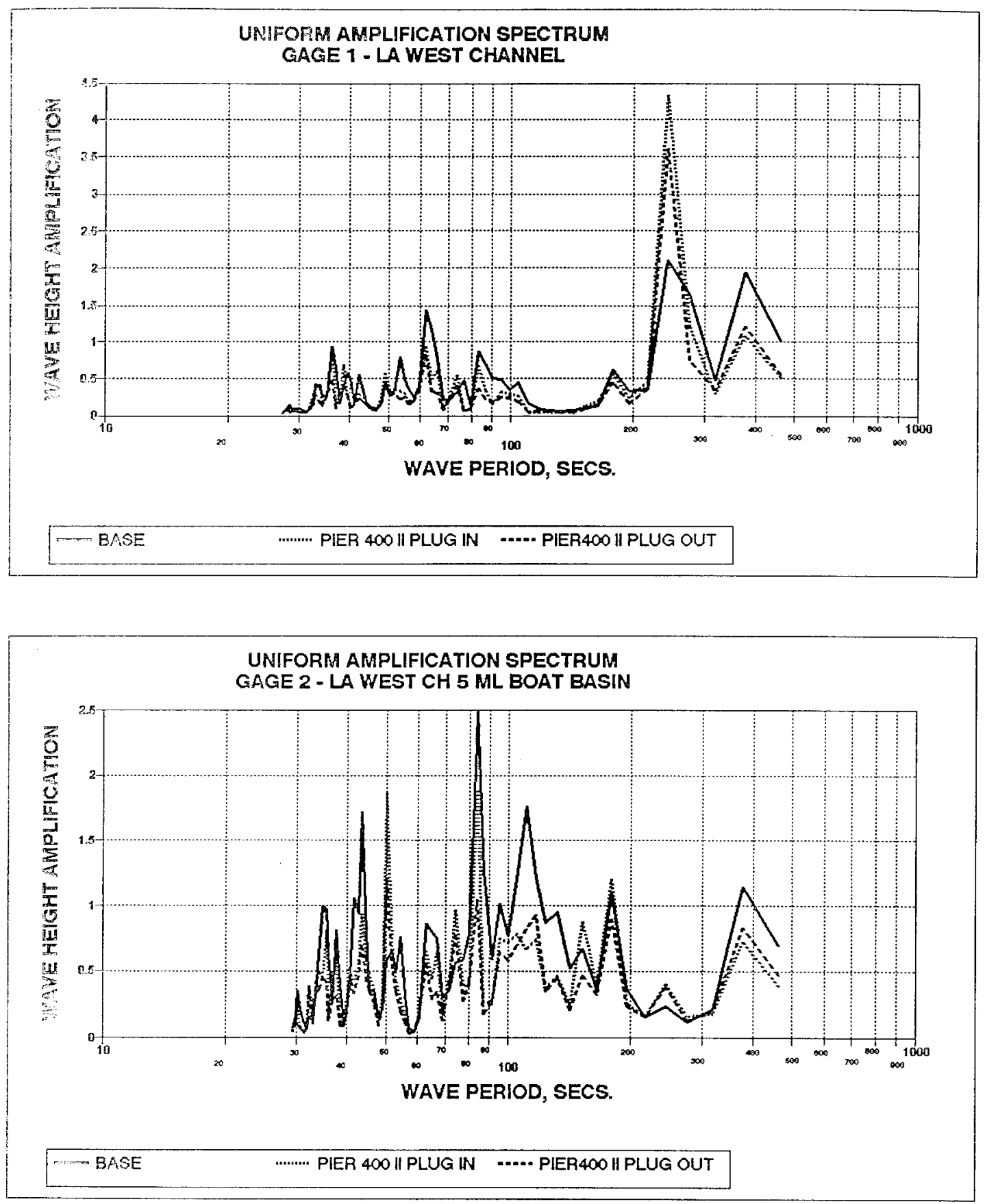


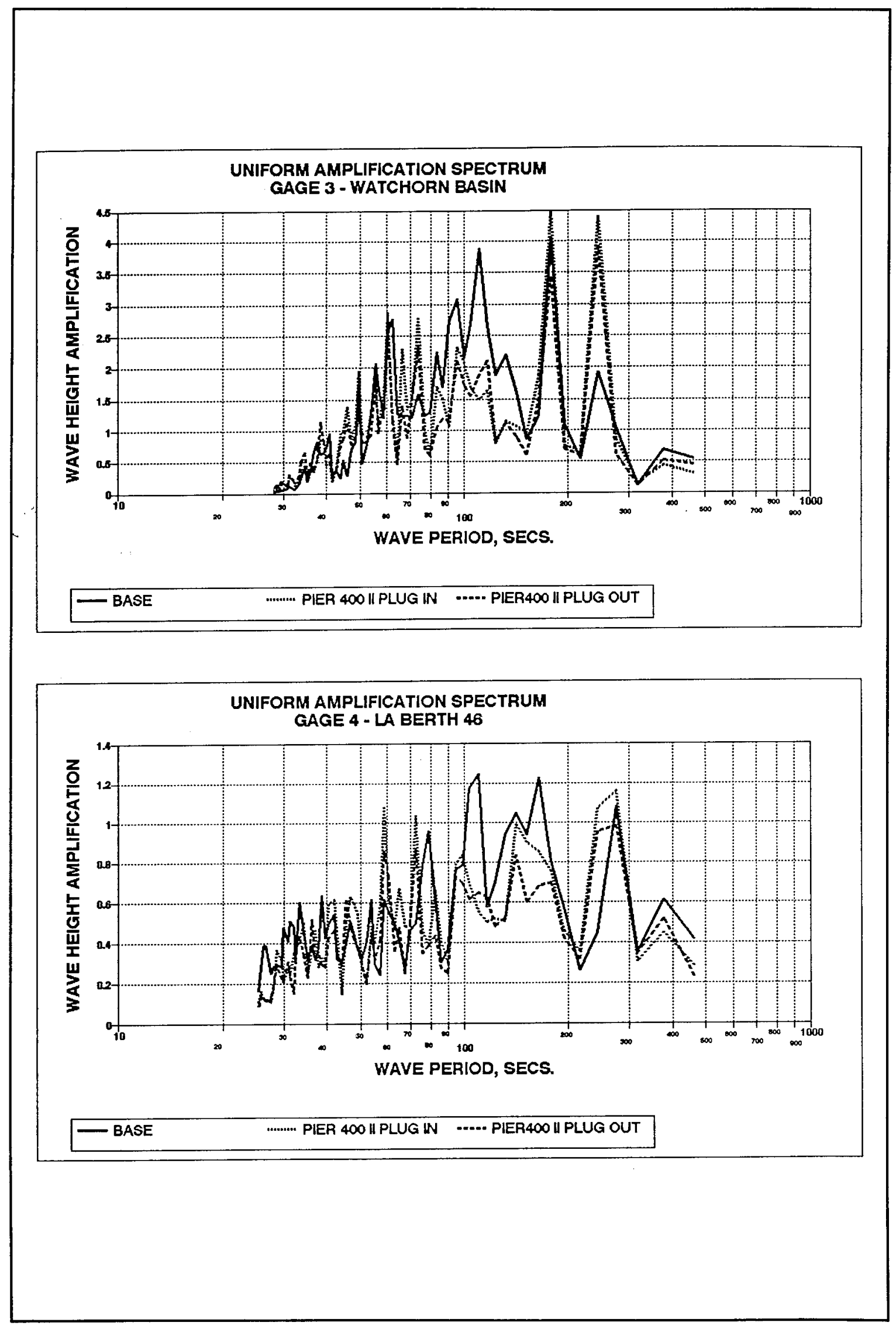



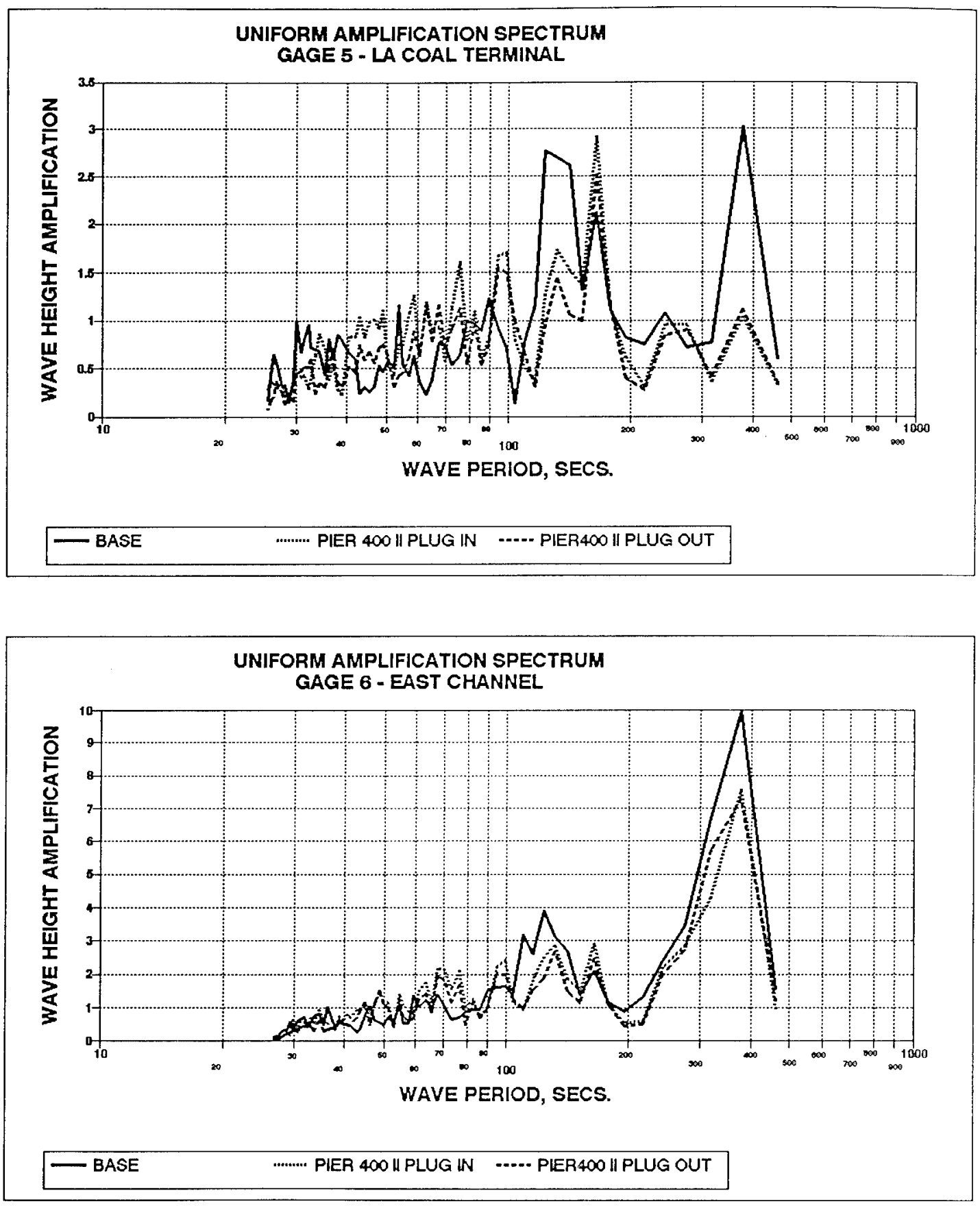


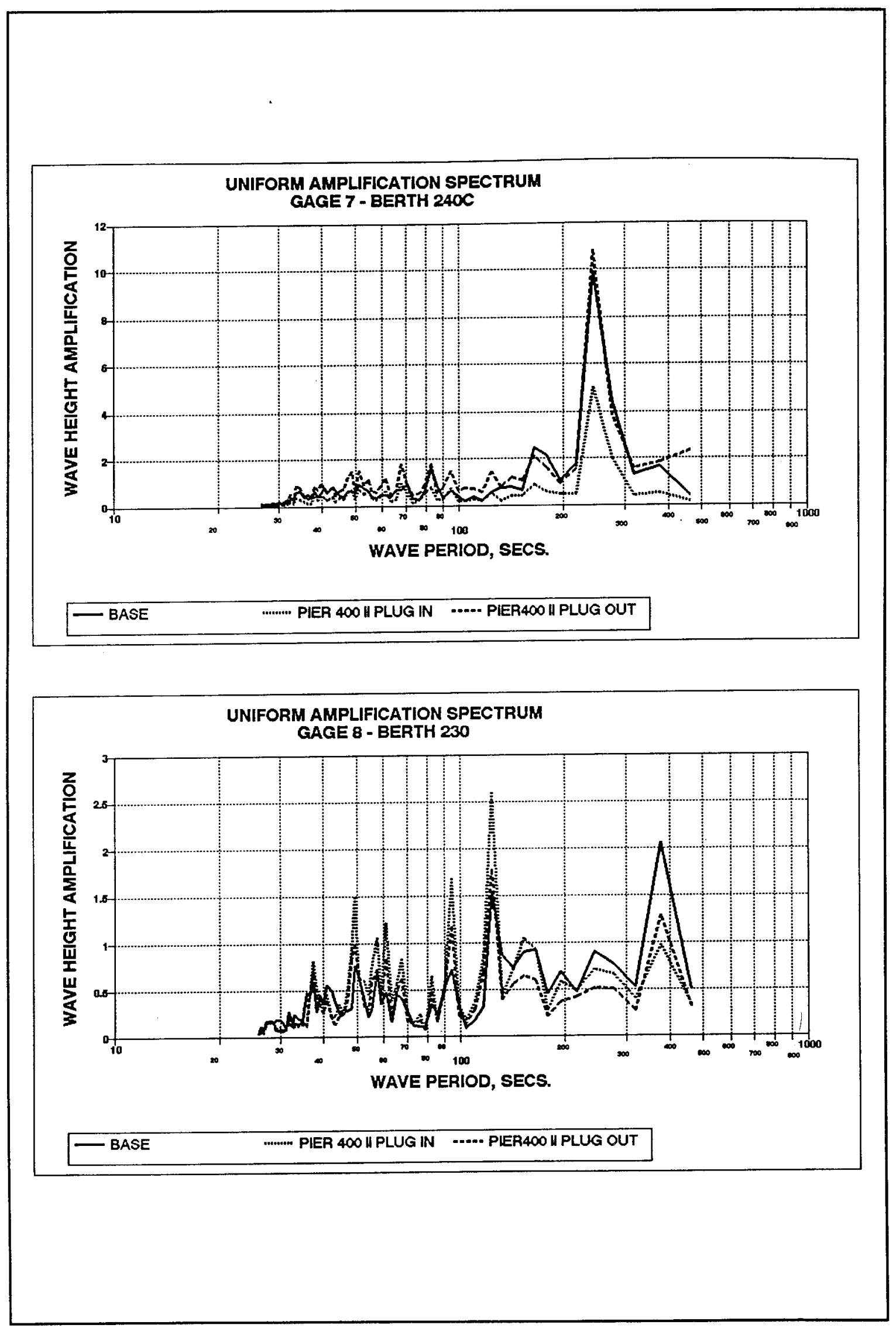



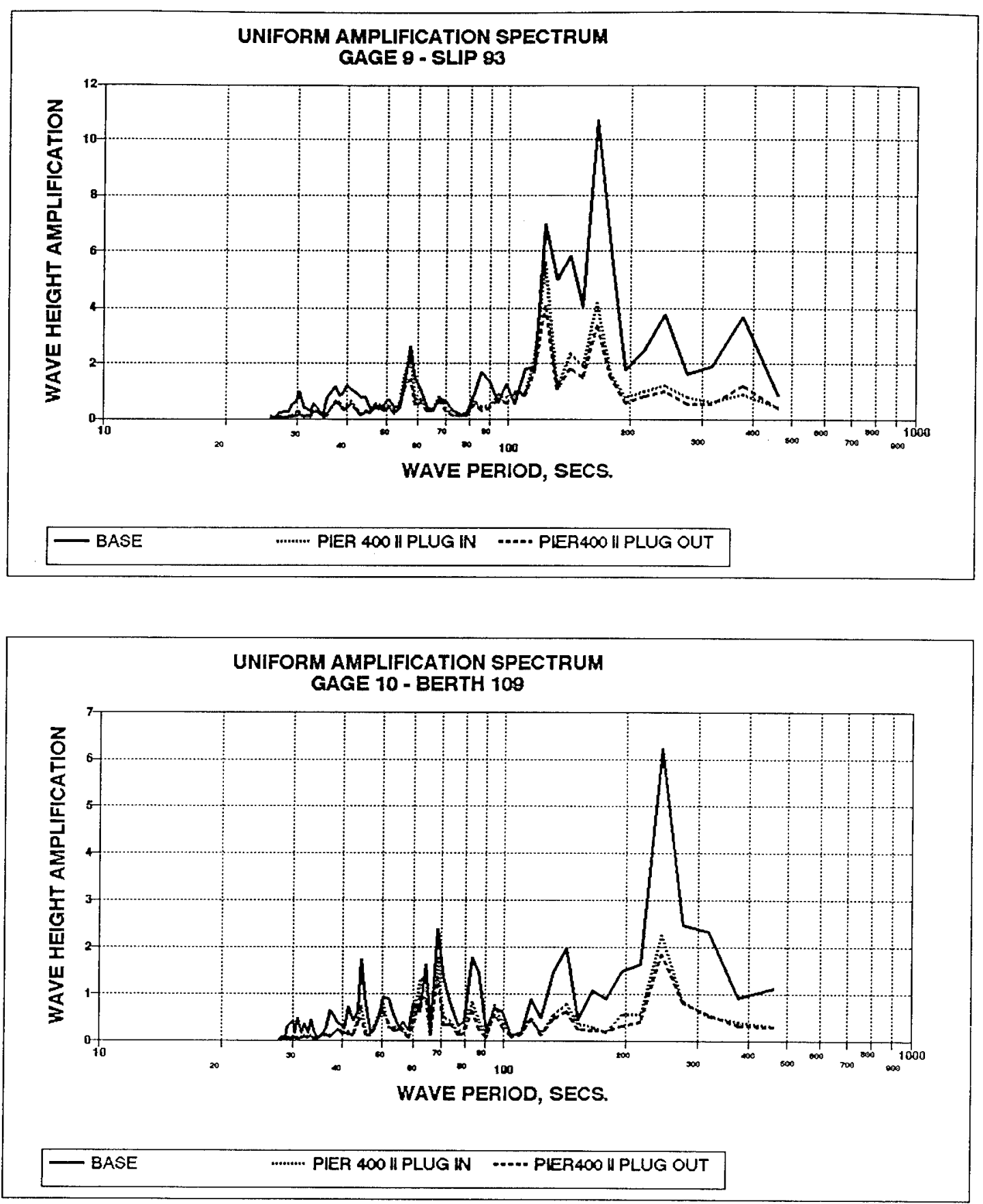

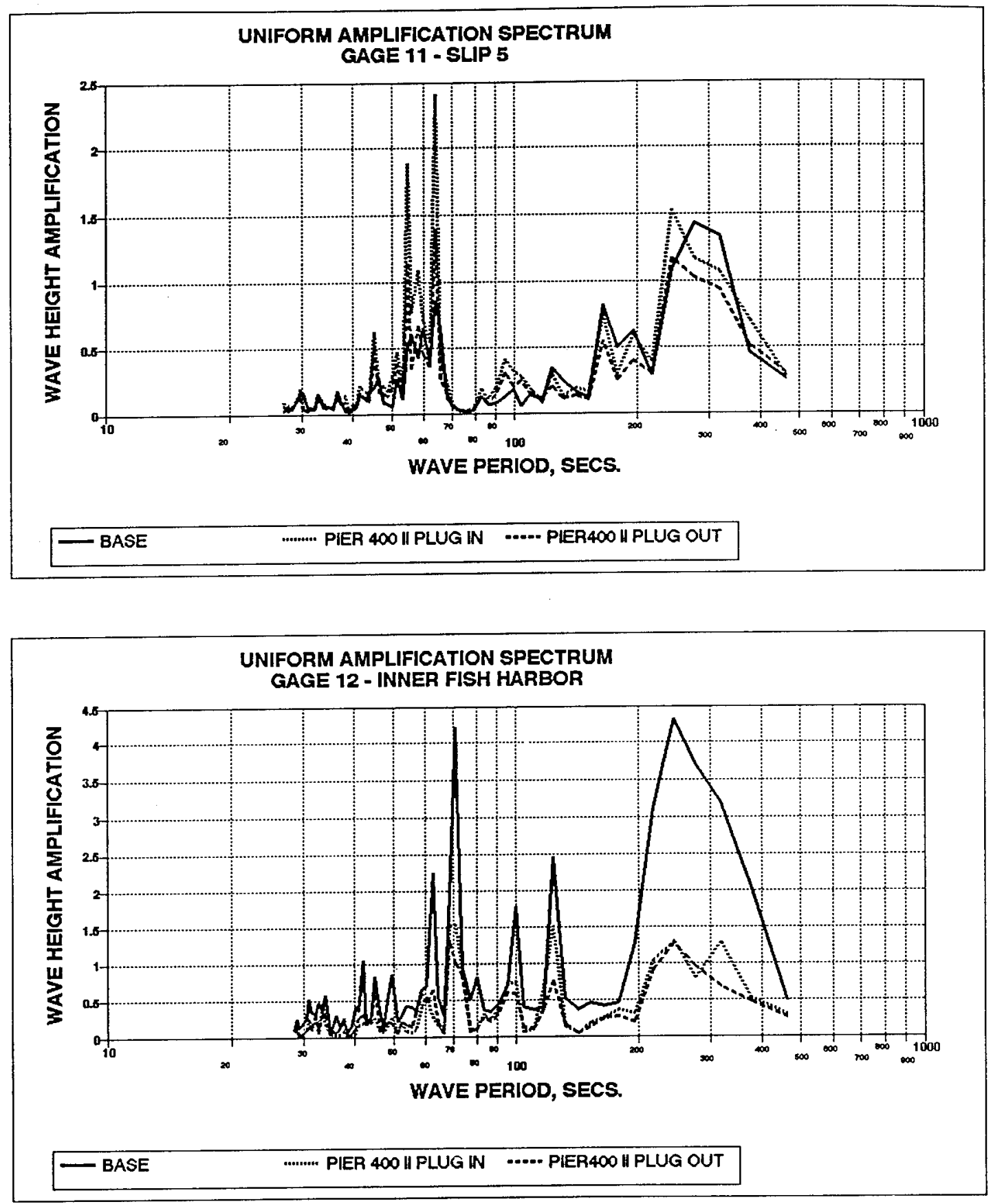

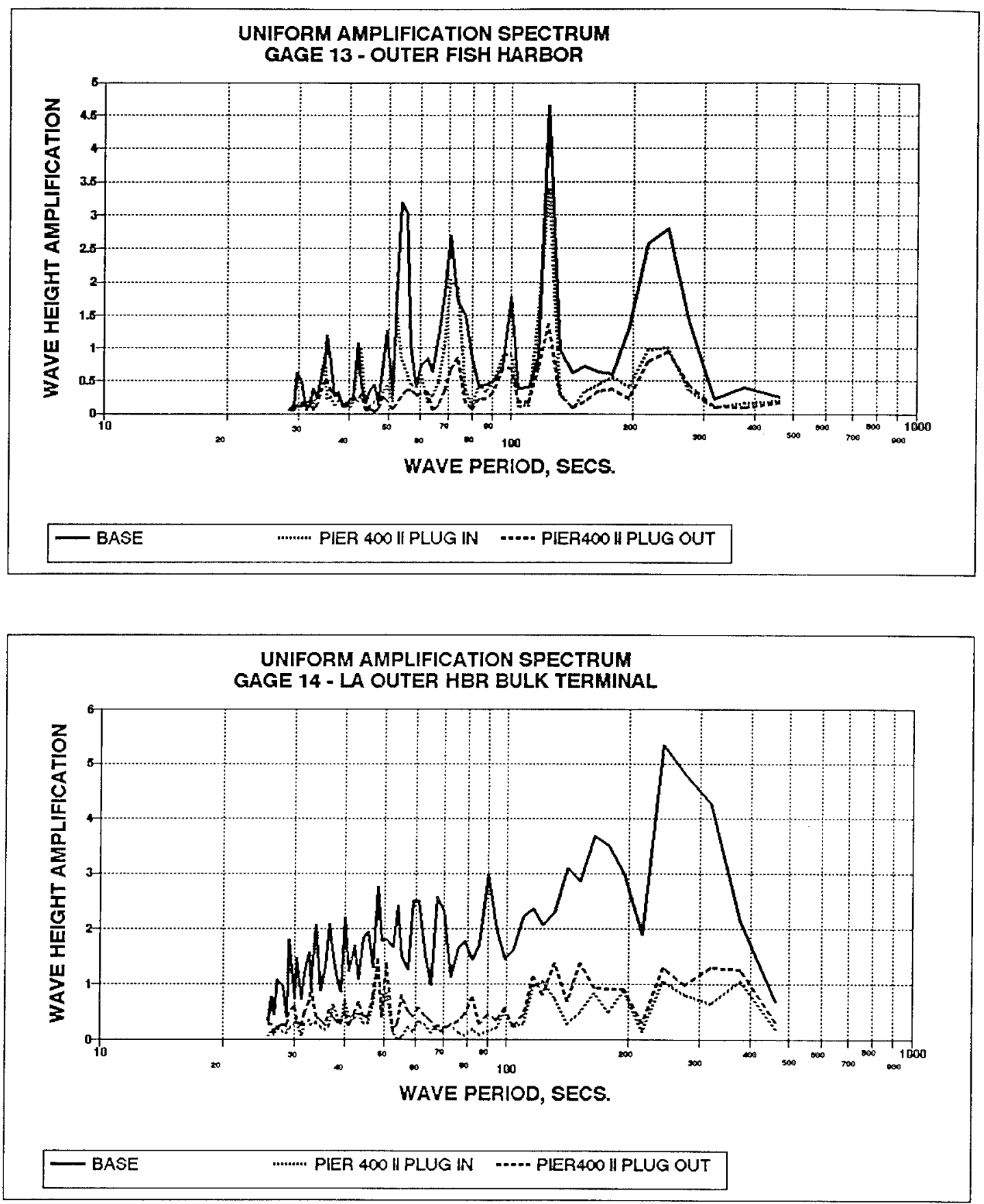

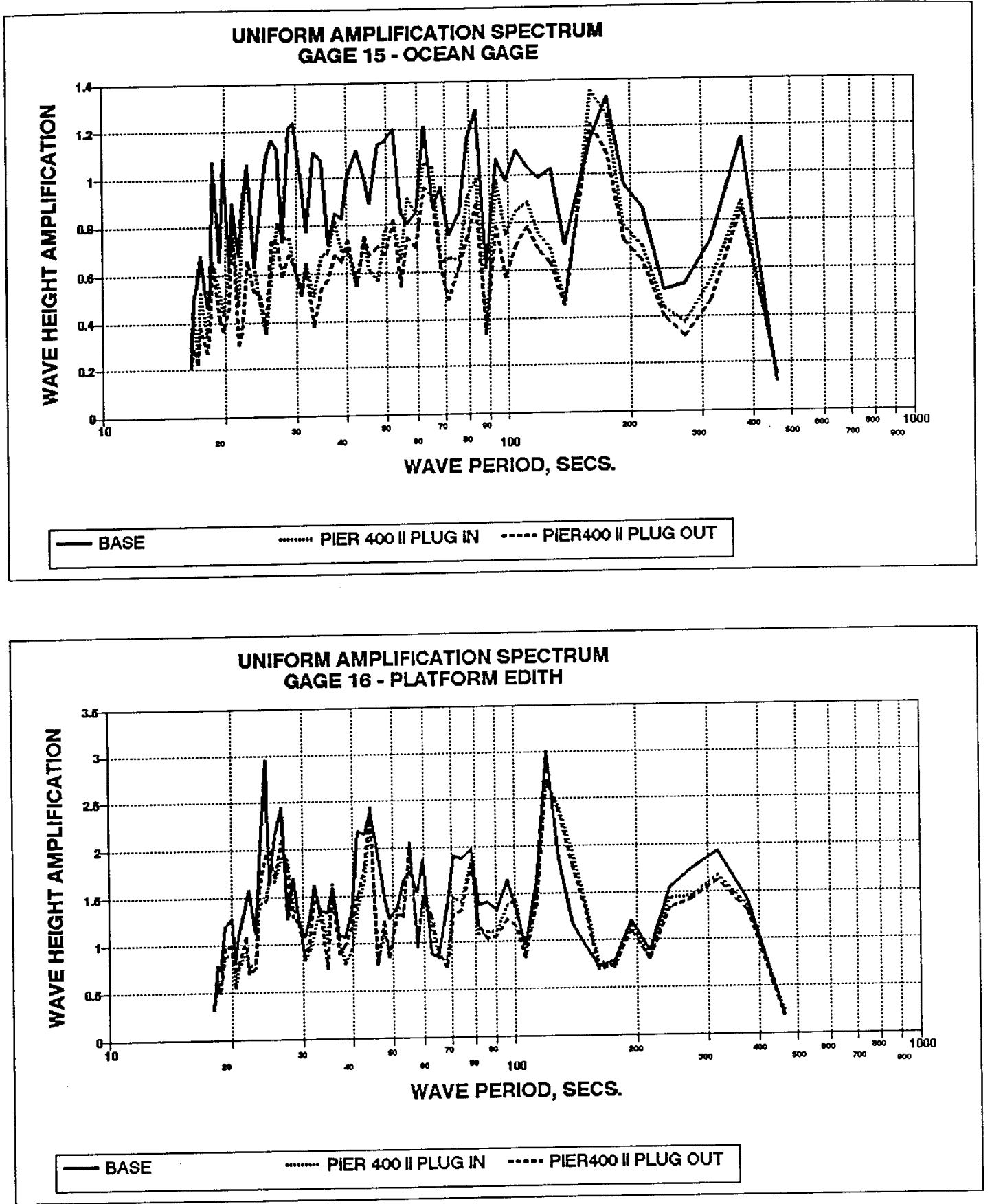

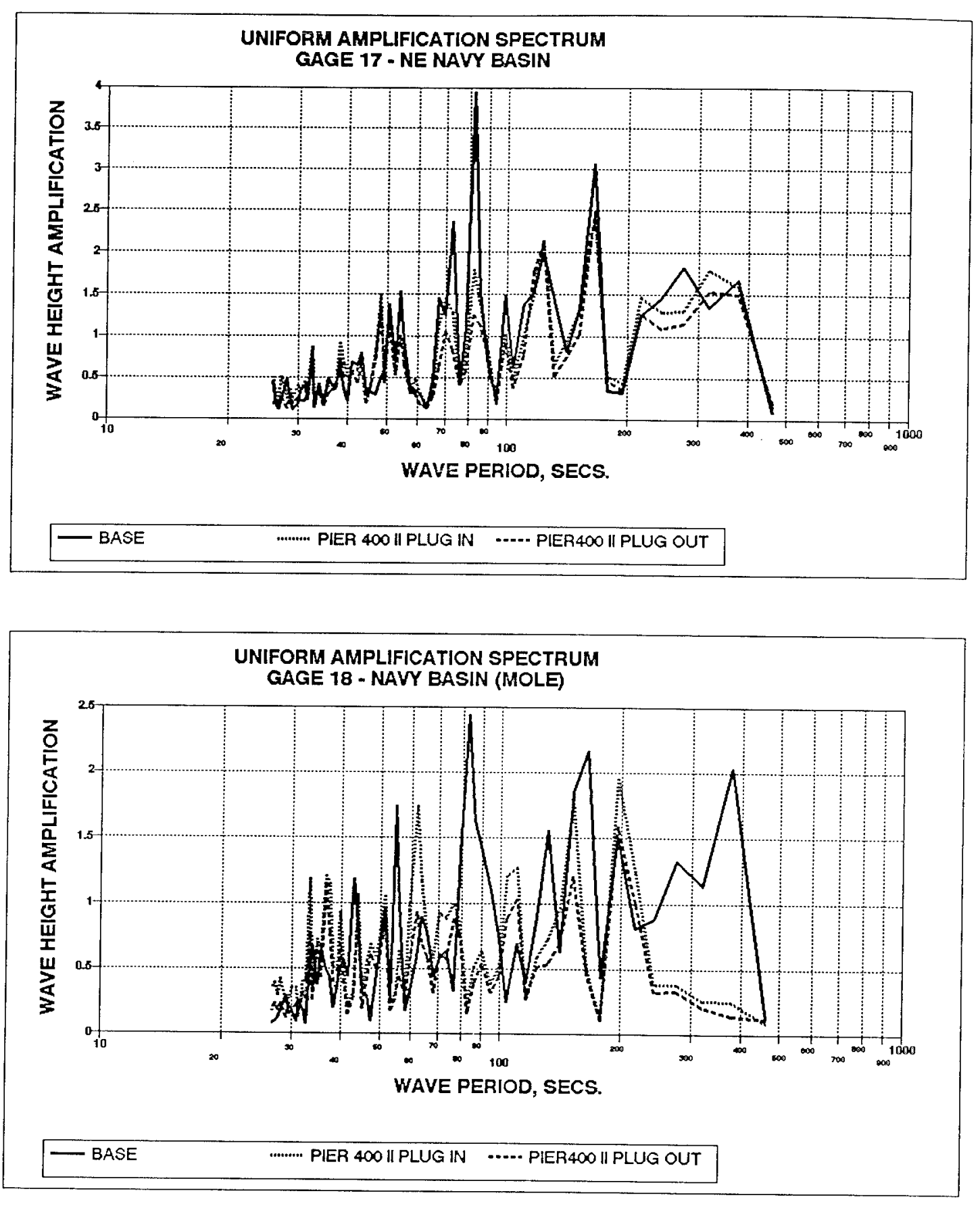

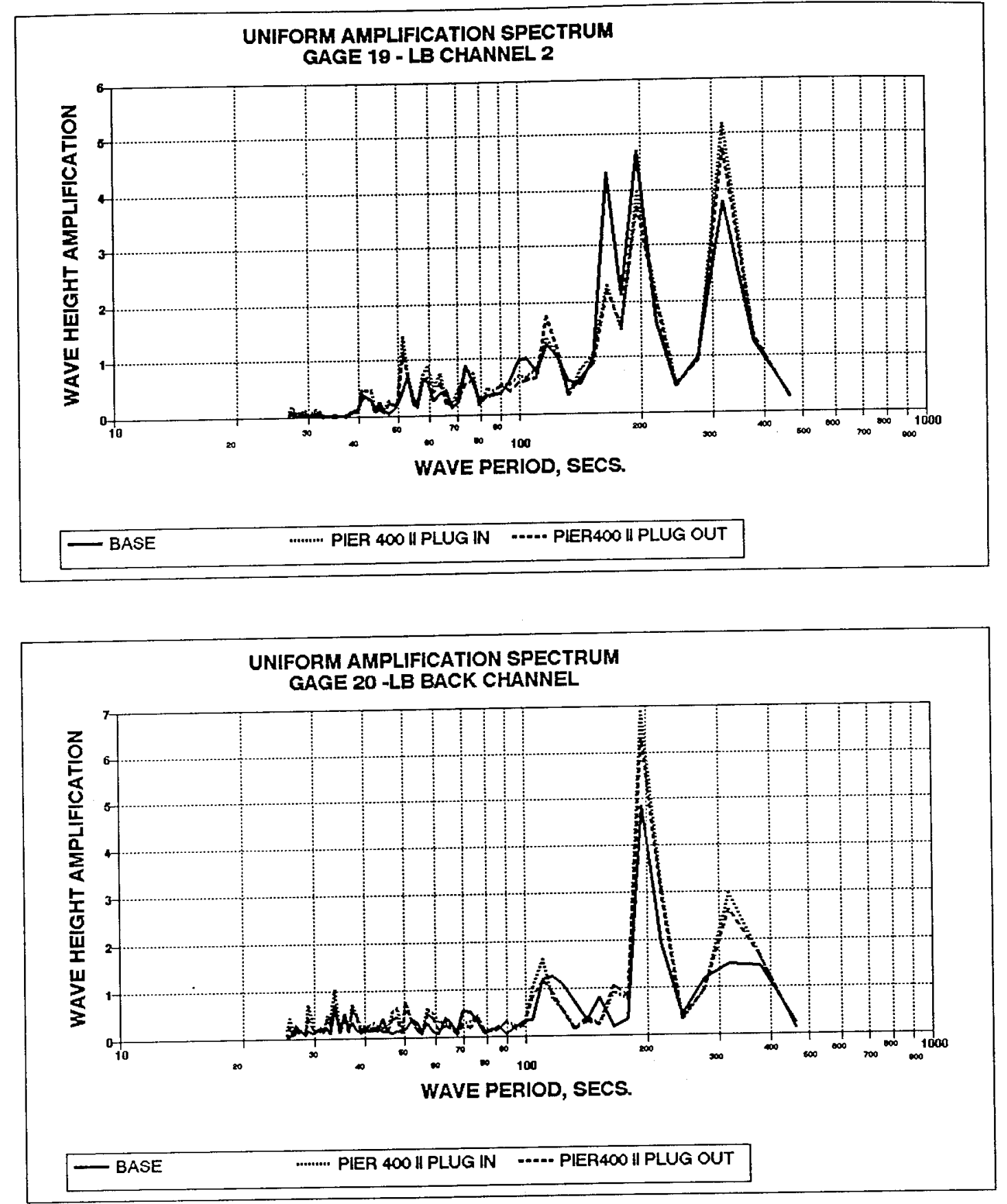

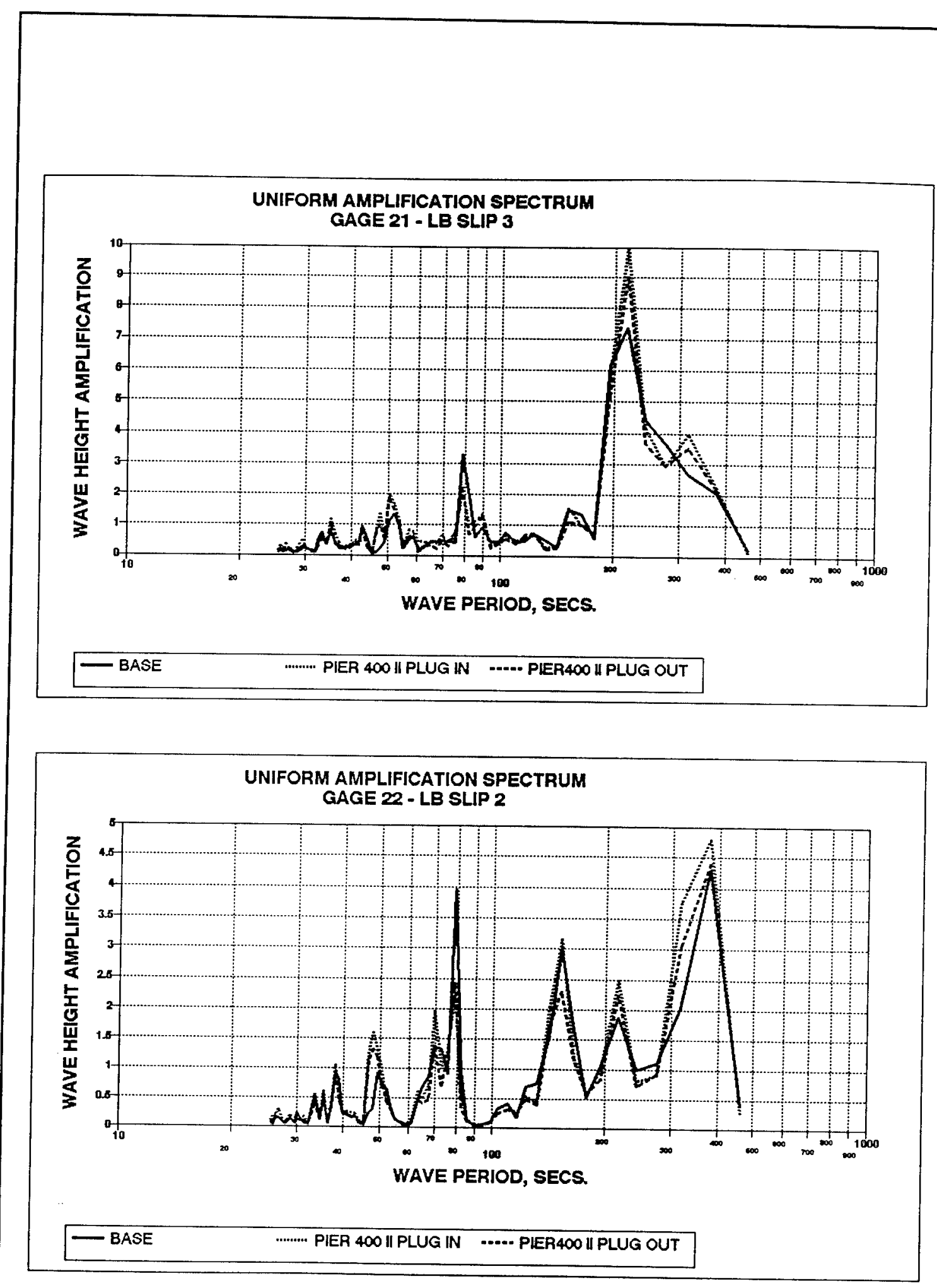

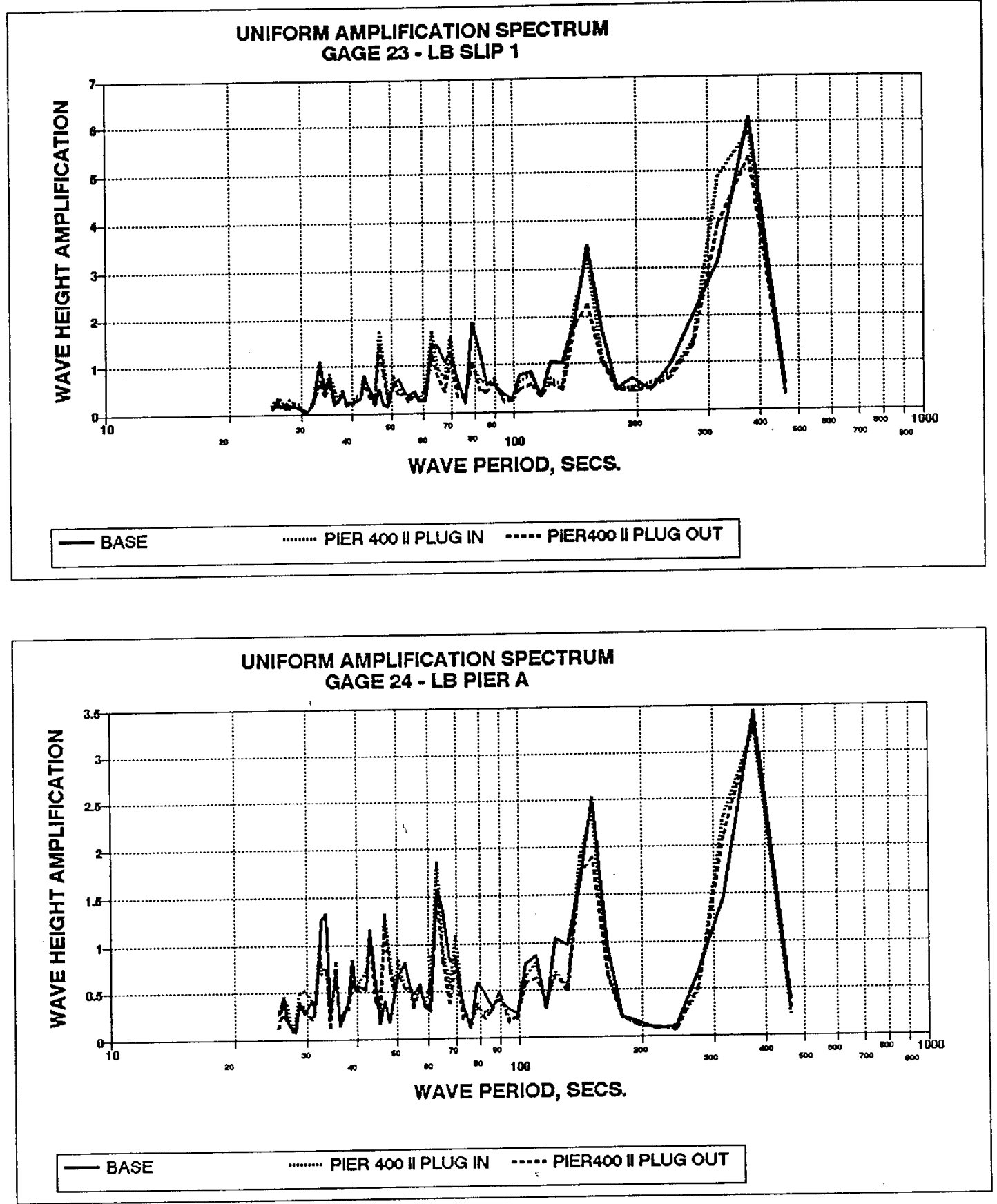

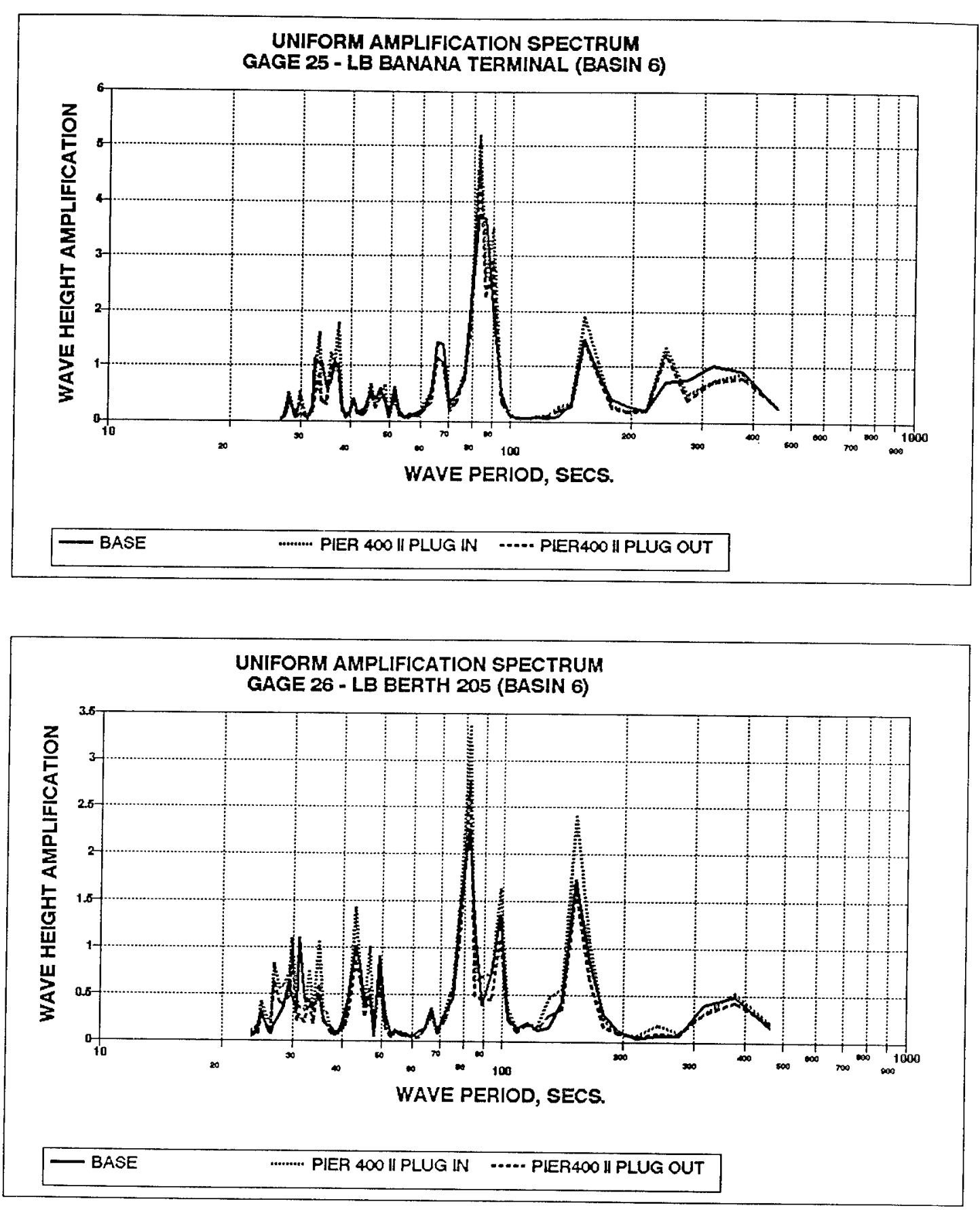

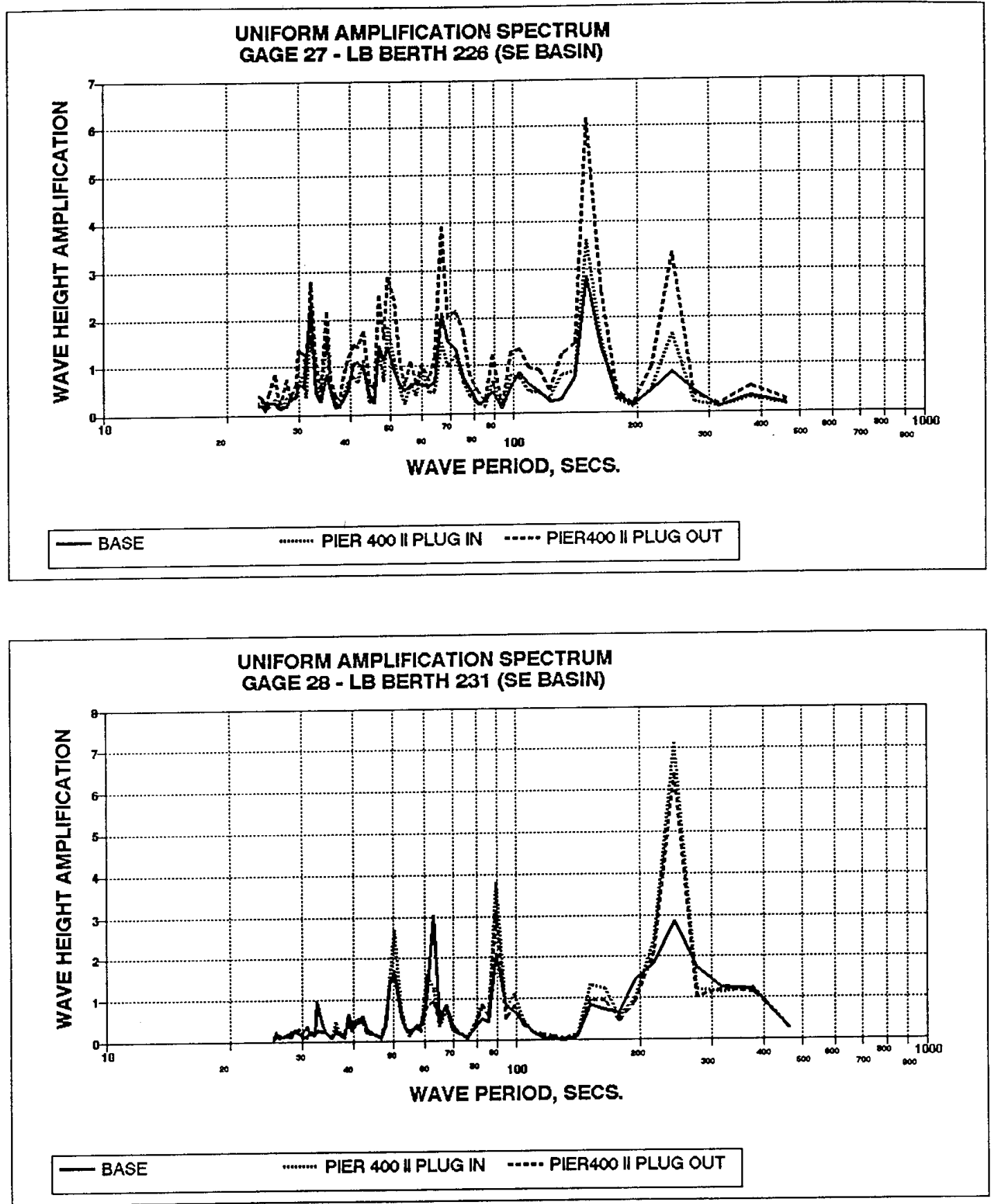


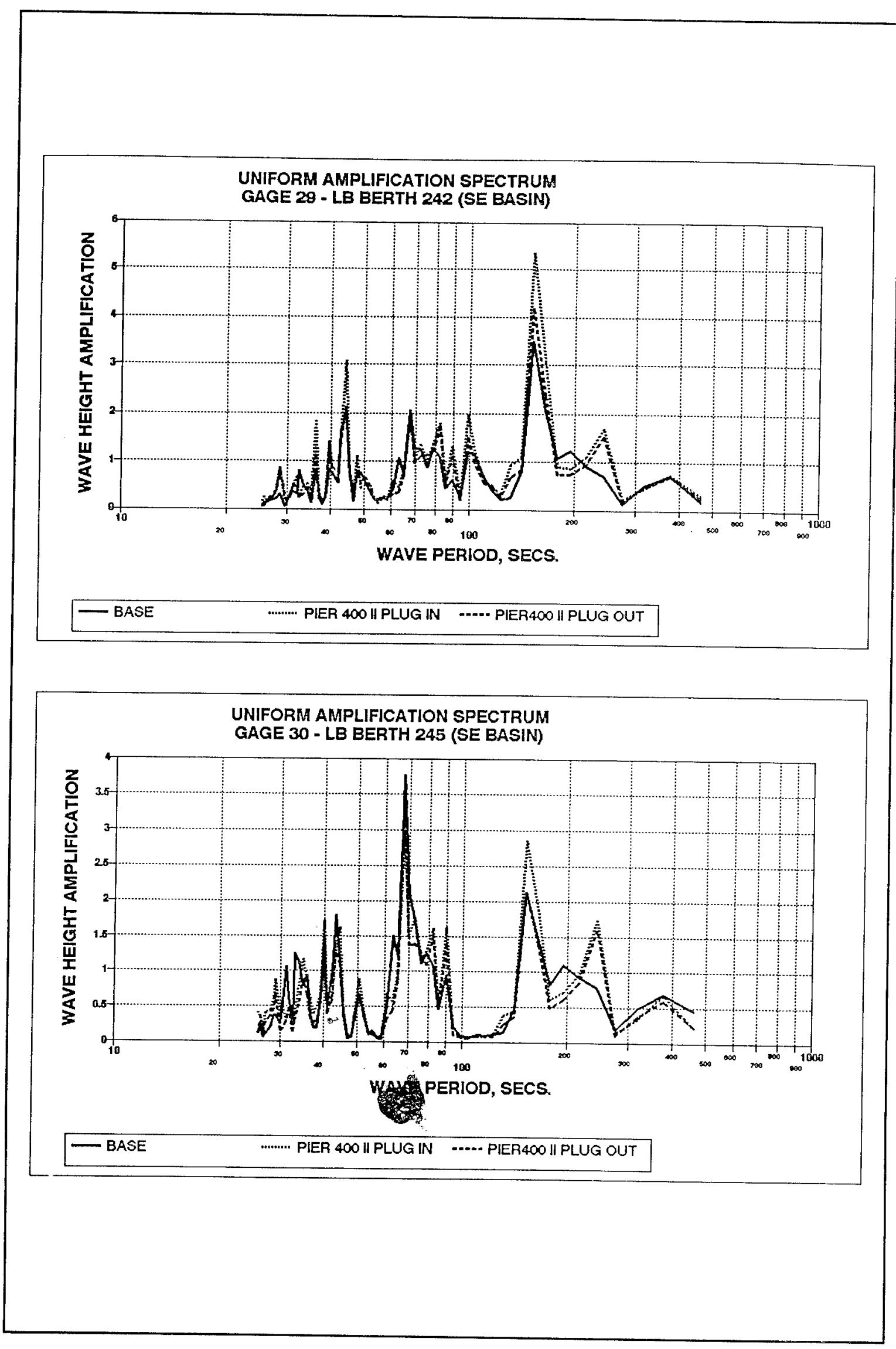




\section{Appendix D Wave Amplification, February Spectrum, Gages 1-55}



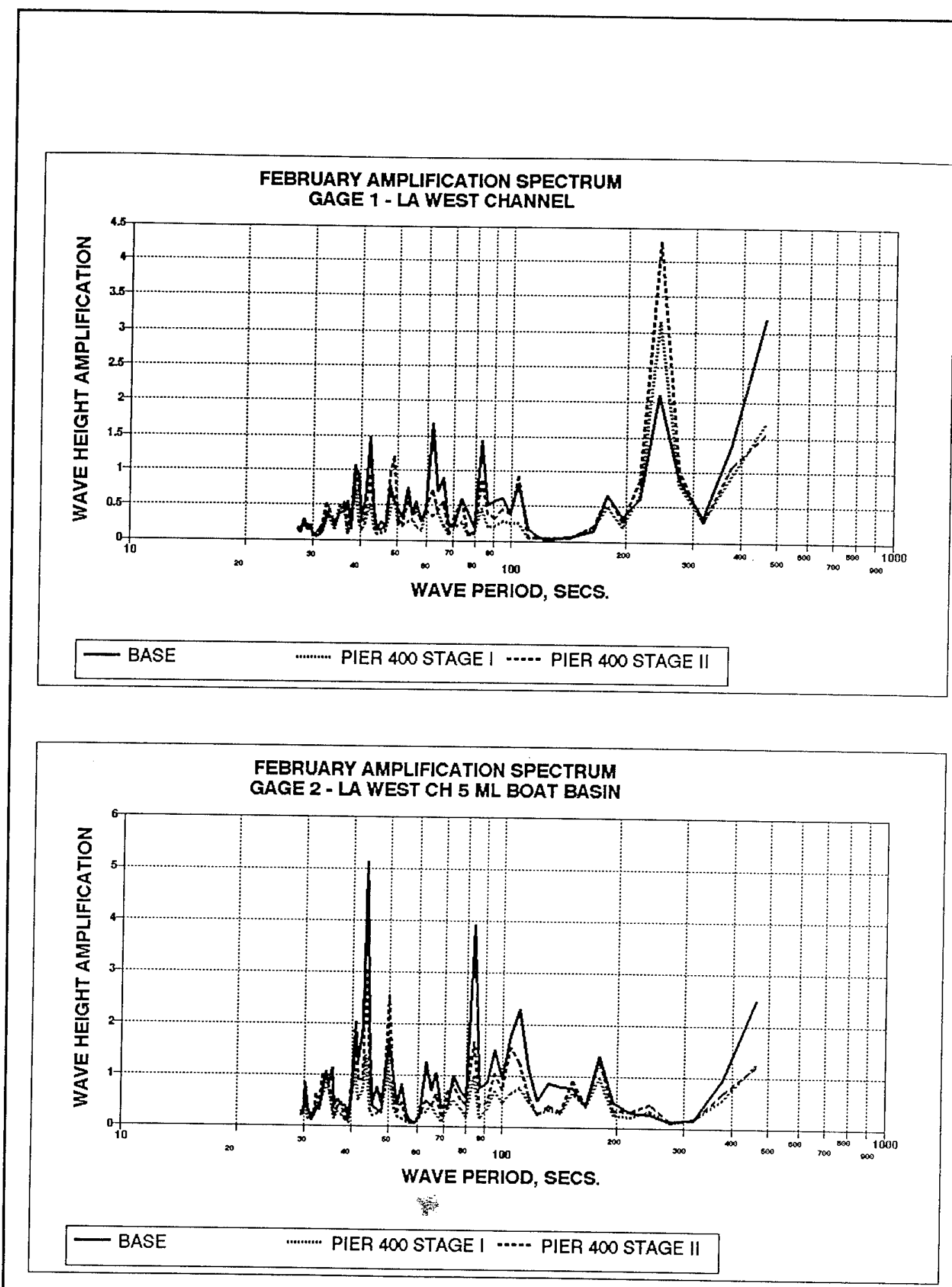

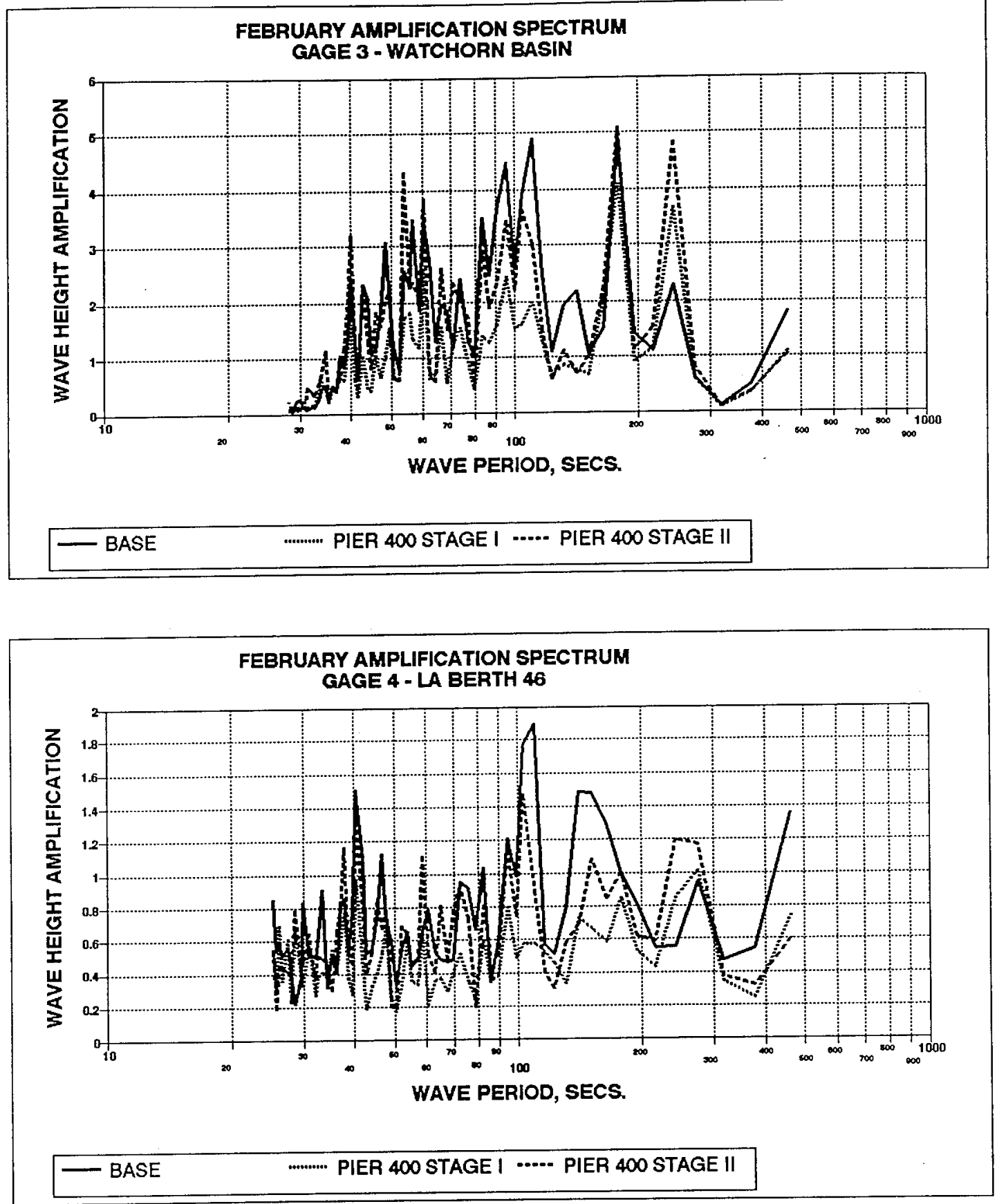

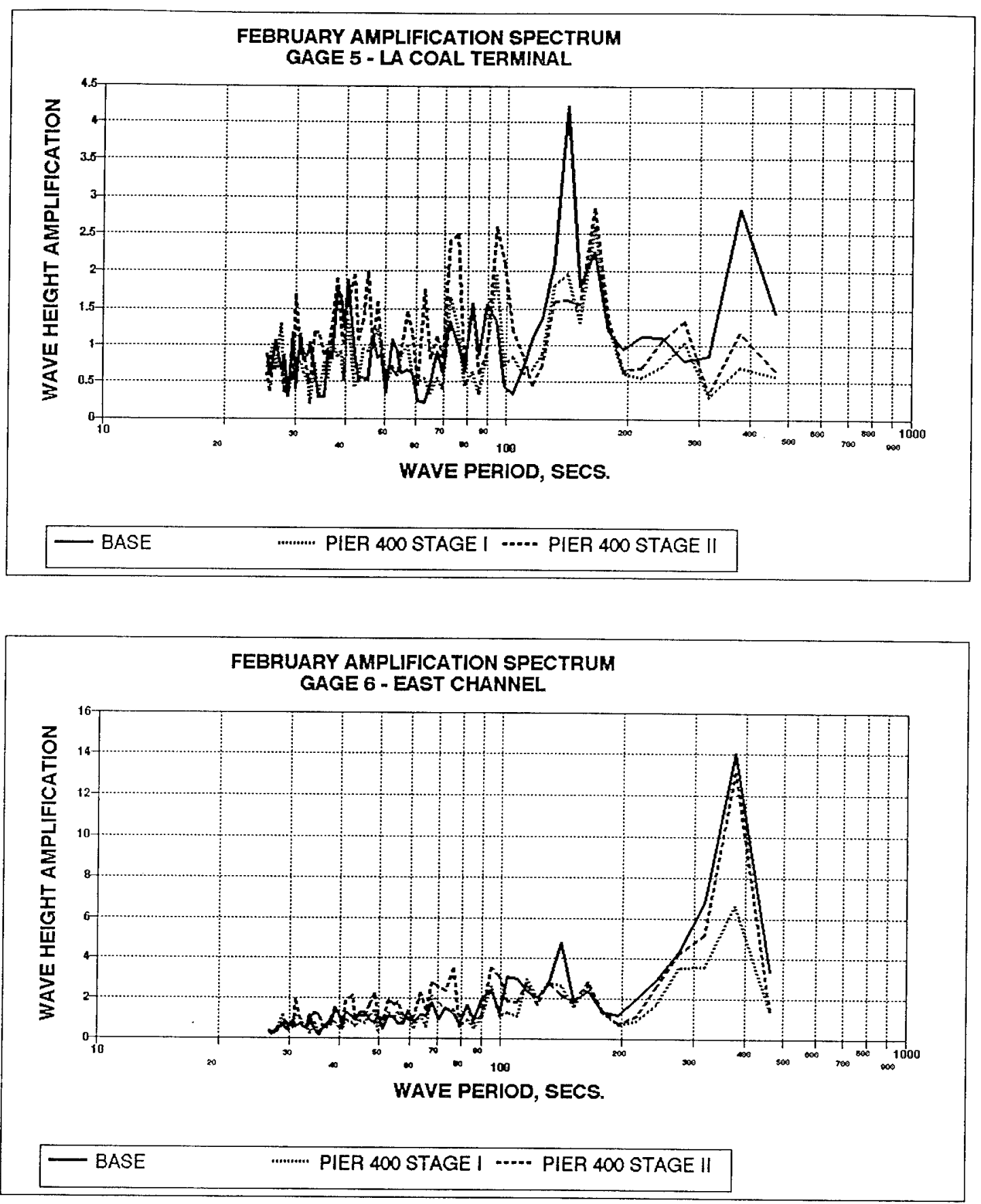

D4 


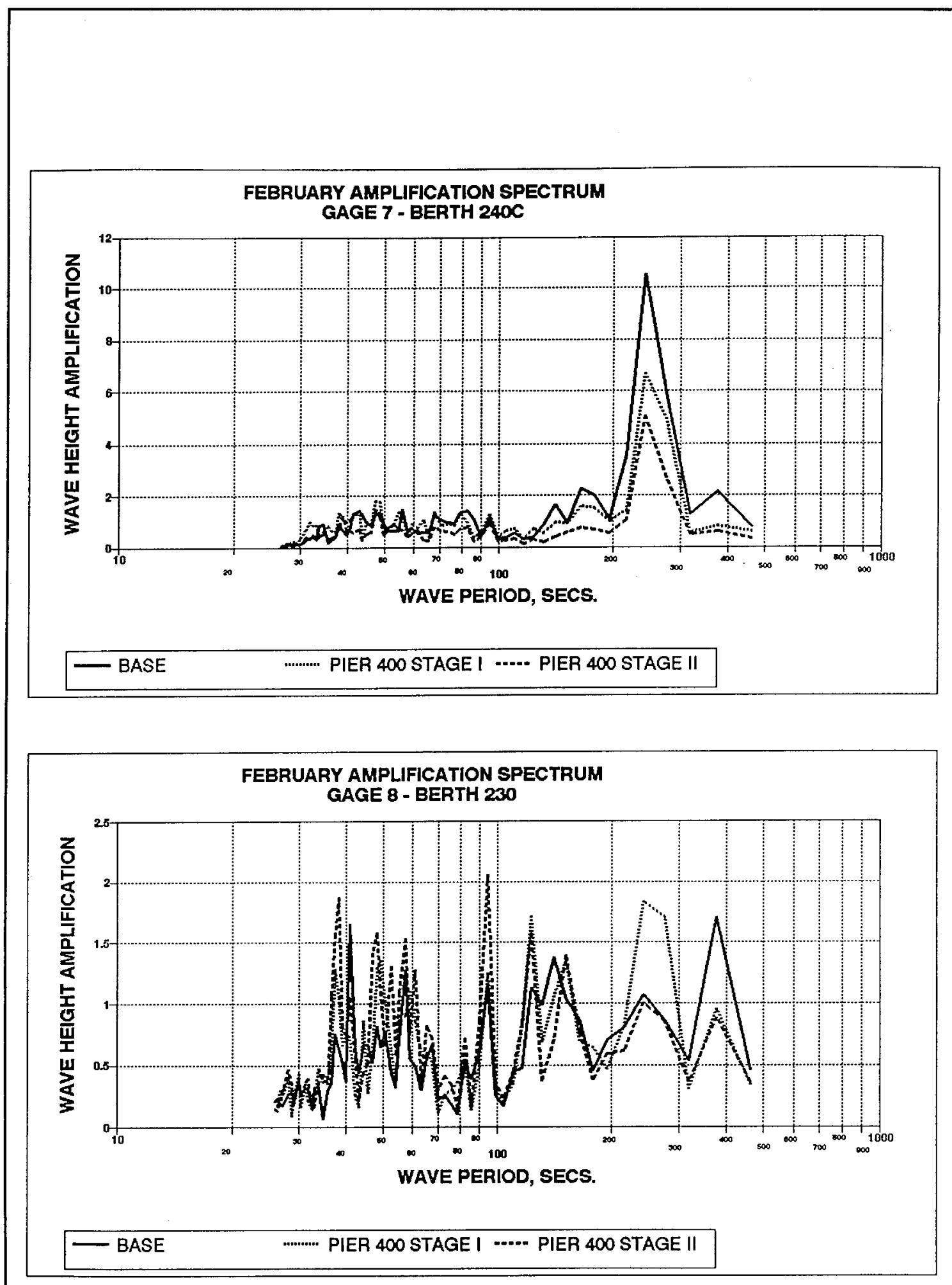



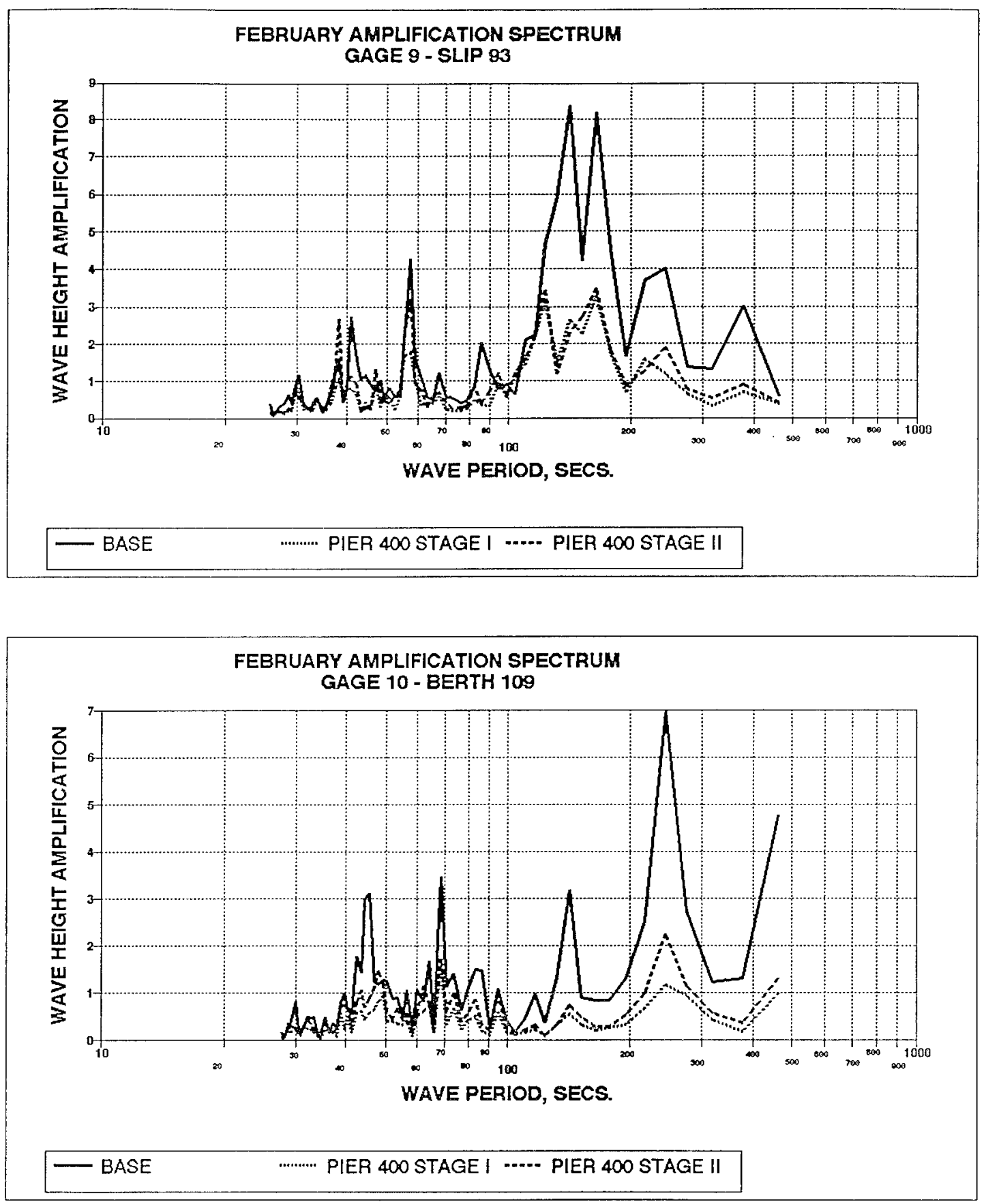

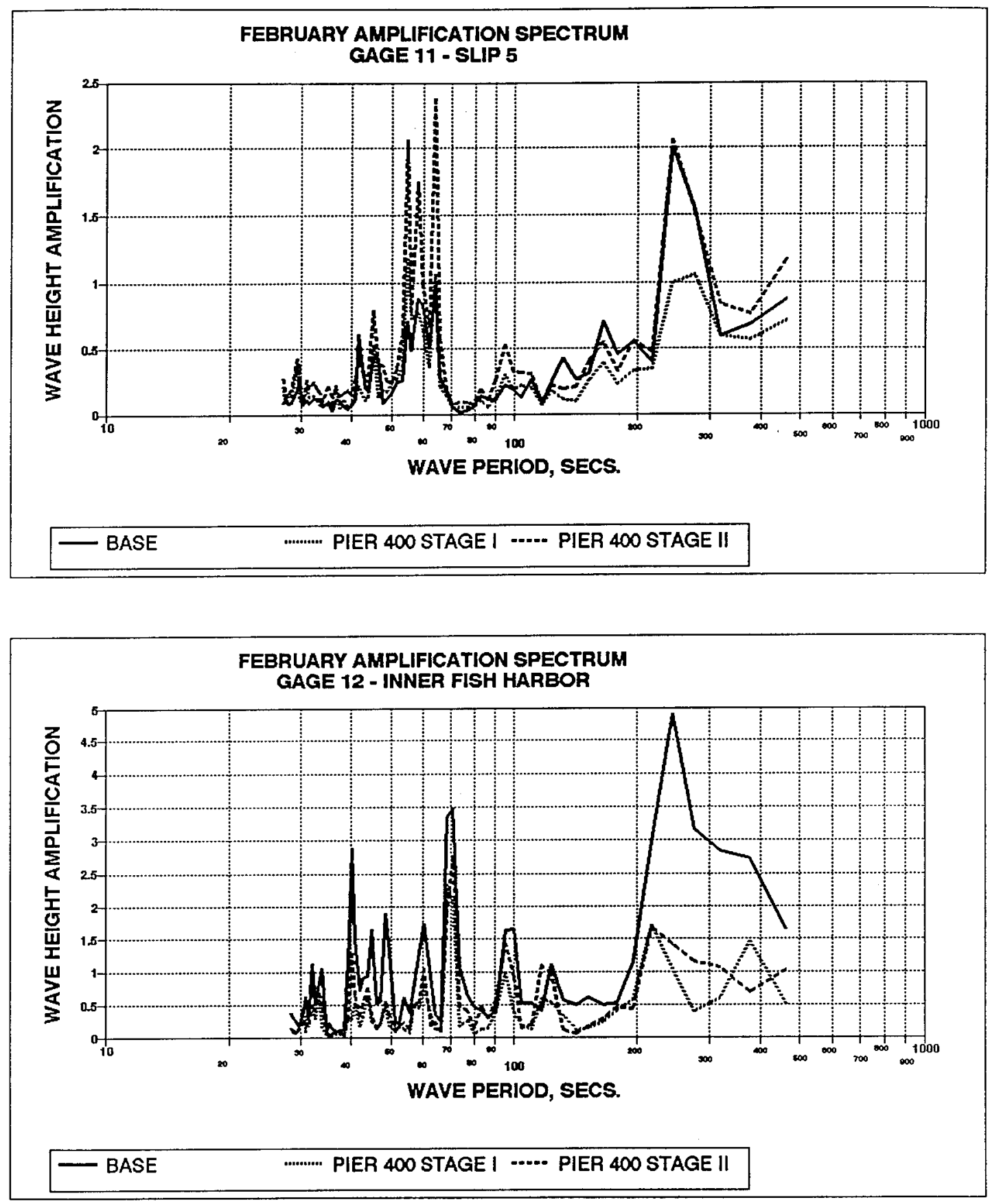

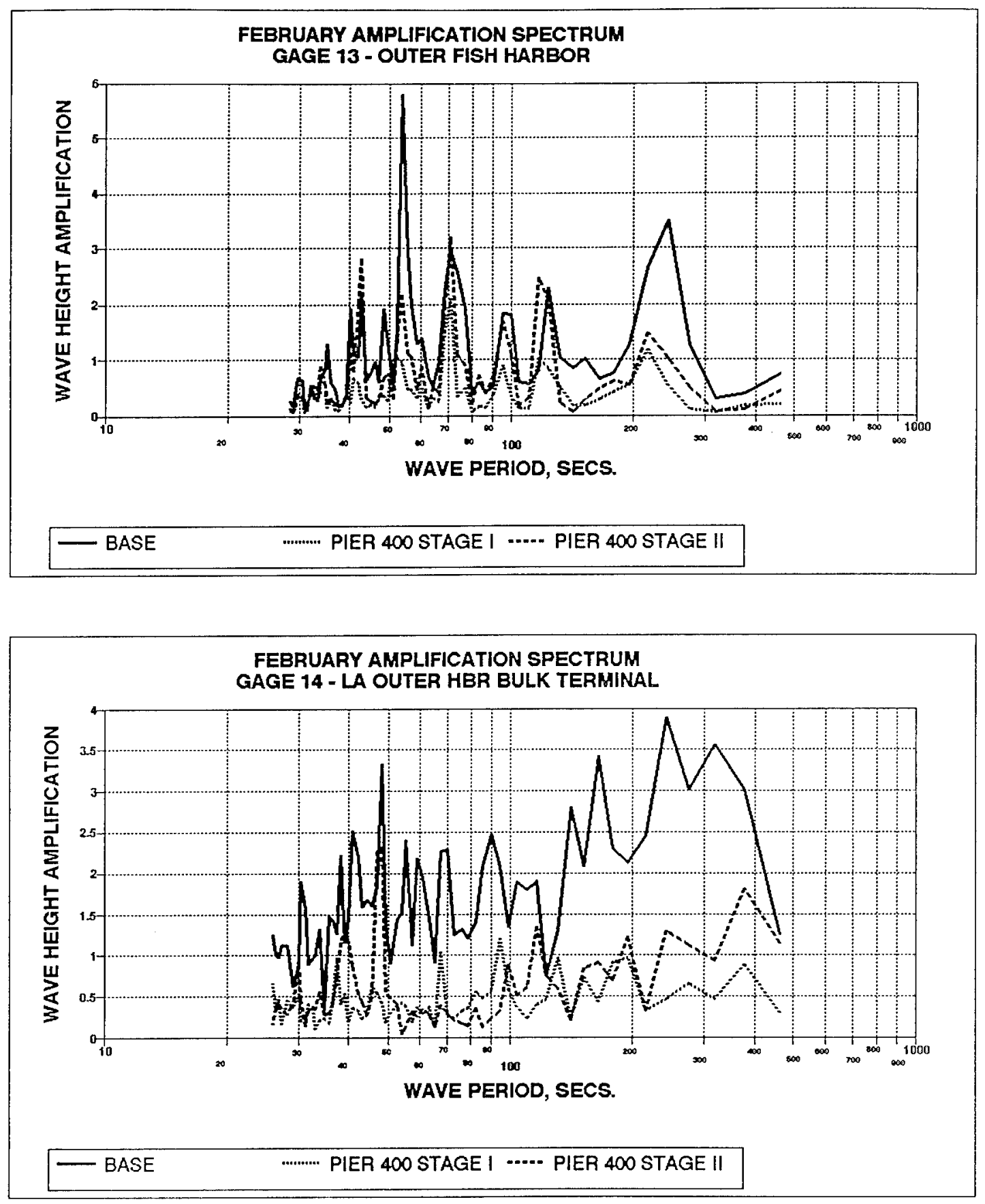

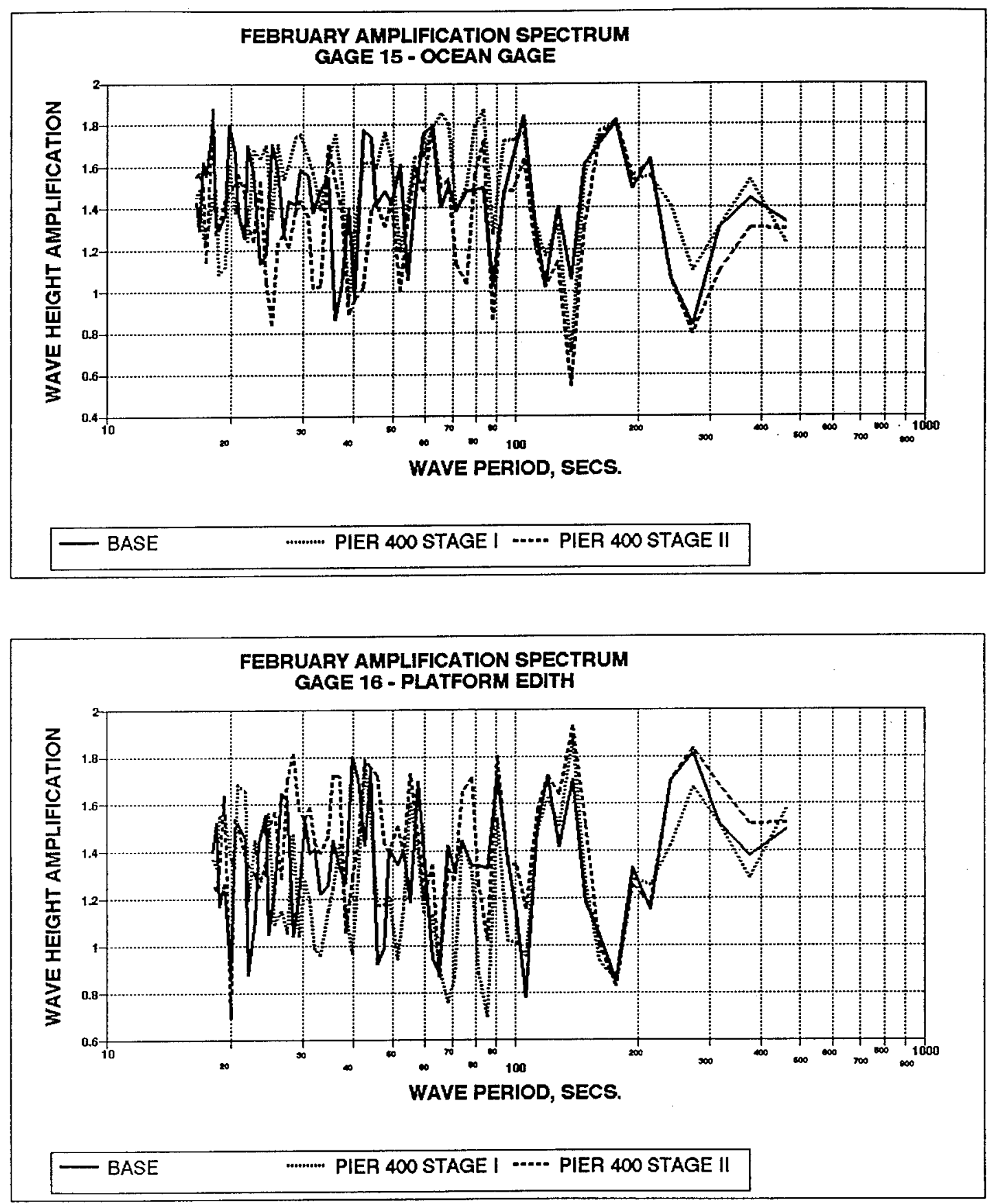

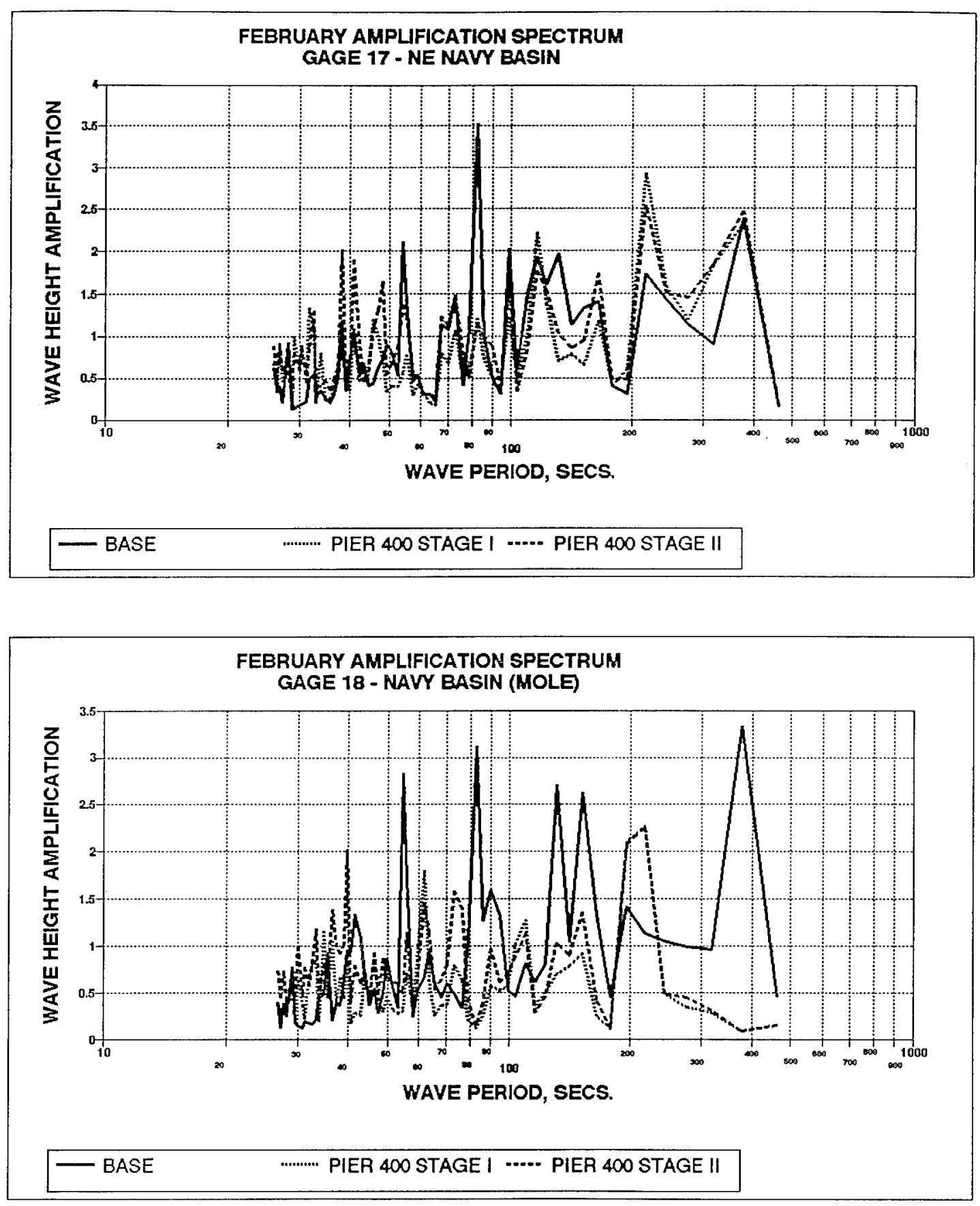

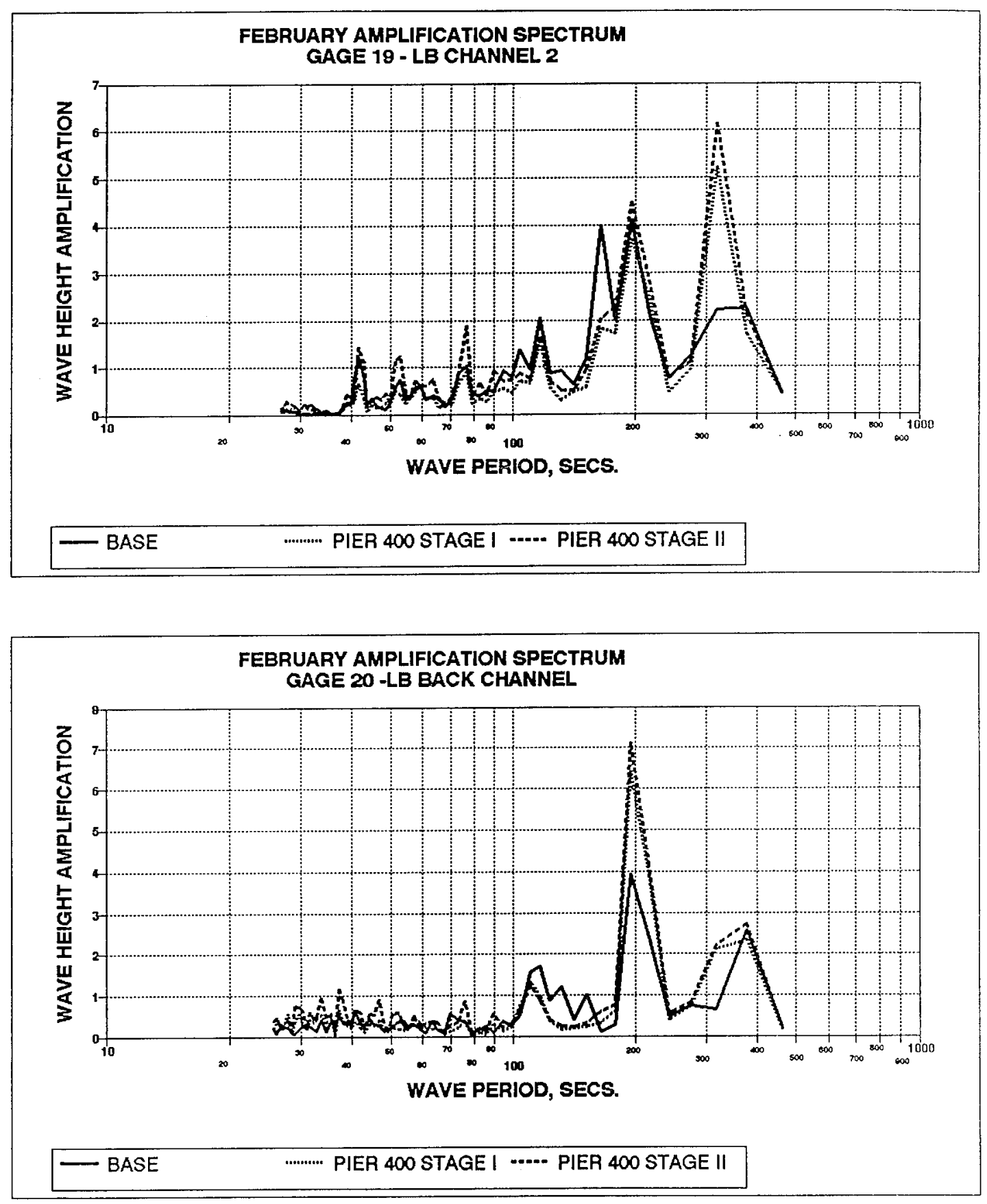

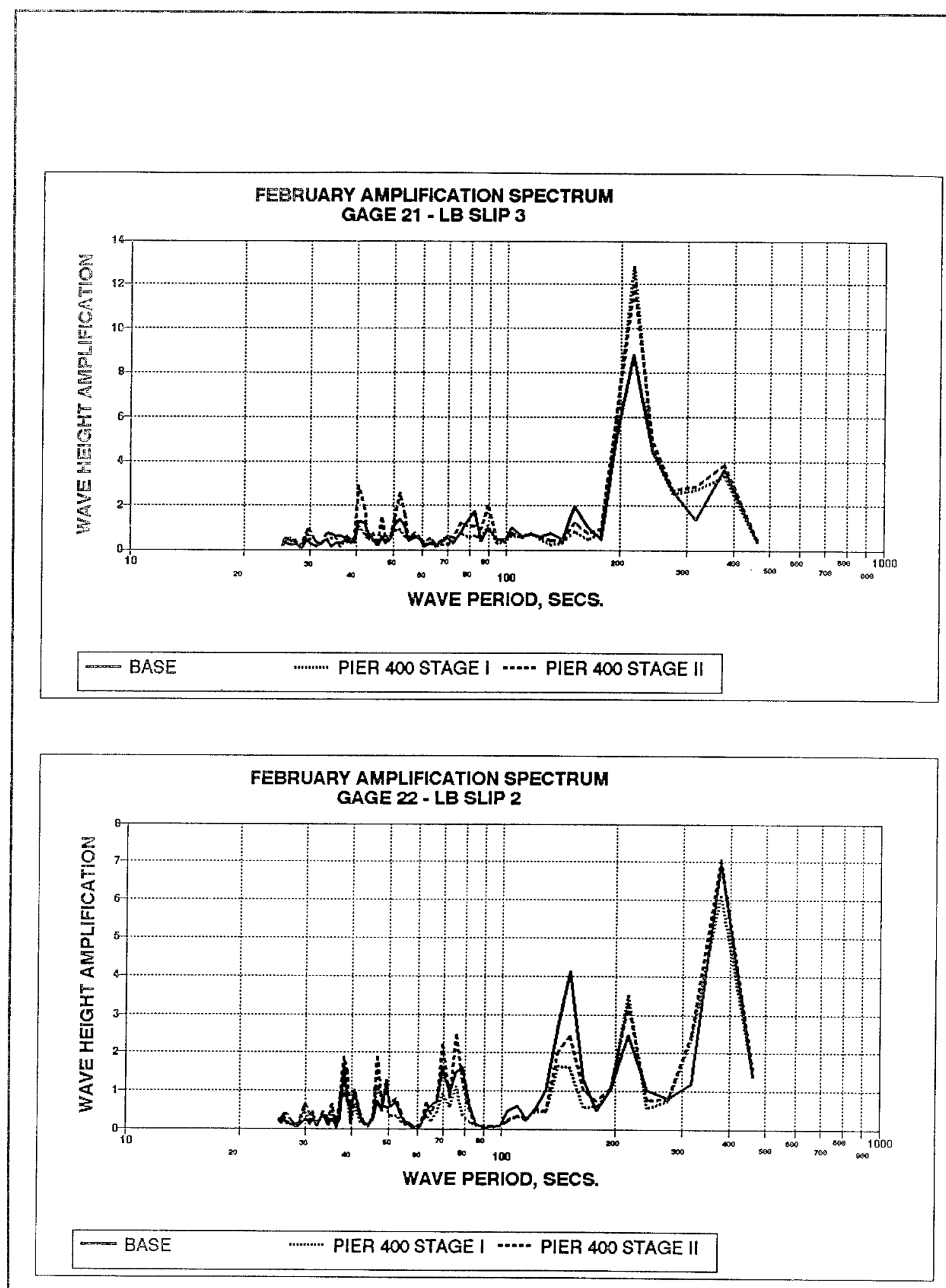

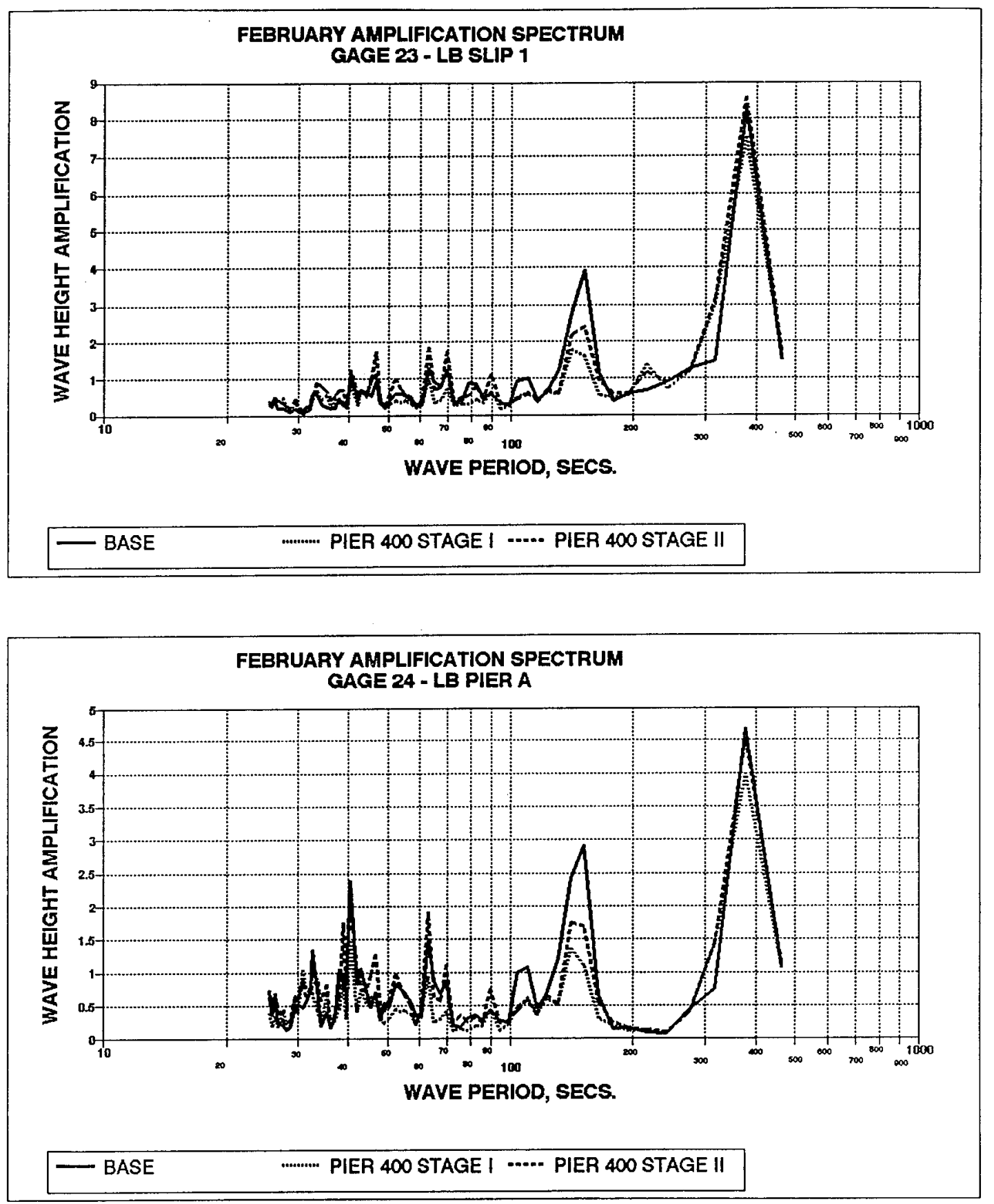

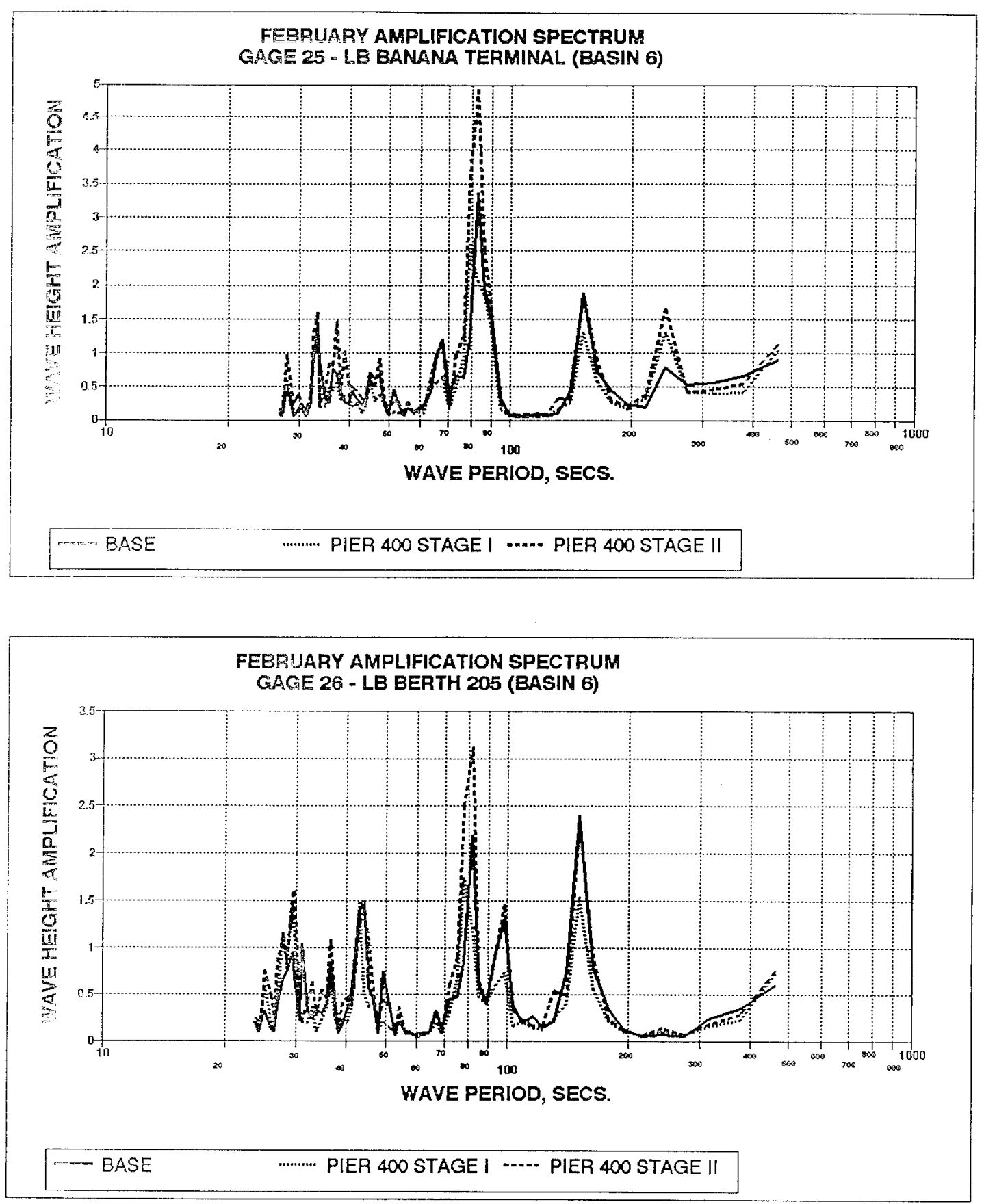

D14 

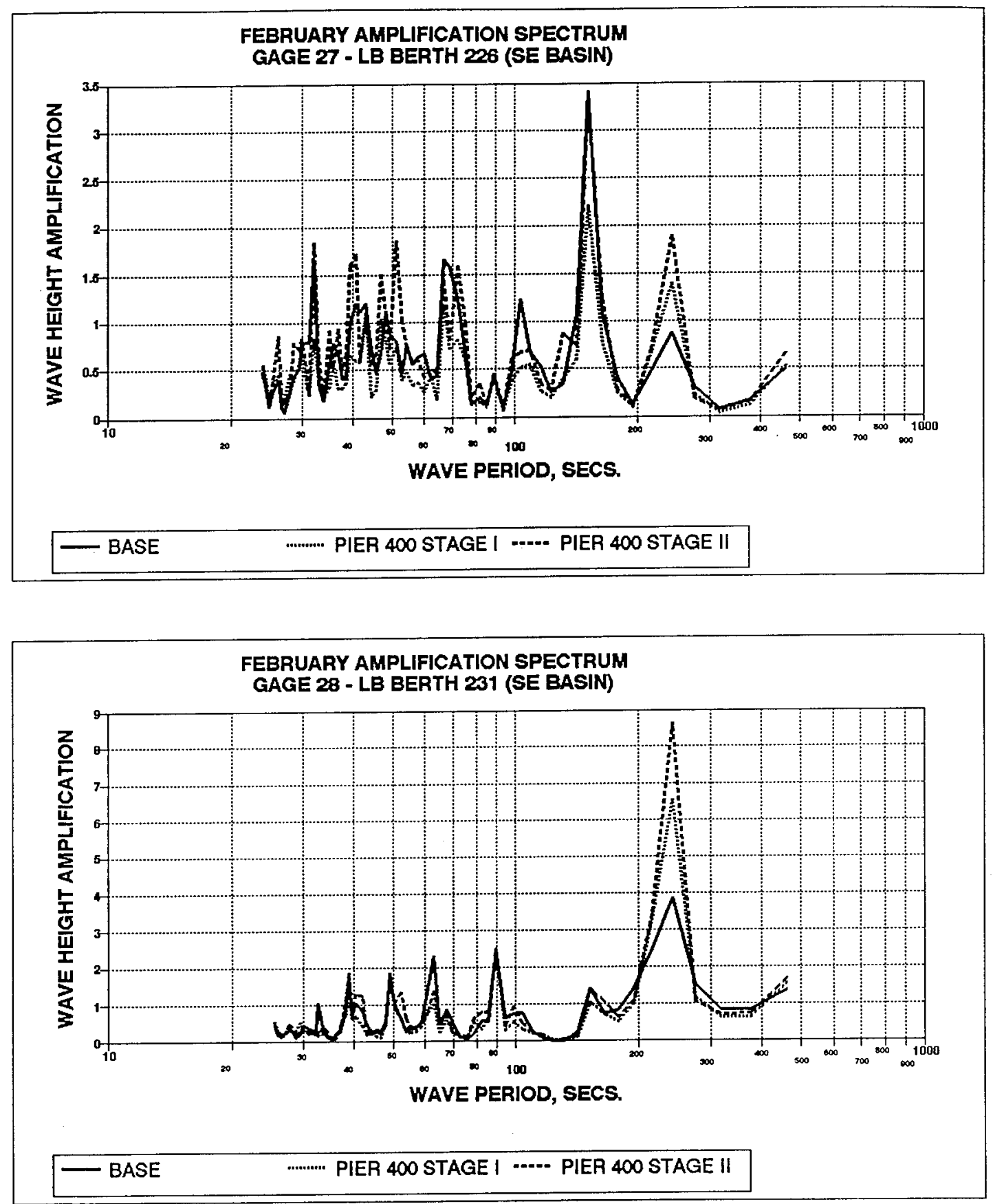

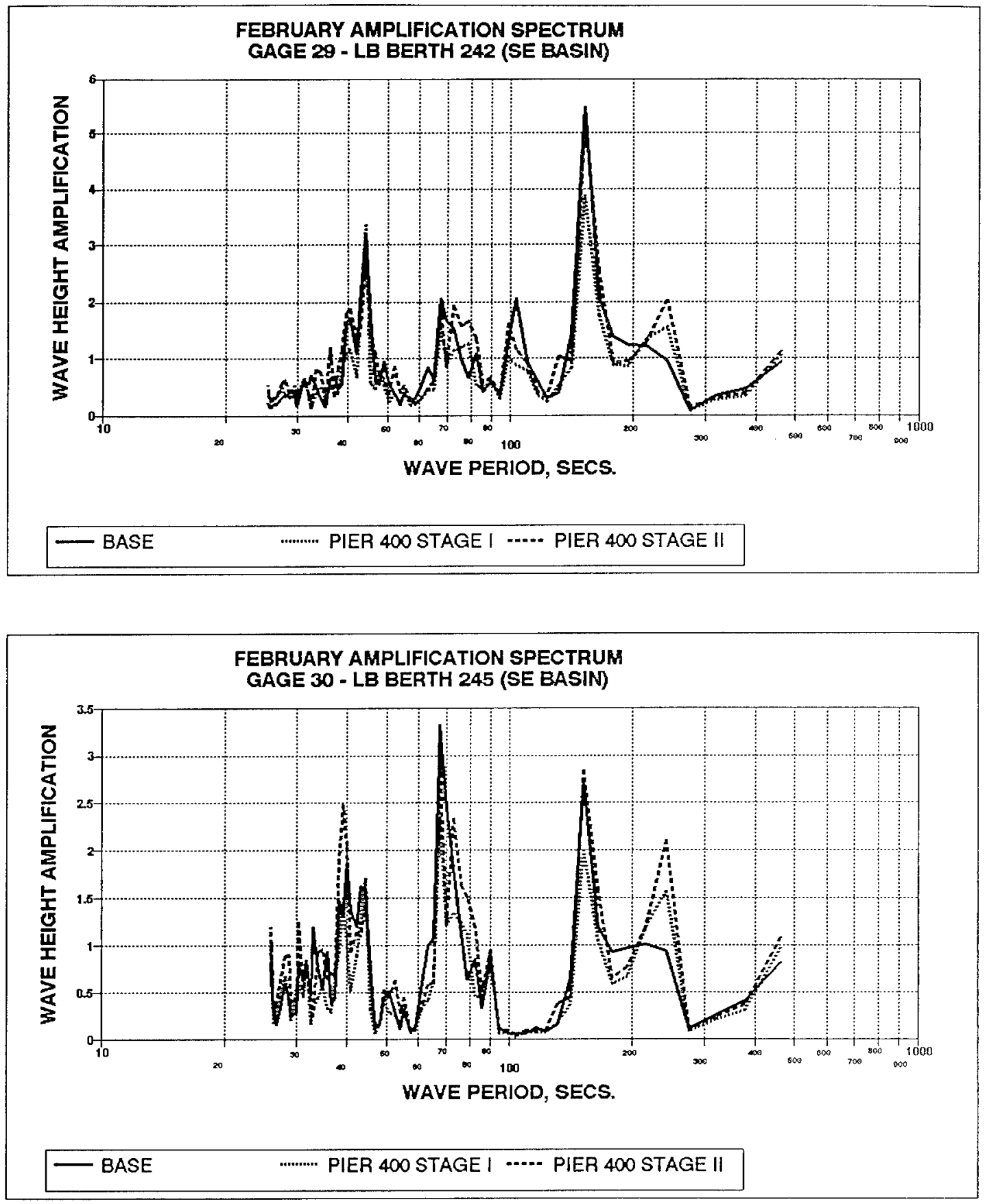

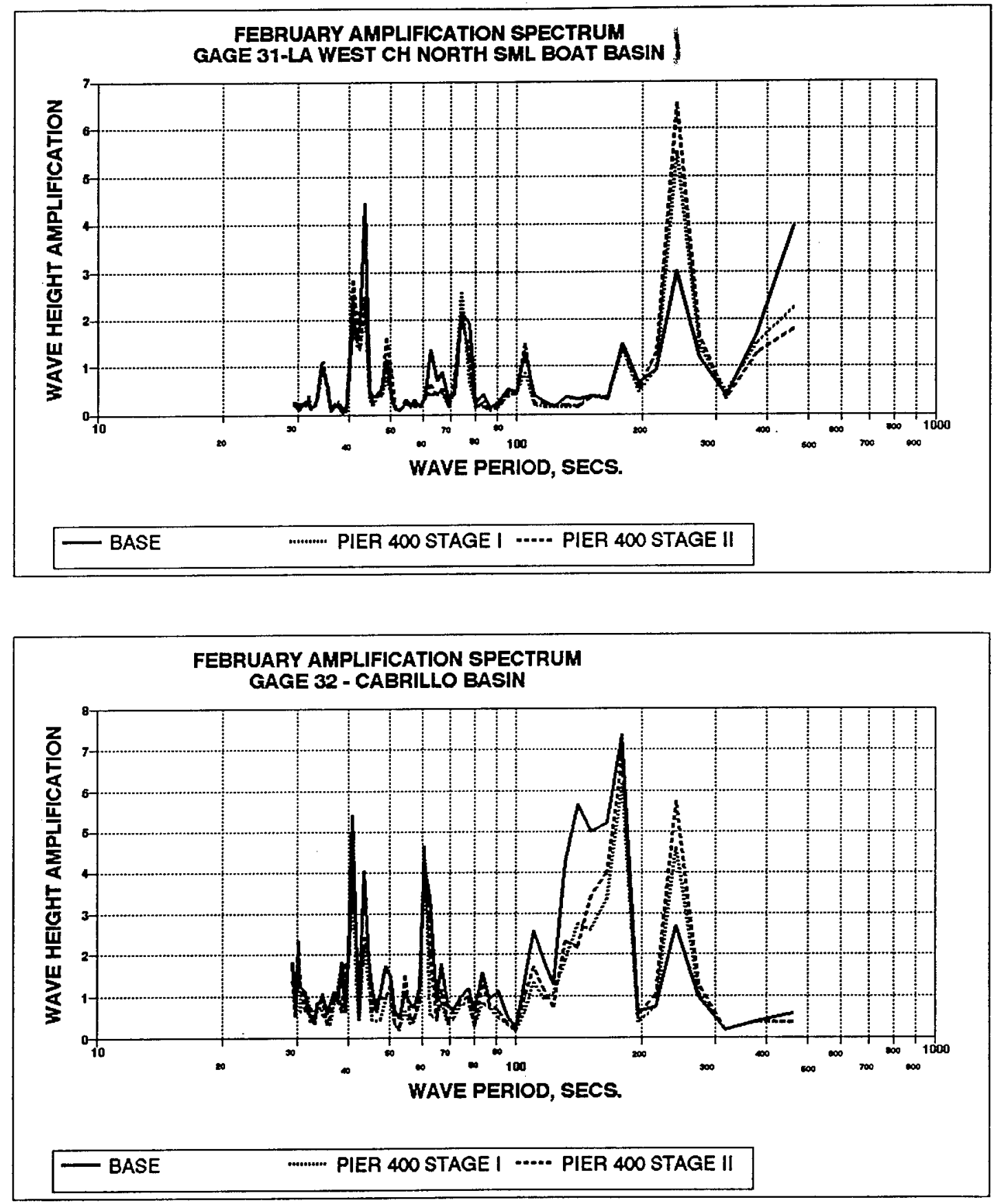

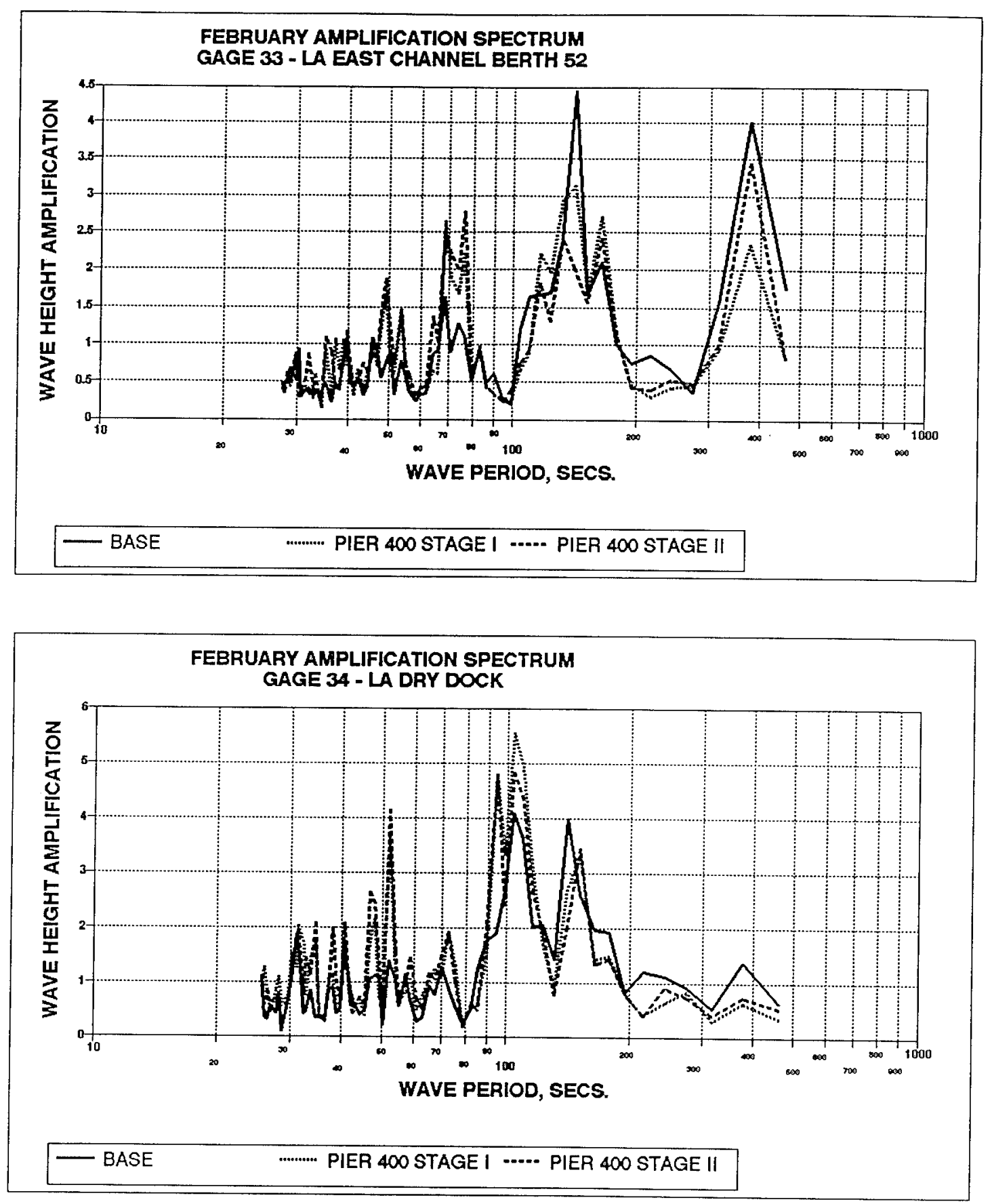

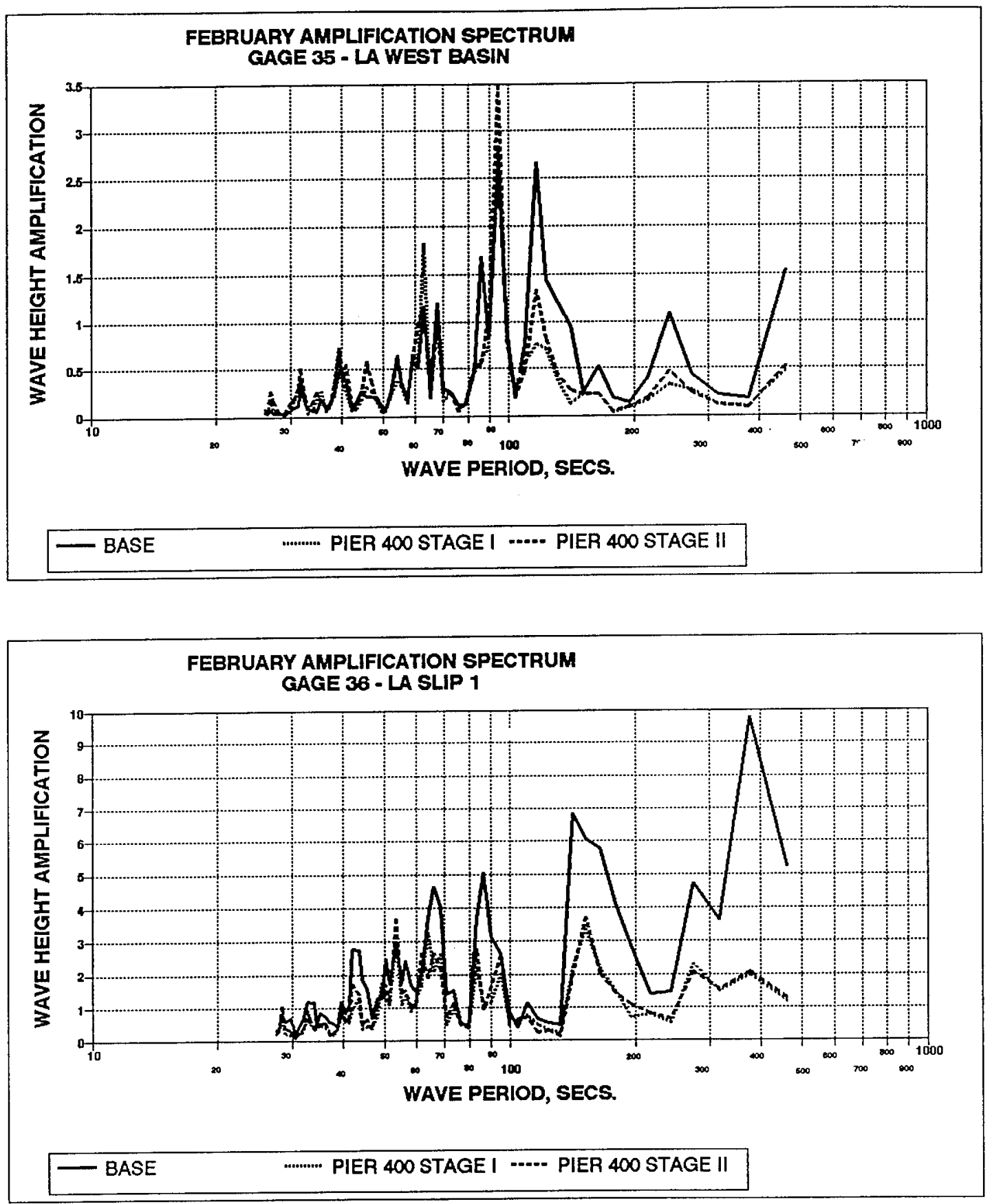

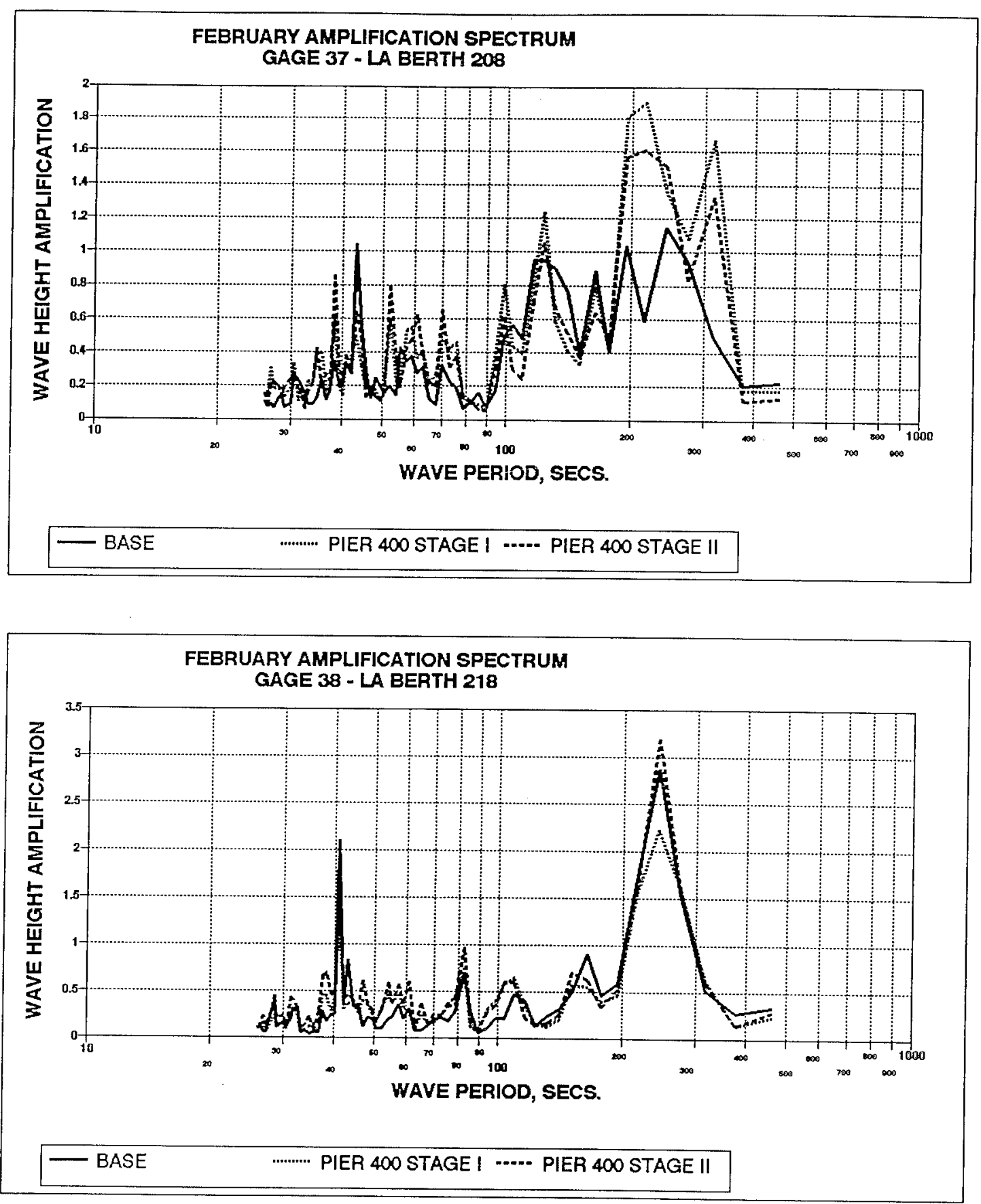

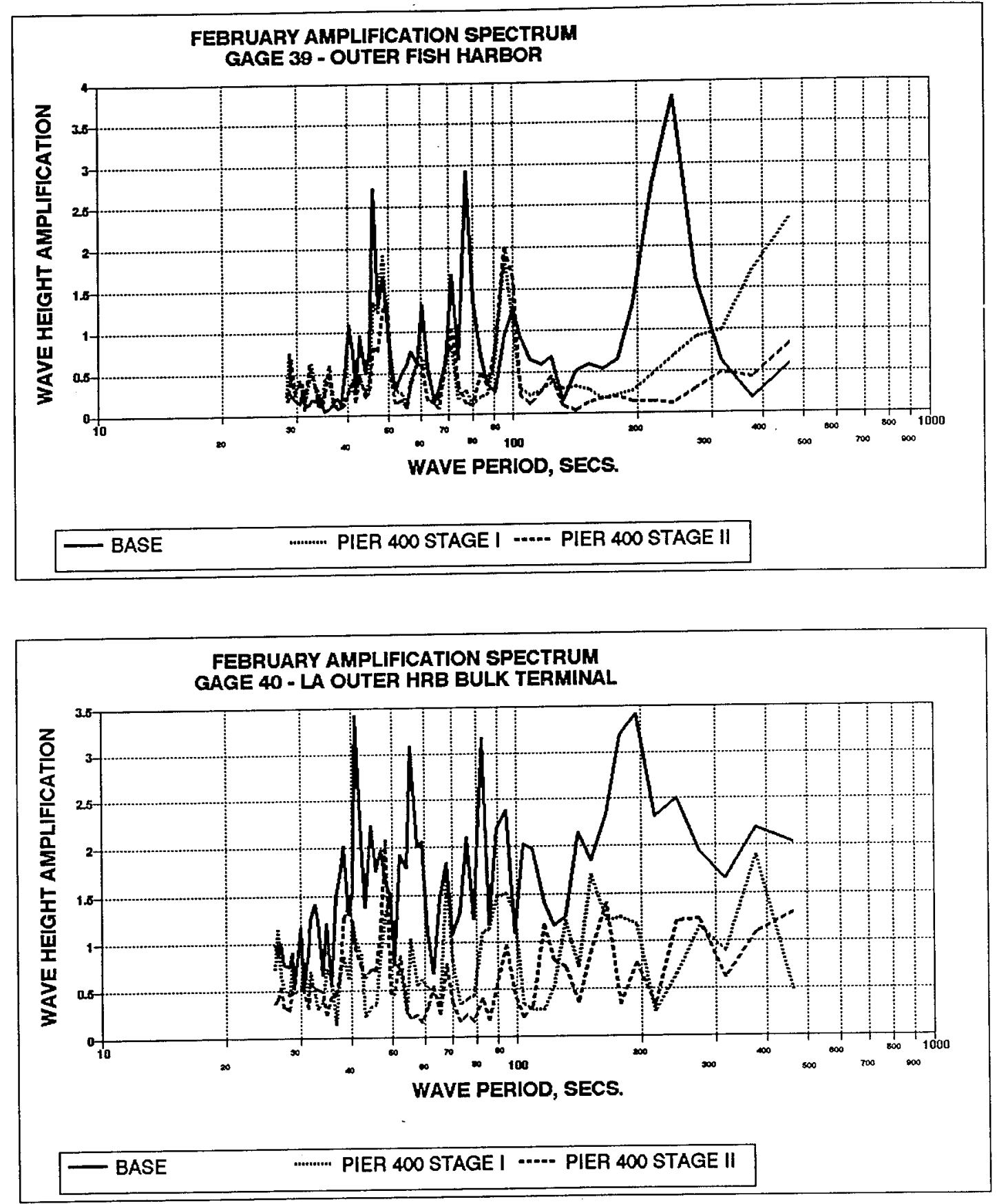

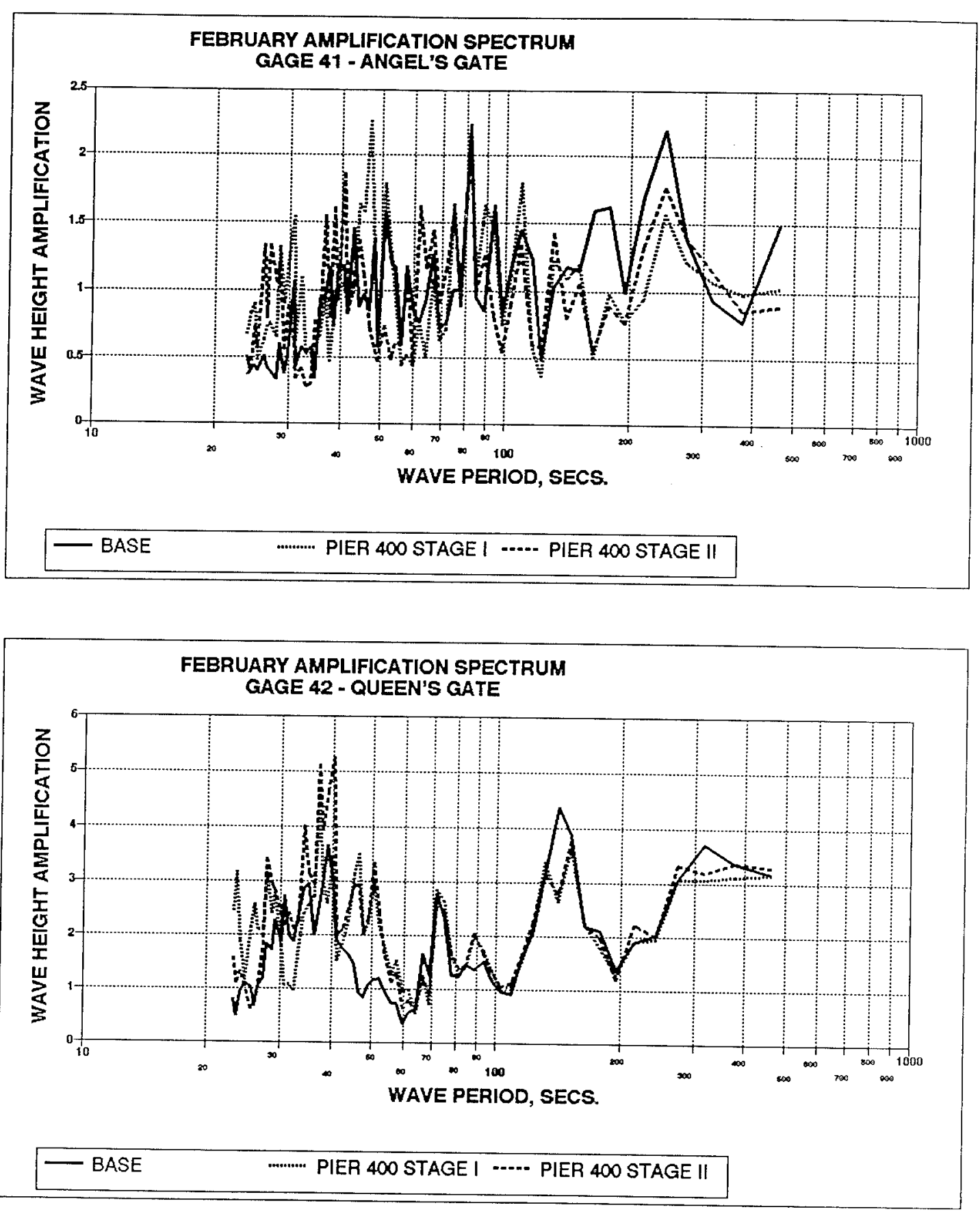

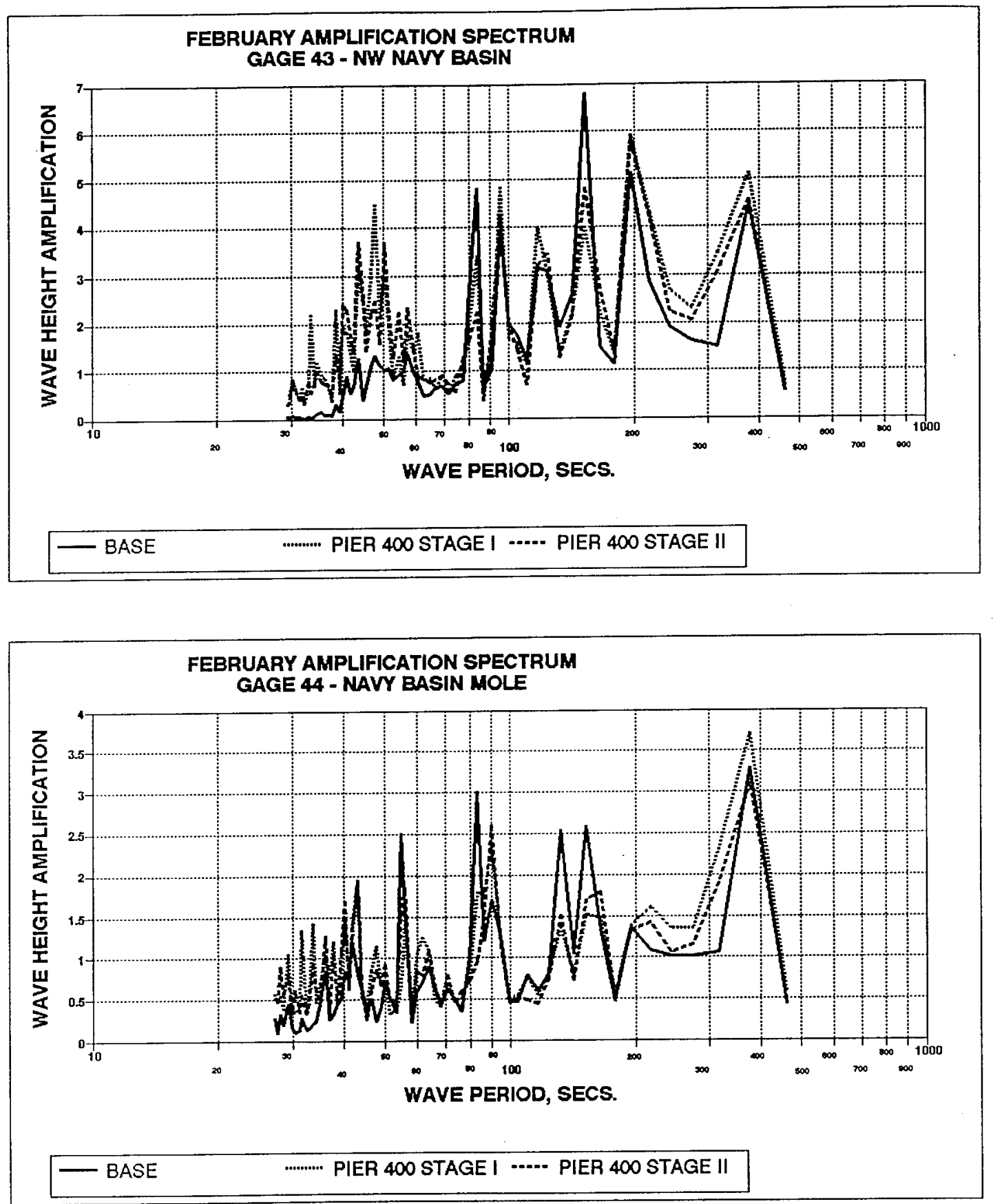

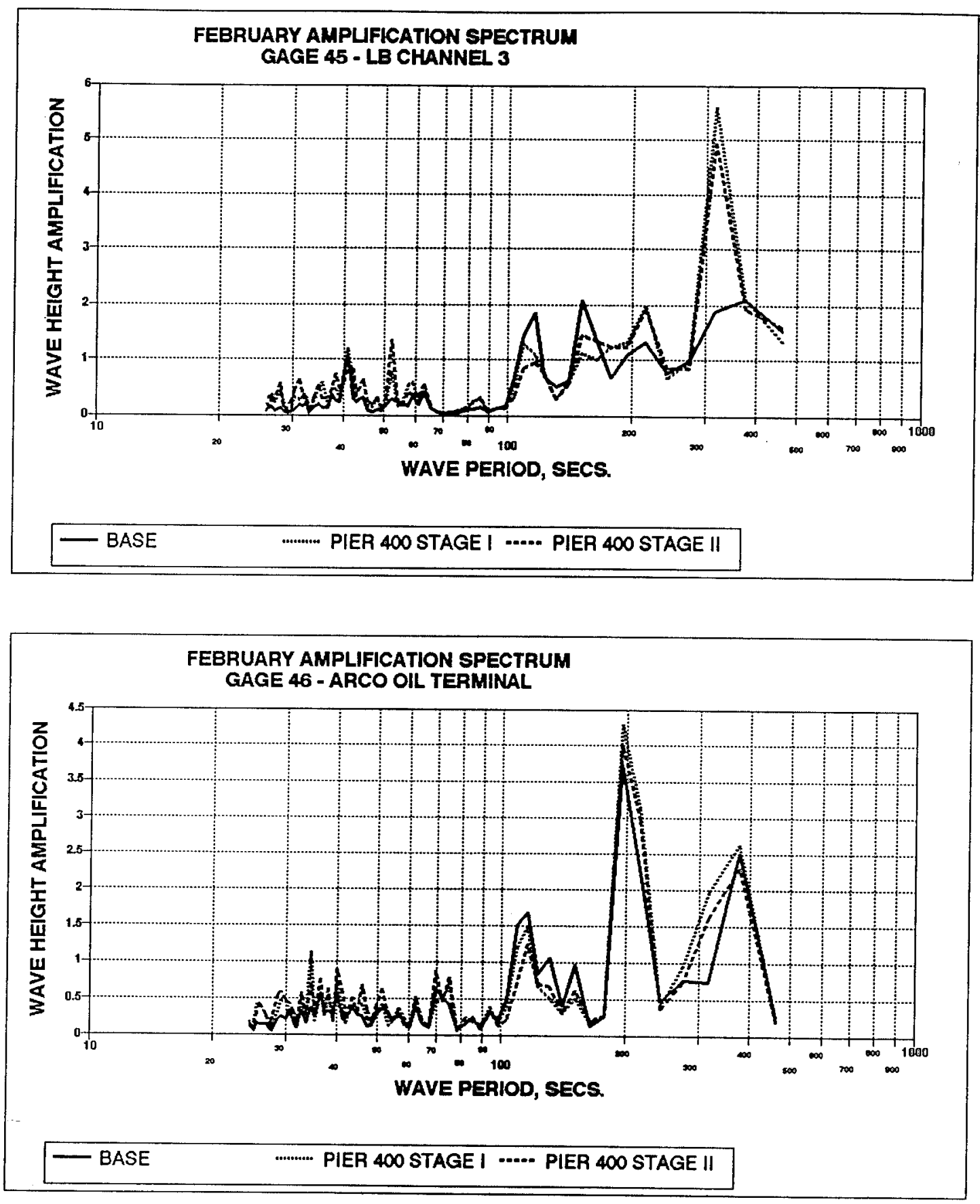


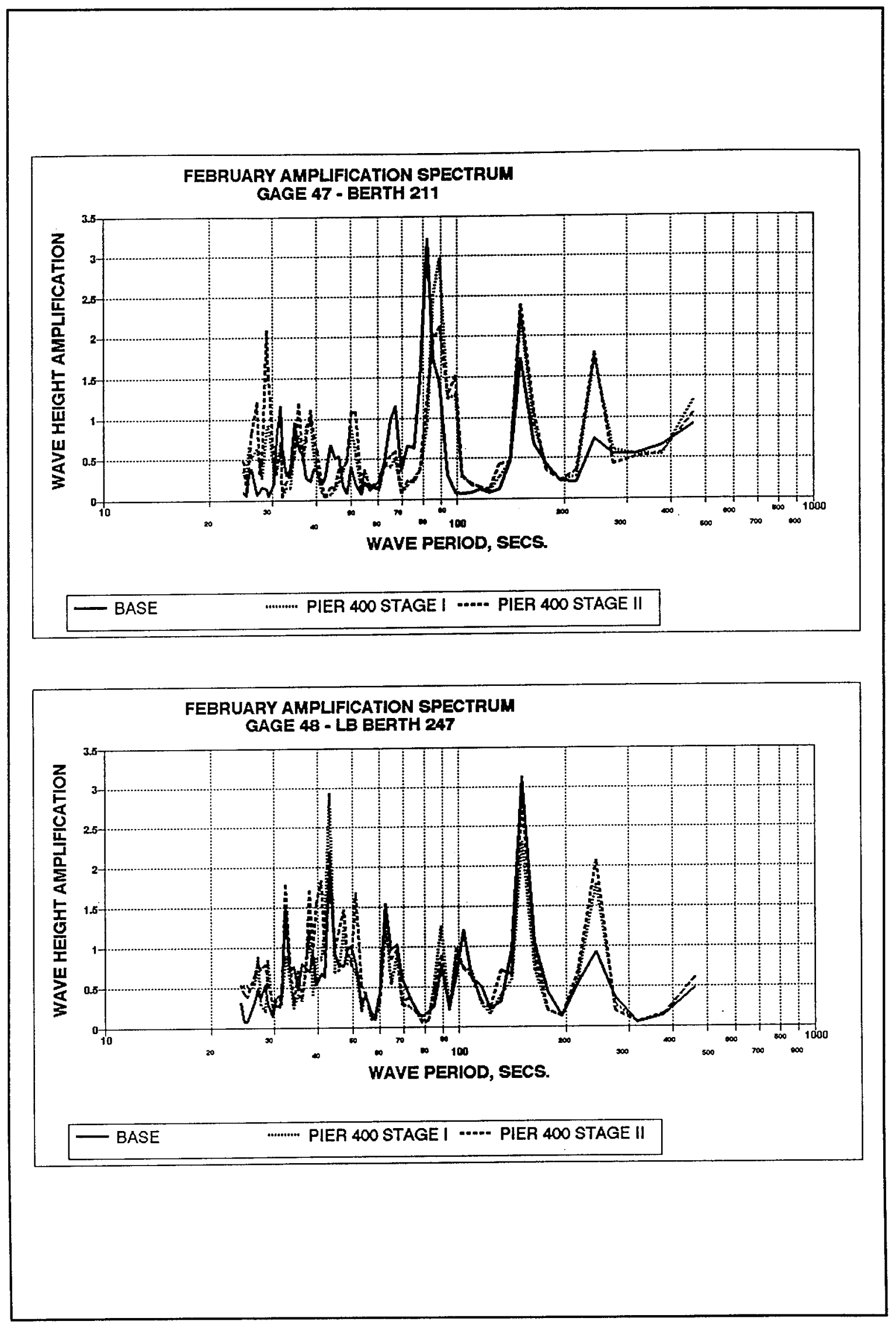



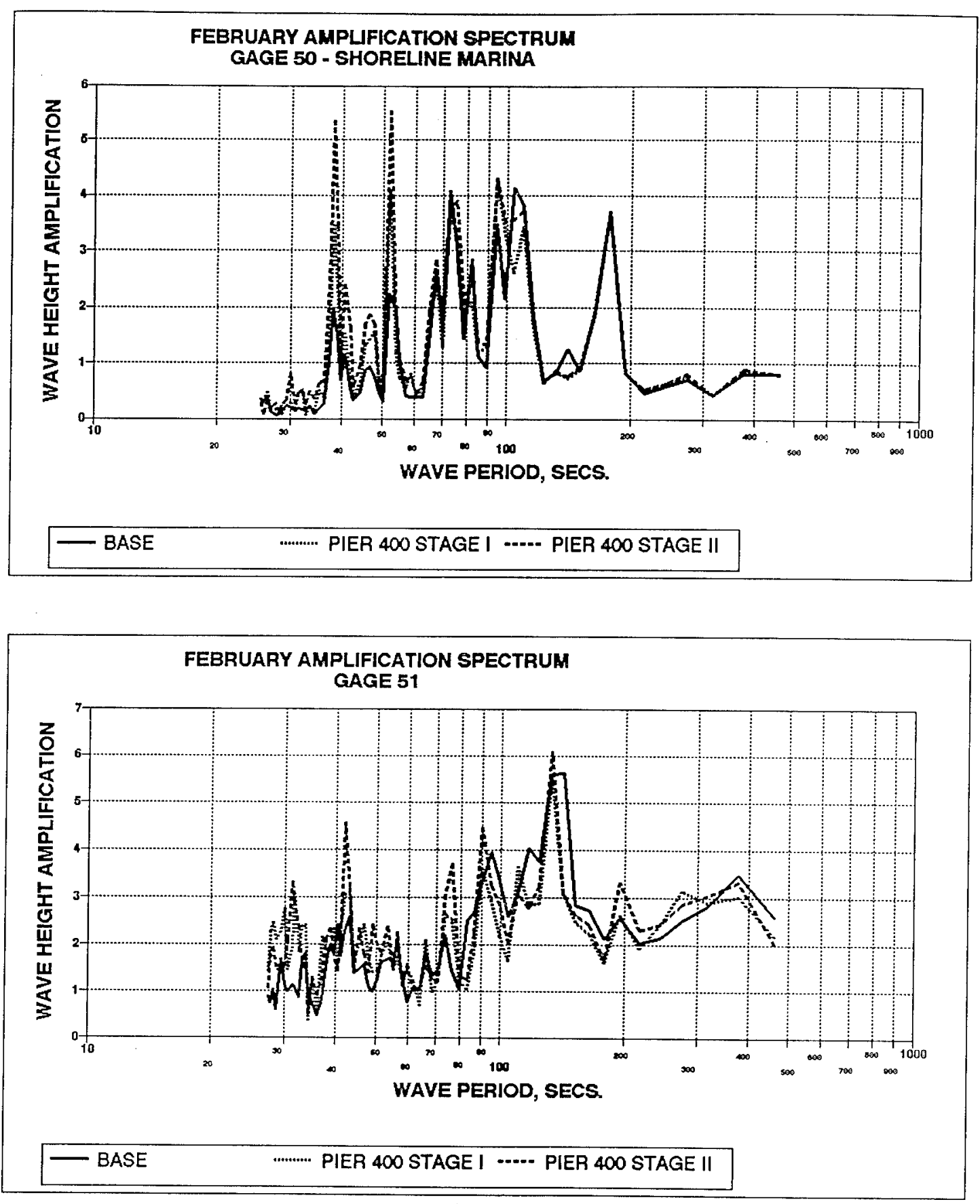

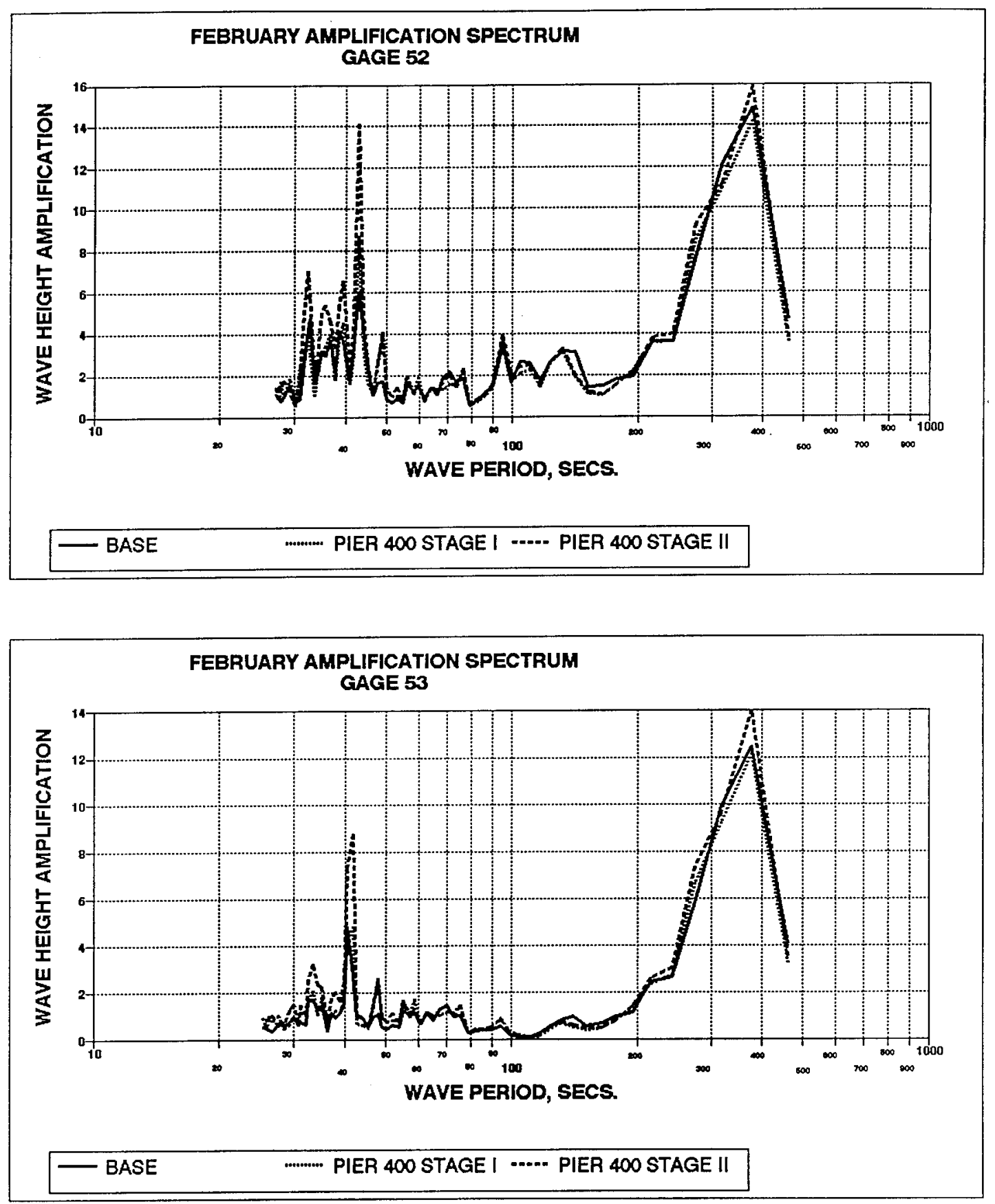

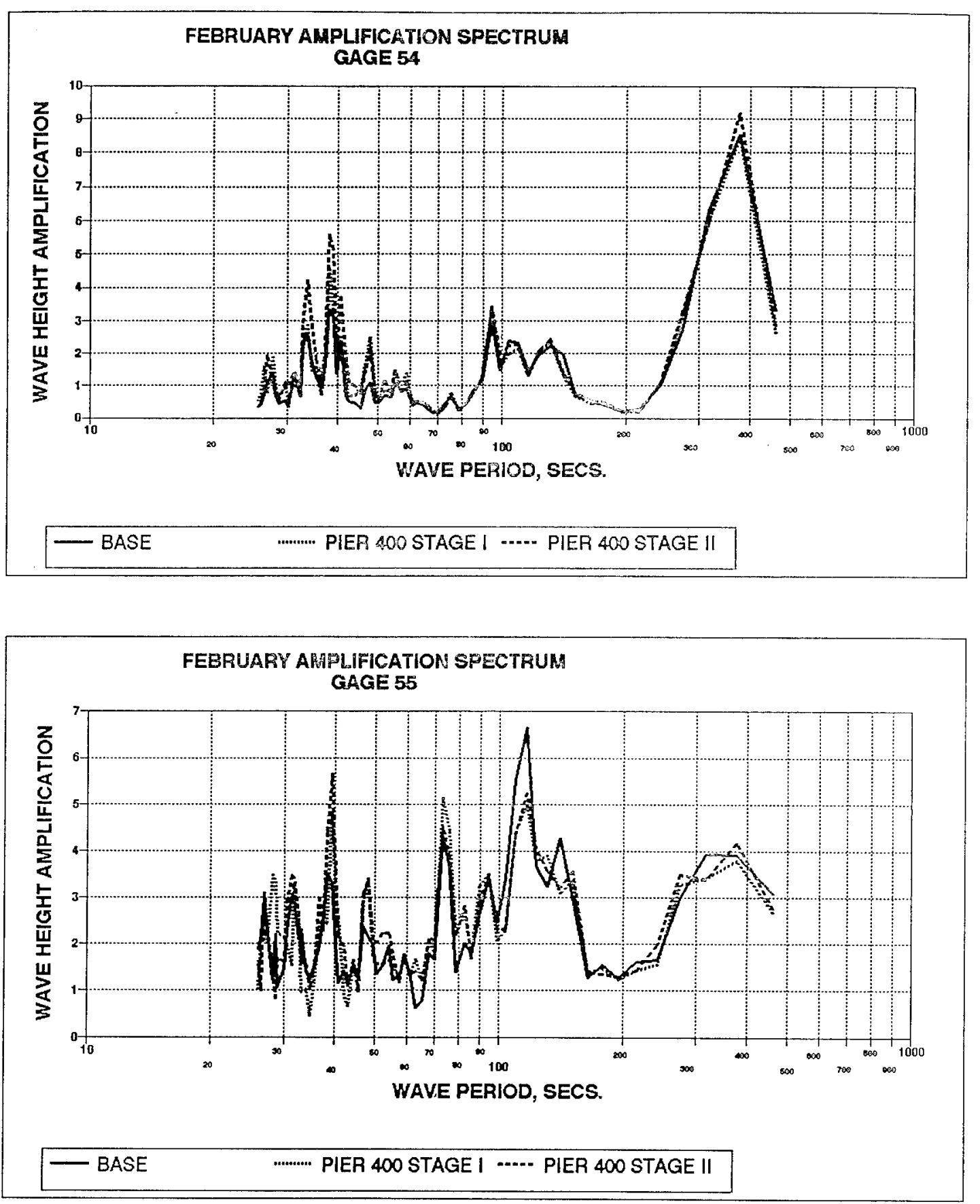


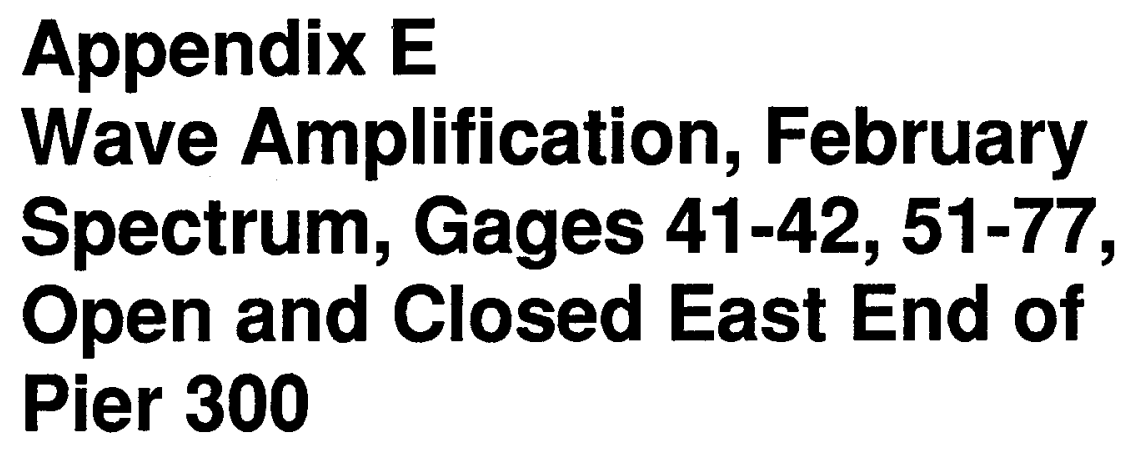



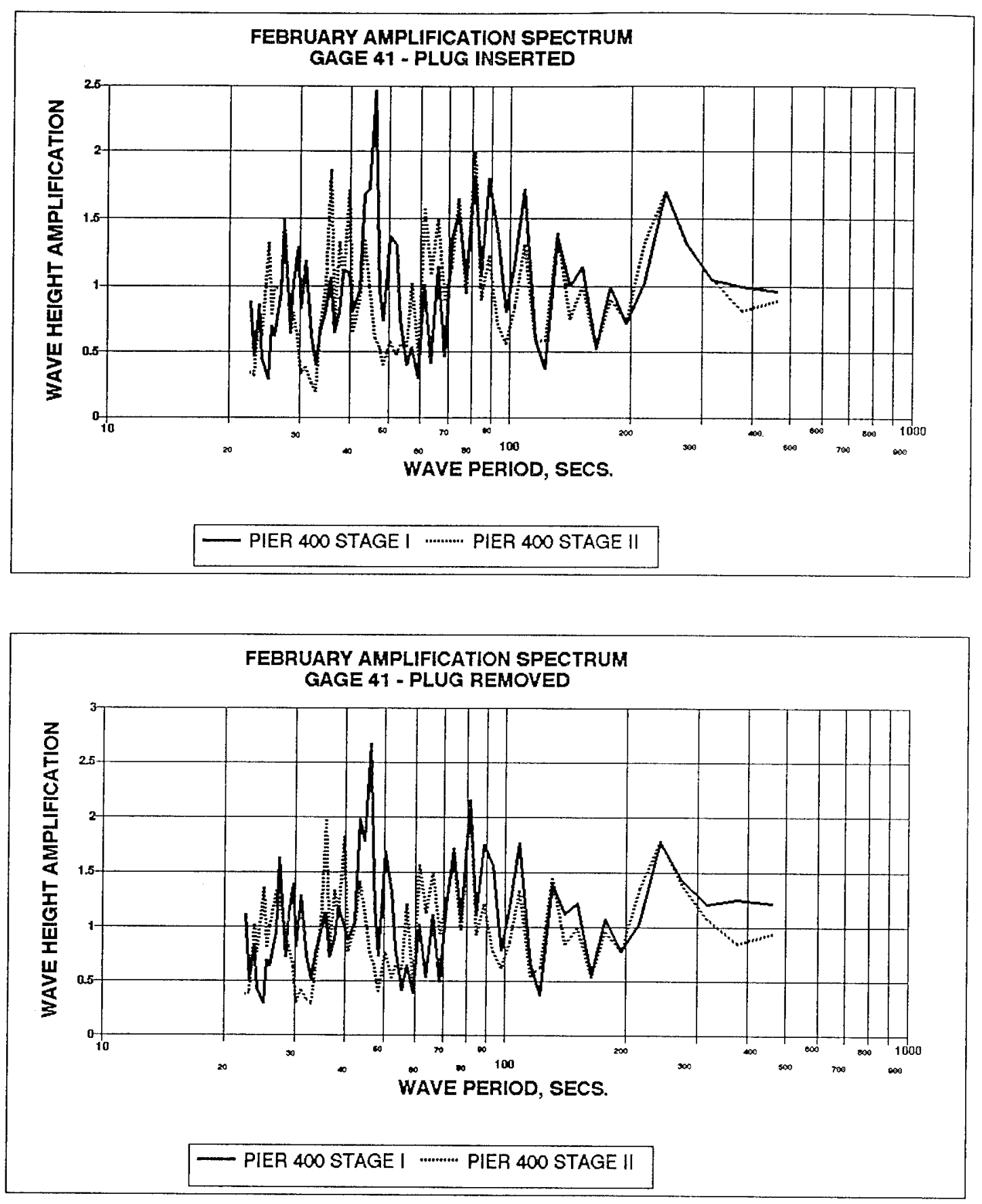

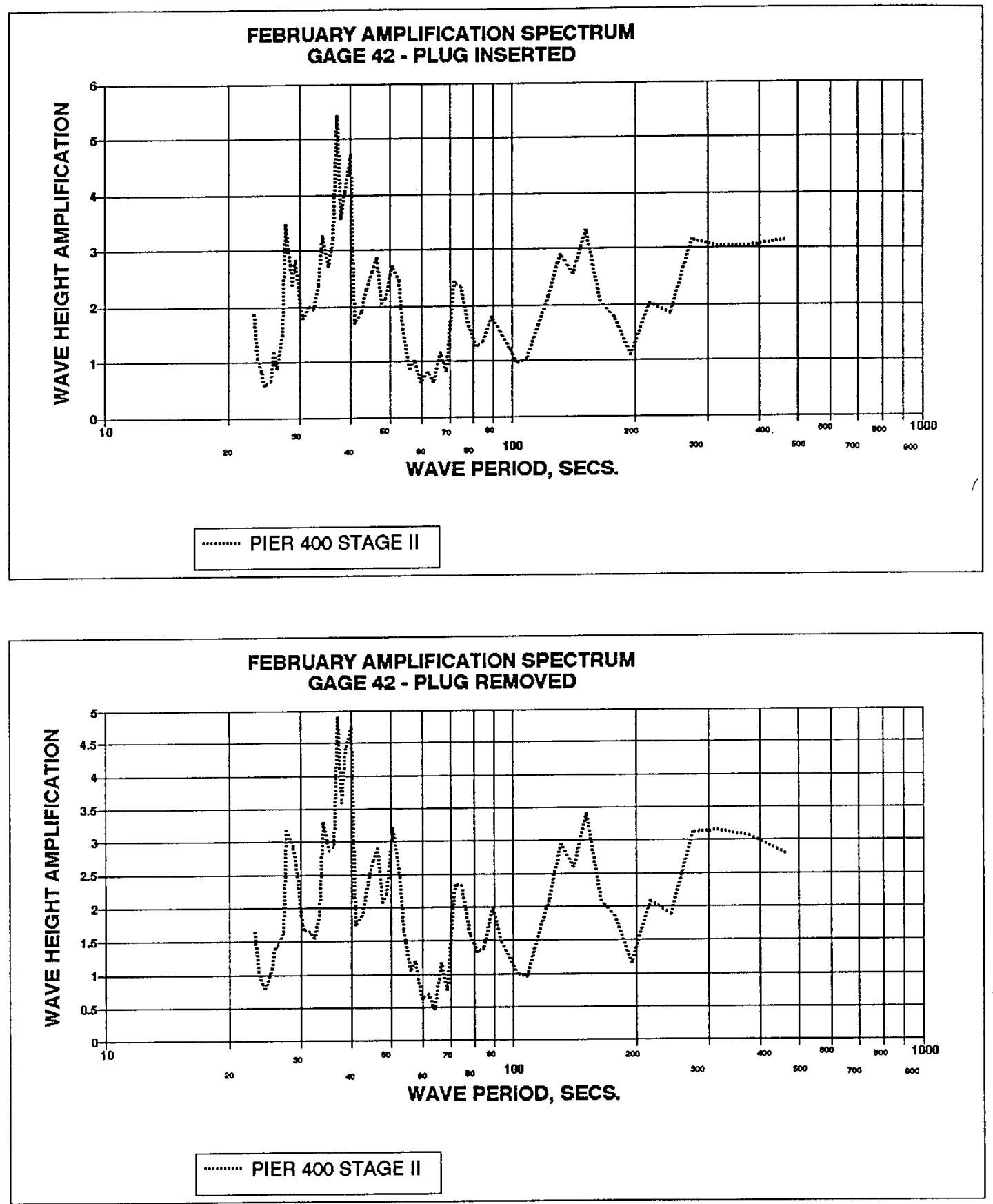

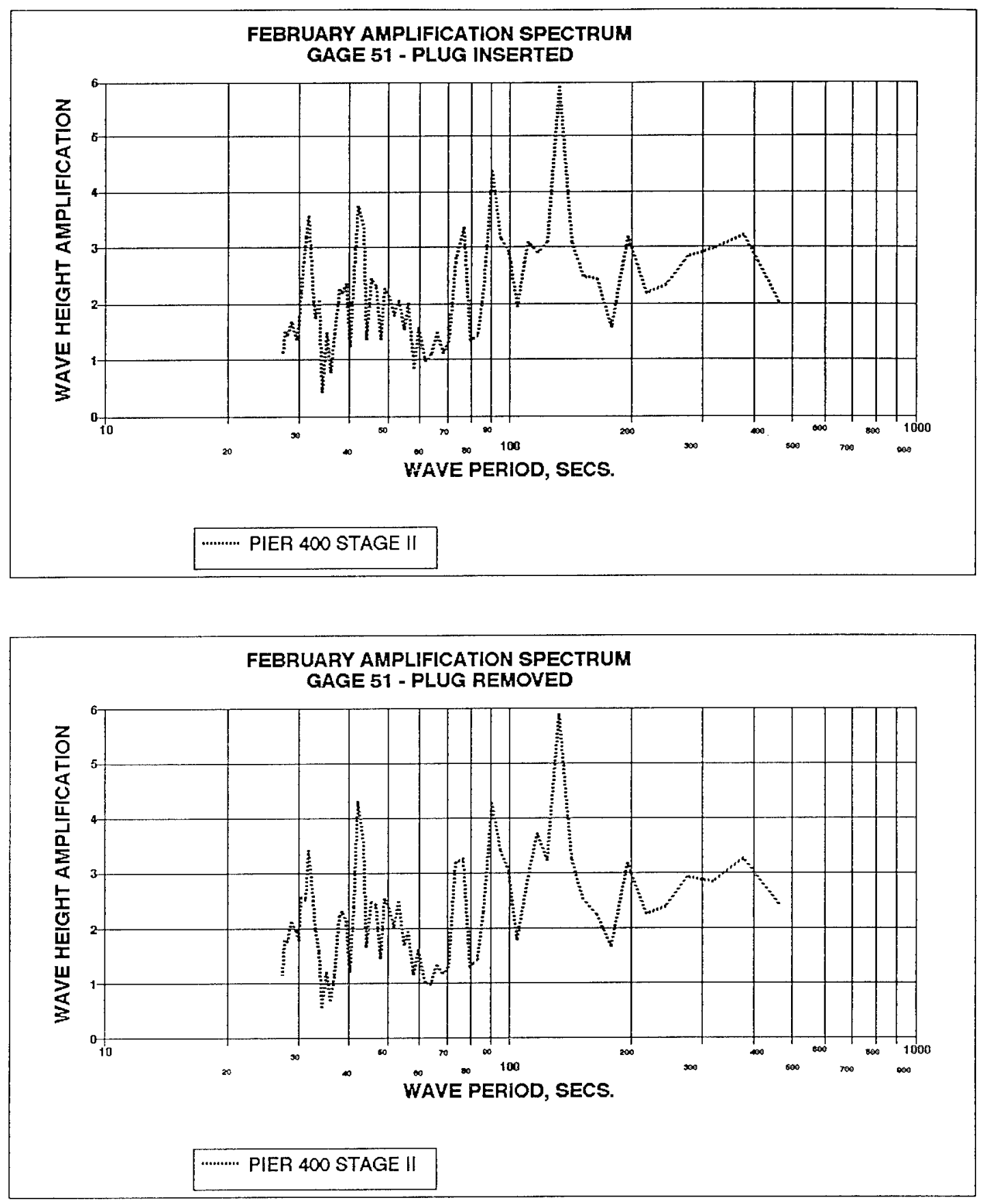

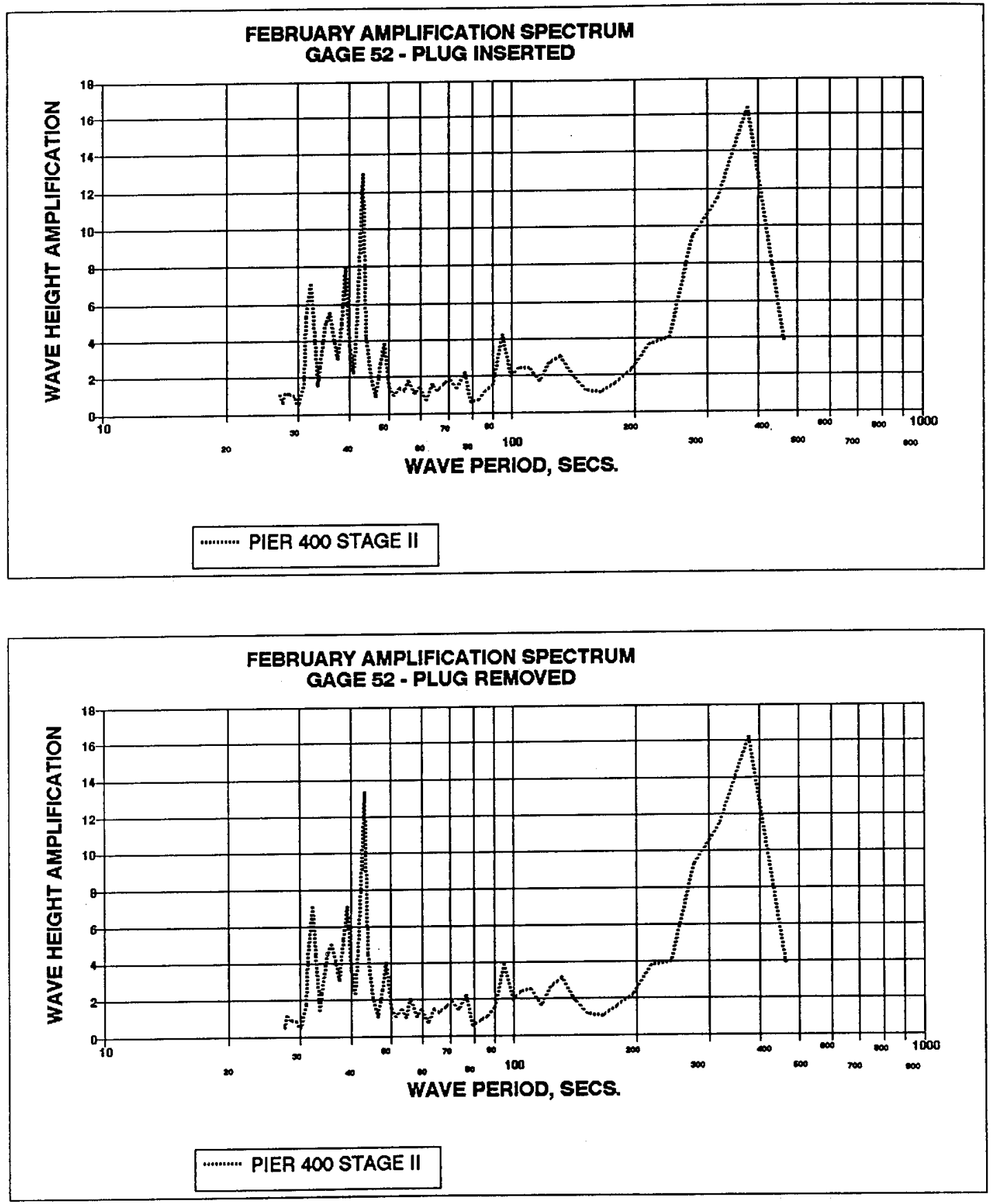

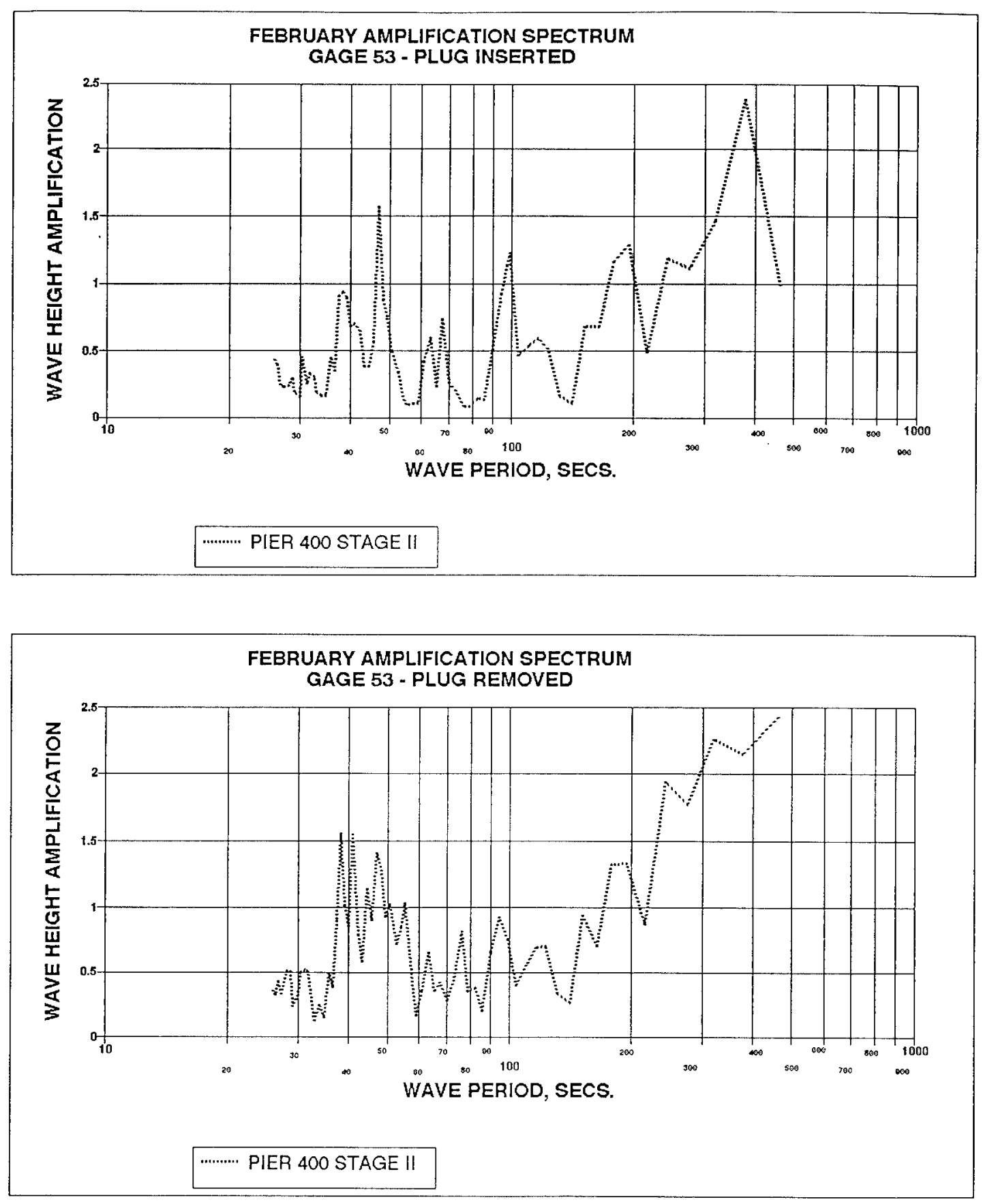

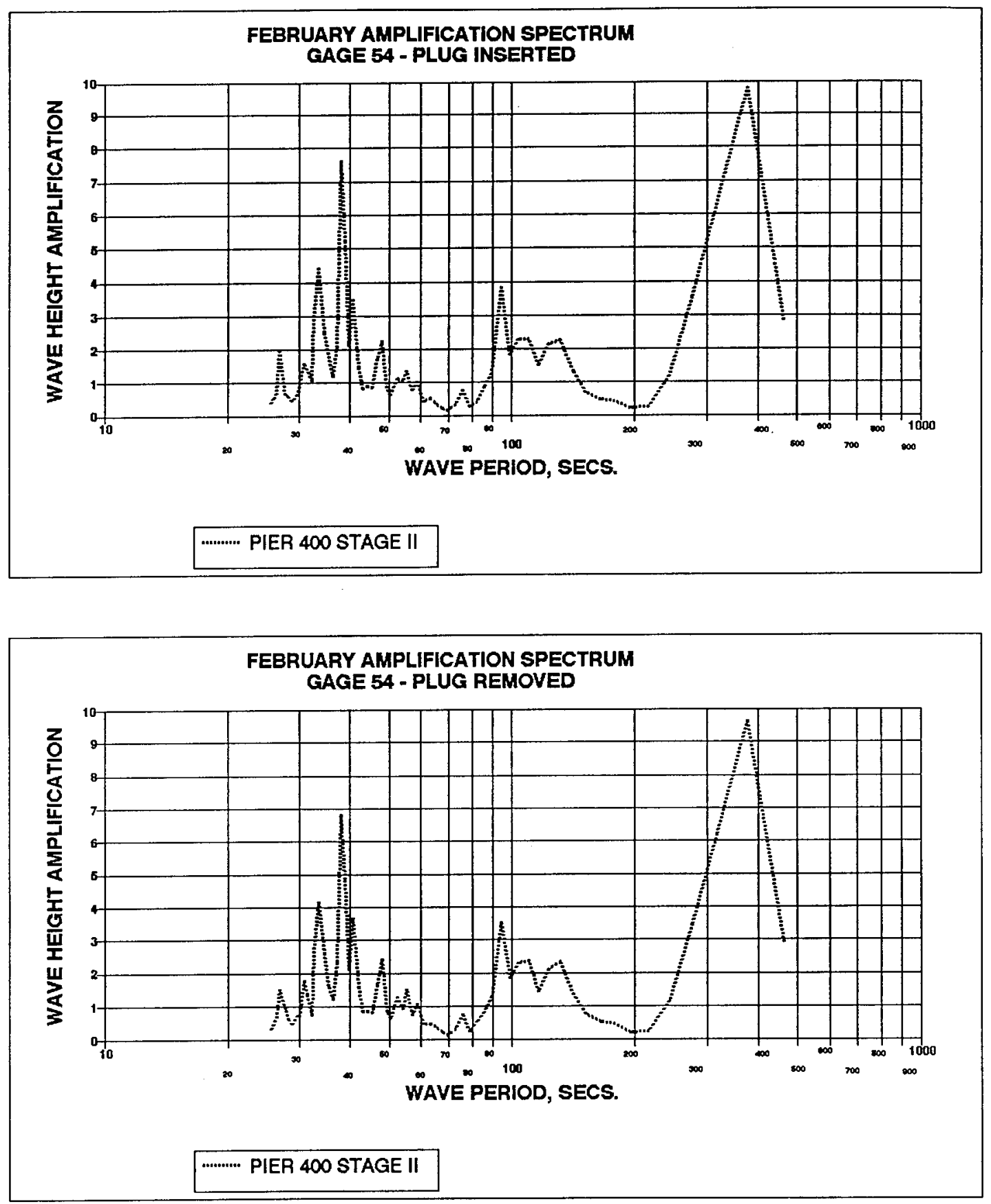

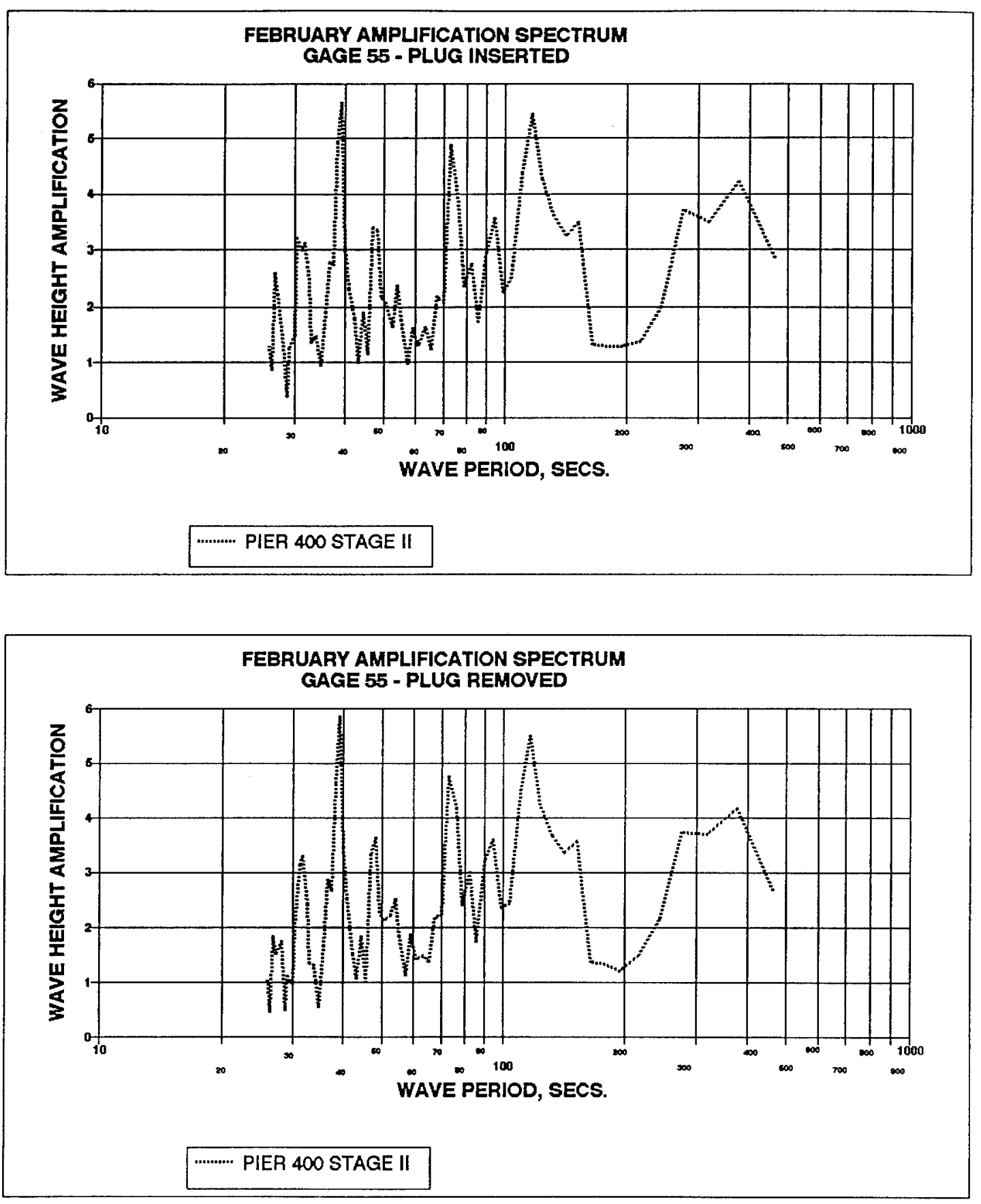

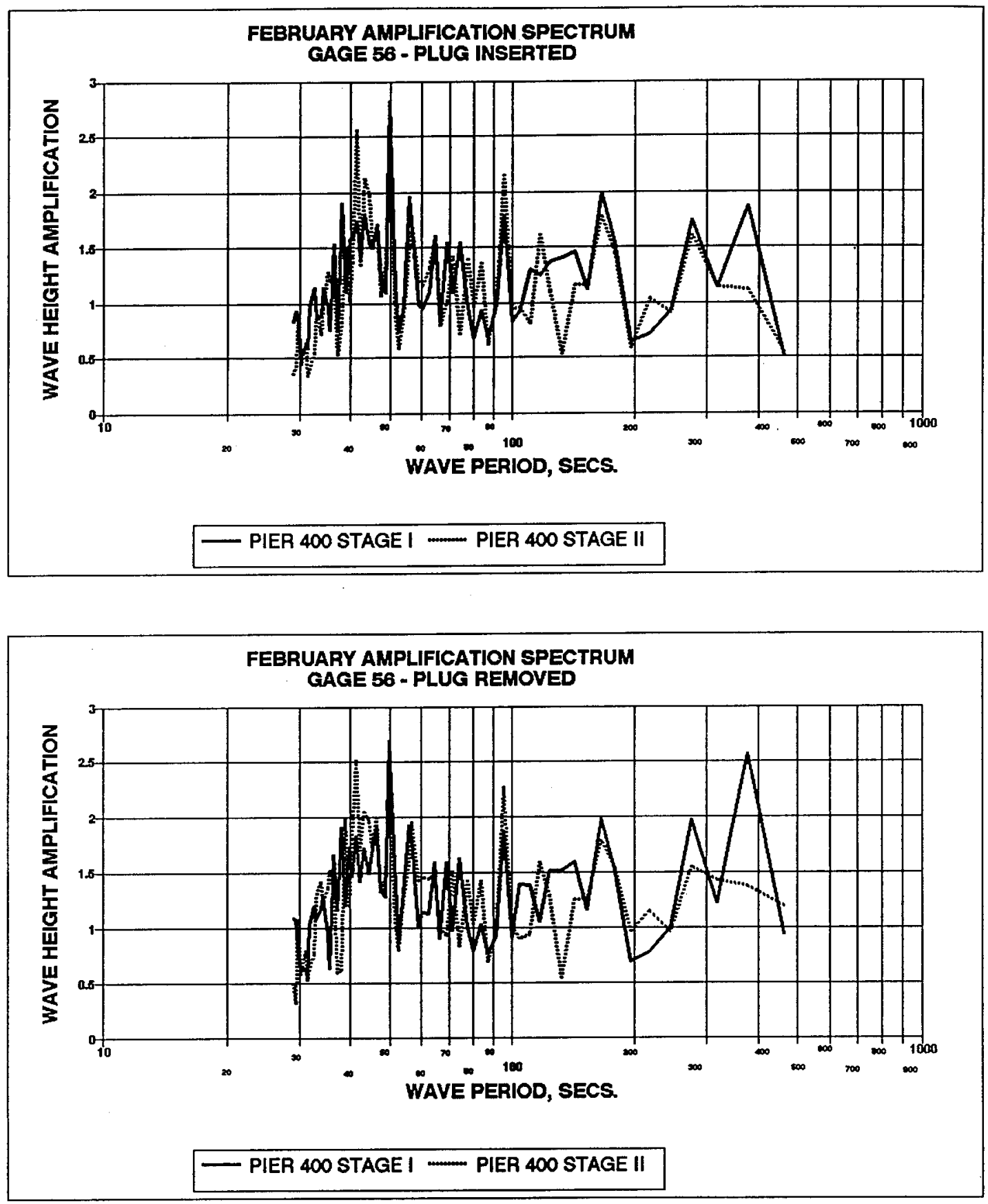

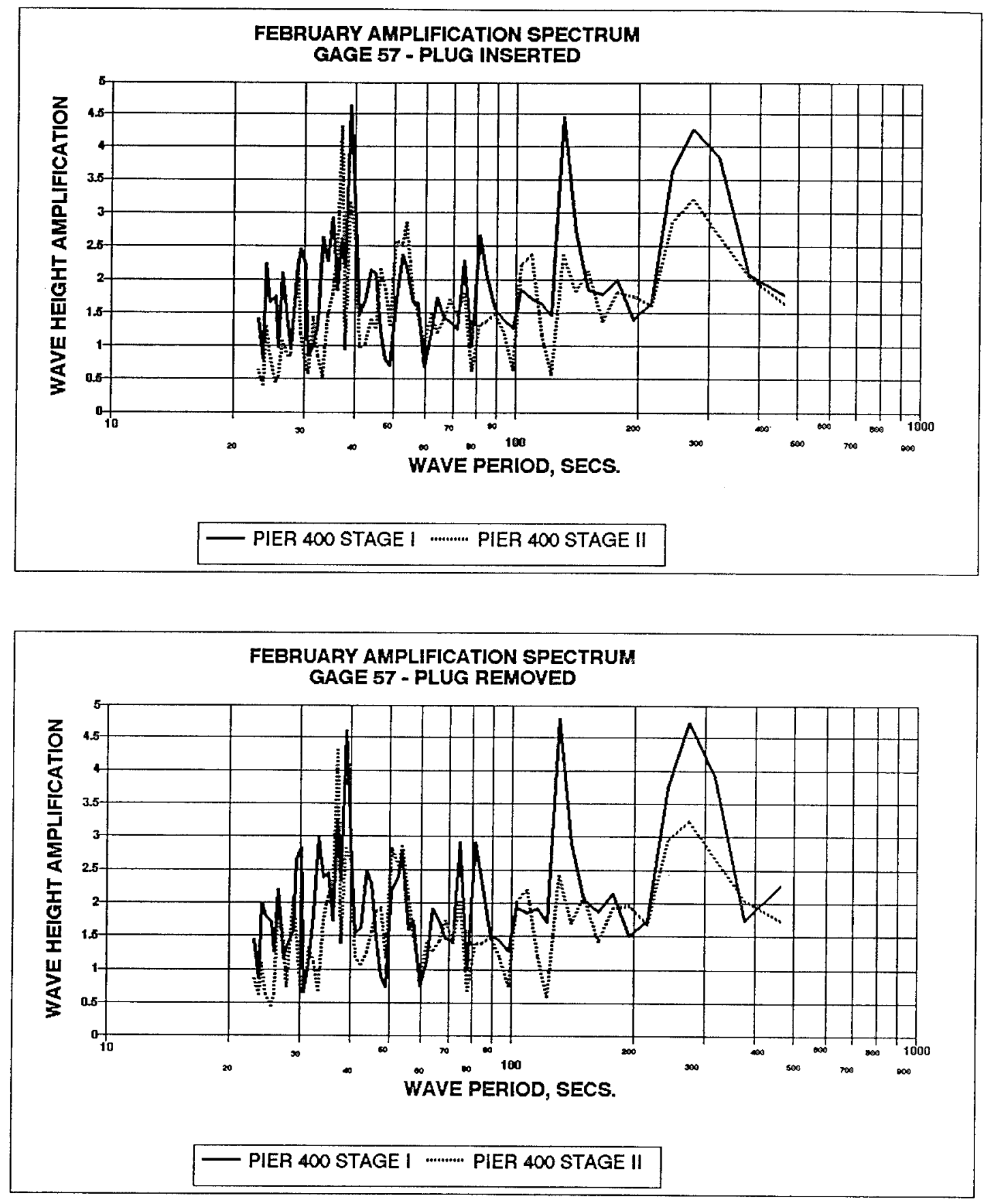

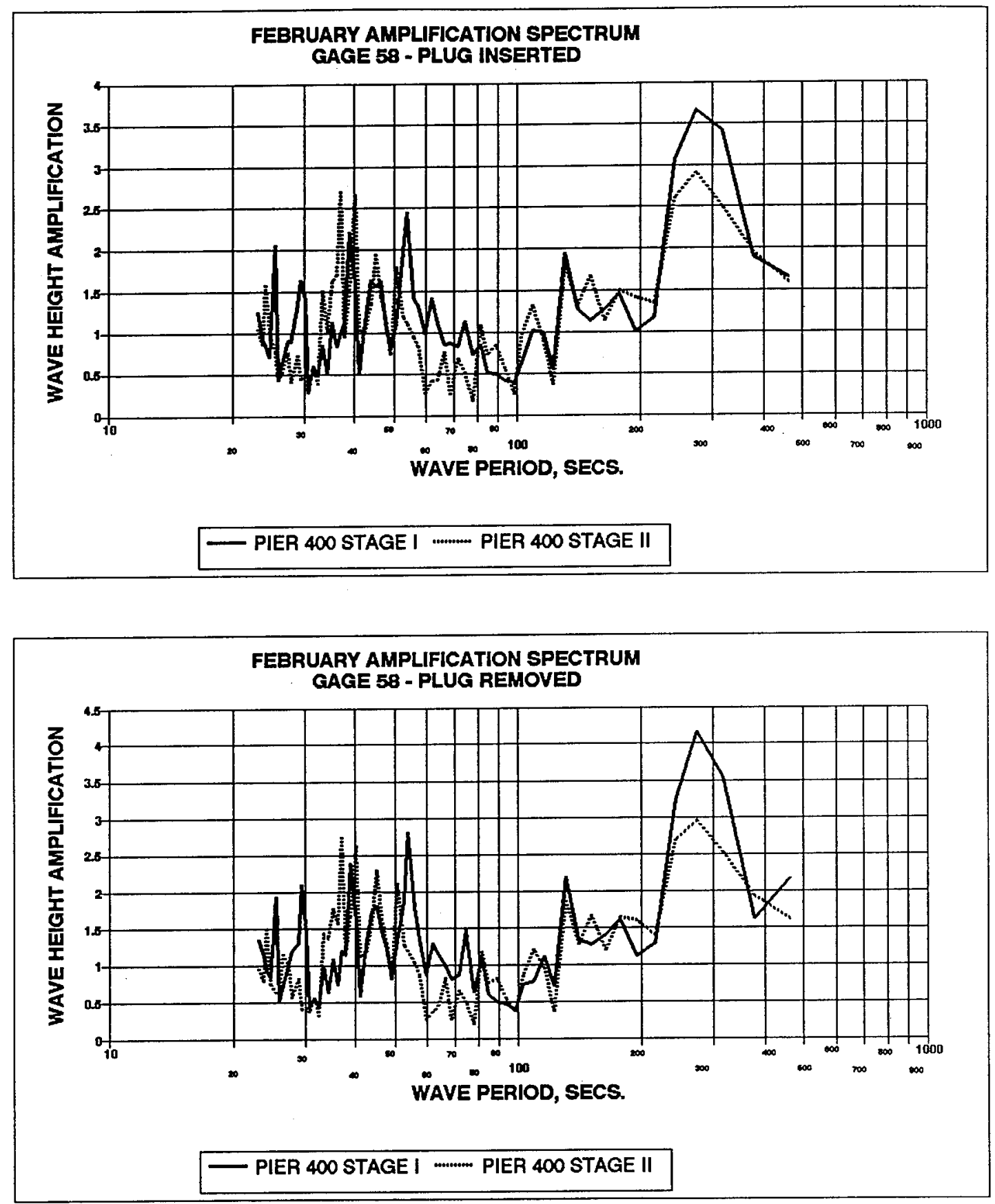

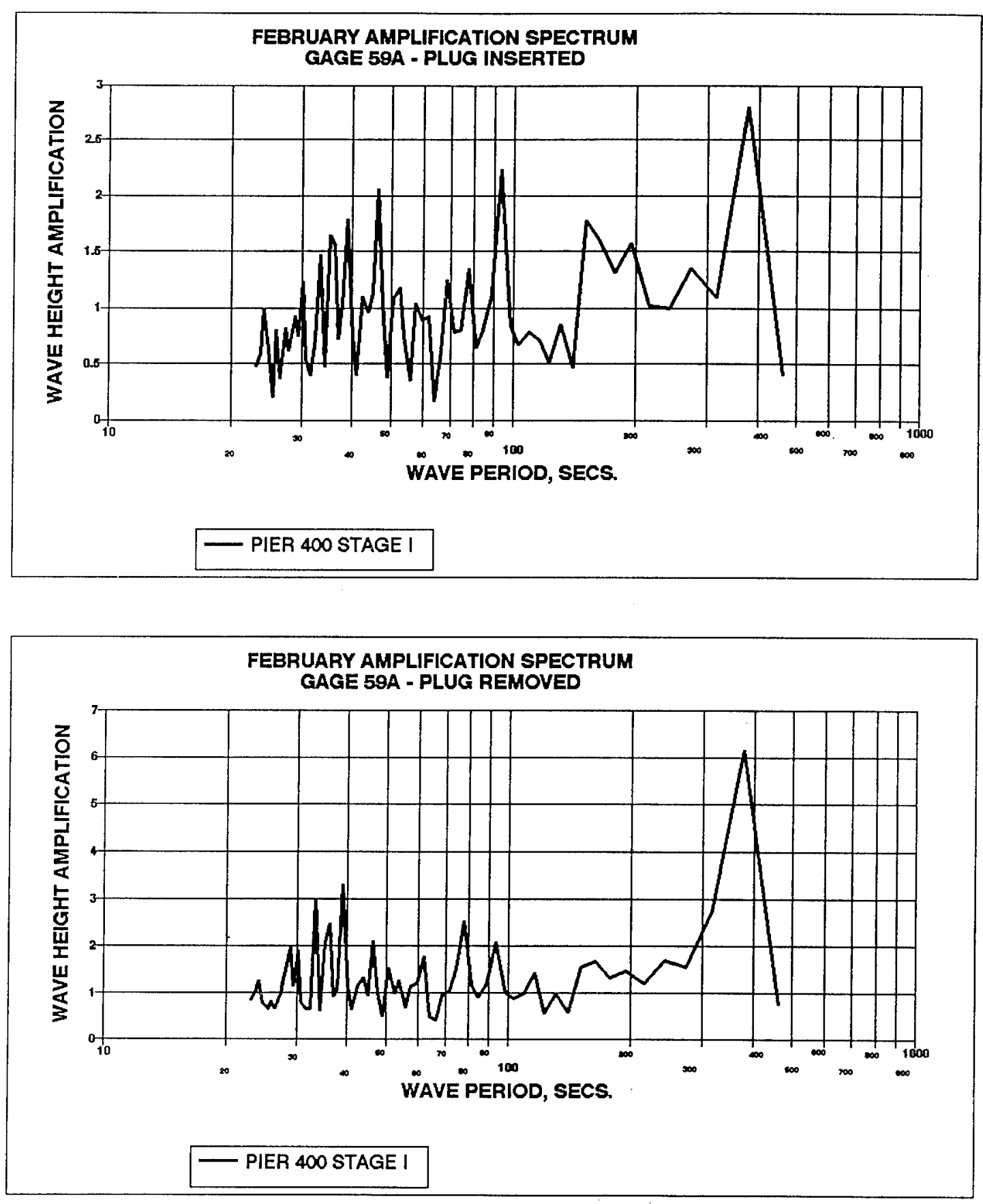

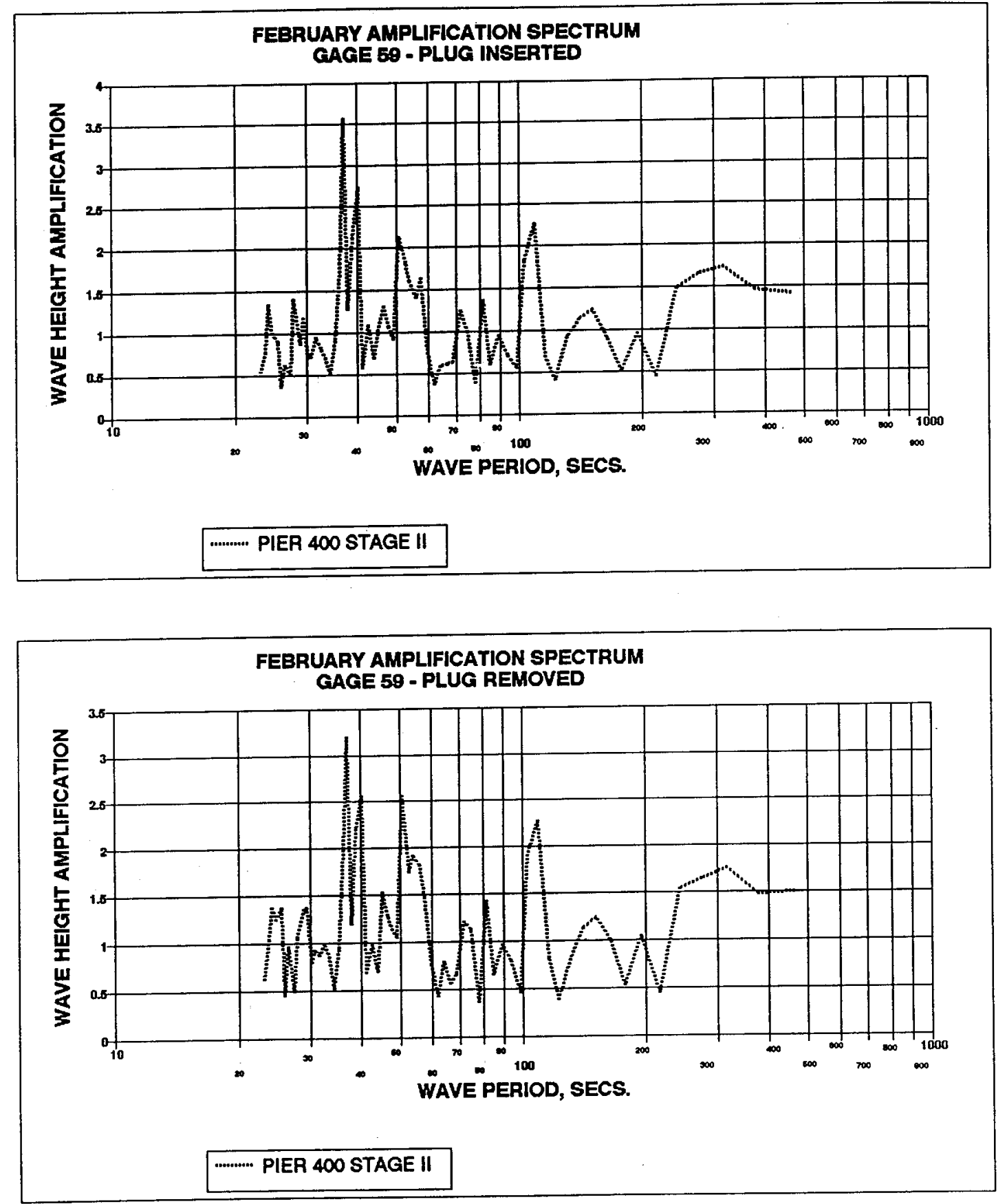

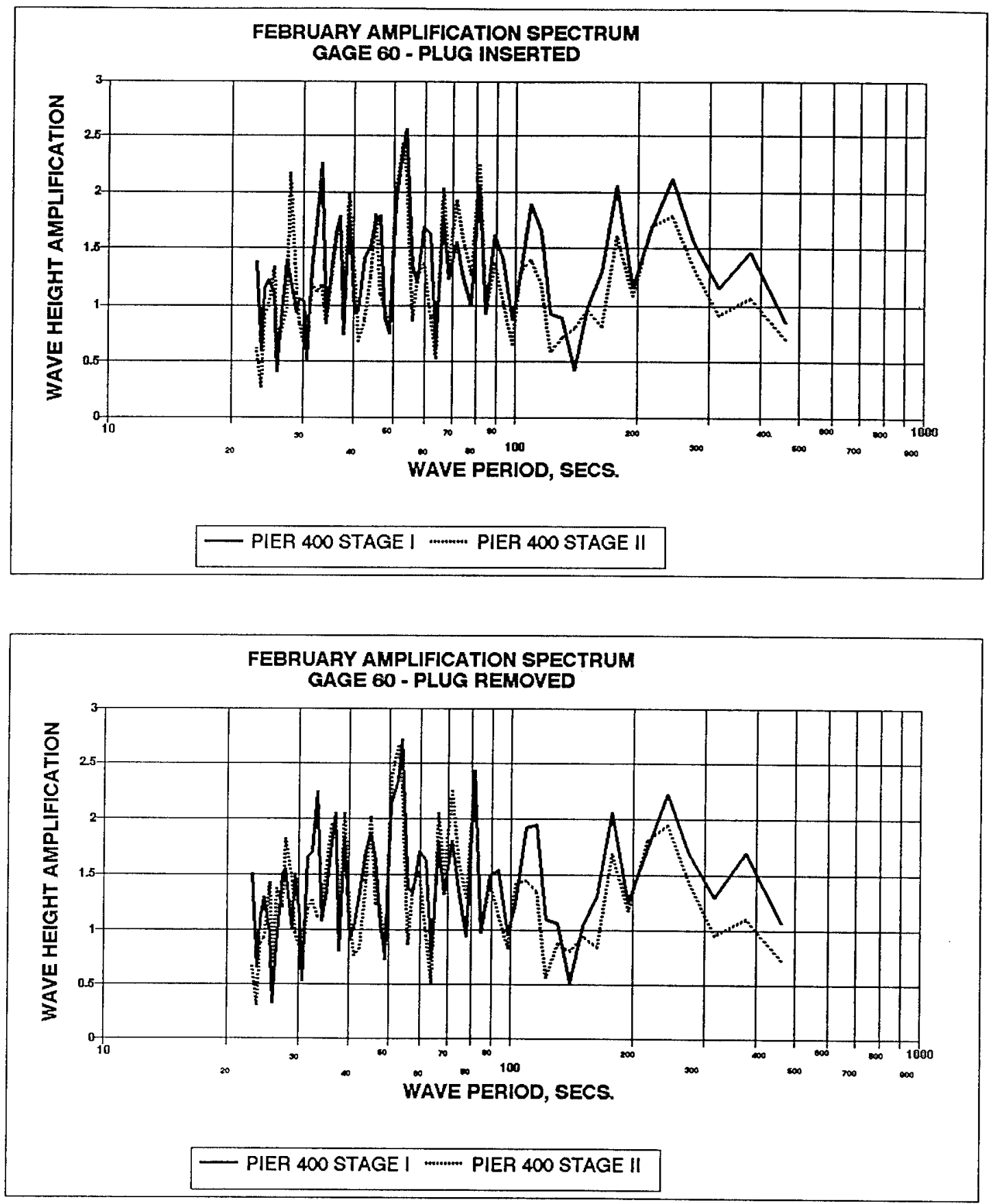

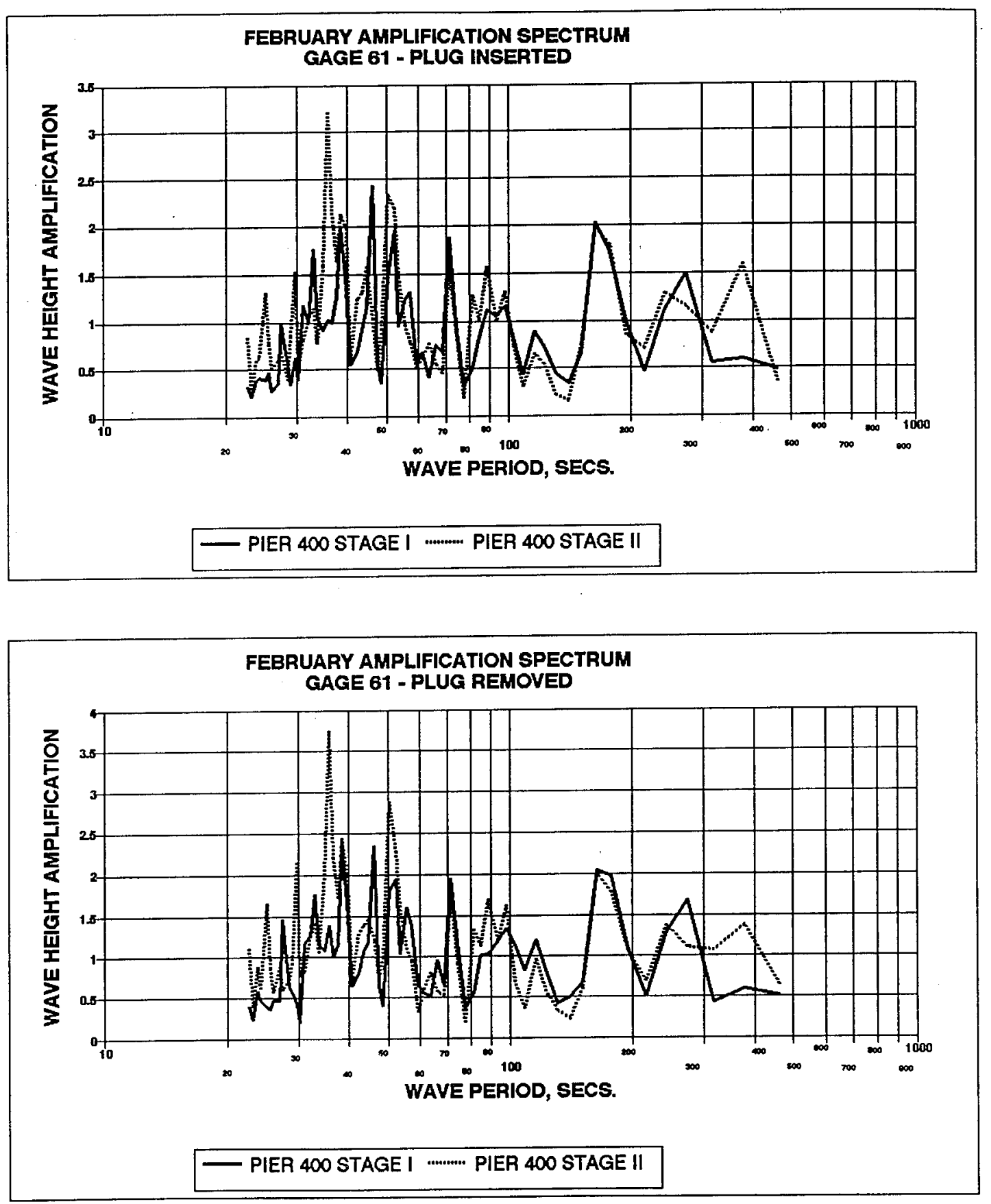

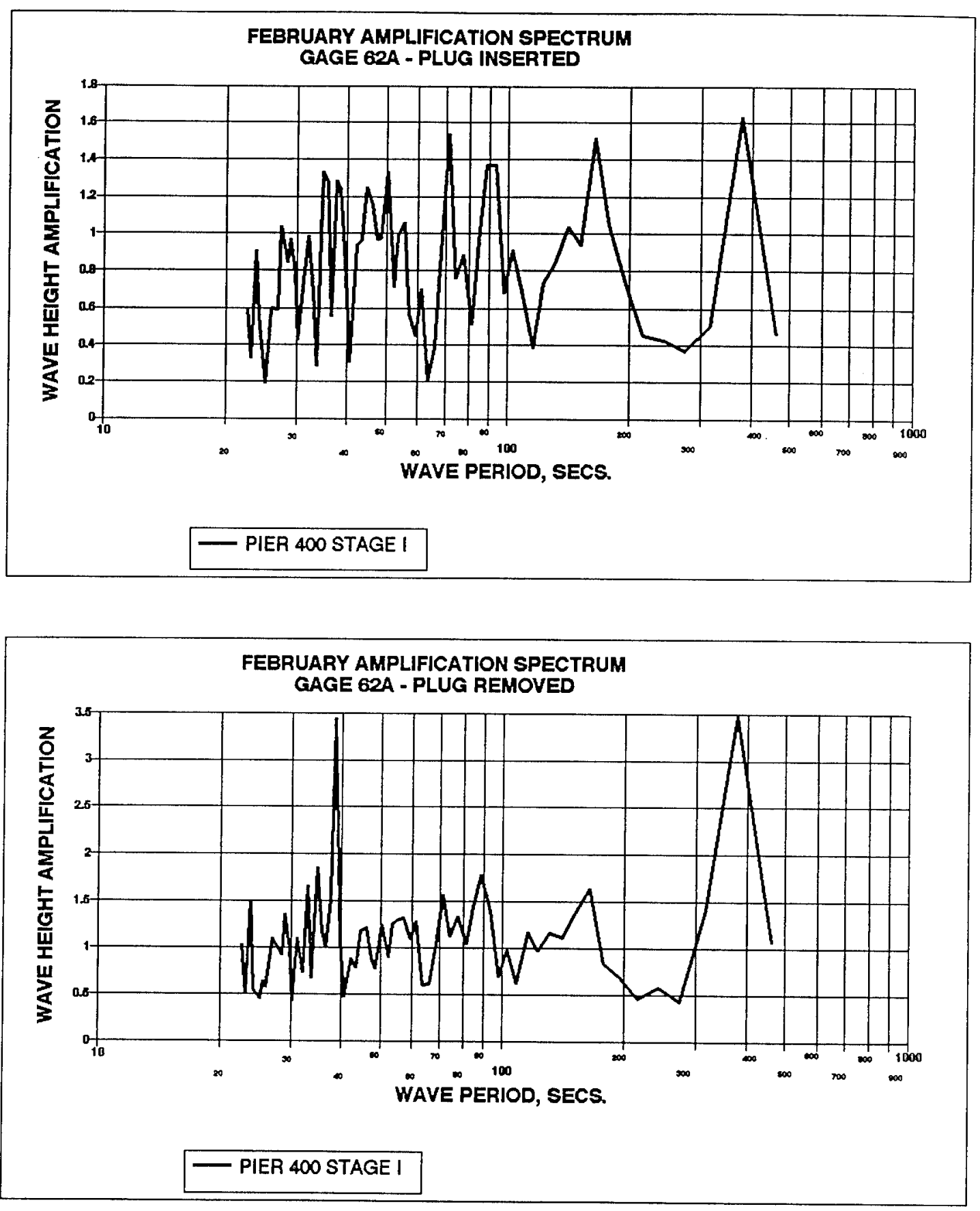

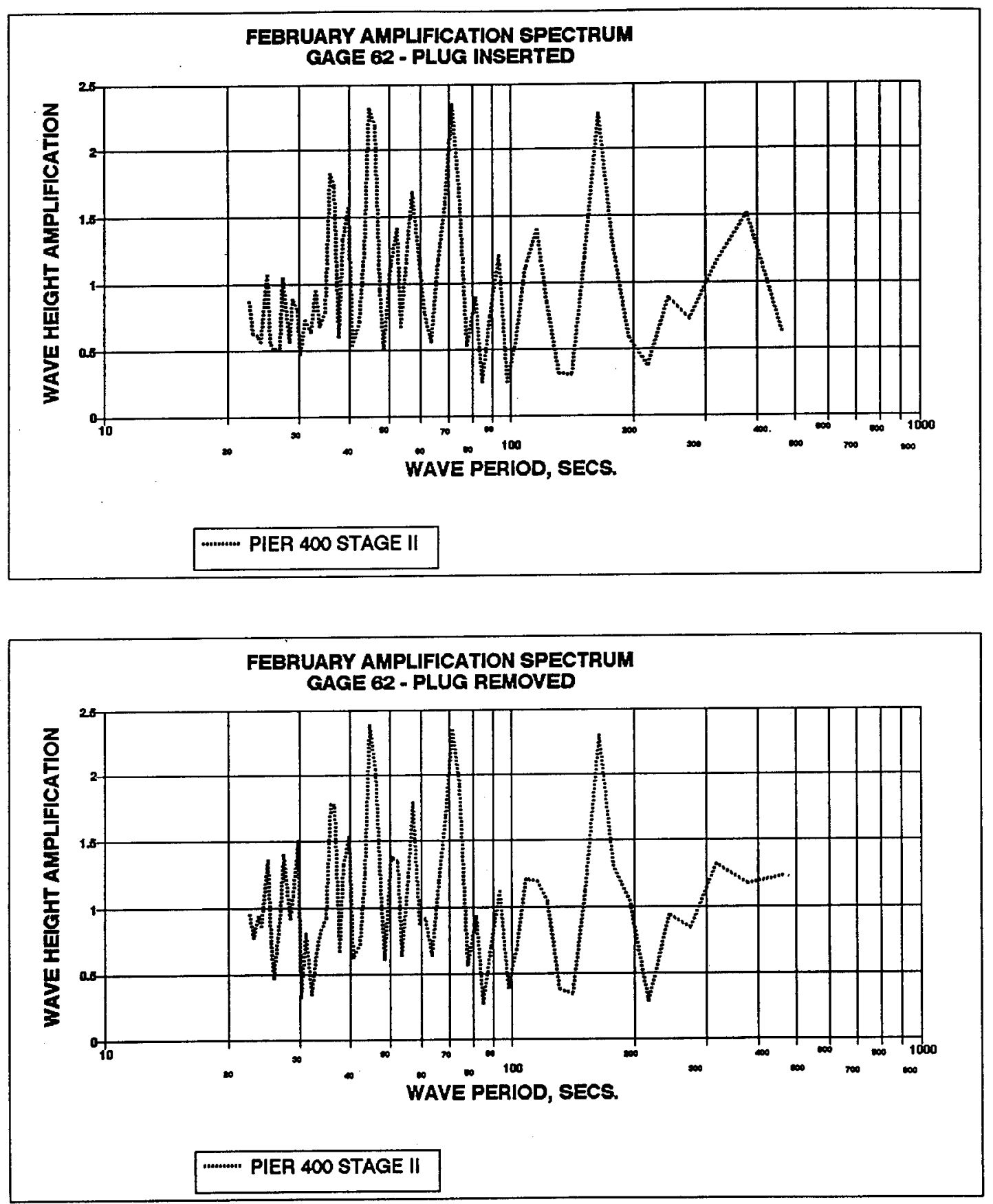


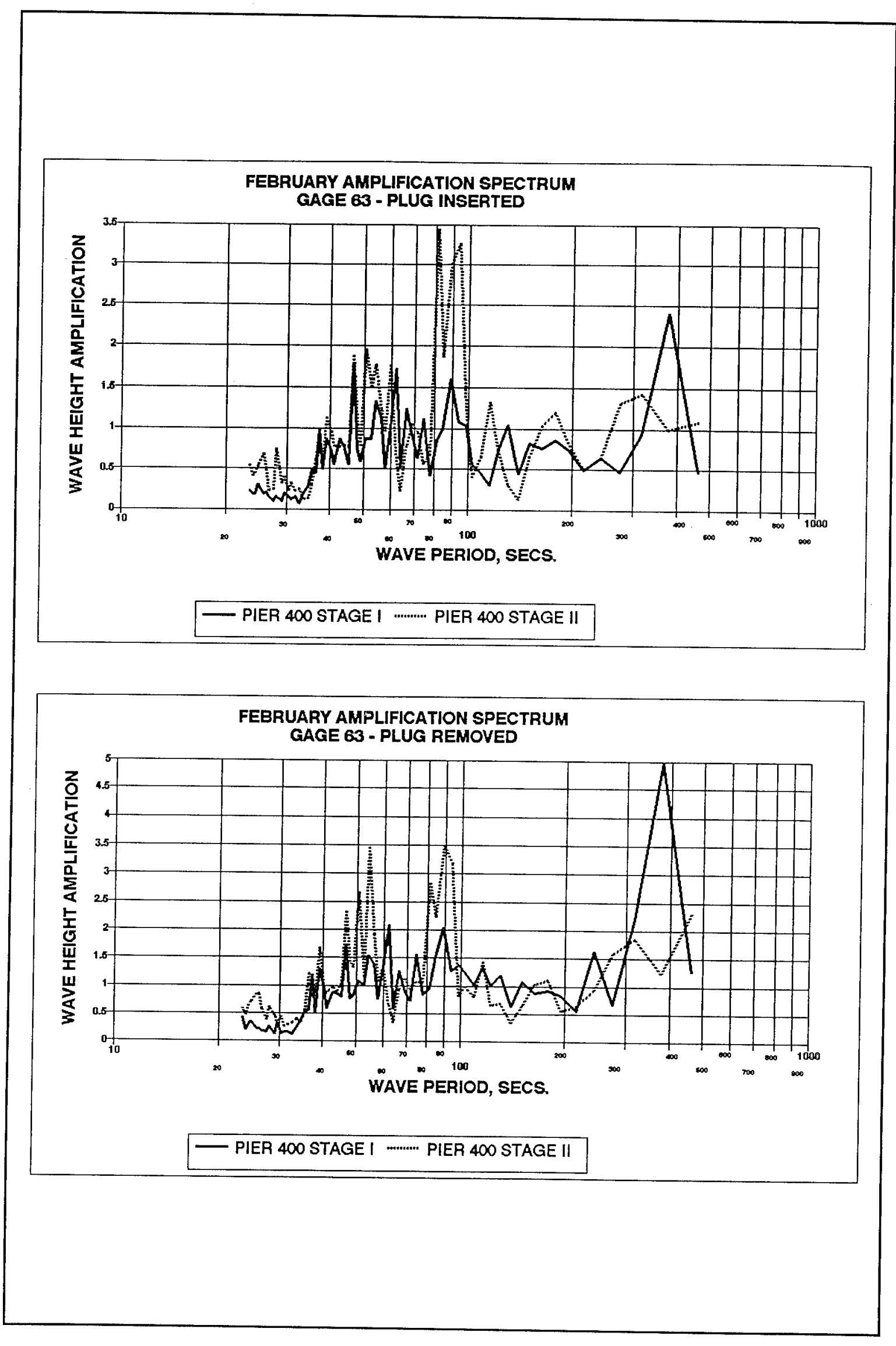



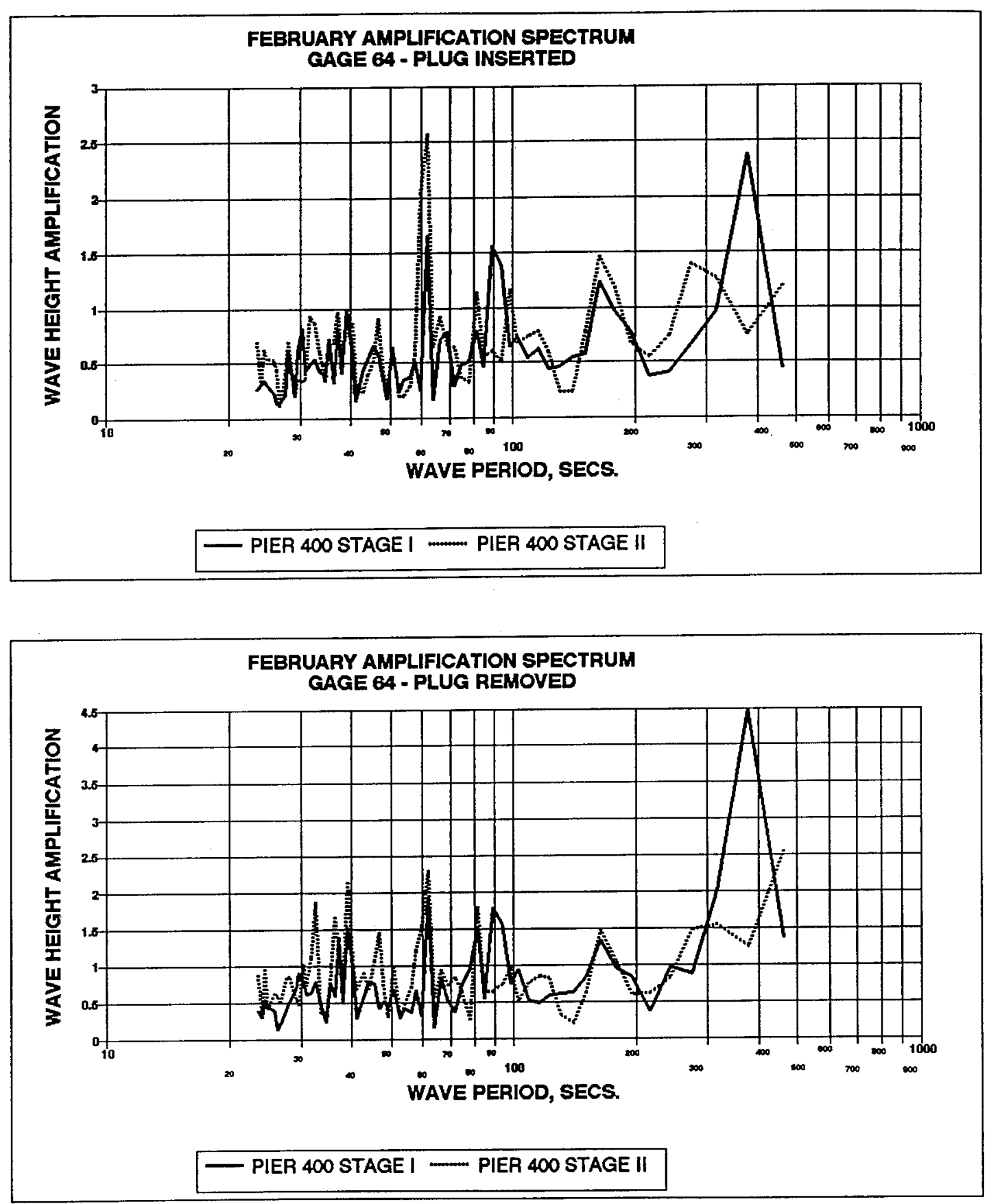

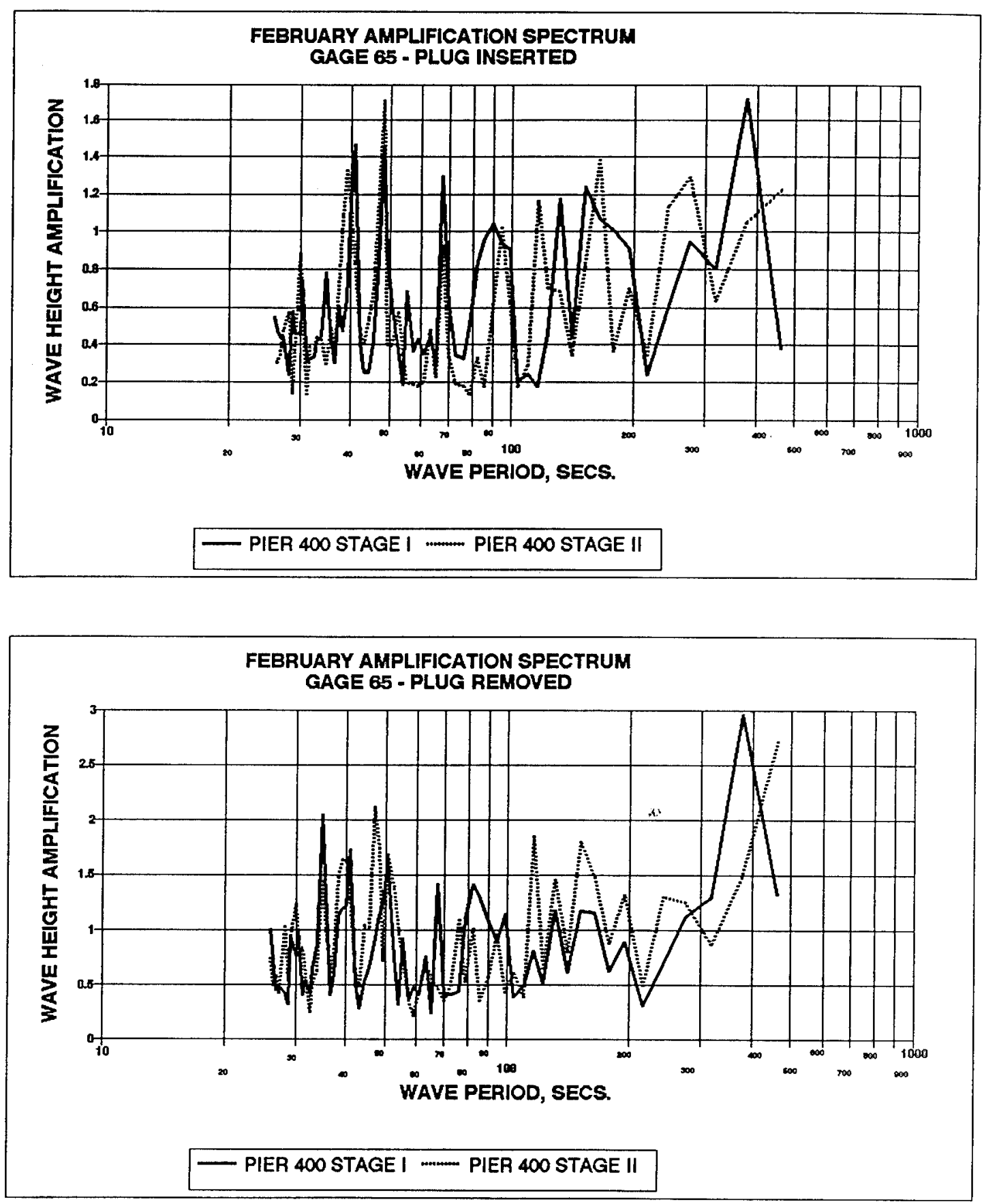

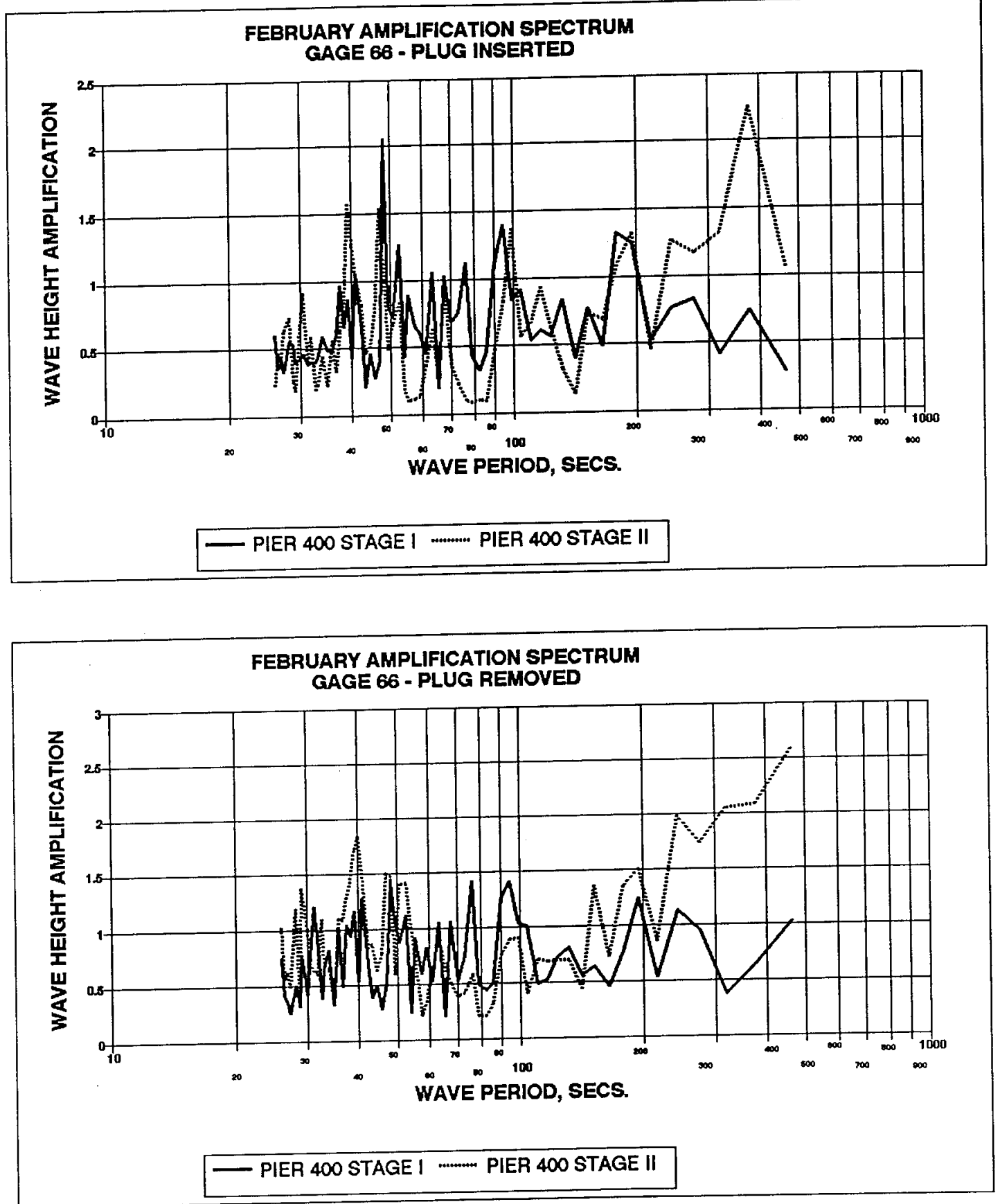

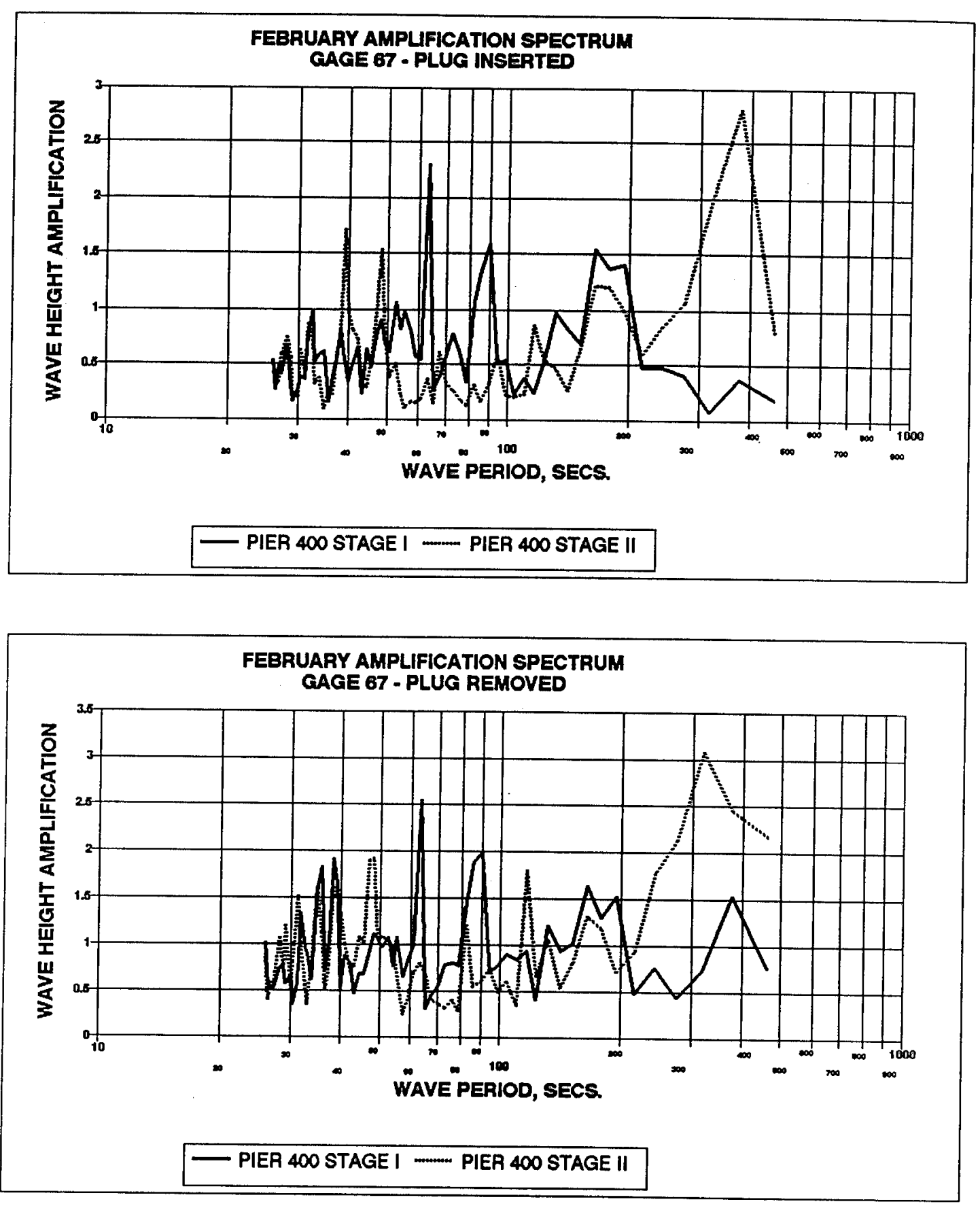

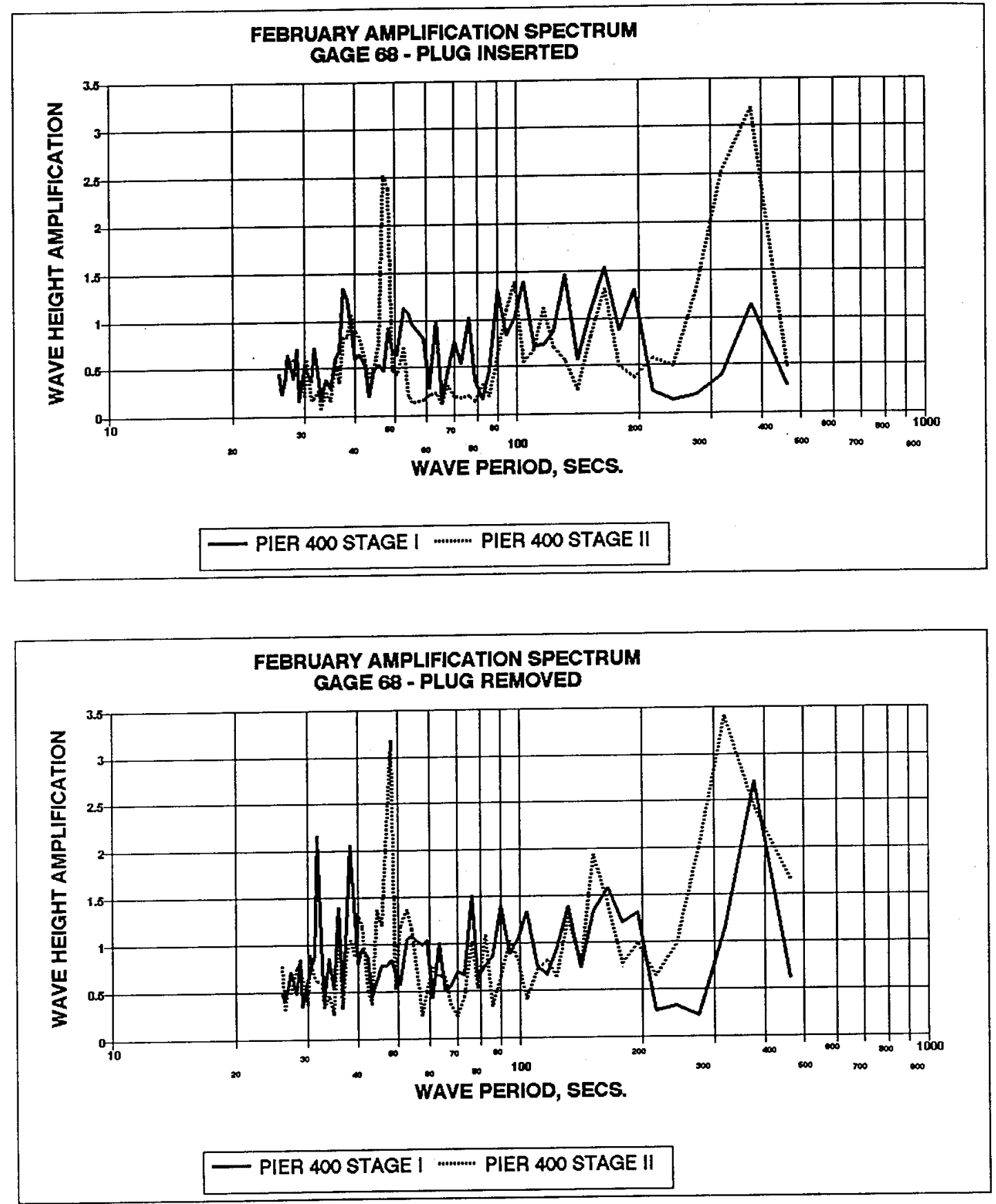

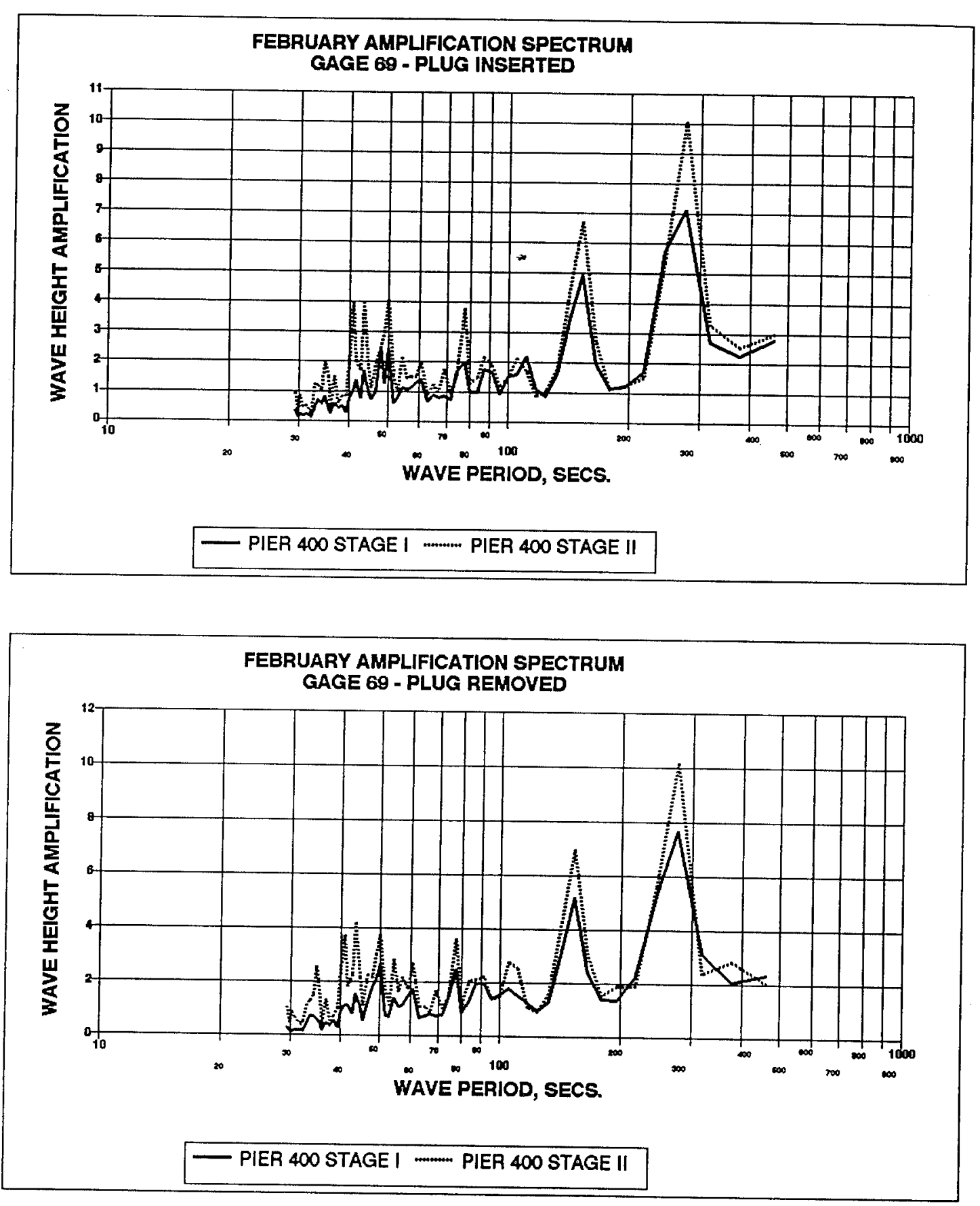

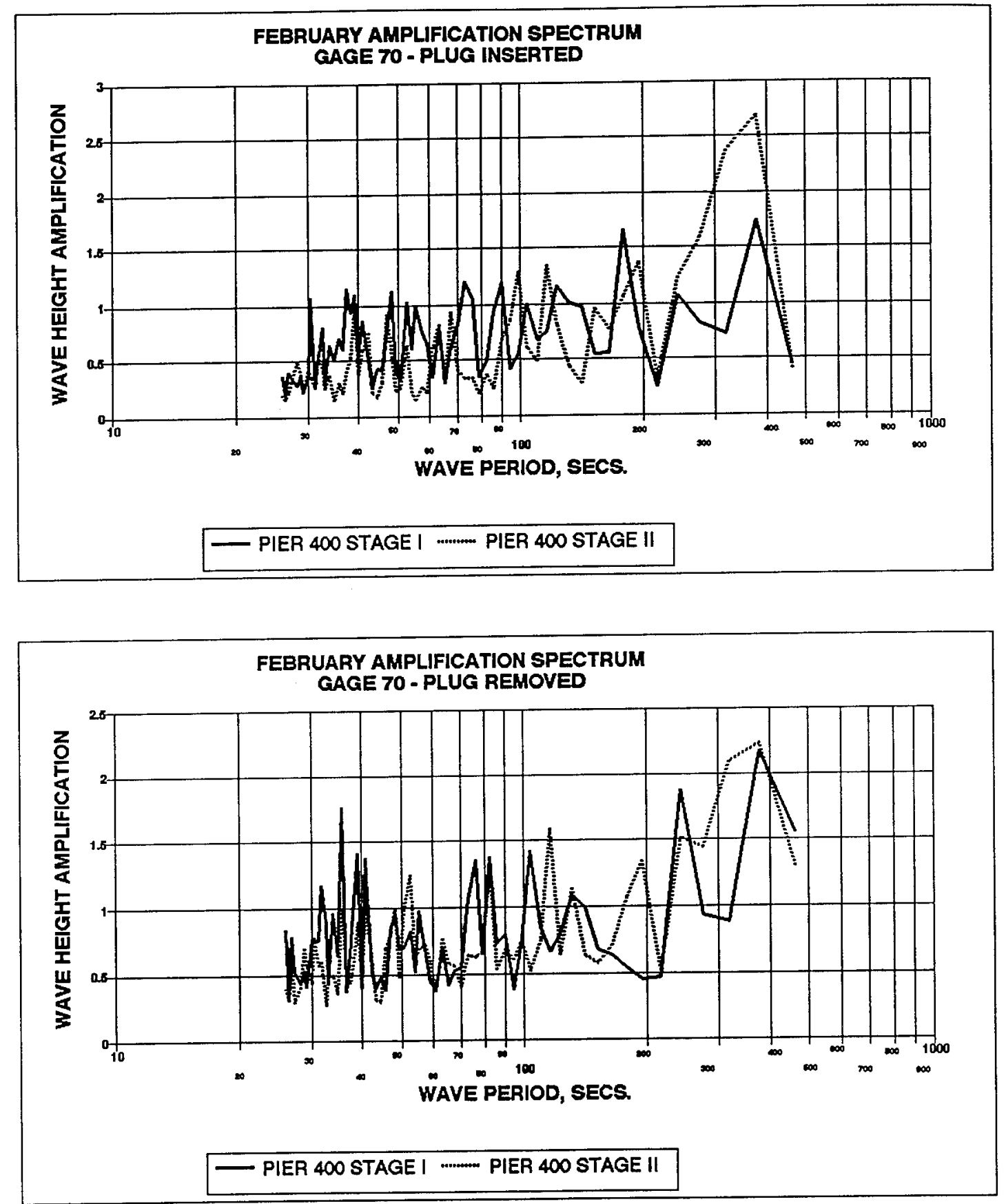

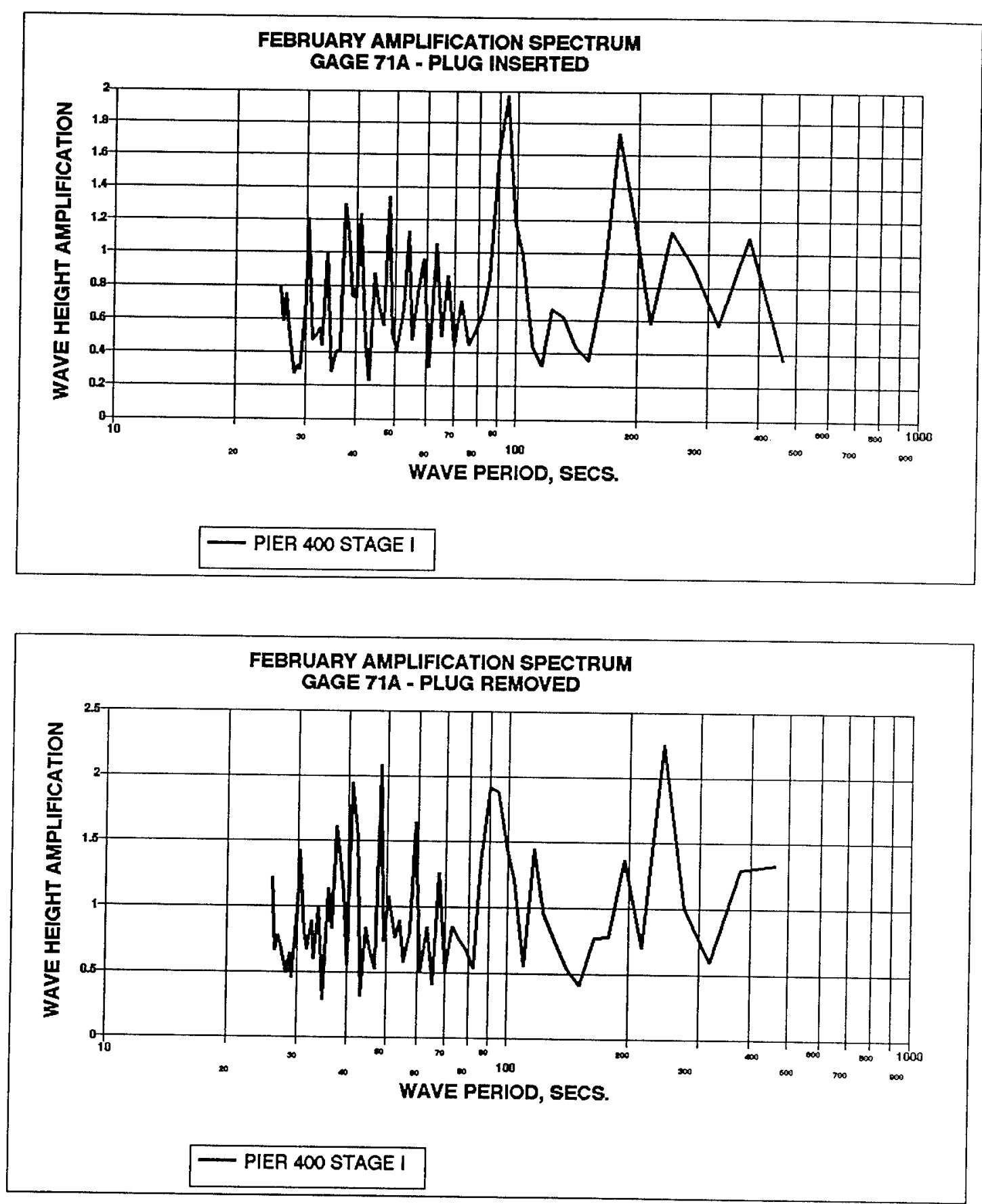

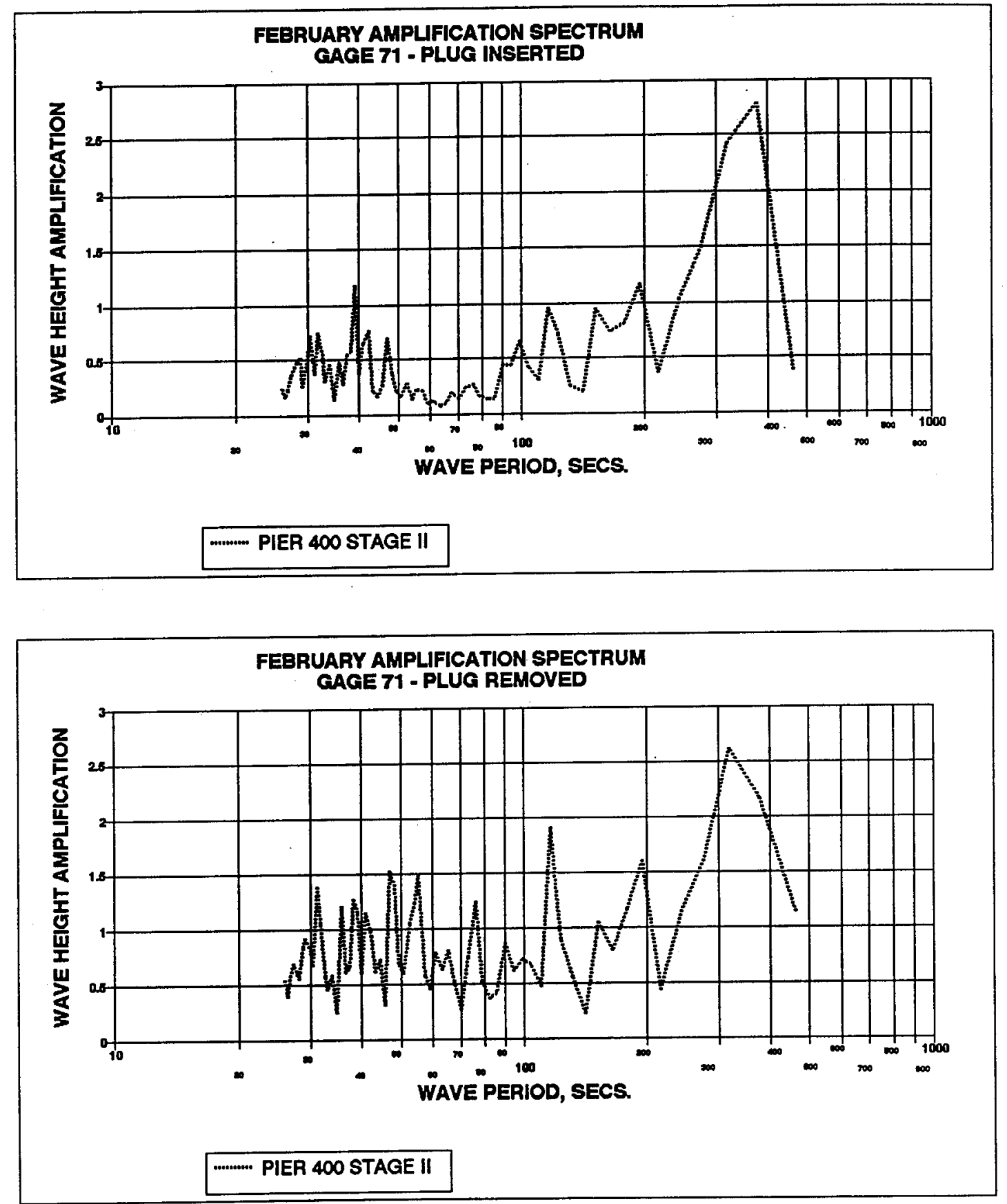

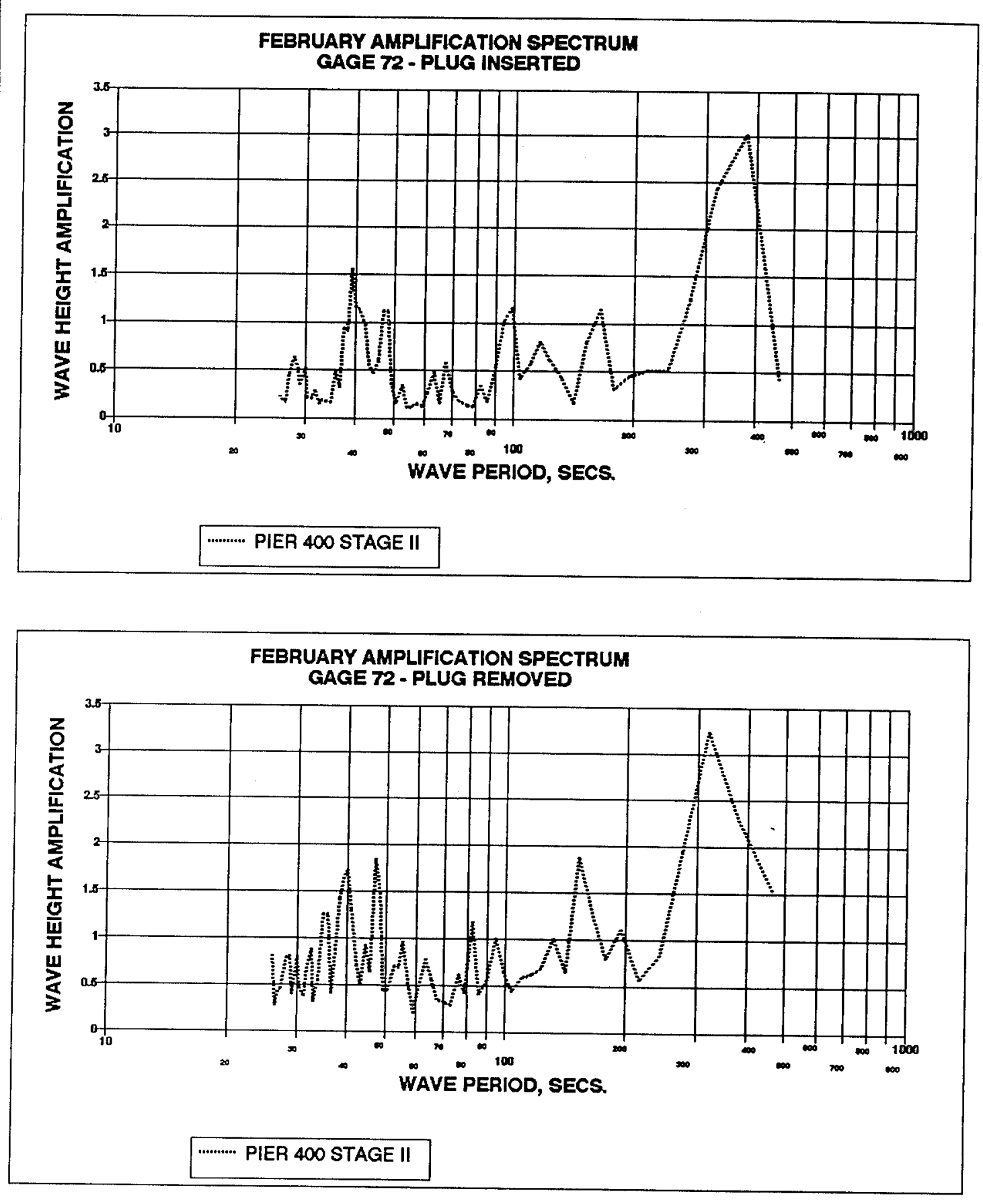

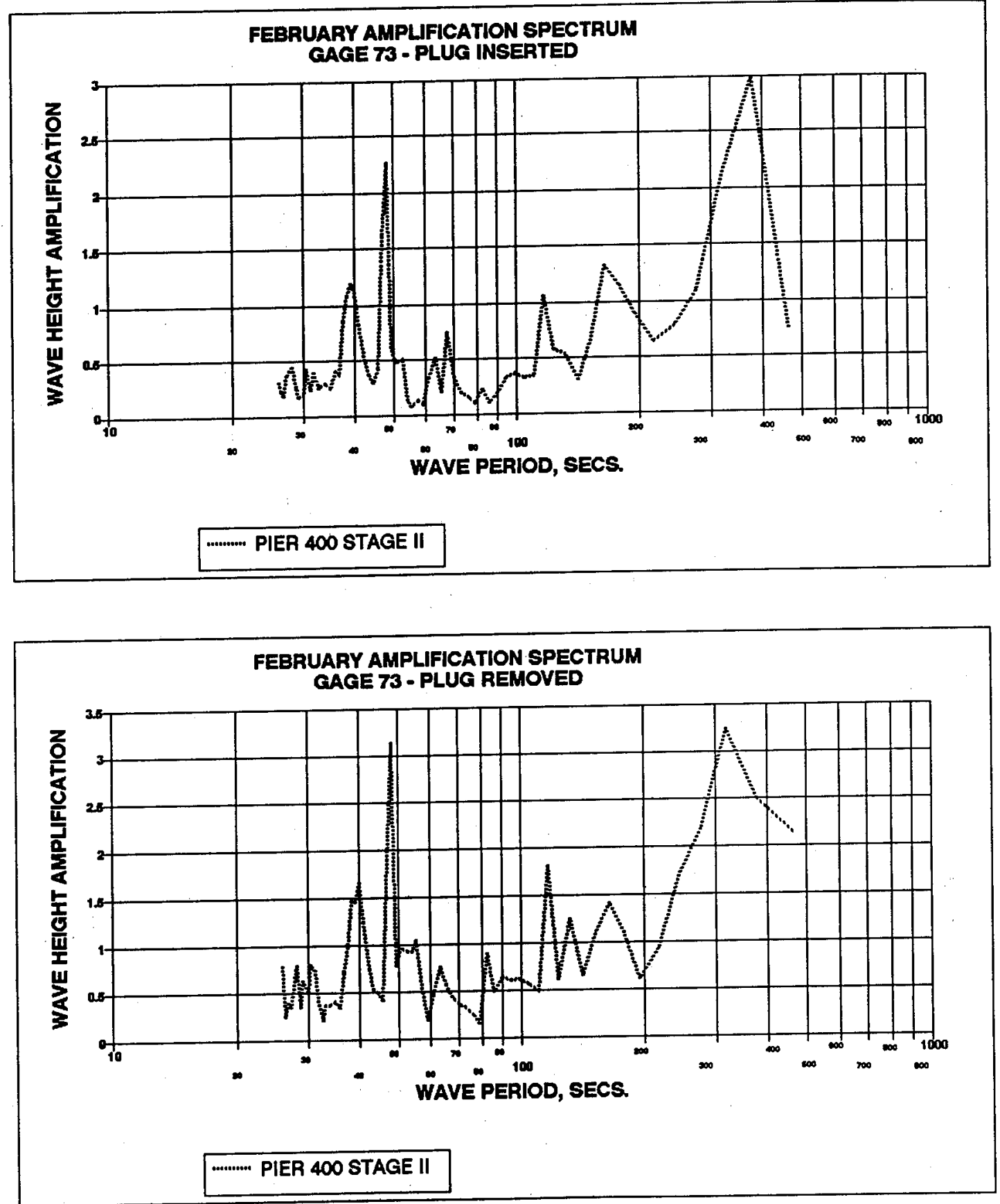

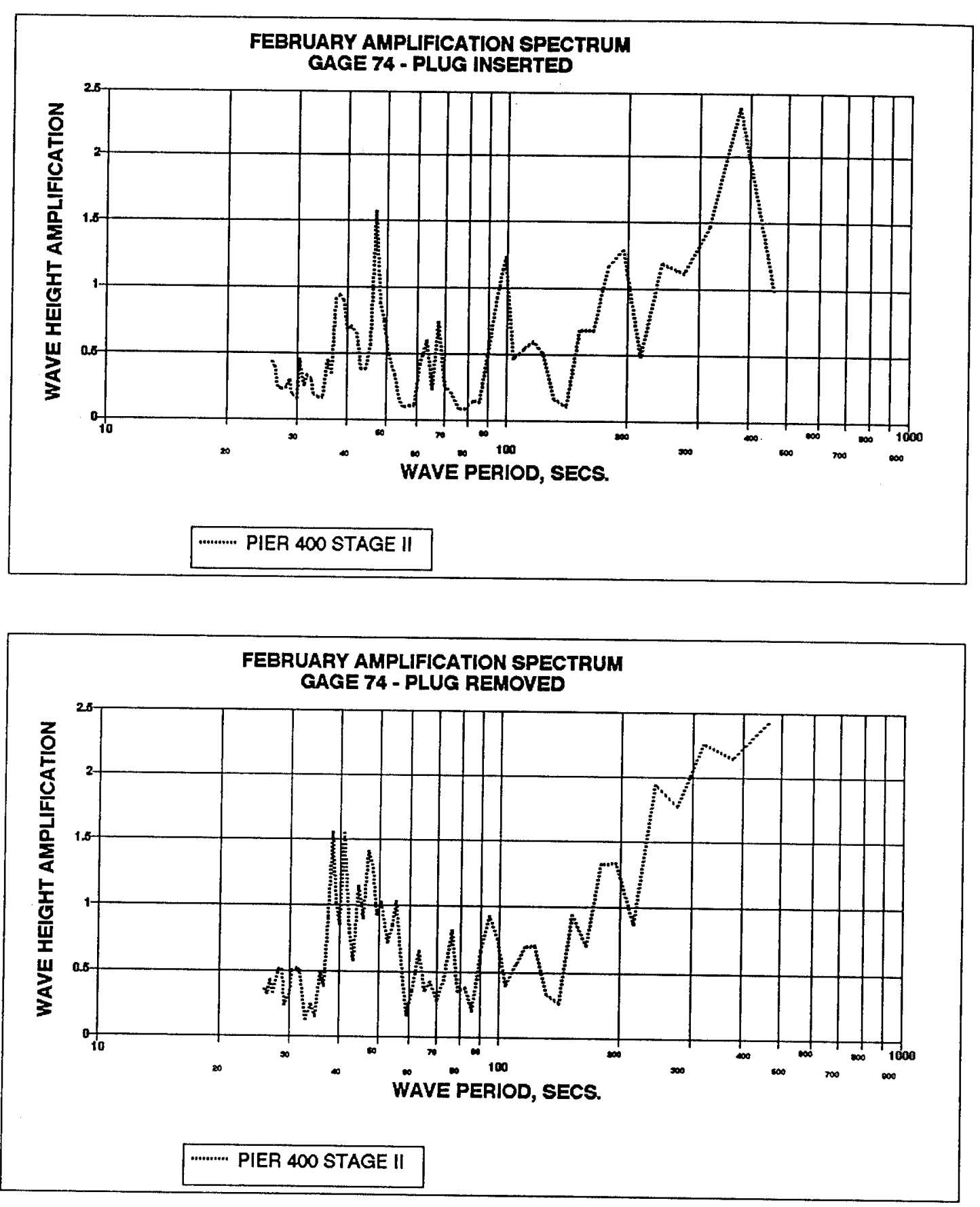

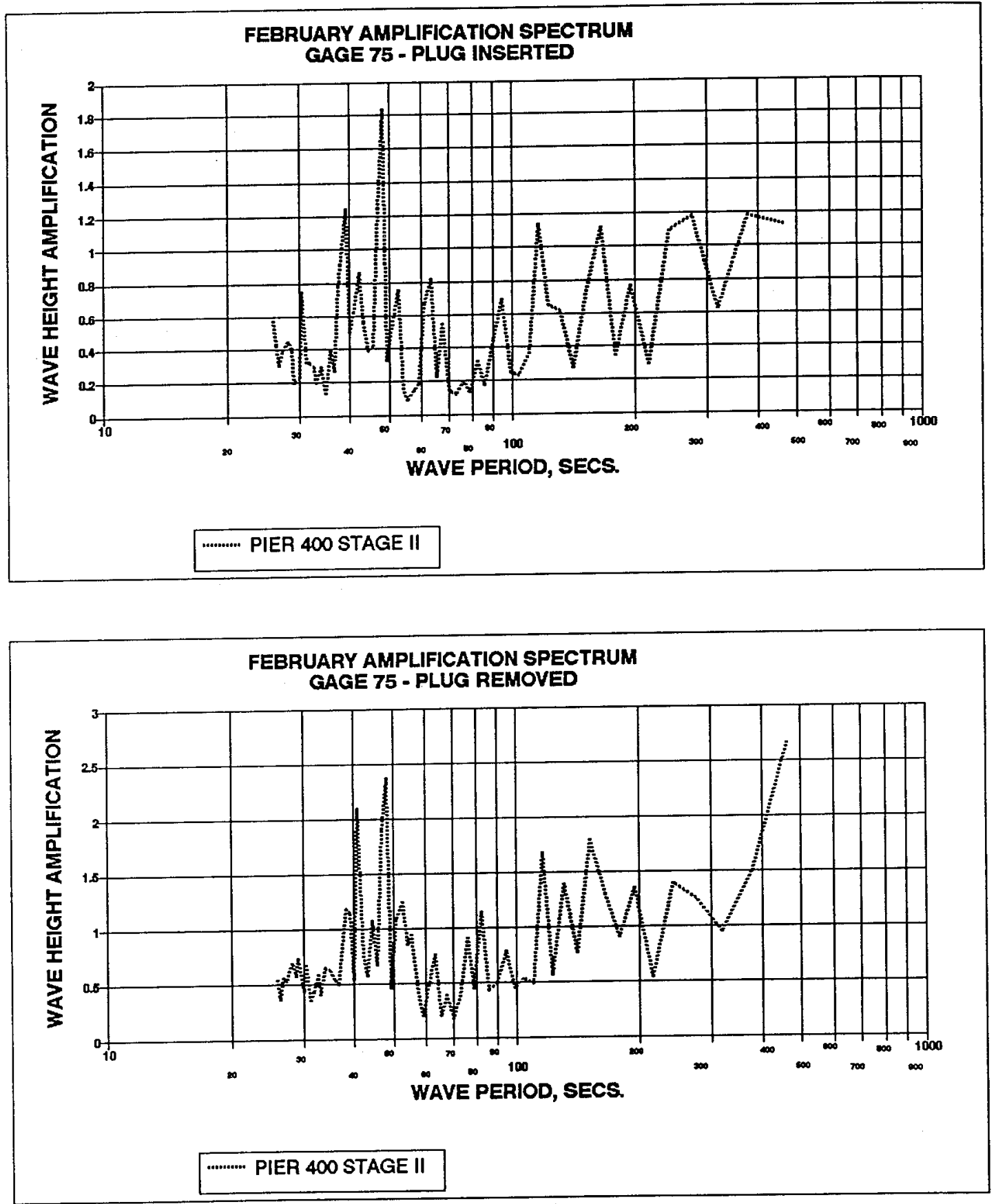

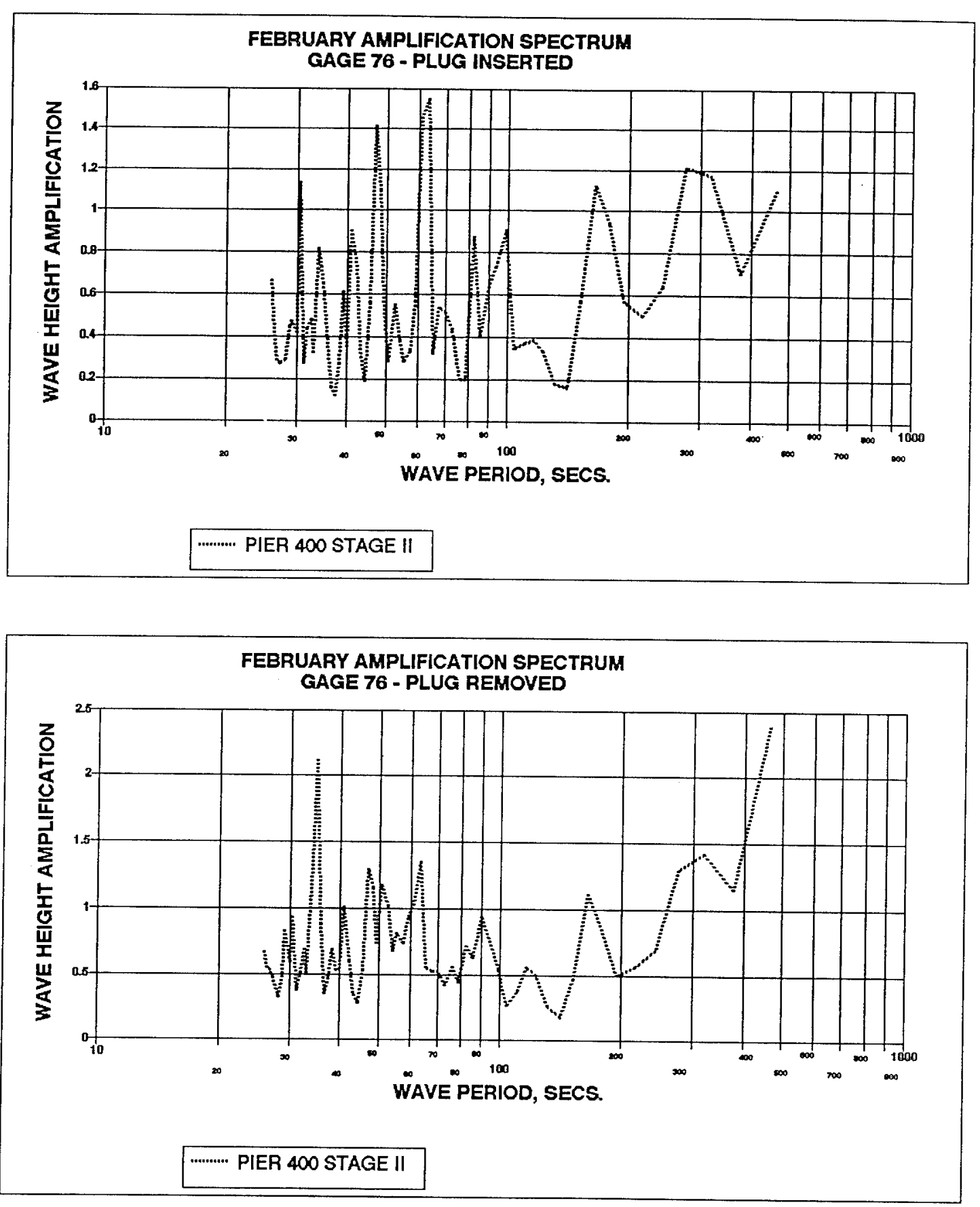


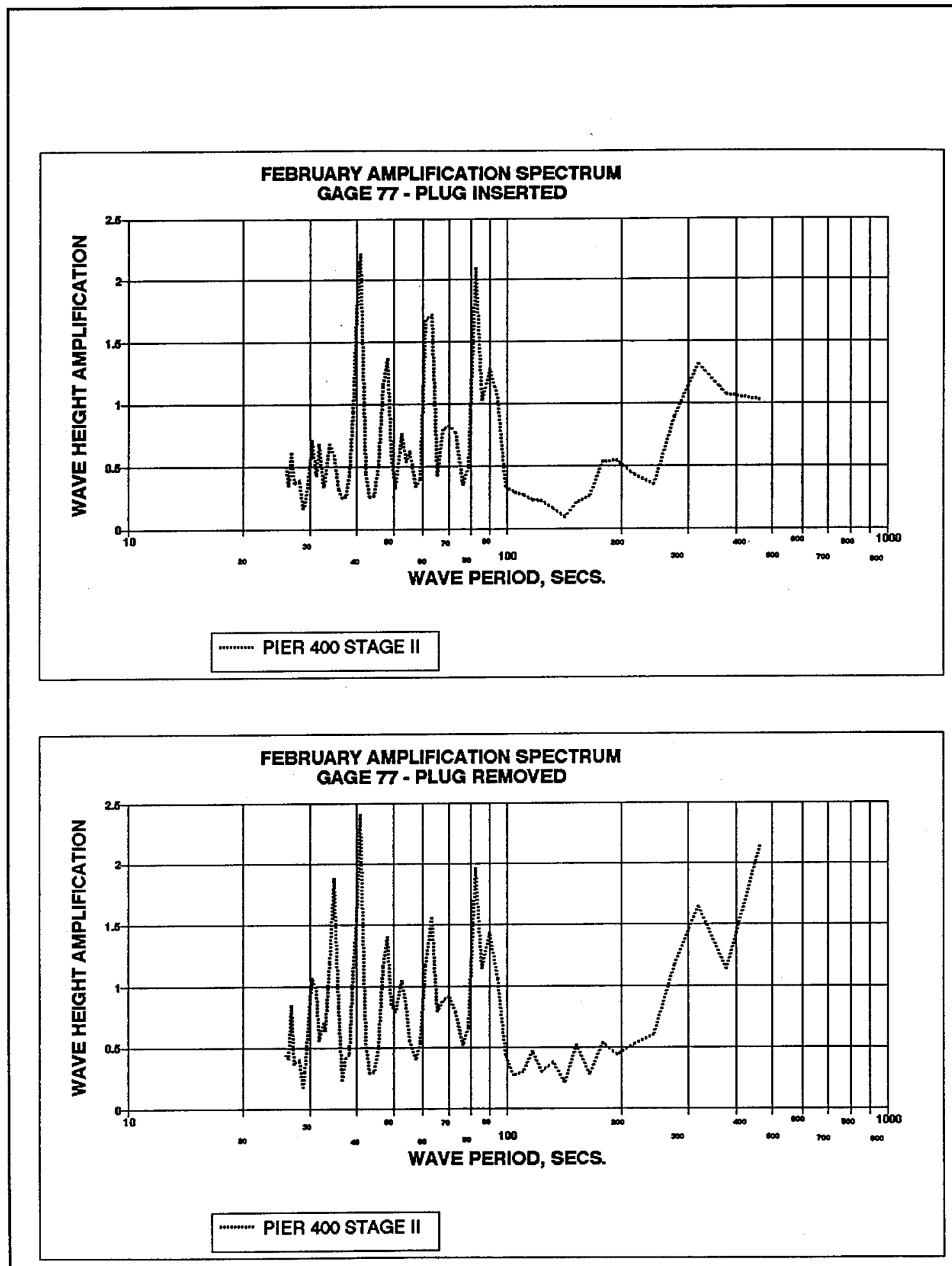




\section{Appendix F Wave Amplification, January Spectrum, Gages 1-55}



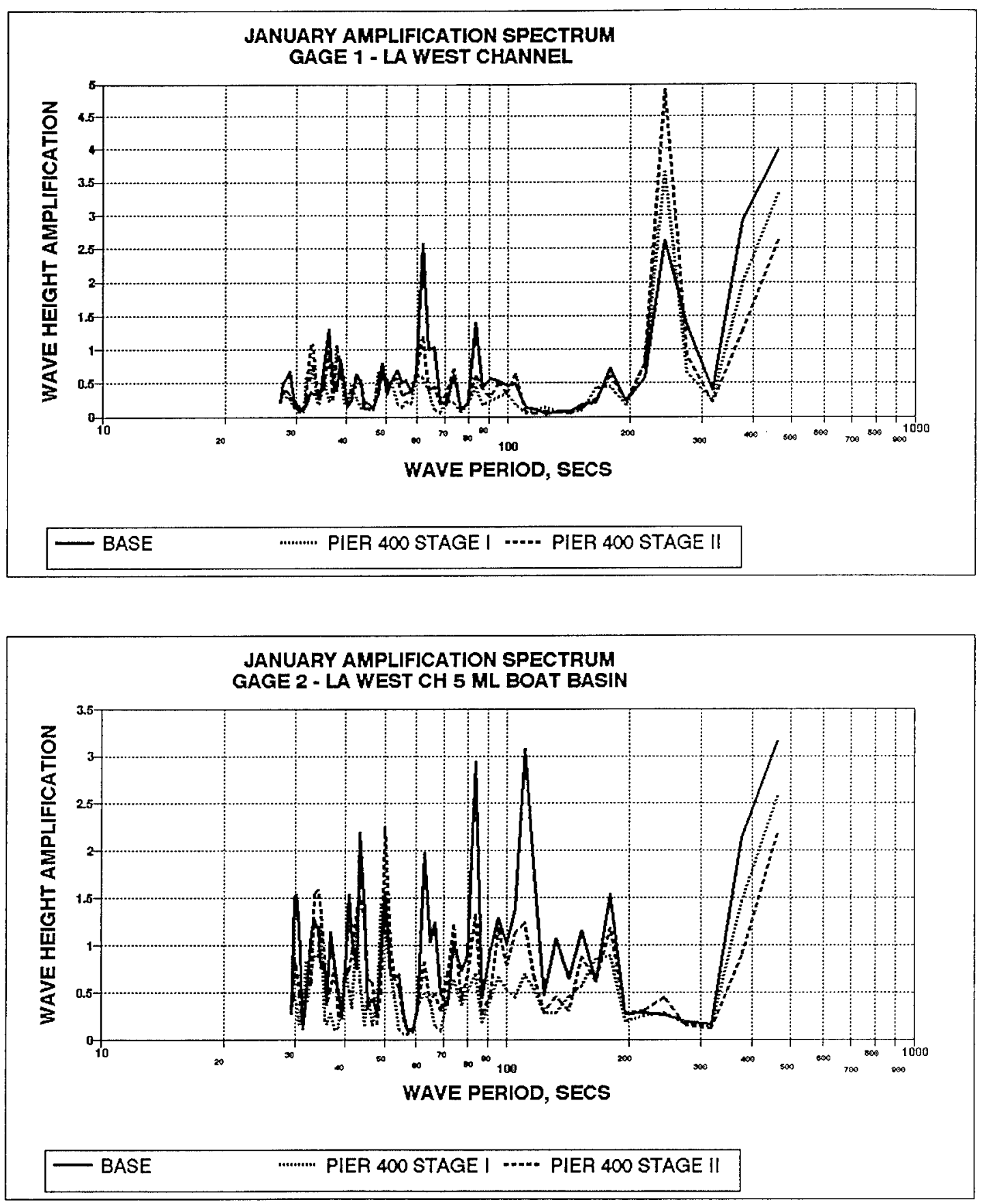


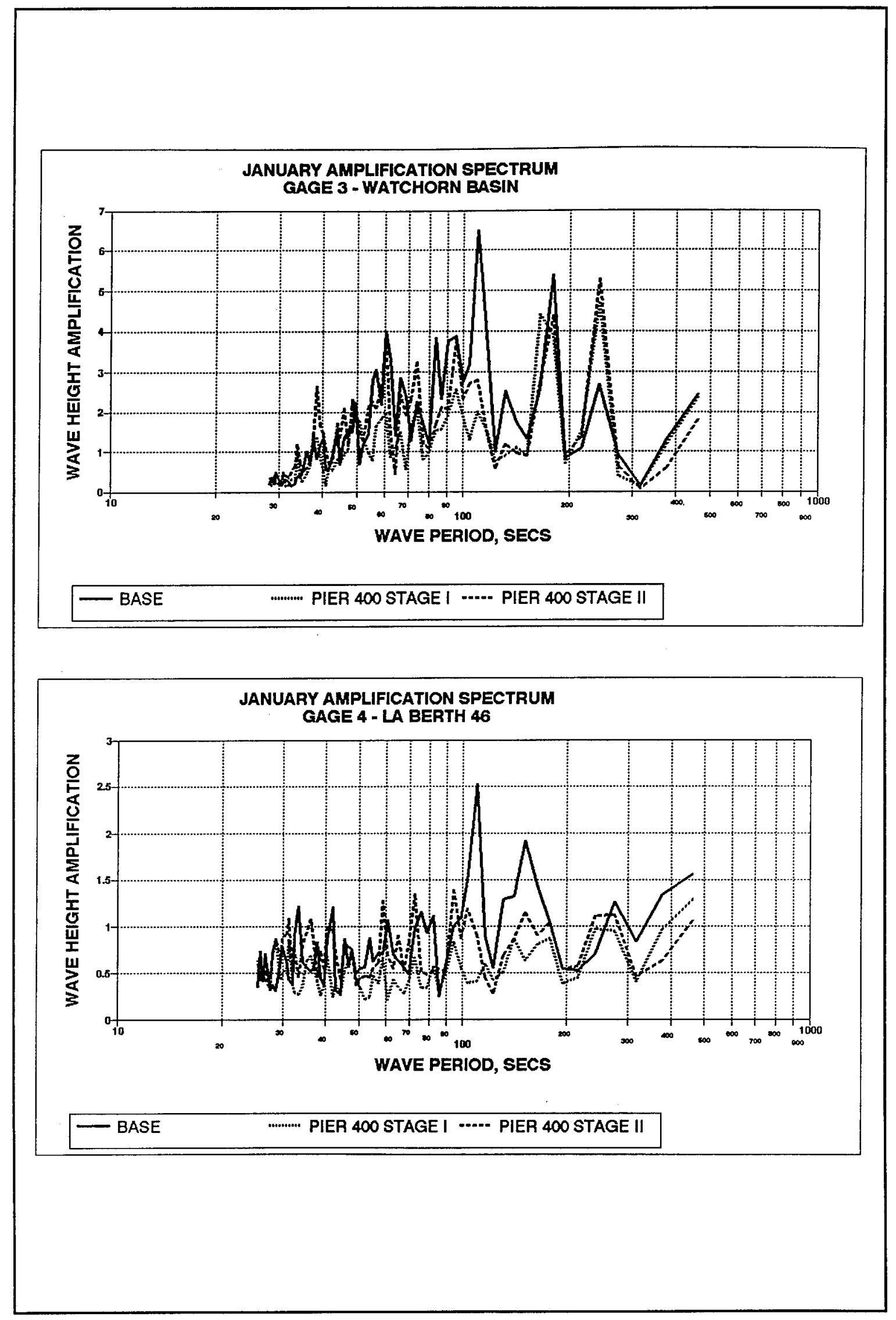



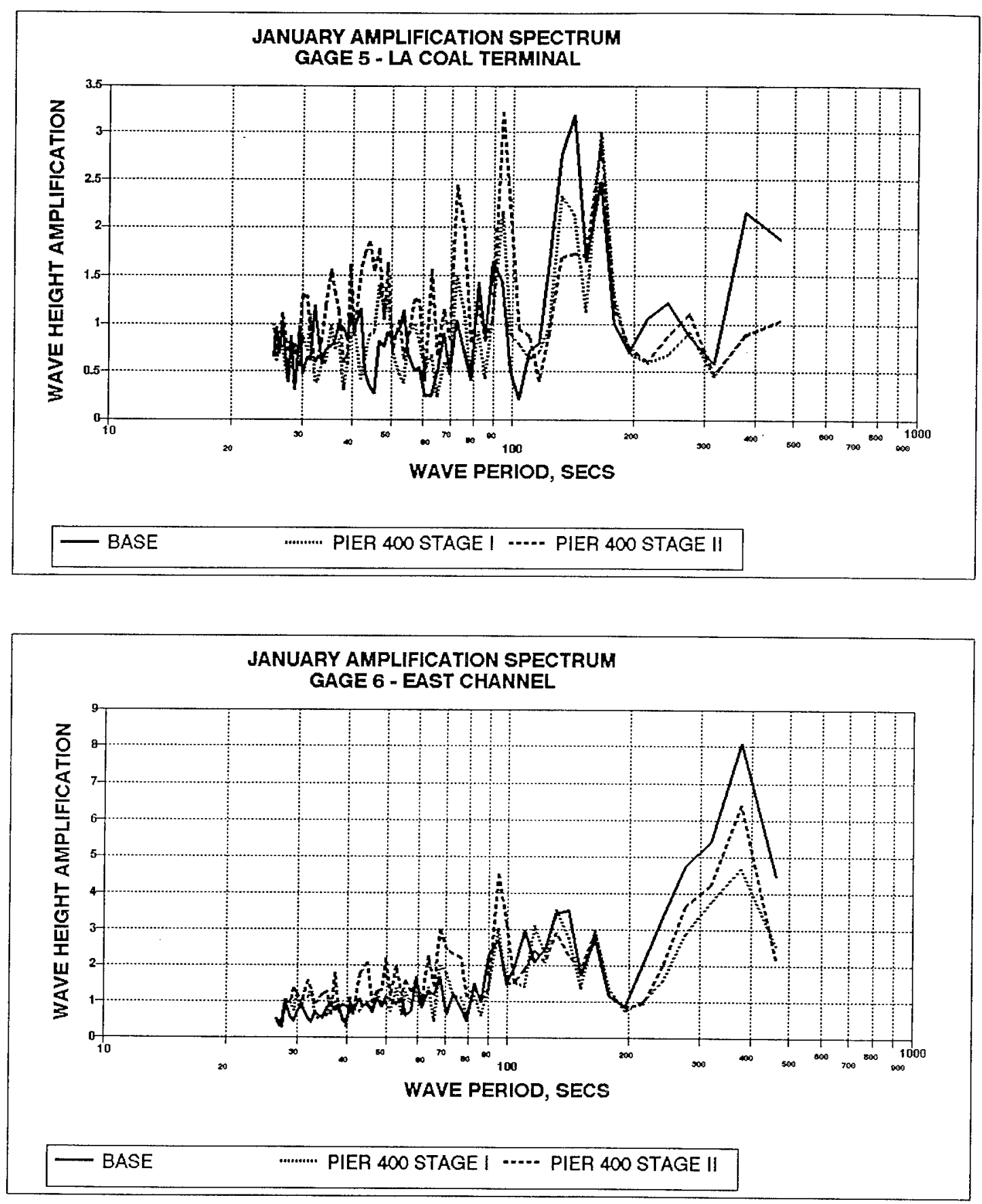

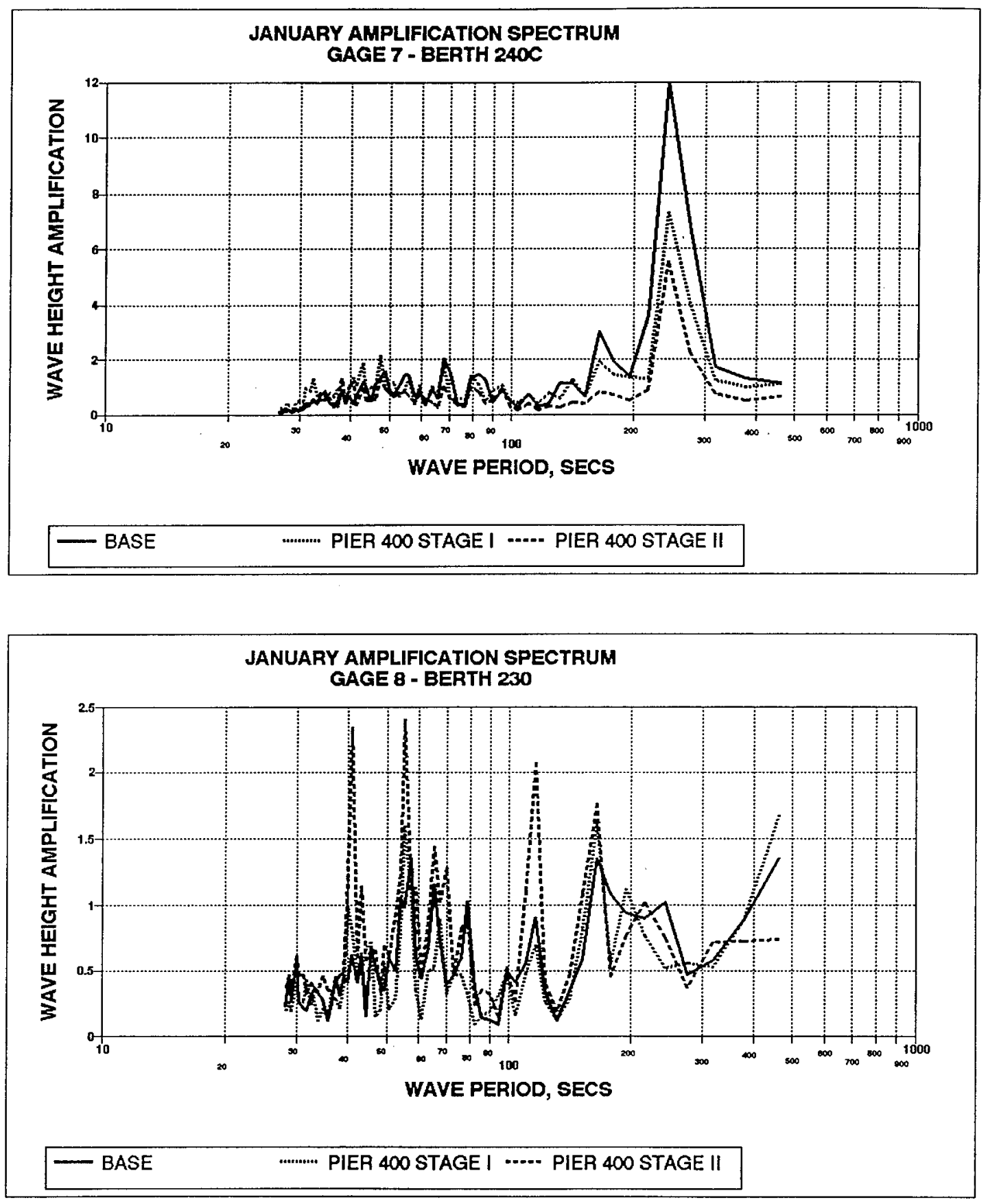

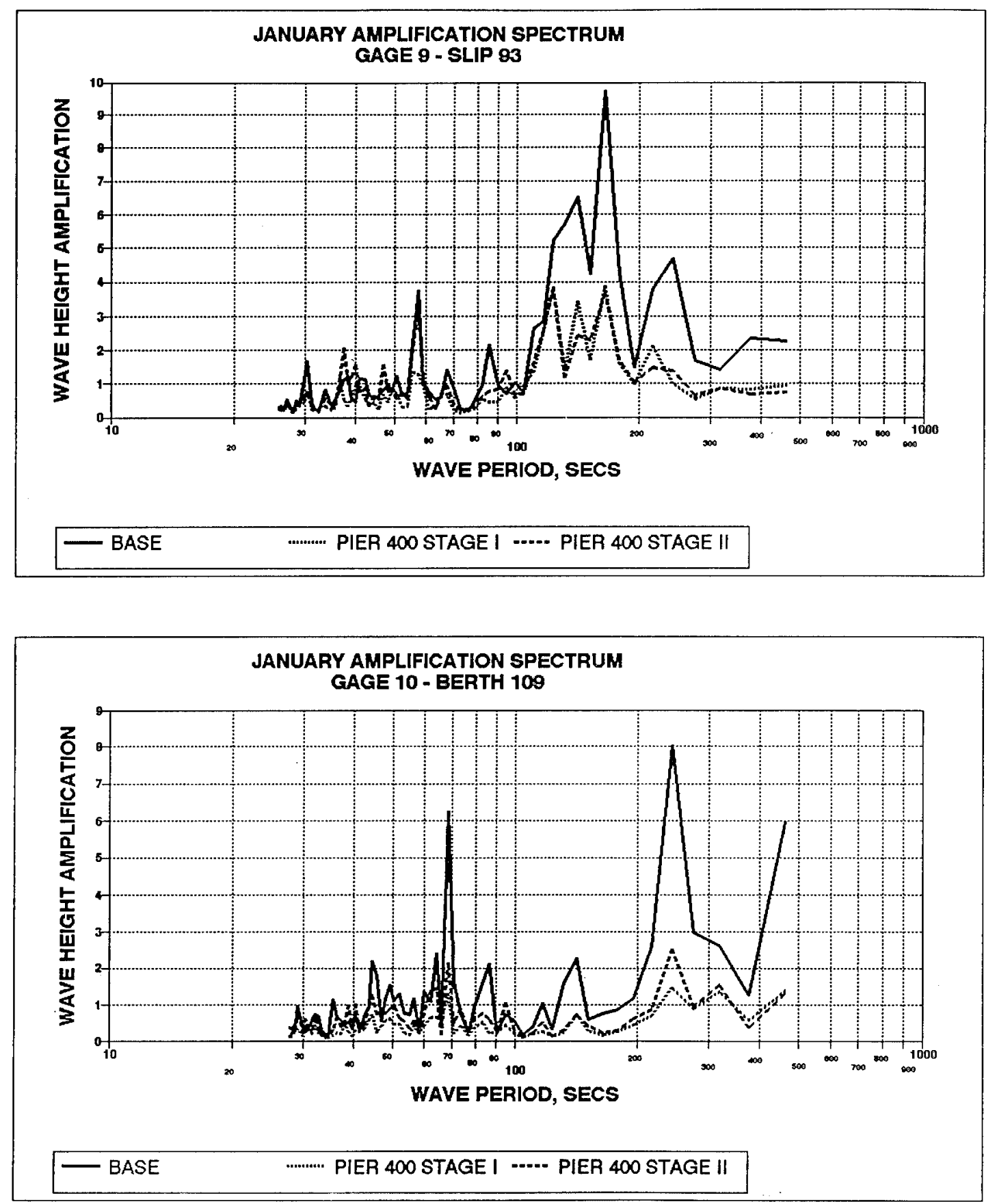

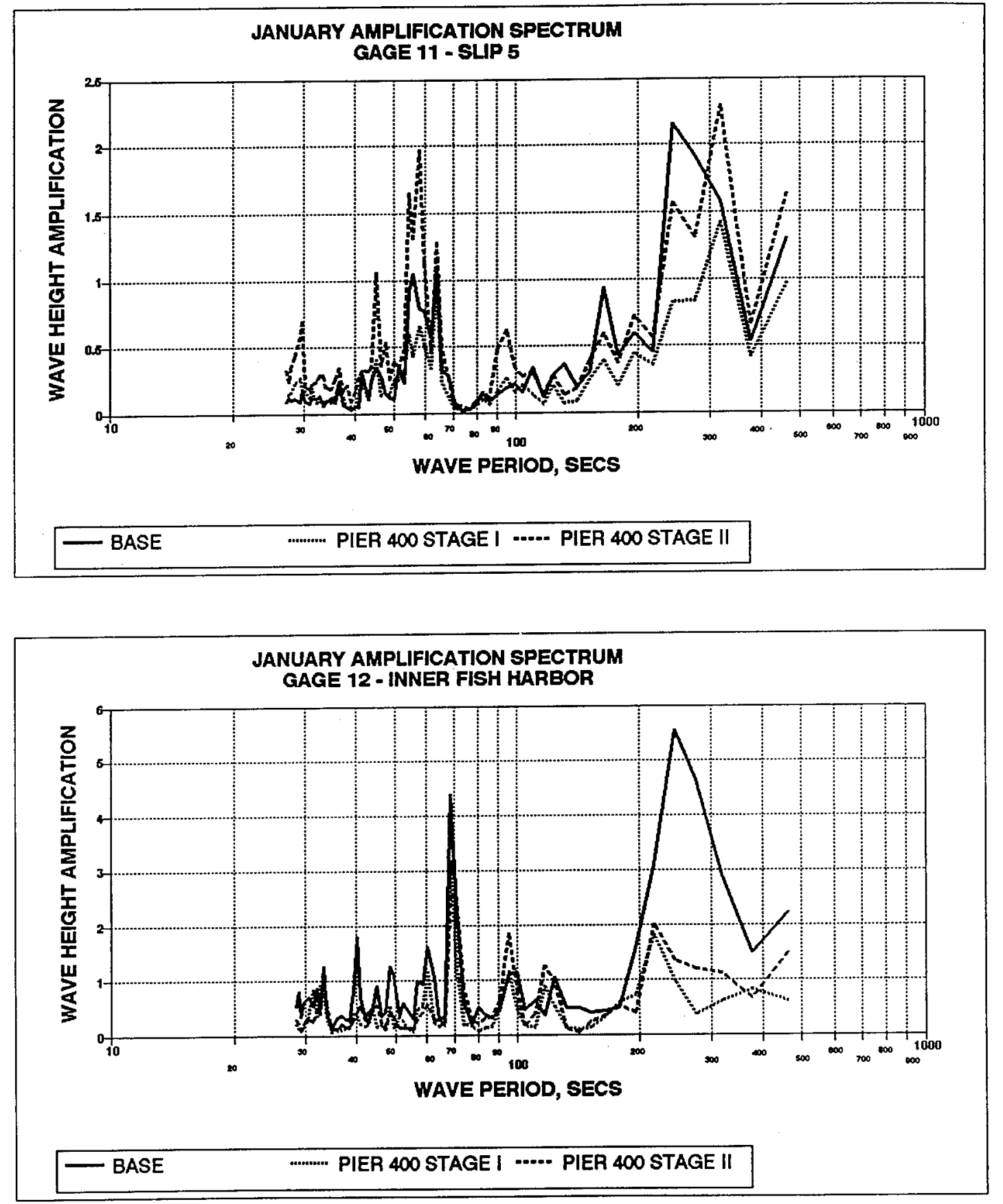


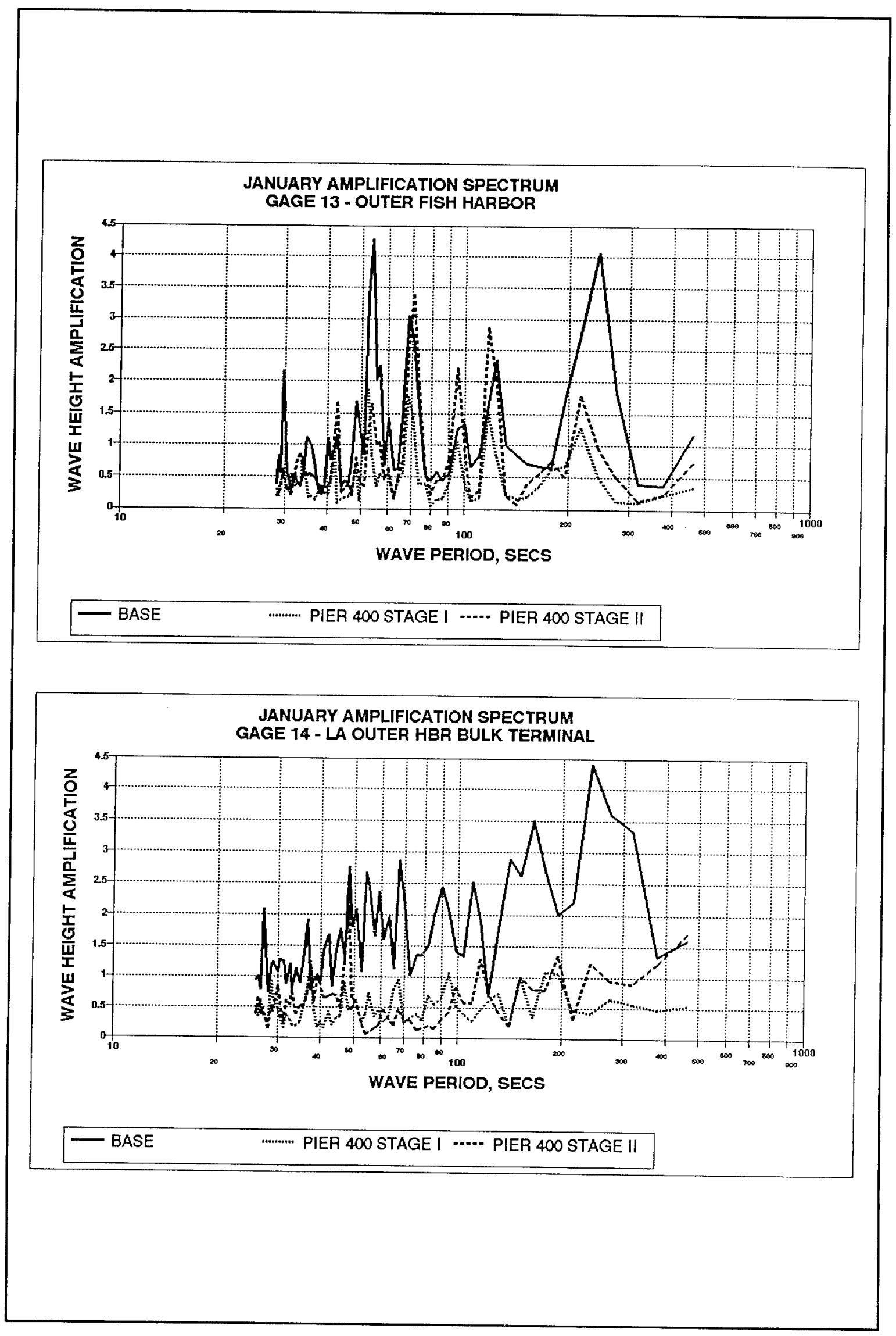



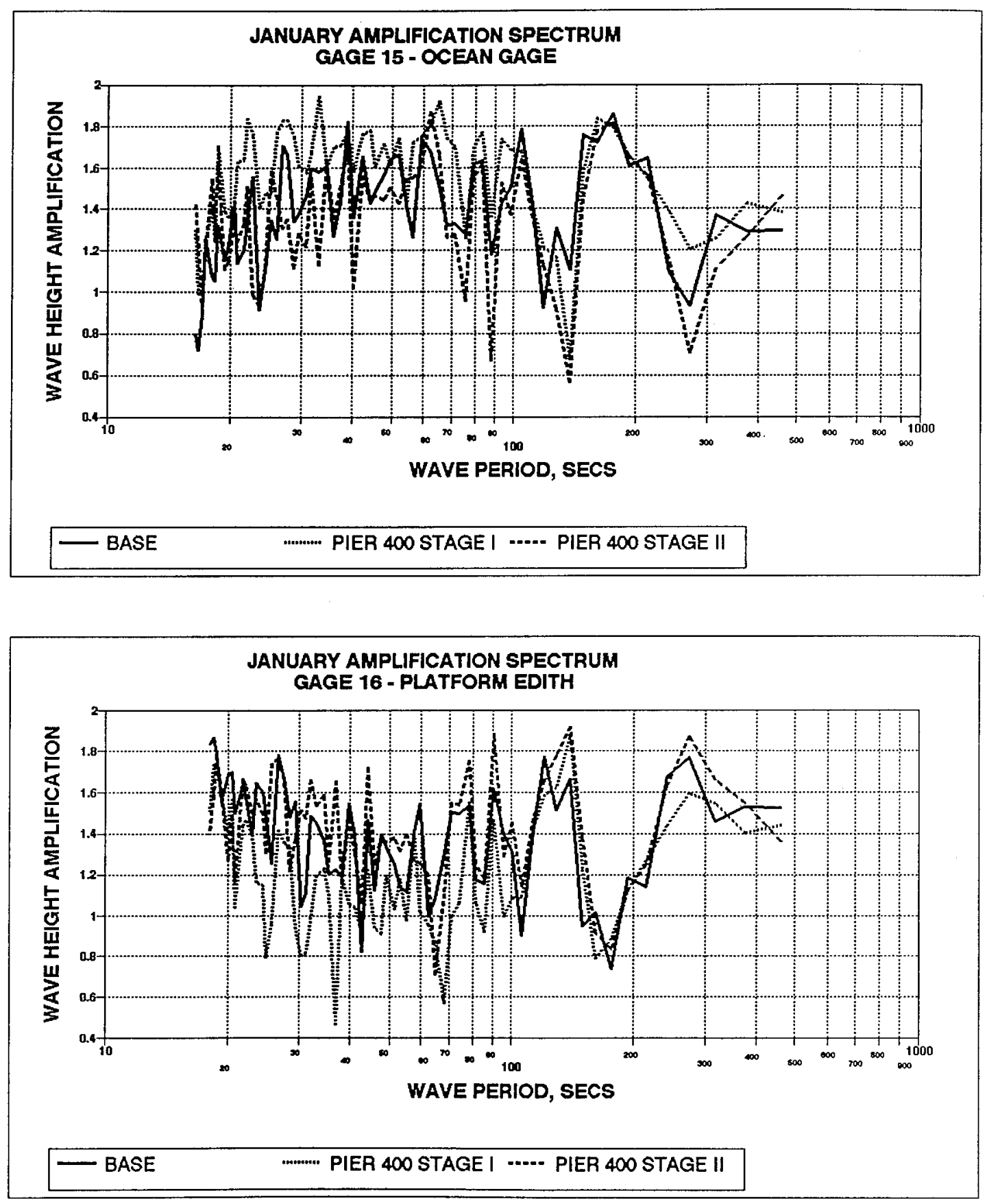

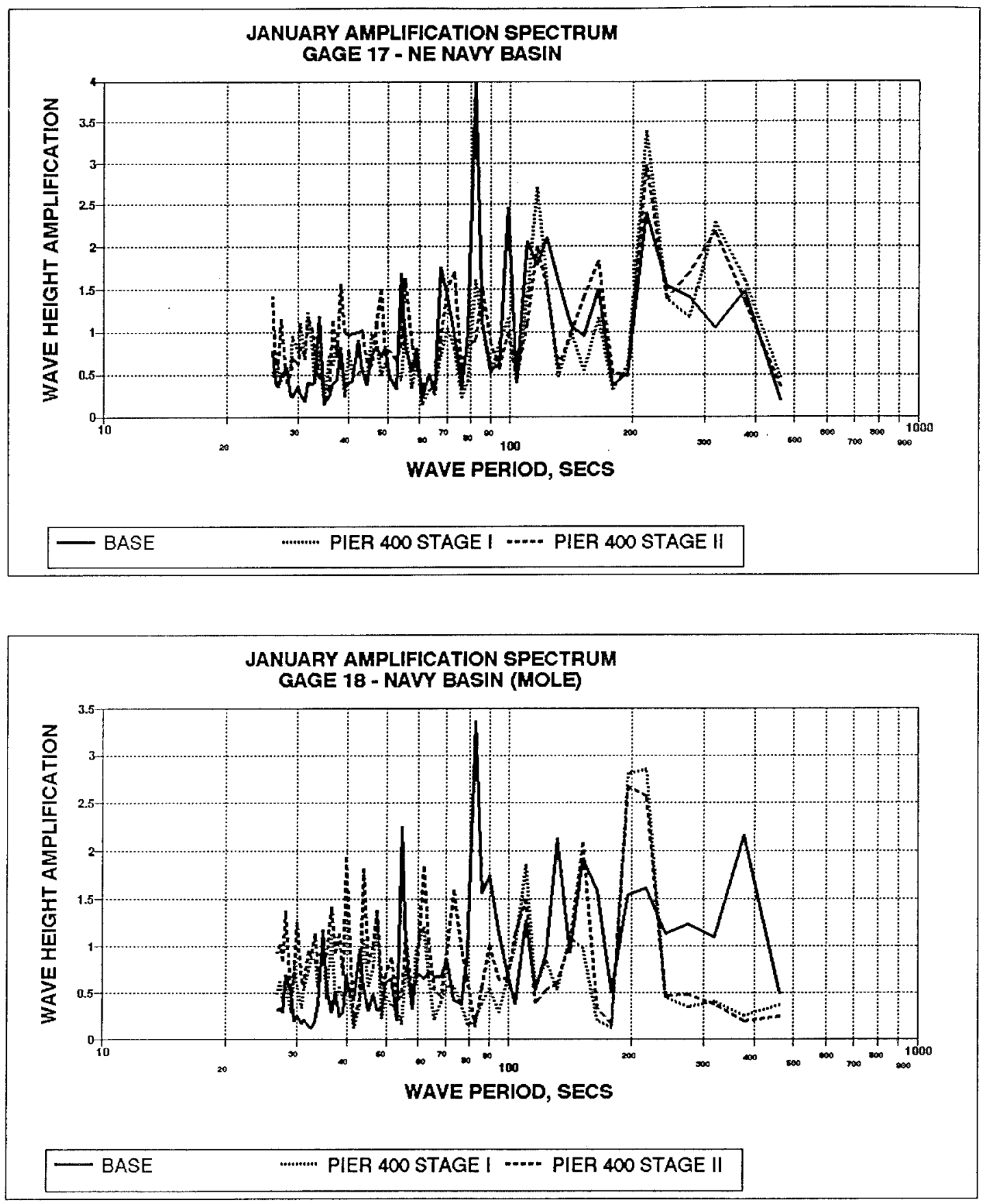

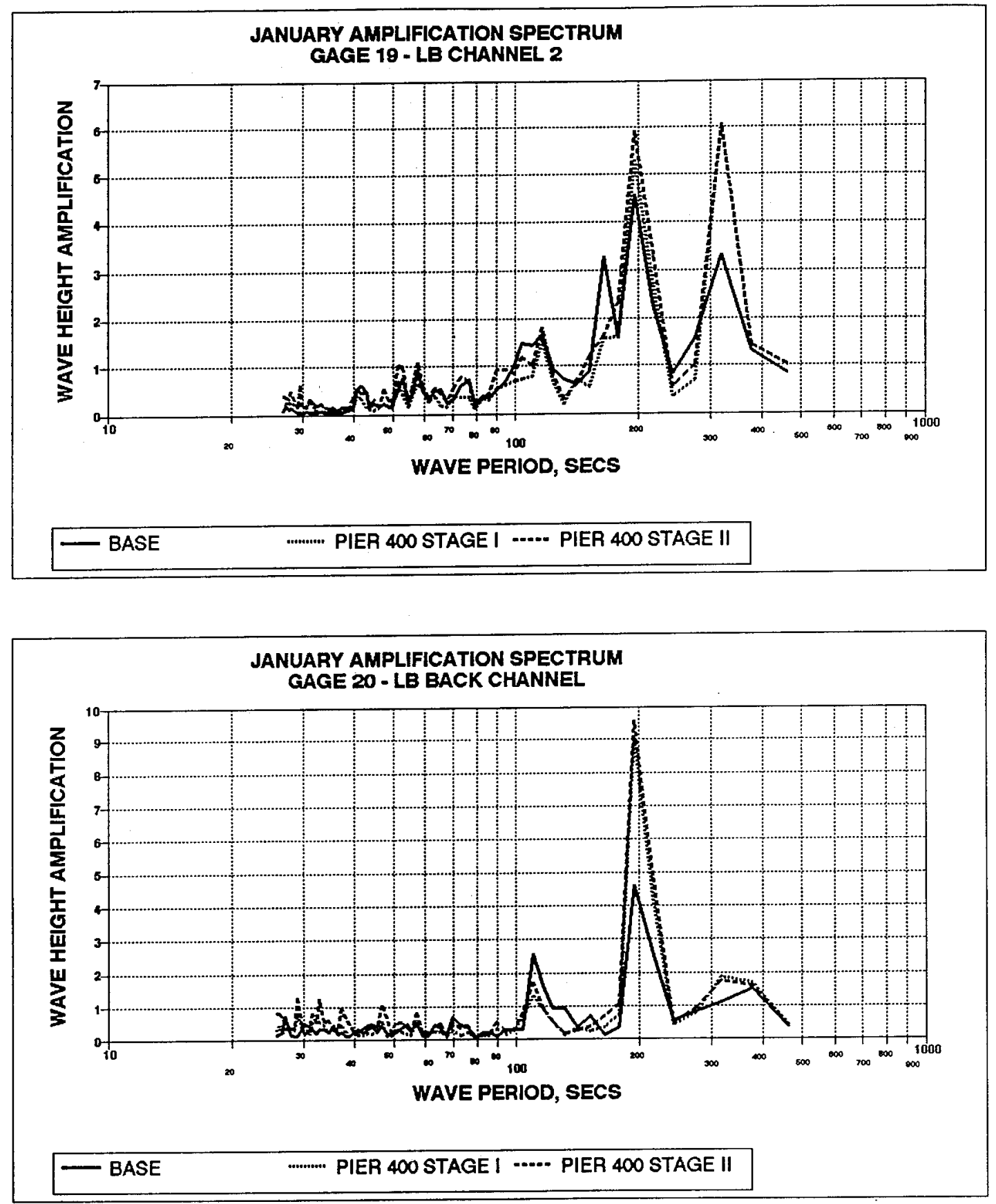

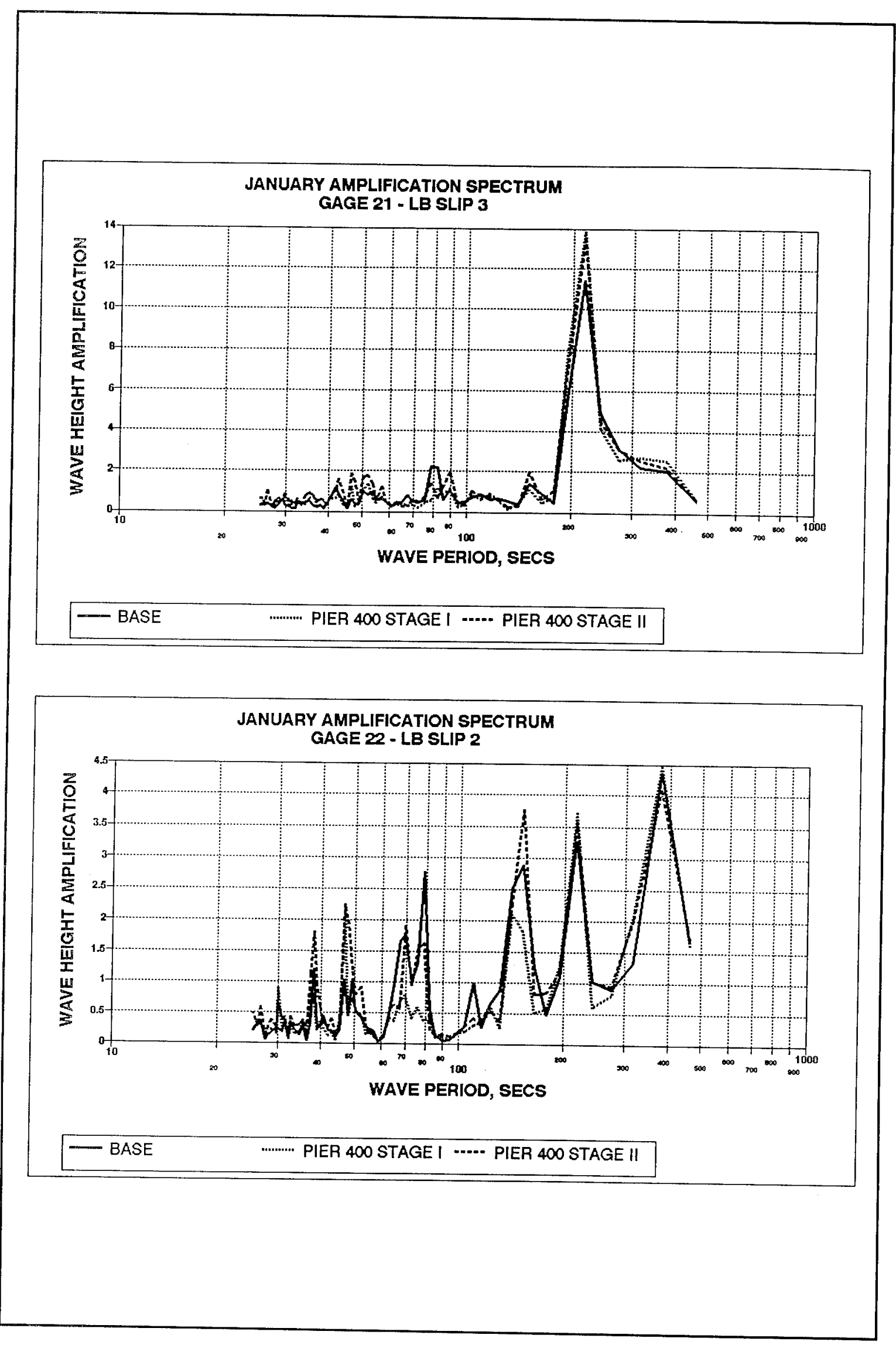

F12

Appendix F January Spectrum, Gages 1-55 

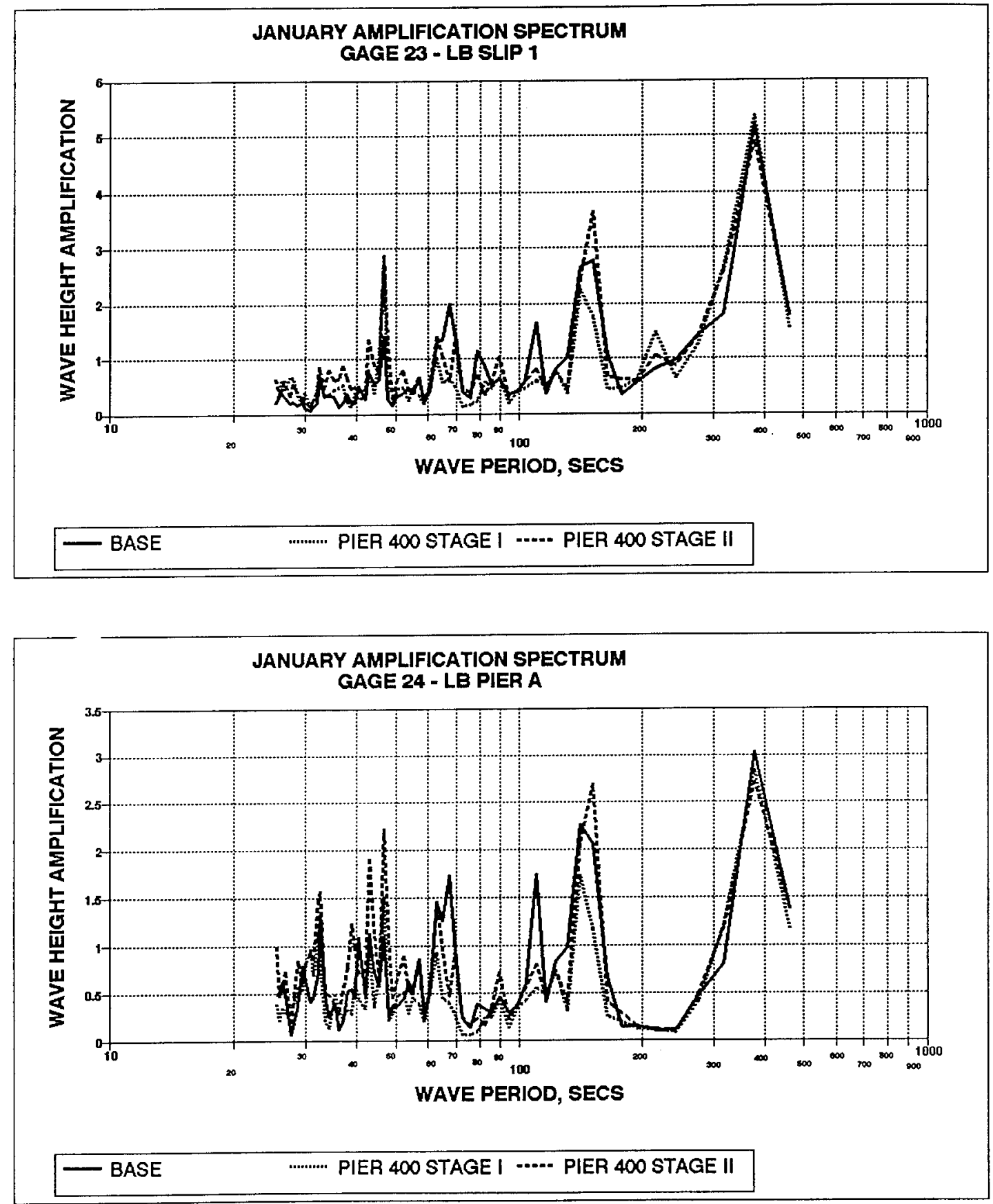

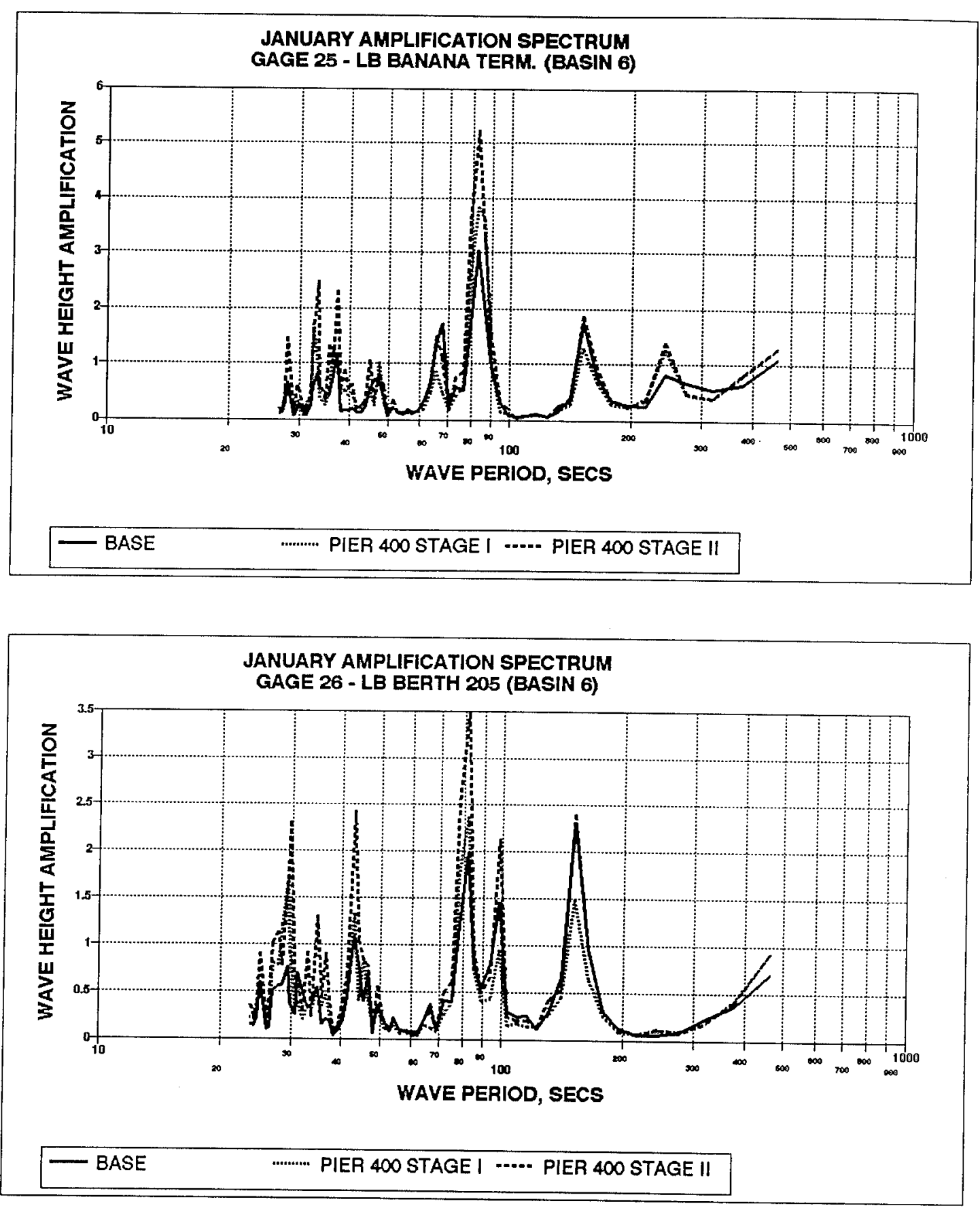

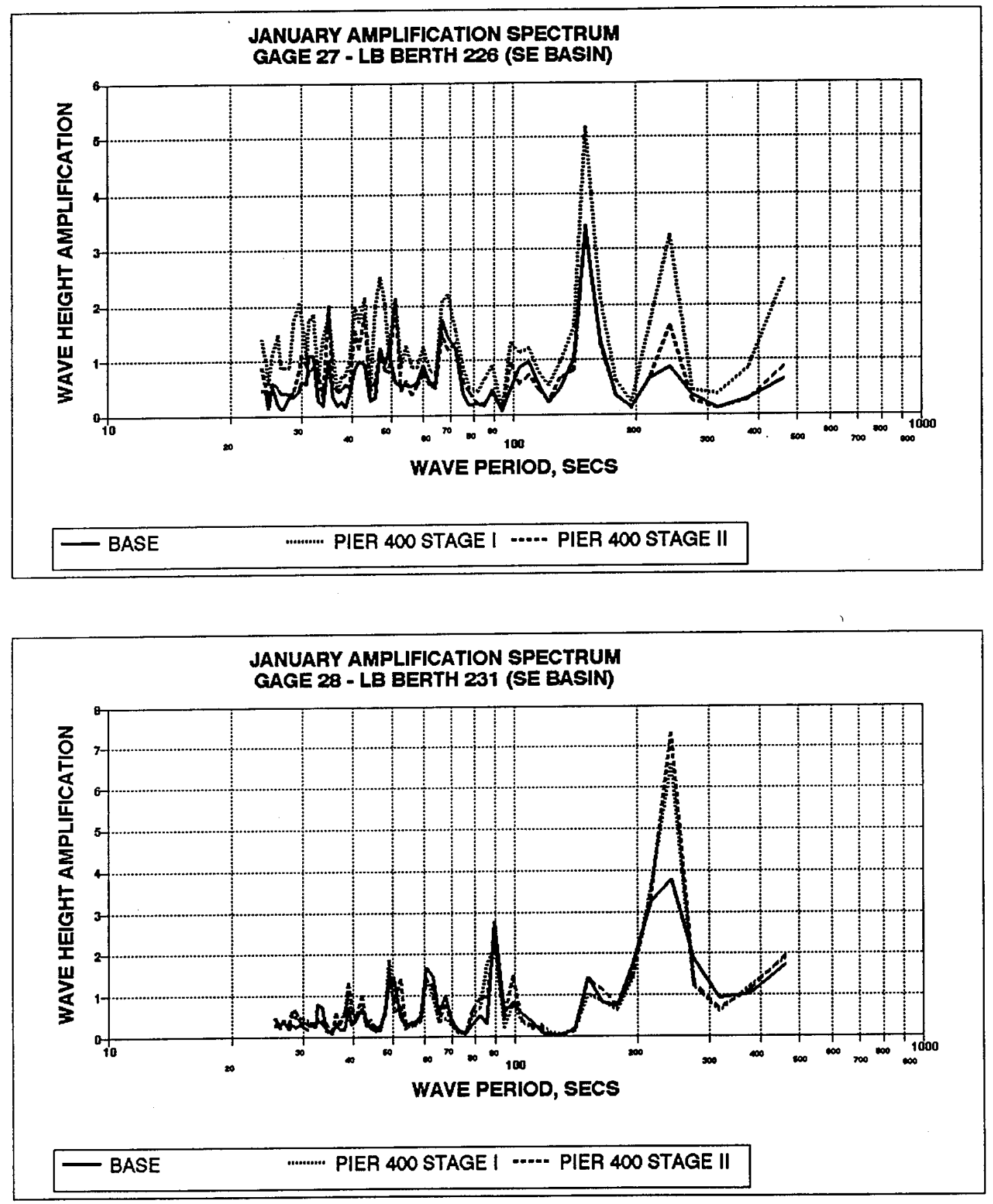

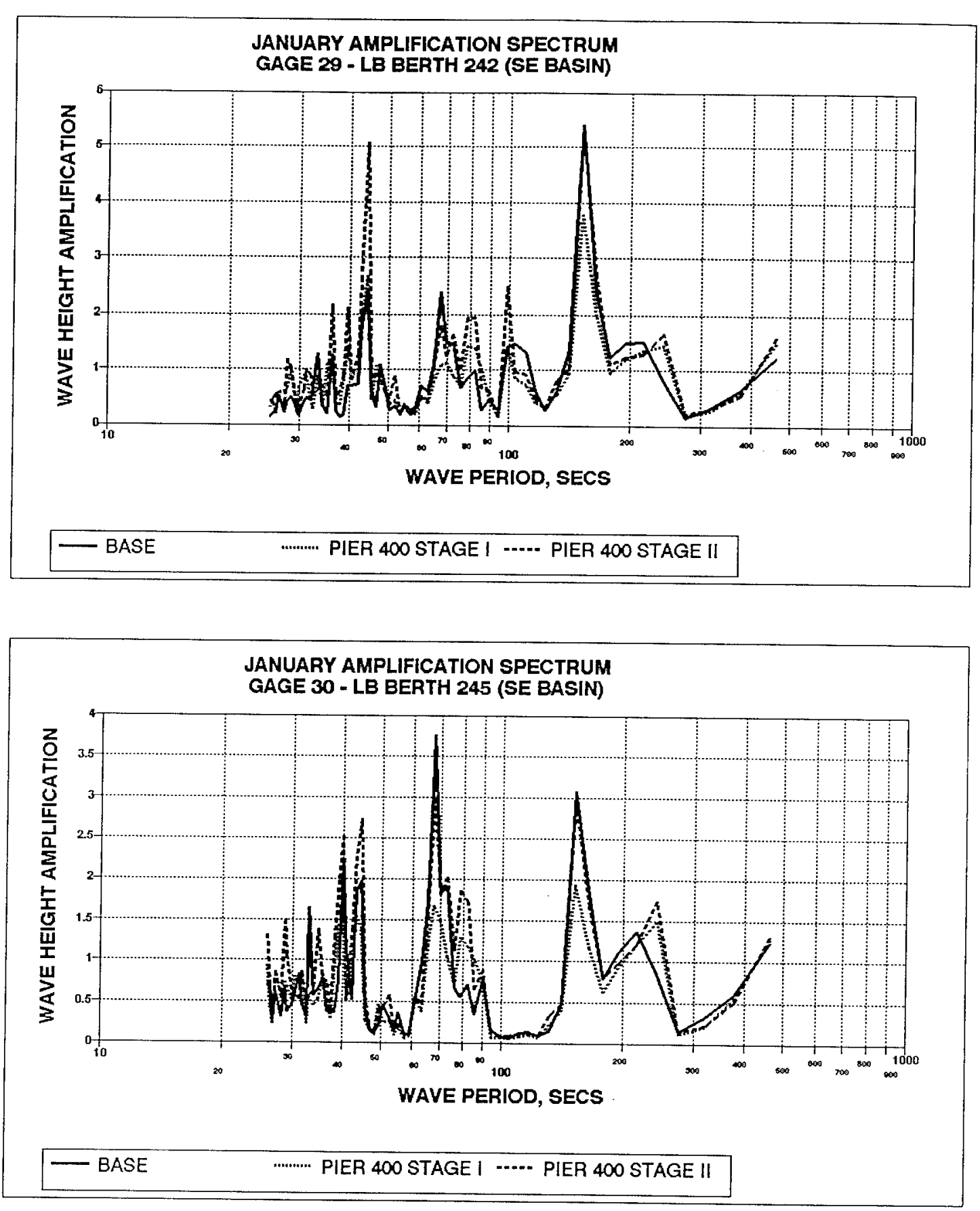

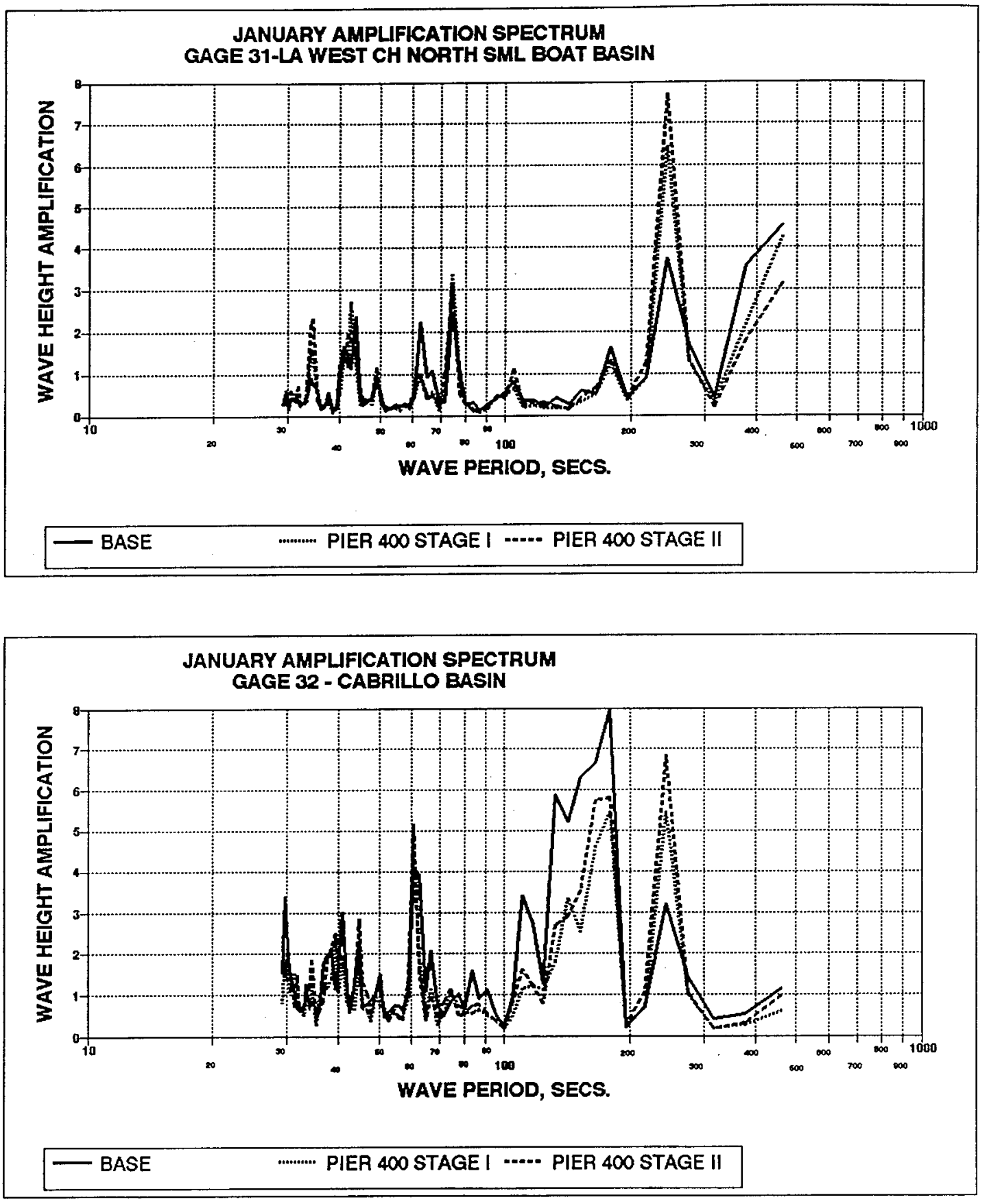

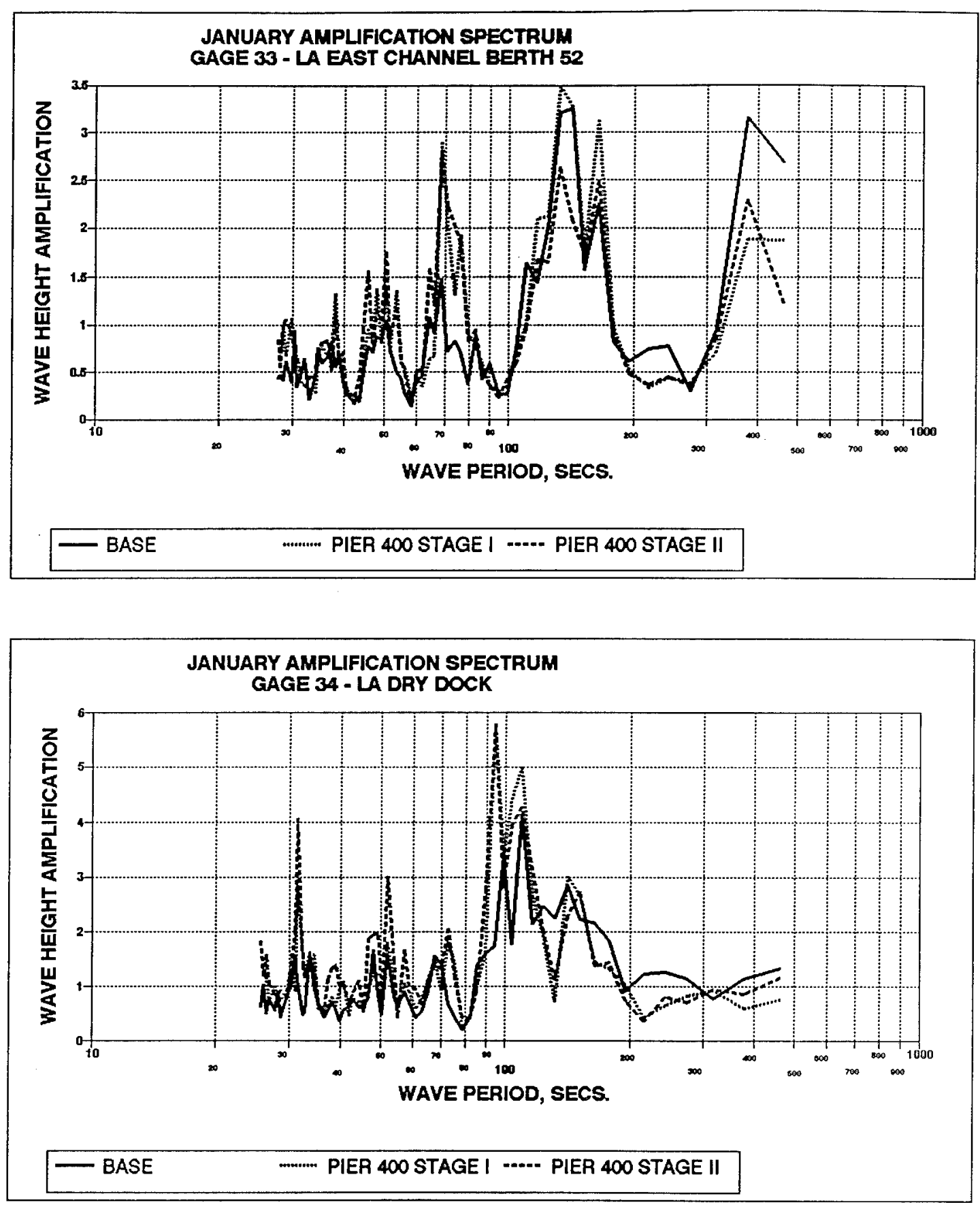

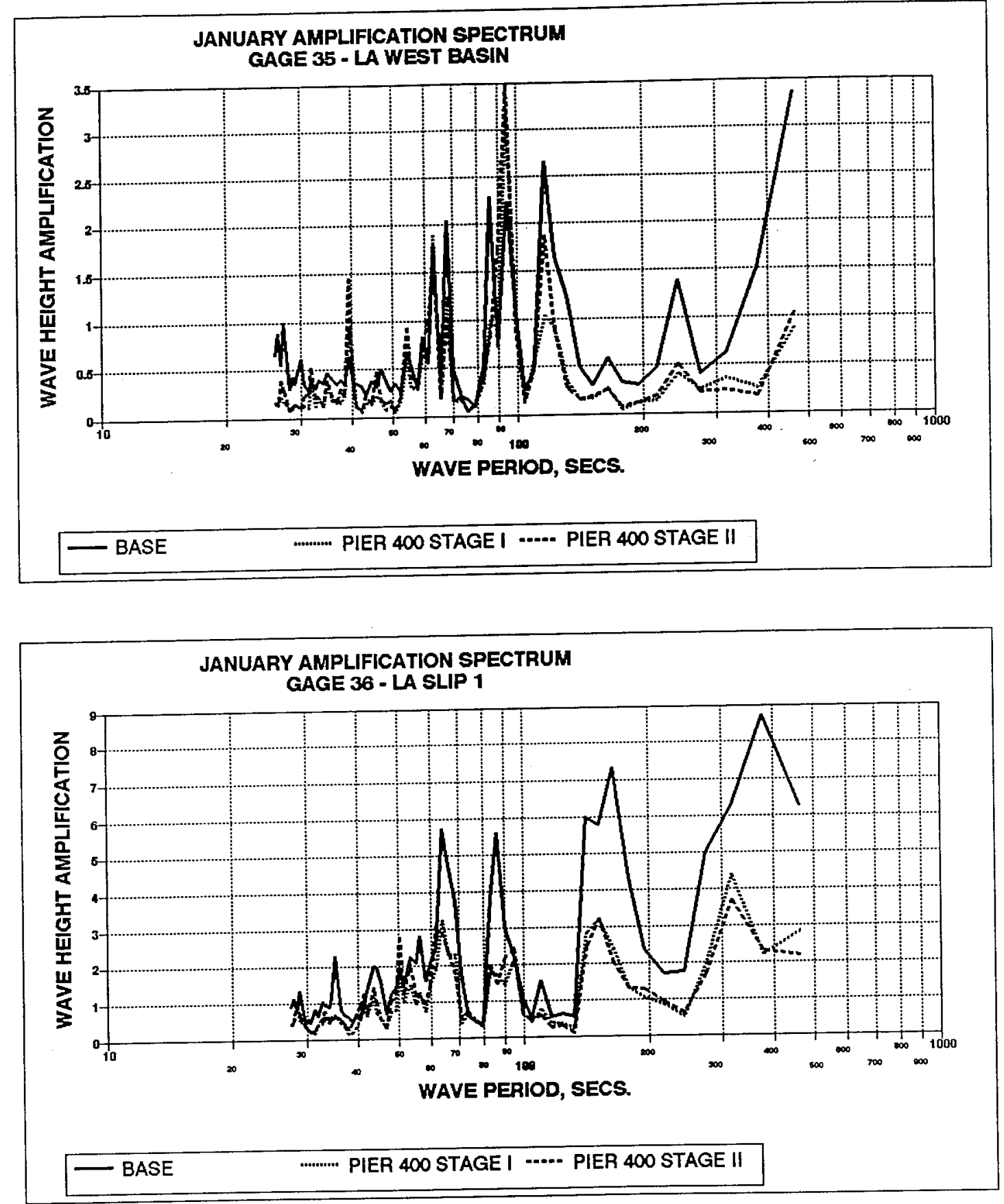


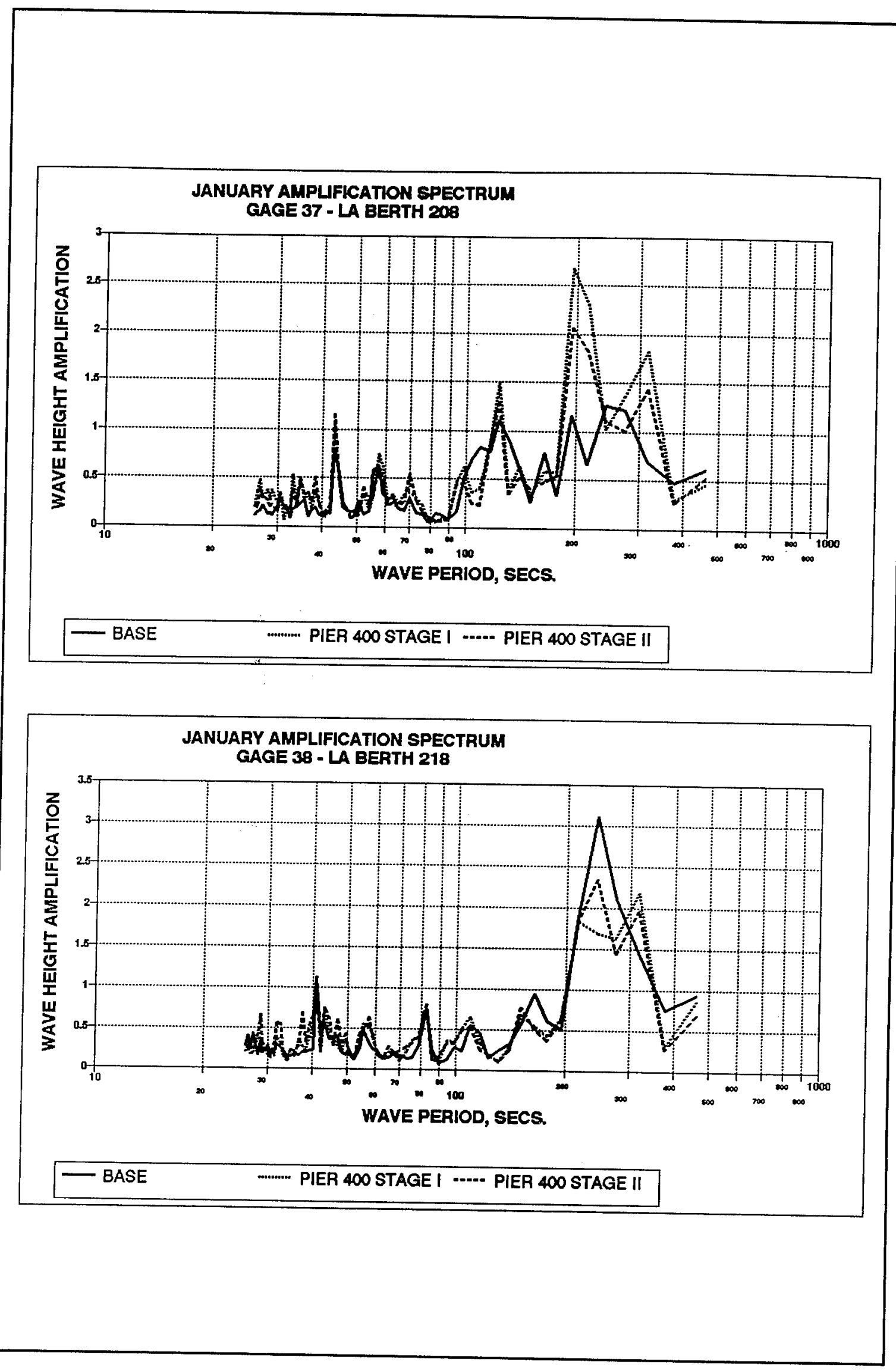



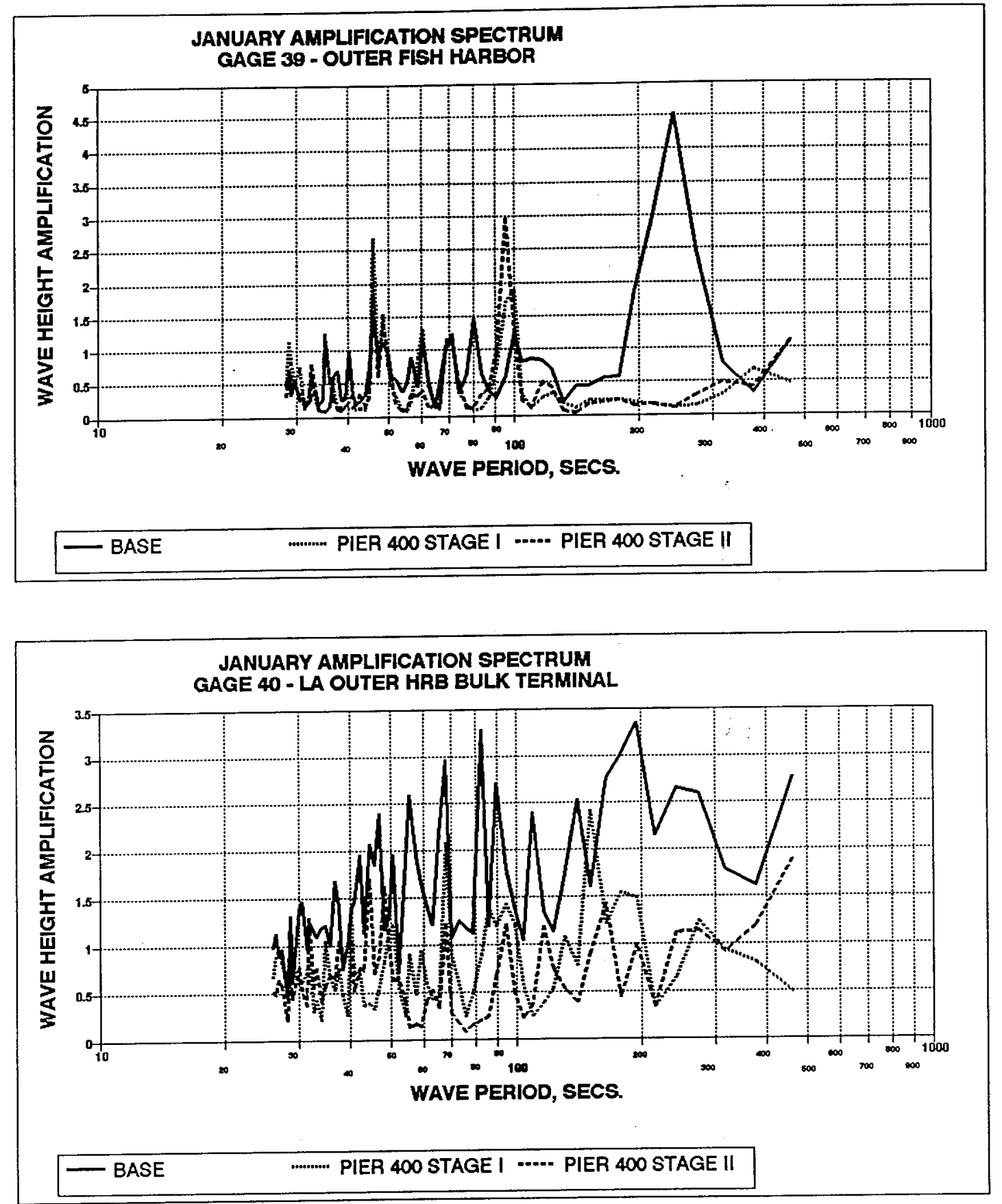

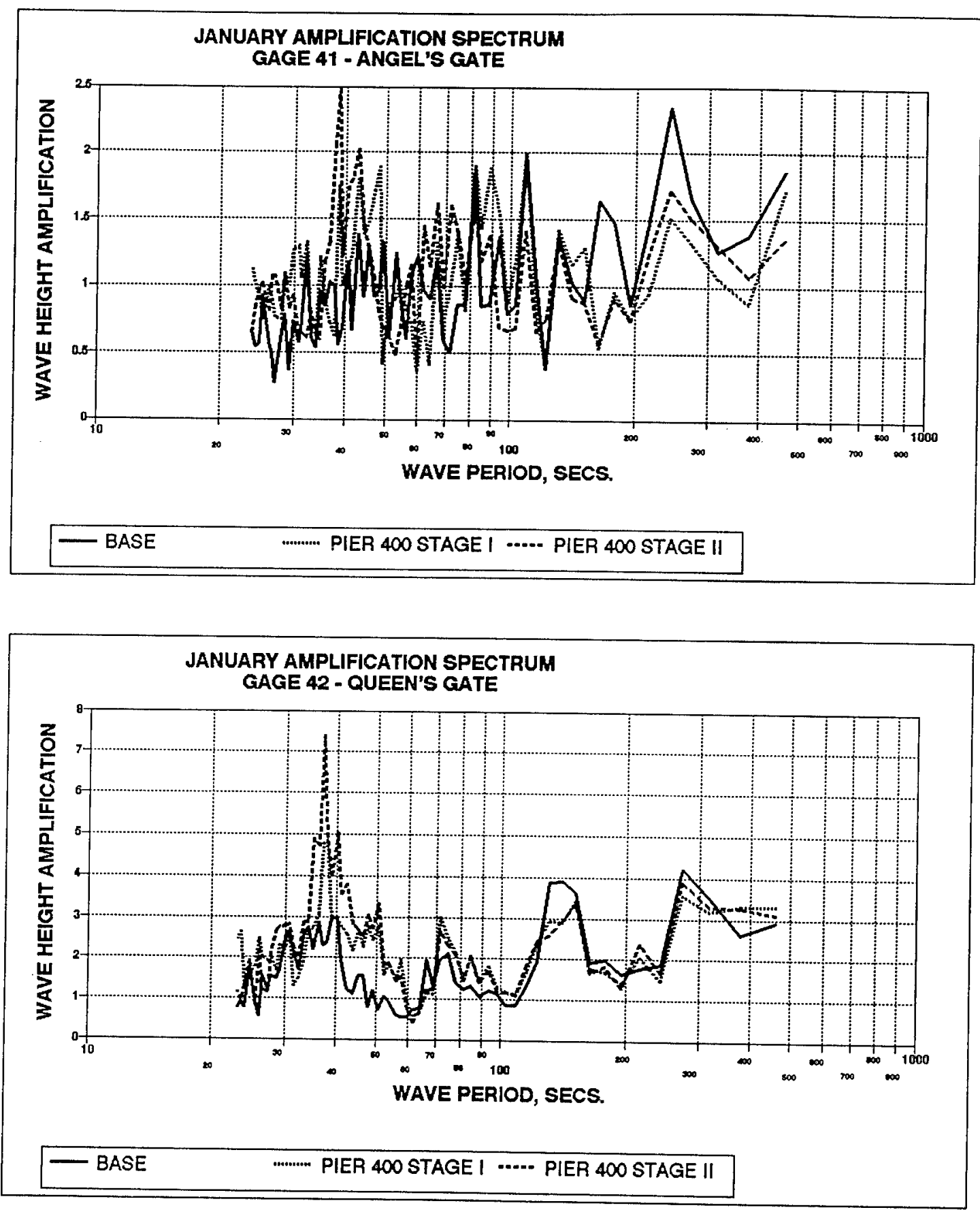

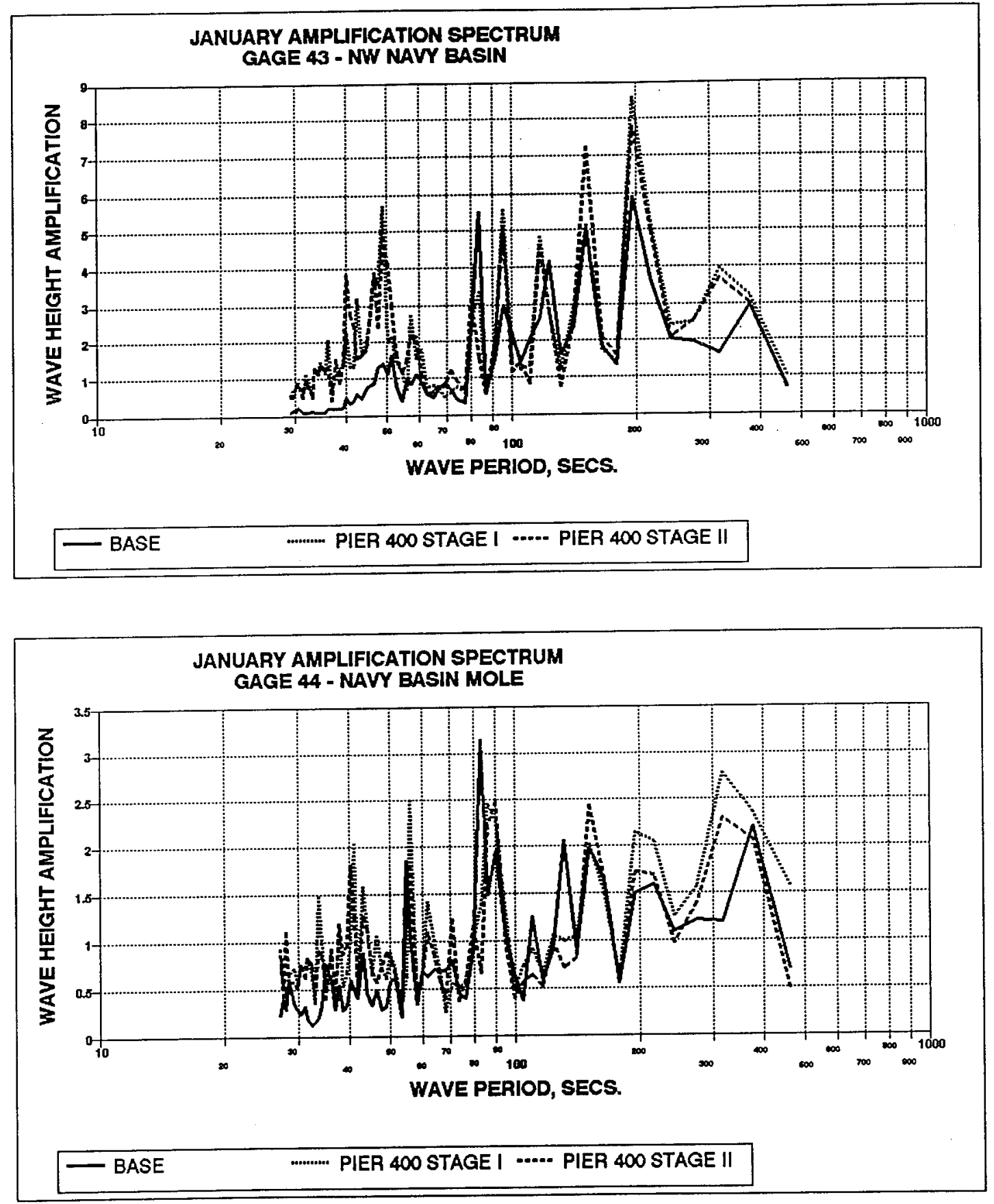


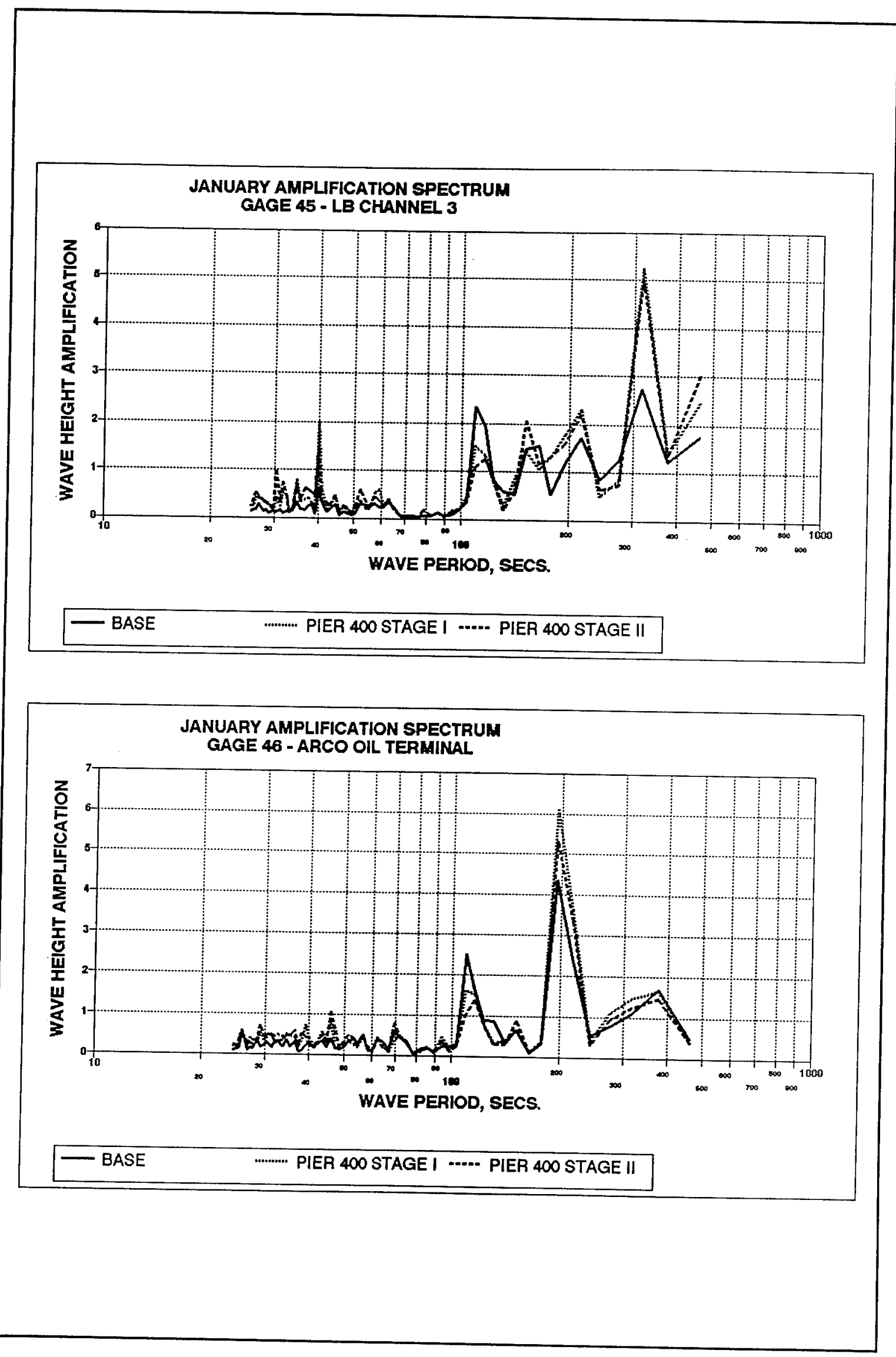



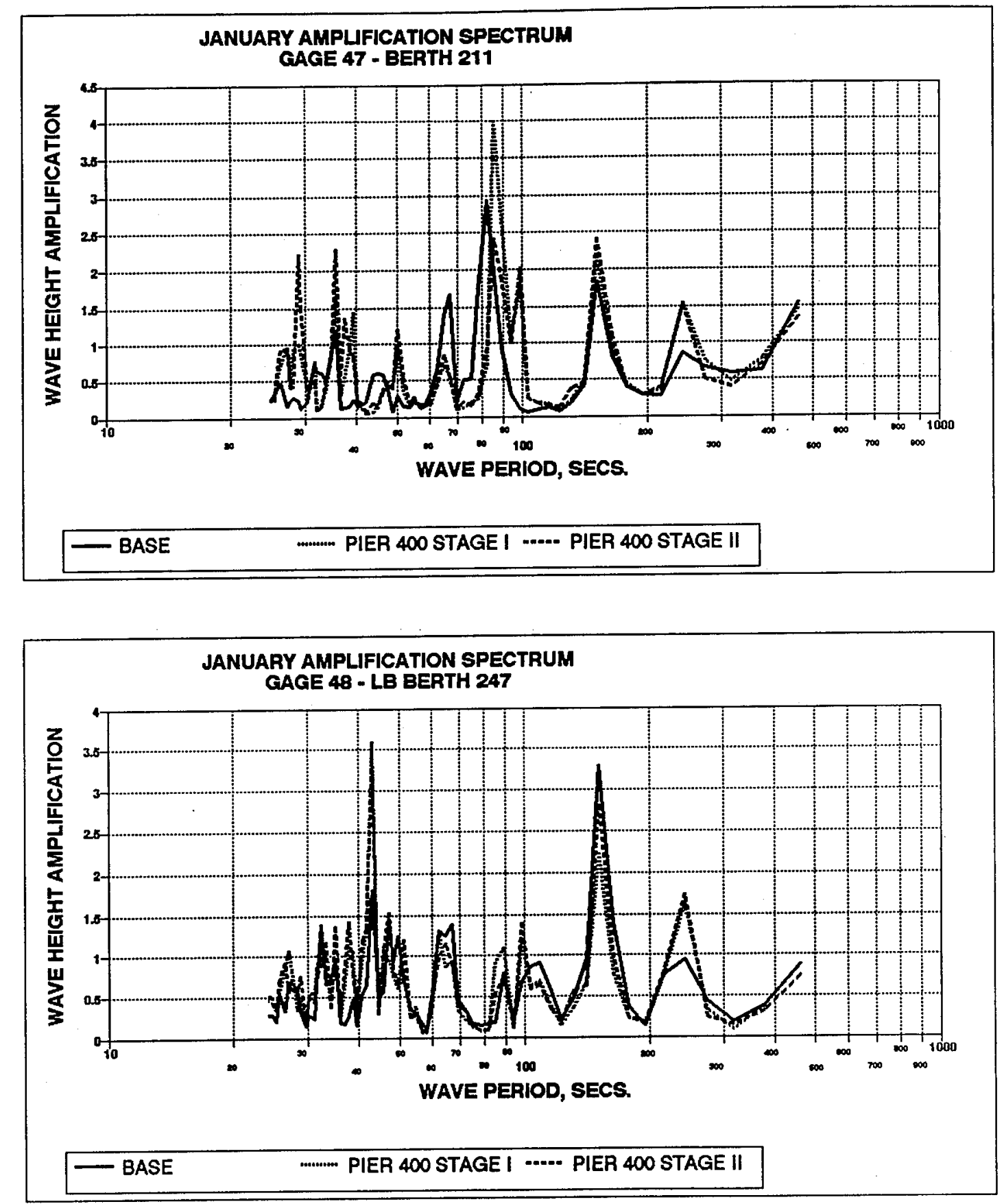

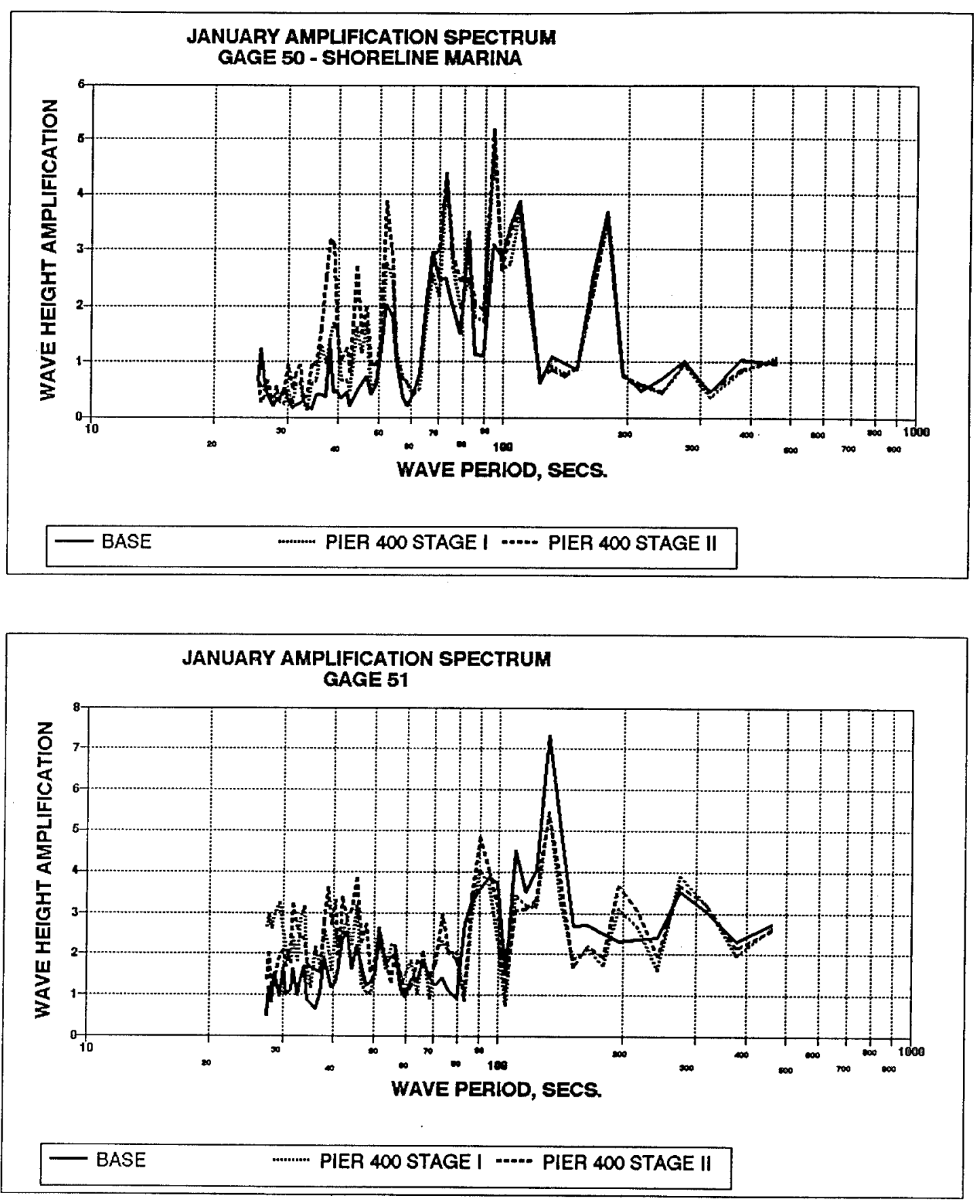

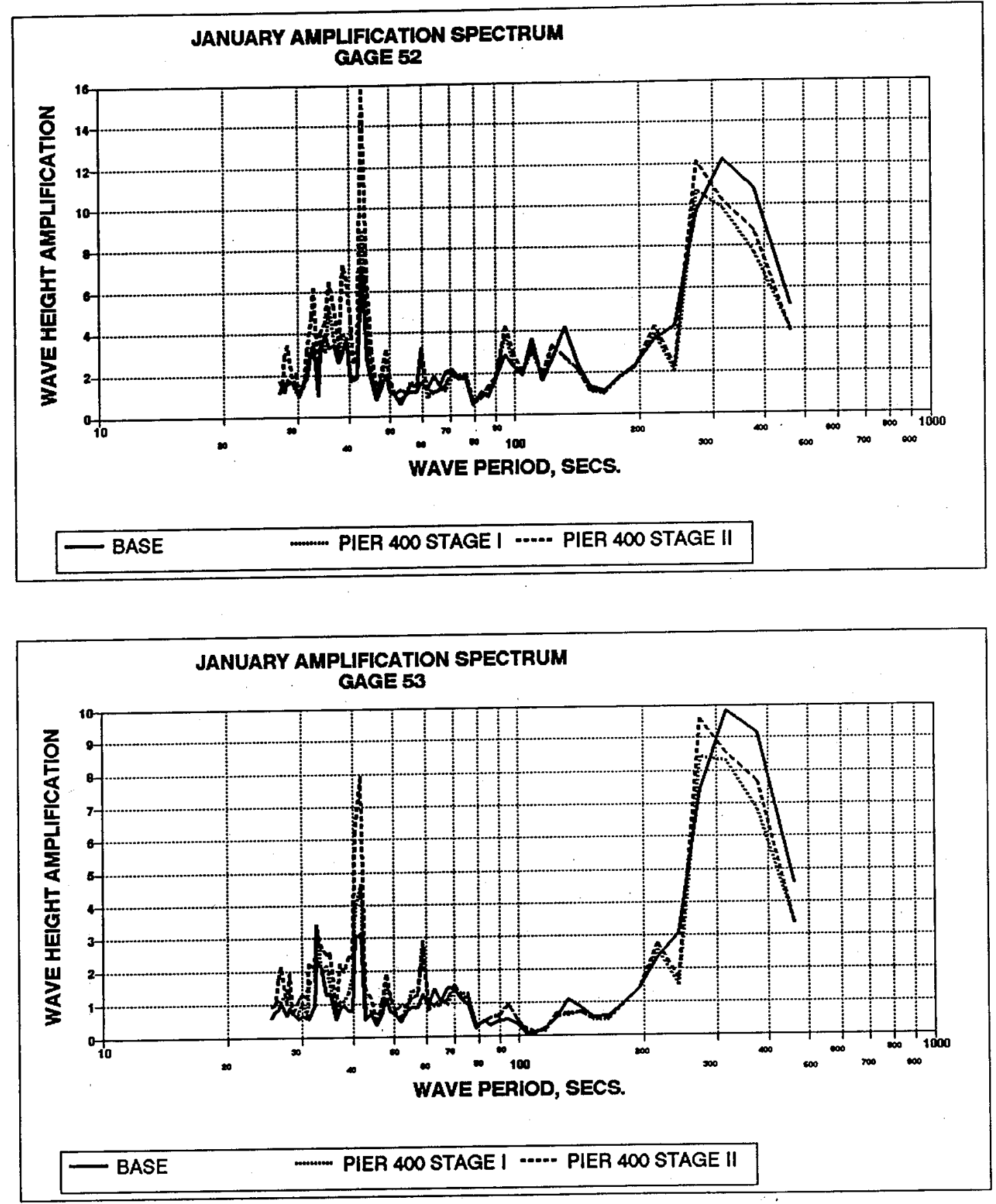

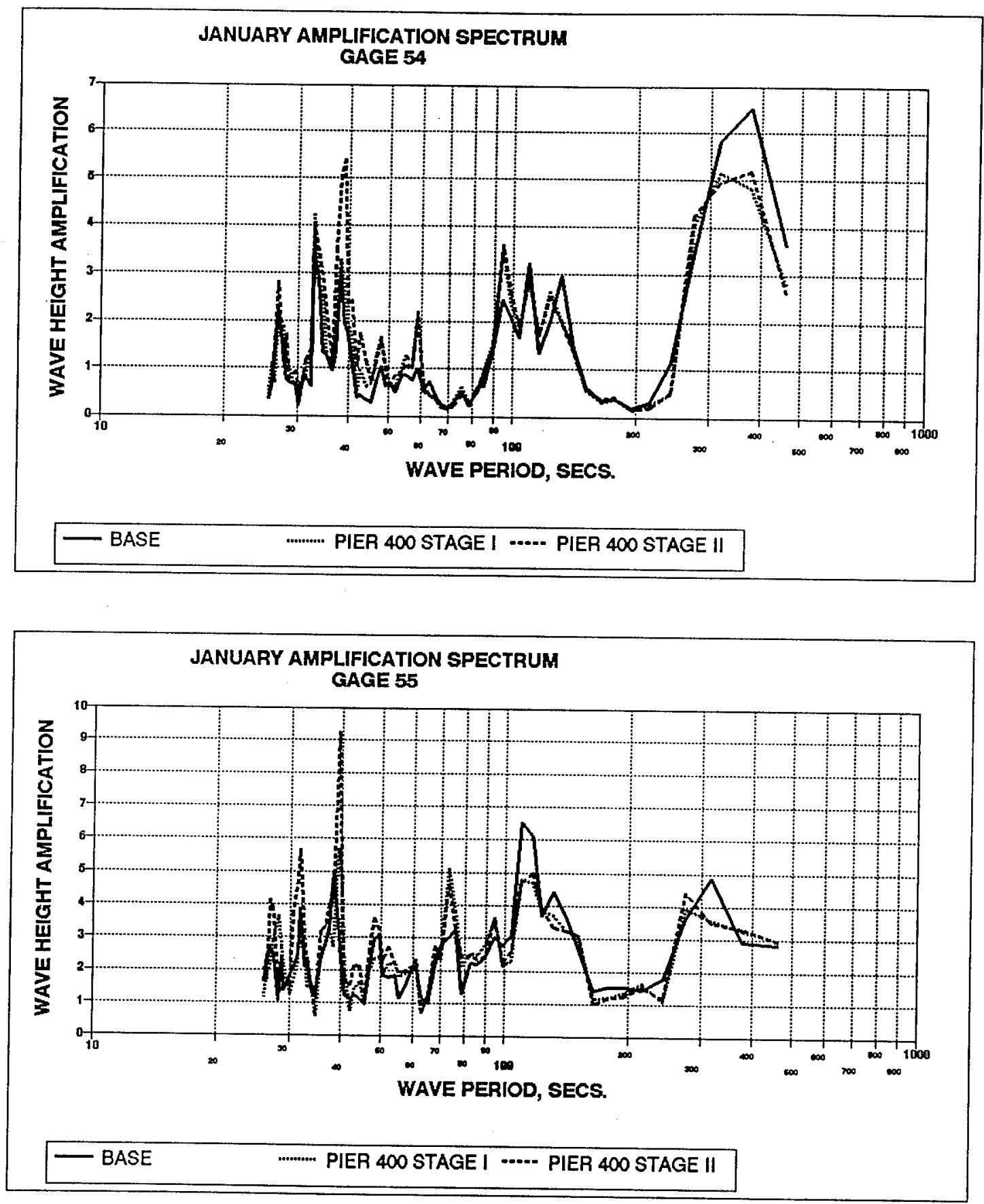


\section{Appendix G \\ Wave Amplification, January \\ Spectrum, Gages 41-42, 51-77, \\ Open and Closed End of Pier 300}



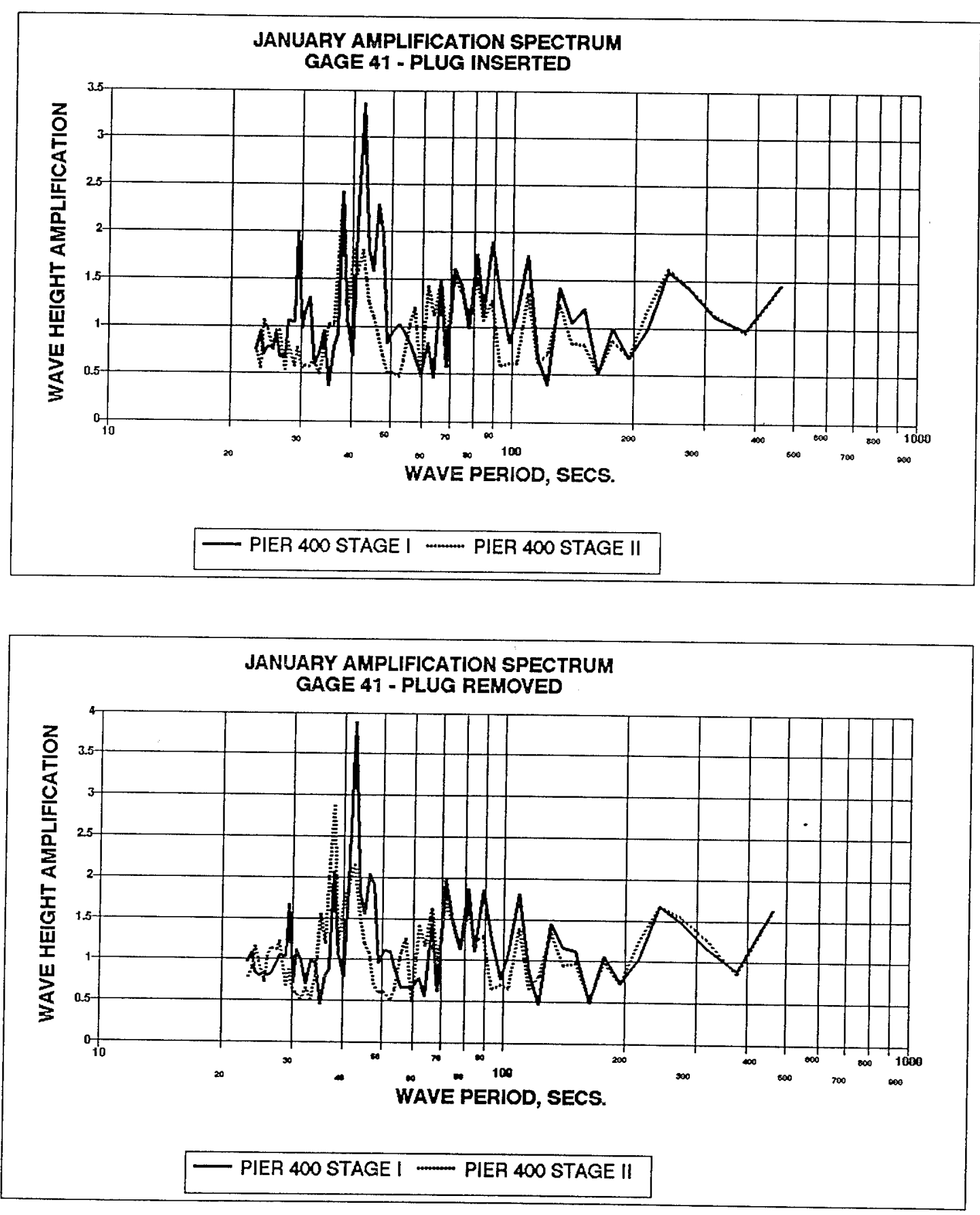

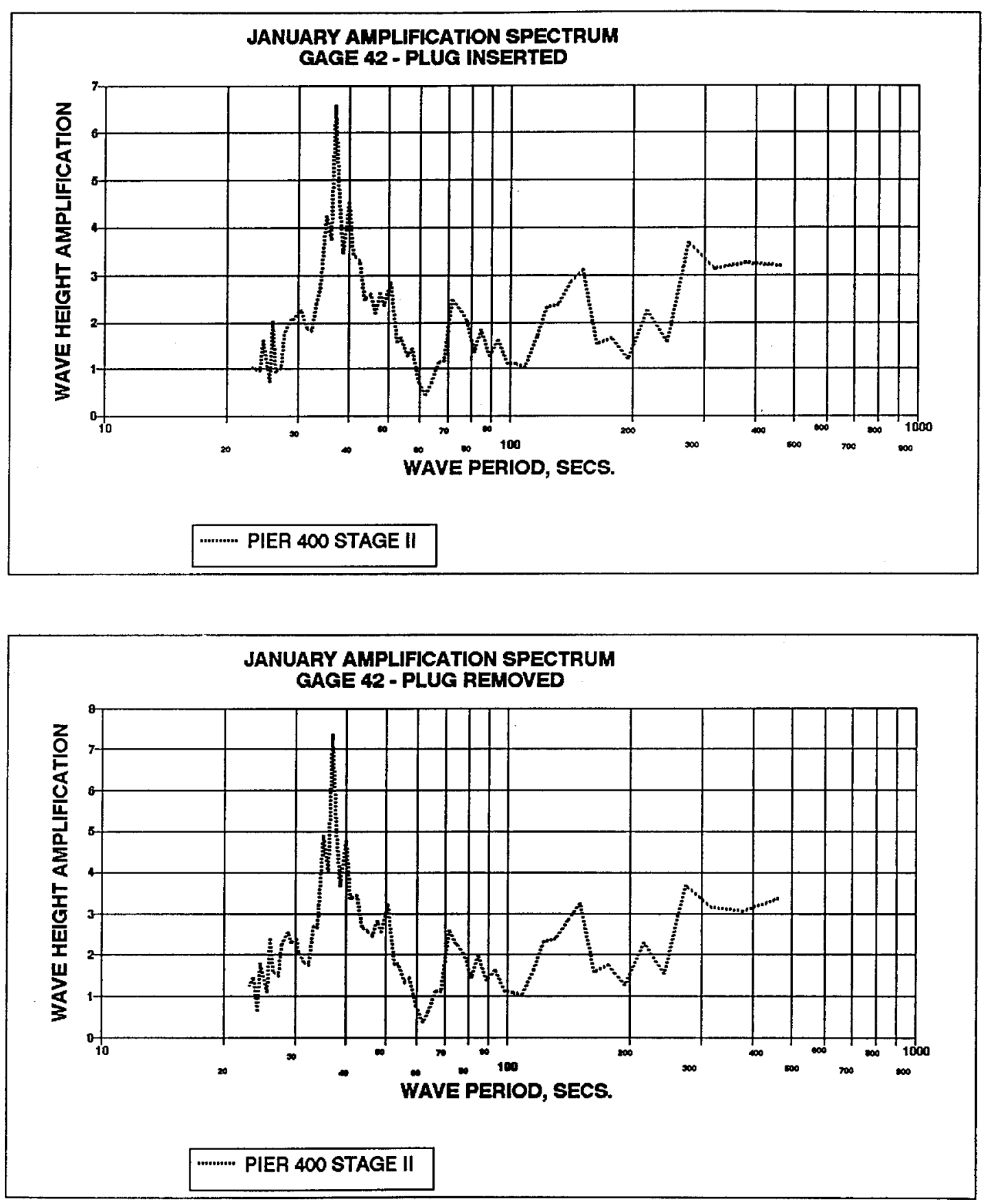

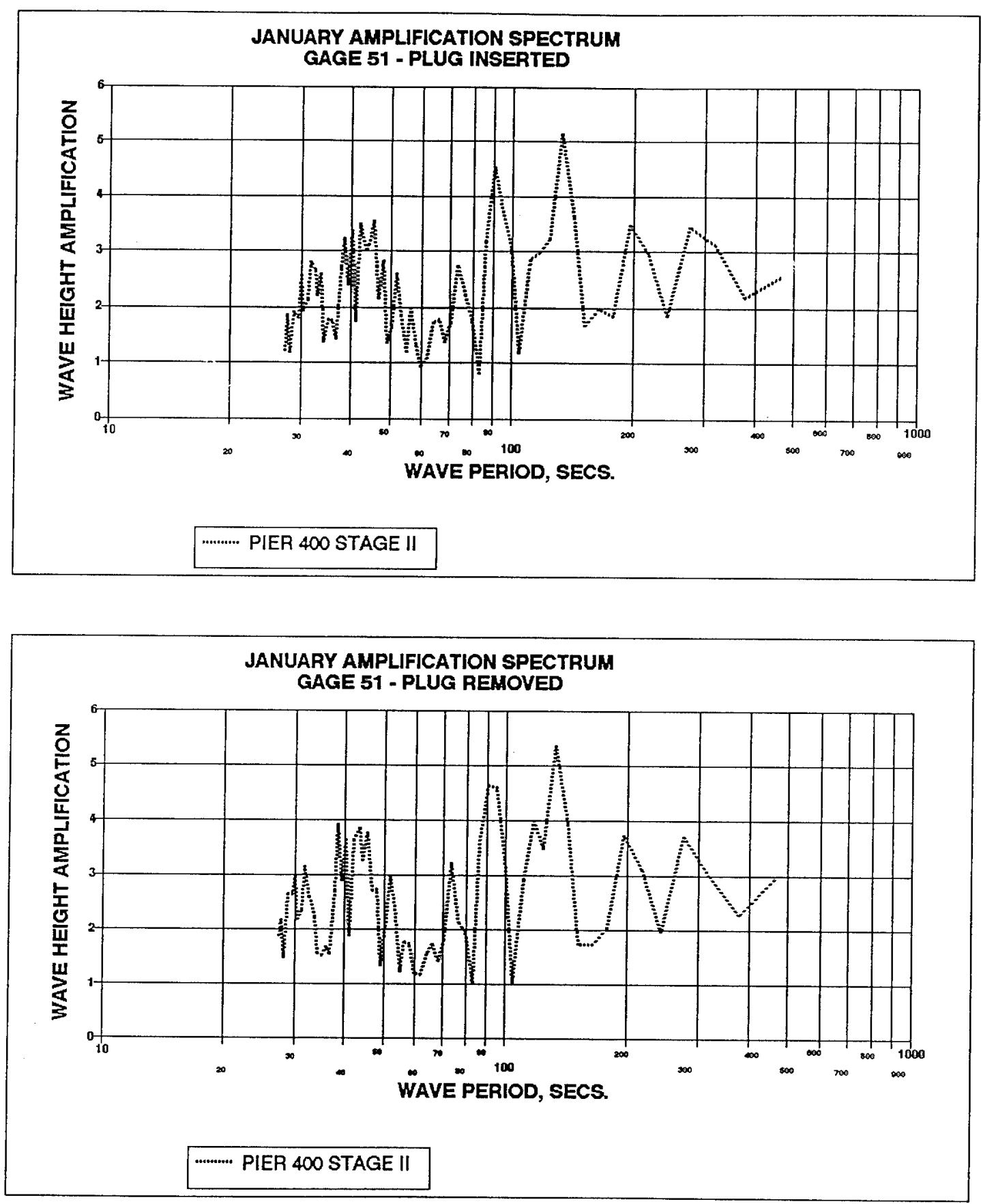


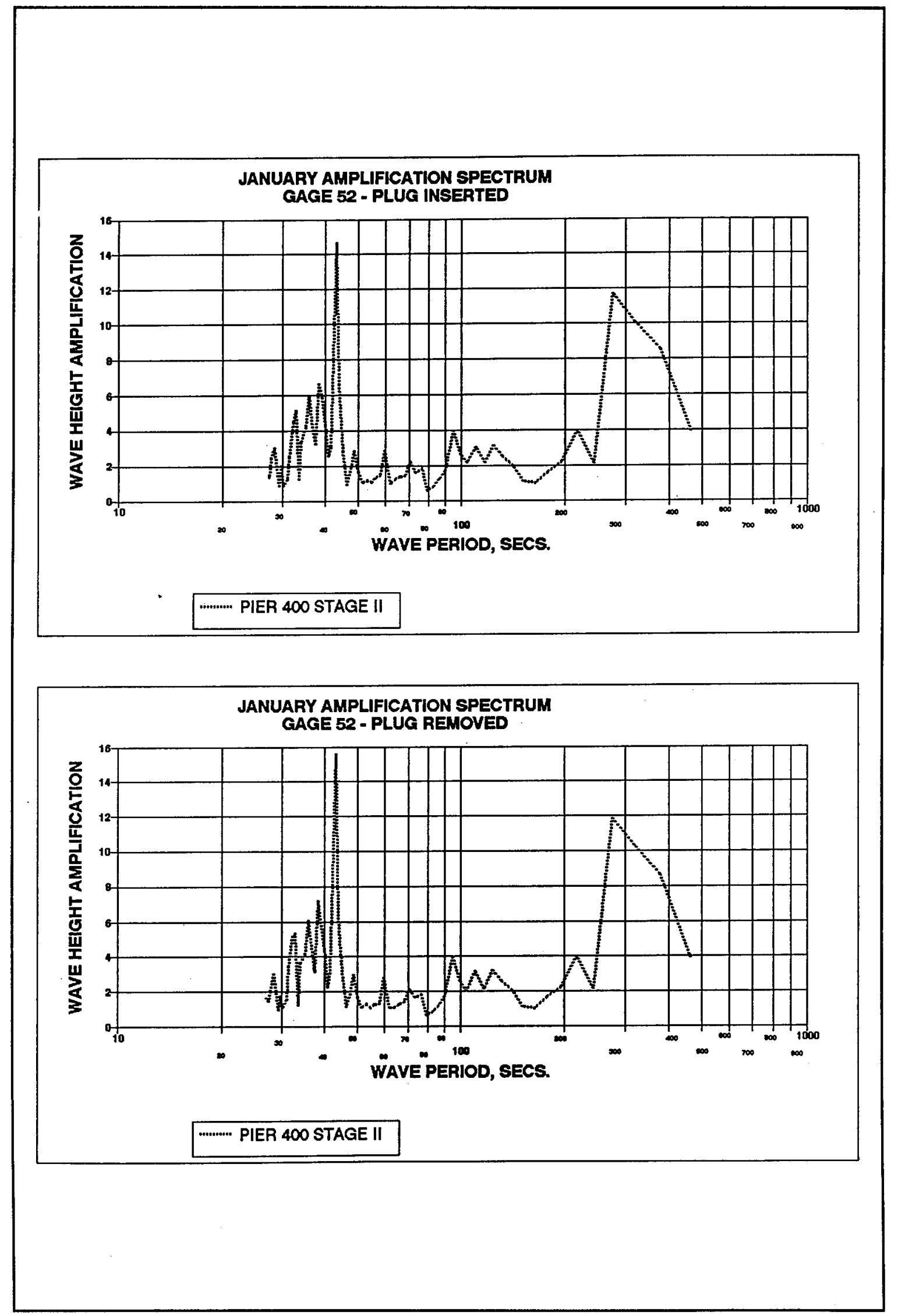




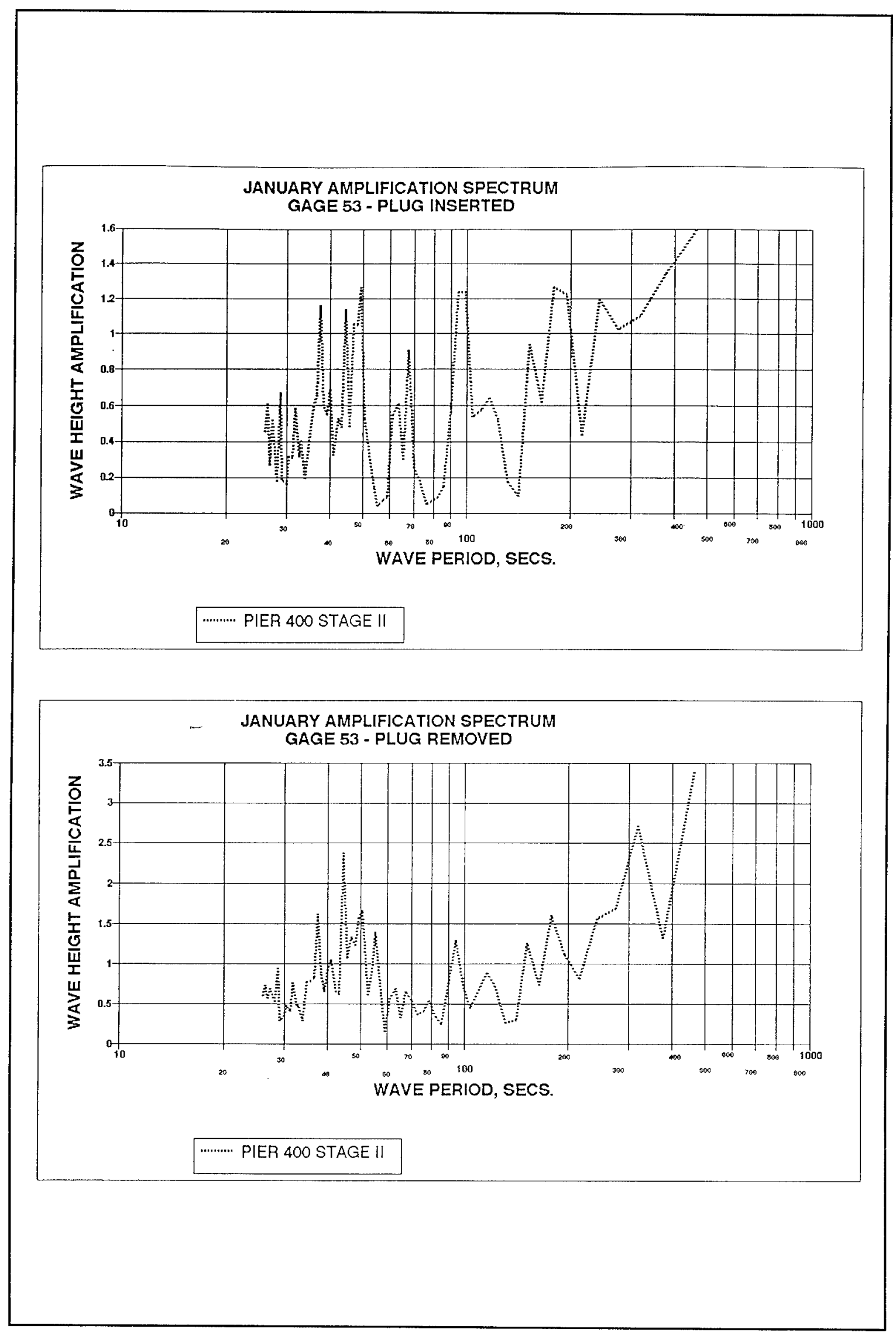



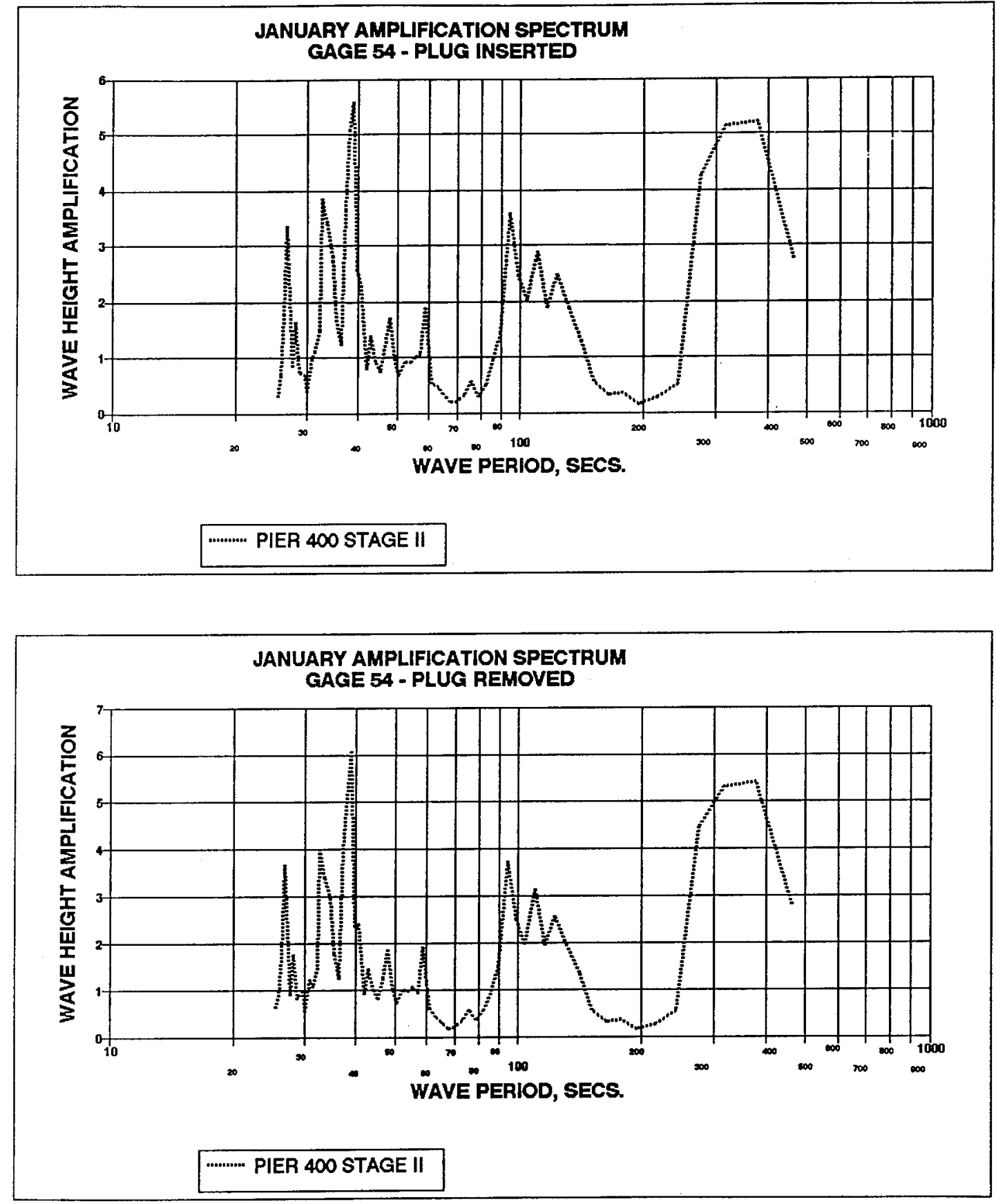

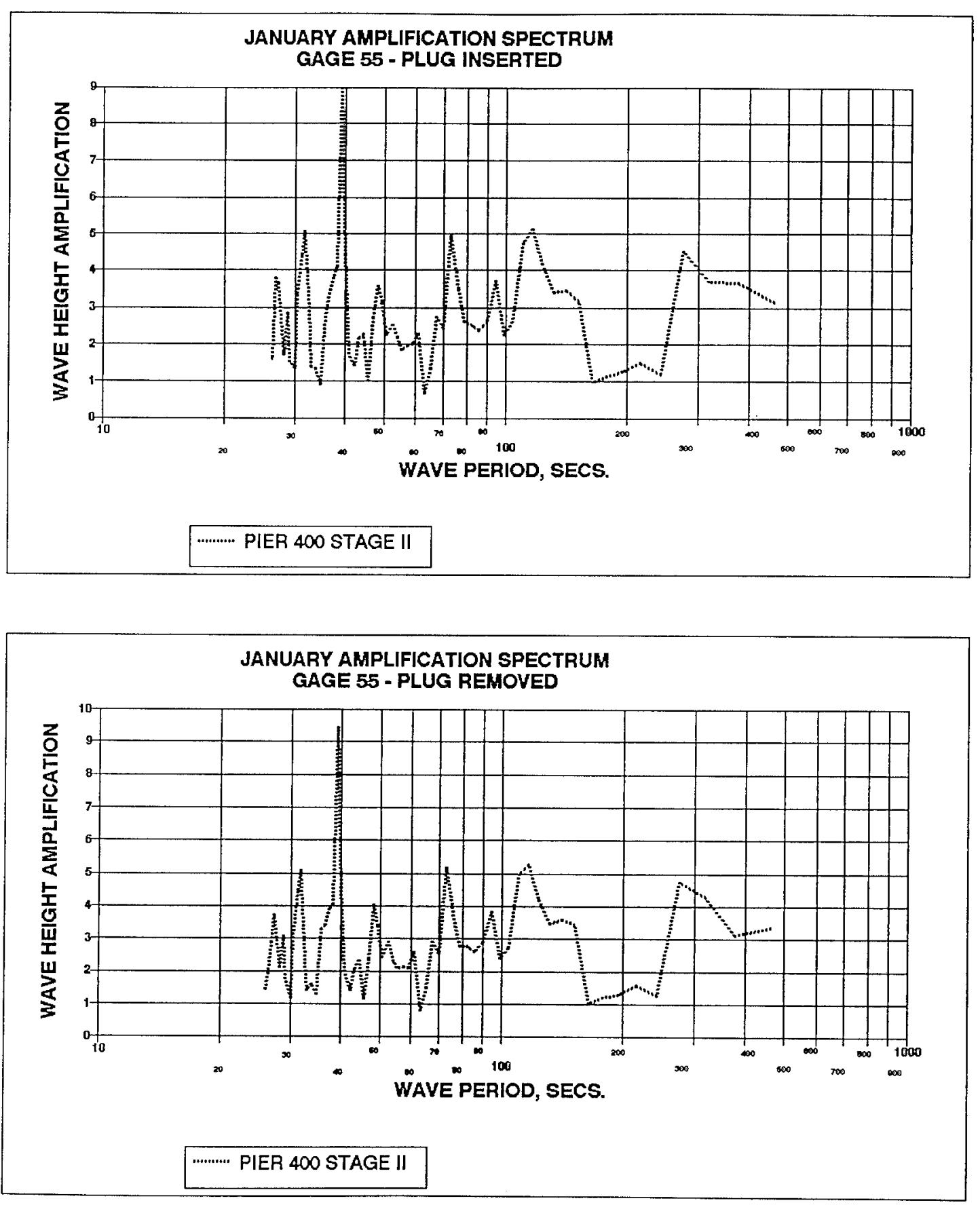

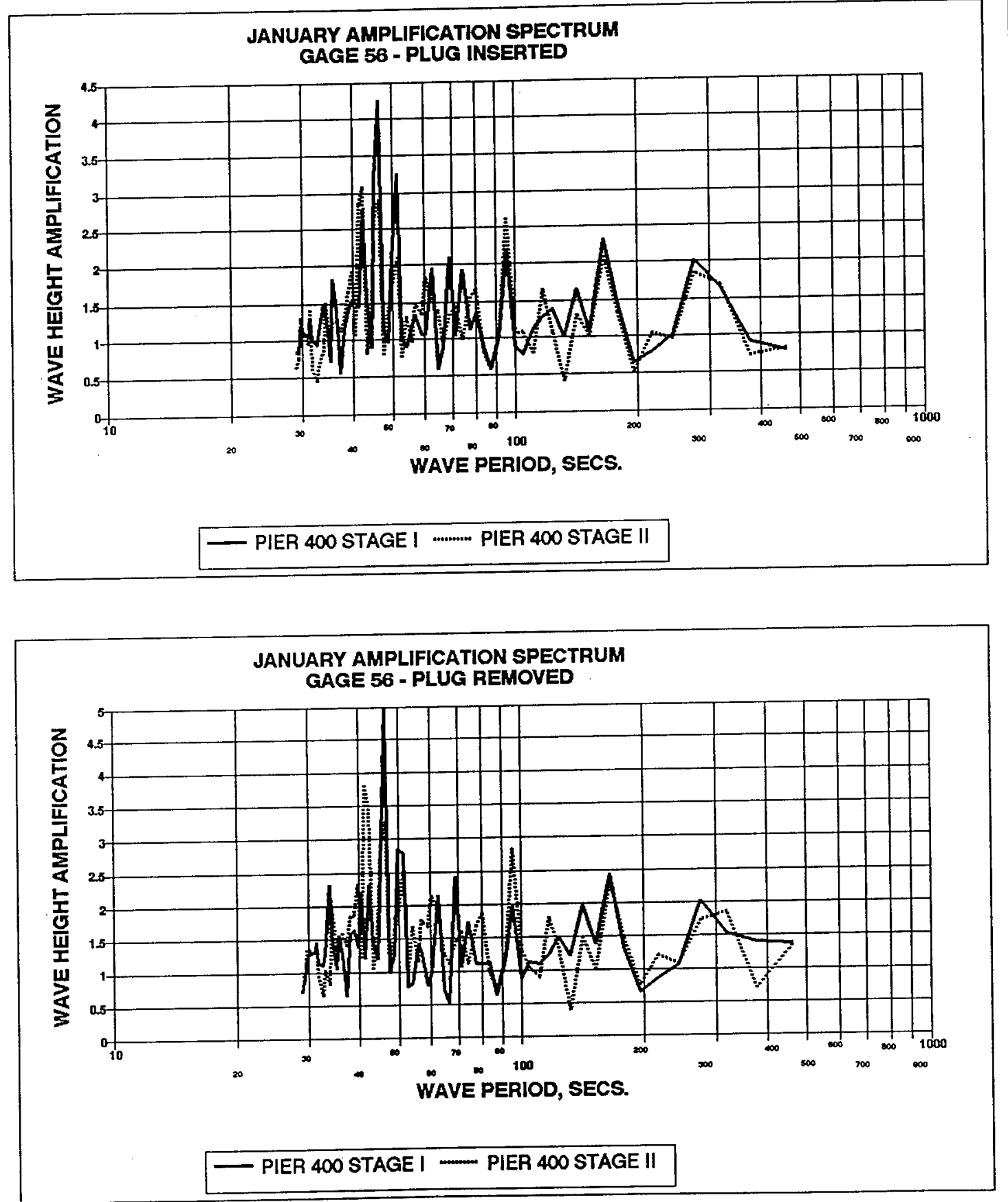

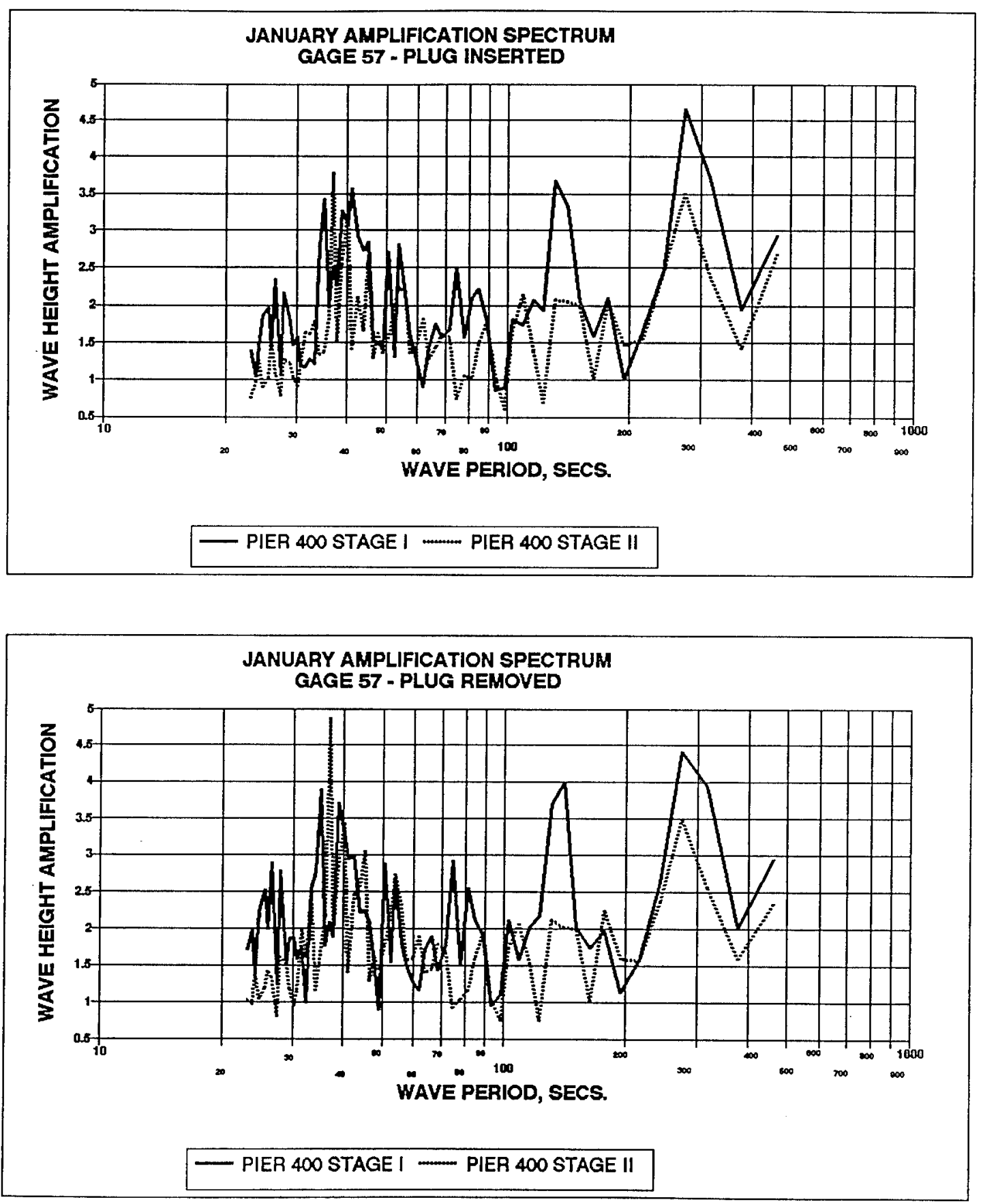

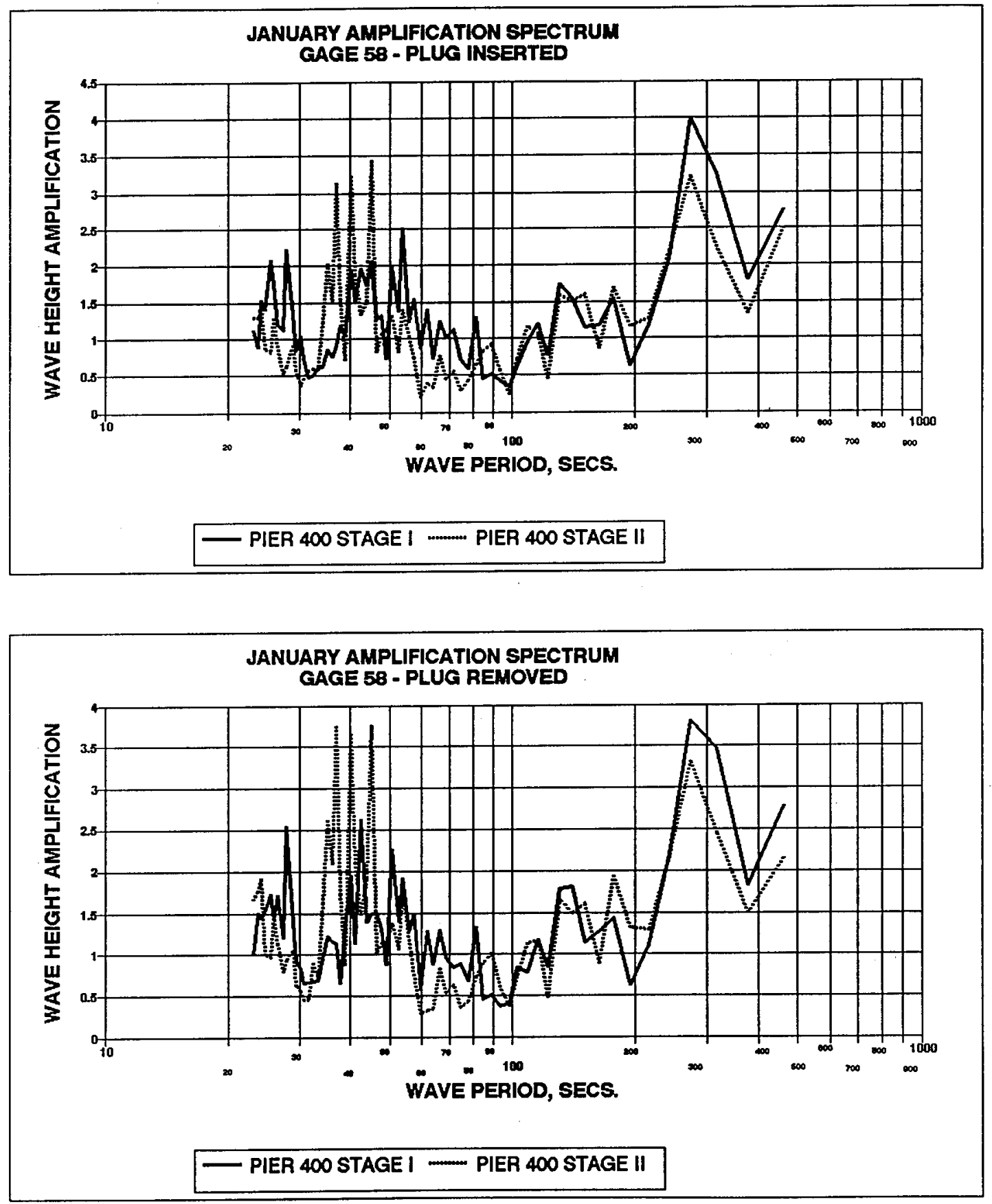


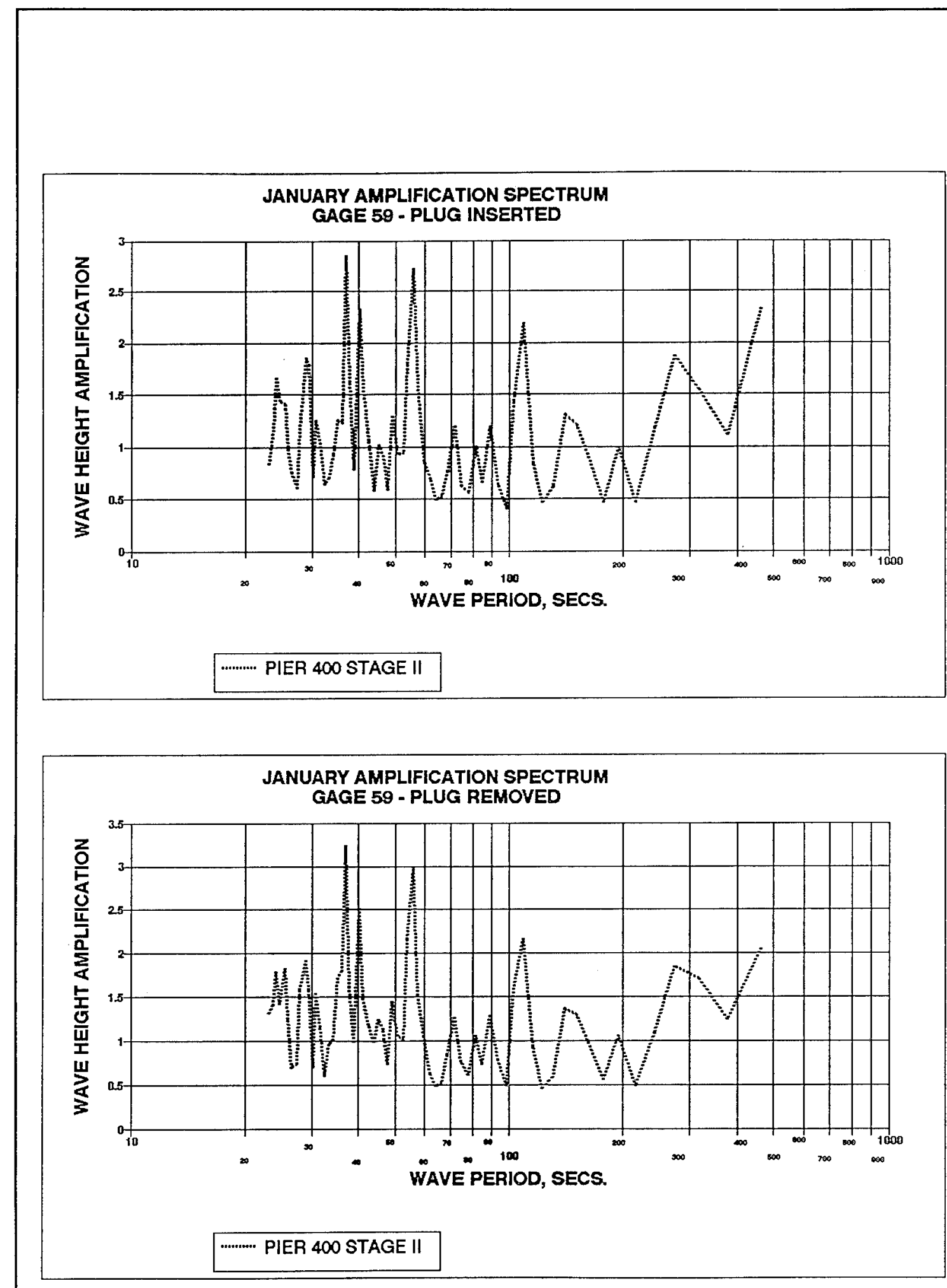



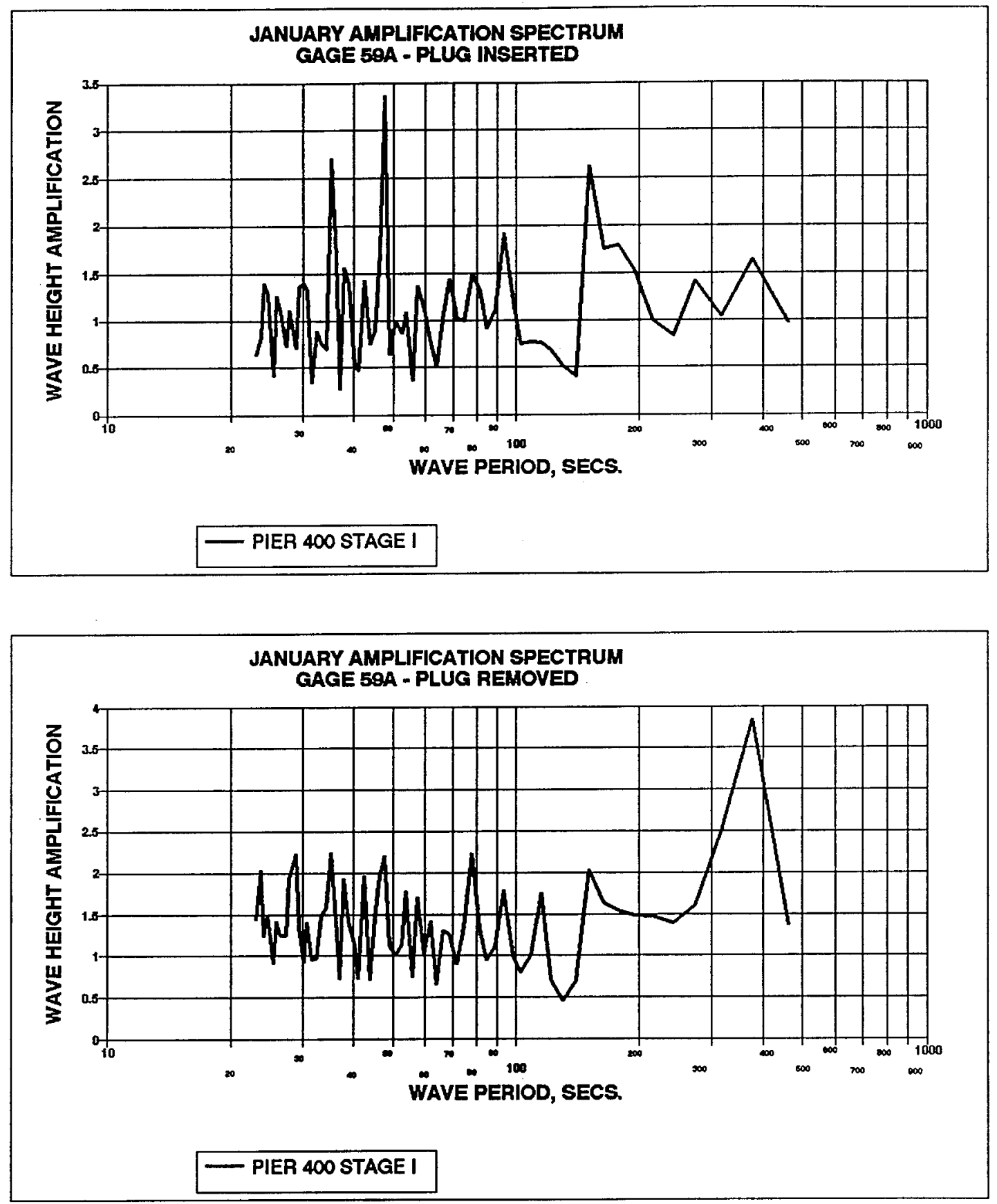

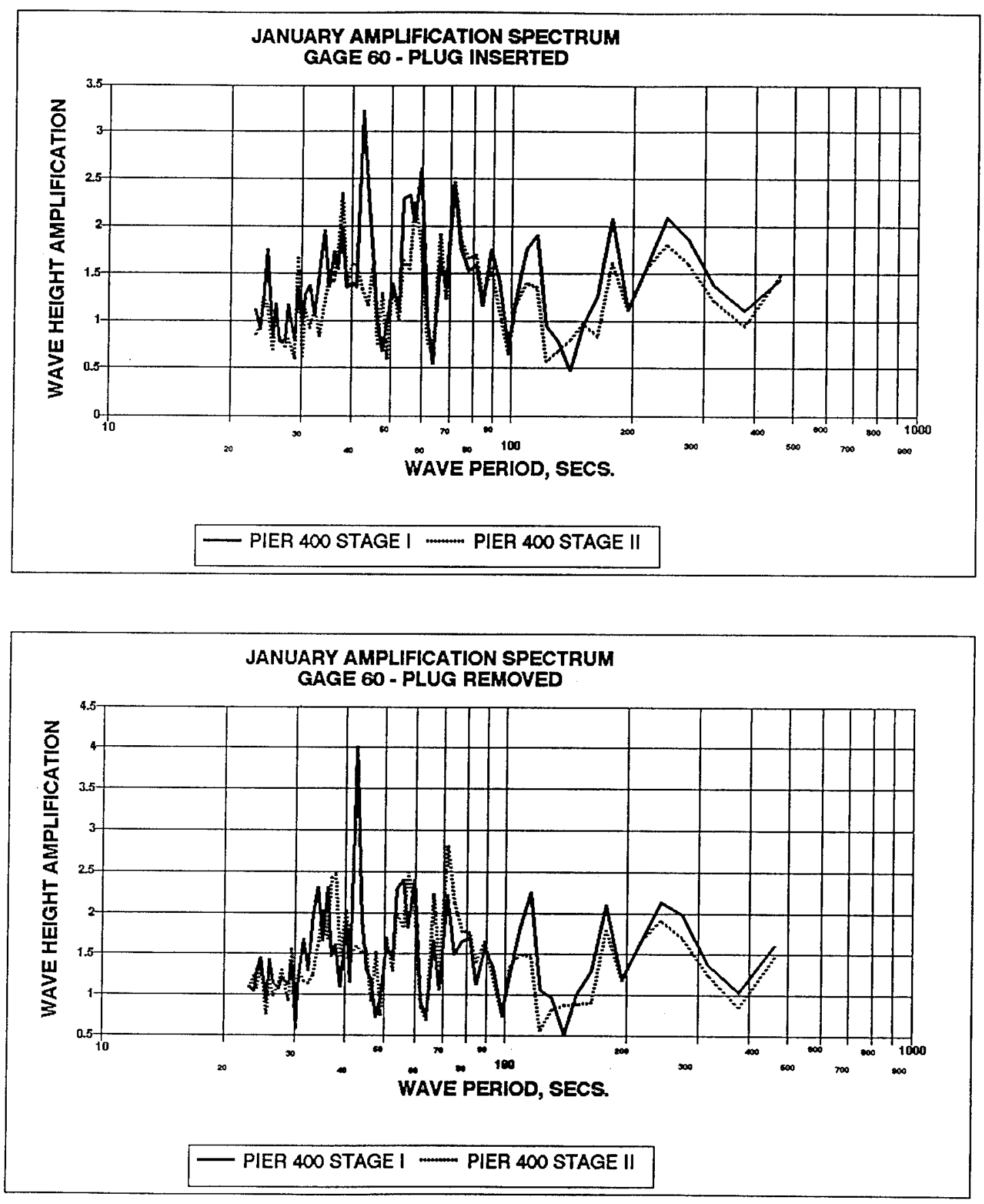

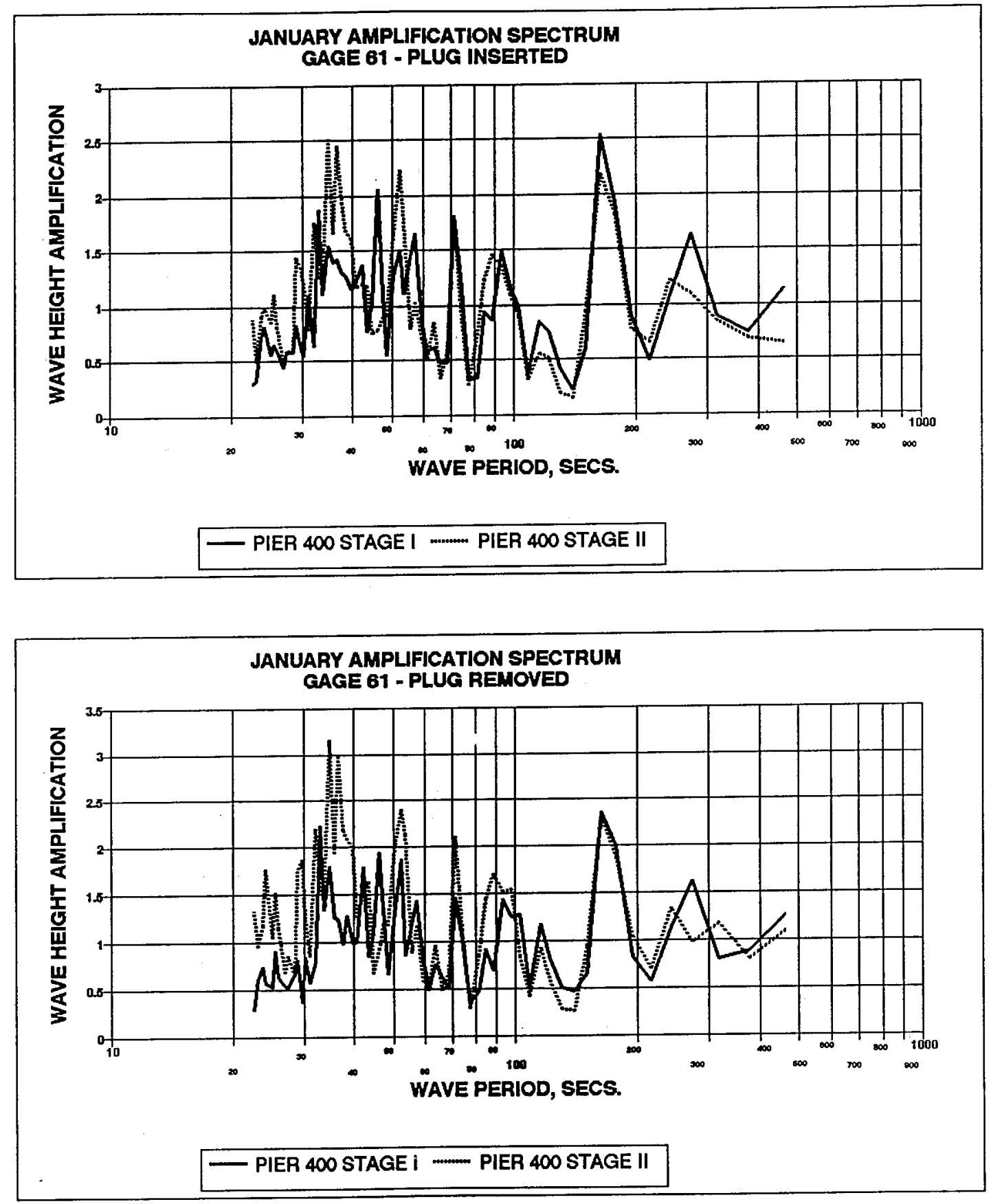


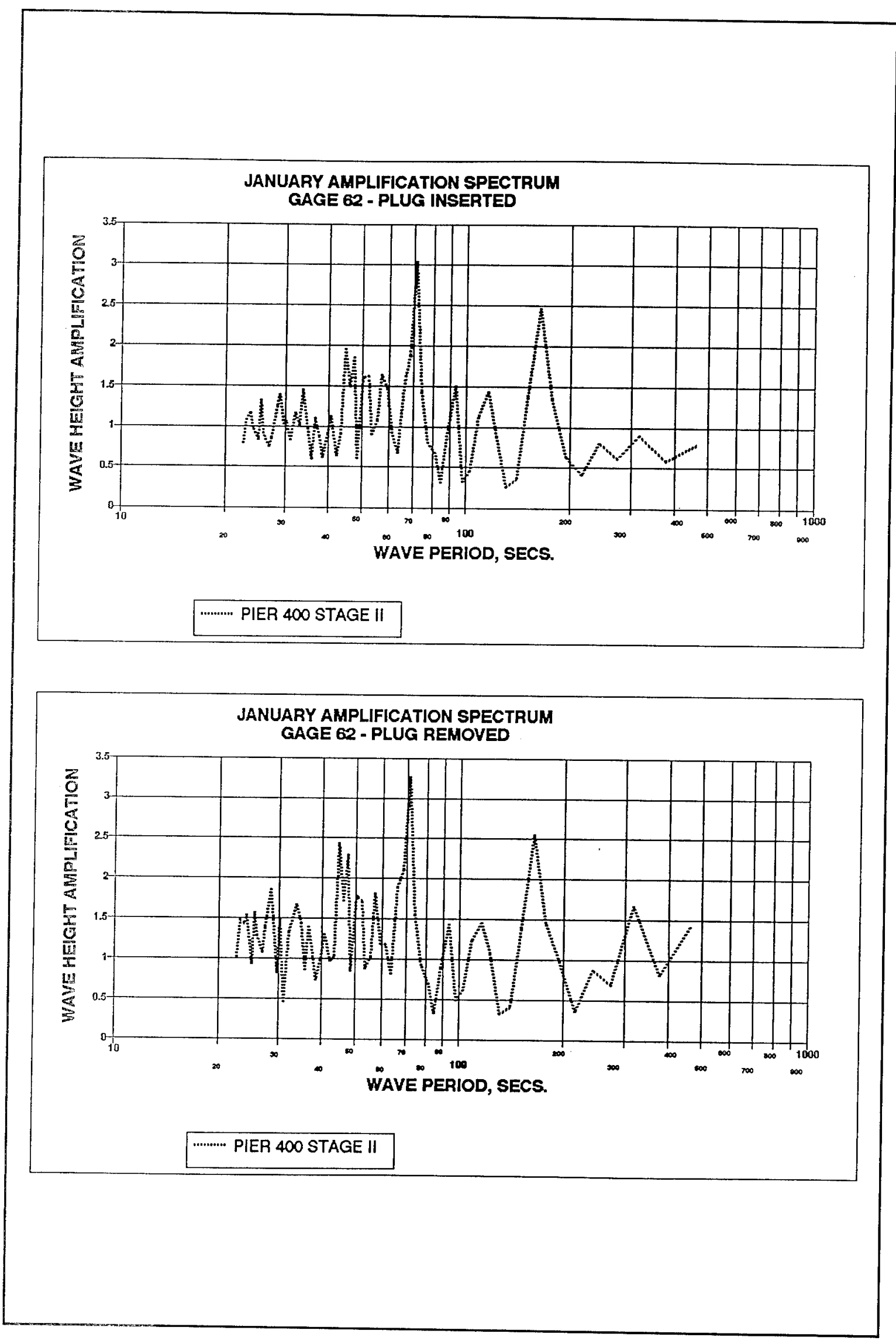



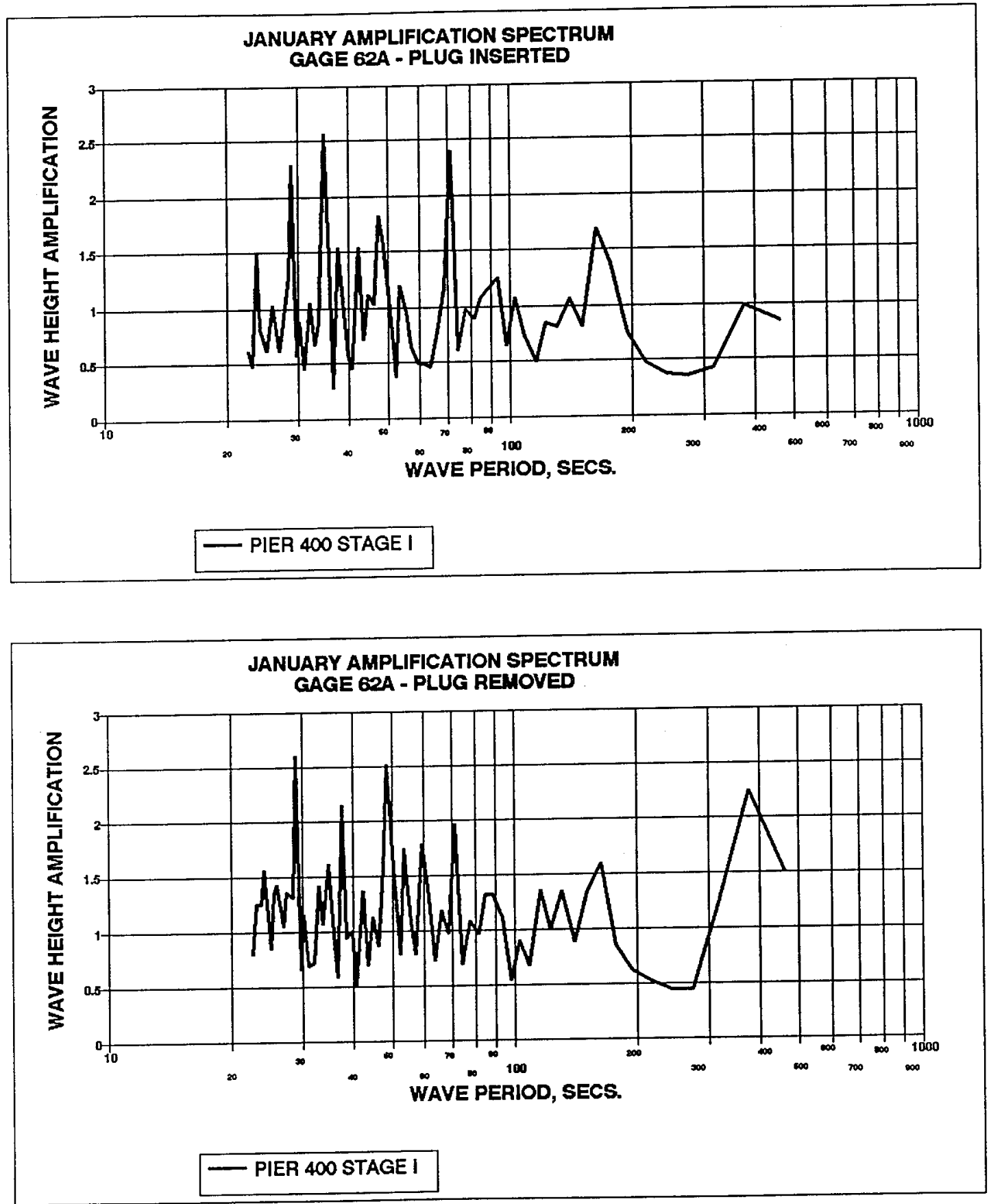

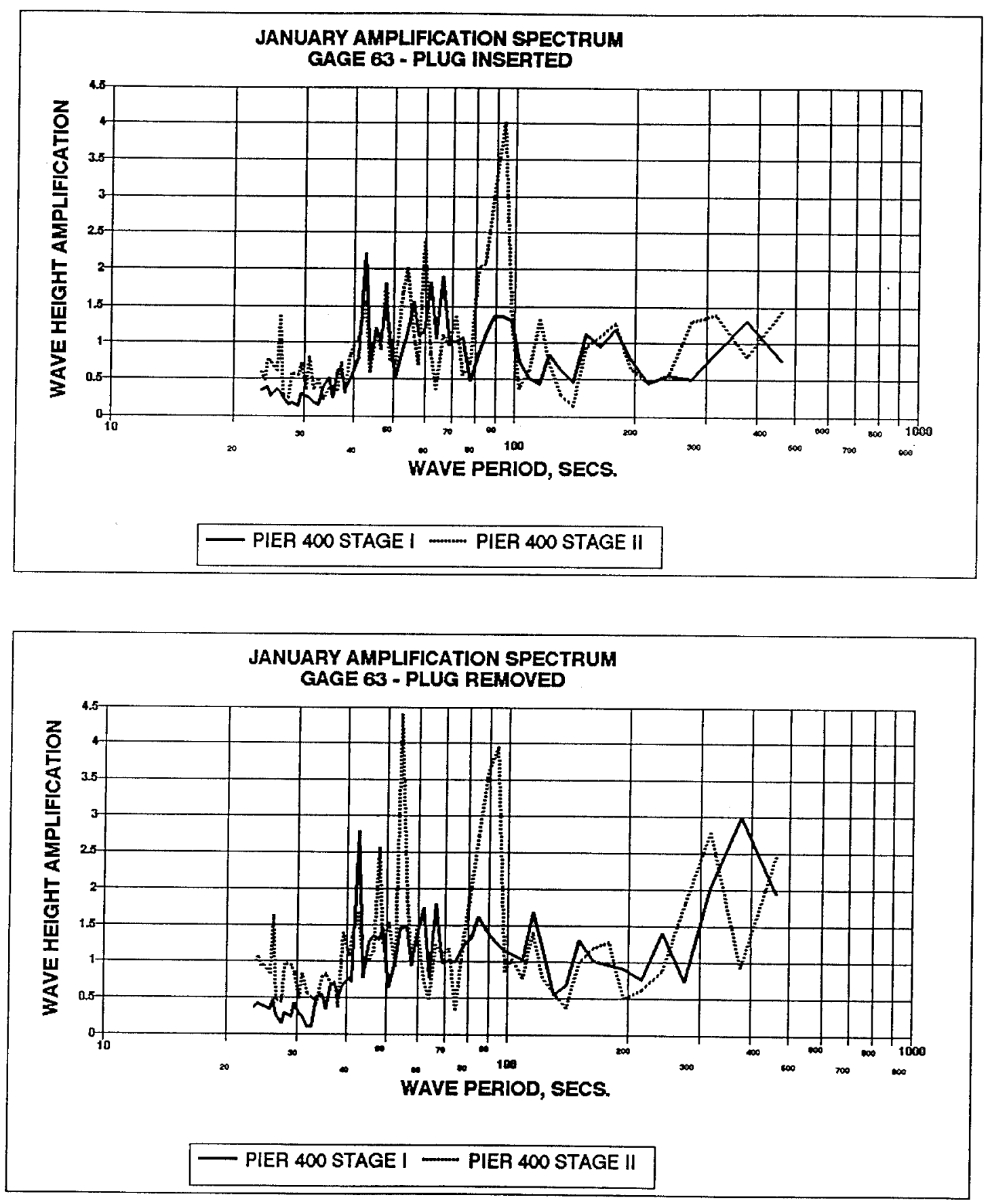

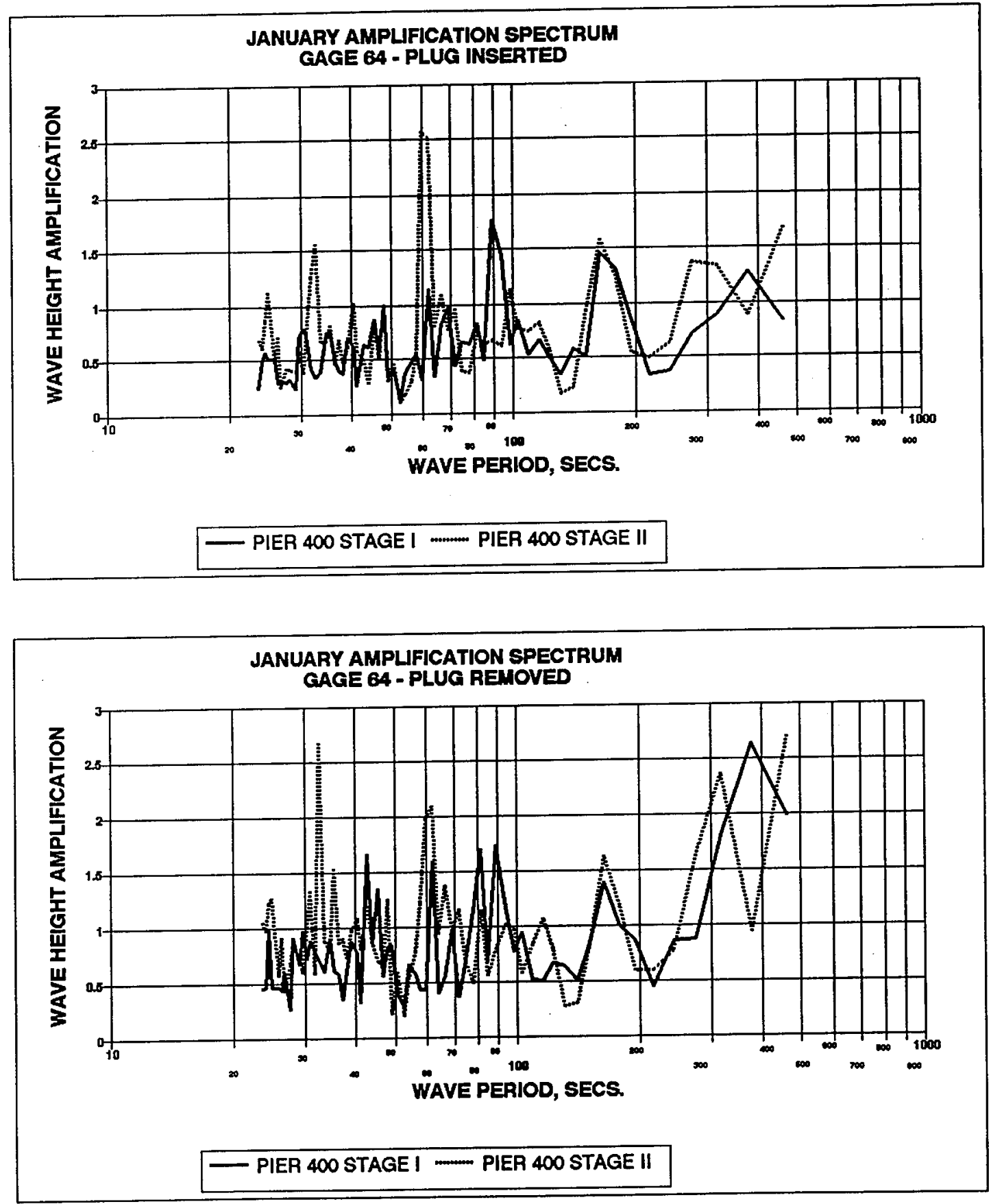

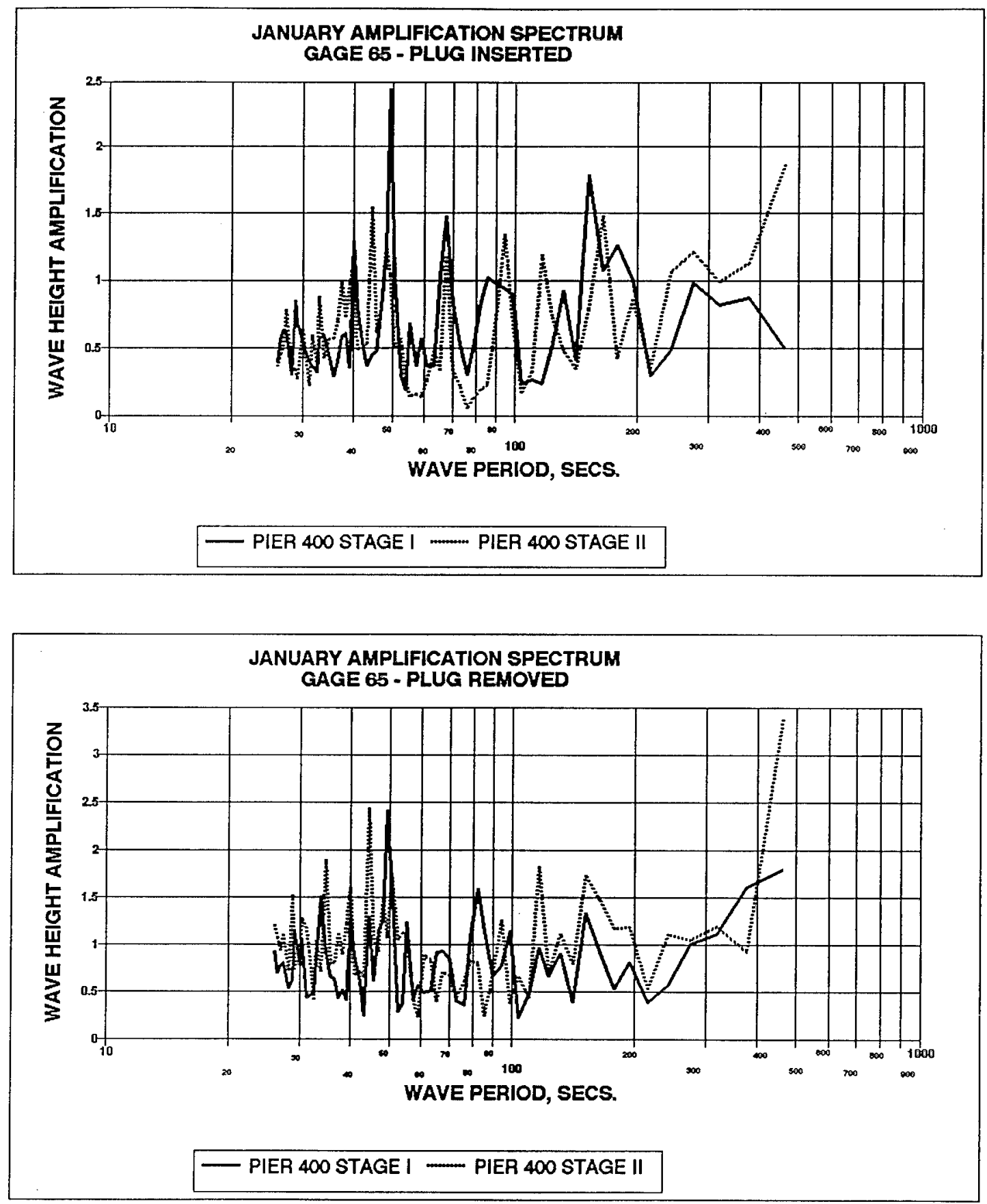

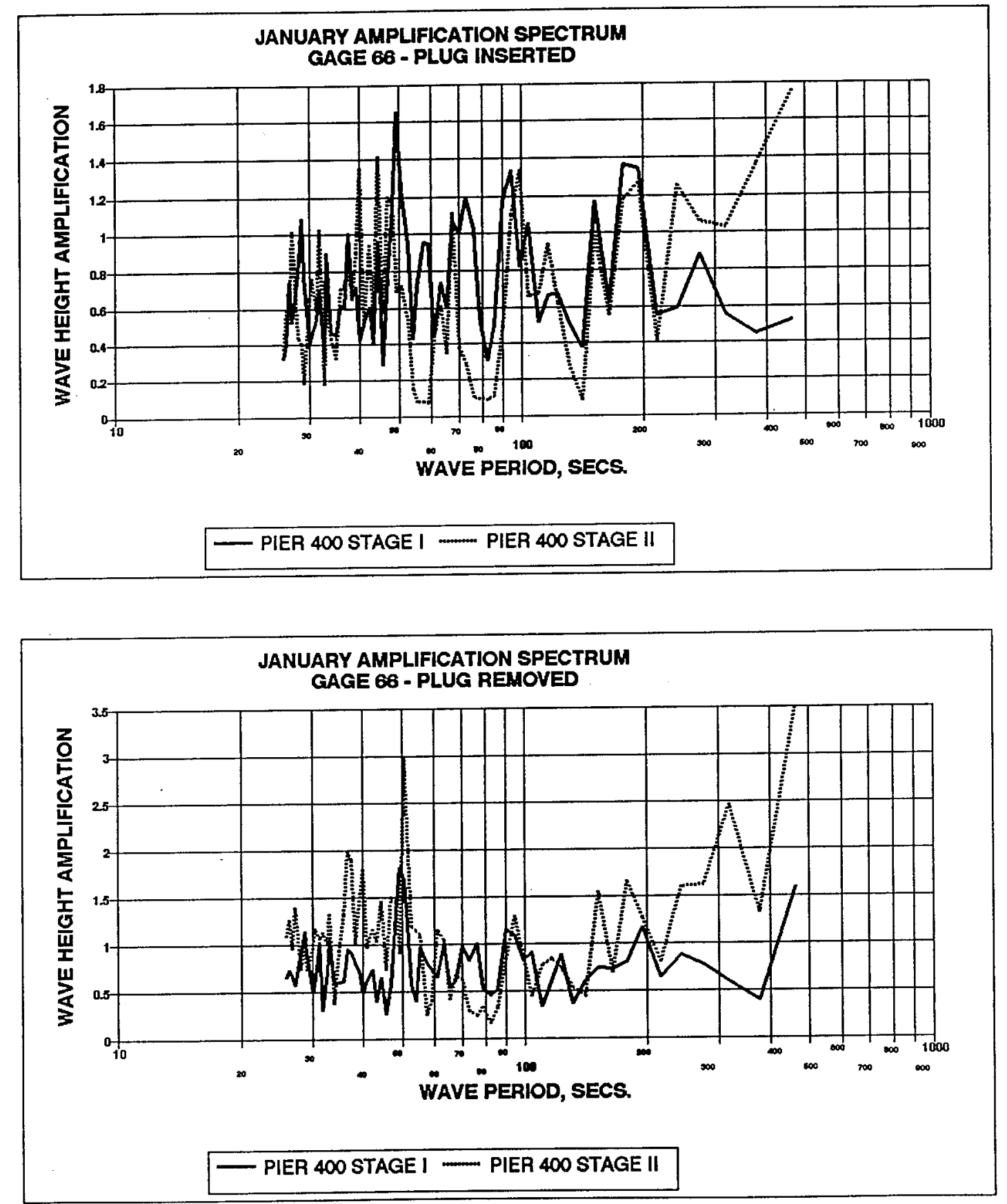

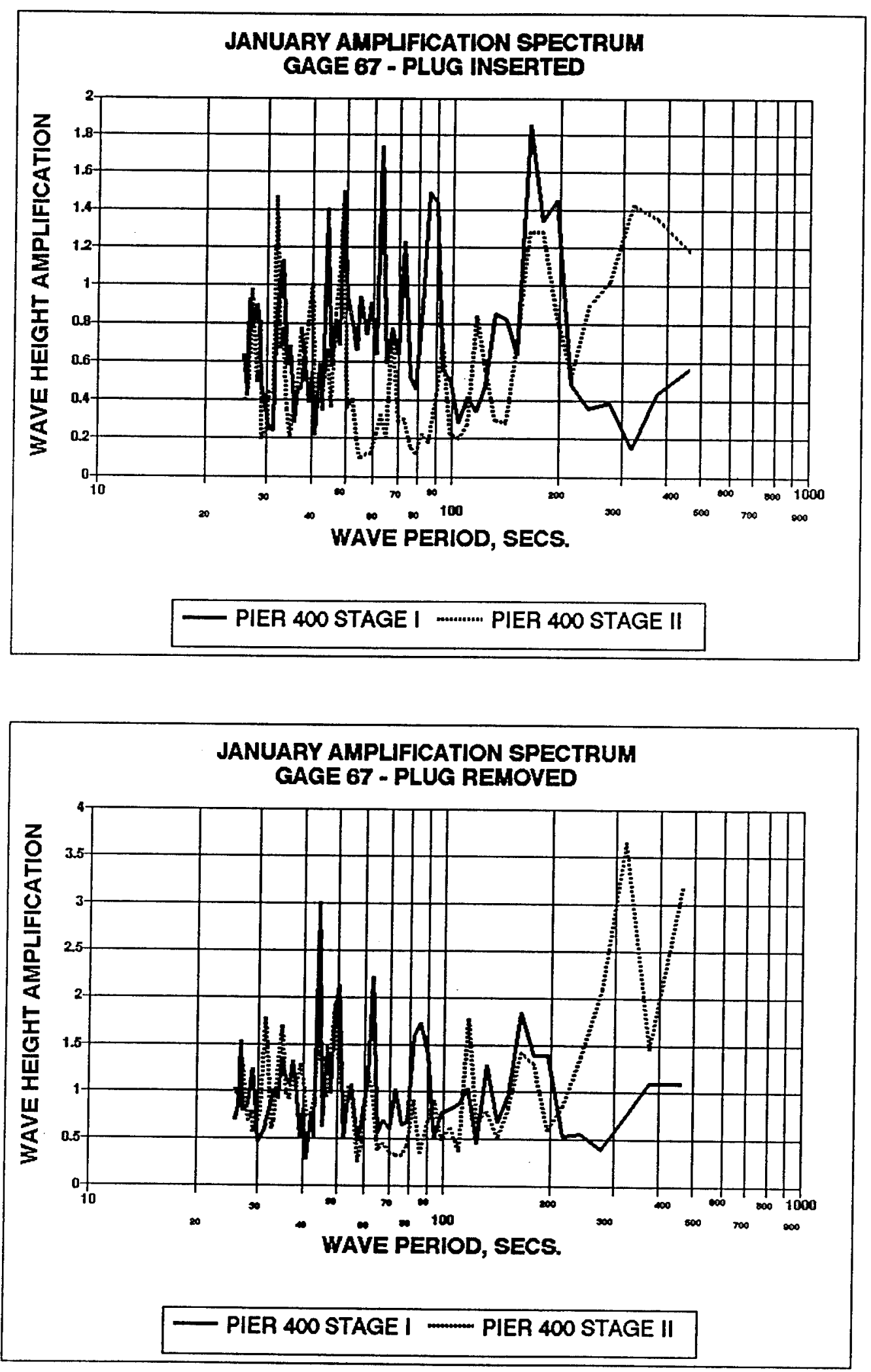

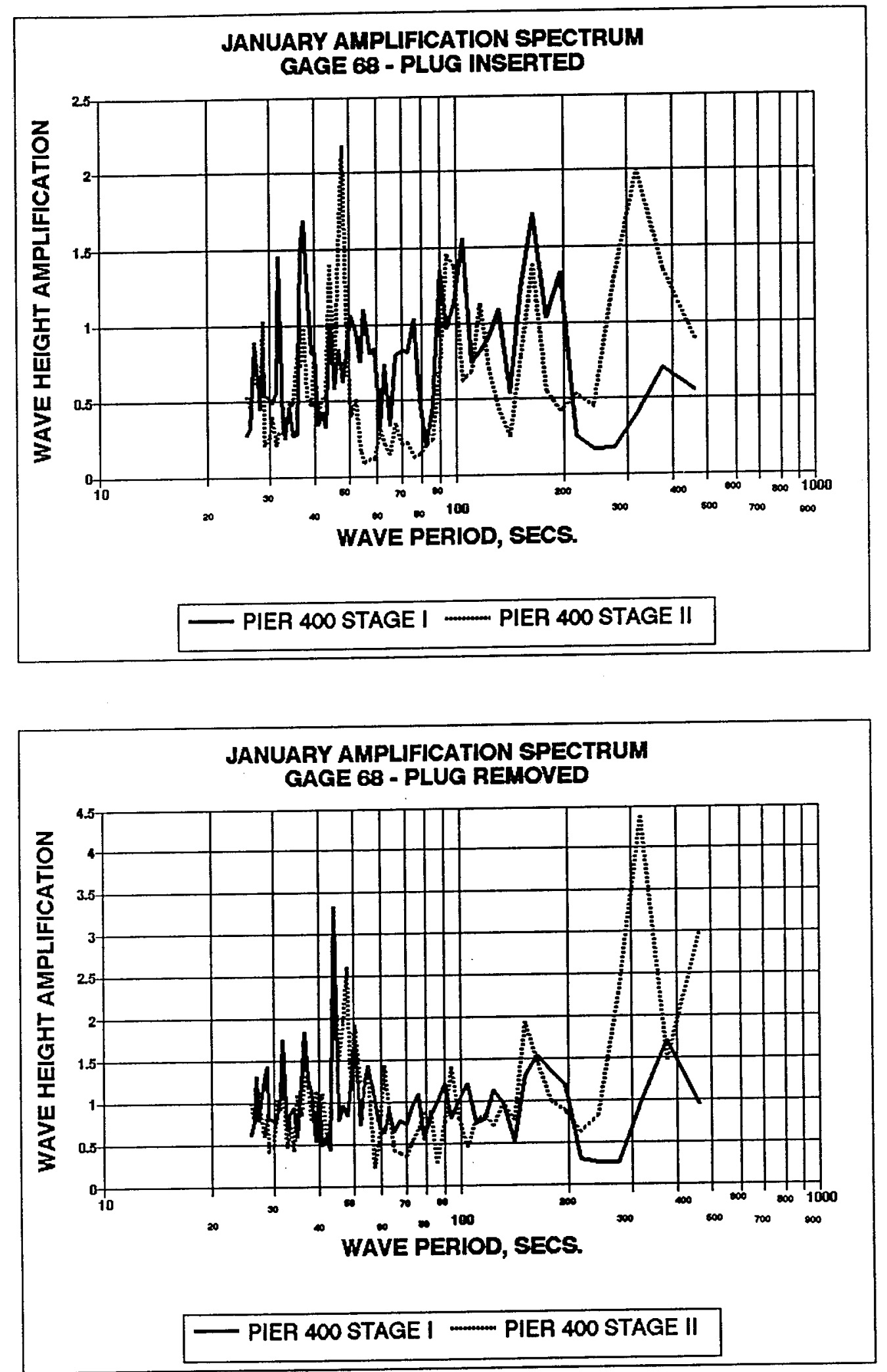

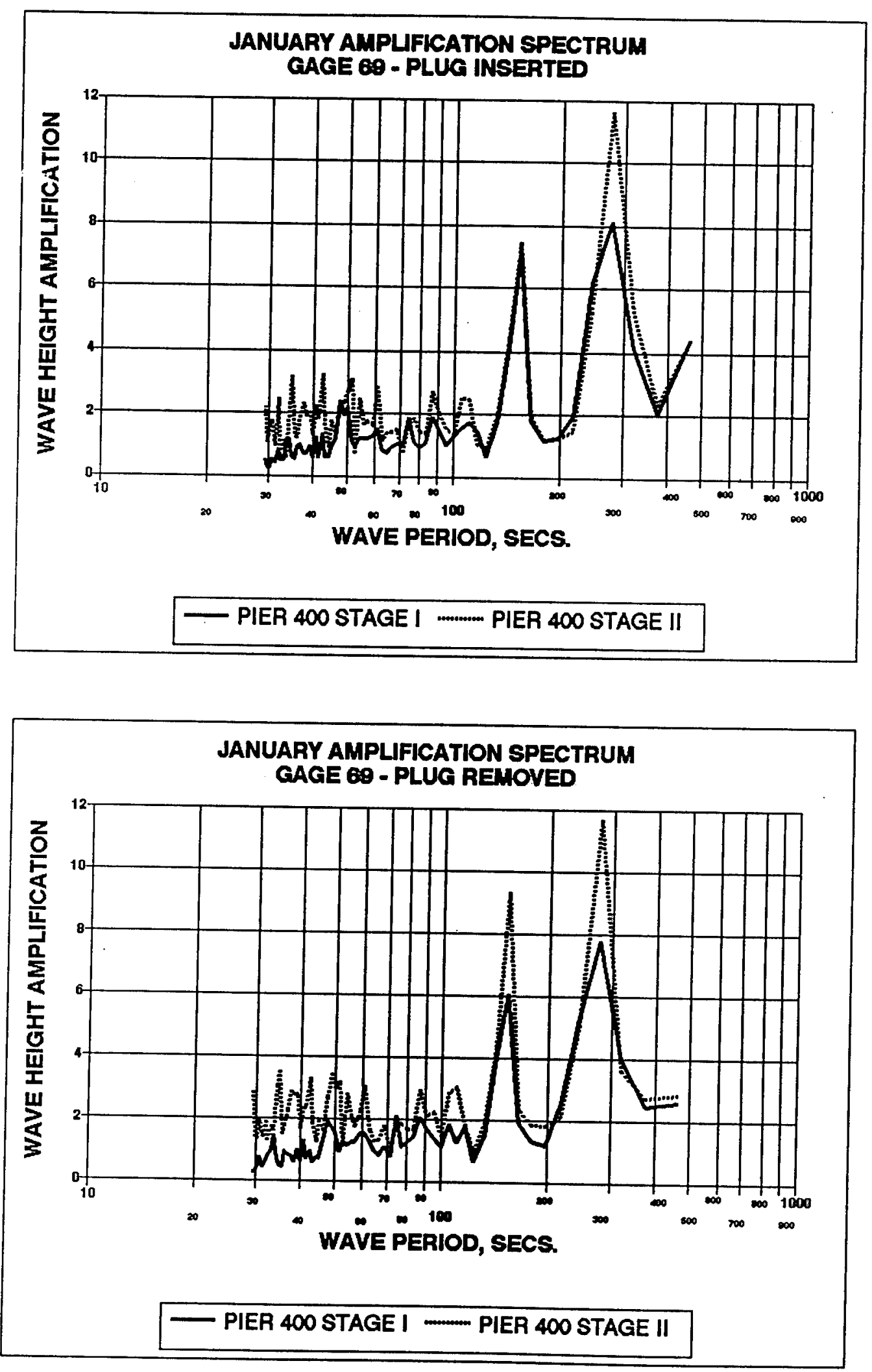

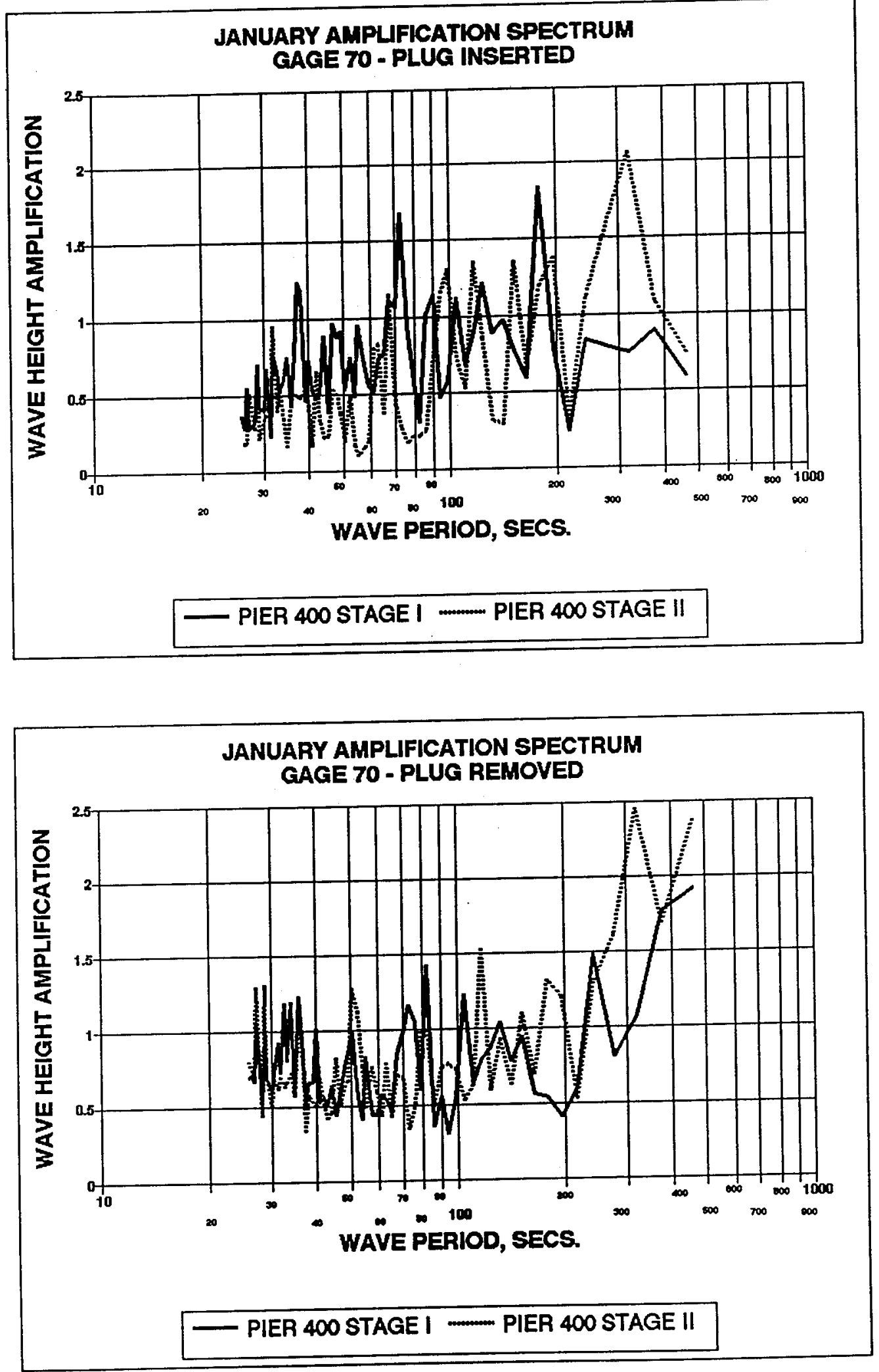

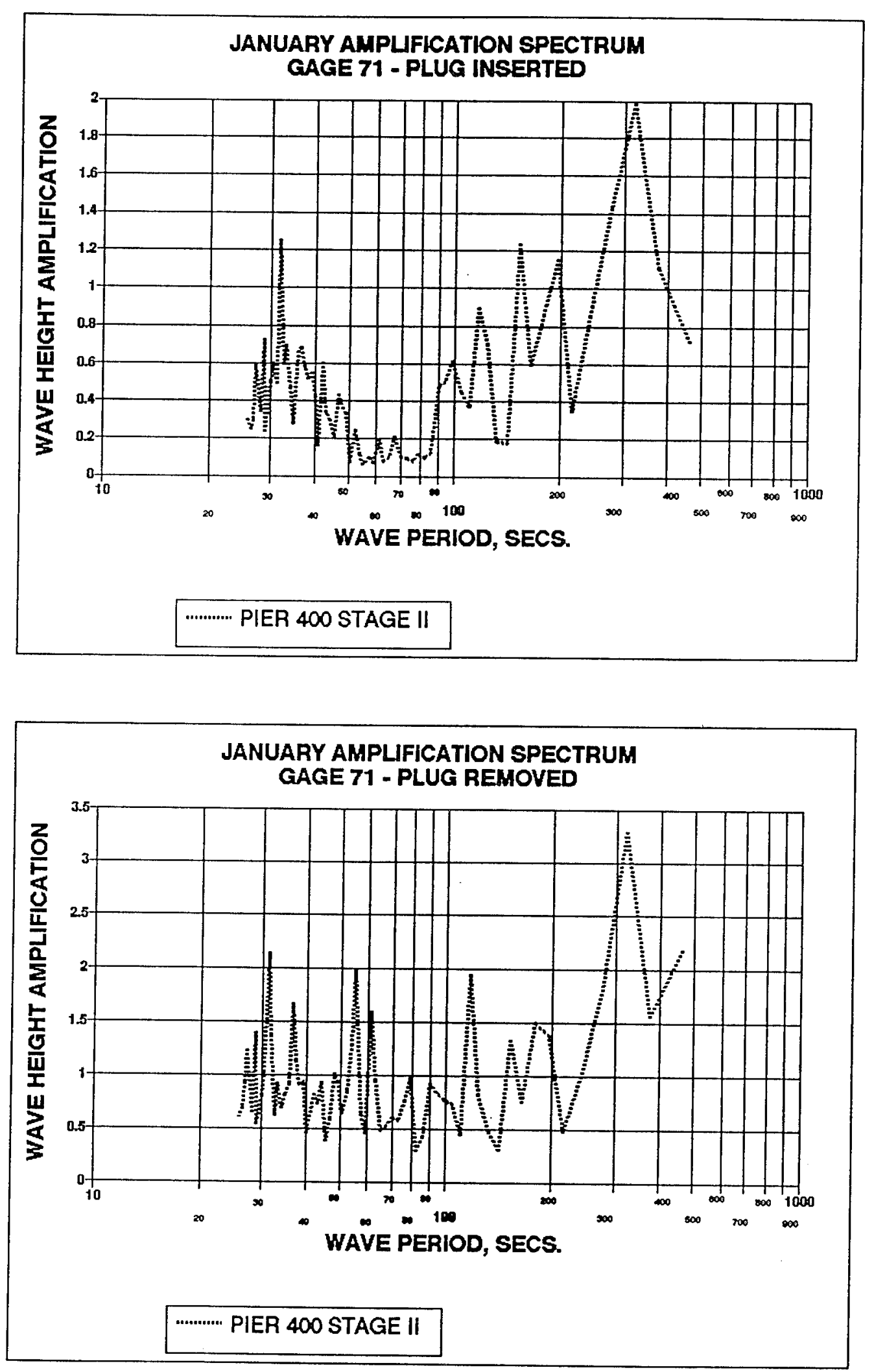

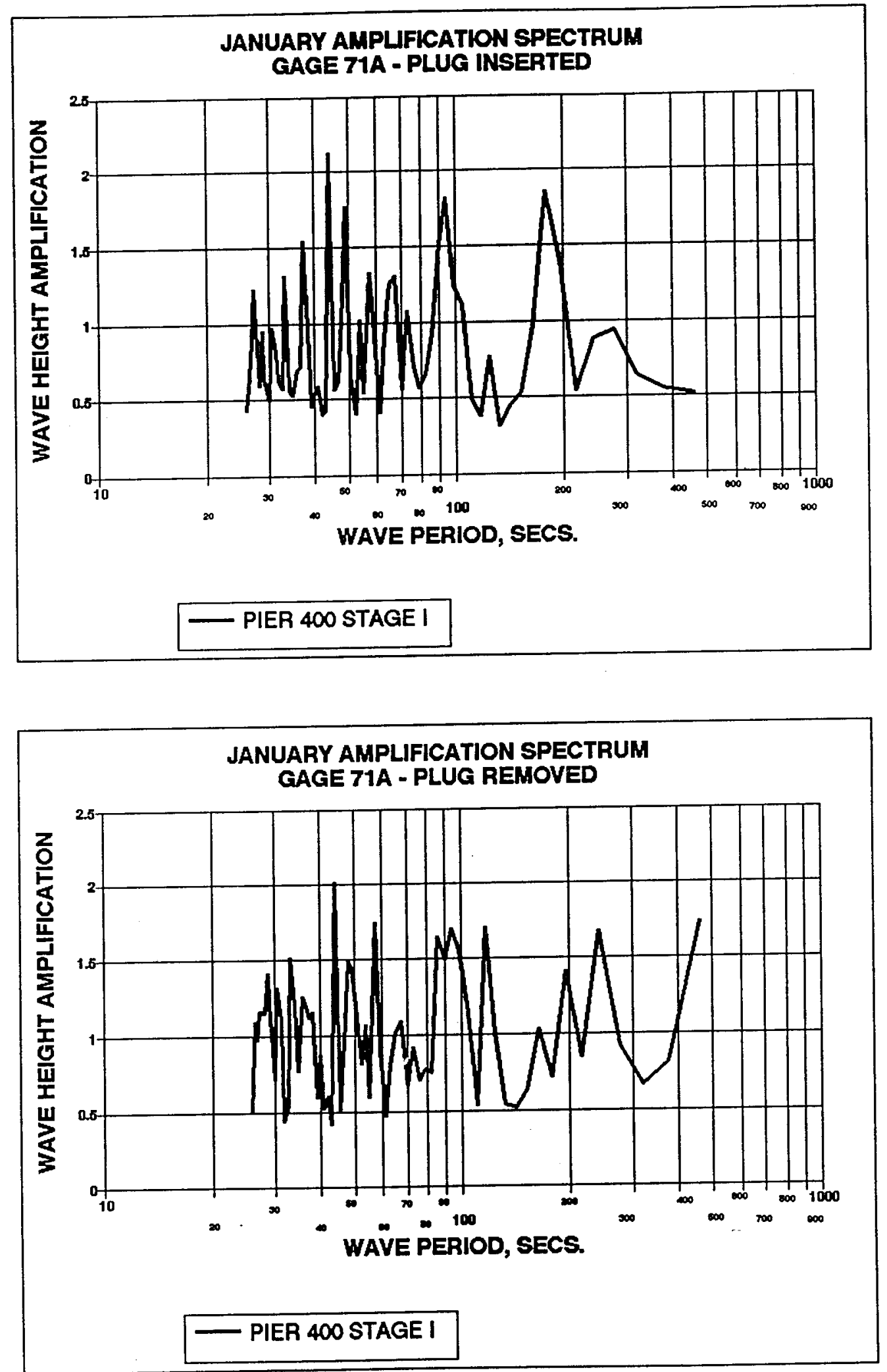

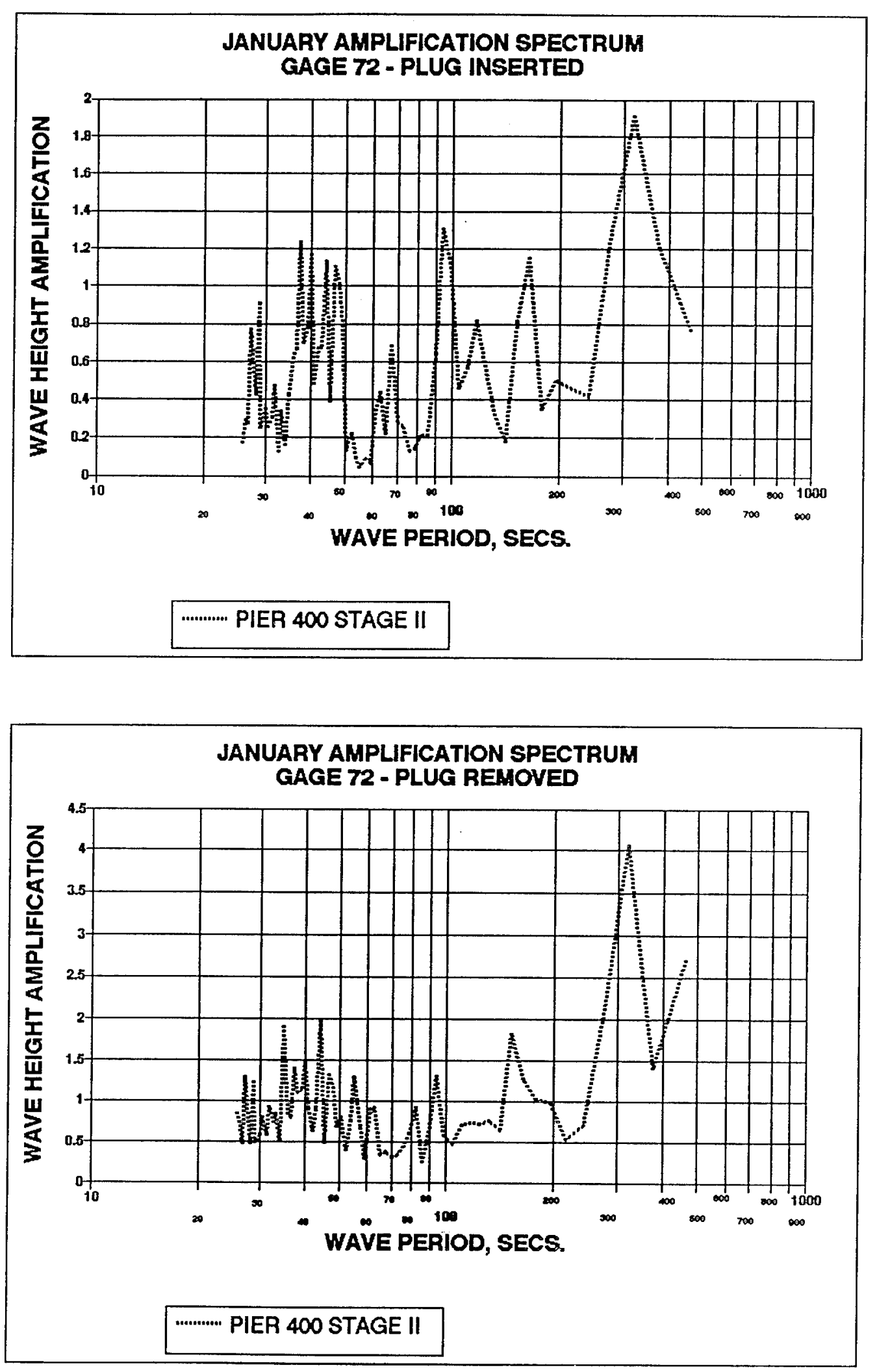


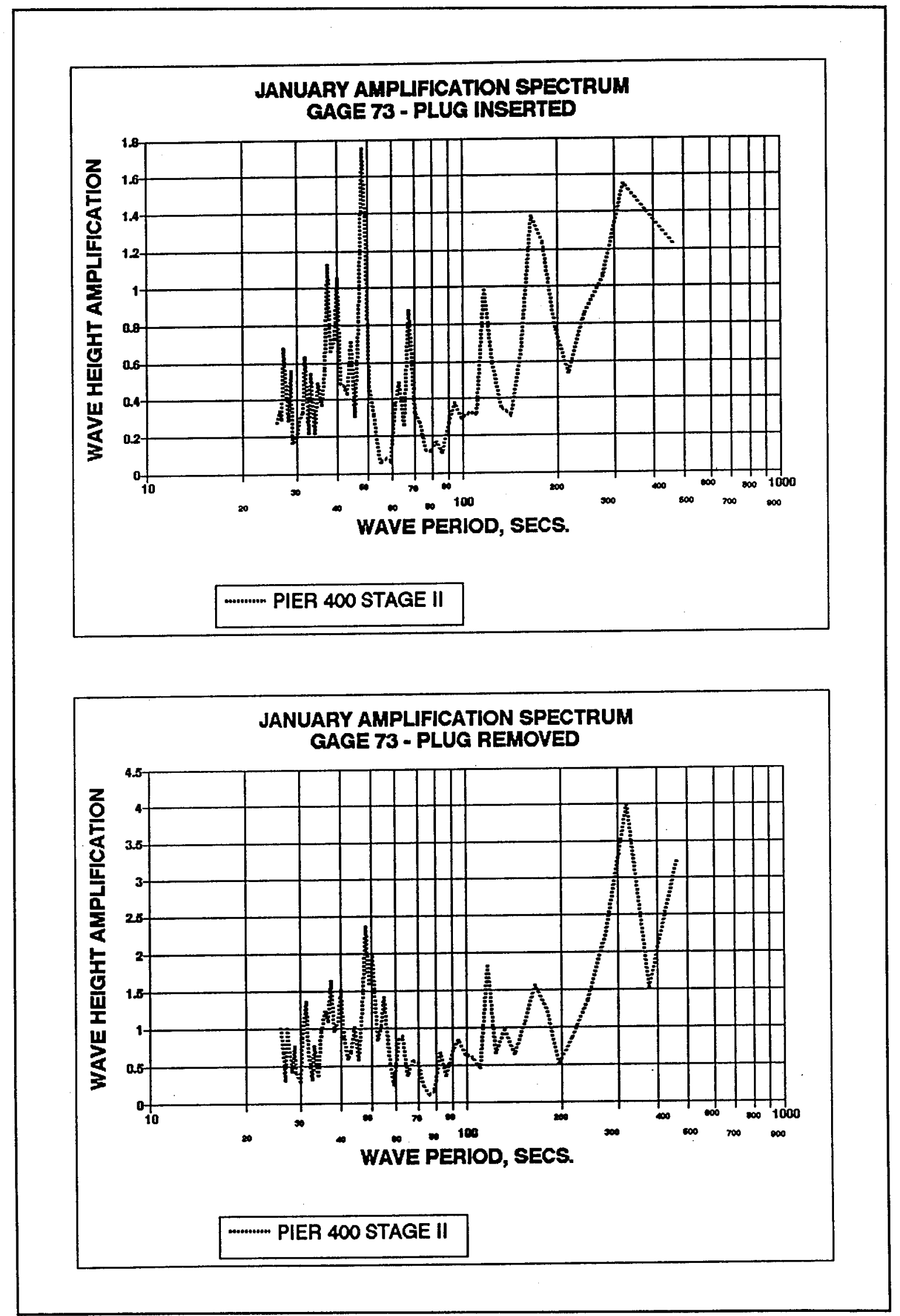



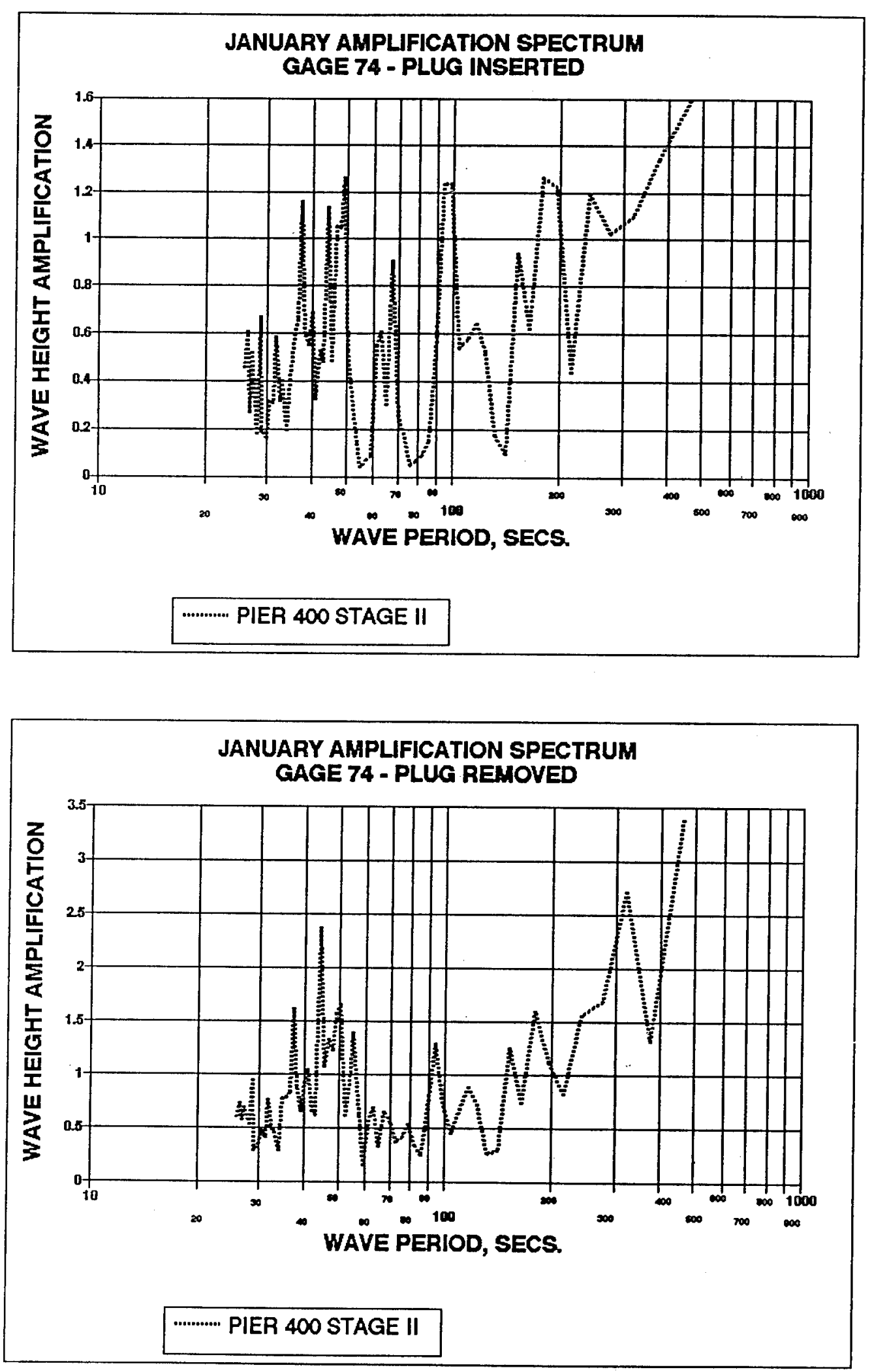

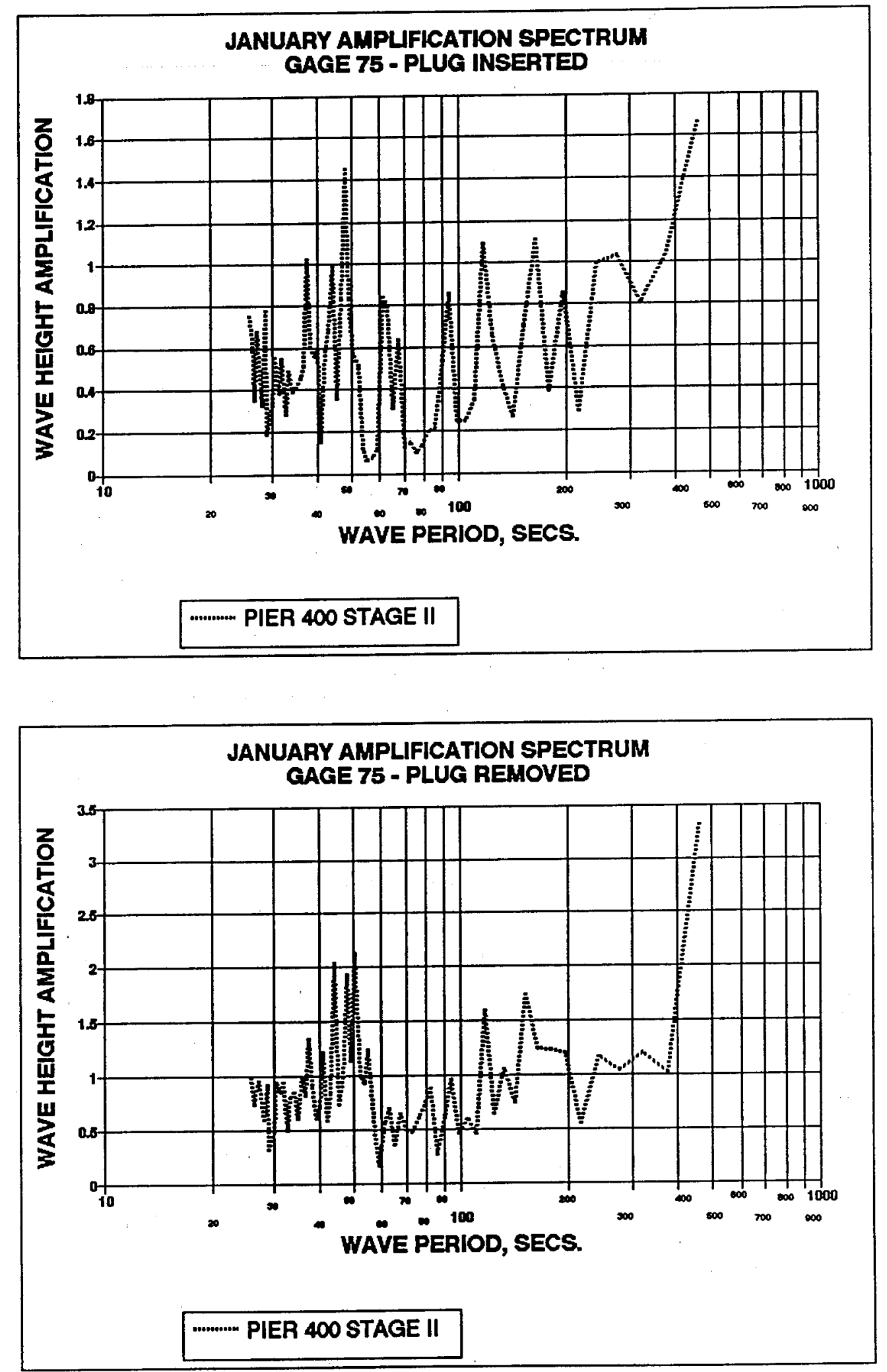

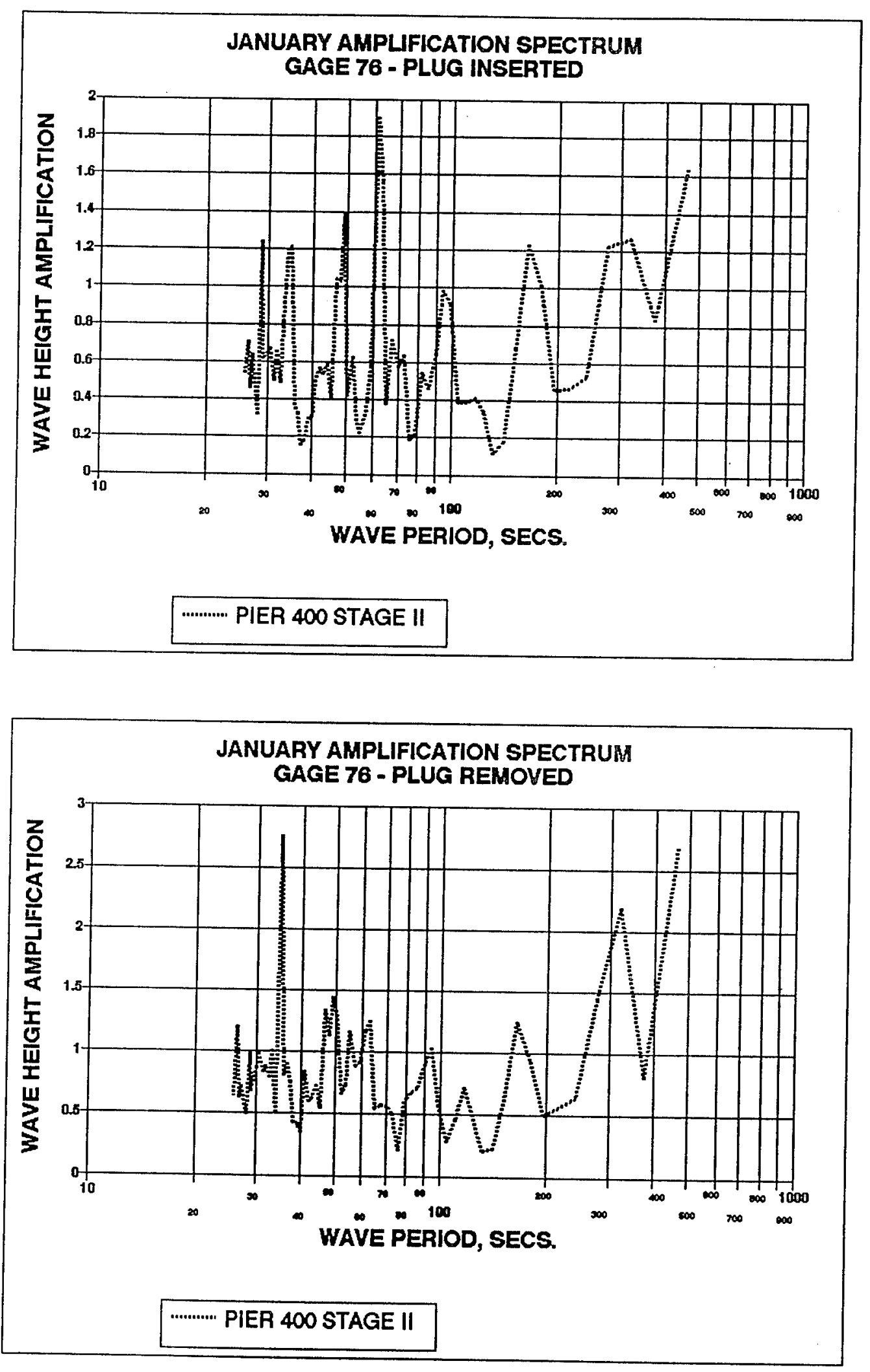

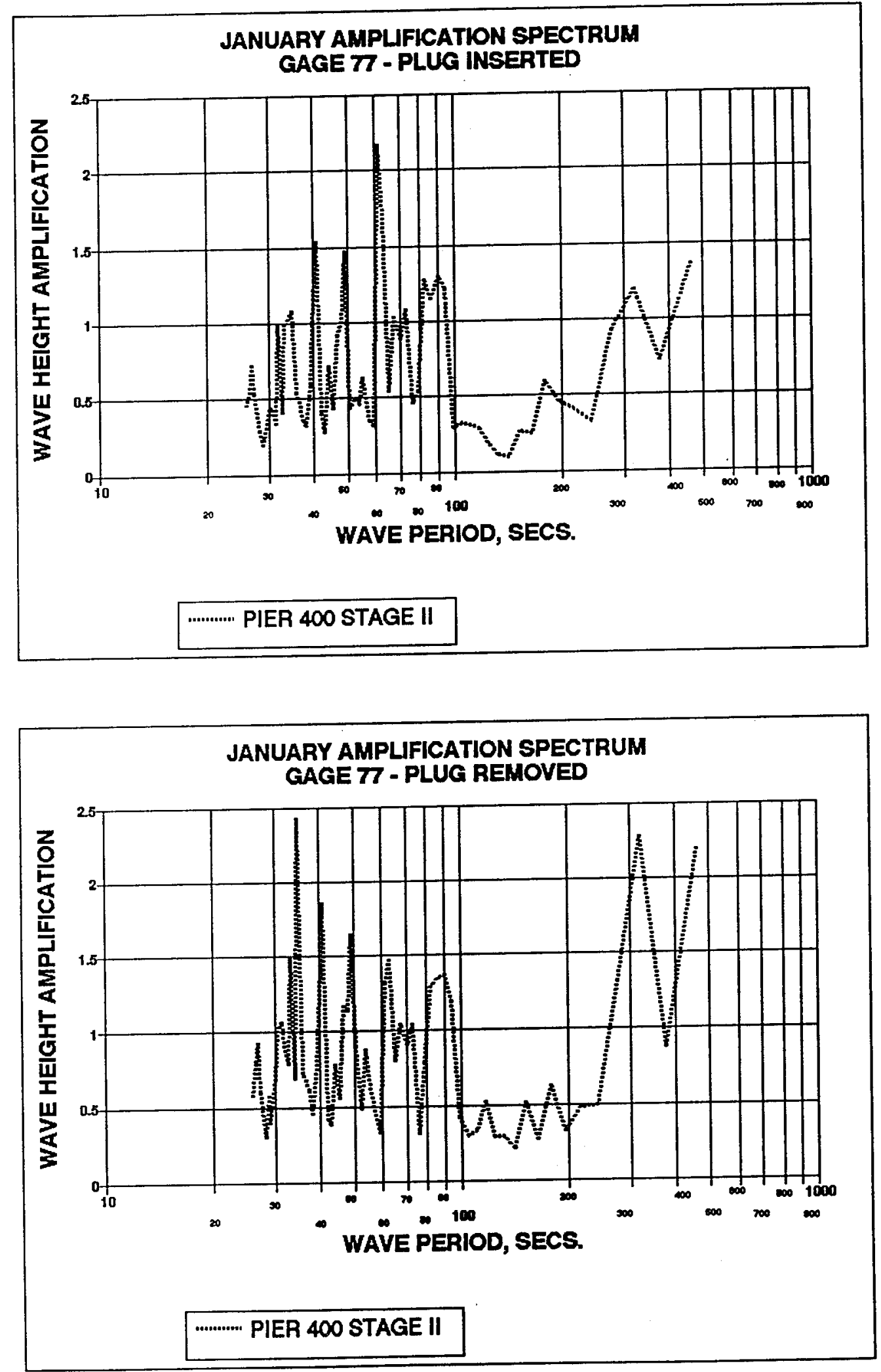
Public reporting burden for this collection of information is estimated to average 1 hour per response, including the time for reviewing instructions, searching existing data sources. gathering and maintaining the data needed, and completing and reviewing the collection of information. Send comments regafding this burden estimate or any other aspect of this Devis Highway, Suite 1204, Arlington, VA 22202-4302, and to the Office of Management and Budget, Paperwork Reduction Project (0704-0188), Washington, DC 20503.

\begin{tabular}{|l|l|l|}
\hline 1. AGENCY USE ONLY (Leave blank) & $\begin{array}{c}\text { 2. REPORT DATE } \\
\text { July } 1995\end{array}$ & $\begin{array}{l}\text { 3. REPORT TYPE AND DA } \\
\text { Final report }\end{array}$ \\
\hline
\end{tabular}

4. TITLE AND SUBTITLE 5. FUNDING NUMBERS

Los Angeles Harbor Pier 400 Harbor Resonance Model Study

6. AUTHOR(S)

William C. Seabergh, Leonette J. Thomas

7. PERFORMING ORGANIZATION NAME(S) AND ADDRESS(ES)

U.S. Army Engineer Waterways Experiment Station

3909 Halls Ferry Road

Vicksburg, MS 39180-6199
8. PERFORMING ORGANZATION REPORT NUMBER

Technical Report CERC-95-8

\section{SPONSORING / MONITORING AGENCY NAME(S) AND ADDRESS(ES)}

U.S. Army Engineer District, Los Angeles

P. O. Box 2711

Los Angeles, CA 90053-2325

\section{SUPPLEMENTARY NOTES}

Available from National Technical Information Service, 5285 Port Royal Road, Springfield, VA 22161.

\section{2a. DISTRIBUTION/AVAILABILITY STATEMENT}

Approved for public release; distribution is unlimited.

\section{SPONSORING/MONITORING} AGENCY REPORT NUMBER

\section{ABSTRACT (Maximum 200 words)}

The Los Angeles - Long Beach Harbors physical model for harbor resonance was used to investigate the effects of Stages 1 and 2 of the Pier 400 Project on long waves (periods $30-500 \mathrm{sec}$ ) at existing and proposed berth locations. Three long-period wave spectra were selected for use. They included two storm conditions: 1 February 1986 and the Martin Luther King Day Storm on 17 January 1988. They were representative of long waves from the west. An average condition wave spectrum was developed based on long-term wave information and was representative of long waves from the south. These spectra were used to program the wave generators and wave data were collected at 77 harbor gages. Stage 1 was initially constructed and tested. No significant wave amplifications were noted at the Pier 300 berths with the solid fill causeway joining Terminal Island and Pier 400 . When a $243.84-\mathrm{m}-(800-\mathrm{ft}-)$ wide gap was opened in the causeway at the end of the Pier 300 channel, some increases in amplification were noted at Pier 300 though overall energy was still relatively low. Most existing berth locations had similar changes for Stages 1 and 2, with decreases in wave amplifications most prevalent. Some increases in wave amplifications as a result of the proposed construction in the Port of Los Angeles were noted at about 4 to 5 percent of the existing berth locations in the $25-$ to $40-\mathrm{sec}$ and $41-$ to 205 -sec energy bands and 10 percent for the 206- to 519-sec energy bands.

\begin{tabular}{|c|c|c|c|}
\hline $\begin{array}{l}\text { 14. SUBJECT TERMS } \\
\text { Harbors }\end{array}$ & Long-Period Waves & & $\begin{array}{l}\text { 15. NUMBER OF PAGES } \\
284\end{array}$ \\
\hline $\begin{array}{l}\text { Harbor Resonance } \\
\text { Long Beach Harbor }\end{array}$ & $\begin{array}{l}\text { Los Angeles Harbor } \\
\text { Physical models }\end{array}$ & & 16. PRICE CODE \\
\hline $\begin{array}{l}\text { 17. SECURITY CLASSIFICATION } \\
\text { OF REPORT } \\
\text { UNCLASSIFIED }\end{array}$ & $\begin{array}{l}\text { 18. SECURITY CLASSIFICATION } \\
\text { OF THIS PAGE }\end{array}$ & $\begin{array}{l}\text { 19. SECURITY CLASSIFICATION } \\
\text { OF ABSTRACT } \\
\text { UNCLASSIFIED }\end{array}$ & 20. LIMITATION OF ABSTRACT \\
\hline & PRINTING OFFICE & $633-144 / 00017$ & ion by ANSi std. $239-18$ \\
\hline
\end{tabular}

